\author{
UNIVERSIDADE DE SÃO PAULO \\ ESCOLA DE ENGENHARIA DE SÃO CARLOS \\ DEPARTAMENTO DE ENGENHARIA DE TRANSPORTES
}

FRANCINE MARVULLE TAN

Potencial de transferência de um índice de mobilidade sustentável para campus universitário 



\title{
Potencial de transferência de um índice de mobilidade sustentável para campus universitário
}

\author{
Dissertação apresentada à Escola de Engenharia de São \\ Carlos, da Universidade de São Paulo, como parte dos \\ requisitos para obtenção do título de Mestre em Ciências - \\ Programa de Pós-Graduação em Engenharia de \\ Transportes. Área de concentração: Planejamento e \\ Operação de Sistemas de Transporte.
}

Orientador: Prof. Titular Antônio Nélson Rodrigues da Silva

São Carlos

2018 
AUTORIZO A REPRODUÇÃO TOTAL OU PARCIAL DESTE TRABALHO, POR QUALQUER MEIO CONVENCIONAL OU ELETRÔNICO, PARA FINS DE ESTUDO E PESQUISA, DESDE QUE CITADA A FONTE.

Ficha catalográfica elaborada pela Biblioteca Prof. Dr. Sérgio Rodrigues Fontes da EESC/USP com os dados inseridos pelo(a) autor(a).

Tan, Francine Marvulle
Potencial de transferência de um índice de
mobilidade sustentável para campus universitário /
Francine Marvulle Tani orientador Antônio Nélson
Rodrigues da Silva. São Carlos, 2018 .
Dissertação (Mestrado) - Programa de Pós-Graduação
em Engenharia de Transportes e Área de Concentração em
Planejamento e Operação de Sistemas de Transporte --
Escola de Engenharia de São Carlos da Universidade de
São Paulo, 2018.
1. mobilidade sustentável. 2. planejamento baseado
emdicadores. 3. indice de mobilidade sustentável. 4.
campus universitário. 5. potencial de transferência. I.
Título.

Eduardo Graziosi Silva - CRB - 8/8907 


\section{FOLHA DE JULGAMENTO}

Candidata: Engenheira FRANCINE MARVULLE TAN.

Título da dissertação: "Potencial de transferência de um índice de mobilidade sustentável para campus universitário".

Data da defesa: 21/03/2018.

Comissão Julgadora:

Resultado:

Prof. Titular Antônio Nélson Rodrigues da Silva

APRONADA

(Orientador)

(Escola de Engenharia de São Carlos/EESC)

Prof. Dr. Pablo Brilhante de Souza

APROVADA

(Universidade Federal da Paraíba/UFPB)

Prof. Associado Fernando Seixas

(Escola Superior de Agricultura Luiz de Queiroz/ESALQ-USP)

Coordenadora do Programa de Pós-Graduação em Engenharia de Transportes:

Profa. Associada Ana Paula Camargo Larocca

Presidente da Comissão de Pós-Graduação:

Prof. Associado Luis Fernando Costa Alberto 




\section{Agradecimentos}

Ao Prof. Antônio Nélson, pela excelente orientação, pelo incentivo, por todo o aprendizado e, principalmente, por ser um exemplo de profissional comprometido, competente, sensato e íntegro.

À Comissão de Mobilidade da USP de Piracicaba, em especial, ao prof. Ciro Abbud Righi, à Ana Maria de Meira e aos estagiários Carlos Henrique de Almeida e João Pedro Giorgi Ferreira Cabral pelo apoio e pela disposição em contribuir para o trabalho.

À Vanessa Rodriguez Lara, minha colega de mestrado, pelo comprometimento e pela imensa colaboração nos levantamentos de campo em Piracicaba e no processo de adaptação do índice.

À Caroline Camilo, minha amiga e estagiária da SGA, pela dedicação e pelo trabalho realizado.

À Angélica de Oliveira, pela disponibilidade e disposição em ajudar.

A todos aqueles que responderam aos questionários e aos especialistas que participaram do painel e contribuíram enormemente para este trabalho.

Aos demais professores e funcionários do departamento de Engenharia de Transportes da EESC-USP.

Aos meus pais, Doralice e Massayoshi, e à minha irmã Denise, pelo apoio e compreensão incondicionais. A todos os meus familiares por me incentivarem e por acreditarem no meu potencial.

Ao Luiz Arthur Nascimento, pelo cuidado, paciência, carinho e companheirismo em todos os momentos.

À minha psicóloga Christina Y. Rodrigues e ao meu psiquiatra Dr. Antônio Tonhom, que foram fundamentais para o meu equilíbrio e para o meu desenvolvimento pessoal. Sou muito grata pelo acompanhamento durante toda essa etapa, pelo aprendizado, pelo apoio e pelos excelentes profissionais que são. 
Aos meus amigos da pós-graduação, em especial, aqueles que compartilharam comigo também os anos de graduação: Bruna Kuramoto, Cláudia Naizer, Denise Capasso, Adrian Grasson e Julia Cocozza.

Aos meus amigos de Marília, pelo acolhimento de sempre, em especial, ao José Arthur Gentile por dividir comigo momentos bons e ruins.

Ao Coletivo de Mulheres do CAASO/UFSCar e à Urze Companhia de Dança por me proporcionarem experiências únicas.

A todas as pessoas que, de forma direta ou indireta, contribuíram para a realização deste trabalho.

Ao CNPq, pelo apoio financeiro concedido durante o programa de mestrado. 
"Não há uma pegada do meu caminho que não passe pelo caminho do outro"

(Simone de Beauvoir) 

TAN, F. M. (2018) Potencial de transferência de um Índice de Mobilidade Sustentável para Campus Universitário. Dissertação (Mestrado) - Escola de Engenharia de São Carlos, Universidade de São Paulo, São Carlos, 2018.

O objetivo do presente trabalho é desenvolver e aplicar um método para avaliação do potencial de transferência de um índice de mobilidade sustentável, com base em três questões. O índice de mobilidade sustentável para campus universitário (IMSCamp), proposto por Oliveira (2015), é transferível para outros contextos? Em caso afirmativo, qual o potencial de transferência do mesmo? A partir das respostas das questões anteriores, qual seria a estrutura mínima para a concepção de um índice de mobilidade para campus universitário possível de ser transferido para qualquer contexto? O método proposto para o estudo foi assim organizado: aplicação do IMSCamp a um novo contexto; análise do seu potencial de transferência por meio de critérios desenvolvidos especificamente para este fim; e organização de um painel de especialistas com o intuito de elencar possíveis indicadores para um índice global de mobilidade sustentável para campus universitário. A avaliação do potencial de transferência, objetivo principal deste estudo, resultou em um valor que indica um baixo potencial de transferência (cerca de $40 \%$ do máximo possível) para o índice. Este resultado indica que foram necessárias mudanças expressivas para adaptá-lo a um novo campus; sendo assim, não se trata de um índice global diretamente aplicável, sem mudanças, a diversos contextos. Apesar disso, foi possível reproduzir o método de aplicação do IMSCamp no campus da USP de Piracicaba, que resultou em um valor de 0,491 (cerca de $50 \%$ do máximo possível), mostrando a viabilidade de seu uso em diferentes contextos, desde que feitos alguns ajustes. Isto obviamente depende da existência de recursos para sua adaptação, o que neste caso não se configurou em uma barreira intransponível. Por fim, o painel de especialistas trouxe evidências de que, dentre os 20 indicadores originais do IMSCamp, 13 mereceram destaque, em termos de relevância e adequação, para compor um índice aplicável a contextos distintos. Seriam eles: Infraestrutura de transporte público urbano, Qualidade das calçadas dentro e de acesso ao campus, Vagas para usuários com restrição de mobilidade, Transporte público urbano, Segurança pública, Acessibilidade dos prédios, Infraestrutura de estacionamento, Bicicletários e paraciclos, Infraestrutura de acesso ao campus, Adequação do modo de transporte, Qualidade das vias no campus, Infraestrutura cicloviária e Ações de educação no trânsito.

Palavras-chave: mobilidade sustentável, planejamento baseado em indicadores, índice de mobilidade sustentável, campus universitário, potencial de transferência. 
TAN, F. M. (2018) Transferability of a sustainable mobility index for university campus. M. Sc. Dissertation - São Carlos School of Engineering, University of São Paulo, São Carlos, 2018.

This study aims to develop and to apply a method for assessing the transferability of a sustainable mobility index for university campus. Three main questions guide the research: Is IMSCamp (an index created by Oliveira, 2015) transferable to a new context? In this case, what is its transferability potential? According to the previous answers, what should be the framework of a sustainable mobility index for university campus that is transferable to any context? The proposed method was organized as follows: application of IMSCamp to a new context; assessment of the transferability potential of this index by means of rating criteria that have been specially developed for this purpose; and organization of a panel of experts to select indicators for a global sustainable mobility index for university campus. The evaluation of the transferability potential, which was the main purpose of this study, indicated a low level of transferability (around $40 \%$ of the maximum value) for the index. This result indicates that considerable adjustments had been required in order to adapt it to a new campus. It means that it is not the case of a global index that may be directly applied without adjustments to various contexts. Nevertheless, it was possible to reproduce the IMSCamp method at the University of São Paulo campus in Piracicaba, which resulted in a value of 0.491 (around $50 \%$ of the maximum possible value), bringing evidence that the index can be applied in different campuses after some adjustments. The application obviously depends on the availability of resources for the adaptations needed, what was not a unsurmountable obstacle in the case studied. Finally, the experts' panel brought evidences that 13 out of the 20 original indicators of IMSCamp have enough relevance and suitability to constitute an index transferable to different contexts. These indicators are: Public transport infrastructure, Quality of sidewalks (inside and around the campus), Parking spaces for people with disability, Public transport, Public safety, Buildings accessibility, Parking infrastructure, Bicycle racks, Infrastructure to access the campus, Suitability of transport modes, Pavement quality inside the campus, Cycling infrastructure and Traffic education initiatives.

Keywords: sustainable mobility, planning based on indicators, sustainable mobility index, university campus, transferability. 
Figura 3.1: Etapas do IMSCamp (adaptado de OLIVEIRA, 2015) 28

Figura 3.2: Conjunto de procedimentos e ferramentas que formam a metodologia, separados em etapas e associados aos recursos utilizados para seu desenvolvimento..44

Figura 4. 1: Modelo hierárquico, composto por 3 Domínios (Educação, Infraestrutura e Gestão e Serviços), 8 Temas (primeira subdivisão interna dos Domínios) e 19 Indicadores (retângulos tracejados), adotado no ÍMSCamp para o campus da USP em Piracicaba ...49 
Tabela 3.1: Estrutura do método adotado, com a descrição das etapas e os subitens que as abordam nas seções Método e Resultados

Tabela 3.2: Análise de sensibilidade da escala de referência do critério "Número de indicadores alterados" para avaliação do potencial de transferência de um índice.

Tabela 3.3: Escala de referência dos critérios definidos para avaliação do potencial de transferência de um índice

Tabela 3.4: Exemplo de aplicação do teste de Friedman. Avaliações de 4 indicadores feitas por 4 especialistas em escala Likert, em que 1 equivale a "discordo totalmente" e 7 a "concordo totalmente".

Tabela 3.5: Exemplo de aplicação do teste de Friedman. Ranks dos 4 indicadores segundo a avaliação dos especialistas. Rank atribuído em ordem crescente, ou seja, quanto menor a nota de avaliação, menor o número do rank.

Tabela 3.6: Exemplo de aplicação do teste de Friedman. Ranks finais de cada indicador, dados pela soma dos ranks individuais atribuídos pelos 4 especialistas.

Tabela 3.7: Exemplo de aplicação do teste de Friedman. Comparações múltiplas entre os ranks dos indicadores, feitas pela operação $\mathrm{Rj}-\mathrm{Ri}$. Em destaque, as diferenças maiores do que o valor de referência $(2,262)$.

Tabela 3.8: Exemplo de aplicação do teste de Friedman. Lista de indicadores organizados por ordem de concordância de relevância segundo o julgamento de 4 especialistas. No topo, a maior concordância.

Tabela 4.1: Distribuição das respostas obtidas no questionário por tipo de vinculação com a universidade

Tabela 4.2: Cálculo do tamanho necessário de amostra para erros amostrais de $2 \%, 3 \%$ e 4\% para população de 4858 indivíduos.

Tabela 4.3: Pesos, escores e contribuição dos indicadores que compõem o Índice de Mobilidade Sustentável adaptado para o campus da USP de Piracicaba (IMSCamp)......50 Tabela 4.4: Referência para classificação de prioridade de intervenção dos indicadores.51 Tabela 4.5: Indicadores presentes no índice de mobilidade do campus da USP de São Carlos e no índice de mobilidade do campus da USP de Piracicaba

Tabela 4.6: Dados para cálculo dos escores de cada critério, com porcentagens calculadas considerando-se os 20 indicadores originais (São Carlos) como 100\%. 
Tabela 4.7: Cálculo dos critérios "Indicadores comuns" e "Indicadores adicionados", com porcentagens calculadas considerando-se os 20 indicadores originais (São Carlos) como $100 \%$

Tabela 4.8: Cálculo do critério "Número de indicadores alterados", com porcentagens calculadas considerando-se os 20 indicadores originais (São Carlos) como 100\% ............54 Tabela 4.9: Avaliação final do potencial de transferência, que varia entre 0 (pior avaliação) e 1 (melhor avaliação)

Tabela 4.10: Somas dos ranks $(\mathrm{Rj})$ dos 20 indicadores analisados no painel de especialistas, organizados em ordem crescente. No topo, o indicador com menor concordância por parte dos avaliadores no quesito adequação.

Tabela 4.11: Somas dos ranks $(\mathrm{Rj})$ dos 20 indicadores analisados no painel de especialistas, organizados em ordem crescente. No topo, o indicador com menor concordância por parte dos avaliadores no quesito relevância. .58

Tabela 4.12: Valores da estatística de Friedman obtidos 60

Tabela 4.13: Comparações múltiplas entre os ranks dos indicadores para o quesito Adequação, feitas pela operação $|\mathrm{Rj}-\mathrm{Ri}|$. Em destaque, as diferenças maiores do que o valor de referência $(65,484)$.

Tabela 4.14: Indicadores selecionados, organizados por ordem de concordância na avaliação dos especialistas (no topo, os de maior concordância) - Quesito adequação ...63 Tabela 4.15: Indicadores selecionados, organizados por ordem de concordância na avaliação dos especialistas (no topo, os de maior concordância) - Quesito relevância.....63 Tabela 5.1: Alterações dos indicadores originais do IMSCamp (OLIVEIRA, 2015) para aplicação no campus da USP de Piracicaba. .68 
Resumo i

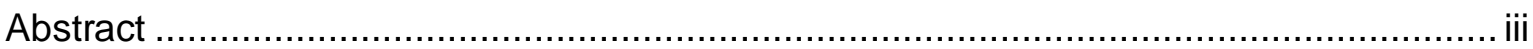

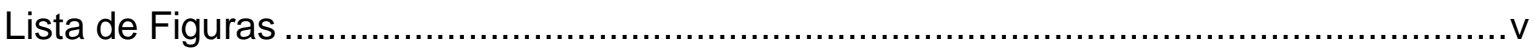

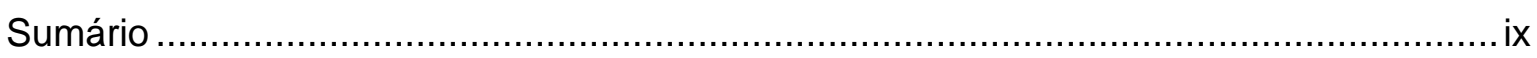

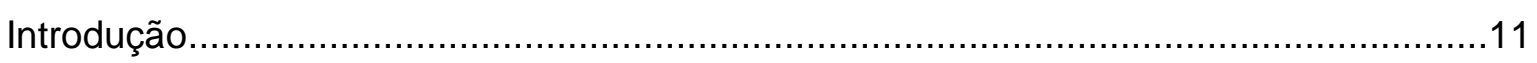

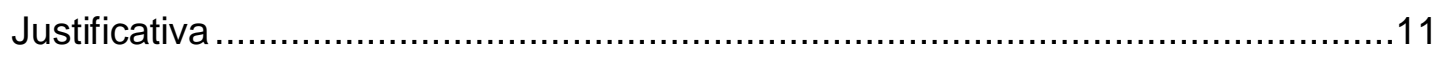

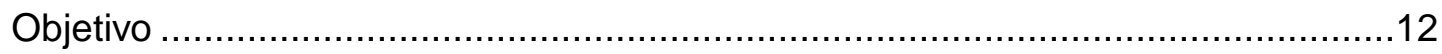

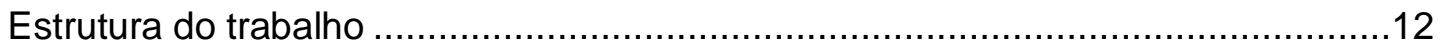

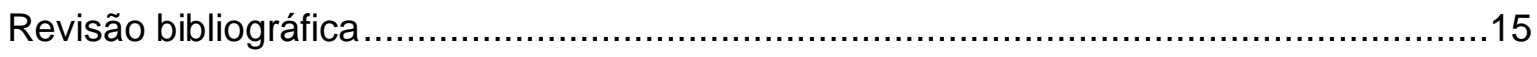

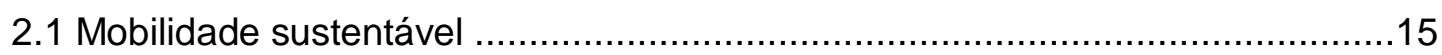

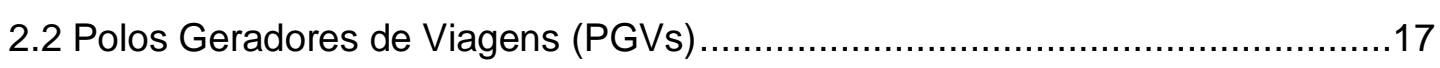

2.3 Planejamento em campi universitários.........................................................18

2.4 Índices como ferramenta de planejamento...................................................22

2.5 Potencial de transferência de índices............................................................24

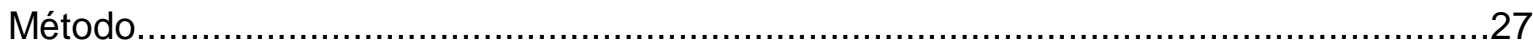

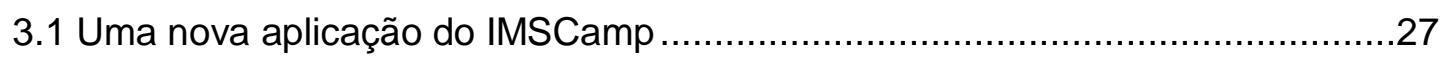

3.2 Potencial de transferência..................................................................... 31

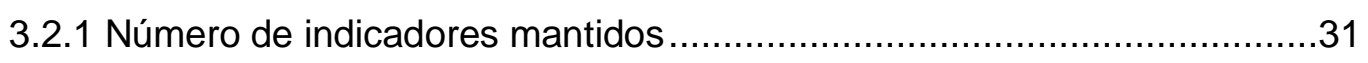

3.2.2 Número de indicadores adicionados ...................................................31

3.2.3 Número de indicadores alterados........................................................

3.2.4 Avaliação do potencial de transferência ..............................................35

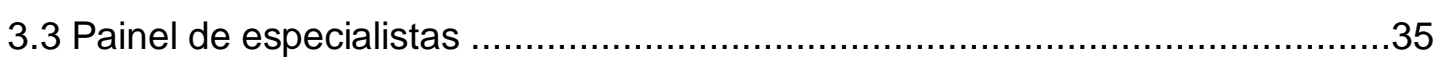

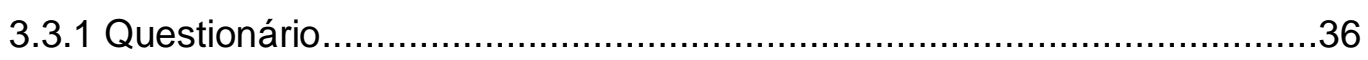

3.3.2 Teste estatístico não paramétrico de Friedman .....................................36

Exemplo de aplicação do teste de Friedman....................................................39

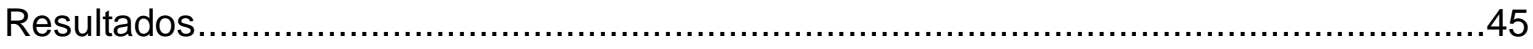

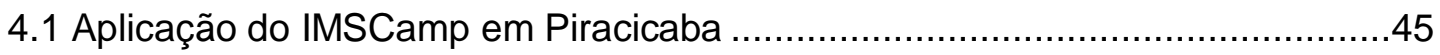

4.2 Aplicação do método de avaliação do potencial de transferência no caso São

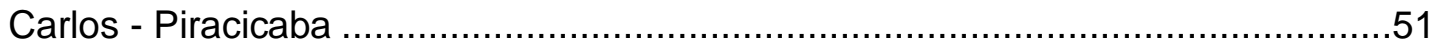

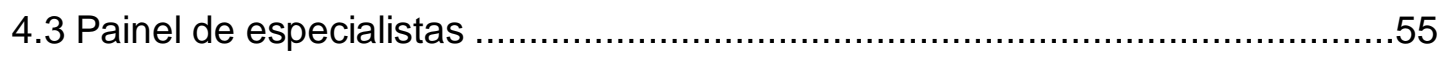

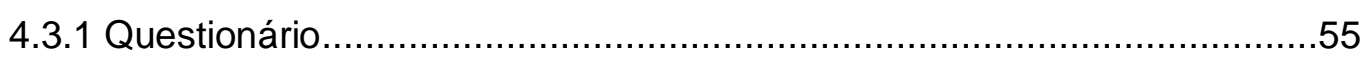

4.3.2 Teste estatístico não paramétrico de Friedman ....................................55

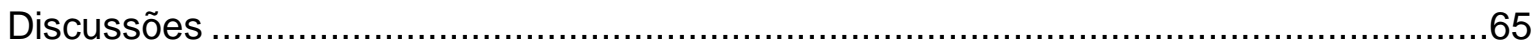

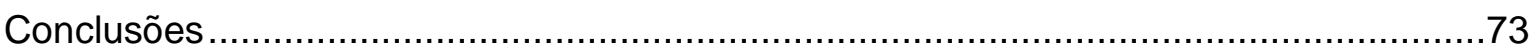

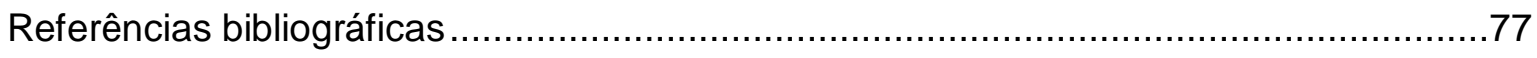


O problema abordado pelo presente estudo é brevemente contextualizado nesta seção, da qual constam a justificativa, o objetivo e a estrutura do documento.

\section{Justificativa}

Campi universitários configuram Polos Geradores de Viagem (PGV), apresentando sistemas viários complexos que podem se assimilar aos de pequenas cidades, produzindo e atraindo um número expressivo de viagens. Para reduzir os potenciais impactos negativos que estes PGV causam no ambiente e na sociedade em que estão inseridos, é necessário que os órgãos gestores realizem um planejamento voltado à mobilidade sustentável.

Uma abordagem utilizada para o processo de planejamento é a aplicação de índices, que permitem o diagnóstico da situação corrente de maneira quantitativa. Além disso, devido ao seu sistema de atribuição de pesos, possibilitam a identificação dos fatores mais críticos do caso estudado e um direcionamento no processo de tomada de decisões, em termos de estabelecer prioridades e elaborar planos de ação efetivos.

A exemplo da maioria dos índices destinados a outros fins, um índice de mobilidade pode ser usado com dois propósitos. O primeiro é o monitoramento das condições de sustentabilidade em um local específico ao longo do tempo, a fim de verificar, por exemplo, o progresso (ou o retrocesso) de intervenções realizadas no local. O segundo propósito é o de comparação entre locais, permitindo um panorama geral da mobilidade de diferentes unidades de análise (por exemplo, campi universitários) e a identificação daquelas que deveriam ser priorizadas em termos de planejamento de intervenções e/ou investimentos.

Desta maneira, o Índice de Mobilidade Sustentável para Campus Universitário proposto por Oliveira (2015), base deste estudo, pode ser empregado para fins de monitoramento no campus em que foi aplicado, caso seja recalculado periodicamente. Contudo, ainda não foi analisado se este índice pode ser aplicado, sem alterações, em novos contextos e se sua estrutura é adequada para contemplar as necessidades de diferentes campi. Dessa forma, também se desconhece se o referido índice pode ser empregado com o propósito de comparação entre campi, já que só é razoável comparar resultados de índices idênticos, ou seja, com pesos e estrutura de 
indicadores iguais. Estes fatos constituem a justificativa para o presente estudo, que se propõe a realizar uma nova aplicação do Índice de Mobilidade Sustentável para Campus Universitário (OLIVEIRA, 2015), analisar seu potencial de transferência para outros contextos e elencar possíveis indicadores para um índice global que permita a comparação entre diferentes campi.

Em suma, o presente estudo busca responder três questões:

1) O índice de mobilidade sustentável para campus universitário proposto por Oliveira (2015) é transferível para novos contextos?

2) Em caso positivo, como avaliar este potencial de transferência?

3) À luz do que for constatado com as respostas às questões acima, qual seria uma estrutura mínima recomendável para a concepção de um índice de mobilidade para campus universitário possível de ser transferido para qualquer contexto?

\section{Objetivo}

O principal objetivo do presente trabalho foi desenvolver e aplicar um método para avaliação do potencial de transferência de um índice de mobilidade sustentável. Já os objetivos secundários foram: aplicar este índice a um novo contexto e elencar possíveis indicadores para um índice global que permita a comparação entre diferentes campi universitários.

\section{Estrutura do trabalho}

O presente documento está organizado em sete capítulos e contempla introdução, revisão bibliográfica, descrição do método utilizado, resultados, discussões, conclusões e referências bibliográficas.

O primeiro capítulo introduz o problema a ser tratado, apresentando justificativa, objetivo e estrutura do trabalho. O segundo capítulo trata da base teórica que fundamenta a pesquisa, apresentando as referências bibliográficas consultadas na concepção e no desenvolvimento da mesma. O capítulo três apresenta o método adotado para cada uma das três questões de pesquisa a serem respondidas, organizadas em tópicos tanto no capítulo três quanto no quatro: a primeira delas (Uma nova aplicação do IMSCamp) segue o método adaptado por Oliveira (2015); a segunda (Potencial de transferência) exigiu a elaboração de um método específico para tal avaliação; e a terceira (Painel de especialistas) consistiu na aplicação de um questionário seguido por um teste estatístico. O capítulo quatro apresenta os 
resultados destes três tópicos. As discussões geradas por esses resultados são abordadas no capítulo cinco. O sexto capítulo trata das conclusões obtidas e sugestões para trabalhos futuros. O documento é finalizado com a lista de referências bibliográficas consultadas (capítulo sete). 
A revisão bibliográfica aborda tópicos relevantes ao presente estudo. A seção está organizada em cinco tópicos: Mobilidade sustentável, Polos Geradores de Viagens, (PGVs), Planejamento em campi universitários, Índices como ferramenta de planejamento e Potencial de transferência de índices.

\subsection{Mobilidade sustentável}

O termo "mobilidade" se difere de "transporte" por tratar da movimentação de bens e pessoas com uma visão sistêmica, ao invés da abordagem tradicional em que os diferentes elementos que o compõe (como planejamento urbano, gestão do uso do solo, gestão do sistema de transporte coletivo, gestão do sistema viário, etc.) são tratados isoladamente (MINISTÉRIO DAS CIDADES, 2007). Segundo a Política Nacional de Mobilidade Urbana Sustentável (BRASIL, 2012), mobilidade urbana é um atributo das cidades, e se trata do deslocamento de pessoas e bens no espaço urbano, o qual ocorre por meio de veículos, vias e demais elementos de infraestrutura.

O tema mobilidade tem sido foco de muitos estudos na atualidade por ser essencial para todas as atividades da sociedade. A mobilidade interfere no desenvolvimento econômico e na qualidade de vida dos indivíduos, na inclusão social, na equidade de acesso e apropriação da cidade e de todos os serviços urbanos (MINISTÉRIO DAS CIDADES, 2007). Contudo, os deslocamentos necessários para realização de atividades (como trabalho, estudo, lazer, compras e serviços) demandam alto consumo de tempo, de espaço e de recursos naturais, financeiros, ambientais e humanos (WHITELEGG e HAQ, 2003).

A maior parte dos efeitos negativos do atual modelo de mobilidade são advindos do uso desenfreado de modos de transporte motorizados. Os usuários do transporte individual usufruem dos benefícios destes modos, porém a maior parte de seus malefícios são transferidos para a sociedade, como poluição e emissões de gases de efeito estufa (contribuindo para as mudanças climáticas), congestionamentos, acidentes de trânsito, consumo de recursos não renováveis (combustíveis fósseis), problemas de saúde decorrentes da exposição à poluição (atmosférica e sonora) e falta de exercício físico, estresse, impacto na ocupação do solo urbano, perda da liberdade de deslocamento, desapropriação e realocação de residências para obras 
viárias, ferrovias e aeroportos (WHITELEGG e HAQ, 2003; MINISTÉRIO DAS CIDADES, 2007).

Para evitar ou reduzir estes impactos negativos, a solução não se resume a substituir os modos de transporte motorizados por alternativas à base de energia limpa, e sim atuar no sentido de se atingir o equilíbrio do uso dos diferentes modos de transporte, priorizando modos não motorizados e coletivos e compreendendo o comportamento dos usuários (OLIVEIRA, 2015; BRASIL, 2012). Além da preferência individual, outros fatores podem interferir na forma como os usuários se deslocam, como idade, gênero, condições financeiras, restrições físicas, habilidades, entre outros (STEIN e RODRIGUES DA SILVA, 2017; MINISTÉRIO DAS CIDADES, 2007). Os serviços e a infraestrutura urbana disponíveis também exercem influência sobre a decisão dos indivíduos, podendo estimular, desestimular ou inviabilizar determinadas condições de mobilidade aos usuários (OLIVEIRA, 2015). Assim, é importante que o planejamento se dê neste sentido, estimulando boas práticas e fornecendo infraestrutura e serviços de qualidade, dando condições para que o usuário faça suas escolhas.

De acordo com The Centre for Sustainable Transportation (2005), MacLaren (1996), Ministério das Cidades (2007) e Litman (2016), e considerando as três dimensões da sustentabilidade (econômica, social e ambiental (LOW, 2003; GUDMUNDSSON, 2004)) as características chave para um sistema de transporte sustentável são:

- Na esfera social: permitir que os usuários realizem seus deslocamentos com autonomia e condições seguras, considerando a equidade entre gerações; assegurar o acesso amplo e democrático ao espaço urbano; atuar no sentido de eliminar ou reduzir segregação espacial; contribuir para inclusão social; dar suporte para que as comunidades sejam autônomas; visar o bem-estar dos indivíduos.

- Na esfera econômica: ser economicamente viável e acessível à população; funcionar de maneira eficiente; oferecer alternativas de modo de transporte aos modos motorizados individuais; favorecer uma economia dinâmica e diversa; contribuir para o desenvolvimento econômico local; prezar pela eficiência de recursos e eficiência operacional.

- Na esfera ambiental: estabelecer limites para emissões e geração de resíduos respeitando a capacidade do planeta; minimizar o consumo de recursos não renováveis; limitar o consumo de recursos renováveis de acordo com a produção dos mesmos; reutilizar e reciclar seus componentes; agir no sentido de minimizar o uso do solo e a produção de ruído; preservar a biodiversidade. 
Litman (2016) incorporou uma quarta esfera a ser considerada para um sistema de transporte sustentável: boa governança e planejamento, cujos objetivos são o planejamento integrado, compreensível e inclusivo e política de preços eficiente.

\subsection{Polos Geradores de Viagens (PGVs)}

De acordo com Kneib et al. (2010) e Parra (2006), Polos Geradores de Viagens (PGVs) são definidos como empreendimentos e locais em que atividades são desenvolvidas, em uma escala que gera grande número de viagens. Originalmente, eram denominados Polos Geradores de Tráfego (PGTs), termo que é definido pela CET (1983, p. 11) como:

Empreendimentos de grande porte [...] que atraem ou produzem grande número de viagens, causando reflexos negativos na circulação em seu entorno imediato e, em certos casos, prejudicando a acessibilidade de toda uma região, ou agravando as condições de segurança de veículos e pedestres.

O Departamento Nacional de Trânsito adota o mesmo conceito em seu Manual de Procedimentos para o Tratamento de Polos Geradores de Tráfego (DENATRAN, 2001, p. 8).

Até então, os PGTs consideravam apenas os impactos em seus arredores relativos ao trânsito e à circulação de veículos. Com o passar do tempo e com os debates acerca dos espaços urbanos, o conceito evoluiu no sentido de abranger não somente os impactos do tráfego motorizado (como congestionamentos, acidentes e fluxo de veículos), mas também dos deslocamentos realizados pelos demais modos de transporte e os impactos socioeconômicos na região e na qualidade de vida da população (KNEIB et al., 2010; REDE IBERO-AMERICANA DE ESTUDO EM POLOS GERADORES DE VIAGENS, 2005).

Os PGVs podem ser classificados de acordo com a sua natureza, ou seja, o tipo de atividade que exercem, e quanto à sua intensidade e ao volume de deslocamentos que geram. Quanto a sua natureza, podem ser empreendimentos como: shopping centers, hospitais, escolas, universidades e demais instituições de ensino, hotéis, hipermercados, estádios, indústrias, conjuntos residenciais, parques e áreas verdes, 
instalações com múltiplos serviços e atividades; e também infraestrutura de transportes como: aeroportos, estações ferroviárias, terminais de carga, portos e rodovias (REDE IBERO-AMERICANA DE ESTUDO EM POLOS GERADORES DE VIAGENS, 2005; CET, 1983; PARRA, 2006). Em relação à intensidade, são classificados segundo a CET (1983) como micropolos e macropolos. Os micropolos apresentam impactos leves, que, quando combinados, podem causar influência nas regiões em que estão localizados; os macropolos geram impactos significativos e requerem maior atenção do ponto de vista de planejamento.

Desta forma, para minimizar os possíveis impactos negativos que os PGVs podem causar em sua vizinhança, é preciso que o planejamento seja específico para seu contexto e realizado visando uma mobilidade sustentável (BALSAS, 2003; PARRA, 2006; MIRALLES-GUASCH e DOMENE, 2010; STEIN, 2013).

Apesar de o gerenciamento da mobilidade em PGVs ter sido foco de estudos nos EUA e na Europa previamente, somente em 1980 este tema começou a ser explorado no Brasil, principalmente devido às mudanças ocorridas nessa década na estrutura espacial das cidades (que passaram a se organizar de forma policêntrica, ou seja, em redes compostas por centro e subcentros, substituindo a antiga configuração monocêntrica, composta por apenas um centro) (KNEIB et al., 2010). Mesmo com o histórico de experiências internacionais, foi necessário que fossem desenvolvidos métodos de gerenciamento de PGVs compatíveis com o contexto brasileiro e com as características particulares de cada polo. O estudo de Rede Ibero-Americana de Estudo em Polos Geradores de Viagens (2015), por exemplo, propõe procedimentos, modelos e parâmetros para analisar os impactos destes empreendimentos.

\subsection{Planejamento em campi universitários}

Campi universitários configuram PGVs de características particulares e alta complexidade, motivo pelo qual devem ser tratados de forma diferenciada (PARRA, 2006; BALSAS, 2003; MEIRELES, 2014; STEIN e RODRIGUES DA SILVA, 2014 e 2017; RODRIGUES et al., 2005; CHUNG et al., 2018). Por abrigarem instituições de ensino e, consequentemente, constituírem uma comunidade de futuros tomadores de decisão, espera-se que os campi exerçam o papel de laboratório de boas práticas em diversos aspectos, inclusive no que diz respeito à mobilidade sustentável (TOLLEY, 1996; FERREIRA, 2011; DELMELLE e DELMELLE, 2012; MEIRELES, 2014; VALE et al., 2018). Além disso, os campi, em geral, apresentam ambientes de uso misto do 
solo, multimodais e caminháveis, sendo, portanto, locais propícios para boas práticas de mobilidade (CHERRY et al., 2018). Dessa forma, é aconselhável que se invista no planejamento desses PGVs, visto que apresentam um alto potencial de impacto positivo na sociedade (SHANNON et al., 2006).

Segundo Rodrigues et al. (2005), campi podem ser pensados como um espaço urbano; portanto, a base dos conceitos de mobilidade urbana sustentável e suas premissas podem ser adaptadas para o gerenciamento no contexto universitário. Para compreender as necessidades de um campus universitário e definir as estratégias a serem aplicadas, devem ser analisados sua área de influência, os tipos de usuários e seus padrões de viagens, compondo um diagnóstico (PARRA, 2006; DELL'OLIO et al., 2014; LONGO et al., 2015). Deve-se considerar que as condições de mobilidade em um campus dependem de fatores internos (como gestão, serviços e infraestrutura) e de fatores externos (políticas de transporte municipais, segurança pública); portanto, apesar de apresentarem uma administração independente, os campi universitários não são autossuficientes, uma vez que dependem da cidade em que estão inseridos (OLIVEIRA, 2015; CADENA et al., 2017)

Há pelo menos uma década existem estudos na bibliografia que buscam formas de melhorar as condições de mobilidade sustentável nos campi universitários (STEIN e RODRIGUES DA SILVA, 2017). Algumas pesquisas recentes são discutidas na sequência.

Em relação à avaliação de políticas e estratégias adotadas em campi universitários, Balsas (2003) realizou um levantamento da bibliografia disponível na época, analisando diversos campi e suas iniciativas para a substituição do modo automóvel por modos mais sustentáveis no ambiente universitário. Silva e Ferreira (2008) e Ferreira (2011) listaram exemplos de boas práticas em campi europeus, destacando que as mesmas apresentam pontos comuns: as ações têm sido implementadas com uma abordagem transversal e têm como foco reverter a dependência do uso do automóvel e incentivar a mudança de mentalidade. Ao abordar o contexto europeu, Ferreira (2011) descreve o projeto Students Today and Citizens Tomorrow (atualmente abreviado para T.aT.), iniciativa europeia que tem como objetivo analisar os padrões de deslocamento da comunidade universitária, propor medidas voltadas para a mobilidade sustentável e contribuir para a conscientização da população acadêmica acerca do tema. A atuação do projeto consiste nas seguintes etapas: realização de um diagnóstico da situação atual de campi em diferentes países; elaboração de planos de 
mobilidade para essas áreas, que incluem estudos de viabilidade técnica e econômica; implementação de serviços de carona e bicicletas compartilhadas; e, finalmente, o monitoramento e a avaliação dos resultados e seus impactos (como emissões de gases poluentes, consumo de combustível e uso de automóveis) (SILVA E FERREIRA, 2008; INTELLIGENT ENERGY EUROPE, 2010).

Dell'Olio et al. (2014) propuseram uma metodologia para avaliação de diferentes ações para o incentivo do uso de modos de transporte sustentáveis para os deslocamentos residência-campus. O método foi aplicado no campus Las Llamas da Universidade de Cantabria em Santander, no Norte da Espanha. Como a metodologia se propunha a ser adequada para aplicação em outros campi, o estudo serviu de base para a preparação de um guia metodológico para a criação de Planos de Mobilidade para Campi Universitários. Além disso, gerou resultados como os fatores de maior influência sobre a escolha do modo de transporte e as iniciativas de estímulo ao uso de modos de transporte sustentáveis mais populares (que, no caso, foram car sharing, carona, políticas de estacionamento e bicicletas compartilhadas).

Longo et al. (2015) elencaram propostas para a Universidade de Trieste, na Itália, que, em seguida, foram ranqueadas de acordo com o grau de prioridade com que se sugere que sejam postas em ação através do modelo baseado em método de análise hierárquica (AHP). Também na Itália, Rotaris e Danielis (2015) avaliaram a eficácia e a eficiência de ações através de uma análise de custo benefício, concebida com o intuito de poder ser replicada em outros campi e também em outros tipos de PGV, como escolas, hospitais, shopping centers e complexos comerciais. Rotaris e Danielis (2015) organizaram ainda uma revisão da bibliografia sobre estudos que abordam estratégias para a mobilidade sustentável em campi universitários em relação a políticas de estacionamento, incentivos para o uso de transporte público, transporte ativo, car sharing e análise de demanda.

No contexto brasileiro, a Universidade de São Paulo estabeleceu diretrizes e instrumentos para a elaboração de Planos de Mobilidade para os campi que a compõem (MARINS et al., 2015), demonstrando interesse e iniciativa acerca dessa questão. O desenvolvimento do trabalho contou com a participação de representantes de órgãos responsáveis pelo planejamento e pela gestão de diversos campi, enriquecendo o trabalho com visões complementares. 
A escolha do modo de transporte foi abordada por Stein e Rodrigues da Silva (2017), que investigaram barreiras, motivações e estratégias para a mobilidade sustentável no campus da USP de São Carlos através de modelo transteórico para a mudança de comportamento. Identificaram que, neste campus, uma parcela significativa de usuários estaria disposta a mudar de modo de transporte, sendo os grupos de estudantes de graduação e de pós-graduação os mais propensos a mudanças. Este resultado pode indicar que, se o campus fornecer as condições adequadas para incentivar essa mudança, existe o potencial de muitos usuários migrarem para modos de transporte mais sustentáveis.

Outros autores que abordaram o processo de escolha do modo de transporte foram Shannon et al. (2006) (potencial de mudança e barreiras e motivações que afetam a escolha do modo de transporte), Molina-Garcia et al. (2010) (relação da escolha do modo de transporte com aspectos psicossociais e ambientais), Miralles e Domene (2010) (potencial de mudança para modos mais sustentáveis), Akar e Clifton (2009) (barreiras e motivações para o uso de bicicleta no deslocamento até o campus) e Bopp et al. (2011) (padrões de comportamento de usuários de modos ativos nos deslocamentos até a universidade e dos usuários, através de critérios demográficos, comportamentais e ambientais).

A escassez de iniciativas voltadas para a interação entre comunidade e campus e para a mobilidade sustentável foi apontada por Dell'Olio et al. (2014) e Oliveira (2015) e motivou o estudo de Gavanas e Tsakalidis (2017). Gavanas e Tsakalidis (2017) questionaram a falta de comunicação entre as instituições de ensino, a qual dificulta com que o know how seja compartilhado e mais universidades estejam aptas a desenvolver suas próprias estruturas de avaliação. Partindo dessa premissa, os autores propuseram um método para o desenvolvimento de uma estrutura adequada para melhorar a acessibilidade e a sustentabilidade dos deslocamentos até a universidade e a interação entre comunidade e campus. O método não incluiu o uso de indicadores, mas foi elaborada uma estrutura para auxiliar na tomada de decisão em relação a iniciativas e investimentos para a melhoria da mobilidade sustentável. A proposta se baseou em diversas etapas: realização de um diagnóstico do campus estudado, revisão de boas práticas, matriz SWOT (da expressão em inglês que se refere aos pontos fortes, pontos fracos, oportunidades e ameaças) para formular a estrutura de políticas e medidas para a melhoria da mobilidade sustentável no trajeto residência-campus, priorização das ações e análise do envolvimento de atores. Como estudo de caso, o método foi testado na Instituição Tecnológica e Educacional de 
Tessália, na Grécia. A análise de boas práticas internacionais abrangeu Planos de Mobilidade e outras iniciativas de diversos campi europeus e americanos. Apesar das iniciativas desta universidade, os autores identificaram que não existe um consenso ou uma estrutura padrão para uma avaliação quantitativa e destacaram a importância de uma estrutura comum que possibilite a troca de informações a fim de avaliar o nível da mobilidade e acessibilidade de cada campus. Destacaram que a falta de uma estrutura comum é prejudicial, pois inviabiliza a realização de comparações, já que cada estudo apresenta diferentes tipos de dados.

\section{4 Índices como ferramenta de planejamento}

Indicadores são ferramentas amplamente utilizadas para fins de planejamento, pois permitem uma análise individual e objetiva, tanto quantitativa como qualitativa, do caso de interesse (CHAKHTOURA e POJANI, 2016). Como abordado por Gudmundsson (2004) e Costa (2008), o uso de indicadores são uma forma de transformar objetivos em metas operacionais e simplificar a complexidade do gerenciamento. Contudo, na maioria dos casos, o emprego de indicadores isolados pode não ser suficiente para realizar as avaliações necessárias, já que cada indicador se restringe a apontar a condição geral do fenômeno estudado sob um aspecto (COSTA, 2008; LITMAN, 2016). Assim, para uma análise completa, costuma-se empregar um conjunto de indicadores, que compõem um índice.

Os índices podem servir de suporte para a tomada de decisões, análises técnicas e discussões com o público em geral. Além disso, podem ser empregados com o intuito de avaliar o desempenho de ações, a partir da comparação com padrões ou objetivos a serem atingidos, podendo, nesta situação, ser chamados de medidas de performance (GUDMUNDSSON, 2004; COSTA, 2008). No caso do planejamento da mobilidade sustentável, os índices permitem o diagnóstico da mobilidade e a identificação dos elementos com potencial de melhoria, além do monitoramento dos impactos das intervenções realizadas ao longo do tempo.

Segundo o sistema de Sustainable Measures (2014), indicadores devem ser relevantes (mostrar algo importante a se conhecer), fáceis de compreender (mesmo por pessoas que não sejam especialistas no assunto), confiáveis e baseados em dados acessíveis (a informação deve estar disponível no momento necessário). Em relação a indicadores específicos de mobilidade sustentável, Costa (2008) aponta que estes devem ser válidos cientificamente, representativos, atrativos à mídia, comparáveis com indicadores concebidos em demais localidades, com custo viável de 
coleta de dados e análise, relevantes para o contexto em que estão inseridos e sensíveis a mudanças.

Para selecionar os indicadores a compor um índice, Litman (2016) levantou algumas considerações: a adoção de poucos indicadores facilita a etapa de coleta de dados, porém pode acarretar na negligência de fatores importantes para o estudo completo do fenômeno. Já uma grande quantidade de indicadores pode ser mais específica e conter mais detalhes, contudo sua coleta de dados e análises podem exigir mais recursos. É necessário, portanto, ponderar estes fatores em cada caso para elencar os indicadores a serem empregados.

Em seu estudo, Litman (2016) coletou e organizou indicadores encontrados na bibliografia de acordo com os temas abordados, fornecendo exemplos de conjuntos de indicadores para o desenvolvimento sustentável. Ao final de sua exploração, o autor recomendou indicadores a serem utilizados de acordo com os três pilares da sustentabilidade (LOW, 2003; GUDMUNDSSON, 2004) e sugeriu como o processo de planejamento deve ocorrer:

- Indicadores referentes à esfera econômica: mobilidade dos usuários por modo de transporte, transporte de carga, densidade do uso de solo, tempo médio de deslocamento e confiabilidade do deslocamento, velocidade média do transporte de cargas e confiabilidade do transporte de cargas, custos de congestionamento per capita, despesas totais de transporte, qualidade dos modos não motorizados, acessibilidade estrutural, proporção de domicílios com acesso à internet.

- Indicadores referentes à esfera social: matriz modal dos deslocamentos até 0 local de estudo/trabalho, dados de acidentes (com e sem vítimas) per capita, qualidade do transporte para pessoas com restrição de mobilidade, acessibilidade do transporte em termos financeiros, avaliação da satisfação geral com o sistema de transporte, design universal e inclusivo para pessoas com necessidades especiais, proporção de pessoas que caminham ou usam a bicicleta com frequência suficiente em termos de saúde, proporção de crianças que caminham ou vão à escola de bicicleta, nível com que recursos culturais são considerados no planejamento de transporte, custo de habitações em locais acessíveis, custos de transporte público.

- Indicadores referentes à esfera ambiental: consumo de energia per capita (por tipo de combustível e modo de transporte), consumo de energia por peso de carga transportada por distância, emissões relacionadas às mudanças 
climáticas, emissões de poluentes, exposição a poluição atmosférica e sonora e impactos na saúde, extensão do solo pavimentado para instalações de transporte, captação de águas pluviais, condições de habitação da comunidade, emissões de poluição de água, preservação de habitações no planejamento de transporte, uso de combustíveis renováveis, eficiência das fontes de energia utilizadas nas instalações de transporte, impactos em habitats naturais e recursos ambientais.

Para o processo de planejamento, Litman (2016) recomendou que o mesmo seja compreensível (considerando todos os impactos significativos e utilizando das melhores práticas disponíveis), inclusivo (buscando o envolvimento de todas as pessoas afetadas, com atenção para os grupos mais vulneráveis) e que se baseie mais em acessibilidade do que em mobilidade (considerando ocupação do solo e outros fatores de acessibilidade).

No contexto das cidades, Costa (2008) criou um índice de mobilidade urbana sustentável (denominado IMUS), o qual permite a avaliação e a monitoração da mobilidade urbana, orientando o planejamento da mobilidade sustentável em centros urbanos. Já Oliveira (2015) elaborou um índice de mobilidade sustentável específico para campus universitário (denominado IMSCamp) e o aplicou no campus da USP de São Carlos.

Os campi universitários podem, contudo, divergir entre si em vários aspectos, como, por exemplo, em seu porte, no ambiente em que estão inseridos (zona urbana ou zona rural), nos cursos que oferecem, etc. Em virtude disto, deve-se buscar um índice que possa ser transferível e passível de ser reaplicado de forma a atender às necessidades dos diferentes contextos. No caso do índice proposto por Oliveira (2015), no entanto, como ele foi concebido e aplicado em um único campus, seu potencial de transferência ainda é não conhecido.

\subsection{Potencial de transferência de índices}

A adaptação de índices consolidados foi explorada em estudos de áreas diversas, como saúde, ciências sociais e geografia (MARSHALL et al., 2003; SMITH et al., 2014; GUILLARD-GONÇALVES et al., 2015), porém não com o foco de uma análise quantitativa do potencial de transferência. 
$\mathrm{Na}$ área de transportes, Chakhtoura e Pojani (2016) apontaram não haver consenso sobre um conjunto de indicadores universal para a avaliação da mobilidade em cidades. Contudo, ressaltaram a importância de uma estrutura padrão que seja flexível e passível de ser ajustada aos diferentes contextos de aplicação, aos dados disponíveis e aos novos desafios, permitindo uma comparação entre localidades similares. Macário e Marques (2008) também trataram das condições de transferência de indicadores entre cidades, partindo da hipótese de que um conjunto de indicadores aplicados com sucesso em uma cidade poderia ser aplicado em uma nova localidade, desde que as cidades apresentassem características semelhantes (geográficas, demográficas, socioeconômicas, culturais, tecnológicas, institucionais e organizacionais). Todavia, salientaram a dificuldade de prever o potencial de transferência de um conjunto de indicadores, recomendando que este potencial seja avaliado posteriormente à adaptação e à aplicação do conjunto de indicadores a um novo caso.

Os estudos acima mencionados tinham como foco, no entanto, índices de mobilidade para cidades. Além disso, não apresentam um método de avaliação quantitativo do potencial de transferência possível de ser replicado para o caso de campi universitários, o que reforça a necessidade do desenvolvimento de um método de avaliação para este propósito.

$\mathrm{Na}$ ausência de índices consolidados de mobilidade sustentável em campi universitários e por se desconhecer se o IMSCamp pode ou não ser aplicado em diferentes contextos, não é possível comparar numericamente as condições de mobilidade entre campi. Para esta função, seria necessário um índice global, padronizado, que contemplasse as múltiplas necessidades que diferentes campi podem apresentar.

Neste contexto, o objetivo do presente trabalho é desenvolver e aplicar um método para avaliação do potencial de transferência de um índice de mobilidade sustentável. Para atingir este objetivo, o índice de mobilidade sustentável para campus universitário desenvolvido por Oliveira (2015) foi inicialmente aplicado a um novo contexto. Em seguida, foi realizada uma comparação com a aplicação original e avaliado o potencial de transferência deste índice através dos critérios desenvolvidos especificamente para este fim. Finalmente, foi realizado um painel de especialistas com o intuito de elencar possíveis indicadores para a concepção de um índice global de mobilidade para campus universitário. 
Para responder as questões identificadas na justificativa do trabalho, o método foi organizado em três itens: a aplicação do IMSCamp a um novo campus; a análise do potencial de transferência do referido índice, a partir da concepção original proposta por Oliveira (2015); e a realização de um painel de especialistas para levantar indicadores potenciais para compor um índice global. A estrutura do método proposta é mostrada na Tabela 3.1.

Tabela 3.1: Estrutura do método adotado, com a descrição das etapas e os subitens que as abordam nas seções Método e Resultados

\begin{tabular}{|c|c|c|c|}
\hline Etapa & $\begin{array}{c}\text { Subitem } \\
\text { relacionado na } \\
\text { seção } \\
\text { "Método" }\end{array}$ & $\begin{array}{c}\text { Subitem } \\
\text { relacionado na } \\
\text { seção } \\
\text { "Resultados" }\end{array}$ & Descrição da etapa \\
\hline
\end{tabular}

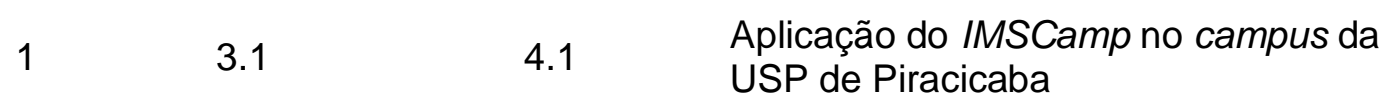

\begin{tabular}{|c|c|c|c|}
\hline \multirow[t]{2}{*}{2} & \multirow[t]{2}{*}{3.2} & \multirow[t]{2}{*}{4.2} & $\begin{array}{l}\text { Desenvolvimento de método de avaliação } \\
\text { de potencial de transferência de um índice } \\
\text { com base em três critérios: Número de } \\
\text { indicadores mantidos, número de } \\
\text { indicadores adicionados e número de } \\
\text { indicadores alterados }\end{array}$ \\
\hline & & & $\begin{array}{l}\text { Aplicação de método de avaliação de } \\
\text { potencial de transferência no caso São } \\
\text { Carlos - Piracicaba }\end{array}$ \\
\hline \multirow{3}{*}{3} & \multirow{3}{*}{3.3} & \multirow{3}{*}{4.3} & $\begin{array}{l}\text { Elaboração e aplicação de painel de } \\
\text { especialistas }\end{array}$ \\
\hline & & & $\begin{array}{l}\text { Avaliação dos resultados com o teste não } \\
\text { paramétrico de Friedman }\end{array}$ \\
\hline & & & $\begin{array}{l}\text { Sugestão de indicadores para a } \\
\text { composição de um índice global }\end{array}$ \\
\hline
\end{tabular}

\subsection{Uma nova aplicação do IMSCamp}

O estudo de caso consistiu em nova aplicação do índice de mobilidade sustentável para campus universitário (IMSCamp), originalmente concebido e aplicado por Oliveira (2015) no campus da USP de São Carlos. O IMSCamp era composto, para o contexto em que foi desenvolvido, por 20 indicadores, cada um com seu método de cálculo 
específico. Para que fosse possível analisar se o índice poderia ser empregado em diferentes contextos, sendo, portanto, um índice transferível, foi realizada uma nova aplicação, em outro campus: no caso, o da USP de Piracicaba.

O campus da USP de São Carlos é constituído por duas áreas: a Área 1, que abriga a maior parte das atividades acadêmicas e que está localizada na região central da cidade, apresentando fácil acesso; e a Área 2, existente desde 2001, com mais de 100 hectares e que está localizada na região periférica do município. O campus abriga 5 unidades de ensino (Escola de Engenharia de São Carlos, Instituto de Ciências Matemáticas e de Computação, Instituto de Física de São Carlos, Instituto de Química de São Carlos e Instituto de Arquitetura e Urbanismo), as quais oferecem 22 cursos de graduação presenciais e 18 programas de pós-graduação (USP, 2017).

O campus da USP de Piracicaba (Escola Superior de Agricultura "Luiz de Queiroz") também está localizado próximo ao centro da cidade e, além disso, apresenta fácil acesso a rodovias. O campus ocupa uma área de 3825,4 hectares, o que corresponde a 48,85\% da área total da Universidade de São Paulo, e compreende 4 estações experimentais (Anhembi, Anhumas, Itatinga e Fazenda Areão). Uma particularidade do campus é a de ser constituído por jardins, parques e prédios históricos tombados como patrimônio Público Estadual. Em termos de atividades acadêmicas, a Escola oferece 7 cursos de graduação e 15 programas de pós-graduação, organizados em 12 departamentos (USP, 2015).

As etapas realizadas para o cálculo do IMSCamp na nova aplicação são apresentadas na Figura 3.1 e detalhadas na sequência.

Figura 3.1: Etapas do IMSCamp (adaptado de OLIVEIRA, 2015)

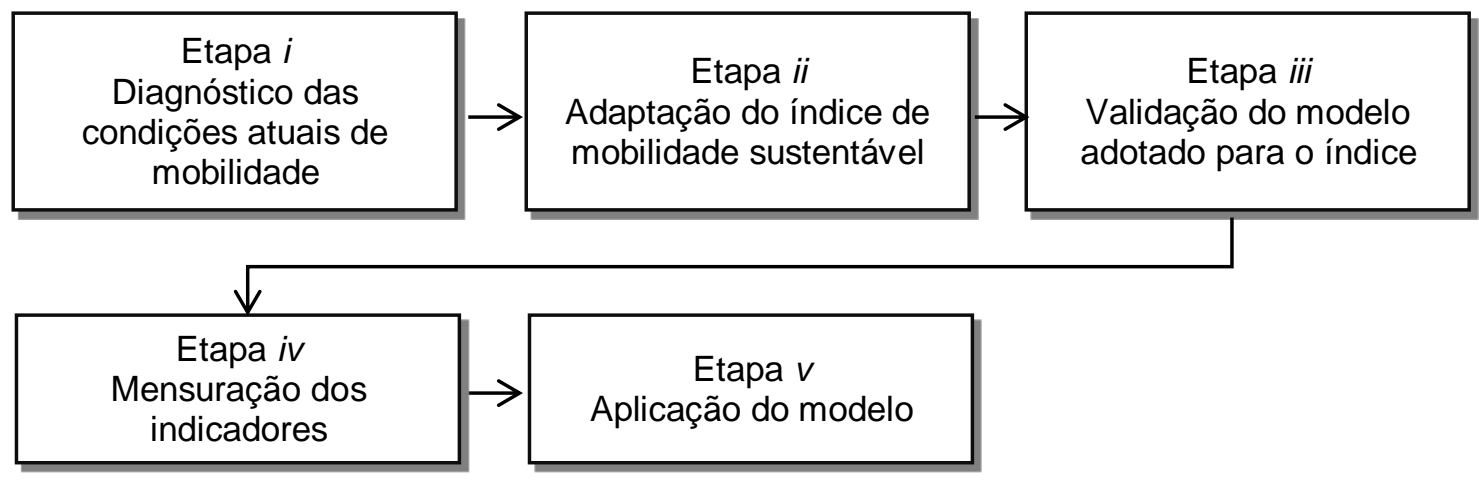


$\mathrm{Na}$ etapa $i$ é feita a contextualização do problema, buscando conhecer o campus e suas particularidades. Procura-se ainda obter a opinião dos usuários do campus acerca de suas necessidades de deslocamento, para compor um diagnóstico das condições atuais de mobilidade. Estas informações são coletadas por meio de questionário e, para análise do erro amostral, são empregadas as Equações 3.1 e 3.2 para amostragem aleatória simples, sob nível de confiança de 95\% (BARBETTA, 2004).

$$
\begin{aligned}
& n_{0}=\frac{z^{2} \times \sigma^{2}}{E_{0}^{2}} \\
& n=\frac{n_{0} \times N}{n_{0}+N}
\end{aligned}
$$

Em que:

$n_{0}$ : uma primeira aproximação para o tamanho da amostra

z: número de desvios padrão da tabela de distribuição normal

$\sigma$ : desvio padrão populacional

$E_{0}$ : erro amostral tolerável

$n$ : tamanho (número de elementos) da amostra

$N$ : tamanho (número de elementos) da população

Tem-se que $\sigma^{2}=p(1-p)$, em que $p$ é a proporção do evento na população. Para o caso crítico, considerado aquele em que a proporção de um evento produz maior variabilidade populacional, adota-se $p=0,5$. Assim, a partir da Equação 3.2 obtém-se a Equação 3.3:

$$
\begin{gathered}
n_{0}=\frac{z^{2} \times\left(\frac{1}{2} \times \frac{1}{2}\right)^{2}}{E_{0}^{2}} \\
n_{0}=\frac{z^{2}}{4 E_{0}^{2}} \\
n_{0}=\frac{1,96^{2}}{4 E_{0}^{2}}
\end{gathered}
$$

A etapa ii consiste em adaptar o índice original para a realidade do novo campus. Esta adaptação consiste essencialmente em: identificar indicadores pouco relevantes para o caso e que deveriam, portanto, ser suprimidos; elaborar indicadores para o caso de existirem aspectos necessários para o campus que não eram contemplados no índice 
original; realizar adaptações e alterações nos indicadores em relação ao método de cálculo no caso de dificuldade ou impossibilidade de obtenção de dados, potencial de melhoria nos indicadores originais, demanda dos usuários e gestores, etc.

Em seguida, a validação do modelo adotado para o índice (etapa iii da Figura 3.1) é feita através da atribuição de pesos a cada um dos indicadores selecionados, segundo diferentes critérios. Dois destes critérios refletem a percepção de usuários e gestores, enquanto que um terceiro critério se baseia na Teoria dos Pontos de Alavancagem, segundo a qual os indicadores relativos à conscientização dos usuários devem apresentar maior peso do que indicadores de gestão e serviços e de infraestrutura, por pressuporem um maior potencial de mudança de comportamento e, consequentemente, maior impacto positivo sobre a mobilidade sustentável (OLIVEIRA, 2015; MEADOWS, 1999). Devem ainda ser identificados os modos de transporte contemplados por cada um dos indicadores, possibilitando uma análise dos pesos relacionados a cada modo e sua adequação à Política Nacional de Mobilidade Urbana (BRASIL, 2012).

$\mathrm{Na}$ etapa iv, coletam-se os dados necessários para o cálculo dos indicadores. Além dos dados obtidos por meio do questionário (aplicado aos usuários do campus na etapa i), é necessário realizar levantamentos de campo, contagens e entrevistas.

De posse dos dados necessários, é possível calcular a pontuação (escore) de cada indicador, a qual reflete a condição dos aspectos abordados, na etapa $v$. Multiplicando o escore de cada indicador pelo seu respectivo peso, calcula-se a contribuição de cada um deles. A soma dessas contribuições compõe o valor final do índice de mobilidade para o campus em estudo.

Além do cálculo do índice, também são sugeridos indicadores a serem tratados com prioridade no processo de planejamento, de forma a direcionar os órgãos gestores do campus da USP de Piracicaba e, eventualmente, auxiliar na elaboração de um Plano de Mobilidade para o campus. Para isso, parte-se do princípio de que indicadores com escore baixo refletem condições ruins de mobilidade e, se tiverem peso alto, têm maior contribuição na diminuição do valor final do índice. Recomenda-se que estes indicadores sejam tratados com prioridade, pois se seus escores forem elevados, 0 impacto positivo no valor do índice será maior. 


\subsection{Potencial de transferência}

O método para avaliação do potencial de transferência foi desenvolvido a partir de três critérios: número de indicadores mantidos, número de indicadores adicionados e número de indicadores alterados. Estes critérios serão detalhados na sequência.

\subsubsection{Número de indicadores mantidos}

Este critério avalia o número de indicadores comuns ao índice original e ao índice adaptado. Entende-se que o caso ideal seria aquele em que todos os indicadores fossem comuns aos dois índices (100\%), o que faria com que o índice possuísse um alto potencial de transferência. Assim, o valor de 100\% corresponde à pontuação máxima de referência (um). Pelo contrário, índices com poucos indicadores comuns têm baixo potencial de transferência. Foi atribuído o valor de $50 \%$ como limite inferior de referência, pois se julgou que um índice que mantém apenas metade de seus indicadores para uma nova aplicação já está descaracterizado. Assim, valores iguais ou menores que 50\% correspondem à pontuação mínima (zero) na escala de referência.

\subsubsection{Número de indicadores adicionados}

Trata-se do número de indicadores que foram adicionados ao índice original para adequá-lo ao novo contexto. Um índice com alto potencial de transferência deve necessitar de poucas alterações em sua estrutura, pois já contempla as necessidades de ambientes diversos. Dessa forma, em um caso ideal, não seria necessário adicionar novos indicadores neste processo de adequação. Adotou-se $0 \%$ para a situação ótima (um) e 50\% para a situação péssima (zero). O valor de $50 \%$ foi atribuído por se considerar que a adição dessa parcela de indicadores seria excessiva e representaria uma necessidade de adaptação significativa, sendo o índice, assim, pouco transferível.

\subsubsection{Número de indicadores alterados}

Este critério se refere às alterações no método de cálculo dos indicadores. Estas alterações podem ser simples ou mais complexas. As alterações designadas como moderadas são aquelas em que um ou mais aspectos do indicador original são modificados para se ajustar a particularidades do novo caso. Já as alterações extremas são aquelas em que o indicador é completamente reformulado.

Para este critério, optou-se por atribuir pesos diferentes às alterações moderadas e às extremas, já que uma alteração extrema reflete um indicador que não é adequado 
para um novo contexto; sendo assim, o índice apresenta fatores que o tornam pouco transferível. No caso, foi adotado peso 2 para alterações moderadas e peso 5 para alterações extremas. Para a aplicação deste critério, deve-se identificar a porcentagem de indicadores que se encontram nas respectivas situações e então se calcula a contribuição dos indicadores com alterações moderadas e alterações extremas, multiplicando-se os pesos pelas porcentagens. Por fim, calcula-se a média ponderada deste critério.

Em relação aos valores de referência, a situação ótima é atingida quando a média ponderada deste critério resulta em zero. É o caso de quando nenhuma alteração é necessária para adequar os indicadores originais à nova aplicação. Em contrapartida, quanto maior a média ponderada resultante, maior o número de alterações exigidas para ajustar o índice. Neste sentido, foi necessário arbitrar o valor a ser utilizado na escala de referência correspondente à situação péssima. Quanto maior for este valor afixado, consequentemente, maior será a tolerância com as alterações. Já a escolha de um valor baixo para definir a escala reflete um posicionamento mais rigoroso, visto que implicará com que muitos casos sejam classificados como correspondentes à situação péssima. Esta avaliação é subjetiva e cabe aos planejadores determinar o que consideram tolerável para definir os valores de referência para a escala do critério. Assim, para gerar avaliações equilibradas e alinhadas com a percepção dos autores, uma análise de sensibilidade foi realizada, buscando um valor de referência razoável para a avaliação.

A análise de sensibilidade se baseou na comparação da média ponderada de 4 situações arbitradas pelos autores:

- Situação 1: 50\% dos indicadores originais necessitaram de alterações moderadas;

- Situação 2: $100 \%$ dos indicadores originais necessitaram de alterações moderadas;

- Situação 3: 50\% dos indicadores originais necessitaram de alterações extremas;

- Situação 4: 100\% dos indicadores originais necessitaram de alterações extremas.

Por indicadores originais entende-se, no caso aqui considerado, o conjunto de 20 indicadores do IMSCamp de Oliveira (2015). As médias ponderadas calculadas para cada uma das 4 situações são mostradas na Tabela 3.2. 
Neste caso, foi interpretado que circunstâncias como as representadas pelas situações 2, 3 e 4 deveriam ser avaliadas como péssimas (ver Tabela 3.2), pois as alterações sofridas pelos indicadores tornariam o índice pouco transferível neste quesito. Assim, buscou-se um valor próximo da média ponderada da situação 1 $(0,143)$ para ser fixado como pior situação na escala de referência. Optou-se por adotar o valor de 0,200; dessa forma, nessa simulação, os três últimos casos mostrados na Tabela 3.2 seriam avaliados como péssimos. Já a média ponderada da situação 1 não teria avaliação péssima, por estar abaixo do valor de 0,200. No entanto, por estar mais próxima de 0,200 do que de 0,000 , refletiria uma condição já bastante desfavorável.

Em resumo, a análise de sensibilidade forneceu elementos para que se fixassem os seguintes valores de referência para a escala de avaliação: 0,000 para o melhor caso (indicadores que não necessitaram de alterações) e 0,2000 para o pior caso. 
Tabela 3.2: Análise de sensibilidade da escala de referência do critério "Número de indicadores alterados" para avaliação do potencial de transferência de um índice

\begin{tabular}{|c|c|c|c|c|c|c|c|c|c|}
\hline \multirow{2}{*}{$\begin{array}{l}\text { Grau de } \\
\text { alteração }\end{array}$} & \multirow{2}{*}{$\begin{array}{l}\text { Peso do } \\
\text { grau de } \\
\text { alteração }\end{array}$} & \multicolumn{2}{|c|}{$\begin{array}{c}\text { Situação 1: } 50 \% \text { dos } \\
\text { indicadores com alterações } \\
\text { moderadas }\end{array}$} & \multicolumn{2}{|c|}{$\begin{array}{c}\text { Situação 2: } 100 \% \text { dos } \\
\text { indicadores com alterações } \\
\text { moderadas }\end{array}$} & \multicolumn{2}{|c|}{$\begin{array}{c}\text { Situação 3: 50\% dos } \\
\text { indicadores com alterações } \\
\text { extremas }\end{array}$} & \multicolumn{2}{|c|}{$\begin{array}{c}\text { Situação 4: } 100 \% \text { dos } \\
\text { indicadores com alterações } \\
\text { extremas }\end{array}$} \\
\hline & & $\begin{array}{c}\text { Porcentagem dos } \\
\text { indicadores originais } \\
\text { alterados }\end{array}$ & $\begin{array}{l}\text { Contri- } \\
\text { buição }\end{array}$ & $\begin{array}{c}\text { Porcentagem dos } \\
\text { indicadores originais } \\
\text { alterados }\end{array}$ & $\begin{array}{l}\text { Contri- } \\
\text { buição }\end{array}$ & $\begin{array}{c}\text { Porcentagem dos } \\
\text { indicadores originais } \\
\text { alterados }\end{array}$ & $\begin{array}{l}\text { Contri- } \\
\text { buiçãão }\end{array}$ & $\begin{array}{c}\text { Porcentagem dos } \\
\text { indicadores originais } \\
\text { alterados }\end{array}$ & $\begin{array}{l}\text { Contri- } \\
\text { buição }\end{array}$ \\
\hline $\begin{array}{l}\text { Alterações } \\
\text { moderadas }\end{array}$ & $2^{a}$ & $0,50^{c}$ & $1,00^{\mathrm{e}}$ & $1,00^{c}$ & $2,00^{e}$ & $0,00^{c}$ & $0,00^{e}$ & $0,00^{c}$ & $0,00^{e}$ \\
\hline $\begin{array}{l}\text { Alterações } \\
\text { extremas }\end{array}$ & $5^{b}$ & $0,00^{d}$ & $0,00^{f}$ & $0,00^{d}$ & $0,00^{f}$ & $0,50^{d}$ & $2,50^{f}$ & $1,00^{d}$ & $5,00^{f}$ \\
\hline \multicolumn{2}{|c|}{ Média ponderada * } & \multicolumn{2}{|l|}{$0,143^{g}$} & \multicolumn{2}{|l|}{$0,286^{g}$} & \multicolumn{2}{|l|}{$0,357^{\mathrm{g}}$} & \multicolumn{2}{|l|}{$0,714^{\mathrm{g}}$} \\
\hline
\end{tabular}

Obs.: A contribuição de cada parcela (denotada por $e$ e $f$ ) é calculada pelo peso multiplicado pela porcentagem de indicadores com alterações: $e=a \times c$;

$f=b \times d$. A média ponderada $(g)$ é calculada pela soma das contribuições dividida pela soma dos pesos: $g=\frac{e+f}{a+b}$.

* Quanto maior o valor, pior. 


\subsubsection{Avaliação do potencial de transferência}

Os três critérios acima mencionados ("Número de indicadores mantidos", "Número de indicadores adicionados" e "Número de indicadores alterados") são avaliados separadamente, com escalas de referência distintas. A Tabela 3.3 resume os valores de referência discutidos nos itens 3.2.1, 3.2.2 e 3.2.3 e definidos para o método. Para o cálculo das contribuições de cada um dos critérios, os escores serão normalizados para uma escala de 0 (péssimo) a 1 (ótimo) por meio de interpolação linear.

Tabela 3.3 - Escala de referência dos critérios definidos para avaliação do potencial de transferência de um índice

\begin{tabular}{lccc}
\hline & \multicolumn{2}{c}{ Escala de referência para normalização } \\
\cline { 2 - 4 } Critério & $\begin{array}{c}\text { Pior } \\
\text { avaliação } \\
\text { (zero) }\end{array}$ & 0 & $\begin{array}{c}\text { Melhor } \\
\text { avaliação } \\
\text { um) }\end{array}$ \\
\cline { 2 - 4 } $\begin{array}{l}\text { Número de } \\
\text { indicadores } \\
\text { mantidos }\end{array}$ & $50 \%$ & Interpolação linear & 1 \\
\hline $\begin{array}{l}\text { Número de } \\
\text { indicadores } \\
\text { adicionados }\end{array}$ & $50 \%$ & Interpolação linear & $100 \%$ \\
\hline $\begin{array}{l}\text { Número de } \\
\text { indicadores } \\
\text { alterados }\end{array}$ & 0,2 & Interpolação linear & $0 \%$ \\
\hline
\end{tabular}

Os três critérios podem apresentar pesos diferentes para compor o valor final do potencial de transferência, de acordo com a importância que lhes é atribuída. No caso, optou-se por adotar os pesos 0,250, 0,250 e 0,500, respectivamente, pela percepção dos autores de que indicadores com muitas alterações têm maior impacto negativo em relação à padronização e à possibilidade de fácil aplicação de um índice em diferentes contextos.

\subsection{Painel de especialistas}

Visto que, neste estudo, o potencial de transferência do IMSCamp é analisado tendo em vista somente duas aplicações (os campi da USP de São Carlos e de Piracicaba), sentiu-se a necessidade de recomendar um conjunto de indicadores para a formulação de um índice com caráter mais global, possível de ser transferido para diversos contextos. O painel de especialistas é proposto com o intuito de identificar o grau de relevância e de adequação dos indicadores de Oliveira (2015), de acordo com a 
percepção de profissionais atuantes em campi universitários diversos. Além disso, também permite identificar eventuais limitações dos indicadores.

O método empregado para o painel de especialistas consiste na aplicação de um questionário e uma análise dos resultados por meio de um teste estatístico.

\subsubsection{Questionário}

O questionário é organizado em duas partes: caracterização do campus em que o especialista atua ou tem experiência e avaliação dos 20 indicadores originais do IMSCamp (OLIVEIRA, 2015). A caracterização se refere à identificação do campus, sua localização (zona rural ou urbana) e apontamento de particularidades que possam interferir nas estratégias de planejamento de transporte. Na avaliação, o respondente é convidado a classificar sua percepção sobre os indicadores, de acordo com três critérios: relevância, adequação e necessidade de adaptações para a aplicação. Os três critérios são explicados ao especialista:

1. Este indicador é RELEVANTE para o seu campus? Ou seja, este aspecto é importante para o planejamento da mobilidade sustentável em seu campus?

2. Este indicador é ADEQUADO para ser aplicado em seu campus? O indicador aborda ações/infraestruturas/serviços existentes ou recomendados em seu campus?

3. Se o indicador não for adequado, qual seria a adaptação necessária para que o mesmo fosse aplicável em seu campus? Quais aspectos deveriam ser alterados, acrescentados ou retirados do indicador para que este se adequasse ao seu campus?

A classificação é então feita por meio de escala Likert com 7 níveis para os dois primeiros critérios (discordo totalmente, discordo, discordo parcialmente, neutro, concordo parcialmente, concordo e concordo totalmente). Para o terceiro critério, a resposta é dada em espaço que permite comentário aberto (caixa de comentário).

\subsubsection{Teste estatístico não paramétrico de Friedman}

Posteriormente à aplicação do questionário, é necessária a aplicação de um teste estatístico para verificar se existe concordância no julgamento dos especialistas em relação aos indicadores, no sentido de apontar aqueles considerados mais adequados e relevantes que os demais.

Neste estudo, optou-se pelo teste não paramétrico de Friedman. Testes não paramétricos são recomendados para problemas que não se adequam à estrutura 
clássica de inferência estatística (NOETHER, 1991). Estes testes não exigem normalidade da população ou igualdade das variâncias e podem ser aplicados em amostras menores com maior eficiência (CONCEIÇÃO, 2017).

De acordo com Noether (1991), o Teste de Friedman é geralmente utilizado nos chamados "problemas dos $n$ rankings", casos em que um número $n$ de pessoas (avaliadores) devem ordenar um número $k$ de objetos por ordem de preferência. Este tipo de experimento tem como objetivo descobrir se existe algum consenso entre as avaliações em relação à ordem de preferência, como é o caso do presente trabalho. $O$ Teste de Friedman examina a consistência dos ranks: quanto maior a concordância entre os avaliadores, maior é o valor da estatística de Friedman (SPRENT e SMEETON, 2007). Um baixo valor dessa estatística pode ser reflexo de duas circunstâncias:

1) Existir uma discordância considerável entre as opiniões dos avaliadores, resultando em ranks altos sendo anulados por ranks baixos atribuídos por outros avaliadores;

2) Os objetos serem ordenados aleatoriamente devido a uma falta de preferência dos avaliadores. Se os objetos diferem pouco uns dos outros, provavelmente os avaliadores os ordenam aleatoriamente.

Para o teste de hipótese (processo que permite aceitar ou rejeitar hipóteses), é necessário definir a hipótese nula e a hipótese alternativa. No caso do teste de Friedman, a hipótese nula é de que os ranks das avaliações de cada um dos indicadores são igualmente prováveis, ou seja, têm distribuição aleatória. Esta é a situação da circunstância 2 apresentada acima, em que não existe uma preferência por parte dos avaliadores. A hipótese alternativa é de que pelo menos um dos indicadores tem relevância e adequação diferenciados, ou seja, os ranks não são aleatórios e existem indicadores mais relevantes e adequados que outros.

No teste de Friedman parte-se dos seguintes pressupostos: a variável de interesse é ordinal (avaliação em escala Likert); as variáveis aleatórias são independentes (avaliadores distintos), ou seja, a avaliação de um especialista não interfere nas demais; para cada avaliador as observações podem ser ordenadas de acordo com algum critério de interesse. 
O teste de Friedman abrange diversas etapas, como determinar os ranks das observações, realizar correções para empate e efetuar comparações múltiplas entre os pares de observações. As etapas e as equações são as seguintes, de acordo com Conceição (2017):

Primeiramente, organizam-se os dados obtidos do questionário de forma que as avaliações dos especialistas constituam os blocos (linhas) e os 20 indicadores sejam os tratamentos (colunas). São atribuídos ranks das observações dentro de cada bloco e, no caso de empates, emprega-se a média da colocação. A estatística de Friedman é então dada pela Equação 3.4 .

$$
T_{1}=\frac{12}{b k(k+1)} \sum_{j=1}^{k} R_{j}{ }^{2}-3 b(k+1)
$$

Em que:

$b$ : Variáveis aleatórias independentes $k$-variadas $\left(X_{i 1}, X_{i 2}, \ldots, X_{i k}\right)$, chamadas $b$ blocos (ou amostras), $i=1, \ldots, b$

$k$ : Condições, efeitos ou tratamentos

R: Ranks atribuídos às observações dentro de cada bloco

A soma dos ranks de todos os tratamentos pode ser calculada pela Equação 3.5.

$$
\sum_{j=1}^{k} R_{j}=\frac{b k(k+1)}{2}
$$

Em caso de empates, deve ser realizada uma correção na estatística de Friedman $\left(T_{1}\right)$. Sendo $A_{1}$ a soma do quadrado dos ranks (Equação 3.6) e $C_{1}$ o fator de correção (Equação 3.7), o valor ajustado de $T_{1}\left(T_{1}^{*}\right)$ é calculado pela Equação 3.8.

$$
\begin{gathered}
A_{i}=\sum_{i=1}^{b} \sum_{j=1}^{k}\left[R\left(X_{i j}\right)\right]^{2} \\
C_{1}=\frac{b k(k+1)^{2}}{4} \\
T_{1}^{*}=\frac{(k-1)\left(\sum_{j=1}^{k} R_{j}{ }^{2}-b C_{1}\right)}{\left(A_{1}-C_{1}\right)}
\end{gathered}
$$


Compara-se o valor de $T_{1}{ }^{*}$ com o valor de Qui Quadrado crítico consultado em tabela de distribuição de acordo com o número de graus de liberdade e nível de significância definido. Caso $\mathrm{T}_{1}{ }^{*}$ seja maior que $\chi^{2}{ }_{\text {crit }}$, a hipótese nula é rejeitada, indicando que os ranks podem não ser aleatórios. Neste caso, devem ser feitas comparações múltiplas entre os pares de tratamentos para identificar quais deles são considerados distintos. Esta distinção é comprovada se a condição estabelecida na Equação 3.9 se verificar.

$$
\left|R_{j}-R_{i}\right|>t_{1-\alpha / 2}\left[\frac{2\left(b A_{1}-\sum R_{j}^{2}\right)}{(b-1)(k-1)}\right]^{(1 / 2)}
$$

Em que $t_{1-\alpha / 2}$ é o quantil $(1-\alpha / 2)$ da distribuição $t$ - Student com $(b-1)(k-1)$ graus de liberdade.

Para demonstrar a aplicação do teste de Friedman, um exemplo numérico com banco de dados simplificado é mostrado na sequência.

\section{Exemplo de aplicação do teste de Friedman}

Propõe-se o seguinte exemplo numérico da aplicação do teste de Friedman em um banco de dados reduzido: 4 especialistas que avaliam 4 indicadores em relação à sua relevância. A avaliação é dada em escala Likert, convertendo-se a resposta "discordo totalmente" para o valor 1 e "concordo totalmente" para o valor 7. As avaliações obtidas são mostradas na Tabela 3.4.

Tabela 3.4: Parte do exemplo de aplicação do teste de Friedman. Avaliações de 4 indicadores feitas por 4 especialistas em escala Likert, em que 1 equivale a "discordo totalmente" e 7 a "concordo totalmente".

\begin{tabular}{ccccc}
\hline \multicolumn{5}{c}{ Avaliações dos indicadores } \\
\hline \multirow{2}{*}{ Avaliadores } & \multicolumn{5}{c}{ Indicadores } \\
\cline { 2 - 5 } & 1 & 2 & 3 & 4 \\
\hline A & 2 & 3 & 3 & 7 \\
\hline B & 1 & 4 & 4 & 5 \\
\hline C & 2 & 3 & 3 & 6 \\
\hline D & 4 & 4 & 5 & 6 \\
\hline
\end{tabular}

Os avaliadores são referidos como blocos (linhas) e os indicadores como tratamentos (colunas). 
São atribuídos ranks dentro de cada bloco, ou seja, linha a linha, e são corrigidos os empates, empregando-se a média da colocação. Os ranks são mostrados na Tabela 3.5. Nas últimas duas linhas, são calculados a soma dos ranks de cada tratamento (indicador) e o quadrado da soma dos ranks.

Tabela 3.5: Parte do exemplo de aplicação do teste de Friedman. Ranks dos 4 indicadores segundo a avaliação dos especialistas. Rank atribuído em ordem crescente, ou seja, quanto menor a nota de avaliação, menor o valor do rank.

\begin{tabular}{ccccc}
\hline \multicolumn{5}{c}{ Ranks dos indicadores } \\
\hline \multirow{2}{*}{ Avaliadores } & \multicolumn{4}{c}{ Indicadores } \\
\cline { 2 - 5 } & 1 & 2 & 3 & 4 \\
\hline A & 1 & 2,5 & 2,5 & 4 \\
\hline$B$ & 1 & 2,5 & 2,5 & 4 \\
\hline C & 1 & 2,5 & 2,5 & 4 \\
\hline$D$ & 1,5 & 1,5 & 3 & 4 \\
\hline$R_{\mathrm{j}}$ & 4,5 & 9 & 10,5 & 256 \\
\hline $\mathrm{R}_{\mathrm{j}}{ }^{2}$ & 20,25 & 81 & 110,25 & 25 \\
\hline
\end{tabular}

A estatística de Friedman é então calculada pela Equação 3.4.

A soma dos ranks ao quadrado é dada por:

$$
\sum_{j=1}^{k} R_{j}^{2}=4,5^{2}+9^{2}+10,5^{2}+16^{2}=467,5
$$

Assim, tem-se:

$$
\begin{gathered}
T_{1}=\frac{12}{4 \times 4(4+1)} \times 467,5-3 \times 4(4+1) \\
T_{1}=10,125
\end{gathered}
$$

Como ocorreram empates nas avaliações, foi necessário realizar uma correção na estatística de Friedman $\left(T_{1}\right)$. Para isso, foram utilizadas as Equações 3.6, 3.7 e 3.8.

Para calcular $A_{1}$, são necessários os quadrados de todos os ranks individuais.

$$
\begin{gathered}
A_{1}=1^{2}+2,5^{2}+2,5^{2}+4^{2}+1^{2}+2,5^{2}+2,5^{2}+4^{2}+1^{2}+2,5^{2}+2,5^{2}+4^{2}+1,5^{2}+1,5^{2}+3^{2}+4^{2} \\
A_{1}=118
\end{gathered}
$$




$$
\begin{gathered}
C_{1}=\frac{4 \times 4(4+1)^{2}}{4} \\
C_{1}=100 \\
T_{1}^{*}=\frac{(4-1)(467,5-4 \times 100)}{118-100} \\
T_{1}^{*}=11,25
\end{gathered}
$$

Compara-se o valor de $\mathrm{T}_{1}{ }^{*}$ com o valor de Qui Quadrado crítico consultado em tabela de distribuição de acordo com o número de graus de liberdade e nível de significância definido.

O número de graus de liberdade é calculado por:

$$
G L=k-1=4-1=3
$$

Assim, para nível de significância de 5\% e 3 graus de liberdade:

$$
\begin{gathered}
\chi^{2}{ }_{\text {crit }}=7,815 \\
T_{1}^{*}>\chi_{\text {crítico }}^{2} \therefore H_{0} \text { é rejeitada }
\end{gathered}
$$

Como $\mathrm{T}_{1}{ }^{*}$ é maior que $\chi^{2}{ }_{\text {crit }}$, a hipótese nula é rejeitada, indicando que os ranks podem não ser aleatórios. Neste caso, devem ser feitas comparações múltiplas entre os pares de tratamentos para identificar quais deles podem ser considerados distintos. Para isto, emprega-se a Equação 3.9.

O número de graus de liberdade a ser empregado é:

$$
G L=(b-1) \times(k-1)=(4-1) \times(4-1)=9
$$

Para nível de significância $5 \%, t_{1-\alpha / 2}$ consultado em tabela de distribuição $t$ de Student para 9 graus de liberdade é 2,262. Portanto, tem-se:

$$
t_{1-\alpha / 2}\left[\frac{2\left(b A_{1}-\sum R_{j}{ }^{2}\right)}{(b-1)(k-1)}\right]^{1 / 2}=2,262 \times\left[\frac{(2 \times((4 \times 118)-467,5)}{(4-1)(4-1)}\right]^{1 / 2}=2,262
$$

Em seguida, são feitas as comparações par a par. Essas comparações são realizadas em relação aos ranks finais de cada indicador, dados pela soma dos ranks individuais atribuídos pelos 4 especialistas e organizados na Tabela 3.6. 
Tabela 3.6: Parte do exemplo de aplicação do teste de Friedman. Ranks finais de cada indicador, dados pela soma dos ranks individuais atribuídos pelos 4 especialistas.

\begin{tabular}{cc}
\hline Indicador & Rank \\
\hline 1 & 4,5 \\
\hline 2 & 9 \\
\hline 3 & 10,5 \\
\hline 4 & 16 \\
\hline
\end{tabular}

Estes ranks são referidos como $R_{j}$ na Tabela 3.5 e nas operações matemáticas realizadas no teste. Portanto, os ranks dos indicadores 1, 2, 3 e 4 são intitulados $R 1$, $\mathrm{R} 2, \mathrm{R} 3$ e $\mathrm{R} 4$ respectivamente.

Os ranks indicam o grau de concordância entre os especialistas em relação à relevância dos indicadores: quanto maior o valor do rank, maior a concordância. Assim, os ranks sugerem que há um consenso de que o indicador 4 é relevante, seguido pelo indicador 3 , em seguida o indicador 2 e, por último, o indicador 1 . Cabe analisar se as diferenças entre o consenso da relevância dos pares de indicadores são significativas; estas serão detectadas pelas comparações múltiplas do teste de Friedman. Se as comparações múltiplas não apontarem diferença, tais indicadores podem ser considerados semelhantes.

A Tabela 3.7 mostra a operação $\left|R_{j}-R_{i}\right|$, parte da Equação 3.9. Em destaque, as diferenças maiores do que o valor 2,262, condição necessária para que os indicadores possam ser considerados de relevância distinta. 
Tabela 3.7: Parte do exemplo de aplicação do teste de Friedman. Comparações múltiplas entre os ranks dos indicadores, feitas pela operação $\left|R_{j}-R_{i}\right|$. Em destaque, as diferenças maiores do que o valor de referência $(2,262)$.

\begin{tabular}{ccccc}
\hline \multicolumn{5}{c}{ Comparações múltiplas entre os ranks dos indicadores $\left(\left|R_{j}-R_{i}\right|\right)$} \\
\hline & $\begin{array}{c}\mathrm{R} 1 \\
(4,5)\end{array}$ & $\begin{array}{c}\mathrm{R} 2 \\
(9)\end{array}$ & $\begin{array}{c}\mathrm{R} 3 \\
(10,5)\end{array}$ & $\begin{array}{c}\mathrm{R} 4 \\
(16)\end{array}$ \\
\hline $\begin{array}{c}\mathrm{R} 1 \\
(4,5)\end{array}$ & 0 & 4,5 & 6 & $\mathbf{1 1 , 5}$ \\
\hline $\begin{array}{c}\mathrm{R} 2 \\
(9)\end{array}$ & 4,5 & 0 & 1,5 & 7 \\
\hline $\begin{array}{c}\mathrm{R} 3 \\
(10,5)\end{array}$ & $\mathbf{6}$ & 1,5 & 0 & $\mathbf{5 , 5}$ \\
\hline $\begin{array}{c}\mathrm{R} 4 \\
(16)\end{array}$ & $\mathbf{1 1 , 5}$ & $\mathbf{7}$ & $\mathbf{5 , 5}$ & 0 \\
\hline
\end{tabular}

Neste caso, as comparações múltiplas dão suporte para que se compreenda que, entre os especialistas:

- Há maior concordância a respeito de o indicador 4 ser relevante do que a respeito de os indicadores 3,2 e 1 serem relevantes.

- Há concordância equivalente a respeito de os indicadores 3 e 2 serem relevantes. Há maior concordância a respeito de o indicador 3 ser relevante do que a respeito de o indicador 1 ser relevante.

- Há maior concordância a respeito de o indicador 2 ser relevante do que a respeito de o indicador 1 ser relevante.

Assim, pode-se organizar os indicadores por ordem de concordância de relevância (no topo, a maior concordância) segundo o julgamento dos especialistas (Tabela 3.8).

Tabela 3.8: Parte do exemplo de aplicação do teste de Friedman. Lista de indicadores organizados por ordem de concordância de relevância segundo o julgamento de 4 especialistas. No topo, a maior concordância.

\begin{tabular}{c}
\hline Indicadores organizados por ordem de concordância de relevância \\
\hline Indicador 4 \\
\hline Indicadores 3 e 2 \\
\hline Indicador 1 \\
\hline
\end{tabular}

O esquema apresentado na Figura 3.2 organiza as etapas do método de maneira visual. 
Figura 3.2: Conjunto de procedimentos e ferramentas que formam a metodologia, separados em etapas e associados aos recursos utilizados para seu desenvolvimento

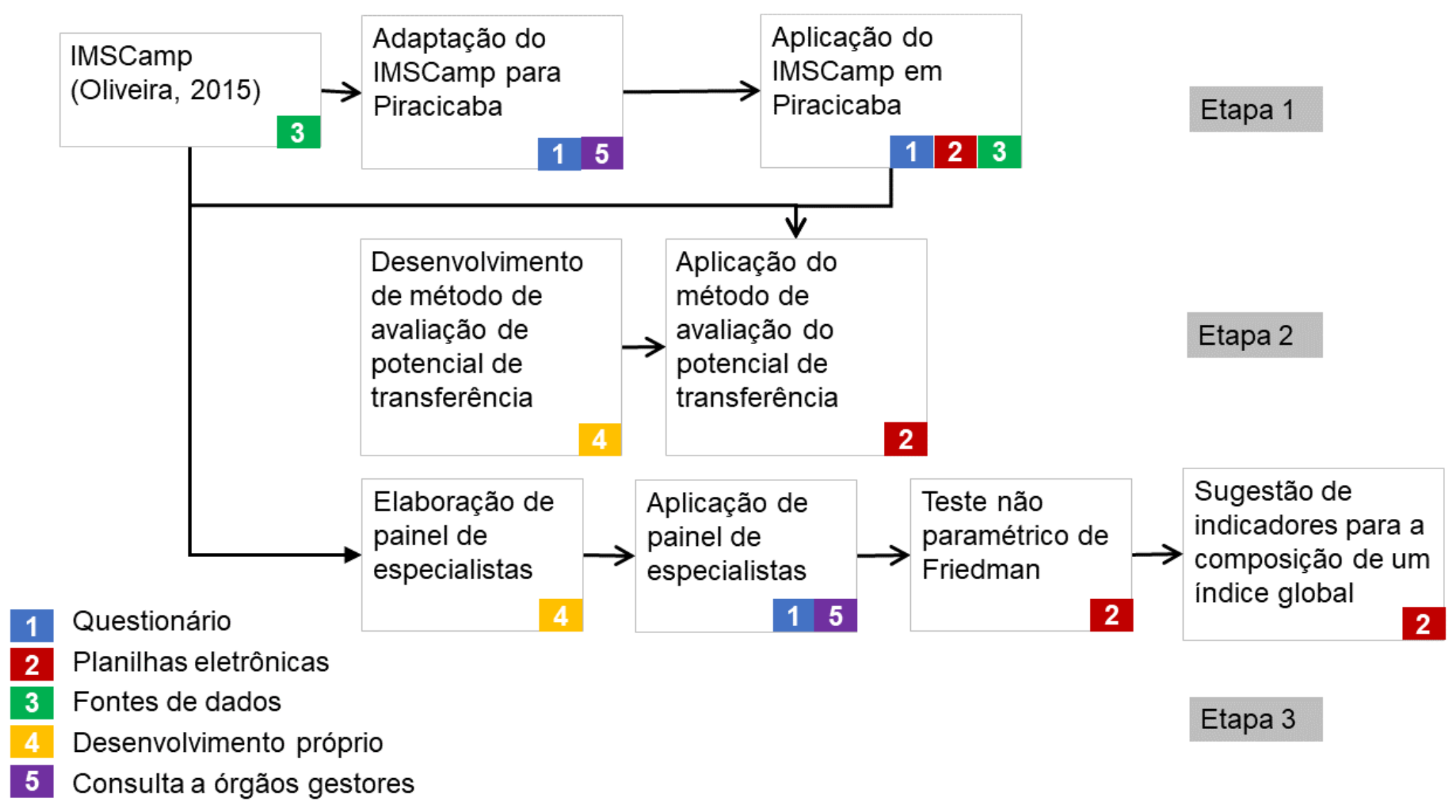


Os resultados obtidos serão apresentados em três subitens: primeiramente, a aplicação do índice de mobilidade sustentável de Oliveira (2015) no campus da USP de Piracicaba; em seguida, a aplicação do método de avaliação do potencial de transferência; e, por fim, o painel de especialistas.

\subsection{Aplicação do IMSCamp em Piracicaba}

A nova aplicação do IMSCamp, objeto deste estudo, ocorreu no campus da USP de Piracicaba. Na etapa $i$ foi realizada uma contextualização do problema por meio de reuniões com os gestores do referido campus. Adicionalmente, obteve-se a manifestação dos usuários através de um questionário online, adaptado de Oliveira (2015), o que possibilitou um diagnóstico das condições atuais de mobilidade.

A adaptação do questionário envolveu alterações de conteúdo, para adequar as perguntas ao novo contexto, e também de estrutura. O questionário original foi dividido em duas fases, de forma a reduzir o tempo necessário para o preenchimento de cada uma delas. Nesta organização, que potencialmente garante maior taxa de respostas completas (pelo menos por fase), a primeira delas abrangeu a caracterização geral dos usuários e seus deslocamentos principais ao campus da USP de Piracicaba. Já a segunda fase foi elaborada em diversas versões, cada uma direcionada a um grupo de respondentes de acordo com seus modos principais de deslocamento. Dessa forma, foi possível escolher as perguntas mais relevantes para cada modo de transporte e aprofundar as análises separadamente.

O questionário aplicado, constituído de 50 perguntas, foi enviado no dia 23 de janeiro de 2017 para 3490 contatos e no dia 30 de março de 2017 para 435 contatos (lista obtida posteriormente devido ao período de matrícula e abrangendo, portanto, os alunos ingressantes do referido ano). Os convites foram enviados aos endereços de email institucionais fornecidos pelas unidades do campus, a fim de atingir todos os grupos de usuários, independentemente do tipo de vinculação (alunos de graduação, alunos de pós-graduação, servidores técnicos/administrativos, servidores docentes e outros). Como frequentadores sem vinculação com a universidade não possuem email institucional e, consequentemente, não receberam o convite para responder ao questionário, foi elaborado um modelo a ser aplicado em campo para coletar estas informações. A plataforma online empregada permitiu o acompanhamento das 
respostas e o rastreamento dos usuários que possam ter ignorado o convite ou respondido parcialmente ao questionário. Tais candidatos foram convidados novamente para iniciar ou prosseguir com o preenchimento, aumentando assim a adesão e a taxa de respostas completas. A pesquisa foi encerrada no dia 18 de abril de 2017 com um total de 1082 respostas (912 completas e 170 parciais).

A Tabela 4.1 mostra os dados de população oficiais do campus da USP de Piracicaba (USP, 2014) comparados com a distribuição das respostas coletadas por tipo de vinculação com a universidade.

Tabela 4.1: Distribuição das respostas obtidas no questionário por tipo de vinculação com a universidade

\begin{tabular}{lccccc}
\hline \multicolumn{1}{c}{ Vinculação } & $\begin{array}{c}\text { Dados da população } \\
\text { (USP, 2014) }\end{array}$ & \multicolumn{2}{c}{$\begin{array}{c}\text { Respostas do } \\
\text { questionário }\end{array}$} & $\begin{array}{c}\text { Parcela da } \\
\text { população } \\
\text { contida na } \\
\text { amostra }\end{array}$ \\
\hline Alunos de graduação & 2133 & $44 \%$ & 373 & $38 \%$ & $17 \%$ \\
\hline Alunos de pós-graduação & 1507 & $31 \%$ & 297 & $31 \%$ & $20 \%$ \\
\hline Servidores docentes & 275 & $6 \%$ & 98 & $10 \%$ & $36 \%$ \\
\hline Servidores técnicos/administrativos & 943 & $19 \%$ & 208 & $21 \%$ & $22 \%$ \\
\hline Total & 4858 & $100 \%$ & 976 & $100 \%$ & $20 \%$ \\
\hline
\end{tabular}

Obs.: Além das categorias citadas, o questionário apresentava as opções de vinculação "sem vinculação com a universidade - visitantes" e "outros". Essas categorias obtiveram 5 e 68 respostas, respectivamente. Como não constavam no banco de dados da população (USP, 2014) e, portanto, não seria possível expandir a amostra dessas classes, estes dados não foram contabilizados nas análises deste estudo.

No que diz respeito à vinculação, a distribuição dos respondentes do questionário foi próxima à realidade da população de usuários regulares do campus. A maior discrepância, em termos de pontos percentuais, foi encontrada na categoria alunos de graduação. Segundo dados oficiais, esta parcela representaria $44 \%$ do total (USP, 2014). No questionário, 38\% dos respondentes declararam pertencer a este grupo.

Para melhor compreensão da representatividade da amostra obtida, foi realizada a análise do erro amostral do número de respostas coletadas no total e separadamente, de acordo com os quatro tipos de vinculação com a universidade.

Dado que a população oficial do campus da USP de Piracicaba é de 4858 indivíduos $(N)$, para erro amostral de $2 \%\left(E_{0}\right)$ os cálculos são os seguintes, de acordo com as Equações 3.2 e 3.3: 


$$
\begin{gathered}
n_{0}=\frac{1,96^{2}}{4 \times 0,02^{2}}=2401 \\
n=\frac{2401 \times 4858}{2401+4858}=1607
\end{gathered}
$$

Isso significa que seriam necessárias 1607 respostas do questionário para constituir uma amostra com erro amostral de $2 \%$ e nível de confiança de 95\%. O valor 1607 corresponde a 33,08\% da população total de 4858 usuários do campus. Como foram obtidas 976 respostas (que correspondem a 20,09\% de 4858), o erro amostral foi maior do que $2 \%$. Assim, os cálculos foram feitos para erro amostral de $3 \%$ e $4 \%$. Os resultados obtidos para erros amostrais de $2 \%, 3 \%$ e $4 \%$ são mostrados na Tabela 4.2.

Tabela 4.2: Cálculo do tamanho necessário de amostra para erros amostrais de $2 \%$, 3\% e 4\% para população de 4858 indivíduos.

\begin{tabular}{lccc}
\hline$N$ (número de elementos da população) & & 4858 \\
\hline$E_{0}$ (erro amostral tolerável) & 0,02 & 0,03 & 0,04 \\
\hline$n_{0}$ (aproximação para o tamanho amostra) & 2401 & 1067 & 600 \\
\hline$n$ (número de elementos da amostra) & 1607 & 875 & 534 \\
\hline$\%$ da população a que $n$ corresponde & $33,08 \%$ & $18,01 \%$ & $11,00 \%$ \\
\hline
\end{tabular}

Em relação ao número total de respondentes, é possível dizer que a amostra apresentou um erro amostral de $3 \%$, pois para este valor era necessária uma amostra de, no mínimo, 18,01\% do total de usuários, e a amostra real foi de $20,09 \%$ do total de usuários.

A mesma análise foi realizada por tipo de vinculação com a universidade. Comparando-se as Tabelas 4.1 (coluna "Parcela da população contida na amostra") e 4.2, é possível identificar o erro amostral de cada uma das categorias. A categoria dos servidores docentes é a mais bem representada (36\%), o que permite com que seu erro amostral seja de $2 \%$. Já as categorias de alunos de pós-graduação e servidores técnicos/administrativos obtiveram amostras menores (20\% e $22 \%$, respectivamente), apresentando erro amostral de 3\%. Apesar do grande número de respostas em valor absoluto, a categoria menos representada é a de alunos de graduação, com 17\% da 
parcela da população contida na amostra. Com isso, para essa categoria o erro amostral é de $4 \%$.

Para melhor representação da realidade, nos casos em que foi necessário, os resultados do questionário analisados foram expandidos de forma a manter a distribuição por vinculação da população do campus.

A etapa ii do método (adaptação do índice de mobilidade sustentável, conforme a Figura 3.1), feita a partir das contribuições do questionário online e de consultas à Comissão de Mobilidade, resultou em um índice com 19 indicadores, organizados em 9 temas e 3 domínios, como mostra a Figura 4.1.

As etapas iii, iv e $v$ (Validação do modelo adotado para o índice, Mensuração dos indicadores e Aplicação do modelo) geraram os resultados mostrados na Tabela 4.3. Os pesos para a validação do modelo foram adotados de acordo com os seguintes critérios: a frequência com que o aspecto avaliado pelo indicador foi mencionado pelos usuários no questionário; consultas à Comissão de Mobilidade; e a Teoria dos Pontos de Alavancagem (OLIVEIRA, 2015; MEADOWS, 1999). Na sequência, foram identificados os modos de transporte contemplados por cada um dos indicadores. A Política Nacional de Mobilidade Urbana (BRASIL, 2012) recomenda que modos não motorizados sejam priorizados no processo de planejamento; os indicadores que contemplam estes modos devem, portanto, apresentar pesos maiores que os demais. Esta análise foi realizada e foram feitos alguns ajustes para atender a essa premissa. 
Figura 4. 1: Modelo hierárquico, composto por 3 Domínios (Educação, Infraestrutura e Gestão e Serviços), 8 Temas (primeira subdivisão interna dos Domínios) e 19 Indicadores (retângulos tracejados), adotado no IMSCamp para o campus da USP em Piracicaba

\section{Índice de mobilidade sustentável do campus universitário (adaptado)}

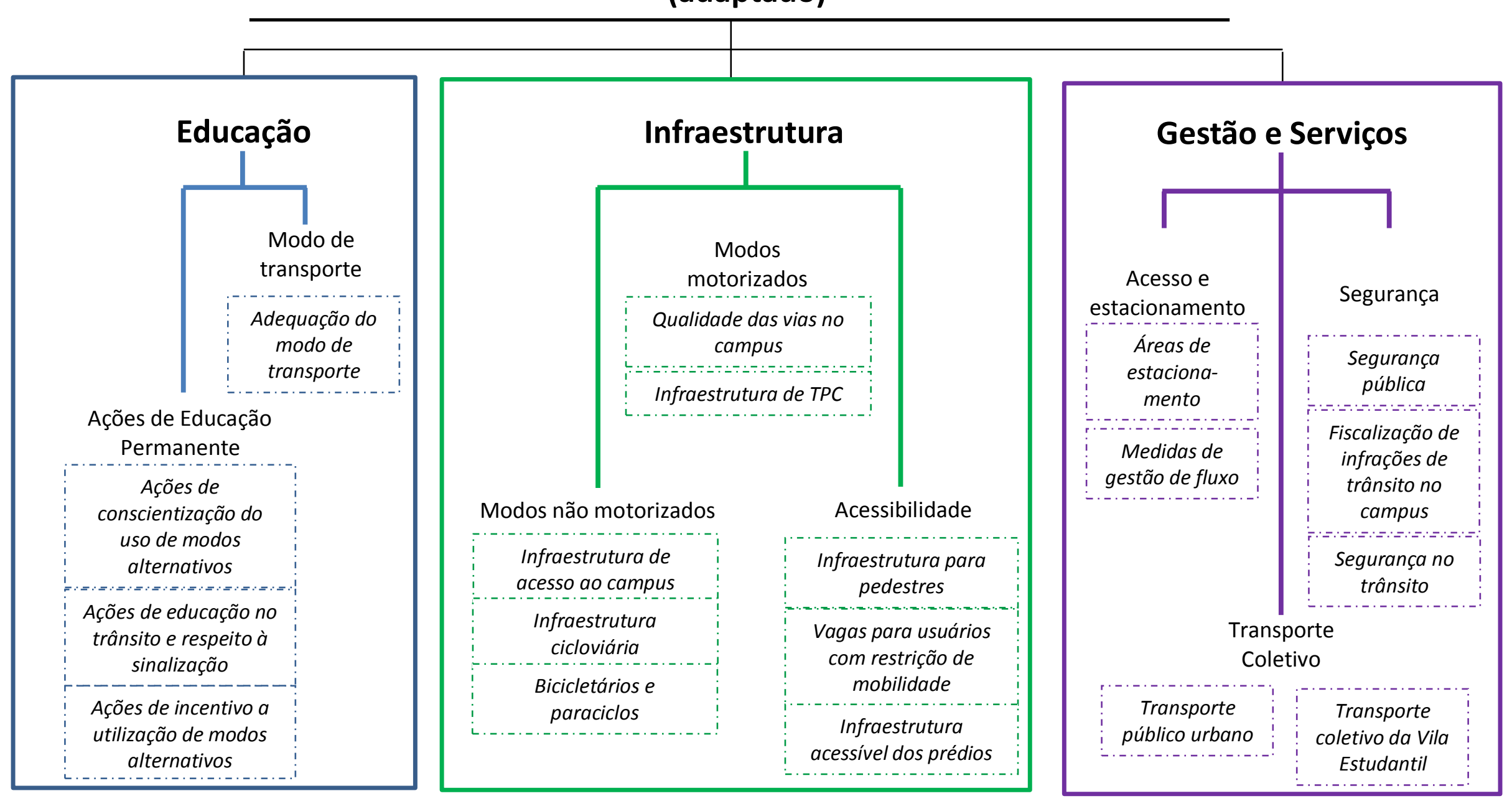


Em síntese, os pesos ( $2^{\mathrm{a}}$ coluna da Tabela 4.3) refletem a importância atribuída a cada indicador ( $1^{\text {a }}$ coluna) e, somados, resultam no valor um. Já os escores (3 $3^{\underline{a}}$ coluna) são independentes de indicador para indicador e podem variar de zero a um (sendo zero o pior caso e um o melhor caso). Multiplicando o peso pelo escore, obtémse a contribuição de cada indicador (4⿳亠丷a coluna) para o valor global do índice, que aparece como uma soma no final da tabela. A $5^{\underline{a}}$ coluna mostra a prioridade de intervenção de cada indicador, sugerida de acordo com a tabela de referência (Tabela 4.4).

Tabela 4.3: Pesos, escores e contribuição dos indicadores que compõem o Índice de Mobilidade Sustentável adaptado para o campus da USP de Piracicaba (IMSCamp).

\begin{tabular}{|c|c|c|c|c|}
\hline Indicadores & Peso & Escore & $\begin{array}{c}\text { Contribuição } \\
\text { para o valor } \\
\text { global do } \\
\text { índice }\end{array}$ & $\begin{array}{l}\text { Prioridade } \\
\text { (5 - máxima } \\
\text { prioridade) }\end{array}$ \\
\hline $\begin{array}{l}\text { 1.1.1 Ações de conscientização do } \\
\text { uso de modos alternativos }\end{array}$ & 0,049 & 0,474 & 0,023 & 2 \\
\hline $\begin{array}{l}1.1 .2 \text { Ações de educação no trânsito e } \\
\text { respeito à sinalização }\end{array}$ & 0,111 & 0,417 & 0,046 & 4 \\
\hline $\begin{array}{l}\text { 1.1.3 Accões de incentivo à utilização } \\
\text { de modos alternativos }\end{array}$ & 0,132 & 0,083 & 0,011 & 5 \\
\hline $\begin{array}{l}\text { 1.2.1 Adequação do modo de } \\
\text { transporte }\end{array}$ & 0,046 & 0,784 & 0,036 & 1 \\
\hline $\begin{array}{l}2.1 .1 \text { Infraestrutura de acesso ao } \\
\text { campus }\end{array}$ & 0,025 & 0,606 & 0,015 & 2 \\
\hline 2.1.2 Infraestrutura cicloviária & 0,164 & 0,537 & 0,088 & 4 \\
\hline 2.1.3 Bicicletários e paraciclos & 0,018 & 0,548 & 0,010 & 2 \\
\hline 2.2.1 Qualidade das vias no campus & 0,017 & 0,636 & 0,011 & 2 \\
\hline $\begin{array}{l}2.2 .2 \text { Infraestrutura do transporte } \\
\text { público urbano }\end{array}$ & 0,016 & 0,330 & 0,005 & 3 \\
\hline 2.3.1 Infraestrutura para pedestres & 0,044 & 0,623 & 0,027 & 2 \\
\hline $\begin{array}{l}\text { 2.3.2 Vagas para usuários com } \\
\text { restrição de mobilidade }\end{array}$ & 0,021 & 0,524 & 0,011 & 2 \\
\hline $\begin{array}{l}\text { 2.3.3 Infraestrutura acessível dos } \\
\text { prédios }\end{array}$ & 0,026 & 0,400 & 0,011 & 2 \\
\hline 3.1.1 Áreas de estacionamento & 0,041 & 0,643 & 0,027 & 2 \\
\hline 3.1.2 Medidas de gestão de fluxo & 0,032 & 0,706 & 0,022 & 1 \\
\hline 3.2.1 Transporte público urbano & 0,061 & 0,326 & 0,020 & 3 \\
\hline $\begin{array}{l}\text { 3.2.2 Transporte coletivo da Vila } \\
\text { Estudantil }\end{array}$ & 0,032 & 0,708 & 0,022 & 1 \\
\hline 3.3.1 Segurança pública & 0,036 & 0,631 & 0,023 & 2 \\
\hline $\begin{array}{l}\text { 3.3.2 Fiscalização de infrações de } \\
\text { trânsito no campus }\end{array}$ & 0,042 & 0,294 & 0,012 & 3 \\
\hline 3.3.3 Segurança no trânsito & 0,086 & 0,811 & 0,070 & 2 \\
\hline Valor do índice & & & 0,491 & \\
\hline
\end{tabular}


Tabela 4.4: Referência para classificação de prioridade de intervenção dos indicadores Escore

\begin{tabular}{c|c|c|c|}
\hline Peso & Alto & Médio & Baixo \\
\hline Alto & 3 & 4 & 5 \\
\hline Médio & 2 & 4 & 4 \\
\hline Baixo & 1 & 2 & 3
\end{tabular}

O valor do índice de mobilidade sustentável para o campus da USP de Piracicaba foi 0,491, o que não reflete boas condições de mobilidade, visto que este valor pode variar de zero (pior caso) a um (melhor caso).

4.2 Aplicação do método de avaliação do potencial de transferência no caso São Carlos - Piracicaba

Comparando-se os indicadores presentes no índice original (São Carlos) e no índice adaptado (Piracicaba), foi elaborada a Tabela 4.5. 
Tabela 4.5: Indicadores presentes no índice de mobilidade do campus da USP de São Carlos e no índice de mobilidade do campus da USP de Piracicaba

\begin{tabular}{|c|c|c|}
\hline Temas & Indicadores & $\begin{array}{l}\text { Local de } \\
\text { aplicação }\end{array}$ \\
\hline \multicolumn{3}{|c|}{ DOMÍNIO CONSCIENTIZAÇÃO } \\
\hline \multirow{3}{*}{$\begin{array}{l}\text { Campanhas educativas e } \\
\text { programas }\end{array}$} & $\begin{array}{l}\text { Ações de conscientização do uso de } \\
\text { modos alternativos }\end{array}$ & SC-P \\
\hline & Ações de educação no trânsito & SC- $P^{+}$ \\
\hline & $\begin{array}{l}\text { Ações de incentivo à utilização de } \\
\text { modos alternativos }\end{array}$ & $\mathrm{SC}-\mathrm{P}^{++}$ \\
\hline \multirow[t]{2}{*}{ Modo de transporte } & Adequação do modo de transporte & SC- $\mathrm{P}^{+}$ \\
\hline & OMÍNIO INFRAESTRUTURA & \\
\hline \multirow{4}{*}{ Acessibilidade } & $\begin{array}{l}\text { Qualidade das calçadas dentro e de } \\
\text { acesso ao campus }\end{array}$ & SC \\
\hline & Infraestrutura para pedestres & $P$ \\
\hline & $\begin{array}{l}\text { Vagas para usuários com restrição de } \\
\text { mobilidade }\end{array}$ & $\mathrm{SC}-\mathrm{P}^{+}$ \\
\hline & Acessibilidade dos prédios & SC- $\mathrm{P}^{+}$ \\
\hline \multirow{4}{*}{ Modos não motorizados } & Infraestrutura de acesso ao campus & SC-P \\
\hline & Infraestrutura cicloviária & SC- $\mathrm{P}^{+}$ \\
\hline & Bicicletários e paraciclos & SC-P \\
\hline & $\begin{array}{l}\text { Instalações de apoio a modos } \\
\text { alternativos }\end{array}$ & SC \\
\hline \multirow{3}{*}{ Modos motorizados } & Infraestrutura do estacionamento & SC \\
\hline & Qualidade das vias no campus & SC-P \\
\hline & $\begin{array}{l}\text { Infraestrutura do transporte público } \\
\text { urbano }\end{array}$ & SC- $P^{+}$ \\
\hline \multicolumn{3}{|c|}{ DOMÍNIO GESTÃO E SERVIÇOS } \\
\hline \multirow{3}{*}{ Segurança } & Segurança pública & SC-P \\
\hline & $\begin{array}{l}\text { Fiscalização de infrações de trânsito no } \\
\text { campus }\end{array}$ & $\mathrm{SC}-\mathrm{P}^{+}$ \\
\hline & Segurança no trânsito & $\mathrm{P}$ \\
\hline \multirow[t]{2}{*}{ Vias e estacionamentos } & $\begin{array}{l}\text { Medidas de gestão das áreas de } \\
\text { estacionamento }\end{array}$ & $\mathrm{SC}-\mathrm{P}^{++}$ \\
\hline & Medidas de gestão de fluxo & SC-P \\
\hline \multirow{3}{*}{ Transporte coletivo } & Transporte público urbano & SC-P \\
\hline & Transporte coletivo da Vila Estudantil & $\mathrm{P}$ \\
\hline & $\begin{array}{l}\text { Transporte coletivo interno/ entre áreas } \\
\text { do campus }\end{array}$ & SC \\
\hline
\end{tabular}

Obs.: Por local de aplicação, a sigla "SC" se refere ao campus da USP de São Carlos, "P" ao campus da USP de Piracicaba e "SC-P" significa que o indicador foi utilizado na aplicação do índice nos dois campi referidos. Dentre os indicadores comuns às duas aplicações, aqueles que sofreram alterações moderadas estão assinalados com o símbolo ${ }^{+}$e aqueles que sofreram alterações extremas, ${ }^{++}$.

De posse do quadro comparativo (Tabela 4.5), a avaliação do potencial de transferência foi iniciada calculando-se os três critérios mencionados no item 3.2: número de indicadores mantidos, número de indicadores adicionados e número de indicadores alterados. A Tabela 4.6 apresenta um resumo com os valores considerados para cada critério. As porcentagens foram calculadas considerando-se 
os 20 indicadores originais (São Carlos) como 100\%. Os escores dos critérios "número de indicadores comuns" e "número de indicadores adicionados" foram normalizados através de interpolação linear das porcentagens de acordo com a escala de referência descrita nos itens 3.2.1 e 3.2.2 e resumida na Tabela 3.3. Os cálculos são apresentados na Tabela 4.7. O critério "número de indicadores alterados" exigiu, anteriormente à interpolação linear, o cálculo da média ponderada de acordo com o grau de alteração dos indicadores (alterações moderadas e extremas). Este processo foi organizado conforme o item 3.2.3 e é mostrado na Tabela 4.8.

Tabela 4.6: Dados para cálculo dos escores de cada critério, com porcentagens calculadas considerando-se os 20 indicadores originais (São Carlos) como 100\%

\begin{tabular}{lcr}
\hline & Número de indicadores & $\%$ \\
\hline Indicadores comuns & 16 & $80 \%$ \\
\hline Sem alterações & 7 & $35 \%$ \\
\hline Com alterações & 9 & $45 \%$ \\
\hline Alterações moderadas & 7 & $35 \%$ \\
\hline Alterações extremas & 2 & $10 \%$ \\
\hline Indicadores adicionados para aplicação em Piracicaba & 3 & $15 \%$ \\
\hline
\end{tabular}

Tabela 4.7: Cálculo dos critérios "Indicadores comuns" e "Indicadores adicionados", com porcentagens calculadas considerando-se os 20 indicadores originais (São Carlos) como $100 \%$

\begin{tabular}{lccccc}
\hline & \multirow{2}{*}{ Número de indicadores } & $\%$ & \multicolumn{3}{c}{ Escala de referência } \\
\cline { 3 - 6 } & & & 0 (péssimo) & 1 (ótimo) & \\
\hline Indicadores comuns & 16 & $80 \%$ & $50 \%$ & $100 \%$ & 0,600 \\
\hline Indicadores adicionados & 3 & $15 \%$ & $50 \%$ & $0 \%$ & 0,700 \\
\hline
\end{tabular}


Tabela 4.8: Cálculo do critério "Número de indicadores alterados", com porcentagens calculadas considerando-se os 20 indicadores originais (São Carlos) como 100\%

\begin{tabular}{|c|c|c|c|c|c|c|c|}
\hline \multirow{2}{*}{$\begin{array}{l}\text { Grau de } \\
\text { alteração }\end{array}$} & \multirow{2}{*}{ Peso } & \multirow{2}{*}{$\begin{array}{l}\text { Número de } \\
\text { indicadores }\end{array}$} & \multirow{2}{*}{$\%$} & \multirow{2}{*}{ Contribuição } & \multicolumn{2}{|c|}{$\begin{array}{l}\text { Escala de } \\
\text { referência }\end{array}$} & \multirow{2}{*}{ - Escore } \\
\hline & & & & & $\begin{array}{c}0 \\
\text { (péssimo) }\end{array}$ & $\begin{array}{c}1 \\
\text { (ótimo) }\end{array}$ & \\
\hline Sem alterações & 0 & 7 & $35 \%$ & 0,000 & & & \\
\hline Alterações moderadas & 2 & 7 & $35 \%$ & 0,700 & & & \\
\hline Alterações extremas & 5 & 2 & $10 \%$ & 0,500 & & & \\
\hline Média ponderada & & & & 0,171 & 0,200 & 0,000 & 0,143 \\
\hline
\end{tabular}

Em outros termos, a média ponderada do critério "Número de indicadores alterados" foi calculado pela equação:

$$
\text { Critério }_{\text {Número deindicadors alterados }}=\frac{0 \times 0,35+2 \times 0,35+5 \times 0,10}{0+2+5}=0,171
$$

Esta média ponderada foi então normalizada, para a escala de zero a um, através de interpolação linear, resultando no escore de 0,143.

De posse dos escores de cada um dos três critérios, o valor final do potencial de transferência do índice foi calculado conforme mostra a Tabela 4.9. O resultado da avaliação revela que este índice tem um baixo potencial de transferência, visto que o valor é próximo de zero, que representa o pior caso. Ou seja, para ser aplicado em um novo contexto, foi necessário que o índice de mobilidade sustentável para campus universitário de Oliveira (2015) fosse revisto e adaptado para contemplar as novas necessidades.

Tabela 4.9: Avaliação final do potencial de transferência, que varia entre 0 (pior avaliação) e 1 (melhor avaliação)

\begin{tabular}{lccc}
\hline \multicolumn{1}{c}{ Critério } & Peso & Escore & $\begin{array}{c}\text { Contribuição } \\
\text { parcial }\end{array}$ \\
\hline Indicadores comuns & 0,25 & 0,600 & 0,150 \\
\hline Indicadores adicionados & 0,25 & 0,700 & 0,175 \\
\hline Indicadores alterados & 0,50 & 0,143 & 0,071 \\
\hline Potencial de transferência & & & 0,396 \\
\hline
\end{tabular}




\subsection{Painel de especialistas}

Os resultados referentes ao painel de especialistas foram organizados em dois itens: questionário e teste estatístico de Friedman, assim como na apresentação do método.

\subsubsection{Questionário}

A aplicação do questionário foi realizada por meio de plataforma online, permitindo, assim, a participação de profissionais de diversas regiões do Brasil. Foram enviados 51 convites e obtidas 24 respostas completas, que retrataram experiências em campi universitários nas seguintes unidades federativas: Amazonas (1 resposta), Alagoas (1 resposta), Ceará (1 resposta), Paraíba (1 resposta), Rio Grande do Norte (1 resposta), Distrito Federal (1 resposta), Goiás (1 resposta), Minas Gerais (4 respostas), Rio de Janeiro (1 resposta), São Paulo (8 respostas), Paraná (3 respostas) e Santa Catarina (1 resposta).

\subsubsection{Teste estatístico não paramétrico de Friedman}

Às avaliações individuais da adequação e da relevância dos indicadores foram atribuídos valores de 1 a 7 , sendo 1 para a resposta "discordo totalmente" e 7 para "concordo totalmente" da escala Likert. Em seguida, foram determinados os ranks de acordo com estes valores e foram realizados os demais processos do teste pretendido.

Os dados completos referentes à aplicação do teste de Friedman se encontram no Apêndice $F$.

Para verificar a confiabilidade do questionário, foi calculado o alfa de Cronbach (CRONBACH, 1951) por meio da Equação 4.1.

$$
\alpha=\frac{k}{k-1}\left(1-\frac{\sum_{i=1}^{k} s_{i}^{2}}{s_{\text {soma }}^{2}}\right)
$$

Em que:

$\alpha$ : alfa de Cronbach

$k$ : número de questões

$S^{2}$ : variância de cada questão

$s^{2}$ soma: variância total do questionário, determinada como a soma de todas as variâncias 
No caso, para os quesitos adequação e relevância tem-se, respectivamente:

$$
\begin{aligned}
& \sum_{i=1}^{k} s_{i}^{2}{ }_{\text {Adequação }} \\
& =2,09+2,68+3,33+2,94+3,21+3,48+4,00+3,04+1,54+1,64 \\
& +1,09+1,00+1,09+1,74+3,00+2,78+0,84+4,96+1,22+4,08=49,73 \\
& s_{\text {soma Adequação }}^{2} \\
& =140+126+103+123+103+83+100+125+139+126+93+111 \\
& +105+98+99+105+128+127+113+112+96+127+111+119=224,17 \\
& \qquad \alpha_{\text {Adequação }}=\frac{20}{20-1}\left(1-\frac{49,73}{224,17}\right)=0,82 \\
& \sum_{i=1}^{k} s_{i}^{2}{ }_{\text {Relevância }} \\
& +0,95+06+2,00+3,04+1,47+1,99+1,11+1,52+1,19+1,52+1,69 \\
& s_{\text {soma Relevância }}^{2}+0,78+1,00+2,86+1,82+0,69+4,37+0,69+3,24=34,62 \\
& =140+126+84+122+115+125+101+125+139+138+107+127 \\
& +105+139+105+140+128+127+117+123+95+129+113+127=226,48 \\
& \quad \alpha_{\text {Relevância }}=\frac{20}{20-1}\left(1-\frac{34,62}{226,48}\right)=0,89
\end{aligned}
$$

TAVAKOL e DENNICK (2011) levantaram estudos sobre os valores do Alfa de Cronbach considerados aceitáveis, os quais variam de 0,70 a 0,95 . Assim, foi considerado que ambos os critérios apresentaram confiabilidade adequada.

As somas dos ranks $\left(R_{\mathrm{j}}\right)$ agrupam as avaliações individuais de cada especialista para cada indicador e são mostradas nas Tabelas 4.10 (para o quesito adequação) e 4.11 (para relevância), já organizadas em ordem crescente. No topo, os indicadores com menor concordância por parte dos avaliadores em seus respectivos quesitos. 
Tabela 4.10: Somas dos ranks (Rj) dos 20 indicadores analisados no painel de especialistas, organizados em ordem crescente. No topo, o indicador com menor concordância por parte dos avaliadores no quesito adequação.

\begin{tabular}{cc}
\hline $\begin{array}{c}\text { Somas dos ranks } \\
\text { (Rj) - Quesito } \\
\text { adequação }\end{array}$ \\
\hline R20 & 178,5 \\
\hline$R 8$ & 183,5 \\
\hline$R 15$ & 198,5 \\
\hline$R 18$ & 208,5 \\
\hline$R 3$ & 219 \\
\hline$R 16$ & 225 \\
\hline$R 1$ & 241,5 \\
\hline$R 2$ & 246,5 \\
\hline$R 6$ & 250,5 \\
\hline$R 9$ & 252,5 \\
\hline$R 4$ & 255 \\
\hline$R 5$ & 257,5 \\
\hline$R 7$ & 258 \\
\hline$R 10$ & 260 \\
\hline$R 14$ & 275,5 \\
\hline$R 19$ & 293 \\
\hline$R 17$ & 305 \\
\hline$R 13$ & 306 \\
\hline$R 12$ & 310,5 \\
\hline$R 11$ & 315,5 \\
\hline & \\
\hline$R$
\end{tabular}


Tabela 4.11: Somas dos ranks (Rj) dos 20 indicadores analisados no painel de especialistas, organizados em ordem crescente. No topo, o indicador com menor concordância por parte dos avaliadores no quesito relevância.

\begin{tabular}{cc}
\hline \multicolumn{2}{c}{$\begin{array}{c}\text { Somas dos ranks } \\
\text { (Rj) - Quesito } \\
\text { relevância }\end{array}$} \\
\hline R20 & 176 \\
\hline$R 15$ & 187 \\
\hline$R 18$ & 188,5 \\
\hline$R 8$ & 208 \\
\hline$R 16$ & 216,5 \\
\hline$R 1$ & 226,5 \\
\hline$R 9$ & 238 \\
\hline$R 2$ & 242 \\
\hline$R 3$ & 242 \\
\hline$R 10$ & 242,5 \\
\hline$R 4$ & 248,5 \\
\hline$R 5$ & 266,5 \\
\hline$R 14$ & 276,5 \\
\hline$R 7$ & 285,5 \\
\hline$R 19$ & 290,5 \\
\hline$R 6$ & 291,5 \\
\hline$R 17$ & 293 \\
\hline$R 11$ & 303 \\
\hline$R 12$ & 308,5 \\
\hline$R 13$ & 309,5 \\
\hline &
\end{tabular}

Em seguida, a estatística de Friedman $\left(T_{1}\right)$ foi calculada pela Equação 3.4 para os quesitos adequação e relevância, separadamente. Como os avaliadores são referidos como blocos (linhas) e os indicadores como tratamentos (colunas), tem-se:

$$
\begin{aligned}
& b=24 \\
& k=20
\end{aligned}
$$

As somas dos ranks ao quadrado são dadas por:

$$
\begin{aligned}
& \sum_{j=1}^{k} R_{j}{ }^{2}{ }_{\text {Adequaça } 0} \\
& =241,5^{2}+246,5^{2}+219^{2}+255^{2}+257,5^{2}+250,5^{2}+258^{2}+183,5^{2} \\
& +252,5^{2}+260^{2}+315,5^{2}+310,5^{2}+306^{2}+275,5^{2}+198,5^{2}+225^{2} \\
& +305^{2}+208,5^{2}+293^{2}+178,5^{2}=1302442
\end{aligned}
$$




$$
\begin{aligned}
& \sum_{j=1}^{k} R_{j}^{2} \text { Relevância } \\
& =226,5^{2}+242^{2}+242^{2}+248,5^{2}+266,5^{2}+291,5^{2}+285,5^{2}+208^{2} \\
& +238^{2}+242,5^{2}+303^{2}+308,5^{2}+309,5^{2}+276,5^{2}+187^{2}+216,5^{2} \\
& +293^{2}+188,5^{2}+290,5^{2}+176^{2}=1304214
\end{aligned}
$$

Assim, os valores da estatística de Friedman são:

$$
\begin{aligned}
& T_{1 \text { Adequação }}=\frac{12}{24 \times 20(20+1)} \times 1302442-3 \times 24(20+1)=38,526 \\
& T_{1 \text { Relevância }}=\frac{12}{24 \times 20(20+1)} \times 1304214-3 \times 24(20+1)=40,636
\end{aligned}
$$

Como ocorreram empates em avaliações dos dois quesitos, foi necessário realizar a correção nas estatísticas $\mathrm{T}_{1}$ (Equações 3.6, 3.7 e 3.8).

$A_{1}$ é a soma dos quadrados dos ranks das avaliações de todos os indicadores feitas por todos os especialistas, que contabilizam 480 avaliações (consultar Apêndice F). Os resultados obtidos para $A_{1}$ do quesito adequação e do quesito relevância são:

$$
\begin{gathered}
A_{1 \text { Adequação }}=64431 \\
A_{1 \text { Relevancia }}=62959,5
\end{gathered}
$$

$\mathrm{C}_{1}$ é comum aos dois quesitos, pois depende somente do número de blocos e de tratamentos. Assim, é dado por:

$$
C_{1}=\frac{24 \times 20(20+1)^{2}}{4}=52920
$$

Portanto, $T_{1}{ }^{*}$ resulta em:

$$
\begin{aligned}
& T_{1 \text { Adequação }}^{*}=\frac{(20-1)(1302442-24 \times 52920)}{64431-52920}=53,417 \\
& T_{1 \text { Relevância }}^{*}=\frac{(20-1)(1304214-24 \times 52920)}{64431-52920}=64,599
\end{aligned}
$$

Os valores da estatística de Friedman obtidos são resumidos na Tabela 4.12. 
Tabela 4.12: Valores da estatística de Friedman obtidos

\begin{tabular}{ccc}
\hline & \multicolumn{2}{c}{ Critérios } \\
\hline Estatística de Friedman & Adequação & Relevância \\
\hline $\mathrm{T}_{1}$ & 38,526 & 40,636 \\
\hline $\mathrm{T}_{1}{ }^{*}$ & 53,417 & 64,599 \\
\hline
\end{tabular}

O número de graus de liberdade é determinado por $(k-1)$. Como se tratam de 20 indicadores, trabalhou-se com 19 graus de liberdade. Adotando-se nível de significância de 5\%, o valor de Qui Quadrado crítico é de 30,144, segundo tabela de distribuição. Como os valores da estatística de Friedman foram maiores do que este número em ambos os quesitos (adequação e relevância), a hipótese nula foi rejeitada; portanto, os dados sugerem que podem existir indicadores mais relevantes e adequados que outros e que a distribuição dos ranks pode não ter sido aleatória.

O processo de comparações múltiplas permitiu identificar os pares de indicadores cujos ranks podem ser considerados como diferentes entre si. Para esta etapa, foi utilizada a Equação 3.8. O número de graus de liberdade a ser empregado é:

$$
G L=(b-1) \times(k-1)=(24-1) \times(20-1)=437
$$

Para nível de significância $5 \%, t_{1-\alpha / 2}$ consultado em tabela de distribuição $t$ de Student para 437 graus de liberdade é 1,960. Portanto, tem-se:

$$
\begin{aligned}
& t_{1-\alpha / 2}\left[\frac{2\left(b A_{1}-\sum R_{j}^{2}\right)}{(b-1)(k-1)}\right]_{\text {Adequação }}^{1 / 2}=1,960 \times\left[\frac{2 \times((24 \times 64431)-1302442)}{(24-1)(20-1)}\right]^{1 / 2}=65,484 \\
& t_{1-\alpha / 2}\left[\frac{2\left(b A_{1}-\sum R_{j}^{2}\right)}{(b-1)(k-1)}\right]_{\text {Relevância }}^{1 / 2}=1,960 \times\left[\frac{2 \times((24 \times 62959,5)-1304214)}{(24-1)(20-1)}\right]^{1 / 2}=60,300
\end{aligned}
$$

As avaliações, ranks e comparações par a par encontram-se no Apêndice F. Contudo, para esclarecer o procedimento, as comparações múltiplas do quesito adequação são mostradas na Tabela 4.13, seguida de sua interpretação. 
Tabela 4.13: Comparações múltiplas entre os ranks dos indicadores para o quesito Adequação, feitas pela operação $\left|R_{j}-R_{i}\right|$. Em destaque, as diferenças maiores do que o valor de referência $(65,484)$.

Comparações múltiplas entre os ranks dos indicadores para o quesito Adequação $\left(\left|R_{\mathrm{j}}-\mathrm{R}_{\mathrm{i}}\right|\right)$

\begin{tabular}{|c|c|c|c|c|c|c|c|c|c|c|c|c|c|c|c|c|c|c|c|c|}
\hline & R20 & R8 & R15 & R18 & R3 & R16 & R1 & R2 & $\mathrm{R} 6$ & R9 & $\mathrm{R} 4$ & R5 & R7 & R10 & R14 & R19 & R17 & R13 & R12 & R11 \\
\hline R20 & 0 & 5 & 20 & 30 & 40,5 & 46,5 & 63 & 68 & 72 & 74 & 76,5 & 79 & 79,5 & 81,5 & 97 & 114,5 & 126,5 & 127,5 & 132 & 137 \\
\hline R8 & 5 & 0 & 15 & 25 & 35,5 & 41,5 & 58 & 63 & 67 & 69 & 71,5 & 74 & 74,5 & 76,5 & 92 & 109,5 & 121,5 & 122,5 & 127 & 132 \\
\hline $\mathrm{R} 15$ & 20 & 15 & 0 & 10 & 20,5 & 26,5 & 43 & 48 & 52 & 54 & 56,5 & 59 & 59,5 & 61,5 & 77 & 94,5 & 106,5 & 107,5 & 112 & 117 \\
\hline R3 & 40,5 & 35,5 & 20,5 & 10,5 & 0 & 6 & 22,5 & 27,5 & 31,5 & 33,5 & 36 & 38,5 & 39 & 41 & 56,5 & 74 & 86 & 87 & 91,5 & 96,5 \\
\hline R16 & 46,5 & 41,5 & 26,5 & 16,5 & 6 & 0 & 16,5 & 21,5 & 25,5 & 27,5 & 30 & 32,5 & 33 & 35 & 50,5 & 68 & 80 & 81 & 85,5 & 90,5 \\
\hline $\mathrm{R} 1$ & 63 & 58 & 43 & 33 & 22,5 & 16,5 & 0 & 5 & 9 & 11 & 13,5 & 16 & 16,5 & 18,5 & 34 & 51,5 & 63,5 & 64,5 & 69 & 74 \\
\hline $\mathrm{R} 6$ & 72 & 67 & 52 & 42 & 31,5 & 25,5 & 9 & 4 & 0 & 2 & 4,5 & 7 & 7,5 & 9,5 & 25 & 2,5 & 4,5 & 5,5 & 60 & 5 \\
\hline R9 & 74 & 69 & 54 & 44 & 33,5 & 27,5 & 11 & 6 & 2 & 0 & 2,5 & 5 & 5,5 & 7,5 & 23 & 40,5 & 52,5 & 53,5 & 58 & 63 \\
\hline $\mathrm{R} 4$ & 76,5 & 71,5 & 56,5 & 46,5 & 36 & 30 & 13,5 & 8,5 & 4,5 & 2,5 & 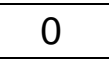 & 2,5 & 3 & 5 & 20,5 & 38 & 50 & 51 & 55,5 & 60,5 \\
\hline R5 & 79 & 74 & 59 & 49 & 38,5 & 32,5 & 16 & 11 & 7 & 5 & 2,5 & 0 & 0,5 & 2,5 & 18 & 35,5 & 47,5 & 48,5 & 53 & 58 \\
\hline $\mathrm{R} 7$ & \begin{tabular}{|l|}
79,5 \\
\end{tabular} & 74,5 & 59,5 & 49,5 & 39 & 33 & 16,5 & 11,5 & 7,5 & 5,5 & 3 & 0,5 & 0 & 2 & 17,5 & 35 & 47 & 48 & 52,5 & 57,5 \\
\hline $\mathrm{R} 10$ & 81,5 & 76,5 & 61,5 & 51,5 & 41 & 35 & 18,5 & 13,5 & 9,5 & 7,5 & 5 & 2,5 & 2 & 0 & 15,5 & 33 & 45 & 46 & 50,5 & 55,5 \\
\hline R13 & 127,5 & 122,5 & 107,5 & 97,5 & 87 & 81 & 64,5 & 59,5 & 55,5 & 53,5 & 51 & 48,5 & 48 & 46 & 30,5 & 13 & 1 & 0 & 4,5 & 9,5 \\
\hline $\mathrm{R} 12$ & 132 & 127 & 112 & 102 & 91,5 & 85,5 & 69 & 64 & 60 & 58 & 55,5 & 53 & 52,5 & 50,5 & 35 & 17,5 & 5,5 & 4,5 & 0 & 5 \\
\hline $\mathrm{R} 11$ & 137 & 132 & 117 & 107 & 96,5 & 90,5 & 74 & 69 & 65 & 63 & 60,5 & 58 & 57,5 & 55,5 & 40 & 22,5 & 10,5 & 9,5 & 5 & 0 \\
\hline
\end{tabular}


No quesito adequação, as comparações múltiplas dão suporte para que se compreenda que, entre os especialistas:

- Há maior concordância a respeito de o indicador 11 ser adequado do que a respeito de os indicadores $2,1,16,3,18,15,8$ e 20 serem adequados.

- Há maior concordância a respeito de o indicador 12 ser adequado do que a respeito de os indicadores $1,16,3,18,15,8$ e 20 serem adequados.

- Há maior concordância a respeito de os indicadores 13, 17 e 19 serem adequados do que a respeito de os indicadores $16,3,18,15,8$ e 20 serem adequados.

- Há maior concordância a respeito de o indicador 14 ser adequado do que a respeito de os indicadores 18, 15, 8 e 20 serem adequados.

- Há maior concordância a respeito de os indicadores 10, 7, 5, 4, 9, 6 serem adequados do que a respeito de os indicadores 8 e 20 serem adequados.

- Há maior concordância a respeito de o indicador 2 ser adequado do que a respeito de o indicador 20 ser adequado.

Como critério de seleção para elencar indicadores com potencial de compor um índice mais global, foram descartados aqueles que apresentaram evidências de menor concordância sobre serem adequados que os demais (ou seja, aqueles não destacados pelas comparações múltiplas). Assim sendo, os indicadores 2, 1, 16, 3, 18 , 15,8 e 20 foram descartados para o quesito adequação.

Os indicadores selecionados para o quesito adequação e para o quesito relevância são mostrados nas Tabelas 4.14 e 4.15 , respectivamente. 
Tabela 4.14: Indicadores selecionados, organizados por ordem de concordância na avaliação dos especialistas (no topo, os de maior concordância) - Quesito adequação

\begin{tabular}{clc}
\hline $\begin{array}{c}\text { Número } \\
\text { do } \\
\text { indicador }\end{array}$ & Nome & $R_{j}$ \\
\hline 11 & Infraestrutura de transporte público urbano & 315,5 \\
\hline 12 & $\begin{array}{l}\text { Qualidade das calçadas dentro e de acesso ao } \\
\text { campus }\end{array}$ & 310,5 \\
\hline 13 & $\begin{array}{l}\text { Vagas para usuários com restrição de } \\
\text { mobilidade }\end{array}$ & 306 \\
\hline 17 & Transporte público urbano & 305 \\
\hline 19 & Segurança pública & 293 \\
\hline 14 & Acessibilidade dos prédios & 275,5 \\
\hline 10 & Infraestrutura de estacionamento & 260 \\
\hline 7 & Bicicletários e paraciclos & 258 \\
\hline 5 & Infraestrutura de acesso ao campus & 257,5 \\
\hline 4 & Adequação do modo de transporte & 255 \\
\hline 9 & Qualidade das vias no campus & 252,5 \\
\hline 6 & Infraestrutura cicloviária & 250,5 \\
\hline 2 & Ações de educação no trânsito & 246,5 \\
\hline
\end{tabular}

Tabela 4.15: Indicadores selecionados, organizados por ordem de concordância na avaliação dos especialistas (no topo, os de maior concordância) - Quesito relevância

\begin{tabular}{clc}
$\begin{array}{c}\text { Número } \\
\text { do } \\
\text { indicador }\end{array}$ & Nome & $R_{j}$ \\
\hline 13 & Vagas para usuários com restrição de mobilidade & 309,5 \\
\hline 12 & $\begin{array}{l}\text { Qualidade das calçadas dentro e de acesso ao } \\
\text { campus }\end{array}$ & 308,5 \\
\hline 11 & Infraestrutura de transporte público urbano & 303 \\
\hline 17 & Transporte público urbano & 293 \\
\hline 6 & Infraestrutura cicloviária & 291,5 \\
\hline 19 & Segurança pública & 290,5 \\
\hline 7 & Bicicletários e paraciclos & 285,5 \\
\hline 14 & Acessibilidade dos prédios & 276,5 \\
\hline 5 & Infraestrutura de acesso ao campus & 266,5 \\
\hline 4 & Adequação do modo de transporte & 248,5 \\
\hline 10 & Infraestrutura de estacionamento & 242,5 \\
\hline 2 & Ações de educação no trânsito & 242 \\
\hline 3 & Ações de incentivo à preferência de modos & 242 \\
\hline 9 & alternativos & 238 \\
\hline & Qualidade das vias no campus &
\end{tabular}

Observa-se que, para os dois critérios (relevância e adequação), houve concordância por parte dos especialistas em empregar o mesmo conjunto de indicadores, com 
exceção do indicador 3, que foi selecionado apenas no quesito relevância. Assim, para um índice mais "global", recomenda-se a utilização dos 13 indicadores contidos nas duas seleções: Infraestrutura de transporte público urbano, Qualidade das calçadas dentro e de acesso ao campus, Vagas para usuários com restrição de mobilidade, Transporte público urbano, Segurança pública, Acessibilidade dos prédios, Infraestrutura de estacionamento, Bicicletários e paraciclos, Infraestrutura de acesso ao campus, Adequação do modo de transporte, Qualidade das vias no campus, Infraestrutura cicloviária e Ações de educação no trânsito. 
A avaliação do potencial de transferência do IMSCamp, objetivo principal deste estudo, resultou em um valor baixo $(0,396)$. Este resultado reflete que foram necessárias mudanças expressivas para adaptá-lo a um novo campus; sendo assim, não se trata de um índice global facilmente aplicável em diversos contextos. A adaptação foi feita a partir da aplicação do índice em dois campi de uma mesma universidade (que, consequentemente, apresentam uma mesma estrutura de gestão), de portes semelhantes, em cidades próximas e com características parecidas. Logo, esperava-se que as necessidades dos dois campi fossem similares e, consequentemente, que resultariam em índices muito semelhantes em termos de estrutura. Dessa forma, imagina-se que uma aplicação em um campus distinto resultaria em um potencial de transferência ainda mais baixo, refletindo o empenho necessário para a etapa de adaptação do índice.

Apesar disso, foi possível reproduzir o método de aplicação do IMSCamp em um novo campus universitário. O processo, composto pelo ajuste dos indicadores, medições dos mesmos e avaliação final do índice através de um escore global, permite uma avaliação quantitativa e também a análise dos indicadores mais críticos e, consequentemente, a identificação de possíveis pontos de melhoria. Nesse sentido, o IMSCamp se mostrou adequado como ferramenta de planejamento. Uma vez adaptado, ele pode aplicado, por exemplo, ao longo do tempo para acompanhamento do desempenho e da eficácia das ações empregadas. As adaptações necessárias para que o índice se adequasse ao novo caso criaram barreiras, mas não impossibilitaram a sua utilização.

O índice de mobilidade sustentável para o campus da USP de Piracicaba resultou no valor de 0,491 , sendo próximo do valor intermediário da escala de avaliação (que varia de zero a um). Quando comparado ao índice do campus da USP de São Carlos $(0,459)$, deduz-se que os dois campi apresentam condições similares em relação à mobilidade sustentável, apresentando uma diferença de $7 \%$ na avaliação (considerando o resultado da aplicação original na USP de São Carlos como 100\%). Contudo, como os índices aplicados não são idênticos (tanto em relação aos indicadores empregados quanto aos pesos atribuídos), não é possível realizar esta comparação direta. Uma comparação mais apropriada talvez fosse a do conjunto dos 7 indicadores mantidos sem alterações nos dois índices (como mostrado na Tabela 
4.5). Ao analisar somente as contribuições de tais indicadores, com pesos igualmente distribuídos, o campus da USP de São Carlos apresentou uma avaliação final de 0,523, enquanto para a USP de Piracicaba o valor foi de 0,553 (diferença de 7\%).

Já a comparação da aplicação dos 16 indicadores comuns (tanto aqueles sem alterações quanto os alterados), com pesos iguais, reforçou o indício de condições próximas: no campus da USP de São Carlos, o conjunto de indicadores resultou no valor 0,463, enquanto em Piracicaba o valor foi de 0,496 (diferença de 6\%). As diferenças observadas em cada uma dessas três análises têm a mesma ordem de grandeza, indicando uma relação de condições de mobilidade ligeiramente mais satisfatórias no campus de Piracicaba do que em São Carlos. Apesar da aparente confirmação, sugere-se que seja empregado um índice completo padronizado para comparações fundamentadas neste sentido.

Quanto ao método proposto para avaliação do potencial de transferência de um índice, cabem algumas ressalvas. Os valores de referência dos três critérios, assim como os pesos para indicadores de alterações moderadas e extremas, foram atribuídos de acordo com a percepção dos autores. Para um refinamento do método, sugere-se que estes parâmetros sejam explorados, podendo ser, por exemplo, estipulados por especialistas, através de painéis e do método de comparação par a par (SAATY, 1980).

A organização em três critérios (número de indicadores mantidos, número de indicadores adicionados e número de indicadores alterados) permite que os resultados dos mesmos sejam analisados separadamente. No primeiro critério, $80 \%$ dos indicadores originais (IMSCamp da USP de São Carlos) foram mantidos, o que resultou em um escore de 0,600 . Os demais $20 \%$ dos indicadores foram excluídos pela dificuldade de obtenção de dados ou por não corresponderem às necessidades do novo caso, entre outros. Já o critério de indicadores adicionados reflete a escassez de indicadores que sejam relevantes para o novo contexto. Neste caso, foi necessário um acréscimo de $15 \%$ no número de indicadores, resultando em um escore de 0,700. O último critério foi o mais crítico, já que recebeu um escore de 0,143 , próximo do valor mínimo (zero). Isso indica que muitos dos indicadores que foram mantidos, ainda assim precisaram ser ajustados para o novo contexto. Isso ocorreu por diversos motivos, como ausência ou dificuldade de obtenção de dados, disponibilidade de dados mais relevantes e que poderiam ser incluídos no método de cálculo, escolha da 
Comissão de Mobilidade, novas considerações pertinentes, demanda dos usuários, etc., como detalhado na Tabela 5.1. 
Tabela 5.1: Alterações dos indicadores originais do IMSCamp (OLIVEIRA, 2015) para aplicação no campus da USP de Piracicaba (SC - indicador presente no índice de São Carlos (original); P - indicador presente no índice de Piracicaba; SC-P - Indicador presente em ambos os índices)
Sem alteração
Alteração moderada
Alteração extrema

\begin{tabular}{|c|c|c|c|c|c|c|}
\hline Temas & Indicadores & Índice & $\begin{array}{c}\text { Indicadores } \\
\text { comuns }\end{array}$ & $\begin{array}{cc}\text { Indicadores } & \text { Indicadores } \\
\text { suprimidos } & \text { adicionados } \\
\end{array}$ & Alterações & Motivos \\
\hline \multicolumn{5}{|c|}{ Domínio Conscientização } & $\begin{array}{l}\text { Alteração na } \\
\text { nomenclatura para } \\
\text { "Domínio } \\
\text { Educação". }\end{array}$ & Demanda da Comissão de Mobilidade. \\
\hline \multirow{3}{*}{$\begin{array}{l}\text { Campanhas } \\
\text { educativas e } \\
\text { programas }\end{array}$} & $\begin{array}{l}\text { Ações de } \\
\text { conscientização do uso } \\
\text { de modos alternativos }\end{array}$ & SC-P & $\mathrm{x}$ & & & \\
\hline & $\begin{array}{l}\text { Ações de educação no } \\
\text { trânsito }\end{array}$ & SC-P & $\mathrm{x}$ & & $\begin{array}{l}\text { Alteração na } \\
\text { nomenclatura para } \\
\text { "Ações de } \\
\text { educação no } \\
\text { trânsito e respeito à } \\
\text { sinalização"; } \\
\text { Inclusão de } \\
\text { avaliação sobre } \\
\text { impacto das ações } \\
\text { no campus no } \\
\text { método de cálculo. } \\
\end{array}$ & $\begin{array}{l}\text { Avaliação sobre impacto das ações no campus já } \\
\text { estava presente no questionário original e considerou- } \\
\text { se pertinente inclui-la no método de cálculo do } \\
\text { indicador. }\end{array}$ \\
\hline & $\begin{array}{l}\text { Ações de incentivo à } \\
\text { utilização de modos } \\
\text { alternativos }\end{array}$ & SC-P & $x$ & & $\begin{array}{l}\text { Alteração no } \\
\text { método de cálculo } \\
\text { para porcentagem } \\
\text { de usuários que } \\
\text { fazem uso de } \\
\text { carona e sistema } \\
\text { de bicicleta } \\
\text { compartilhada. } \\
\end{array}$ & $\begin{array}{l}\text { Inexistência de programas de benefícios oferecidos pela } \\
\text { universidade. Optou-se por contabilizar a porcentagem } \\
\text { de usuários atingidos por ações de incentivo (carona e } \\
\text { sistema de bicicleta compartilhada). }\end{array}$ \\
\hline $\begin{array}{l}\text { Modo de } \\
\text { transporte }\end{array}$ & $\begin{array}{l}\text { Adequação do modo de } \\
\text { transporte }\end{array}$ & SC-P & $\mathrm{x}$ & & $\begin{array}{l}\text { Alteração no } \\
\text { método de cálculo } \\
\text { (OLIVEIRA et al., } \\
\text { 2016). }\end{array}$ & $\begin{array}{l}\text { Método de Oliveira et al. (2016) contorna possível viés } \\
\text { do indicador. }\end{array}$ \\
\hline
\end{tabular}




\begin{tabular}{|c|c|c|c|c|c|c|c|}
\hline Temas & Indicadores & Índice & $\begin{array}{l}\text { Indicadores } \\
\text { comuns }\end{array}$ & $\begin{array}{l}\text { Indicadores } \\
\text { suprimidos }\end{array}$ & $\begin{array}{l}\text { Indicadores } \\
\text { adicionados }\end{array}$ & Alterações & Motivos \\
\hline & Domín & o Infraes & trutura & & & & \\
\hline \multirow{4}{*}{ Acessibilidade } & $\begin{array}{l}\text { Qualidade das calçadas } \\
\text { dentro e de acesso ao } \\
\text { campus }\end{array}$ & SC & & $x$ & & & $\begin{array}{l}\text { Campus da USP de Piracicaba apresenta área } \\
\text { tombada, sem possibilidade de reformas e } \\
\text { intervenções. Exclusão do indicador por demanda da } \\
\text { Comissão de Mobilidade. }\end{array}$ \\
\hline & $\begin{array}{l}\text { Infraestrutura para } \\
\text { pedestres }\end{array}$ & $P$ & & & $\mathrm{x}$ & & $\begin{array}{l}\text { Devido à exclusão do indicador "Qualidade das } \\
\text { calçadas dentro e de acesso ao campus", observou-se } \\
\text { ausência de indicador sobre infraestrutura para } \\
\text { pedestres. }\end{array}$ \\
\hline & $\begin{array}{l}\text { Vagas para usuários } \\
\text { com restrição de } \\
\text { mobilidade }\end{array}$ & SC-P & $x$ & & & $\begin{array}{l}\text { Suprimida a análise da } \\
\text { porcentagem de vagas que } \\
\text { possuem sinalização horizontal } \\
\text { e vertical de acordo com o } \\
\text { especificado pelas normas. }\end{array}$ & $\begin{array}{l}\text { Coleta de dados demandaria equipe adicional e } \\
\text { prorrogação de prazo. }\end{array}$ \\
\hline & $\begin{array}{l}\text { Acessibilidade dos } \\
\text { prédios }\end{array}$ & SC-P & $x$ & & & $\begin{array}{l}\text { Distinção das avaliações de } \\
\text { usuários com restrição de } \\
\text { mobilidade e atribuição de } \\
\text { maior peso às mesmas. }\end{array}$ & $\begin{array}{l}\text { Forma de reconhecer e evidenciar a opinião de usuários } \\
\text { que necessitam e fazem uso de equipamentos de } \\
\text { acessibilidade universal. }\end{array}$ \\
\hline \multirow{4}{*}{$\begin{array}{l}\text { Modos não } \\
\text { motorizados }\end{array}$} & $\begin{array}{l}\text { Infraestrutura de acesso } \\
\text { ao campus }\end{array}$ & SC-P & $x$ & & & & \\
\hline & Infraestrutura cicloviária & SC-P & $x$ & & & $\begin{array}{l}\text { Inclusão da análise da } \\
\text { sinalização para ciclistas no } \\
\text { método de cálculo. }\end{array}$ & $\begin{array}{l}\text { Alocação de sinalização específica para o modo } \\
\text { bicicleta em um indicador pertinente. }\end{array}$ \\
\hline & Bicicletários e paraciclos & SC-P & $x$ & & & & \\
\hline & $\begin{array}{l}\text { Instalações de apoio a } \\
\text { modos alternativos }\end{array}$ & SC & & $x$ & & & $\begin{array}{l}\text { Campus organizado em múltiplos departamentos, } \\
\text { pavilhões e blocos. } \\
\text { Levantamento demandaria equipe adicional e } \\
\text { prorrogação de prazo. } \\
\text { Baixa demanda dos usuários. }\end{array}$ \\
\hline
\end{tabular}




\begin{tabular}{|c|c|c|c|c|c|c|c|}
\hline Temas & Indicadores & Índice & $\begin{array}{c}\text { Indicadores } \\
\text { comuns }\end{array}$ & $\begin{array}{l}\text { Indicadores } \\
\text { suprimidos }\end{array}$ & $\begin{array}{l}\text { Indicadores } \\
\text { adicionados }\end{array}$ & Alterações & Motivos \\
\hline \multirow{3}{*}{$\begin{array}{l}\text { Modos } \\
\text { motorizados }\end{array}$} & $\begin{array}{l}\text { Infraestrutura do } \\
\text { estacionamento }\end{array}$ & SC & & $x$ & & & \\
\hline & $\begin{array}{l}\text { Qualidade das vias no } \\
\text { campus }\end{array}$ & SC-P & $x$ & & & & \\
\hline & $\begin{array}{l}\text { Infraestrutura do } \\
\text { transporte público urbano }\end{array}$ & SC-P & $x$ & & & $\begin{array}{l}\text { Suprimida a análise de } \\
\text { distância entre usuários e local } \\
\text { de recarga de passe escolar. }\end{array}$ & $\begin{array}{l}\text { Coleta de dados e compatibilização em SIG } \\
\text { demandariam equipe adicional e prorrogação de } \\
\text { prazo. }\end{array}$ \\
\hline \multicolumn{8}{|c|}{ Domínio Gestão e Serviços } \\
\hline \multirow{3}{*}{ Segurança } & Segurança pública & SC-P & $\mathrm{x}$ & & & & \\
\hline & $\begin{array}{l}\text { Fiscalização de infrações } \\
\text { de trânsito no campus }\end{array}$ & SC-P & $x$ & & & $\begin{array}{l}\text { Inclusão do número de } \\
\text { infrações de trânsito no campus } \\
\text { no método de cálculo. }\end{array}$ & $\begin{array}{l}\text { Disponibilidade de dados do número de infrações de } \\
\text { trânsito no campus, que foram considerados } \\
\text { relevantes para o indicador. }\end{array}$ \\
\hline & Segurança no trânsito & $\mathrm{P}$ & & & $x$ & & $\begin{array}{l}\text { Demanda dos usuários, histórico de acidentes, } \\
\text { disponibilidade dos dados de acidentes com vítimas e } \\
\text { sem vítimas. }\end{array}$ \\
\hline \multirow[t]{2}{*}{$\begin{array}{c}\text { Vias e } \\
\text { estacionamentos }\end{array}$} & $\begin{array}{l}\text { Medidas de gestão das } \\
\text { áreas de estacionamento }\end{array}$ & SC-P & $x$ & & & $\begin{array}{l}\text { Método de cálculo alterado } \\
\text { para análise de ocupação dos } \\
\text { estacionamentos apenas. }\end{array}$ & $\begin{array}{l}\text { Bolsões de estacionamento não mapeados, } \\
\text { levantamento demandaria equipe adicional e } \\
\text { prorrogação de prazo, aspecto não abordado pelos } \\
\text { usuários. }\end{array}$ \\
\hline & $\begin{array}{l}\text { Medidas de gestão de } \\
\text { fluxo }\end{array}$ & SC-P & $x$ & & & & \\
\hline \multirow{3}{*}{$\begin{array}{l}\text { Transporte } \\
\text { coletivo }\end{array}$} & $\begin{array}{l}\text { Transporte público } \\
\text { urbano }\end{array}$ & SC-P & $x$ & & & & \\
\hline & $\begin{array}{l}\text { Transporte coletivo da } \\
\text { Vila Estudantil }\end{array}$ & $\mathrm{P}$ & & & $x$ & & \\
\hline & $\begin{array}{l}\text { Transporte coletivo } \\
\text { interno/ entre áreas do } \\
\text { campus }\end{array}$ & SC & & $x$ & & & \\
\hline
\end{tabular}


O painel de especialistas foi uma tentativa de identificar os indicadores do IMSCamp que abrangem os temas mais importantes para o processo de planejamento de campi universitários e que poderiam, potencialmente, compor um índice mais "universal". Foram obtidas respostas das 5 regiões do Brasil; contudo, a distribuição da participação dos avaliadores não foi uniforme. A região Norte contou apenas com a contribuição de um especialista do campus da UFAM (Universidade Federal do Amazonas), enquanto a região Sudeste foi representada por 13 especialistas, 8 dos quais de campi do estado de São Paulo. Deve-se buscar, portanto, uma representatividade equilibrada de todas as regiões brasileiras para uma análise imparcial e de forma a considerar as necessidades dos mais diversos campi se o objetivo for a elaboração de um índice aplicável em nível nacional.

O método empregado fundamenta a ideia de que os 13 indicadores selecionados pelos especialistas e após análise pelo teste de Friedman refletem todas as necessidades partilhadas pelos campi examinados. Contudo, a avaliação dos especialistas foi solicitada apenas em relação aos 20 indicadores do IMSCamp. Foram coletadas suas sugestões sobre a possibilidade de criação de novos indicadores, porém estas informações não foram examinadas neste estudo e podem contribuir para complementar o índice.

Mais uma ressalva do método é o teste de Friedman ter sido aplicado na totalidade das avaliações dos especialistas, e não separadamente, por grupos, de acordo com o perfil de cada campus. Sugere-se que seja feita uma análise neste sentido, a fim de compreender como as necessidades variam de acordo com o perfil dos campi e quais características são determinantes para o processo de planejamento. 
Para destacar as principais conclusões do estudo, serão retomadas as questões de pesquisa apresentadas na justificativa para a pesquisa, bem como alguns pontos da seção de Discussões.

1) O índice de mobilidade sustentável para campus universitário proposto por Oliveira (2015) é transferível para novos contextos?

A aplicação do índice em um novo contexto foi possível, no sentido de que o método elaborado por Oliveira (2015) (resumido na Figura 3.1: diagnóstico, adaptação do índice, validação do índice, mensuração dos indicadores e aplicação do modelo) é replicável se seguidas as etapas descritas. Contudo, a etapa de adaptação do índice exigiu alterações significativas em sua estrutura, atividade que demandou envolvimento por parte dos gestores e da comunidade do campus. Como a transferência foi realizada entre campi de uma mesma universidade, de portes semelhantes e de população aproximada, imaginase que a adaptação do índice para um novo caso seria ainda mais complexa e dispendiosa. Este pode ser um fator limitante para a aplicação em novos contextos, pois os órgãos gestores podem não dispor de recursos (humanos, financeiros e/ou de tempo) para conceber as adaptações necessárias para essa transferência.

2) Em caso positivo, como avaliar este potencial de transferência?

Para avaliar o potencial de transferência do Índice de Mobilidade Sustentável para Campus Universitário (IMSCamp) em uma escala mais abrangente e de maneira justa, seria necessário aplicá-lo em diversos campi e analisar essas experiências. Contudo, o presente trabalho propôs avaliar o potencial de transferência tendo como base uma única nova aplicação. Elaborado e empregado o método de avaliação do potencial de transferência, o resultado obtido foi de 0,396 para a aplicação no campus da USP de Piracicaba. Sendo a escala de zero (pior caso) a um (melhor caso), pode-se dizer que o IMSCamp é pouco transferível.

Apesar de o potencial de transferência ter resultado em um valor baixo, ainda assim a aplicação do IMSCamp a um novo caso foi possível, como explanado na resposta da primeira questão. Em resumo, parece ser possível aplicar o IMSCamp em diferentes 
contextos, contanto que haja recursos para realizar a sua adaptação, que pode ser mais ou menos complexa e custosa. O empenho necessário para este processo é justamente o aspecto mensurado pelo potencial de transferência: quanto mais próximo de zero, mais trabalhoso é o processo de adaptação do índice. A partir da experiência obtida neste estudo, a perspectiva de o índice original ser transferido para um novo campus sem sofrer nenhuma alteração é muito baixa (possivelmente nula).

3) À luz do que for constatado com as respostas às questões acima, qual seria uma estrutura mínima recomendável para a concepção de um índice de mobilidade para campus universitário possível de ser transferido para qualquer contexto?

Como mostrado nos resultados do teste de Friedman (item 4.3.2), os indicadores com maior concordância por parte dos especialistas em termos de relevância e adequação são os seguintes:

- Infraestrutura de transporte público urbano

- Qualidade das calçadas dentro e de acesso ao campus

- Vagas para usuários com restrição de mobilidade

- Transporte público urbano

- Segurança pública

- Acessibilidade dos prédios

- Infraestrutura de estacionamento

- Bicicletários e paraciclos

- Infraestrutura de acesso ao campus

- Adequação do modo de transporte

- Qualidade das vias no campus

- Infraestrutura cicloviária

- Ações de educação no trânsito

Contudo, como comentado na seção de Discussões, os especialistas foram solicitados a avaliar somente o conjunto dos 20 indicadores originais do IMSCamp. Para a elaboração de um índice global, é necessário explorar e compreender quais temas são relevantes para múltiplos campi e que podem não estar contidos no conjunto de indicadores abordado neste estudo.

Pode-se concluir, portanto, que o presente trabalho cumpriu seu objetivo principal (desenvolver e aplicar um método para avaliação do potencial de transferência de um 
índice de mobilidade sustentável) e também seus objetivos secundários (aplicar este índice a um novo contexto e elencar possíveis indicadores para um índice global que permita a comparação entre diferentes campi universitários).

Os procedimentos apresentados neste trabalho podem contribuir para a comparação de índices de diversas áreas e, principalmente, para o desenvolvimento de uma ferramenta de avaliação da mobilidade sustentável aplicável em uma escala mais abrangente e passível de comparação. Algumas sugestões para trabalhos futuros são:

- Emprego de um índice padronizado (de mesma estrutura e mesmos pesos) em diferentes campi, de forma a orientar na solução de problemas e no compartilhamento de soluções entre os mesmos;

- Reaplicação periódica do índice em um mesmo campus para monitoramento das condições de mobilidade ao longo do tempo;

- Refinamento do método de avaliação de potencial de transferência proposto em relação aos critérios escolhidos, valores de referência e pesos;

- Aplicação do método de avaliação de potencial de transferência em outras áreas;

- Análise dos dados coletados no painel de especialistas combinando avaliações e perfis dos campi abrangidos. 
AKAR, G.; CLIFTON, K. Influence of individual perceptions and bicycle infrastructure on decision to bike. Transportation Research Record: Journal of the Transportation Research Board, v. 2140, p. 165-172, dez. 2009.

BALSAS, C. J. Sustainable transportation planning on college campuses. Transport Policy, v. 10, n. 1, p. 35-49, jan. 2003.

BARBETTA, P. A. Estatística aplicada às ciências sociais. 5. ed., 2. reimpr ed. Florianópolis: Ed. da UFSC, 2004.

BOPP, M.; KACZYNSKI, A.; WITTMAN, P. Active commuting patterns at a large, midwestern college campus. Journal of American College Health, v. 59, p. 605-611, ago. 2011.

BRASIL. Lei oㅜ 12.587, 3 de janeiro de 2012. Política Nacional de Mobilidade Urbana. Brasília, DF, 04 jan. 2012, p.1

CADENA, R. P.; DE ANDRADE, M. O.; DE FREITAS DOURADO, A. B. Analysis of mobility on universities campuses in metropolises of emerging countries through the combination of inductive reasoning and monographic procedure methods. Transportation Research Procedia, v. 25, p. 5003-5022, 2017.

CET, Companhia de Engenharia de Tráfego. Polos Geradores de Tráfego. Boletim Técnico oㅡ 32. São Paulo: 1983. 154 p. Disponível em: <www.cetsp.com.br/media/65486/bt32-\%20polos\%20geradores\%20de\%20trafego.pdf> Acesso em: 12 fev. 2018.

CHAKHTOURA, C.; POJANI, D. Indicator-based evaluation of sustainable transport plans: A framework for Paris and other large cities. Transport Policy, v. 50, p. 15-28, ago. 2016.

CHERRY, C.R.; RIGGS, W.; APPLEYARD, B.; DHAKAL, N.; FROST, A.; JEFFERS, S. T. New and unique aspects of university campus transportation data to improve planning methods. Trabalho apresentado no $97^{\text {th }}$ Annual Meeting of Transportation Research Board, Washington D.C., 2018.

CHUNG, B., HASNINE, M. S., HABIB, K. N. How far to live and with whom? The role of modal accessibility on Toronto student's choice of living arrangements and the 
distance they are willing to live from university. Trabalho apresentado no $97^{\text {th }}$ Annual Meeting of Transportation Research Board, Washington D.C., 2018.

CONCEIÇÃO, K. S. Notas de Aula da Disciplina SME 0810 - Métodos NãoParamétricos, Parte VII, ICMC-USP, nov. 2017, 47 f.

CONWAY, T. M.; DALTON, C.; LOO, J.; BENAKOUN, L. Developing ecological footprint scenarios on university campuses. International Journal of Sustainability in Higher Education, v. 9, p. 4-20, 11 jan. 2008.

COSTA, M. S. Um índice de mobilidade urbana sustentável. São Carlos: USP, 2008. 248 f. Tese (Doutorado) - Programa de Pós-Graduação em Engenharia de Transportes, Universidade de São Paulo, São Carlos, 2008.

CRONBACH, L. J. Coefficient alpha and the internal structure of tests. Psychometrika, v. 16, n. 3, p. 297-334, 1951.

DELL'OLIO, L.; BORDAGARAY, M.; BARREDA, R.; IBEAS, A. A methodology to promote sustainable mobility in college campuses. Transportation Research Procedia, v. 3, p. 838-847, 2014.

DELMELLE, E. M.; DELMELLE, E. C. Exploring spatio-temporal commuting patterns in a university environment. Transport Policy, v. 21, p. 1-9, maio 2012.

DENATRAN. Manual de procedimentos para o tratamento de pólos geradores de tráfego. Brasília: 2001. 81 p. Disponível em: <www.capacidades.gov.br> Acesso em: 12 fev de 2018.

FERREIRA, D. A cultura da mobilidade sustentável no Instituto Politécnico de Leiria. Aveiro: Universidade de Aveiro, 2011. 191 f. Dissertação (Mestrado) - Secção Autônoma de Ciências Sociais, Jurídicas e Políticas, Universidade de Aveiro, Aveiro, 2011.

GAVANAS, N.; TSAKALIDIS, A. Forming the framework for sustainable commuting to higher education: The case of the Technological Educational Institution of Thessaly, Greece. Fresenius Environmental Bulletin, v. 26, n. 9/2017, p. 5622-5634, 2017.

GUDMUNDSSON, H. Sustainable transport and performance indicators. Issues in Environmental Science and Technology, v. 20, p. 35-63, 2004.

GUILLARD-GONÇALVES, C.; CUTTER, S. L.; EMRICH, C. T.; ZÊZERE, J. L. Application of Social Vulnerability Index (SoVI) and delineation of natural risk zones in Greater Lisbon, Portugal. Journal of Risk Research, v. 18, p. 651-674, maio 2014. 
INTELLIGENT ENERGY EUROPE. Students today citizens tomorrow, making university life more sustainable. 2010. Disponível em: $<$ https://www.ucy.ac.cy/environment/documents/publishings/TAT_Intelligent_Energy_Eu.p df> Acesso em: 13 fev. 2018.

KNEIB, E. C.; MARQUES DA SILVA, P. C.; PORTUGAL, L. DA S. Impactos decorrentes da implantação de pólos geradores de viagens na estrutura espacial das cidades. Transportes, v. XVIII, n. 1, p. 27-35, mar. 2010.

LITMAN, T. Well measured: Developing indicators for comprehensive and sustainable transport planning. Victoria: 2016. 107 p. Disponível em: <http://www.vtpi.org/wellmeas.pdf> Acesso em 12 fev. 2018.

LONGO, G.; MEDEOSSI, G.; PADOANO, E. Multi-criteria analysis to support mobility management at a university campus. Transportation Research Procedia, v. 5, p. 175185, 2015.

LOW, N. Is urban transport sustainable? In: LOW, N. e GLEESON, B. Making urban transport sustainable. Londres: Palgrave Macmillan, 2003. p. 1-22.

MACÁRIO, R.; MARQUES, C. F. Transferability of sustainable urban mobility measures. Research in Transportation Economics, v. 22, n. 1, p. 146-156, jan. 2008.

MACLAREN, V. W. Urban Sustainability Reporting. Journal of the American Planning Association, v. 62, n. 2, p. 184-202, 30 jun. 1996.

MARINS, K. R. C.; RODRIGUES DA SILVA, A. N.; OLIVEIRA, A. M.; VILELA, M. M.; KAKO, K.; COSTA, D.; GOMES, M. M.; RIGHI, C. A.; ZORIGIAN, C. M.; MARTE, C. L. Uma política de mobilidade para a Universidade de São Paulo. In: II ENCONTRO NACIONAL DE TECNOLOGIA URBANA - ENURB, 2015, Passo Fundo. Anais II Encontro Nacional de Tecnologia Urbana - ENURB. Passo Fundo: UPF Editora, 2015. p. 54-63.

MARSHALL, M. N.; SHEKELLE, P. G.; MCGLYNN, E. A.; CAMPBELL, S.; BROOK, R. H.; ROLAND, M. O. Can health care quality indicators be transferred between countries? Quality and Safety in Health Care, v. 12, n. 1, p. 8-12, 1 fev. 2003.

MEADOWS, D. Leverage points: Places to intervene in a system. The Sustainability Institute, Santa Barbara, 19 p., 1999. 
MEIRELES, T. F. Mobilidade Sustentável no acesso a Campi Universitários - Estudo de caso: Universidade do Minho. Braga: UMinho, 2014. 321 f. Dissertação (Mestrado) Mestrado Integrado em Engenharia Civil, Universidade do Minho, Braga, 2014

MINISTÉRIO DAS CIDADES. Caderno de Referência para Elaboração de Plano de Mobilidade Urbana. Secretaria Nacional de Transporte e da Mobilidade Urbana SeMob. 2007.

MIRALLES-GUASCH, C.; DOMENE, E. Sustainable transport challenges in a suburban university: The case of the Autonomous University of Barcelona. Transport Policy, v. 17, n. 6, p. 454-463, nov. 2010.

MOLINA-GARCÍA, J.; CASTILLO, I.; SALLIS, J. F. Psychosocial and environmental correlates of active commuting for university students. Preventive Medicine, v. 51, n. 2 , p. 136-138, ago. 2010.

NOETHER, G. E. Introduction to statistics: the nonparametric way. New York: Springer-Verlag, 1991.

OLIVEIRA, A. M. Um índice para o planejamento de mobilidade com foco em grandes polos geradores de viagens - Desenvolvimento e aplicação em um campus universitário. São Carlos: USP, 2015. 197 f. Dissertação (Mestrado) - Programa de PósGraduação em Engenharia de Transportes, Universidade de São Paulo, São Carlos, 2015.

OLIVEIRA, A. M.; TAN, F. M.; RODRIGUES DA SILVA, A. N. Adequação do modo de transporte: um indicador de mobilidade sustentável em campus universitário. 2016. Trabalho apresentado no XXX Congresso de Pesquisa e Ensino em Transportes, ANPET, Rio de Janeiro, 2016.

PARRA, M. C. Gerenciamento da mobilidade em campi universitários: problemas dificuldades e possíveis soluções no caso Ilha do Fundão - UFRJ. Rio de Janeiro: UFRJ, 2006, 120 f. Dissertação (Mestrado) - Programa de Pós-Graduação em Engenharia, Universidade Federa do Rio de Janeiro, Rio de Janeiro, 2006.

REDE IBERO-AMERICANA DE ESTUDOS EM POLOS GERADORES DE VIAGENS Relatório da 1a Reunião de Trabalho. Rio de Janeiro: 2005. 20 p. Disponível em: $<$ http://redpgv.coppe.ufrj.br/arquivos/1aReuniao_Relatorio_Abril_de_2005.pdf> Acesso em 12 fev 2018. 
ROBINSON, O. J.; TEWKESBURY, A.; KEMP, S.; WILLIAMS, I. D. Towards a universal carbon footprint standard: A case study of carbon management at universities. Journal of Cleaner Production, v. 172, p. 4435-4455, jan. 2018.

RODRIGUES, D. S., RAMOS, R. A. R., MENDES, J. F. G. Modelo de avaliação da qualidade de vida aplicado a campi universitários. 2005. Trabalho apresentado no I PLURIS - Congresso Luso Brasileiro para o Planejamento Urbano Regional Integrado Sustentável, São Carlos, 2005.

ROTARIS, L.; DANIELIS, R. Commuting to college: The effectiveness and social efficiency of transportation demand management policies. Transport Policy, v. 44, p. 158-168, nov. 2015.

SAATY, T. L. The analytic hierarchy process: planning, priority setting, resource allocation. New York: McGraw-Hill International Book Co, 1980.

SHANNON, T.; GILES-CORTI, B.; PIKORA, T.; BULSARA, M.; SHILTON, T.; BULL, F. Active commuting in a university setting: Assessing commuting habits and potential for modal change. Transport Policy, v. 13, n. 3, p. 240-253, mai. 2006.

SILVA, J. P.; FERREIRA, D. European best practice on sustainable mobility in university campus. $2008 . \quad$ Disponível em: $<$ https://ec.europa.eu/energy/intelligent/projects/sites/ieeprojects/files/projects/documents/t.at._best_practice_report_en.pdf>Acesso em: 13 fev. 2018.

SMITH, L. M.; WADE, C. M.; CASE, J. L.; HARWELL, L. C.; STRAUB, K. R.; SUMMERS, J. K. Evaluating the transferability of a U.S. Human Well-Being Index (HWBI) framework to Native American populations. Social Indicators Research, v. 124, p. 157-182, 1 out. 2014

SPRENT, P.; SMEETON, N. C. Applied nonparametric statistical methods. $4^{\text {a }}$ ed. Boca Raton: Chapman \& Hall/CRC, 2007.

STEIN, P. P. Barreiras, motivações e estratégias para mobilidade sustentável no campus São Carlos da USP. São Carlos: USP, 2013, 260 f. Dissertação (Mestrado) Programa de Pós-Graduação em Engenharia de Transportes, Universidade de São Paulo, São Carlos, 2013.

STEIN, P. P.; RODRIGUES DA SILVA, A. N. Influência de perfis e localizações dos usuários nas taxas de geração de viagens de estabelecimentos de ensino superior. Journal of Transport Literature, v. 8, p. 89-106, jul. 2014. 
STEIN, P. P.; RODRIGUES DA SILVA, A. N. Barriers, motivators and strategies for sustainable mobility at the USP campus in São Carlos, Brazil. Case Studies on Transport Policy, nov. 2017 (disponível online).

STEIN, P. P.; SILVA, C. A. P.; RODRIGUES DA SILVA, A. N. Impactos nas distâncias de caminhada decorrentes de acessos exclusivos para pedestres em um campus universitário. Paranoá: Caderno de Arquitetura e Urbanismo, v. 6, p. 113-121, 2012.

SUSTAINABLE MEASURES. Indicators of Sustainability. 2014. Disponível em: <http://www.sustainablemeasures.com >. Acesso em: 12 fev. 2018.

TAVAKOL, M; DENNICK, R. Making sense of Cronbach's alpha. International Journal of Medical Education, v. 2, p. 53, 2011.

\section{THE CENTRE FOR SUSTAINABLE TRANSPORTATION Defining sustainable transportation. Canadá: $2005 . \quad$ Disponível em:} $<$ https://www.wellingtonpark.org.au/assets/wellingtonpark_CSTdefiningsustainabletranspo rtation2005.pdf> Acesso em: 12 fev. 2018.

TOLLEY, R. Green campuses: cutting the environmental cost of commuting. Journal of Transport Geography, v. 4, n. 3, p. 213-217, set. 1996.

USP. Anuário estatístico USP 2014. Universidade de São Paulo, 2015. Disponível em: <https://uspdigital.usp.br/anuario>. Acesso em 27 de abril de 2017.

USP. ESALQ: passado, presente e futuro. Universidade de São Paulo, 2015. Disponível em: <www4.esalq.usp.br>. Acesso em 15 de abril de 2018.

USP. Sobre o Campus da USP em São Carlos. Universidade de São Paulo, 2017. Disponível em: <www.saocarlos.usp.br>. Acesso em 15 de abril de 2018.

VALE, D. S.; PEREIRA, M.; VIANA, C. M. Different destination, different commuting pattern? Analyzing the influence of the campus location on commuting. Journal of Transport and Land Use, v. 11, n. 1, 2018.

WHALEN, K. E.; PÁEZ, A.; CARRASCO, J. A. Mode choice of university students commuting to school and the role of active travel. Journal of Transport Geography, v. 31, p. 132-142, jul. 2013.

WHITELEGG, J.; HAQ, G. (Eds.). The Earthscan reader on world transport policy and practice. London; Sterling, VA: Earthscan, 2003. 


\section{APÊNDICE A \\ ESTRUTURA DO QUESTIONÁRIO ONLINE (PARTES 1 E 2)}

POTENCIAL DE TRANSFERÊNCIA DE UM ÍNDICE DE MOBILIDADE SUSTENTÁVEL PARA CAMPUS UNIVERSITÁRIO

Francine Marvulle Tan

São Carlos

2018 


\section{Sumário}

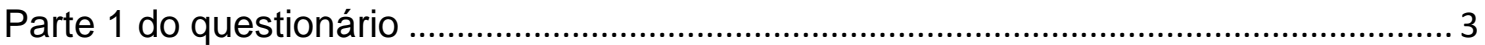

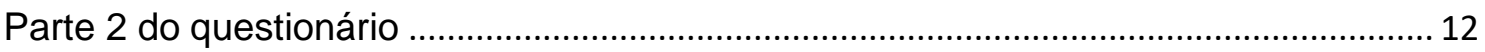

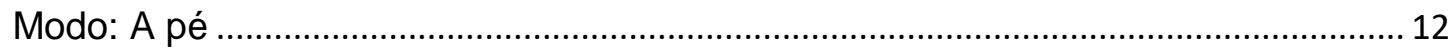

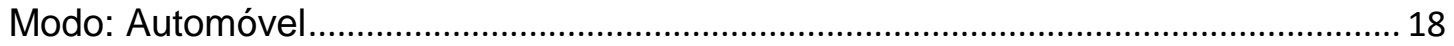

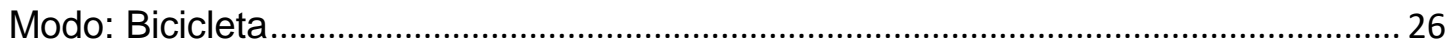

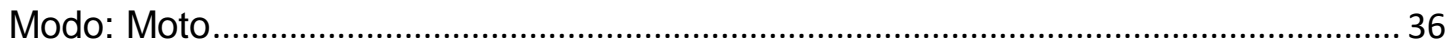

Modo: Transporte Público Urbano ............................................................................... 43

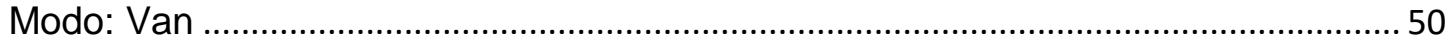




\section{Parte 1 do questionário}

Gênero
a) Aluno de graduação
b) Aluno de pós-graduação
c) Servidor docente
d) Servidor técnico/administrativo
e) Sem vinculação com a universidade - visitante
f) Outro (especifique)

Idade
a) Menos de 18 anos
b) 18 a 24 anos
c) 25 a 30 anos
d) 31 a 39 anos
e) 40 a 49 anos
f) 50 a 59 anos
g) 60 anos ou mais

Você possui alguma restrição de mobilidade?
a) Não
b) $\operatorname{Sim}$

Independente do modo de transporte que utiliza, qual tempo você acha aceitável para realizar o deslocamento casa-universidade?
a) menos de 5 minutos
b) de 10 a 15 minutos
c) de 15 a 20 minutos
d) de 20 a 25 minutos
e) de 25 a 30 minutos
f) de 30 a 35 minutos
g) de 35 a 40 minutos
h) de 40 a 45 minutos
i) de 45 a 50 minutos
j) de 5 a 10 minutos
k) de 50 minutos a 1 hora
l) mais de 1 hora

Principal vinculação com a universidade
a) Aluno de graduação
b) Aluno de pós-graduação
c) Outros
d) Sem vinculação com a universidade - visitante
e) Servidor docente
f) Servidor técnico/administrativo 
Curso de graduação
a) Administração
b) Ciências Biológicas
c) Ciências dos Alimentos
d) Ciências Econômicas
e) Engenharia Agronômica
f) Engenharia Florestal
g) Gestão Ambiental

Você mora na moradia estudantil?
a) Não
b) $\mathrm{Sim}$

Em qual unidade da moradia estudantil você mora?
a) Moradia interna (dentro do campus)
b) Vila estudantil

Curso de pós-graduação
a) Administração
b) Bioenergia (interinstitucional)
c) Ciência Animal e Pastagens
d) Ciência e Tecnologia de Alimentos
e) Ecologia Aplicada (interunidades)
f) Economia Aplicada
g) Engenharia de Sistemas Agrícolas
h) Entomologia
i) Estatística e Experimentação Agronômica
j) Fisiologia e Bioquímica de Plantas
k) Fitopatologia
l) Fitotecnia
m) Genética e Melhoramento de Plantas
n) Internacional Biologia Celular e Molecular Vegetal
o) Microbiologia Agrícola
p) Outro (especifique)

Setor no campus dos servidores docentes
a) CENA - Centro de Energia Nuclear na Agricultura
b) Departamento de Agroindústria, Alimentos e Nutrição (LAN)
c) Departamento de Ciência do Solo (LSO)
d) Departamento de Ciências Biológicas (LCB)
e) Departamento de Ciências Exatas (LCE)
f) Departamento de Ciências Florestais (LCF)
g) Departamento de Economia, Administração e Sociologia (LES)
h) Departamento de Engenharia de Biossistemas (LEB)
i) Departamento de Entomologia e Acarologia (LEA)
j) Departamento de Fitopatologia e Nematologia (LFN)
k) Departamento de Genética (LGN)
I) Departamento de Produção Vegetal (LPV) 
m) Departamento de Zootecnia (LZT)

n) PUSP-LQ - Prefeitura do Campus USP Luiz de Queiroz

Setor no campus dos servidores técnicos/administrativos

a) Almoxarifado

b) Apoio à Pesquisa

c) Apoio Institucional

d) Assistência Acadêmica

e) Assistência Administrativa

f) Assistência Financeira

g) Atividades Internacionais

h) Biblioteca Central

i) Biblioteca Setorial - LES

j) CENA - Centro de Energia Nuclear na Agricultura

k) CEPEA

l) CeTI-LQ - Centro de Tecnologia da Informação "Luiz de Queiroz"

m) Contabilidade

n) Cultura e Ext. Universitária

o) Departamento de Agroindústria, Alimentos e Nutrição (LAN)

p) Departamento de Ciência do Solo (LSO)

q) Departamento de Ciências Biológicas (LCB)

r) Departamento de Ciências Exatas (LCE)

s) Departamento de Ciências Florestais (LCF)

t) Departamento de Economia, Administração e Sociologia (LES)

u) Departamento de Engenharia de Biossistemas (LEB)

v) Departamento de Entomologia e Acarologia (LEA)

w) Departamento de Fitopatologia e Nematologia (LFN)

x) Departamento de Genética (LGN)

y) Departamento de Produção Vegetal (LPV)

z) Departamento de Zootecnia (LZT)

aa) Diretoria

bb) Divisão de Comunicação

cc) Estações Experimentais

dd) Expediente

ee) Ger. Ambiental e Resid. Químicos

ff) Graduação

gg) Gráfica

hh) Informática

ii) Licitações

jj) Material

kk) Outro

II) Pessoal

mm) Pós-Graduação

nn) PUSP-LQ - Prefeitura da USP Campus "Luiz de Queiroz"

oo) Scientia Agricola

pp) Serviços Gerais

qq) Transportes

Departamento de pós-graduação

a) Departamento de Agroindústria, Alimentos e Nutrição (LAN)

b) Departamento de Ciência do Solo (LSO)

c) Departamento de Ciências Biológicas (LCB) 
d) Departamento de Ciências Exatas (LCE)

e) Departamento de Ciências Florestais (LCF)

f) Departamento de Economia, Administração e Sociologia (LES)

g) Departamento de Engenharia de Biossistemas (LEB)

h) Departamento de Entomologia e Acarologia (LEA)

i) Departamento de Fitopatologia e Nematologia (LFN)

j) Departamento de Genética (LGN)

k) Departamento de Produção Vegetal (LPV)

l) Departamento de Zootecnia (LZT)

m) Outro (especifique)

Você tem residência na cidade de Piracicaba
a) Não
b) $\operatorname{Sim}$

Qual modo você geralmente utiliza para se deslocar até a cidade de Piracicaba
a) Ônibus
b) Automóvel (na condição de carona)
c) Automóvel (na condição de motorista)
d) Motocicleta
e) Van

De maneira geral, onde você inicia o seu deslocamento para a universidade
a) Casa
b) Trabalho
c) Outro

Com quantas pessoas você mora em Piracicaba (ou região)
a) Moro sozinho (a)
b) 1 pessoa
c) 2 pessoas
d) 3 pessoas
e) 4 pessoas
f) 5 pessoas
g) 6 pessoas
h) 7 pessoas
i) 8 pessoas
j) 9 pessoas
k) 10 pessoas
l) mais de 10 pessoas

As pessoas com quem você mora dependem de você para seus deslocamentos regulares? Exemplo: filhos pequenos, pessoas que não dirigem, pessoas com restrição de mobilidade, etc.
a) Não
b) Sim, 1 pessoa
c) Sim, 2 pessoas
d) Sim, 3 pessoas
e) Sim, 4 pessoas
f) Sim, mais de 4 pessoas 
Qual acesso do campus da ESALQ/CENA você normalmente utiliza?
a) Acesso para pedestres (Av. Carlos Botelho)
b) Entrada Principal (próxima ao monumento "A" encarnado)
c) Entrada Entomologia (Av. Pádua Dias)
d) CENA (Av. Centenário)
e) Entrada Engenharia Monte Alegre (Estrada Monte Alegre)
f) Entrada da Atlética (Av. São João)

Na sua rotina de deslocamentos regulares a partir da residência (em Piracicaba ou região), você tem acesso a quais modos de transporte?

Bicicleta
a) Não possuo
b) 1
c) 2
d) 3
e) Mais de 3

Motocicleta
a) Não possuo
b) 1
c) 2
d) 3
e) Mais de 3

Automóvel
a) Não possuo
b) 1
c) 2
d) 3
e) Mais de 3

Com que frequência você vai à ESALQ/CENA?
a) Raramente
b) 1 dia a cada quinzena
c) 1 dia por semana
d) 2 dias por semana
e) 3 dias por semana
f) 4 dias por semana
g) 5 dias por semana
h) 6 dias por semana
i) 7 dias por semana
j) Não frequento a ESALQ/CENA

Há quanto tempo você frequenta a ESALQ/CENA?
a) há menos de 1 ano
b) 1 ano
c) 2 anos
d) 3 anos
e) 4 anos
f) 5 anos
g) 6 anos
h) 7 anos
i) 8 anos 

j) 9 anos
k) 10 anos
l) entre 11 e 15 anos
m) entre 16 e 20 anos
n) entre 21 e 25 anos
o) entre 26 e 30 anos
p) entre 31 e 35 anos
q) entre 36 e 40 anos
r) entre 41 e 45 anos
s) entre 46 e 50 anos
t) entre 51 e 55 anos
u) há mais de 55 anos

Qual acesso do campus da ESALQ/CENA você normalmente utiliza?
a) Acesso para pedestres (Av. Carlos Botelho)
b) Entrada Principal (próxima ao monumento "A" encarnado)
c) Entrada Entomologia (Av. Pádua Dias)
d) CENA (Av. Centenário)
e) Entrada Engenharia Monte Alegre (Estrada Monte Alegre)
f) Entrada da Atlética (Av. São João)

De acordo com a resposta da questão anterior, qual é, portanto, o modo de transporte principal que você utiliza para se deslocar até a ESALQ/CENA?
a) A pé
b) Automóvel
c) Bicicleta
d) Motocicleta
e) Ônibus do transporte público urbano
f) Outro (especifique)
g) Skate
h) Van

Com que frequência você vai à Fazenda Areão?
a) Raramente
b) 1 dia a cada quinzena
c) 1 dia por semana
d) 2 dias por semana
e) 3 dias por semana
f) 4 dias por semana
g) 5 dias por semana
h) 6 dias por semana
i) Não frequento a Fazenda Areão

Há quanto tempo você frequenta a Fazenda Areão?
a) há menos de 1 ano
b) 1 ano
c) 2 anos
d) 3 anos
e) 4 anos
f) 5 anos
g) 6 anos
h) 7 anos
i) 8 anos
j) 9 anos
k) 10 anos 

l) entre 11 e 15 anos
m) entre 16 e 20 anos
n) entre 21 e 25 anos
o) entre 26 e 30 anos
p) entre 31 e 35 anos
q) entre 36 e 40 anos
r) entre 46 e 50 anos
s) há mais de 55 anos

Qual é o modo de transporte principal que você utiliza para se deslocar até a Fazenda Areão?
a) A pé
b) Automóvel
c) Bicicleta
d) Motocicleta
e) Ônibus do transporte público urbano
f) Van
g) Outro (especifique)

Você tem conhecimento ou participou de alguma AÇÃO DE CONSCIENTIZAÇÃO ao uso de modos mais sustentáveis promovida neste campus?
a) Não
b) Sim

De quais ações você tem conhecimento ou participou? (se for necessário, marque mais de uma alternativa).
a) Semana de recepção
b) Semana da mobilidade
c) Passeio de bicicleta
d) Marcador de livros
e) Adesivos nos bicicletários
f) Cinema
g) Panfletagem
h) Redes sociais
i) Email
j) Outras (especifique)

Como você classifica a influência destas ações no seu cotidiano?
a) Fizeram-me refletir sobre o meu modo de deslocamento
b) Motivaram-me a mudar meus hábitos de deslocamento. Atualmente utilizo com frequência modos que julgo mais sustentáveis.
c) Motivaram-me a, esporadicamente, fazer caminhadas, utilizar bicicleta e/ou oferecer carona para o campus
d) Não influenciaram em absolutamente nada

Você tem conhecimento ou participou de alguma AÇÃO DE EDUCAÇÃO NO TRÂNSITO promovida neste campus?
a) Não
b) Sim

De quais ações você tem conhecimento ou participou? (se for necessário, marque mais de uma alternativa)
a) Semana de recepção
b) Semana da mobilidade
c) Passeio de bicicleta
d) Marcador de livros
e) Adesivos nos bicicletários
f) Cinema
g) Panfletagem 
h) Redes sociais
i) Email
j) Outras (especifique)

Como você classifica a influência destas ações no seu comportamento?

a) Fizeram-me refletir como o meu modo de deslocamento afeta a segurança no trânsito

b) Motivaram-me a prestar mais atenção nas regras de trânsito, em prol da minha segurança e dos demais usuários do sistema viário

c) Não influenciaram em absolutamente nada

Como você avalia a influência destas ações na circulação interna do campus, nos seguintes aspectos:

Agressividade

a) Aumentou

b) Diminuiu

c) Não houve alteração

Desrespeito à faixa de pedestres
a) Aumentou
b) Diminuiu
c) Não houve alteração

Desrespeito aos ciclistas e as ciclofaixas
a) Aumentou
b) Diminuiu
c) Não houve alteração

Excesso de velocidade
a) Aumentou
b) Diminuiu
c) Não houve alteração

Desrespeito à sinalização
a) Aumentou
b) Diminuiu
c) Não houve alteração

Desrespeito às regras de trânsito
a) Aumentou
b) Diminuiu
c) Não houve alteração

Na sua opinião, qual a importância da mobilidade sustentável em um campus universitário?
a) Importante
b) Indiferente
c) Muito importante
d) Pouco importante

De maneira geral, como você avalia a mobilidade interna do campus da USP Piracicaba (deslocamentos internos)?
a) Boa
b) Excelente
c) Péssima 
d) Regular

e) Ruim

De maneira geral, como você avalia a mobilidade para se acessar o campus da USP Piracicaba (cidade $x$ campus)?
a) Boa
b) Excelente
c) Péssima
d) Regular
e) Ruim 


\section{Parte 2 do questionário}

\section{Modo: A pé}

Analisando o campus da ESALQ/CENA como um todo, você o considera acessível aos usuários com algum tipo de restrição de mobilidade?

a) Sim. Nunca notei obstáculos que dificultassem a acessibilidade aos usuários com algum tipo de restrição de mobilidade nas dependências do campus

b) Grande parte do campus é acessível. Algumas áreas possuem obstáculos, mas de maneira geral considero o campus acessível aos usuários com algum tipo de restrição de mobilidade

c) Pequena parte do campus é acessível. Há diversas áreas que não oferecem condições básicas de acessibilidade aos usuários com algum tipo de restrição de mobilidade

d) Não. O campus não oferece condições básicas de acessibilidade aos usuários com algum tipo de restrição de mobilidade

e) Não sou capaz de opinar, pois nunca analisei o campus sob este aspecto

Dentre os prédios que frequenta na ESALQ/CENA, como você avalia a acessibilidade para os usuários com algum tipo de restrição de mobilidade?

a) Ótima. Prédios totalmente equipados para receber os usuários com algum tipo de restrição de mobilidade

b) Boa. Prédios parcialmente equipados, mas possuem condições satisfatórias para atender os usuários com algum tipo de restrição de mobilidade

c) Regular. Prédios pouco equipados, com limitações para atender os usuários com algum tipo de restrição de mobilidade

d) Ruim. Prédios não equipados para receber os usuários com algum tipo de restrição de mobilidade

e) Não sou capaz de avaliar, pois nunca analisei os prédios da ESALQ/CENA sob este aspecto

$\mathrm{Na}$ etapa anterior do questionário, você nos informou que seu modo principal para os deslocamentos à ESALQ/CENA é o modo A PÉ. Quais fatores o/a levam a optar por este modo?

Benefícios para saúde
a) Sem importância
b) Pouco importante
c) De alguma importância
d) Muito importante
e) Extremamente importante

Potencial economia financeira
a) Sem importância
b) Pouco importante
c) De alguma importância
d) Muito importante
e) Extremamente importante 
Não precisar procurar local para estacionar
a) Sem importância
b) Pouco importante
c) De alguma importância
d) Muito importante
e) Extremamente importante

Contribuição pessoal para a redução dos níveis de poluição do ar
a) Sem importância
b) Pouco importante
c) De alguma importância
d) Muito importante
e) Extremamente importante

Gosto de caminhar
a) Sem importância
b) Pouco importante
c) De alguma importância
d) Muito importante
e) Extremamente importante

Meus amigos vêm a pé
a) Sem importância
b) Pouco importante
c) De alguma importância
d) Muito importante
e) Extremamente importante

Flexibilidade (poder sair no momento em que desejar, fazer paradas durante o trajeto, etc.)
a) Sem importância
b) Pouco importante
c) De alguma importância
d) Muito importante
e) Extremamente importante

Quais fatores o/a desestimulam a utilizar os demais modos que não o modo a pé em seus deslocamentos?

Tempo envolvido no trajeto dos demais modos (tempo de espera, percurso, atrasos)
a) Sem importância
b) Pouco importante
c) De alguma importância
d) Muito importante
e) Extremamente importante

Inexistência de ciclovias contínuas das avenidas principais até o campus
a) Sem importância
b) Pouco importante
c) De alguma importância
d) Muito importante
e) Extremamente importante 
Baixa qualidade do transporte público
a) Sem importância
b) Pouco importante
c) De alguma importância
d) Muito importante
e) Extremamente importante

Insegurança pública (assaltos, furtos, assédio)
a) Sem importância
b) Pouco importante
c) De alguma importância
d) Muito importante
e) Extremamente importante

Perigo com o trânsito
a) Sem importância
b) Pouco importante
c) De alguma importância
d) Muito importante
e) Extremamente importante

Não possuo carteira de habilitação
a) Sem importância
b) Pouco importante
c) De alguma importância
d) Muito importante
e) Extremamente importante

Não sei quais linhas de ônibus vão para a USP
a) Sem importância
b) Pouco importante
c) De alguma importância
d) Muito importante
e) Extremamente importante

Há quanto tempo você utiliza o modo a pé para se deslocar até a ESALQ/CENA?
a) Há menos de 6 meses
b) Há mais de 6 meses

Dos deslocamentos que você faz hoje a pé, qual modo você utilizava antes?
a) Bicicleta
b) Transporte público urbano
c) Van operada pela USP (Vila Estudantil)
d) Automóvel
e) Automóvel, na condição de CARONA - estaciona no campus
f) Automóvel, na condição de CARONA - não estaciona no campus
g) Motocicleta
h) Skate
i) Patins
j) Nenhum. Antes deste período não frequentava o campus
k) Outro (especifique) 
Classifique, somente para os turnos em que você costuma acessar ou se deslocar AO REDOR da ESALQ/CENA, qual a sua sensação de segurança em relação a assaltos e outros tipos de violência ou assédio:

Manhã
a) Seguro
b) Parcialmente seguro
c) Inseguro

Tarde
a) Seguro
b) Parcialmente seguro
c) Inseguro

Noite
a) Seguro
b) Parcialmente seguro
c) Inseguro

Você presenciou ou sofreu algum tipo de violência ou assédio NO ENTORNO da ESALQ/CENA?
a) $\operatorname{Sim}$
b) Não

Que tipo de violência ou assédio você presenciou ou sofreu NO ENTORNO da ESALQ/CENA? (se for necessário, marque mais de uma alternativa)
a) Sofri um assalto
b) Sofri mais de um assalto
c) Presenciei um assalto
d) Presenciei mais de um assalto
e) Sofri uma tentativa de assalto
f) Sofri mais de uma tentativa de assalto
g) Presenciei uma tentativa de assalto
h) Presenciei mais de uma tentativa de assalto
i) Sofri assédio sexual, uma vez
j) Sofri assédio sexual, mais de uma vez
k) Presenciei um ato de assédio sexual
l) Presenciei mais de um ato de assédio sexual
m) Sofri assédio moral, uma vez
n) Sofri assédio moral, mais de uma vez
o) Presenciei um ato de assédio moral
p) Presenciei mais de um ato de assédio moral
q) Outros (especifique)

Classifique, somente para os turnos em que você costuma acessar ou se deslocar DENTRO da ESALQ/CENA, qual a sua sensação de segurança em relação a assaltos e outros tipos de violência ou assédio:

Manhã

a) Seguro 
b) Parcialmente seguro

c) Inseguro

Tarde
a) Seguro
b) Parcialmente seguro
c) Inseguro

Noite
a) Seguro
b) Parcialmente seguro
c) Inseguro

Você presenciou ou sofreu algum tipo de violência ou assédio DENTRO da ESALQ/CENA?
a) $\operatorname{Sim}$
b) Não

Que tipo de violência ou assédio você presenciou ou sofreu DENTRO da ESALQ/CENA? (se for necessário, marque mais de uma alternativa)
a) Sofri um assalto
b) Sofri mais de um assalto
c) Presenciei um assalto
d) Presenciei mais de um assalto
e) Sofri uma tentativa de assalto
f) Sofri mais de uma tentativa de assalto
g) Presenciei uma tentativa de assalto
h) Presenciei mais de uma tentativa de assalto
i) Sofri assédio sexual, uma vez
j) Sofri assédio sexual, mais de uma vez
k) Presenciei um ato de assédio sexual
l) Presenciei mais de um ato de assédio sexual
m) Sofri assédio moral, uma vez
n) Sofri assédio moral, mais de uma vez
o) Presenciei um ato de assédio moral
p) Presenciei mais de um ato de assédio moral
q) Outros (especifique)

Com relação a medidas de segurança no ENTORNO e DENTRO da ESALQ/CENA, você é favorável a (se for necessário, marque mais de uma alternativa):
a) Instalação de mais câmeras de monitoramento
b) Melhoria da iluminação
c) Intensificação das rondas no ENTORNO do campus, pela Guarda Universitária (PPUSP)
d) Intensificação das rondas no ENTORNO do campus, pela Policia Militar
e) Intensificação das rondas no ENTORNO do campus, pela Guarda Municipal
f) Intensificação de rondas DENTRO do campus, pela Guarda Universitária (PPUSP)
g) Realização de rondas DENTRO do campus, pela Policia Militar
h) Realização de rondas DENTRO do campus, pela Policia Militar, mas somente nos horários mais críticos como à noite e durante grandes eventos
i) Realização de rondas DENTRO do campus, pela Guarda Municipal 
j) Realização de rondas DENTRO do campus, pela Guarda Municipal, mas somente nos horários mais críticos como à noite e durante grandes eventos

k) Nenhuma das alternativas

Como você descreveria o trajeto do seu ponto de origem até o campus Luiz de Queiroz (ESALQ/CENA)?

a) O trajeto me incomoda em alguns aspectos; gostaria que fosse mais agradável e/ou menos demorado

b) O trajeto representa um sofrimento para mim; é um alívio chegar ao campus

c) O trajeto é indiferente para mim, não me sinto incomodado nem confortável

d) O trajeto é satisfatório para mim

e) O trajeto é agradável para mim

f) Outro (especifique)

Como você avalia a sinalização do campus Luiz de Queiroz (ESALQ/CENA)?

Sinalização de trânsito (horizontal e vertical)
a) Inexistente
b) Insuficiente
c) Suficiente, porém em mau estado de conservação
d) Suficiente, porém fora dos padrões
e) Suficiente

Sinalização informativa (indicação de prédios, serviços, etc)
a) Inexistente
b) Insuficiente
c) Suficiente, porém em mau estado de conservação
d) Suficiente, porém fora dos padrões
e) Suficiente

Na sua opinião, qual a importância destes aspectos para uma mobilidade mais sustentável na USP de Piracicaba? Ordene os temas marcando-os com os respectivos números ou arrastando as caixas de acordo com a prioridade (no topo, o mais importante)

a) Ciclofaixas/ciclovias dentro do campus e para acesso ao mesmo

b) Infraestrutura essencial para pedestres (calçadas adequadas, iluminação, arborização, sinalização, etc.)

c) Alternativa para deslocamentos internos ao campus (sistema de transporte coletivo, sistema de bicicletas compartilhadas, etc.)

d) Educação no trânsito (respeito aos limites de velocidade e à sinalização, melhor convívio entre motoristas, ciclistas e pedestres, etc.)

e) Ação conjunta com Prefeitura Municipal para melhoria da mobilidade na ligação entre cidade e campus

f) Bolsões de estacionamento internos e externos ao campus

g) Melhoria da qualidade do serviço de transporte público da cidade

h) Restrição do uso de automóveis dentro do campus

i) Acessibilidade (rampas de acesso, calçadas adequadas, elevadores, piso tátil, respeito a vagas de estacionamento prioritárias, etc.)

j) Infraestrutura de apoio para pedestres e ciclistas (bebedouros, bancos, vestiários, guarda-volume, bicicletários, oficina para consertos, etc.) 


\section{Modo: Automóvel}

Analisando o campus da ESALQ/CENA como um todo, você o considera acessível aos usuários com algum tipo de restrição de mobilidade?

a) Sim. Nunca notei obstáculos que dificultassem a acessibilidade aos usuários com algum tipo de restrição de mobilidade nas dependências do campus

b) Grande parte do campus é acessível. Algumas áreas possuem obstáculos, mas de maneira geral considero o campus acessível aos usuários com algum tipo de restrição de mobilidade

c) Pequena parte do campus é acessível. Há diversas áreas que não oferecem condições básicas de acessibilidade aos usuários com algum tipo de restrição de mobilidade

d) Não. O campus não oferece condições básicas de acessibilidade aos usuários com algum tipo de restrição de mobilidade

e) Não sou capaz de opinar, pois nunca analisei o campus sob este aspecto

Dentre os prédios que frequenta na ESALQ/CENA, como você avalia a acessibilidade para os usuários com algum tipo de restrição de mobilidade?

a) Ótima. Prédios totalmente equipados para receber os usuários com algum tipo de restrição de mobilidade

b) Boa. Prédios parcialmente equipados, mas possuem condições satisfatórias para atender os usuários com algum tipo de restrição de mobilidade

c) Regular. Prédios pouco equipados, com limitações para atender os usuários com algum tipo de restrição de mobilidade

d) Ruim. Prédios não equipados para receber os usuários com algum tipo de restrição de mobilidade

e) Não sou capaz de avaliar, pois nunca analisei os prédios da ESALQ/CENA sob este aspecto

$\mathrm{Na}$ etapa anterior do questionário, você nos informou que seu modo principal para os deslocamentos à ESALQ/CENA é o AUTOMÓVEL. Quais fatores o/a levam a optar por este modo?

Insegurança pública (assaltos, furtos e/ou assédio)
a) Sem importância
b) Pouco importante
c) De alguma importância
d) Muito importante
e) Extremamente importante

Condições climáticas (chuva, vento, calor, frio)
a) Sem importância
b) Pouco importante
c) De alguma importância
d) Muito importante
e) Extremamente importante

Conforto
a) Sem importância
b) Pouco importante
c) De alguma importância 
d) Muito importante

e) Extremamente importante

Conveniência
a) Sem importância
b) Pouco importante
c) De alguma importância
d) Muito importante
e) Extremamente importante

Flexibilidade (poder sair no momento em que desejar, fazer paradas durante o trajeto, etc.)
a) Sem importância
b) Pouco importante
c) De alguma importância
d) Muito importante
e) Extremamente importante

Estacionamento gratuito no campus
a) Sem importância
b) Pouco importante
c) De alguma importância
d) Muito importante
e) Extremamente importante

Baixa qualidade do transporte público
a) Sem importância
b) Pouco importante
c) De alguma importância
d) Muito importante
e) Extremamente importante

Quais fatores o/a desestimulam a utilizar os demais modos que não o automóvel em seus deslocamentos?

Tempo envolvido no trajeto dos demais modos (tempo de espera, percurso, atrasos)
a) Sem importância
b) Pouco importante
c) De alguma importância
d) Muito importante
e) Extremamente importante

Distância longa a ser percorrida
a) Sem importância
b) Pouco importante
c) De alguma importância
d) Muito importante
e) Extremamente importante

Condições climáticas (chuva, vento, calor, frio)
a) Sem importância
b) Pouco importante
c) De alguma importância
d) Muito importante 
e) Extremamente importante

Inexistência de ciclovias contínuas das avenidas principais até o campus
a) Sem importância
b) Pouco importante
c) De alguma importância
d) Muito importante
e) Extremamente importante

Baixa qualidade do transporte público
a) Sem importância
b) Pouco importante
c) De alguma importância
d) Muito importante
e) Extremamente importante

Insegurança pública (assaltos, furtos, assédio)
a) Sem importância
b) Pouco importante
c) De alguma importância
d) Muito importante
e) Extremamente importante

Perigo com o trânsito
a) Sem importância
b) Pouco importante
c) De alguma importância
d) Muito importante
e) Extremamente importante

Há quanto tempo você utiliza o automóvel para se deslocar até a ESALQ/CENA?
a) Há menos de 6 meses
b) Há mais de 6 meses

Dos deslocamentos que você faz hoje de automóvel, qual modo você utilizava antes?
a) A pé
b) Bicicleta
c) Transporte público urbano
d) Van operada pela USP (Vila Estudantil)
e) Automóvel, na condição de MOTORISTA
f) Automóvel, na condição de CARONA - estaciona no campus
g) Automóvel, na condição de CARONA - não estaciona no campus
h) Motocicleta
i) Skate
j) Patins
k) Nenhum. Antes deste período não frequentava o campus
l) Outro (especifique)

Você estaciona seu carro em apenas um lugar durante sua permanência no campus ou troca de vaga conforme realiza suas atividades?
a) Estaciono em lugar fixo
b) Troco de vaga conforme realizo minhas atividades 
c) Não estaciono dentro do campus

d) Não me preocupo com isso, porque não sou o motorista (pego carona)

Local onde estaciona

1. Pavilhão de Engenharia

2. Pavilhão de Economia e Sociologia

3. Museu e Centro de Ciências "Luiz de Queiroz"

4. Galpão USP Recicla

5. Divisões Administrativa (DA) ede Manutenção e Operação (DVMANOPER)

6. Departamento de Entomologia e Acarologia (LEA)

7. Departamento de Engenharia de Biossistemas (LEB)

8. Prédio da Pesqusa, Cultura e Extensão Universitária

9. Edifício Central

10. Sala dos Grupos Musicais da ESALQ

11. Microscopia Eletrônica

12. Pavilhão de Horticultura

a) 15. Departamento de Ciências Florestais (LCF) e Ipef

b) 17. Departamento de Ciência do Solo (LSO)

c) 18. Restaurante Universitário (R.U.)

d) 19. Centro de Vivência (C.V.)

e) 20. Pavilhão de Química

f) 21. Edifício "Prof. Friedrich Gustav Brieger" (LGN)

g) 22. Pavilhão de Ciências Humanas (LAN - 3 e LES)

h) 23. Edifício "Prof. José Theófilo do Amaral Gurgel" (LGN)

i) 24. Centro de Tecnologia da Informação do Campus "Luiz de Queiroz" (CeTI-LQ) e Seção Técnica de Informática da ESALQ (Siesalq)

j) 25. Divisão de Atendimento à Comunidade (DVATCOM)

k) 26. Laboratório de Biotecnologia Agrícola "Prof. Otto Jesu Crocomo" (LCB)

l) 27. Centro de Estudos Linguísticos (CEL)

m) 28. Centro de Convivência Infantil (CCIn)

n) 29. Departamento de Zootecnia (LZT | não-ruminantes)

o) 30. Departamento de Genética (LGN)

p) 31. Pavilhão de Agricultura (LPV e LSO)

q) 32. Serviço Médico

r) 34. Serviço de Graduação

s) 35. Pavilhão Walter Ramos Jardim (LZT | ruminantes)

t) 36. Edifício Professor Jayme Rocha de Almeida (LAN - 1)

u) 37. Departamento de Agroindústria, Alimentos e Nutrição (LAN - 2)

v) 38. Central de Aulas

w) 39. Novo restaurante

x) 41. Biblioteca Central

y) 42. Serviço de Pós-Graduação

z) 43. Edifício "Professor Salvador de Toledo Piza Jr." (Pavilhão de Zoologia)

aa) 44. Serviço Odontológico

bb) 46. Restaurante dos Docentes

cc) 48. CENA

dd) 51. Praça Esportiva - Ginásio de Esportes

Com que frequência você dá carona para outras pessoas até o campus? Ou pega carona?
a) Frequentemente
b) Raramente
c) Nunca 
Em média, a quantas pessoas você dá carona até o campus? Se você pega carona, quantas pessoas vão com você no carro?
a) 1 pessoa
b) 2 pessoas
c) 3 pessoas
d) 4 pessoas

Classifique, somente para os turnos em que você costuma acessar ou se deslocar AO REDOR da ESALQ/CENA, qual a sua sensação de segurança em relação a assaltos e outros tipos de violência ou assédio:

Manhã
a) Seguro
b) Parcialmente seguro
c) Inseguro

Tarde
a) Seguro
b) Parcialmente seguro
c) Inseguro

Noite
a) Seguro
b) Parcialmente seguro
c) Inseguro

Você presenciou ou sofreu algum tipo de violência ou assédio NO ENTORNO da ESALQ/CENA?
a) $\operatorname{Sim}$
b) Não

Que tipo de violência ou assédio você presenciou ou sofreu NO ENTORNO da ESALQ/CENA? (se for necessário, marque mais de uma alternativa)
a) Sofri um assalto
b) Sofri mais de um assalto
c) Presenciei um assalto
d) Presenciei mais de um assalto
e) Sofri uma tentativa de assalto
f) Sofri mais de uma tentativa de assalto
g) Presenciei uma tentativa de assalto
h) Presenciei mais de uma tentativa de assalto
i) Sofri assédio sexual, uma vez
j) Sofri assédio sexual, mais de uma vez
k) Presenciei um ato de assédio sexual
l) Presenciei mais de um ato de assédio sexual
m) Sofri assédio moral, uma vez
n) Sofri assédio moral, mais de uma vez
o) Presenciei um ato de assédio moral
p) Presenciei mais de um ato de assédio moral 
q) Outros (especifique)

Classifique, somente para os turnos em que você costuma acessar ou se deslocar DENTRO da ESALQ/CENA, qual a sua sensação de segurança em relação a assaltos e outros tipos de violência ou assédio:

Manhã
d) Seguro
e) Parcialmente seguro
f) Inseguro

Tarde

d) Seguro

e) Parcialmente seguro

f) Inseguro

Noite

d) Seguro

e) Parcialmente seguro

f) Inseguro

Você presenciou ou sofreu algum tipo de violência ou assédio DENTRO da ESALQ/CENA?
a) $\mathrm{Sim}$
b) Não

Que tipo de violência ou assédio você presenciou ou sofreu DENTRO da ESALQ/CENA? (se for necessário, marque mais de uma alternativa)
a) Sofri um assalto
b) Sofri mais de um assalto
c) Presenciei um assalto
d) Presenciei mais de um assalto
e) Sofri uma tentativa de assalto
f) Sofri mais de uma tentativa de assalto
g) Presenciei uma tentativa de assalto
h) Presenciei mais de uma tentativa de assalto
i) Sofri assédio sexual, uma vez
j) Sofri assédio sexual, mais de uma vez
k) Presenciei um ato de assédio sexual
l) Presenciei mais de um ato de assédio sexual
m) Sofri assédio moral, uma vez
n) Sofri assédio moral, mais de uma vez
o) Presenciei um ato de assédio moral
p) Presenciei mais de um ato de assédio moral
q) Outros (especifique)

Com relação a medidas de segurança no ENTORNO e DENTRO da ESALQ/CENA, você é favorável a (se for necessário, marque mais de uma alternativa):

a) Instalação de mais câmeras de monitoramento 
b) Melhoria da iluminação

c) Intensificação das rondas no ENTORNO do campus, pela Guarda Universitária (PPUSP)

d) Intensificação das rondas no ENTORNO do campus, pela Policia Militar

e) Intensificação das rondas no ENTORNO do campus, pela Guarda Municipal

f) Intensificação de rondas DENTRO do campus, pela Guarda Universitária (PPUSP)

g) Realização de rondas DENTRO do campus, pela Policia Militar

h) Realização de rondas DENTRO do campus, pela Policia Militar, mas somente nos horários mais críticos como à noite e durante grandes eventos

i) Realização de rondas DENTRO do campus, pela Guarda Municipal

j) Realização de rondas DENTRO do campus, pela Guarda Municipal, mas somente nos horários mais críticos como à noite e durante grandes eventos

k) Nenhuma das alternativas

Como você descreveria o trajeto do seu ponto de origem até o campus Luiz de Queiroz (ESALQ/CENA)?

a) O trajeto me incomoda em alguns aspectos; gostaria que fosse mais agradável e/ou menos demorado

b) O trajeto representa um sofrimento para mim; é um alívio chegar ao campus

c) O trajeto é indiferente para mim, não me sinto incomodado nem confortável

d) O trajeto é satisfatório para mim

e) O trajeto é agradável para mim

f) Outro (especifique)

Como você avalia a sinalização do campus Luiz de Queiroz (ESALQ/CENA)?

Sinalização de trânsito (horizontal e vertical)

f) Inexistente

g) Insuficiente

h) Suficiente, porém em mau estado de conservação

i) Suficiente, porém fora dos padrões

j) Suficiente

Sinalização informativa (indicação de prédios, serviços, etc)

f) Inexistente

g) Insuficiente

h) Suficiente, porém em mau estado de conservação

i) Suficiente, porém fora dos padrões

j) Suficiente

Na sua opinião, qual a importância destes aspectos para uma mobilidade mais sustentável na USP de Piracicaba? Ordene os temas marcando-os com os respectivos números ou arrastando as caixas de acordo com a prioridade 1 a mais importante.

a) Ciclofaixas/ciclovias dentro do campus e para acesso ao mesmo

b) Infraestrutura essencial para pedestres (calçadas adequadas, iluminação, arborização, sinalização, etc.)

c) Educação no trânsito (respeito aos limites de velocidade e à sinalização, melhor convívio entre motoristas, ciclistas e pedestres, etc.)

d) Ação conjunta com Prefeitura Municipal para melhoria da mobilidade na ligação entre cidade e campus 
e) Bolsões de estacionamento internos e externos ao campus

f) Melhoria da qualidade do serviço de transporte público da cidade

g) Restrição do uso de automóveis dentro do campus

h) Acessibilidade (rampas de acesso, calçadas adequadas, elevadores, piso tátil, respeito a vagas de estacionamento prioritárias, etc.)

i) Infraestrutura de apoio para pedestres e ciclistas (bebedouros, bancos, vestiários, guarda-volume, bicicletários, oficina para consertos, etc.) 


\section{Modo: Bicicleta}

Analisando o campus da ESALQ/CENA como um todo, você o considera acessível aos usuários com algum tipo de restrição de mobilidade?

a) Sim. Nunca notei obstáculos que dificultassem a acessibilidade aos usuários com algum tipo de restrição de mobilidade nas dependências do campus

b) Grande parte do campus é acessível. Algumas áreas possuem obstáculos, mas de maneira geral considero o campus acessível aos usuários com algum tipo de restrição de mobilidade

c) Pequena parte do campus é acessível. Há diversas áreas que não oferecem condições básicas de acessibilidade aos usuários com algum tipo de restrição de mobilidade

d) Não. O campus não oferece condições básicas de acessibilidade aos usuários com algum tipo de restrição de mobilidade

e) Não sou capaz de opinar, pois nunca analisei o campus sob este aspecto

Dentre os prédios que frequenta na ESALQ/CENA, como você avalia a acessibilidade para os usuários com algum tipo de restrição de mobilidade?

a) Ótima. Prédios totalmente equipados para receber os usuários com algum tipo de restrição de mobilidade

b) Boa. Prédios parcialmente equipados, mas possuem condições satisfatórias para atender os usuários com algum tipo de restrição de mobilidade

c) Regular. Prédios pouco equipados, com limitações para atender os usuários com algum tipo de restrição de mobilidade

d) Ruim. Prédios não equipados para receber os usuários com algum tipo de restrição de mobilidade

e) Não sou capaz de avaliar, pois nunca analisei os prédios da ESALQ/CENA sob este aspecto

$\mathrm{Na}$ etapa anterior do questionário, você nos informou que seu modo principal para os deslocamentos à ESALQ/CENA é a BICICLETA. Quais fatores o/a levam a optar por este modo?

Benefícios para saúde
a) Sem importância
b) Pouca importância
c) De alguma importância
d) Muito importante
e) Extremamente importante

Potencial economia financeira
a) Sem importância
b) Pouca importância
c) De alguma importância
d) Muito importante
e) Extremamente importante

Contribuição pessoal para a redução dos níveis de poluição do ar
a) Sem importância
b) Pouca importância
c) De alguma importância 
d) Muito importante

e) Extremamente importante

Gosto de pedalar
a) Sem importância
b) Pouca importância
c) De alguma importância
d) Muito importante
e) Extremamente importante

Possibilidade de socialização (encontrar pessoas)
a) Sem importância
b) Pouca importância
c) De alguma importância
d) Muito importante
e) Extremamente importante

Flexibilidade (poder sair no momento em que desejar, fazer paradas durante o trajeto, etc.)
a) Sem importância
b) Pouca importância
c) De alguma importância
d) Muito importante
e) Extremamente importante

Eu não gosto de dirigir
a) Sem importância
b) Pouca importância
c) De alguma importância
d) Muito importante
e) Extremamente importante

Quais fatores o/a desestimulam a utilizar os demais modos que não a bicicleta em seus deslocamentos?

Tempo envolvido no trajeto dos demais modos (tempo de espera, percurso, atrasos)
a) Sem importância
b) Pouca importância
c) De alguma importância
d) Muito importante
e) Extremamente importante

Distância longa a ser percorrida
a) Sem importância
b) Pouca importância
c) De alguma importância
d) Muito importante
e) Extremamente importante

Condições climáticas (chuva, vento, calor, frio)
a) Sem importância
b) Pouca importância
c) De alguma importância
d) Muito importante 
e) Extremamente importante

Baixa qualidade do transporte público
a) Sem importância
b) Pouca importância
c) De alguma importância
d) Muito importante
e) Extremamente importante

Insegurança pública (assaltos, furtos, assédio)
a) Sem importância
b) Pouca importância
c) De alguma importância
d) Muito importante
e) Extremamente importante

Distância de viagem
a) Sem importância
b) Pouca importância
c) De alguma importância
d) Muito importante
e) Extremamente importante

Ausência de calçadas adequadas até o campus
a) Sem importância
b) Pouca importância
c) De alguma importância
d) Muito importante
e) Extremamente importante

Há quanto tempo você utiliza o modo bicicleta para se deslocar até a ESALQ/CENA?
a) Há menos de 6 meses
b) Há mais de 6 meses

Dos deslocamentos que você faz hoje de bicicleta, qual modo você utilizava antes?
a) A pé
b) Transporte público urbano
c) Van operada pela USP (Vila Estudantil)
d) Automóvel
e) Automóvel, na condição de CARONA - estaciona no campus
f) Automóvel, na condição de CARONA - não estaciona no campus
g) Motocicleta
h) Skate
i) Patins
j) Nenhum. Antes deste período não frequentava o campus
k) Outro (especifique) 
Estado de conservação

Ótimo, em boas condições de uso.
Regular, o bicicletário está desgastado.
Ruim, quase inutilizável.

SIESALQ

Departamento de Genética

Ciências Humanas

Pavilhão da Química

Pavilhão da Agricultura

Departamento de Genética

(Alameda das Palmeiras)

Guarda Universitária

Casa do Estudante (CEU)

Entrada Principal(A

encarnado)

CETI ESALQ

Antigo Restaurante

Universitário

Antigo Restaurante

Universitário 2

Prof Walter Accorsi

LERF

Ciência do Solo

Ciências Florestais

Restaurante Universitário

Salvador de Toledo Piza

Agroindústria Prédio II

Central de aulas (ao lado do

Restaurante Universitário)

Central de aulas

Agroindústria Prédio I

Zootecnia

Serviço de Graduação

Nicolau Athanassof

Pós-Graduação

Biblioteca Central

Horticultura 1

Horticultura 2 e 3

Edifício Central

Engenharia

Economia e Sociologia

Entomologia

"Ceninha"

Banco do Brasil

Santander 
Estado da cobertura

Ótimo, em boas Regular, está Ruim, quase Não possui condições de uso. desgastada. inutilizável. cobertura.

SIESALQ

Departamento de Genética

Ciências Humanas

Pavilhão da Química

Pavilhão da Agricultura

Departamento de Genética

(Alameda das Palmeiras)

Guarda Universitária

Casa do Estudante (CEU)

Entrada Principal(A

encarnado)

CETI ESALQ

Antigo Restaurante

Universitário

Antigo Restaurante

Universitário 2

Prof Walter Accorsi

LERF

Ciência do Solo

Ciências Florestais

Restaurante Universitário

Salvador de Toledo Piza

Agroindústria Prédio II

Central de aulas (ao lado do

Restaurante Universitário)

Central de aulas

Agroindústria Prédio I

Serviço de Graduação

Nicolau Athanassof

Pós-Graduação

Biblioteca Central

Horticultura 1

Horticultura 2 e 3

Edifício Central

Museu

Engenharia

Economia e Sociologia

Entomologia

"Ceninha"

Banco do Brasil

Santander 
Localização

Ótimo, em boas Regular, está Ruim, quase Não possui condições de uso. desgastada. inutilizável. cobertura.

SIESALQ

Departamento de Genética

Ciências Humanas

Pavilhão da Química

Pavilhão da Agricultura

Departamento de Genética

(Alameda das Palmeiras)

Guarda Universitária

Casa do Estudante (CEU)

Entrada Principal(A

encarnado)

CETI ESALQ

Antigo Restaurante

Universitário

Antigo Restaurante

Universitário 2

Prof Walter Accorsi

LERF

Ciência do Solo

Ciências Florestais

Restaurante Universitário

Salvador de Toledo Piza

Agroindústria Prédio II

Central de aulas (ao lado do

Restaurante Universitário)

Central de aulas

Agroindústria Prédio I

Serviço de Graduação

Nicolau Athanassof

Pós-Graduação

Biblioteca Central

Horticultura 1

Horticultura 2 e 3

Edifício Central

Museu

Engenharia

Economia e Sociologia

Entomologia

"Ceninha"

Banco do Brasil

Santander 
Classifique, somente para os turnos em que você costuma acessar ou se deslocar AO REDOR da ESALQ/CENA, qual a sua sensação de segurança em relação a assaltos e outros tipos de violência ou assédio

Manhã
a) Seguro
b) Parcialmente seguro
c) Inseguro

Tarde
a) Seguro
b) Parcialmente seguro
c) Inseguro

Noite
a) Seguro
b) Parcialmente seguro
c) Inseguro

Você presenciou ou sofreu algum tipo de violência, furto ou assédio NO ENTORNO da ESALQ/CENA?
a) $\operatorname{Sim}$
b) Não

Que tipo de violência, furto ou assédio você presenciou ou sofreu NO ENTORNO da ESALQ/CENA? (se for necessário, marque mais de uma alternativa)
a) Tive a bicicleta roubada ou furtada
b) Sofri um assalto
c) Sofri mais de um assalto
d) Presenciei um assalto
e) Presenciei mais de um assalto
f) Sofri uma tentativa de assalto
g) Sofri mais de uma tentativa de assalto
h) Presenciei uma tentativa de assalto
i) Presenciei mais de uma tentativa de assalto
j) Sofri assédio sexual, uma vez
k) Sofri assédio sexual, mais de uma vez
l) Presenciei um ato de assédio sexual
m) Presenciei mais de um ato de assédio sexual
n) Sofri assédio moral, uma vez
o) Sofri assédio moral, mais de uma vez
p) Presenciei um ato de assédio moral
q) Presenciei mais de um ato de assédio moral
r) Outros (especifique)

A sua bicicleta foi:
a) Furtada
b) Roubada mediante abordagem 
Quando o furto/roubo ocorreu?
a) há menos de 6 meses
b) entre 6 meses e 1 ano
c) entre 1 e 2 anos
d) entre 2 e 3 anos
e) entre 3 e 4 anos
f) entre 4 e 5 anos
g) há mais de 5 anos

Classifique, somente para os turnos em que você costuma acessar ou se deslocar DENTRO da ESALQ/CENA, qual a sua sensação de segurança em relação a assaltos e outros tipos de violência ou assédio:

Manhã
a) Seguro
b) Parcialmente seguro
c) Inseguro

Tarde
a) Seguro
b) Parcialmente seguro
c) Inseguro

Noite
a) Seguro
b) Parcialmente seguro
c) Inseguro

Você presenciou ou sofreu algum tipo de violência, furto ou assédio DENTRO da ESALQ/CENA?
a) $\operatorname{Sim}$
b) Não

Que tipo de violência, furto ou assédio você presenciou ou sofreu DENTRO da ESALQ/CENA? (se for necessário, marque mais de uma alternativa)
a) Tive a bicicleta roubada ou furtada
b) Sofri um assalto
c) Sofri mais de um assalto
d) Presenciei um assalto
e) Presenciei mais de um assalto
f) Sofri uma tentativa de assalto
g) Sofri mais de uma tentativa de assalto
h) Presenciei uma tentativa de assalto
i) Presenciei mais de uma tentativa de assalto
j) Sofri assédio sexual, uma vez
k) Sofri assédio sexual, mais de uma vez
l) Presenciei um ato de assédio sexual
m) Presenciei mais de um ato de assédio sexual
n) Sofri assédio moral, uma vez 
o) Sofri assédio moral, mais de uma vez

p) Presenciei um ato de assédio moral

q) Presenciei mais de um ato de assédio moral

r) Outros (especifique)

Com relação a medidas de segurança no ENTORNO e DENTRO da ESALQ/CENA, você é favorável a (se for necessário, marque mais de uma alternativa):

a) Instalação de mais câmeras de monitoramento

b) Melhoria da iluminação

c) Intensificação das rondas no ENTORNO do campus, pela Guarda Universitária (PPUSP)

d) Intensificação das rondas no ENTORNO do campus, pela Policia Militar

e) Intensificação das rondas no ENTORNO do campus, pela Guarda Municipal

f) Intensificação de rondas DENTRO do campus, pela Guarda Universitária (PPUSP)

g) Realização de rondas DENTRO do campus, pela Policia Militar

h) Realização de rondas DENTRO do campus, pela Policia Militar, mas somente nos horários mais críticos como à noite e durante grandes eventos

i) Realização de rondas DENTRO do campus, pela Guarda Municipal

j) Realização de rondas DENTRO do campus, pela Guarda Municipal, mas somente nos horários mais críticos como à noite e durante grandes eventos

k) Nenhuma das alternativas

Como você descreveria o trajeto do seu ponto de origem até o campus Luiz de Queiroz (ESALQ/CENA)?

a) O trajeto me incomoda em alguns aspectos; gostaria que fosse mais agradável e/ou menos demorado

b) O trajeto representa um sofrimento para mim; é um alívio chegar ao campus

c) O trajeto é indiferente para mim, não me sinto incomodado nem confortável

d) O trajeto é satisfatório para mim

e) O trajeto é agradável para mim

f) Outro (especifique)

Como você avalia a sinalização do campus Luiz de Queiroz (ESALQ/CENA)?

Sinalização de trânsito (horizontal e vertical)
a) Inexistente
b) Insuficiente
c) Suficiente, porém em mau estado de conservação
d) Suficiente, porém fora dos padrões
e) Suficiente

Sinalização informativa (indicação de prédios, serviços, etc)
a) Inexistente
b) Insuficiente
c) Suficiente, porém em mau estado de conservação
d) Suficiente, porém fora dos padrões
e) Suficiente 
Na sua opinião, qual a importância destes aspectos para uma mobilidade mais sustentável na USP de Piracicaba? Ordene os temas marcando-os com os respectivos números ou arrastando as caixas de acordo com a prioridade (no topo, o mais importante)

a) Ciclofaixas/ciclovias dentro do campus e para acesso ao mesmo

b) Infraestrutura essencial para pedestres (calçadas adequadas, iluminação, arborização, sinalização, etc.)

c) Alternativa para deslocamentos internos ao campus (sistema de transporte coletivo, sistema de bicicletas compartilhadas, etc.)

d) Educação no trânsito (respeito aos limites de velocidade e à sinalização, melhor convívio entre motoristas, ciclistas e pedestres, etc.)

e) Ação conjunta com Prefeitura Municipal para melhoria da mobilidade na ligação entre cidade e campus

f) Bolsões de estacionamento internos e externos ao campus

g) Melhoria da qualidade do serviço de transporte público da cidade

h) Restrição do uso de automóveis dentro do campus

i) Acessibilidade (rampas de acesso, calçadas adequadas, elevadores, piso tátil, respeito a vagas de estacionamento prioritárias, etc.)

j) Infraestrutura de apoio para pedestres e ciclistas (bebedouros, bancos, vestiários, guarda-volume, bicicletários, oficina para consertos, etc.) 


\section{Modo: Moto}

Analisando o campus da ESALQ/CENA como um todo, você o considera acessível aos usuários com algum tipo de restrição de mobilidade?

a) Sim. Nunca notei obstáculos que dificultassem a acessibilidade aos usuários com algum tipo de restrição de mobilidade nas dependências do campus

b) Grande parte do campus é acessível. Algumas áreas possuem obstáculos, mas de maneira geral considero o campus acessível aos usuários com algum tipo de restrição de mobilidade

c) Pequena parte do campus é acessível. Há diversas áreas que não oferecem condições básicas de acessibilidade aos usuários com algum tipo de restrição de mobilidade

d) Não. O campus não oferece condições básicas de acessibilidade aos usuários com algum tipo de restrição de mobilidade

e) Não sou capaz de opinar, pois nunca analisei o campus sob este aspecto

Dentre os prédios que frequenta na ESALQ/CENA, como você avalia a acessibilidade para os usuários com algum tipo de restrição de mobilidade?

a) Ótima. Prédios totalmente equipados para receber os usuários com algum tipo de restrição de mobilidade

b) Boa. Prédios parcialmente equipados, mas possuem condições satisfatórias para atender os usuários com algum tipo de restrição de mobilidade

c) Regular. Prédios pouco equipados, com limitações para atender os usuários com algum tipo de restrição de mobilidade

d) Ruim. Prédios não equipados para receber os usuários com algum tipo de restrição de mobilidade

e) Não sou capaz de avaliar, pois nunca analisei os prédios da ESALQ/CENA sob este aspecto

$\mathrm{Na}$ etapa anterior do questionário, você nos informou que seu modo principal para os deslocamentos à ESALQ/CENA é a MOTOCICLETA. Quais fatores o/a levam a optar por este modo?

Insegurança pública (assaltos, furtos e/ou assédio)
a) Sem importância
b) Pouco importante
c) De alguma importância
d) Muito importante
e) Extremamente importante

Conforto
a) Sem importância
b) Pouco importante
c) De alguma importância
d) Muito importante
e) Extremamente importante

Conveniência
a) Sem importância
b) Pouco importante
c) De alguma importância 
d) Muito importante

e) Extremamente importante

Flexibilidade (poder sair no momento em que desejar, fazer paradas durante o trajeto, etc.)
a) Sem importância
b) Pouco importante
c) De alguma importância
d) Muito importante
e) Extremamente importante

Estacionamento gratuito no campus
a) Sem importância
b) Pouco importante
c) De alguma importância
d) Muito importante
e) Extremamente importante

Preciso transportar materiais ou preciso da motocicleta para fins de trabalho
a) Sem importância
b) Pouco importante
c) De alguma importância
d) Muito importante
e) Extremamente importante

Distância de viagem
a) Sem importância
b) Pouco importante
c) De alguma importância
d) Muito importante
e) Extremamente importante

Quais fatores o/a desestimulam a utilizar os demais modos que não a motocicleta em seus deslocamentos?

Tempo envolvido no trajeto dos demais modos (tempo de espera, percurso, atrasos)
a) Sem importância
b) Pouco importante
c) De alguma importância
d) Muito importante
e) Extremamente importante

Distância longa a ser percorrida
a) Sem importância
b) Pouco importante
c) De alguma importância
d) Muito importante
e) Extremamente importante

Condições climáticas (chuva, vento, calor, frio)
a) Sem importância
b) Pouco importante
c) De alguma importância
d) Muito importante 
e) Extremamente importante

Inexistência de ciclovias contínuas das avenidas principais até o campus
a) Sem importância
b) Pouco importante
c) De alguma importância
d) Muito importante
e) Extremamente importante

Baixa qualidade do transporte público
a) Sem importância
b) Pouco importante
c) De alguma importância
d) Muito importante
e) Extremamente importante

Insegurança pública (assaltos, furtos, assédio)
a) Sem importância
b) Pouco importante
c) De alguma importância
d) Muito importante
e) Extremamente importante

Perigo com o trânsito
a) Sem importância
b) Pouco importante
c) De alguma importância
d) Muito importante
e) Extremamente importante

Há quanto tempo você utiliza a motocicleta para se deslocar até a ESALQ/CENA?
a) Há menos de 6 meses
b) Há mais de 6 meses

Você estaciona sua motocicleta em apenas um lugar durante sua permanência no campus ou troca de vaga conforme realiza suas atividades?
a) Estaciono em lugar fixo
b) Troco de vaga conforme realizo minhas atividades
c) Não estaciono dentro do campus
d) Não me preocupo com isso, porque não sou o motorista (pego carona)

Local de estacionamento

a) Divisões Administrativa (DA) ede Manutenção e Operação (DVMANOPER)

b) Edifício Central

c) Sala dos Grupos Musicais da ESALQ

d) Restaurante Universitário (R.U.)

e) Edifício "Prof. José Theófilo do Amaral Gurgel" (LGN)

f) Departamento de Zootecnia (LZT | não-ruminantes)

g) Pavilhão Walter Ramos Jardim (LZT | ruminantes)

h) Edifício Professor Jayme Rocha de Almeida (LAN - 1)

i) Departamento de Agroindústria, Alimentos e Nutrição (LAN - 2) 


\section{j) Biblioteca Central}

Com que frequência você dá carona para outras pessoas até o campus? Ou pega carona?
a) Frequentemente
b) Raramente
c) Nunca

Classifique, somente para os turnos em que você costuma acessar ou se deslocar AO REDOR da ESALQ/CENA, qual a sua sensação de segurança em relação a assaltos e outros tipos de violência ou assédio:

Manhã
a) Seguro
b) Parcialmente seguro
c) Inseguro

Tarde
a) Seguro
b) Parcialmente seguro
c) Inseguro

Noite
a) Seguro
b) Parcialmente seguro
c) Inseguro

Você presenciou ou sofreu algum tipo de violência ou assédio NO ENTORNO da ESALQ/CENA?
a) $\operatorname{Sim}$
b) Não

Que tipo de violência ou assédio você presenciou ou sofreu NO ENTORNO da ESALQ/CENA? (se for necessário, marque mais de uma alternativa)
a) Sofri um assalto
b) Sofri mais de um assalto
c) Presenciei um assalto
d) Presenciei mais de um assalto
e) Sofri uma tentativa de assalto
f) Sofri mais de uma tentativa de assalto
g) Presenciei uma tentativa de assalto
h) Presenciei mais de uma tentativa de assalto
i) Sofri assédio sexual, uma vez
j) Sofri assédio sexual, mais de uma vez
k) Presenciei um ato de assédio sexual
l) Presenciei mais de um ato de assédio sexual
m) Sofri assédio moral, uma vez
n) Sofri assédio moral, mais de uma vez
o) Presenciei um ato de assédio moral 
p) Presenciei mais de um ato de assédio moral

q) Outros (especifique)

Classifique, somente para os turnos em que você costuma acessar ou se deslocar DENTRO da ESALQ/CENA, qual a sua sensação de segurança em relação a assaltos e outros tipos de violência ou assédio:

Manhã
a) Seguro
b) Parcialmente seguro
c) Inseguro

Tarde
a) Seguro
b) Parcialmente seguro
c) Inseguro

Noite
a) Seguro
b) Parcialmente seguro
c) Inseguro

Você presenciou ou sofreu algum tipo de violência ou assédio DENTRO da ESALQ/CENA?
a) $\mathrm{Sim}$
b) Não

Que tipo de violência ou assédio você presenciou ou sofreu DENTRO da ESALQ/CENA? (se for necessário, marque mais de uma alternativa)
a) Sofri um assalto
b) Sofri mais de um assalto
c) Presenciei um assalto
d) Presenciei mais de um assalto
e) Sofri uma tentativa de assalto
f) Sofri mais de uma tentativa de assalto
g) Presenciei uma tentativa de assalto
h) Presenciei mais de uma tentativa de assalto
i) Sofri assédio sexual, uma vez
j) Sofri assédio sexual, mais de uma vez
k) Presenciei um ato de assédio sexual
l) Presenciei mais de um ato de assédio sexual
m) Sofri assédio moral, uma vez
n) Sofri assédio moral, mais de uma vez
o) Presenciei um ato de assédio moral
p) Presenciei mais de um ato de assédio moral
q) Outros (especifique) 
Com relação a medidas de segurança no ENTORNO e DENTRO da ESALQ/CENA, você é favorável a (se for necessário, marque mais de uma alternativa):

a) Instalação de mais câmeras de monitoramento

b) Melhoria da iluminação

c) Intensificação das rondas no ENTORNO do campus, pela Guarda Universitária (PPUSP)

d) Intensificação das rondas no ENTORNO do campus, pela Policia Militar

e) Intensificação das rondas no ENTORNO do campus, pela Guarda Municipal

f) Intensificação de rondas DENTRO do campus, pela Guarda Universitária (PPUSP)

g) Realização de rondas DENTRO do campus, pela Policia Militar

h) Realização de rondas DENTRO do campus, pela Policia Militar, mas somente nos horários mais críticos como à noite e durante grandes eventos

i) Realização de rondas DENTRO do campus, pela Guarda Municipal

j) Realização de rondas DENTRO do campus, pela Guarda Municipal, mas somente nos horários mais críticos como à noite e durante grandes eventos

k) Nenhuma das alternativas

Como você descreveria o trajeto do seu ponto de origem até o campus Luiz de Queiroz (ESALQ/CENA)?

a) O trajeto me incomoda em alguns aspectos; gostaria que fosse mais agradável e/ou menos demorado

b) O trajeto representa um sofrimento para mim; é um alívio chegar ao campus

c) O trajeto é indiferente para mim, não me sinto incomodado nem confortável

d) O trajeto é satisfatório para mim

e) O trajeto é agradável para mim

f) Outro (especifique)

Como você avalia a sinalização do campus Luiz de Queiroz (ESALQ/CENA)?

Sinalização de trânsito (horizontal e vertical)
a) Inexistente
b) Insuficiente
c) Suficiente, porém em mau estado de conservação
d) Suficiente, porém fora dos padrões
e) Suficiente

Sinalização informativa (indicação de prédios, serviços, etc)
a) Inexistente
b) Insuficiente
c) Suficiente, porém em mau estado de conservação
d) Suficiente, porém fora dos padrões
e) Suficiente

Na sua opinião, qual a importância destes aspectos para uma mobilidade mais sustentável na USP de Piracicaba? Ordene os temas marcando-os com os respectivos números ou arrastando as caixas de acordo com a prioridade (no topo, o mais importante)

a) Ciclofaixas/ciclovias dentro do campus e para acesso ao mesmo

b) Infraestrutura essencial para pedestres (calçadas adequadas, iluminação, arborização, sinalização, etc.) 
c) Educação no trânsito (respeito aos limites de velocidade e à sinalização, melhor convívio entre motoristas, ciclistas e pedestres, etc.)

d) Ação conjunta com Prefeitura Municipal para melhoria da mobilidade na ligação entre cidade e campus

e) Bolsões de estacionamento internos e externos ao campus

f) Melhoria da qualidade do serviço de transporte público da cidade

g) Restrição do uso de automóveis dentro do campus

h) Acessibilidade (rampas de acesso, calçadas adequadas, elevadores, piso tátil, respeito a vagas de estacionamento prioritárias, etc.)

i) Infraestrutura de apoio para pedestres e ciclistas (bebedouros, bancos, vestiários, guarda-volume, bicicletários, oficina para consertos, etc.) 


\section{Modo: Transporte Público Urbano}

Analisando o campus da ESALQ/CENA como um todo, você o considera acessível aos usuários com algum tipo de restrição de mobilidade?

a) Sim. Nunca notei obstáculos que dificultassem a acessibilidade aos usuários com algum tipo de restrição de mobilidade nas dependências do campus

b) Grande parte do campus é acessível. Algumas áreas possuem obstáculos, mas de maneira geral considero o campus acessível aos usuários com algum tipo de restrição de mobilidade

c) Pequena parte do campus é acessível. Há diversas áreas que não oferecem condições básicas de acessibilidade aos usuários com algum tipo de restrição de mobilidade

d) Não. O campus não oferece condições básicas de acessibilidade aos usuários com algum tipo de restrição de mobilidade

e) Não sou capaz de opinar, pois nunca analisei o campus sob este aspecto

Dentre os prédios que frequenta na ESALQ/CENA, como você avalia a acessibilidade para os usuários com algum tipo de restrição de mobilidade?

a) Ótima. Prédios totalmente equipados para receber os usuários com algum tipo de restrição de mobilidade

b) Boa. Prédios parcialmente equipados, mas possuem condições satisfatórias para atender os usuários com algum tipo de restrição de mobilidade

c) Regular. Prédios pouco equipados, com limitações para atender os usuários com algum tipo de restrição de mobilidade

d) Ruim. Prédios não equipados para receber os usuários com algum tipo de restrição de mobilidade

e) Não sou capaz de avaliar, pois nunca analisei os prédios da ESALQ/CENA sob este aspecto

Na etapa anterior do questionário, você nos informou que seu modo principal para os deslocamentos à ESALQ/CENA é o ÔNIBUS DO TRANSPORTE PÚBLICO URBANO. Quais fatores o/a levam a optar por este modo?

Insegurança pública (assaltos, furtos e/ou assédio)
a) Sem importância
b) Pouco importante
c) De alguma importância
d) Muito importante
e) Extremamente importante

O ônibus para a USP passa perto da minha casa
a) Sem importância
b) Pouco importante
c) De alguma importância
d) Muito importante
e) Extremamente importante

Contribuição pessoal para a redução dos níveis de poluição do ar
a) Sem importância
b) Pouco importante
c) De alguma importância
d) Muito importante
e) Extremamente importante 
Não precisar procurar local para estacionar
a) Sem importância
b) Pouco importante
c) De alguma importância
d) Muito importante
e) Extremamente importante

Potencial economia financeira
a) Sem importância
b) Pouco importante
c) De alguma importância
d) Muito importante
e) Extremamente importante

Não gosto de dirigir
a) Sem importância
b) Pouco importante
c) De alguma importância
d) Muito importante
e) Extremamente importante

Tempo de deslocamento
a) Sem importância
b) Pouco importante
c) De alguma importância
d) Muito importante
e) Extremamente importante

Quais fatores o/a desestimulam a utilizar os demais modos que não o ônibus do transporte público urbano em seus deslocamentos?

Distância longa a ser percorrida
a) Sem importância
b) Pouco importante
c) De alguma importância
d) Muito importante
e) Extremamente importante

Condições climáticas (chuva, vento, calor, frio)
a) Sem importância
b) Pouco importante
c) De alguma importância
d) Muito importante
e) Extremamente importante

Inexistência de ciclovias contínuas das avenidas principais até o campus
a) Sem importância
b) Pouco importante
c) De alguma importância
d) Muito importante
e) Extremamente importante 
Insegurança pública (assaltos, furtos, assédio)
a) Sem importância
b) Pouco importante
c) De alguma importância
d) Muito importante
e) Extremamente importante

Perigo com o trânsito
a) Sem importância
b) Pouco importante
c) De alguma importância
d) Muito importante
e) Extremamente importante

Esforço físico
a) Sem importância
b) Pouco importante
c) De alguma importância
d) Muito importante
e) Extremamente importante

Ausência de calçadas adequadas até o campus
a) Sem importância
b) Pouco importante
c) De alguma importância
d) Muito importante
e) Extremamente importante

Há quanto tempo você utiliza o ônibus do transporte público urbano para se deslocar até a ESALQ/CENA?
a) Há menos de 6 meses
b) Há mais de 6 meses

Dos deslocamentos que você faz hoje de ônibus do transporte público urbano, qual modo você utilizava antes?
a) A pé
b) Bicicleta
c) Automóvel
d) Van operada pela USP (Vila Estudantil)
e) Automóvel, na condição de MOTORISTA
f) Automóvel, na condição de CARONA - estaciona no campus
g) Automóvel, na condição de CARONA - não estaciona no campus
h) Motocicleta
i) Skate
j) Patins
k) Nenhum. Antes deste período não frequentava o campus
l) Outro (especifique)

Como você avalia a frequência de atendimento?

a) Ótima (intervalo de atendimento de 15 minutos ou menos) 

b) Boa
c) Regular
d) Ruim (intervalo de atendimento de 60 minutos ou mais)

Como você avalia a pontualidade?
a) Ótima (nunca atrasa)
b) Boa
c) Regular
d) Ruim (sempre atrasa)

Como você avalia o tempo de viagem?
a) Ótimo (praticamente o mesmo tempo que levaria de automóvel)
b) Bom
c) Regular
d) Ruim (duas ou mais vezes o tempo que levaria de automóvel)

Como você avalia a lotação dos veículos?
a) Ótima (veículo com assentos livres)
b) Boa
c) Regular
d) Ruim (veículo lotado)

Ponto de ônibus em que você desce quando vai à USP.
a) Av. Independência, em frente ao Posto Shell
b) Av. Carlos Botelho, próximo à esquina com Av. Centenário
c) CEBTEC, Av. Centenário, próximo à esquina com Av. Carlos Botelho
d) Em frente à FEALQ, Rod. Luiz de Queiroz, próximo à esquina com Av. Duque de Caxias.
e) CENA. Rod. Luiz de Queiroz, próximo à esquina com R. Padre Lopes, sentido Centro
f) CENA. Av. Centenário, próximo à esquina com R. Padre Lopes, sentido Rio Piracicaba
g) Av. Centenário, próximo ao cruzamento com a Estrada Monte Alegre
h) Dentro da ESALQ, na Alameda Principal, em frente ao Departamento de Genética
i) Av. Centenário, em frente à rotatória próxima à entrada principal (A encarnado)
j) Dentro da ESALQ, rotatória do A Encarnado
k) Dentro da ESALQ, na Alameda dos Alecrins, próximo à esquina com Alameda Principal
I) Av. Centenário, próximo ao cruzamento com a Estrada Monte Alegre, em frente à "Nova Mercantil Veículos"
m) Estrada Monte Alegre, próximo à entrada da Engenharia
n) Utilizo um ponto de ônibus próximo ao campus que não está na lista.

Como você avalia a distância de caminhada do ponto de ônibus até a portaria do campus?
a) Ótima: distância inferior a $50 \mathrm{~m}$, aproximadamente até meia quadra
b) Boa: distância entre 50 e $150 \mathrm{~m}$, aproximadamente até uma quadra e meia
c) Regular: distância entre 150 e 250 m, aproximadamente até duas quadras e meia
d) Ruim: distância igual ou superior a 250 m, mais que duas quadras e meia 
Em qual horário você normalmente utiliza este ponto de ônibus?
a) Manhã
b) Tarde
c) Noite

Ponto em que vai embora da USP.

a) Av. Independência, em frente ao Posto Shell

b) Av. Carlos Botelho, próximo à esquina com Av. Centenário

c) CEBTEC, Av. Centenário, próximo à esquina com Av. Carlos Botelho

d) Em frente à FEALQ, Rod. Luiz de Queiroz, próximo à esquina com Av. Duque de Caxias.

e) CENA. Rod. Luiz de Queiroz, próximo à esquina com R. Padre Lopes, sentido Centro

f) CENA. Av. Centenário, próximo à esquina com R. Padre Lopes, sentido Rio Piracicaba

g) Av. Centenário, próximo ao cruzamento com a Estrada Monte Alegre

h) Dentro da ESALQ, na Alameda Principal, em frente ao Departamento de Genética

i) Av. Centenário, em frente à rotatória próxima à entrada principal ( $A$ encarnado)

j) Dentro da ESALQ, rotatória do A Encarnado

k) Dentro da ESALQ, na Alameda dos Alecrins, próximo à esquina com Alameda Principal

l) Av. Centenário, próximo ao cruzamento com a Estrada Monte Alegre, em frente à "Nova Mercantil Veículos"

m) Estrada Monte Alegre, próximo à entrada da Engenharia

n) Utilizo um ponto de ônibus próximo ao campus que não está na lista.

Como você avalia a distância de caminhada da portaria do campus até o ponto de ônibus?
a) Ótima: distância inferior a $50 \mathrm{~m}$, aproximadamente até meia quadra
b) Boa: distância entre 50 e $150 \mathrm{~m}$, aproximadamente até uma quadra e meia
c) Regular: distância entre 150 e $250 \mathrm{~m}$, aproximadamente até duas quadras e meia
d) Ruim: distância igual ou superior a $250 \mathrm{~m}$, mais que duas quadras e meia

Em qual horário você normalmente utiliza este ponto de ônibus?
a) Manhã
b) Tarde
c) Noite

Você presenciou ou sofreu algum tipo de violência ou assédio NO ENTORNO da ESALQ/CENA?
a) $\operatorname{Sim}$
b) Não

Que tipo de violência ou assédio você presenciou ou sofreu NO ENTORNO da ESALQ/CENA? (se for necessário, marque mais de uma alternativa)
a) Sofri um assalto
b) Sofri mais de um assalto
c) Presenciei um assalto
d) Presenciei mais de um assalto
e) Sofri uma tentativa de assalto 
f) Sofri mais de uma tentativa de assalto

g) Presenciei uma tentativa de assalto

h) Presenciei mais de uma tentativa de assalto

i) Sofri assédio sexual, uma vez

j) Sofri assédio sexual, mais de uma vez

k) Presenciei um ato de assédio sexual

l) Presenciei mais de um ato de assédio sexual

m) Sofri assédio moral, uma vez

n) Sofri assédio moral, mais de uma vez

o) Presenciei um ato de assédio moral

p) Presenciei mais de um ato de assédio moral

q) Outros (especifique)

Com relação a medidas de segurança no ENTORNO e DENTRO da ESALQ/CENA, você é favorável a (se for necessário, marque mais de uma alternativa):

a) Instalação de mais câmeras de monitoramento

b) Melhoria da iluminação

c) Intensificação das rondas no ENTORNO do campus, pela Guarda Universitária (PPUSP)

d) Intensificação das rondas no ENTORNO do campus, pela Policia Militar

e) Intensificação das rondas no ENTORNO do campus, pela Guarda Municipal

f) Intensificação de rondas DENTRO do campus, pela Guarda Universitária (PPUSP)

g) Realização de rondas DENTRO do campus, pela Policia Militar

h) Realização de rondas DENTRO do campus, pela Policia Militar, mas somente nos horários mais críticos como à noite e durante grandes eventos

i) Realização de rondas DENTRO do campus, pela Guarda Municipal

j) Realização de rondas DENTRO do campus, pela Guarda Municipal, mas somente nos horários mais críticos como à noite e durante grandes eventos

k) Nenhuma das alternativas

Como você descreveria o trajeto do seu ponto de origem até o campus Luiz de Queiroz (ESALQ/CENA)?

a) O trajeto me incomoda em alguns aspectos; gostaria que fosse mais agradável e/ou menos demorado

b) O trajeto representa um sofrimento para mim; é um alívio chegar ao campus

c) O trajeto é indiferente para mim, não me sinto incomodado nem confortável

d) O trajeto é satisfatório para mim

e) O trajeto é agradável para mim

f) Outro (especifique)

Na sua opinião, qual a importância destes aspectos para uma mobilidade mais sustentável na USP de Piracicaba? Ordene os temas marcando-os com os respectivos números ou arrastando as caixas de acordo com a prioridade (no topo, o mais importante)

a) Ciclofaixas/ciclovias dentro do campus e para acesso ao mesmo

b) Infraestrutura essencial para pedestres (calçadas adequadas, iluminação, arborização, sinalização, etc.)

c) Educação no trânsito (respeito aos limites de velocidade e à sinalização, melhor convívio entre motoristas, ciclistas e pedestres, etc.)

d) Ação conjunta com Prefeitura Municipal para melhoria da mobilidade na ligação entre cidade e campus 
e) Bolsões de estacionamento internos e externos ao campus

f) Melhoria da qualidade do serviço de transporte público da cidade

g) Restrição do uso de automóveis dentro do campus

h) Acessibilidade (rampas de acesso, calçadas adequadas, elevadores, piso tátil, respeito a vagas de estacionamento prioritárias, etc.)

i) Infraestrutura de apoio para pedestres e ciclistas (bebedouros, bancos, vestiários, guarda-volume, bicicletários, oficina para consertos, etc.) 


\section{Modo: Van}

Analisando o campus da ESALQ/CENA como um todo, você o considera acessível aos usuários com algum tipo de restrição de mobilidade?

f) Sim. Nunca notei obstáculos que dificultassem a acessibilidade aos usuários com algum tipo de restrição de mobilidade nas dependências do campus

g) Grande parte do campus é acessível. Algumas áreas possuem obstáculos, mas de maneira geral considero o campus acessível aos usuários com algum tipo de restrição de mobilidade

h) Pequena parte do campus é acessível. Há diversas áreas que não oferecem condições básicas de acessibilidade aos usuários com algum tipo de restrição de mobilidade

i) Não. O campus não oferece condições básicas de acessibilidade aos usuários com algum tipo de restrição de mobilidade

j) Não sou capaz de opinar, pois nunca analisei o campus sob este aspecto

Dentre os prédios que frequenta na ESALQ/CENA, como você avalia a acessibilidade para os usuários com algum tipo de restrição de mobilidade?

f) Ótima. Prédios totalmente equipados para receber os usuários com algum tipo de restrição de mobilidade

g) Boa. Prédios parcialmente equipados, mas possuem condições satisfatórias para atender os usuários com algum tipo de restrição de mobilidade

h) Regular. Prédios pouco equipados, com limitações para atender os usuários com algum tipo de restrição de mobilidade

i) Ruim. Prédios não equipados para receber os usuários com algum tipo de restrição de mobilidade

j) Não sou capaz de avaliar, pois nunca analisei os prédios da ESALQ/CENA sob este aspecto

$\mathrm{Na}$ etapa anterior do questionário, você nos informou que seu modo principal para os deslocamentos à ESALQ/CENA é a VAN OPERADA PELA USP (Vila Estudantil). Quais fatores o/a levam a optar por este modo?

Conveniência

a) Sem importância

b) Pouco importante

c) De alguma importância

d) Muito importante

e) Extremamente importante

Contribuição pessoal para a redução dos níveis de poluição do ar
a) Sem importância
b) Pouco importante
c) De alguma importância
d) Muito importante
e) Extremamente importante

Possibilidade de socialização (encontrar pessoas)

f) Sem importância

g) Pouco importante

h) De alguma importância 
i) Muito importante

j) Extremamente importante

Não precisar procurar local para estacionar

f) Sem importância

g) Pouco importante

h) De alguma importância

i) Muito importante

j) Extremamente importante

Se desejar, inclua outros fatores, indicando o grau de importância entre parênteses. Exemplo: Distância de viagem (Muito importante), Não sei dirigir (De alguma importância).

Quais fatores o/a desestimulam a utilizar os demais modos que não a van operada pela USP em seus deslocamentos?

Distância longa a ser percorrida

f) Sem importância

g) Pouco importante

h) De alguma importância

i) Muito importante

j) Extremamente importante

Condições climáticas (chuva, vento, calor, frio)

f) Sem importância

g) Pouco importante

h) De alguma importância

i) Muito importante

j) Extremamente importante

Inexistência de ciclovias contínuas das avenidas principais até o campus

f) Sem importância

g) Pouco importante

h) De alguma importância

i) Muito importante

j) Extremamente importante

Insegurança pública (assaltos, furtos, assédio)

f) Sem importância

g) Pouco importante

h) De alguma importância

i) Muito importante

j) Extremamente importante

Perigo com o trânsito

f) Sem importância

g) Pouco importante

h) De alguma importância

i) Muito importante

j) Extremamente importante

Esforço físico

f) Sem importância 
g) Pouco importante

h) De alguma importância

i) Muito importante

j) Extremamente importante

Ausência de calçadas adequadas até o campus

f) Sem importância

g) Pouco importante

h) De alguma importância

i) Muito importante

j) Extremamente importante

Se desejar, inclua outros fatores, indicando o grau de importância entre parênteses. Exemplo: Preciso carregar materiais (Extremamente importante), Tempo de deslocamento (Muito importante).

Há quanto tempo você utiliza a van operada pela USP para se deslocar até a ESALQ/CENA?

c) Há menos de 6 meses

d) Há mais de 6 meses

Dos deslocamentos que você faz hoje com a van operada pela USP, qual modo você utilizava antes?
a) A pé
b) Bicicleta
c) Automóvel
d) Van operada pela USP (Vila Estudantil)
e) Automóvel, na condição de MOTORISTA
f) Automóvel, na condição de CARONA - estaciona no campus
g) Automóvel, na condição de CARONA - não estaciona no campus
h) Motocicleta
i) Skate
j) Patins
k) Nenhum. Antes deste período não frequentava o campus
l) Outro (especifique)

Como você avalia a frequência de atendimento?
e) Ótima (intervalo de atendimento de 15 minutos ou menos)
f) Boa
g) Regular
h) Ruim (intervalo de atendimento de 60 minutos ou mais)

Como você avalia a pontualidade?
e) Ótima (nunca atrasa)
f) Boa
g) Regular
h) Ruim (sempre atrasa) 
Como você avalia o tempo de viagem?

e) Ótimo (praticamente o mesmo tempo que levaria de automóvel)

f) Bom

g) Regular

h) Ruim (duas ou mais vezes o tempo que levaria de automóvel)

Como você avalia a lotação dos veículos?

e) Ótima (veículo com assentos livres)

f) Boa

g) Regular

h) Ruim (veículo lotado)

Classifique, somente para os turnos em que você costuma acessar ou se deslocar AO REDOR da ESALQ/CENA, qual a sua sensação de segurança em relação a assaltos e outros tipos de violência ou assédio:

Manhã
a) Seguro
b) Parcialmente seguro
c) Inseguro

Tarde
a) Seguro
b) Parcialmente seguro
c) Inseguro

Noite
a) Seguro
b) Parcialmente seguro
c) Inseguro

Você presenciou ou sofreu algum tipo de violência ou assédio NO ENTORNO da ESALQ/CENA?

a) $\operatorname{Sim}$

b) Não

Que tipo de violência ou assédio você presenciou ou sofreu NO ENTORNO da ESALQ/CENA? (se for necessário, marque mais de uma alternativa)
a) Sofri um assalto
b) Sofri mais de um assalto
c) Presenciei um assalto
d) Presenciei mais de um assalto
e) Sofri uma tentativa de assalto
f) Sofri mais de uma tentativa de assalto
g) Presenciei uma tentativa de assalto
h) Presenciei mais de uma tentativa de assalto
i) Sofri assédio sexual, uma vez
j) Sofri assédio sexual, mais de uma vez
k) Presenciei um ato de assédio sexual 
I) Presenciei mais de um ato de assédio sexual

m) Sofri assédio moral, uma vez

n) Sofri assédio moral, mais de uma vez

o) Presenciei um ato de assédio moral

p) Presenciei mais de um ato de assédio moral

q) Outros (especifique)

Classifique, somente para os turnos em que você costuma acessar ou se deslocar DENTRO da ESALQ/CENA, qual a sua sensação de segurança em relação a assaltos e outros tipos de violência ou assédio:

Manhã
a) Seguro
b) Parcialmente seguro
c) Inseguro

Tarde
a) Seguro
b) Parcialmente seguro
c) Inseguro

Noite
a) Seguro
b) Parcialmente seguro
c) Inseguro

Você presenciou ou sofreu algum tipo de violência ou assédio DENTRO da ESALQ/CENA?
a) $\operatorname{Sim}$
b) Não

Que tipo de violência ou assédio você presenciou ou sofreu N DENTRO da ESALQ/CENA? (se for necessário, marque mais de uma alternativa)
a) Sofri um assalto
b) Sofri mais de um assalto
c) Presenciei um assalto
d) Presenciei mais de um assalto
e) Sofri uma tentativa de assalto
f) Sofri mais de uma tentativa de assalto
g) Presenciei uma tentativa de assalto
h) Presenciei mais de uma tentativa de assalto
i) Sofri assédio sexual, uma vez
j) Sofri assédio sexual, mais de uma vez
k) Presenciei um ato de assédio sexual
l) Presenciei mais de um ato de assédio sexual
m) Sofri assédio moral, uma vez
n) Sofri assédio moral, mais de uma vez
o) Presenciei um ato de assédio moral
p) Presenciei mais de um ato de assédio moral
q) Outros (especifique) 
Com relação a medidas de segurança no ENTORNO e DENTRO da ESALQ/CENA, você é favorável a (se for necessário, marque mais de uma alternativa):

a) Instalação de mais câmeras de monitoramento

b) Melhoria da iluminação

c) Intensificação das rondas no ENTORNO do campus, pela Guarda Universitária (PPUSP)

d) Intensificação das rondas no ENTORNO do campus, pela Policia Militar

e) Intensificação das rondas no ENTORNO do campus, pela Guarda Municipal

f) Intensificação de rondas DENTRO do campus, pela Guarda Universitária (PPUSP)

g) Realização de rondas DENTRO do campus, pela Policia Militar

h) Realização de rondas DENTRO do campus, pela Policia Militar, mas somente nos horários mais críticos como à noite e durante grandes eventos

i) Realização de rondas DENTRO do campus, pela Guarda Municipal

j) Realização de rondas DENTRO do campus, pela Guarda Municipal, mas somente nos horários mais críticos como à noite e durante grandes eventos

k) Nenhuma das alternativas

Como você descreveria o trajeto do seu ponto de origem até o campus Luiz de Queiroz (ESALQ/CENA)?

a) O trajeto me incomoda em alguns aspectos; gostaria que fosse mais agradável e/ou menos demorado

b) O trajeto representa um sofrimento para mim; é um alívio chegar ao campus

c) O trajeto é indiferente para mim, não me sinto incomodado nem confortável

d) O trajeto é satisfatório para mim

e) O trajeto é agradável para mim

f) Outro (especifique)

Como você avalia a sinalização do campus Luiz de Queiroz (ESALQ/CENA)?

Sinalização de trânsito (horizontal e vertical)

a) Inexistente

b) Insuficiente

c) Suficiente, porém em mau estado de conservação

d) Suficiente, porém fora dos padrões

e) Suficiente

Sinalização informativa (indicação de prédios, serviços, etc)

a) Inexistente

b) Insuficiente

c) Suficiente, porém em mau estado de conservação

d) Suficiente, porém fora dos padrões

e) Suficiente

Na sua opinião, qual a importância destes aspectos para uma mobilidade mais sustentável na USP de Piracicaba? Ordene os temas marcando-os com os respectivos números ou arrastando as caixas de acordo com a prioridade (no topo, o mais importante)

a) Ciclofaixas/ciclovias dentro do campus e para acesso ao mesmo 
b) Infraestrutura essencial para pedestres (calçadas adequadas, iluminação, arborização, sinalização, etc.)

c) Educação no trânsito (respeito aos limites de velocidade e à sinalização, melhor convívio entre motoristas, ciclistas e pedestres, etc.)

d) Ação conjunta com Prefeitura Municipal para melhoria da mobilidade na ligação entre cidade e campus

e) Bolsões de estacionamento internos e externos ao campus

f) Melhoria da qualidade do serviço de transporte público da cidade

g) Restrição do uso de automóveis dentro do campus

h) Acessibilidade (rampas de acesso, calçadas adequadas, elevadores, piso tátil, respeito a vagas de estacionamento prioritárias, etc.)

j) Infraestrutura de apoio para pedestres e ciclistas (bebedouros, bancos, vestiários, guarda-volume, bicicletários, oficina para consertos, etc.) 


\section{APÊNDICE B \\ RESPOSTAS DO QUESTIONÁRIO ONLINE (PARTE 1)}

\section{POTENCIAL DE TRANSFERÊNCIA DE UM ÍNDICE DE MOBILIDADE SUSTENTÁVEL PARA CAMPUS UNIVERSITÁRIO}

Francine Marvulle Tan

São Carlos

2018 


\section{Sumário}

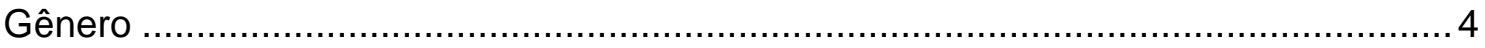

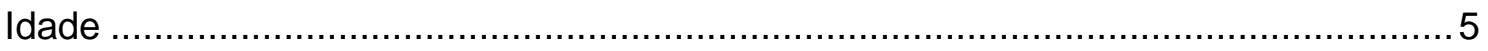

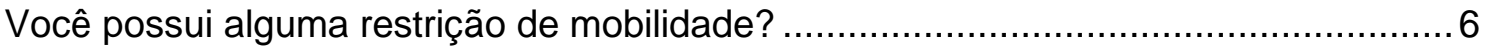

Independente do modo de transporte que utiliza, qual tempo você acha aceitável para realizar o deslocamento casa-universidade? .......................................................... 7

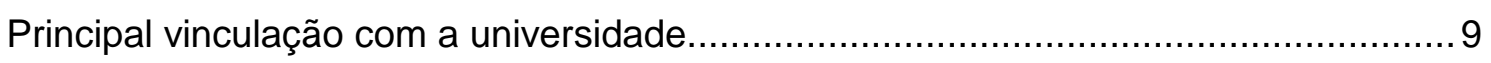

Curso de graduação ................................................................................. 10

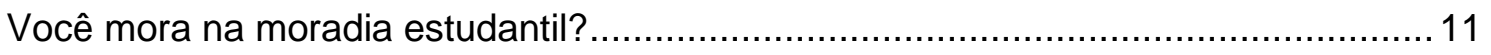

Em qual unidade da moradia estudantil você mora? ............................................... 11

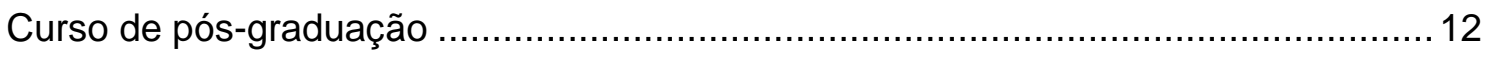

Setor no campus dos servidores docentes .................................................. 13

Setor no campus dos servidores técnicos/administrativos .................................... 14

Departamento de pós-graduação ........................................................................ 16

Você tem residência na cidade de Piracicaba? .......................................................... 17

Qual modo você geralmente utiliza para se deslocar até a cidade de Piracicaba? .....18

De maneira geral, onde você inicia o seu deslocamento para a universidade? ........... 19

Com quantas pessoas você mora em Piracicaba (ou região)? .................................20

As pessoas com quem você mora dependem de você para seus deslocamentos

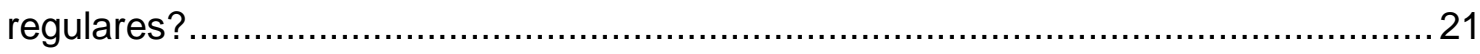

Qual acesso do campus da ESALQ/CENA você normalmente utiliza? .......................22

$\mathrm{Na}$ sua rotina de deslocamentos regulares a partir da residência (em Piracicaba ou região), você tem acesso a quais modos de transporte? .........................................23

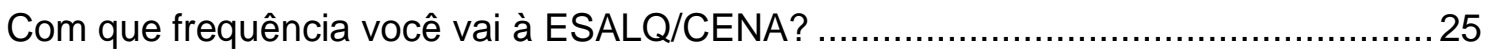

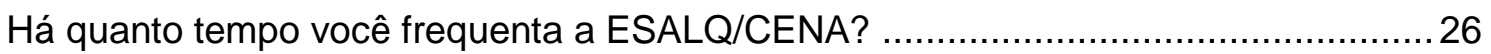

Qual acesso do campus da ESALQ/CENA você normalmente utiliza? .......................28

De acordo com a resposta da questão anterior, qual é, portanto, o modo de transporte principal que você utiliza para se deslocar até a ESALQ/CENA? ............................... 30

Com que frequência você vai à Fazenda Areão? ....................................................... 32

Há quanto tempo você frequenta a Fazenda Areão? ............................................... 33

Qual é o modo de transporte principal que você utiliza para se deslocar até a Fazenda Areão?.

Você tem conhecimento ou participou de alguma AÇÃO DE CONSCIENTIZAÇÃO ao uso de modos mais sustentáveis promovida neste campus? ...................................... 35

De quais ações você tem conhecimento ou participou? (se for necessário, marque

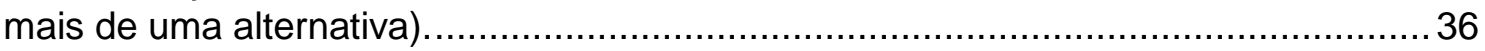

Como você classifica a influência destas ações no seu cotidiano? ............................... 37

Você tem conhecimento ou participou de alguma AÇÃO DE EDUCAÇÃO NO

TRÂNSITO promovida neste campus? 
De quais ações você tem conhecimento ou participou? (se for necessário, marque



Como você classifica a influência destas ações no seu comportamento? .................... 40

Como você avalia a influência destas ações na circulação interna do campus............41

Na sua opinião, qual a importância da mobilidade sustentável em um campus universitário?

De maneira geral, como você avalia a mobilidade interna do campus da USP

Piracicaba (deslocamentos internos)?

De maneira geral, como você avalia a mobilidade para se acessar o campus da USP

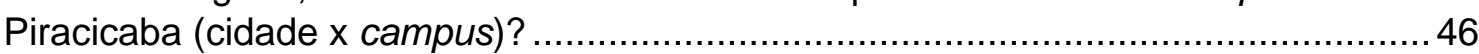

Sugestões e comentários ................................................................................... 47 
Gênero

Respostas: 1049

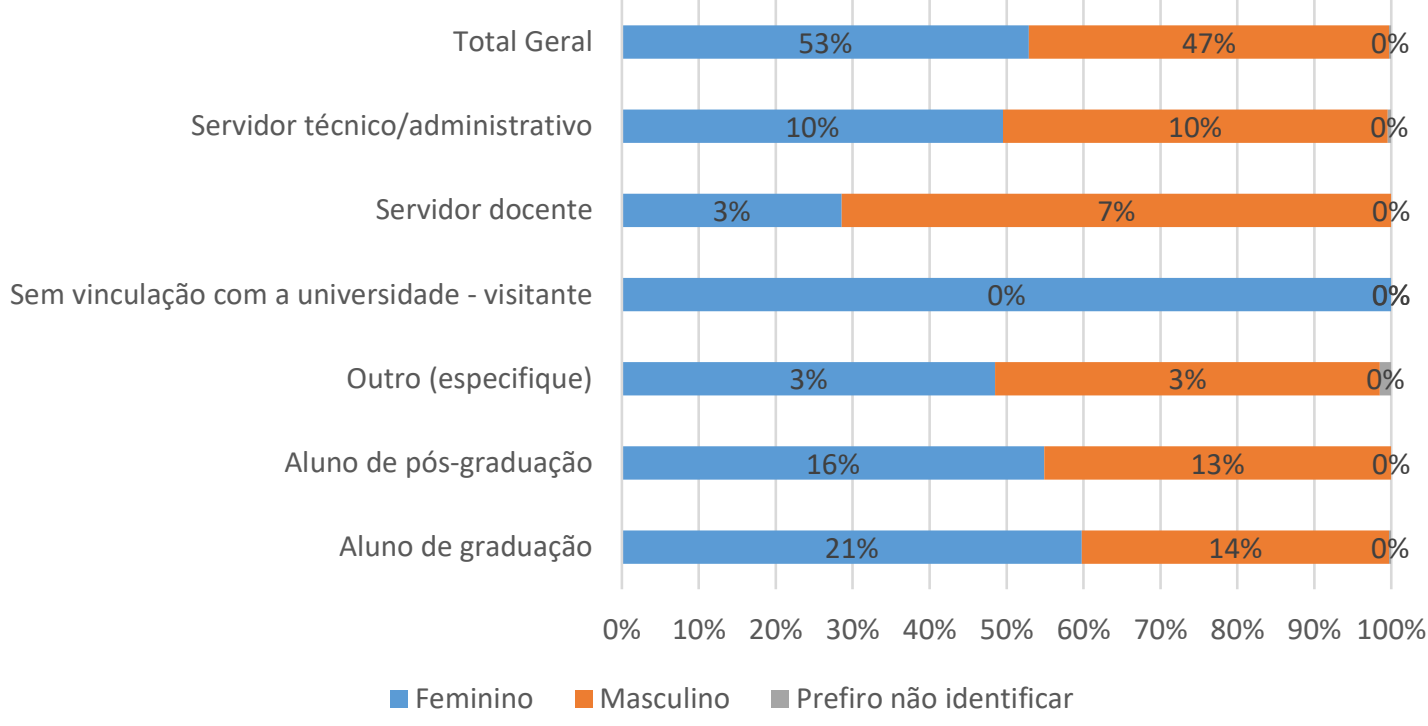

Feminino Masculino

\begin{tabular}{lcccc}
\hline Aluno de graduação & 223 & $21 \%$ & 149 & $14 \%$ \\
\hline Aluno de pós-graduação & 163 & $16 \%$ & 134 & $13 \%$ \\
\hline Servidor docente & 28 & $3 \%$ & 70 & $7 \%$ \\
\hline Servidor técnico/administrativo & 103 & $10 \%$ & 104 & $10 \%$ \\
\hline $\begin{array}{l}\text { Sem vinculação com a universidade - } \\
\text { visitante }\end{array}$ & 5 & $0 \%$ & & $0 \%$ \\
\hline Outro (especifique) & 33 & $3 \%$ & 34 & $3 \%$ \\
\hline Total & 555 & $53 \%$ & 491 & $47 \%$
\end{tabular}


Idade

Respostas: 1049

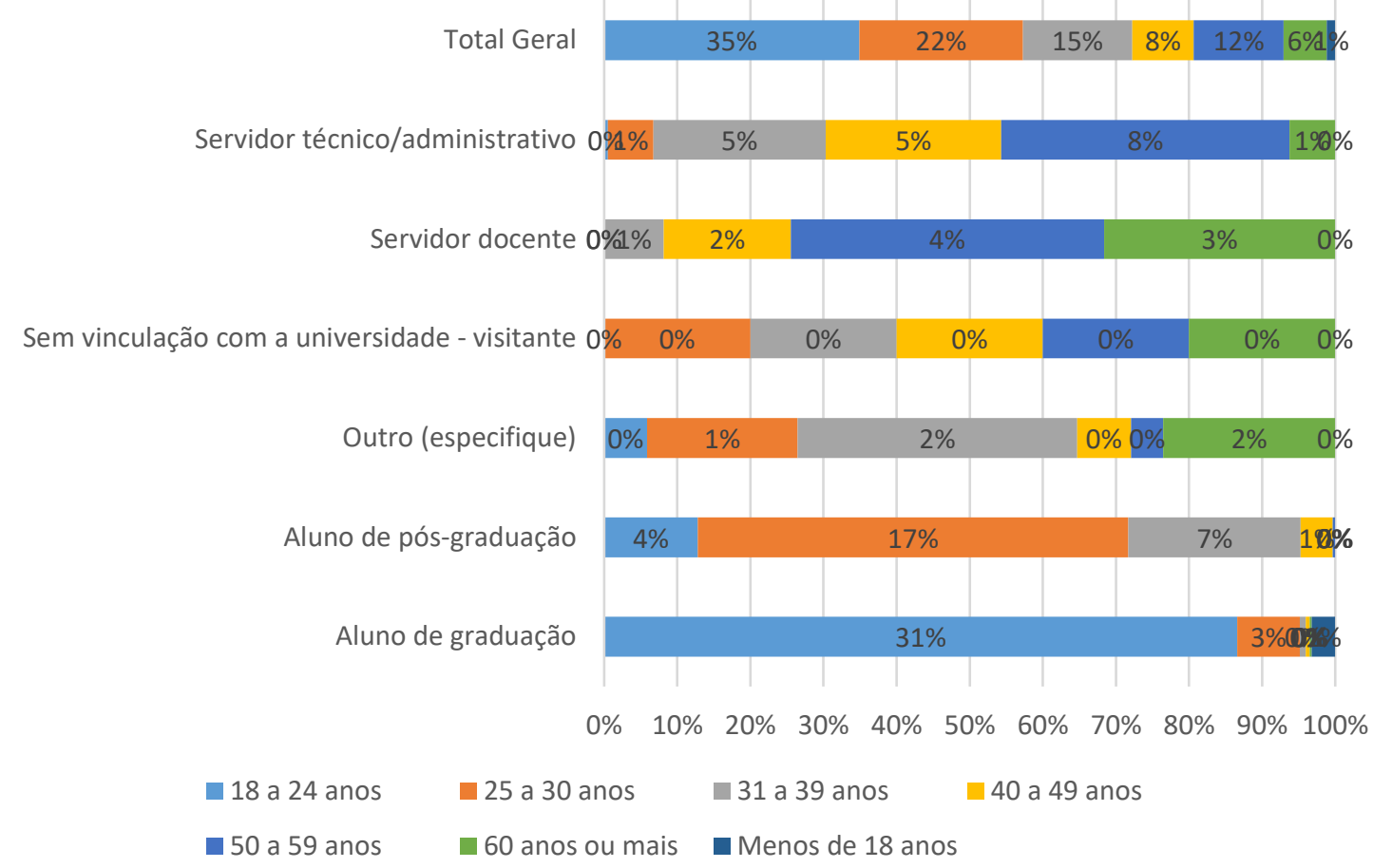

\begin{tabular}{|c|c|c|c|c|c|c|c|c|c|c|c|}
\hline \multirow[b]{2}{*}{18 a 24 anos } & \multicolumn{2}{|c|}{$\begin{array}{l}\text { Aluno de } \\
\text { graduação }\end{array}$} & \multicolumn{2}{|c|}{$\begin{array}{l}\text { Aluno de } \\
\text { pós- } \\
\text { graduação }\end{array}$} & \multicolumn{2}{|c|}{$\begin{array}{c}\text { Outro } \\
\text { (especifique) }\end{array}$} & \multicolumn{2}{|c|}{$\begin{array}{c}\text { Sem } \\
\text { vinculação } \\
\text { com a } \\
\text { universidade } \\
\text { - visitante }\end{array}$} & $\begin{array}{l}\text { Servidor } \\
\text { docente }\end{array}$ & \multicolumn{2}{|c|}{$\begin{array}{c}\text { Servidor } \\
\text { técnico/administrativo }\end{array}$} \\
\hline & 323 & $31 \%$ & 38 & $3,62 \%$ & 4 & $0,38 \%$ & & $0,00 \%$ & $0,00 \%$ & 1 & $0,10 \%$ \\
\hline 25 a 30 anos & 32 & $3 \%$ & 175 & $16,68 \%$ & 14 & $1,33 \%$ & 1 & $0,10 \%$ & $0,00 \%$ & 13 & $1,24 \%$ \\
\hline 31 a 39 anos & 3 & $0 \%$ & 70 & $6,67 \%$ & 26 & $2,48 \%$ & 1 & $0,10 \%$ & $8 \quad 0,76 \%$ & 49 & $4,67 \%$ \\
\hline 40 a 49 anos & 2 & $0 \%$ & 13 & $1,24 \%$ & 5 & $0,48 \%$ & 1 & $0,10 \%$ & $171,62 \%$ & 50 & $4,77 \%$ \\
\hline 50 a 59 anos & & $0 \%$ & 1 & $0,10 \%$ & 3 & $0,29 \%$ & 1 & $0,10 \%$ & $42 \quad 4,00 \%$ & 82 & $7,82 \%$ \\
\hline 60 anos ou mais & 1 & $0 \%$ & & $0,00 \%$ & 16 & $1,53 \%$ & 1 & $0,10 \%$ & $312,96 \%$ & 13 & $1,24 \%$ \\
\hline $\begin{array}{l}\text { Menos de } 18 \\
\text { anos }\end{array}$ & 12 & $1 \%$ & & $0,00 \%$ & & $0,00 \%$ & & $0,00 \%$ & $0,00 \%$ & & $0,00 \%$ \\
\hline
\end{tabular}


Você possui alguma restrição de mobilidade? Respostas: 1049



$$
\begin{aligned}
& \text { — Não } \\
& \text { - Sim }
\end{aligned}
$$


Independente do modo de transporte que utiliza, qual tempo você acha aceitável para realizar o deslocamento casa-universidade?

Respostas: 1049

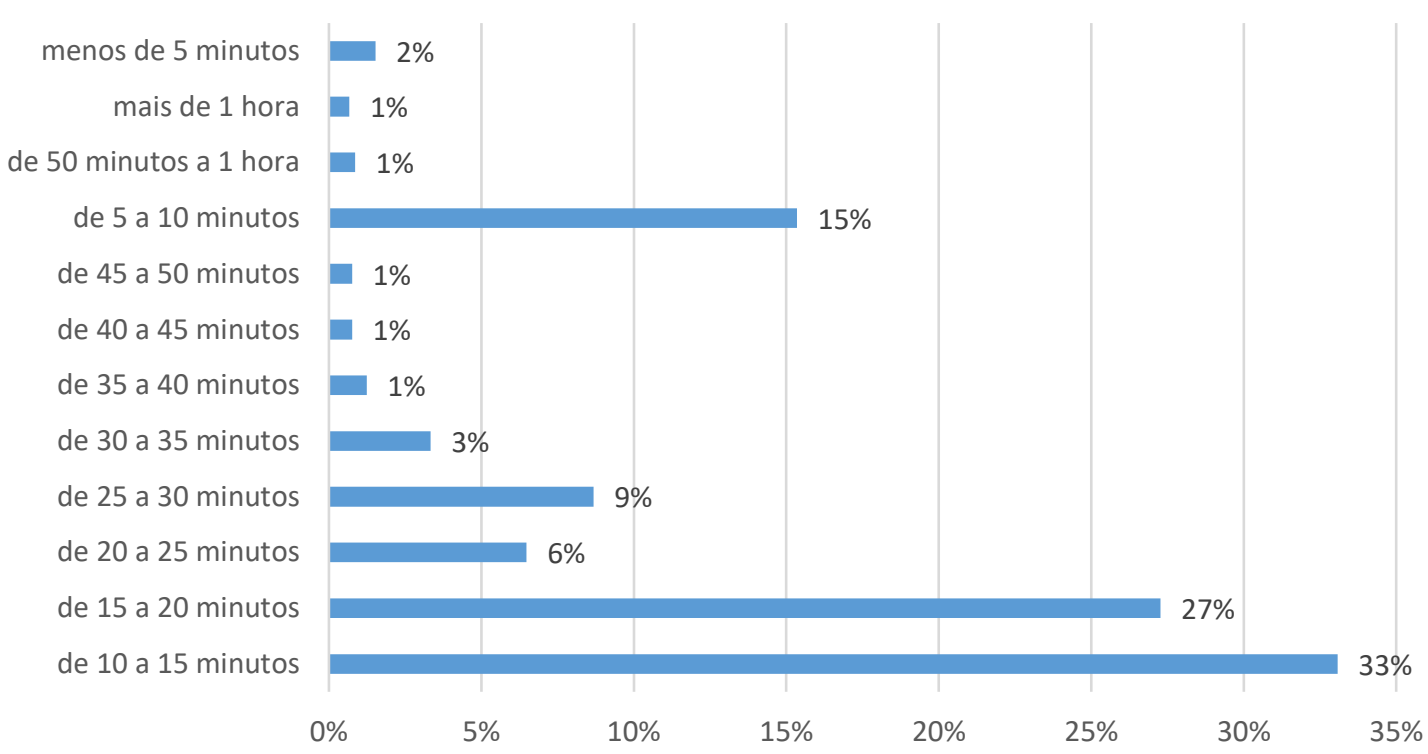

\begin{tabular}{lrr} 
de 10 a 15 minutos & 347 & $33 \%$ \\
\hline de 15 a 20 minutos & 286 & $27 \%$ \\
\hline de 20 a 25 minutos & 68 & $6 \%$ \\
\hline de 25 a 30 minutos & 91 & $9 \%$ \\
\hline de 30 a 35 minutos & 35 & $3 \%$ \\
\hline de 35 a 40 minutos & 13 & $1 \%$ \\
\hline de 40 a 45 minutos & 8 & $1 \%$ \\
\hline de 45 a 50 minutos & 8 & $1 \%$ \\
\hline de 5 a 10 minutos & 161 & $15 \%$ \\
\hline de 50 minutos a 1 hora & 9 & $1 \%$ \\
\hline mais de 1 hora & 7 & $1 \%$ \\
\hline menos de 5 minutos & 16 & $2 \%$
\end{tabular}




\section{Por vinculação}

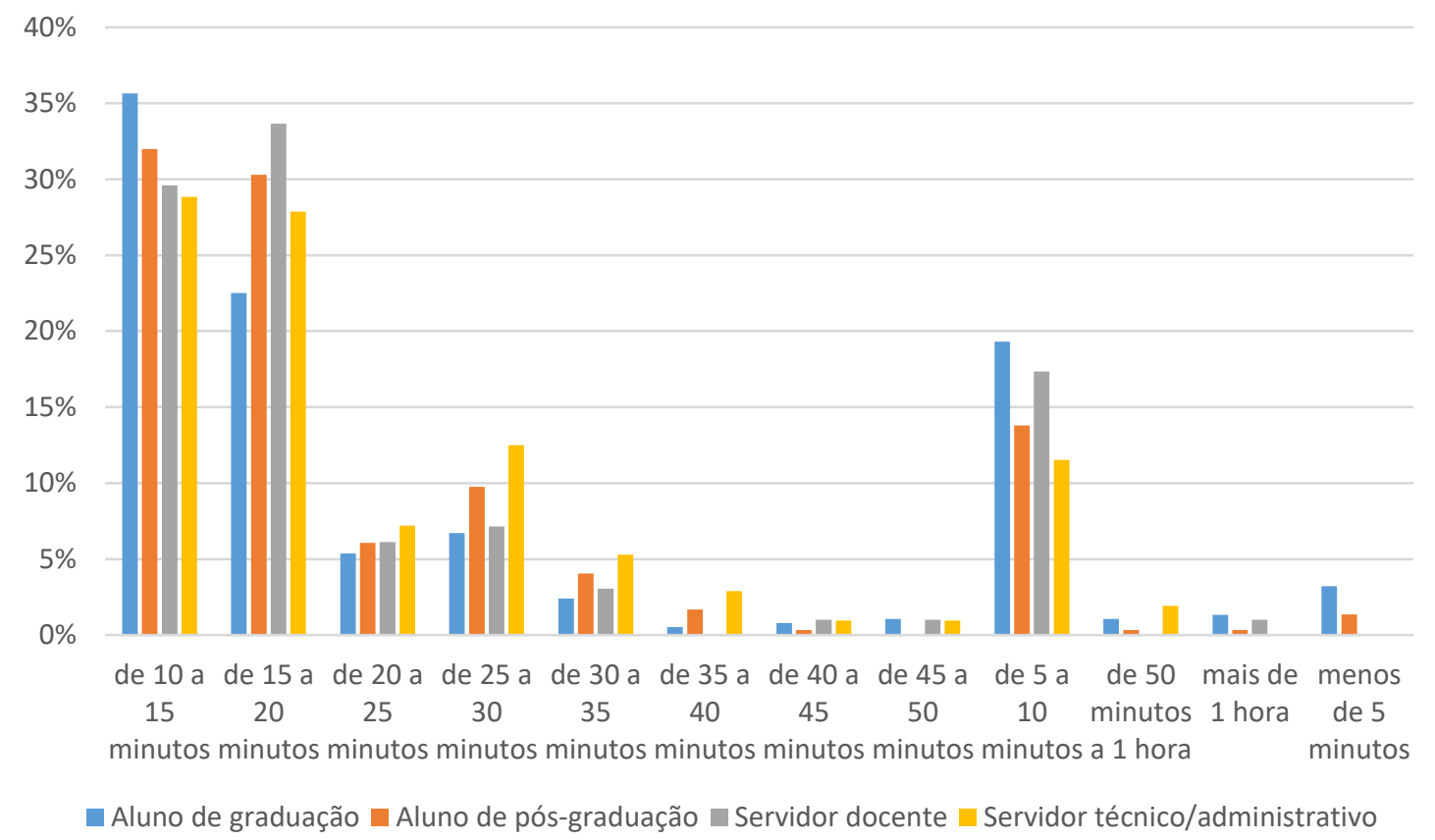

\begin{tabular}{|c|c|c|c|c|c|c|c|c|}
\hline \multirow[b]{2}{*}{ de 10 a 15 minutos } & \multicolumn{2}{|c|}{$\begin{array}{l}\text { Aluno de } \\
\text { graduação }\end{array}$} & \multicolumn{2}{|c|}{$\begin{array}{c}\text { Aluno de } \\
\text { pós- } \\
\text { graduação }\end{array}$} & \multicolumn{2}{|c|}{$\begin{array}{l}\text { Servidor } \\
\text { docente }\end{array}$} & \multicolumn{2}{|c|}{$\begin{array}{c}\text { Servidor } \\
\text { técnico/administrativo }\end{array}$} \\
\hline & 133 & $35,66 \%$ & 95 & $31,99 \%$ & 29 & $29,59 \%$ & 60 & $28,85 \%$ \\
\hline de 15 a 20 minutos & 84 & $22,52 \%$ & 90 & $30,30 \%$ & 33 & $33,67 \%$ & 58 & $27,88 \%$ \\
\hline de 20 a 25 minutos & 20 & $5,36 \%$ & 18 & $6,06 \%$ & 6 & $6,12 \%$ & 15 & $7,21 \%$ \\
\hline de 25 a 30 minutos & 25 & $6,70 \%$ & 29 & $9,76 \%$ & 7 & $7,14 \%$ & 26 & $12,50 \%$ \\
\hline de 30 a 35 minutos & 9 & $2,41 \%$ & 12 & $4,04 \%$ & 3 & $3,06 \%$ & 11 & $5,29 \%$ \\
\hline de 35 a 40 minutos & 2 & $0,54 \%$ & 5 & $1,68 \%$ & & $0,00 \%$ & 6 & $2,88 \%$ \\
\hline de 40 a 45 minutos & 3 & $0,80 \%$ & 1 & $0,34 \%$ & 1 & $1,02 \%$ & 2 & $0,96 \%$ \\
\hline de 45 a 50 minutos & 4 & $1,07 \%$ & & $0,00 \%$ & 1 & $1,02 \%$ & 2 & $0,96 \%$ \\
\hline de 5 a 10 minutos & 72 & $19,30 \%$ & 41 & $13,80 \%$ & 17 & $17,35 \%$ & 24 & $11,54 \%$ \\
\hline $\begin{array}{l}\text { de } 50 \text { minutos a } 1 \\
\text { hora }\end{array}$ & 4 & $1,07 \%$ & 1 & $0,34 \%$ & & $0,00 \%$ & 4 & $1,92 \%$ \\
\hline mais de 1 hora & 5 & $1,34 \%$ & 1 & $0,34 \%$ & 1 & $1,02 \%$ & & $0,00 \%$ \\
\hline menos de 5 minutos & 12 & $3,22 \%$ & 4 & $1,35 \%$ & & $0,00 \%$ & & $0,00 \%$ \\
\hline
\end{tabular}


Principal vinculação com a universidade

Respostas: 1049

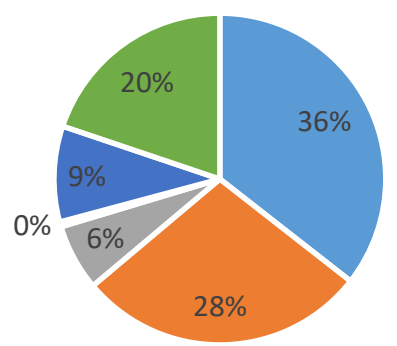

$$
\begin{aligned}
& \text { - Aluno de graduação } \\
& \text { - Aluno de pós-graduação } \\
& \text { - Outros } \\
& \text { - Sem vinculação com a } \\
& \text { universidade - visitante }
\end{aligned}
$$

Aluno de graduação

$37336 \%$

Aluno de pós-graduação

$29728 \%$

Outros

$686 \%$

Sem vinculação com a universidade - visitante $\quad 5 \quad 0 \%$

Servidor docente

$98 \quad 9 \%$

Servidor técnico/administrativo

$20820 \%$ 
Curso de graduação

Respostas: 370

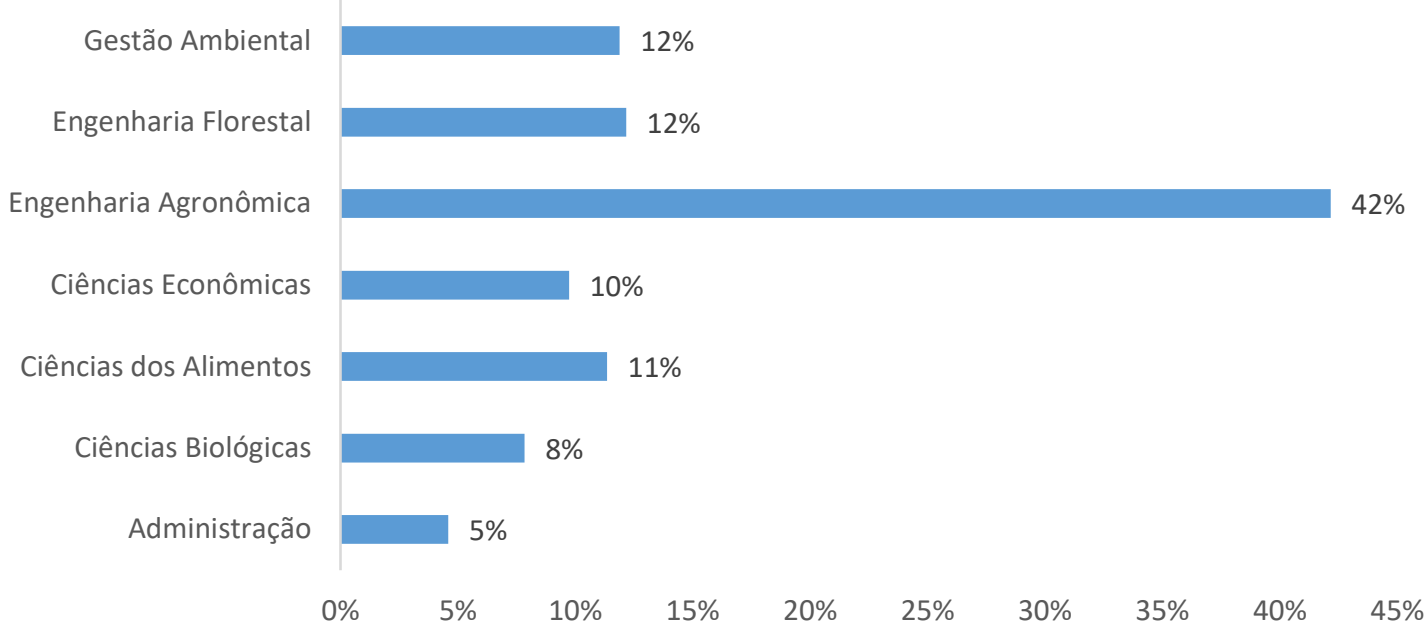

\begin{tabular}{lrr} 
Administração & 17 & $5 \%$ \\
\hline Ciências Biológicas & 29 & $8 \%$ \\
\hline Ciências dos Alimentos & 42 & $11 \%$ \\
\hline Ciências Econômicas & 36 & $10 \%$ \\
\hline Engenharia & 156 & $42 \%$ \\
\hline Agronômica & 45 & $12 \%$ \\
\hline Engenharia Florestal & 44 & $12 \%$
\end{tabular}


Você mora na moradia estudantil?

Respostas: 370

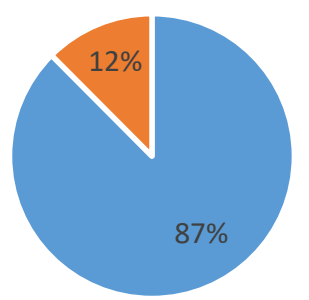

- Não

- Sim

Em qual unidade da moradia estudantil você mora?

Respostas: 48

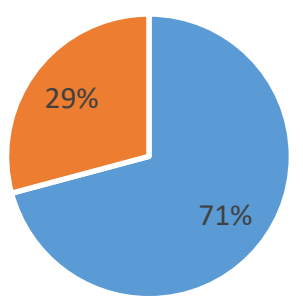

- Moradia interna (dentro do campus)

\begin{tabular}{lll} 
Moradia interna (dentro do campus) & 34 & $71 \%$ \\
\hline Vila estudantil & 14 & $29 \%$
\end{tabular}


Curso de pós-graduação

Respostas: 290

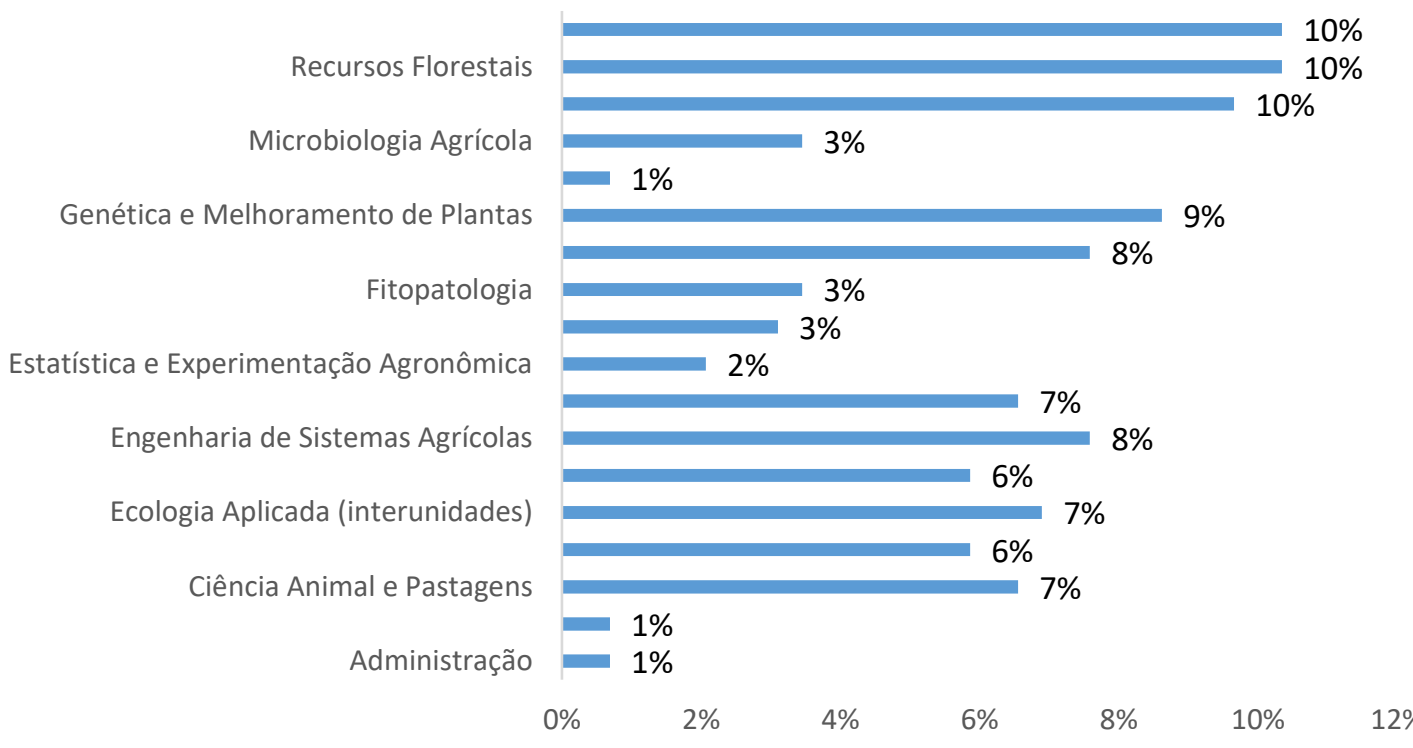

\begin{tabular}{lrr} 
Administração & 2 & $1 \%$ \\
\hline Bioenergia (interinstitucional) & 2 & $1 \%$ \\
\hline Ciência Animal e Pastagens & 19 & $7 \%$ \\
\hline Ciência e Tecnologia de Alimentos & 17 & $6 \%$ \\
\hline Ecologia Aplicada (interunidades) & 20 & $7 \%$ \\
\hline Economia Aplicada & 17 & $6 \%$ \\
\hline Engenharia de Sistemas Agrícolas & 22 & $8 \%$ \\
\hline Entomologia & 19 & $7 \%$ \\
\hline Estatística e Experimentação Agronômica & 6 & $2 \%$ \\
\hline Fisiologia e Bioquímica de Plantas & 9 & $3 \%$ \\
\hline Fitopatologia & 10 & $3 \%$ \\
\hline Fitotecnia & 22 & $8 \%$ \\
\hline Genética e Melhoramento de Plantas & 25 & $9 \%$ \\
\hline Internacional Biologia Celular e Molecular Vegetal & 2 & $1 \%$ \\
\hline Microbiologia Agrícola & 10 & $3 \%$ \\
\hline Outro (especifique) & 28 & $10 \%$ \\
\hline Recursos Florestais & 30 & $10 \%$ \\
\hline Solos e Nutrição de Plantas & 30 & $10 \%$
\end{tabular}


Setor no campus dos servidores docentes Respostas: 95

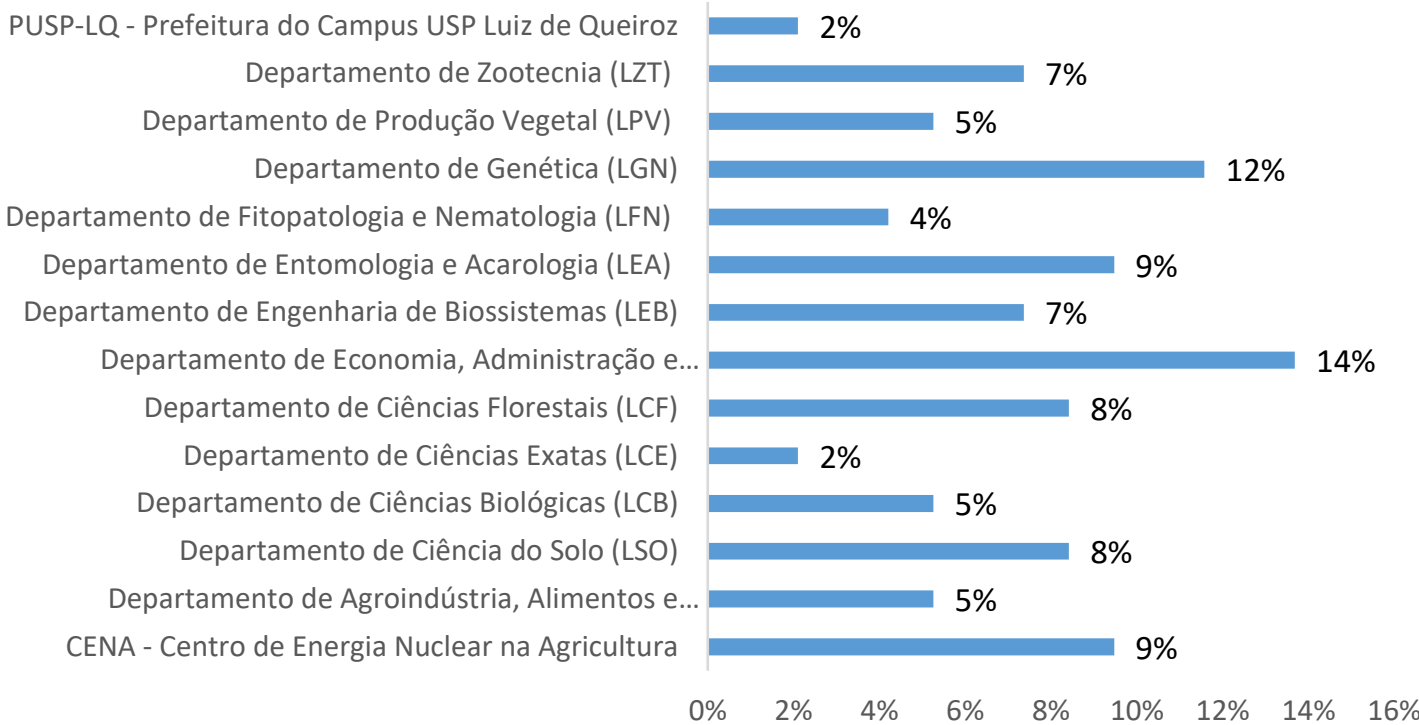

\begin{tabular}{lrr} 
CENA - Centro de Energia Nuclear na Agricultura & 9 & $9 \%$ \\
\hline Departamento de Agroindústria, Alimentos e Nutrição (LAN) & 5 & $5 \%$ \\
\hline Departamento de Ciência do Solo (LSO) & 8 & $8 \%$ \\
\hline Departamento de Ciências Biológicas (LCB) & 5 & $5 \%$ \\
\hline Departamento de Ciências Exatas (LCE) & 2 & $2 \%$ \\
\hline Departamento de Ciências Florestais (LCF) & 8 & $8 \%$ \\
\hline Departamento de Economia, Administração e Sociologia (LES) & 13 & $14 \%$ \\
\hline Departamento de Engenharia de Biossistemas (LEB) & 7 & $7 \%$ \\
\hline Departamento de Entomologia e Acarologia (LEA) & 9 & $9 \%$ \\
\hline Departamento de Fitopatologia e Nematologia (LFN) & 4 & $4 \%$ \\
\hline Departamento de Genética (LGN) & 11 & $12 \%$ \\
\hline Departamento de Produção Vegetal (LPV) & 5 & $5 \%$ \\
\hline Departamento de Zootecnia (LZT) & 7 & $7 \%$ \\
\hline PUSP-LQ - Prefeitura do Campus USP Luiz de Queiroz & 2 & $2 \%$
\end{tabular}


Setor no campus dos servidores técnicos/administrativos Respostas: 199

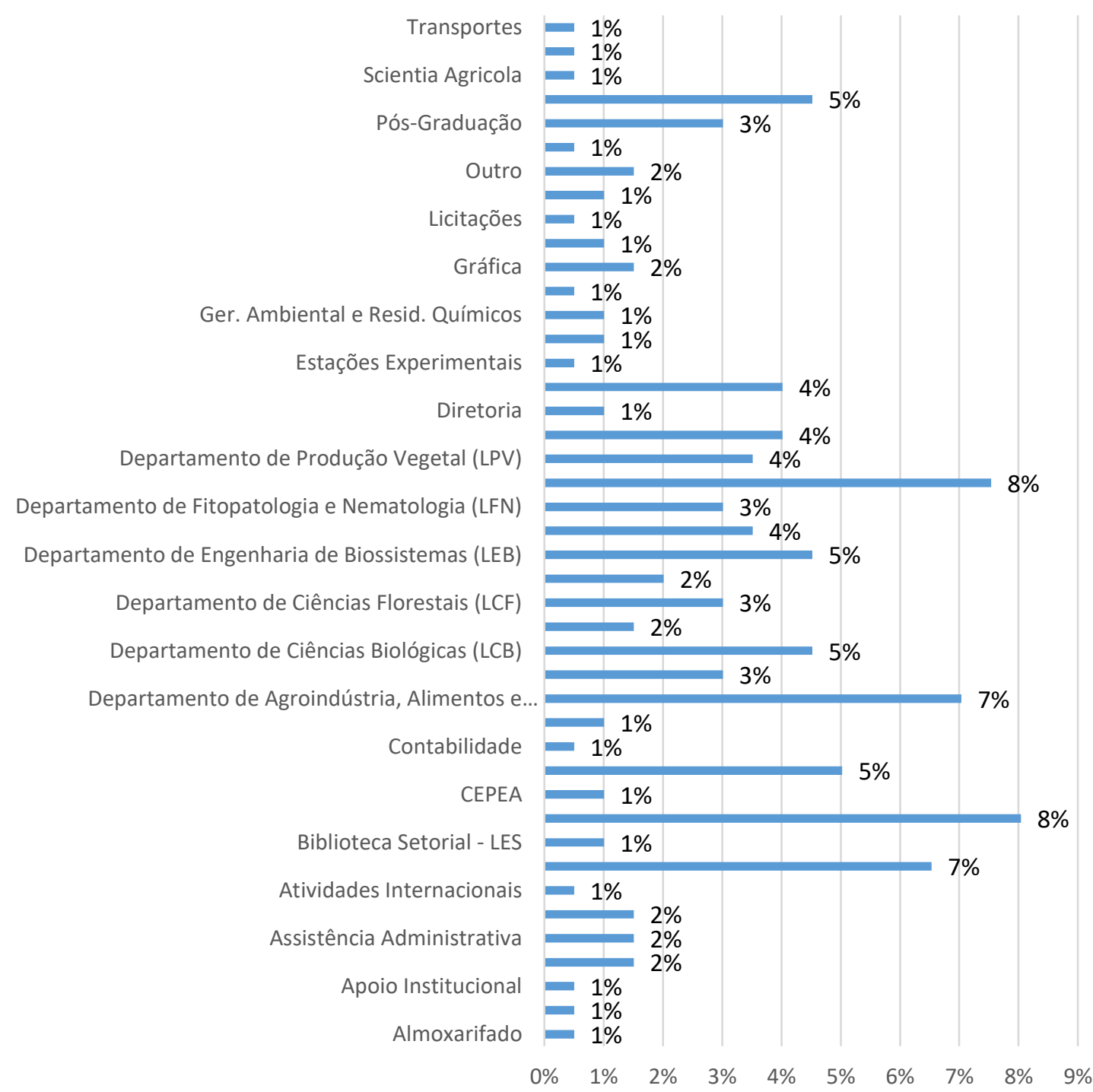




\begin{tabular}{|c|c|c|}
\hline Almoxarifado & 1 & $1 \%$ \\
\hline Apoio à Pesquisa & 1 & $1 \%$ \\
\hline Apoio Institucional & 1 & $1 \%$ \\
\hline Assistência Acadêmica & 3 & $2 \%$ \\
\hline Assistência Administrativa & 3 & $2 \%$ \\
\hline Assistência Financeira & 3 & $2 \%$ \\
\hline Atividades Internacionais & 1 & $1 \%$ \\
\hline Biblioteca Central & 13 & $7 \%$ \\
\hline Biblioteca Setorial - LES & 2 & $1 \%$ \\
\hline CENA - Centro de Energia Nuclear na Agricultura & 16 & $8 \%$ \\
\hline CEPEA & 2 & $1 \%$ \\
\hline CeTI-LQ - Centro de Tecnologia da Informação "Luiz de Queiroz" & 10 & $5 \%$ \\
\hline Contabilidade & 1 & $1 \%$ \\
\hline Cultura e Ext. Universitária & 2 & $1 \%$ \\
\hline Departamento de Agroindústria, Alimentos e Nutrição (LAN) & 14 & $7 \%$ \\
\hline Departamento de Ciência do Solo (LSO) & 6 & $3 \%$ \\
\hline Departamento de Ciências Biológicas (LCB) & 9 & $5 \%$ \\
\hline Departamento de Ciências Exatas (LCE) & 3 & $2 \%$ \\
\hline Departamento de Ciências Florestais (LCF) & 6 & $3 \%$ \\
\hline Departamento de Economia, Administração e Sociologia (LES) & 4 & $2 \%$ \\
\hline Departamento de Engenharia de Biossistemas (LEB) & 9 & $5 \%$ \\
\hline Departamento de Entomologia e Acarologia (LEA) & 7 & $4 \%$ \\
\hline Departamento de Fitopatologia e Nematologia (LFN) & 6 & $3 \%$ \\
\hline Departamento de Genética (LGN) & 15 & $8 \%$ \\
\hline Departamento de Produção Vegetal (LPV) & 7 & $4 \%$ \\
\hline Departamento de Zootecnia (LZT) & 8 & $4 \%$ \\
\hline Diretoria & 2 & $1 \%$ \\
\hline Divisão de Comunicação & 8 & $4 \%$ \\
\hline Estações Experimentais & 1 & $1 \%$ \\
\hline Expediente & 2 & $1 \%$ \\
\hline Ger. Ambiental e Resid. Químicos & 2 & $1 \%$ \\
\hline Graduação & 1 & $1 \%$ \\
\hline Gráfica & 3 & $2 \%$ \\
\hline Informática & 2 & $1 \%$ \\
\hline Licitações & 1 & $1 \%$ \\
\hline Material & 2 & $1 \%$ \\
\hline Outro & 3 & $2 \%$ \\
\hline Pessoal & 1 & $1 \%$ \\
\hline Pós-Graduação & 6 & $3 \%$ \\
\hline PUSP-LQ - Prefeitura da USP Campus "Luiz de Queiroz" & 9 & $5 \%$ \\
\hline Scientia Agricola & 1 & $1 \%$ \\
\hline Serviços Gerais & 1 & $1 \%$ \\
\hline Transportes & 1 & $1 \%$ \\
\hline
\end{tabular}


Departamento de pós-graduação

Respostas: 67

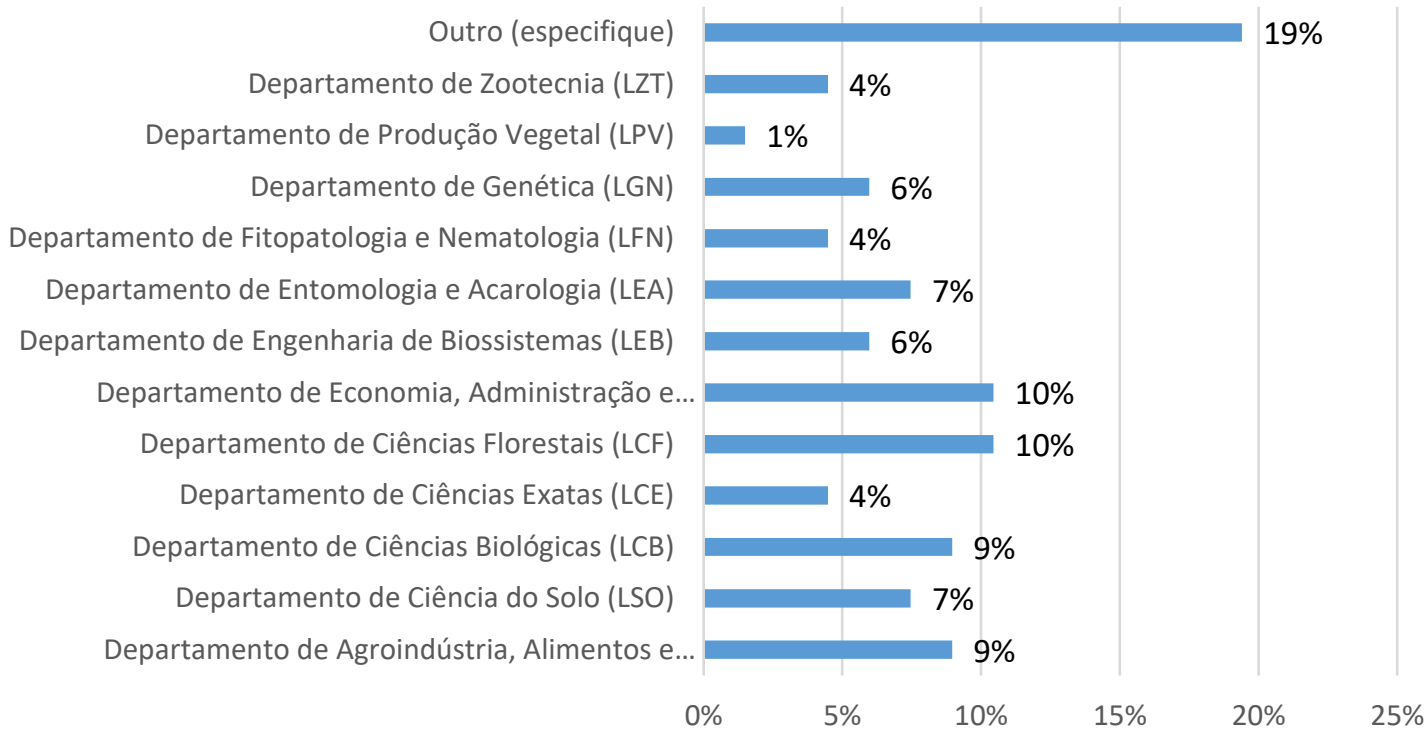

\begin{tabular}{lrr} 
Departamento de Agroindústria, Alimentos e Nutrição (LAN) & 6 & $9 \%$ \\
\hline Departamento de Ciência do Solo (LSO) & 5 & $7 \%$ \\
\hline Departamento de Ciências Biológicas (LCB) & 6 & $9 \%$ \\
\hline Departamento de Ciências Exatas (LCE) & 3 & $4 \%$ \\
\hline Departamento de Ciências Florestais (LCF) & 7 & $10 \%$ \\
\hline $\begin{array}{l}\text { Departamento de Economia, Administração e Sociologia } \\
\text { (LES) }\end{array}$ & 7 & $10 \%$ \\
\hline Departamento de Engenharia de Biossistemas (LEB) & 4 & $6 \%$ \\
\hline Departamento de Entomologia e Acarologia (LEA) & 5 & $7 \%$ \\
\hline Departamento de Fitopatologia e Nematologia (LFN) & 3 & $4 \%$ \\
\hline Departamento de Genética (LGN) & 4 & $6 \%$ \\
\hline Departamento de Produção Vegetal (LPV) & 1 & $1 \%$ \\
\hline Departamento de Zootecnia (LZT) & 3 & $4 \%$ \\
\hline Outro (especifique) & 13 & $19 \%$
\end{tabular}


Você tem residência na cidade de Piracicaba?

Respostas: 985

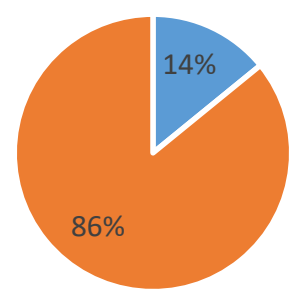

- Não

- Sim

\begin{tabular}{lll} 
Não & 139 & $14 \%$ \\
\hline Sim & 846 & $86 \%$
\end{tabular}


Qual modo você geralmente utiliza para se deslocar até a cidade de Piracicaba? Respostas: 136

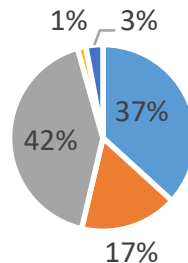

$$
\text { - Ônibus }
$$

- Automóvel (na condição de carona)

- Automóvel (na condição de motorista)

\begin{tabular}{lrr} 
Ônibus & 50 & $37 \%$ \\
\hline Automóvel (na condição de carona) & 23 & $17 \%$ \\
\hline Automóvel (na condição de motorista) & 57 & $42 \%$ \\
\hline Motocicleta & 2 & $1 \%$ \\
\hline Van & 4 & $3 \%$
\end{tabular}


De maneira geral, onde você inicia o seu deslocamento para a universidade? Respostas: 798

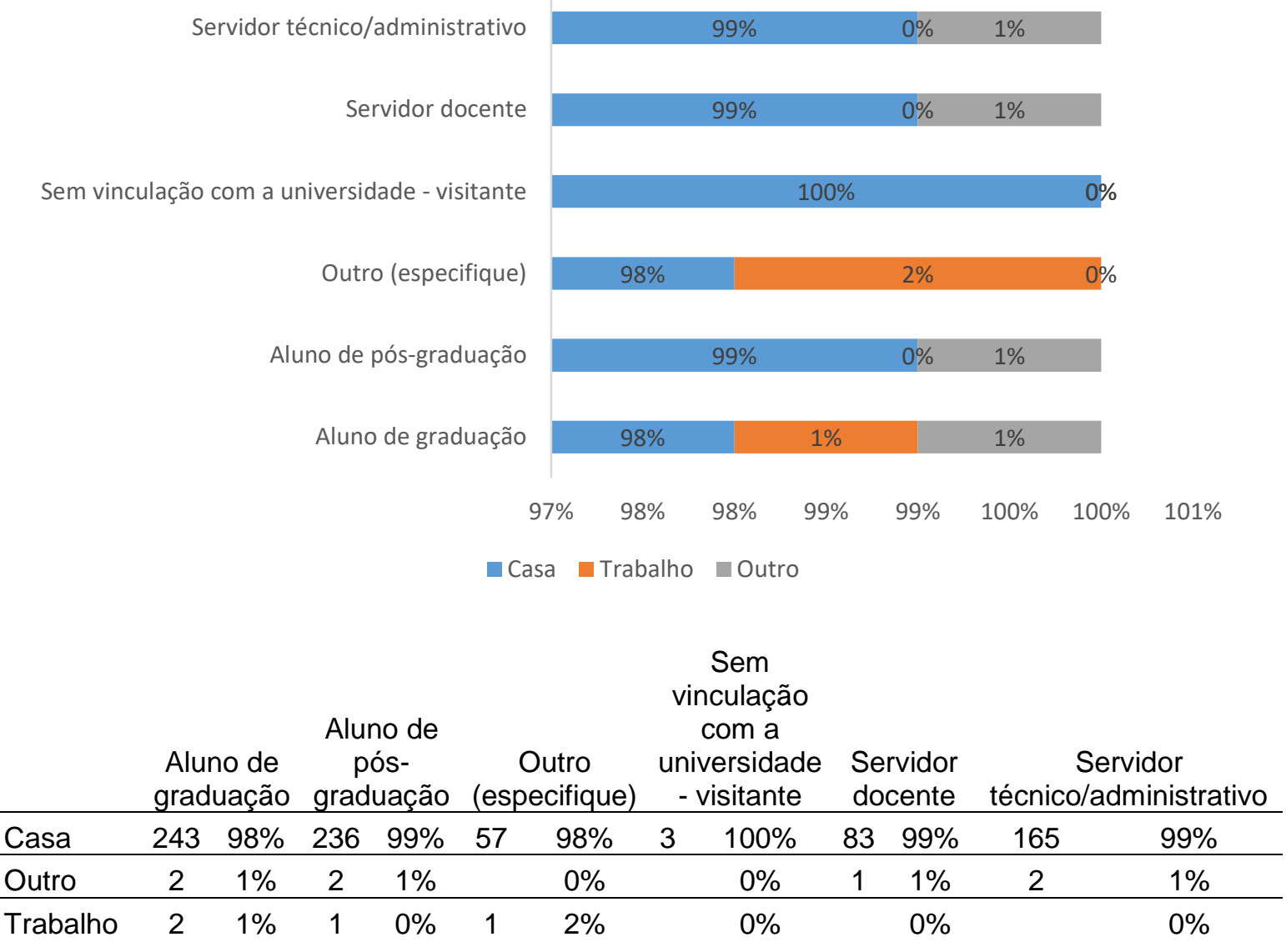


Com quantas pessoas você mora em Piracicaba (ou região)?

Respostas: 918

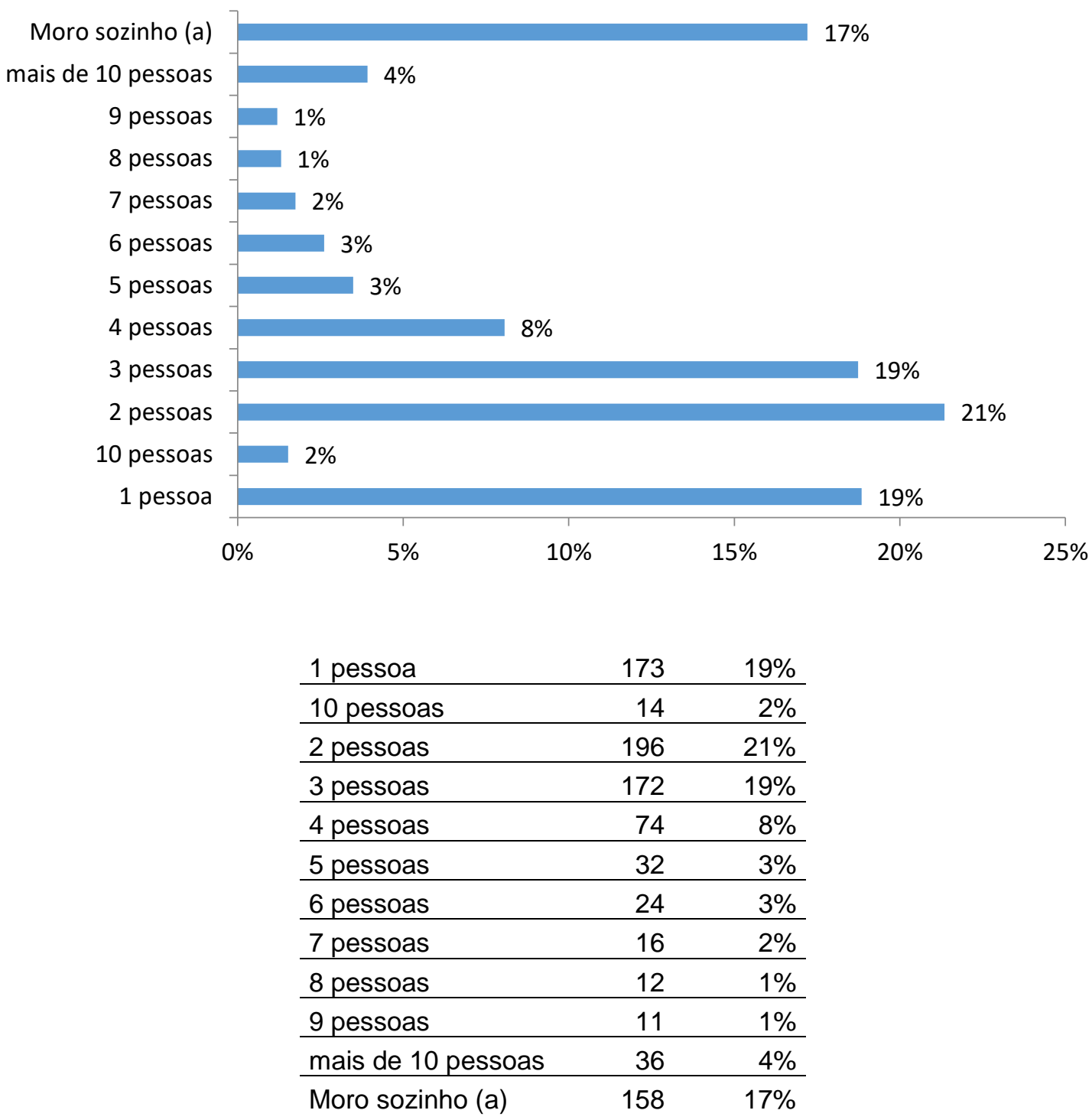


As pessoas com quem você mora dependem de você para seus deslocamentos regulares? Exemplo: filhos pequenos, pessoas que não dirigem, pessoas com restrição de mobilidade, etc. Respostas: 918

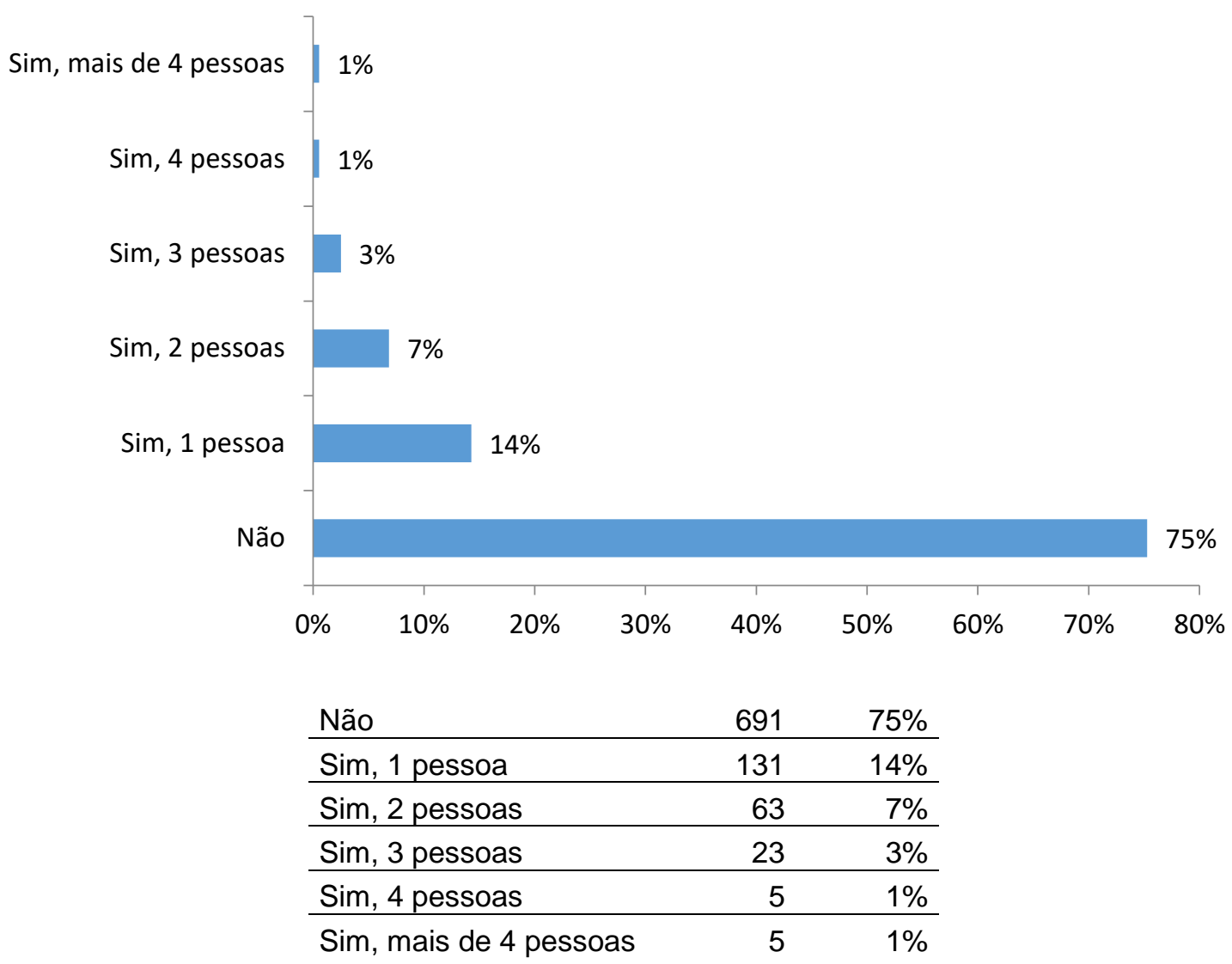


Qual acesso do campus da ESALQ/CENA você normalmente utiliza? Respostas: 848

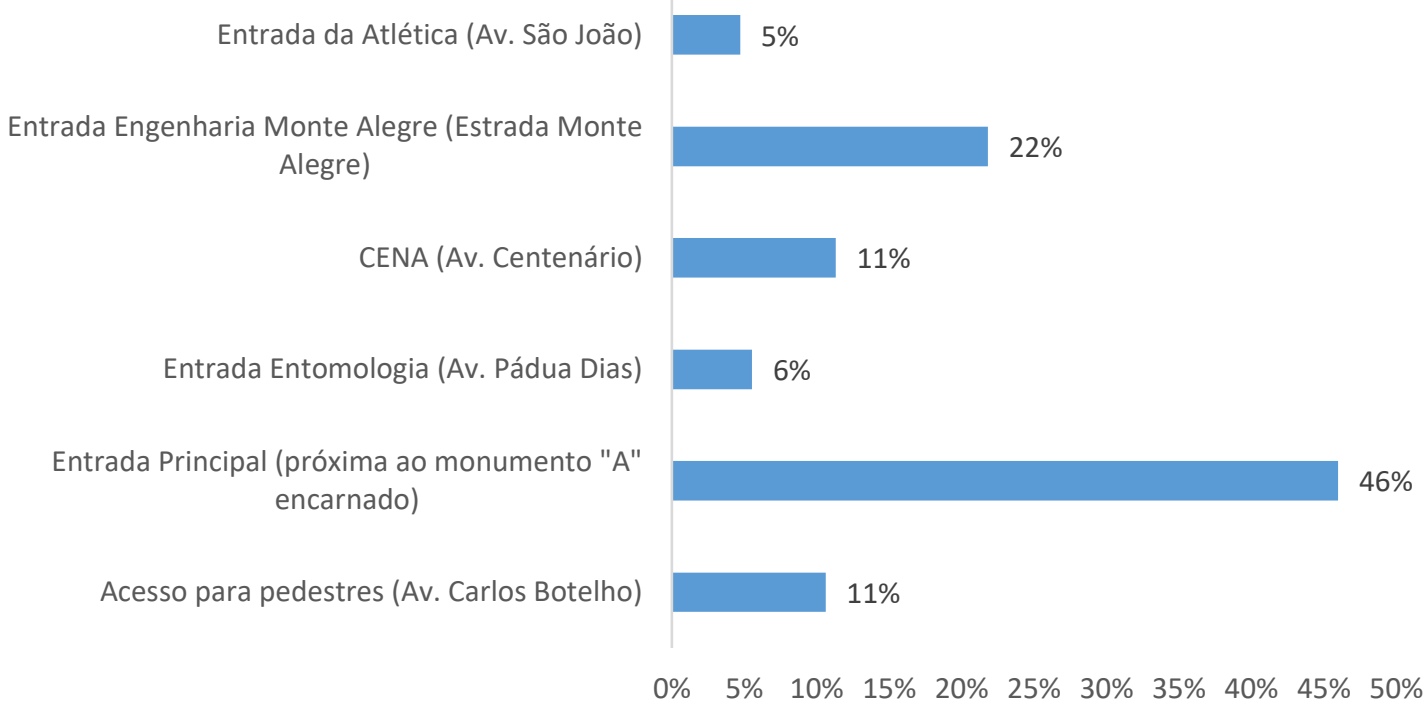

\begin{tabular}{lrr} 
Acesso para pedestres (Av. Carlos Botelho) & 90 & $11 \%$ \\
\hline Entrada Principal (próxima ao monumento "A" encarnado) & 390 & $46 \%$ \\
\hline Entrada Entomologia (Av. Pádua Dias) & 47 & $6 \%$ \\
\hline CENA (Av. Centenário) & 96 & $11 \%$ \\
\hline Entrada Engenharia Monte Alegre (Estrada Monte Alegre) & 185 & $22 \%$ \\
\hline Entrada da Atlética (Av. São João) & 40 & $5 \%$
\end{tabular}


Na sua rotina de deslocamentos regulares a partir da residência (em Piracicaba ou região), você tem acesso a quais modos de transporte?

Respostas: 921

\section{Bicicleta}

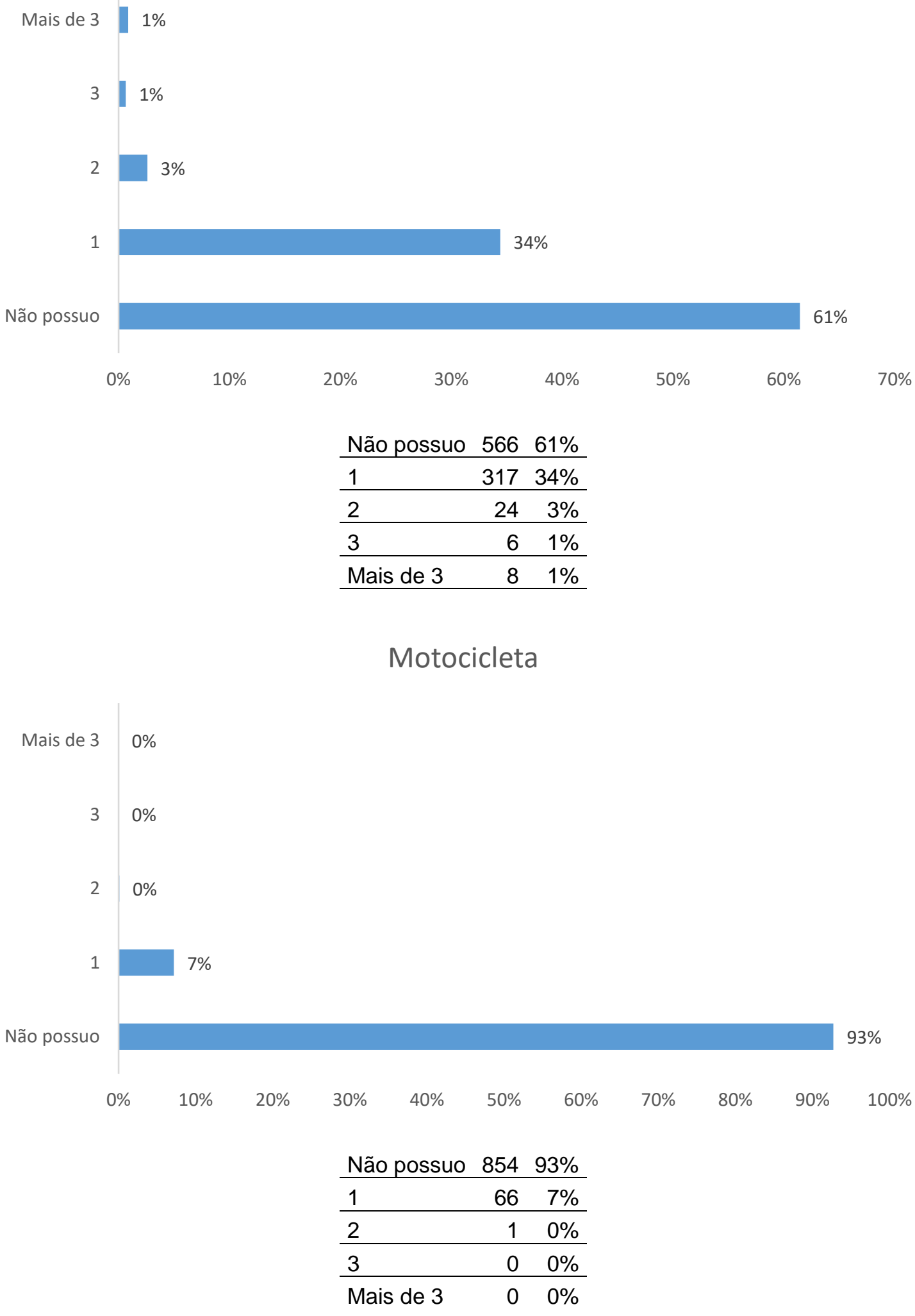


Automóvel

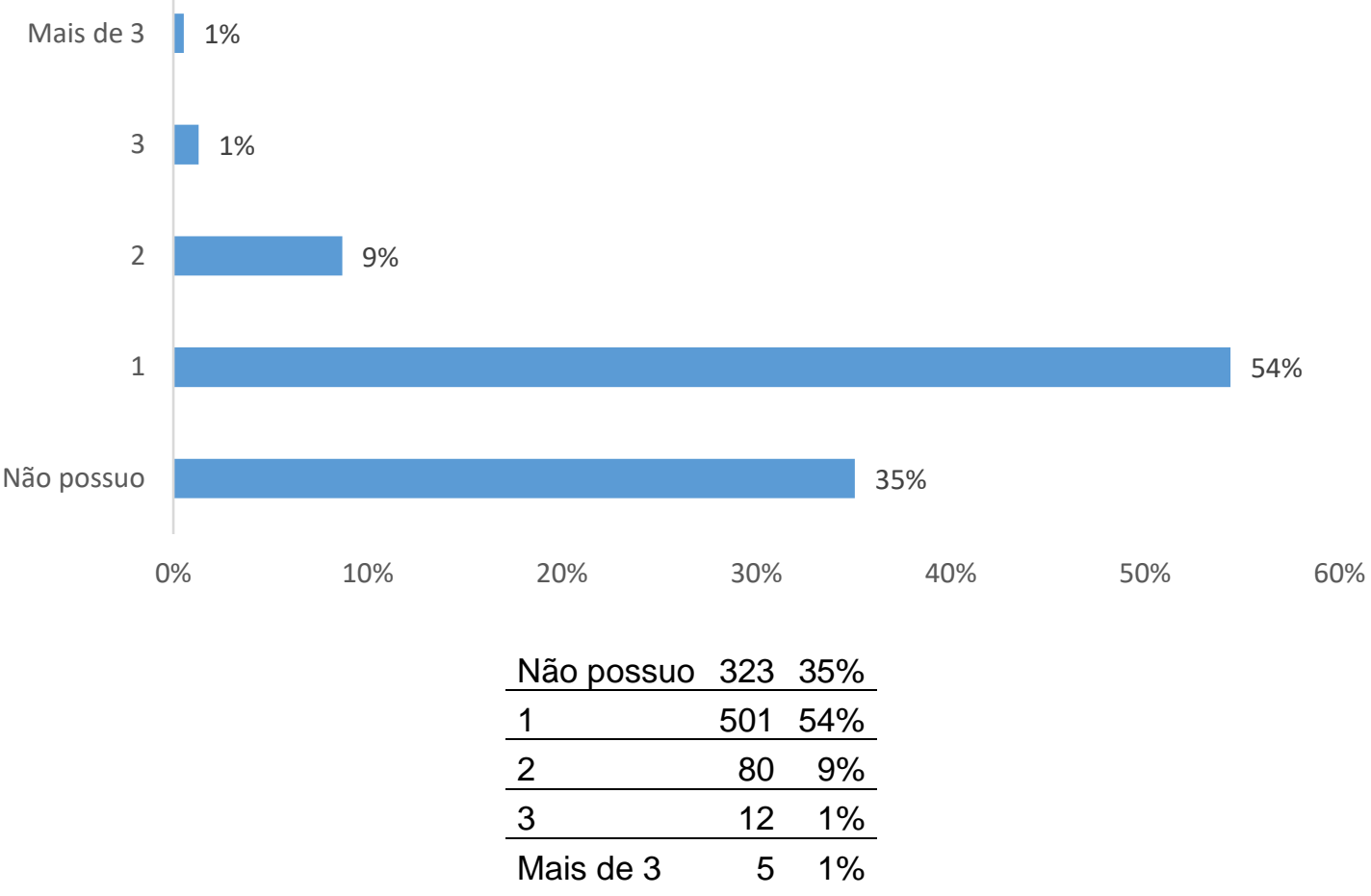


Com que frequência você vai à ESALQ/CENA?

Respostas: 919

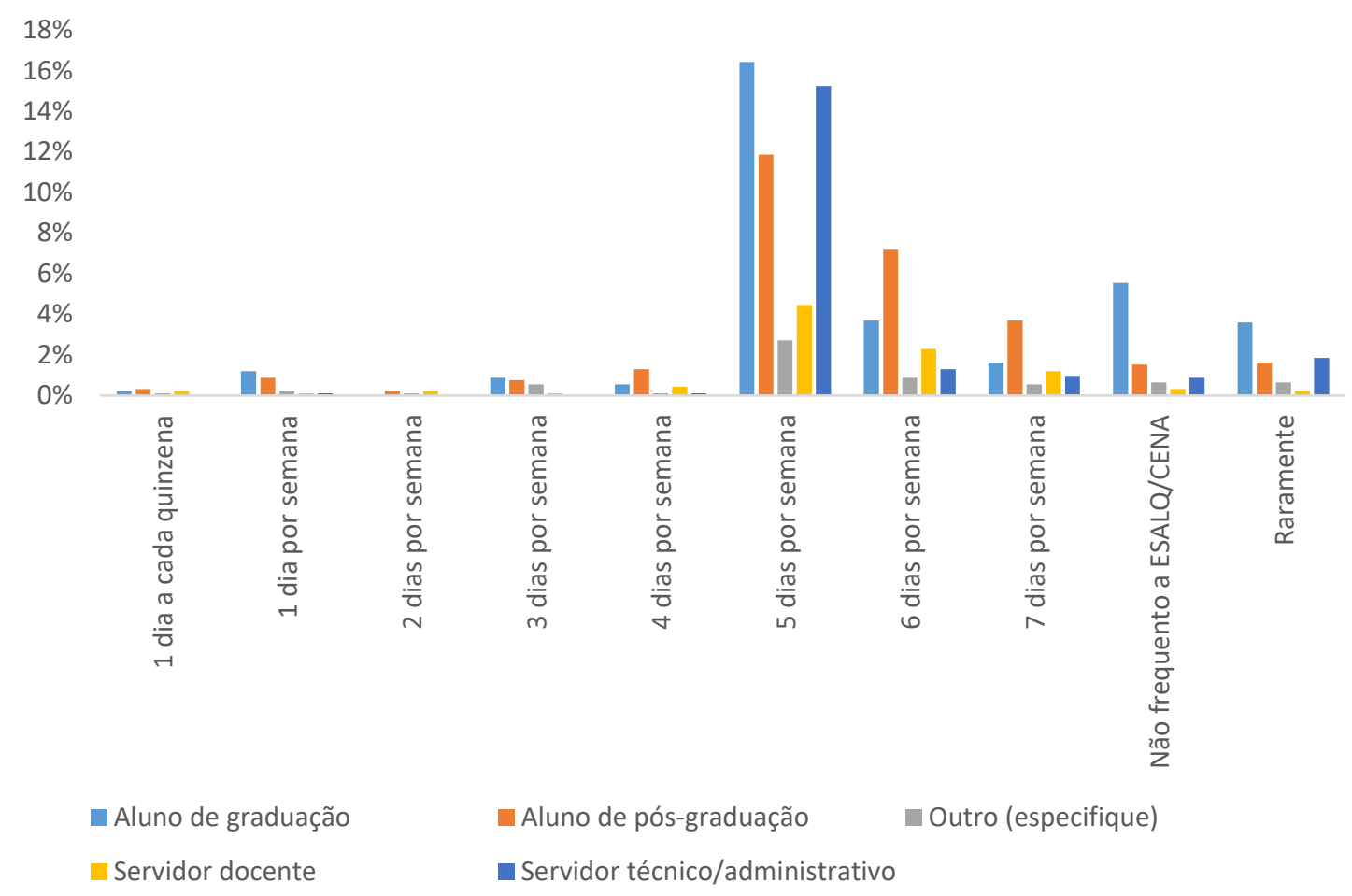

\begin{tabular}{lcccccccccc} 
& $\begin{array}{c}\text { Aluno de } \\
\text { graduação }\end{array}$ & $\begin{array}{c}\text { Aluno de pós- } \\
\text { graduação }\end{array}$ & \multicolumn{1}{c}{ Outro } & $\begin{array}{c}\text { Servidor } \\
\text { docente }\end{array}$ & $\begin{array}{c}\text { Servidor técnico/ } \\
\text { administrativo }\end{array}$ \\
\hline $\begin{array}{l}1 \text { dia a cada } \\
\text { quinzena }\end{array}$ & 2 & $0 \%$ & 3 & $0 \%$ & 1 & $0 \%$ & 2 & $0 \%$ & & $0 \%$ \\
\hline 1 dia por semana & 11 & $1 \%$ & 8 & $1 \%$ & 2 & $0 \%$ & 1 & $0 \%$ & 1 & $0 \%$ \\
\hline 2 dias por semana & & $0 \%$ & 2 & $0 \%$ & 1 & $0 \%$ & 2 & $0 \%$ & & $0 \%$ \\
\hline 3 dias por semana & 8 & $1 \%$ & 7 & $1 \%$ & 5 & $1 \%$ & 1 & $0 \%$ & & $0 \%$ \\
\hline 4 dias por semana & 5 & $1 \%$ & 12 & $1 \%$ & 1 & $0 \%$ & 4 & $0 \%$ & 1 & $0 \%$ \\
\hline 5 dias por semana & 151 & $16 \%$ & 109 & $12 \%$ & 25 & $3 \%$ & 41 & $4 \%$ & 140 & $15 \%$ \\
\hline 6 dias por semana & 34 & $4 \%$ & 66 & $7 \%$ & 8 & $1 \%$ & 21 & $2 \%$ & 12 & $1 \%$ \\
\hline 7 dias por semana & 15 & $2 \%$ & 34 & $4 \%$ & 5 & $1 \%$ & 11 & $1 \%$ & 9 & $1 \%$ \\
\hline $\begin{array}{l}\text { Não frequento a } \\
\text { ESALQ/CENA }\end{array}$ & 51 & $6 \%$ & 14 & $2 \%$ & 6 & $1 \%$ & 3 & $0 \%$ & 8 & $1 \%$ \\
\hline Raramente & 33 & $4 \%$ & 15 & $2 \%$ & 6 & $1 \%$ & 2 & $0 \%$ & 17 & $2 \%$
\end{tabular}


Há quanto tempo você frequenta a ESALQ/CENA?

Respostas: 832

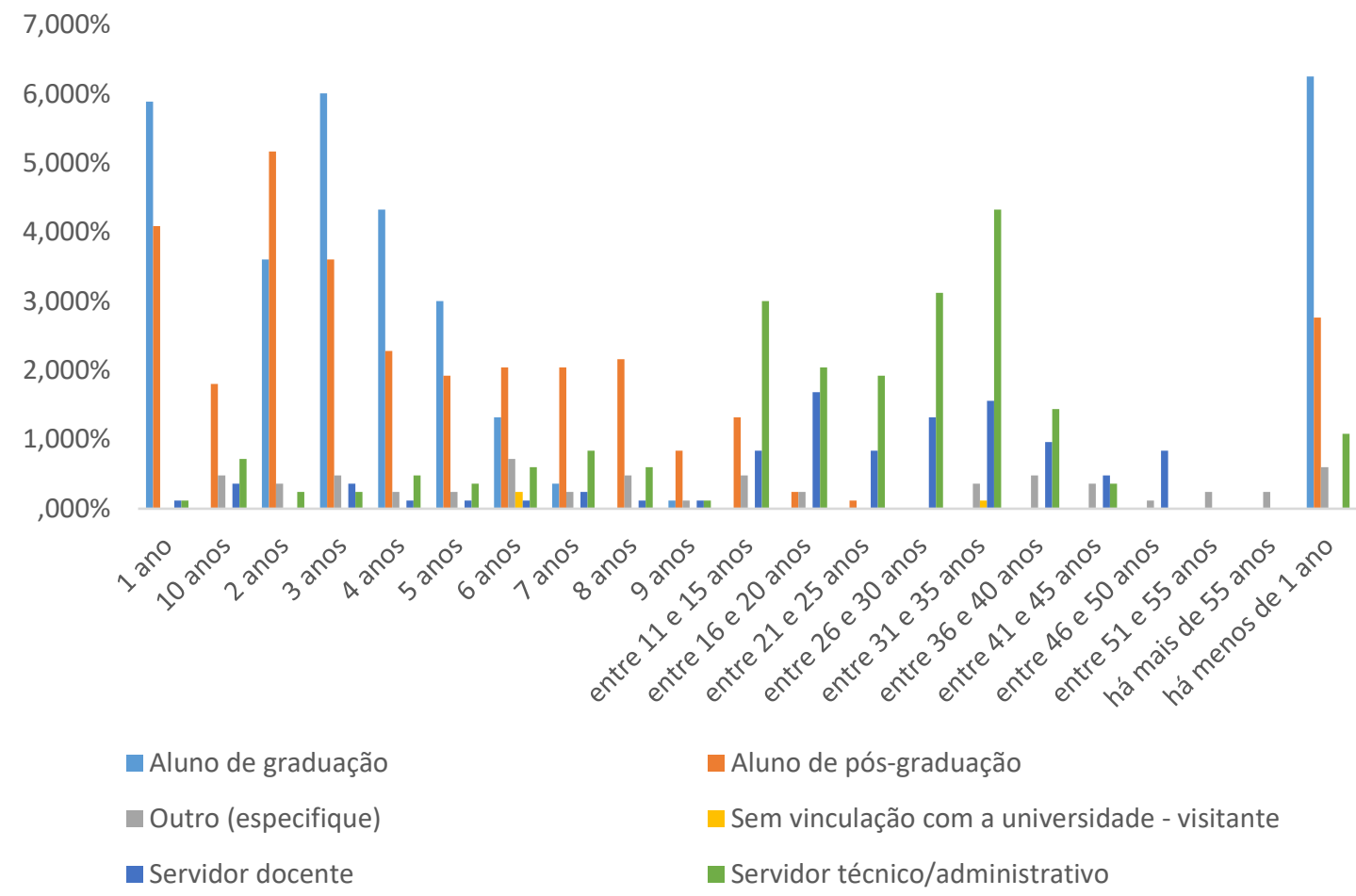




\begin{tabular}{|c|c|c|c|c|c|c|c|c|c|c|}
\hline \multirow[b]{2}{*}{$\begin{array}{l}\text { há menos de } \\
1 \text { ano }\end{array}$} & \multicolumn{2}{|c|}{$\begin{array}{l}\text { Aluno de } \\
\text { graduação }\end{array}$} & \multicolumn{2}{|c|}{$\begin{array}{l}\text { Aluno de pós- } \\
\text { graduação }\end{array}$} & \multicolumn{2}{|c|}{$\begin{array}{c}\text { Outro } \\
\text { (especifique) }\end{array}$} & \multicolumn{2}{|c|}{$\begin{array}{l}\text { Servidor } \\
\text { docente }\end{array}$} & \multicolumn{2}{|c|}{$\begin{array}{c}\text { Servidor } \\
\text { técnico/ } \\
\text { administrativo }\end{array}$} \\
\hline & 52 & $6 \%$ & 23 & $3 \%$ & 5 & $1 \%$ & & $0 \%$ & 9 & $1 \%$ \\
\hline 1 ano & 49 & $6 \%$ & 34 & $4 \%$ & & $0 \%$ & 1 & $0 \%$ & 1 & $0 \%$ \\
\hline 2 anos & 30 & $4 \%$ & 43 & $5 \%$ & 3 & $0 \%$ & & $0 \%$ & 2 & $0 \%$ \\
\hline 3 anos & 50 & $6 \%$ & 30 & $4 \%$ & 4 & $0 \%$ & 3 & $0 \%$ & 2 & $0 \%$ \\
\hline 4 anos & 36 & $4 \%$ & 19 & $2 \%$ & 2 & $0 \%$ & 1 & $0 \%$ & 4 & $0 \%$ \\
\hline 5 anos & 25 & $3 \%$ & 16 & $2 \%$ & 2 & $0 \%$ & 1 & $0 \%$ & 3 & $0 \%$ \\
\hline 6 anos & 11 & $1 \%$ & 17 & $2 \%$ & 6 & $1 \%$ & 1 & $0 \%$ & 5 & $1 \%$ \\
\hline 7 anos & 3 & $0 \%$ & 17 & $2 \%$ & 2 & $0 \%$ & 2 & $0 \%$ & 7 & $1 \%$ \\
\hline 8 anos & & $0 \%$ & 18 & $2 \%$ & 4 & $0 \%$ & 1 & $0 \%$ & 5 & $1 \%$ \\
\hline 9 anos & 1 & $0 \%$ & 7 & $1 \%$ & 1 & $0 \%$ & 1 & $0 \%$ & 1 & $0 \%$ \\
\hline 10 anos & & $0 \%$ & 15 & $2 \%$ & 4 & $0 \%$ & 3 & $0 \%$ & 6 & $1 \%$ \\
\hline entre 11 e 15 anos & & $0 \%$ & 11 & $1 \%$ & 4 & $0 \%$ & 7 & $1 \%$ & 25 & $3 \%$ \\
\hline entre 16 e 20 anos & & $0 \%$ & 2 & $0 \%$ & 2 & $0 \%$ & 14 & $2 \%$ & 17 & $2 \%$ \\
\hline entre 21 e 25 anos & & $0 \%$ & 1 & $0 \%$ & & $0 \%$ & 7 & $1 \%$ & 16 & $2 \%$ \\
\hline entre 26 e 30 anos & & $0 \%$ & & $0 \%$ & & $0 \%$ & 11 & $1 \%$ & 26 & $3 \%$ \\
\hline entre 31 e 35 anos & & $0 \%$ & & $0 \%$ & 3 & $0 \%$ & 13 & $2 \%$ & 36 & $4 \%$ \\
\hline entre 36 e 40 anos & & $0 \%$ & & $0 \%$ & 4 & $0 \%$ & 8 & $1 \%$ & 12 & $1 \%$ \\
\hline entre 41 e 45 anos & & $0 \%$ & & $0 \%$ & 3 & $0 \%$ & 4 & $0 \%$ & 3 & $0 \%$ \\
\hline entre 46 e 50 anos & & $0 \%$ & & $0 \%$ & 1 & $0 \%$ & 7 & $1 \%$ & & $0 \%$ \\
\hline entre 51 e 55 anos & & $0 \%$ & & $0 \%$ & 2 & $0 \%$ & & $0 \%$ & & $0 \%$ \\
\hline há mais de 55 ano & & $0 \%$ & & $0 \%$ & 2 & $0 \%$ & & $0 \%$ & & $0 \%$ \\
\hline
\end{tabular}


Qual acesso do campus da ESALQ/CENA você normalmente utiliza? Respostas: 832

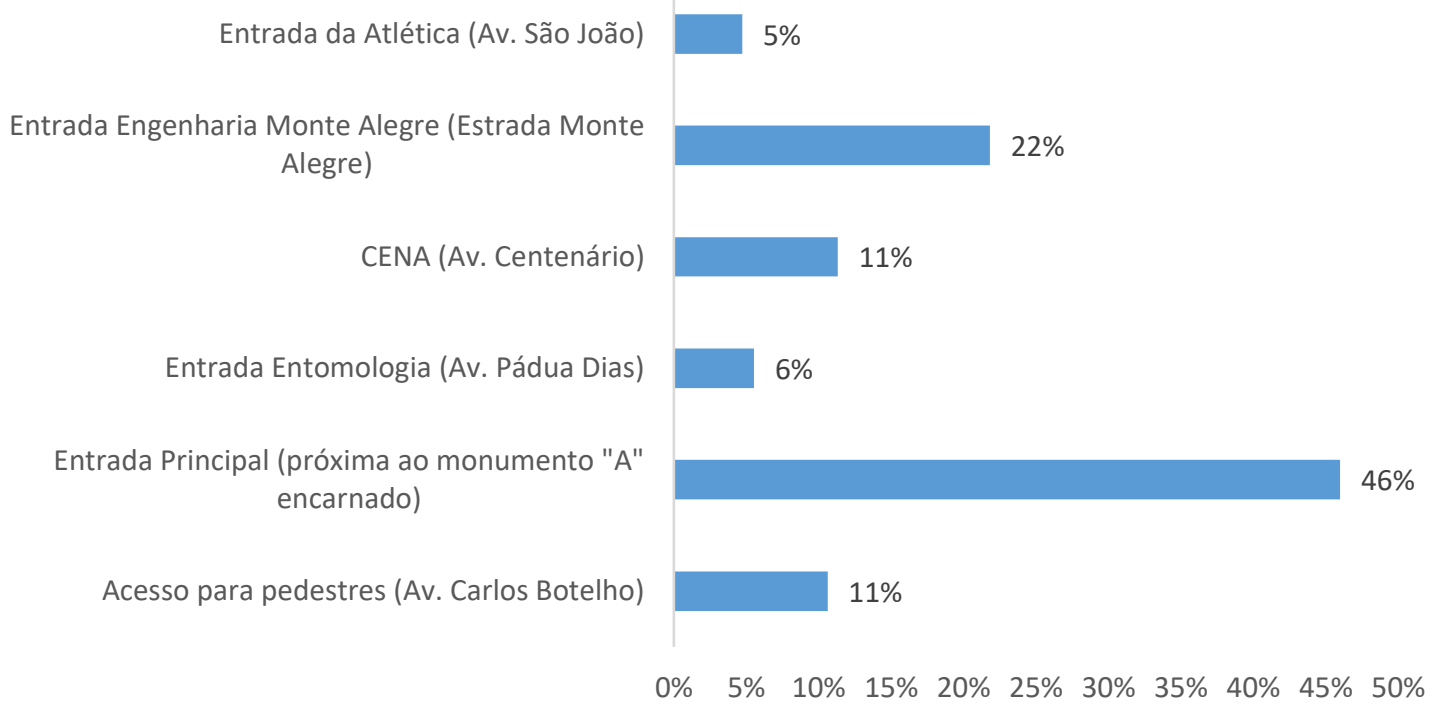

\begin{tabular}{lrr} 
Acesso para pedestres (Av. Carlos Botelho) & 90 & $11 \%$ \\
\hline Entrada Principal (próxima ao monumento "A" encarnado) & 390 & $46 \%$ \\
\hline Entrada Entomologia (Av. Pádua Dias) & 47 & $6 \%$ \\
\hline CENA (Av. Centenário) & 96 & $11 \%$ \\
\hline Entrada Engenharia Monte Alegre (Estrada Monte Alegre) & 185 & $22 \%$ \\
\hline Entrada da Atlética (Av. São João) & 40 & $5 \%$
\end{tabular}




\section{Por vinculação}

Entrada da Atlética (Av. São João) Entrada Engenharia Monte Alegre (Estrada Monte Alegre)

CENA (Av. Centenário)

Entrada Entomologia (Av. Pádua Dias)

Entrada Principal (próxima ao monumento "A" encarnado)

Acesso para pedestres (Av. Carlos Botelho)

$\begin{array}{lllllllllllllll}0 \% & 5 \% & 10 \% & 15 \% & 20 \% & 25 \% & 30 \% & 35 \% & 40 \% & 45 \% & 50 \%\end{array}$

n Aluno de graduação $\square$ Aluno de pós-graduação $\square$ Servidor docente $\square$ Servidor técnico/administrativo

\begin{tabular}{|c|c|c|c|c|c|c|c|c|}
\hline \multirow[b]{2}{*}{$\begin{array}{l}\text { Acesso para pedestres } \\
\text { (Av. Carlos Botelho) }\end{array}$} & \multicolumn{2}{|c|}{$\begin{array}{l}\text { Aluno de } \\
\text { graduação }\end{array}$} & \multicolumn{2}{|c|}{$\begin{array}{l}\text { Aluno de pós- } \\
\text { graduação }\end{array}$} & \multicolumn{2}{|c|}{$\begin{array}{l}\text { Servidor } \\
\text { docente }\end{array}$} & \multicolumn{2}{|c|}{$\begin{array}{c}\text { Servidor } \\
\text { técnico/administrativo }\end{array}$} \\
\hline & 50 & $6 \%$ & 34 & $4 \%$ & 1 & $\begin{array}{c}0 \\
\% \\
\end{array}$ & 3 & $0 \%$ \\
\hline $\begin{array}{l}\text { Entrada Principal (próxima } \\
\text { ao monumento "A" } \\
\text { encarnado) }\end{array}$ & 117 & $15 \%$ & 107 & $14 \%$ & 42 & $\begin{array}{l}5 \\
\%\end{array}$ & 90 & $11 \%$ \\
\hline $\begin{array}{l}\text { Entrada Entomologia (Av. } \\
\text { Pádua Dias) }\end{array}$ & 18 & $2 \%$ & 17 & $2 \%$ & 0 & $\begin{array}{l}0 \\
\% \\
\%\end{array}$ & 10 & $1 \%$ \\
\hline CENA (Av. Centenário) & 23 & $3 \%$ & 26 & $3 \%$ & 11 & $\begin{array}{c}1 \\
\% \\
\end{array}$ & 29 & $4 \%$ \\
\hline $\begin{array}{l}\text { Entrada Engenharia Monte } \\
\text { Alegre (Estrada Monte } \\
\text { Alegre) }\end{array}$ & 51 & $6 \%$ & 56 & $7 \%$ & 29 & $\begin{array}{c}4 \\
\%\end{array}$ & 40 & $5 \%$ \\
\hline $\begin{array}{l}\text { Entrada da Atlética (Av. } \\
\text { São João) }\end{array}$ & 14 & $2 \%$ & 13 & $2 \%$ & 2 & $\begin{array}{l}0 \\
\%\end{array}$ & 8 & $1 \%$ \\
\hline
\end{tabular}


De acordo com a resposta da questão anterior, qual é, portanto, o modo de transporte principal que você utiliza para se deslocar até a ESALQ/CENA?

Respostas: 822

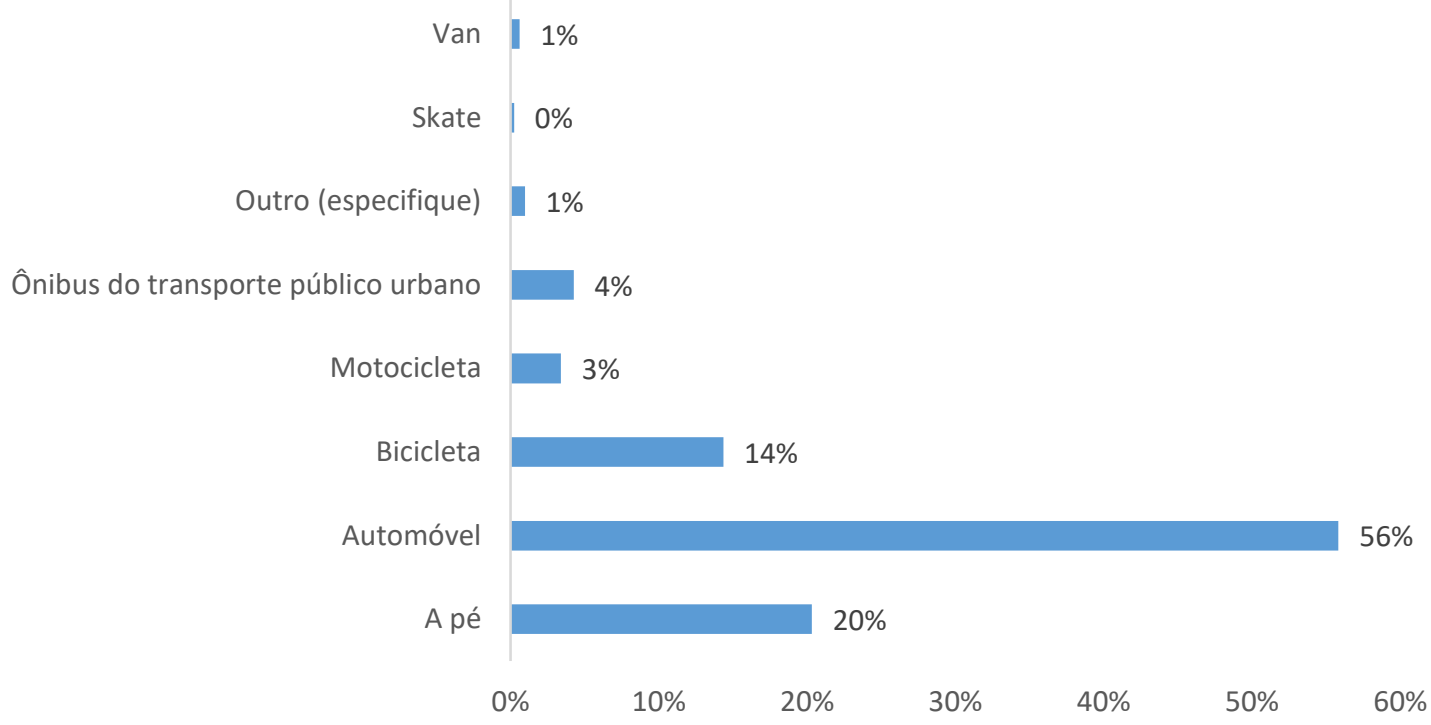

\begin{tabular}{lrr} 
A pé & 167 & $20 \%$ \\
\hline Automóvel & 459 & $56 \%$ \\
\hline Bicicleta & 118 & $14 \%$ \\
\hline Motocicleta & 28 & $3 \%$ \\
\hline Ônibus do transporte público urbano & 35 & $4 \%$ \\
\hline Outro (especifique) & 8 & $1 \%$ \\
\hline Skate & 2 & $0 \%$ \\
\hline Van & 5 & $1 \%$
\end{tabular}




\section{Por vinculação}

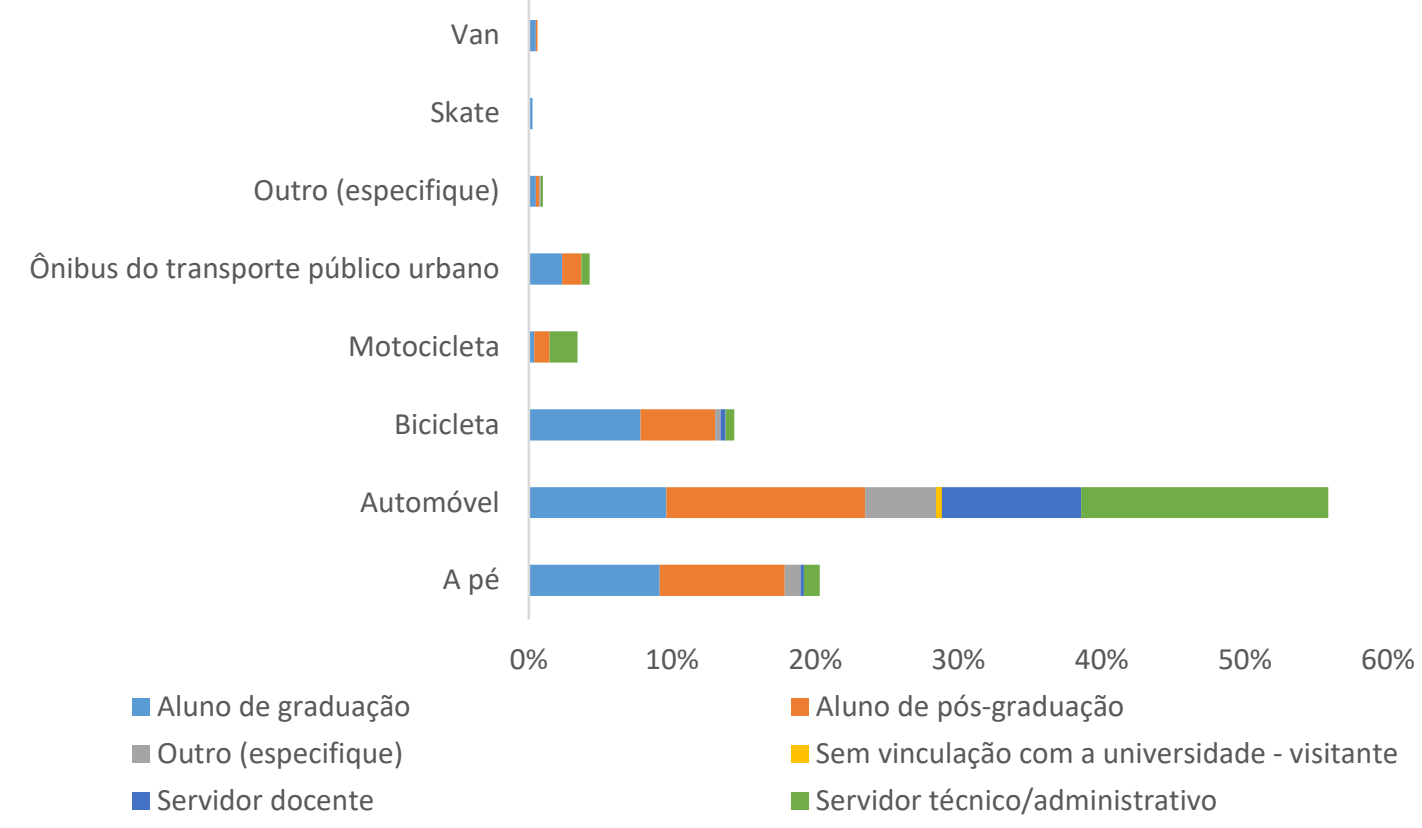

\begin{tabular}{lcccccccccc} 
& $\begin{array}{c}\text { Aluno de } \\
\text { graduação }\end{array}$ & \multicolumn{2}{c}{$\begin{array}{c}\text { Aluno de pós- } \\
\text { graduação }\end{array}$} & \multicolumn{2}{c}{ Outro } & $\begin{array}{c}\text { Servidor } \\
\text { docente }\end{array}$ & $\begin{array}{c}\text { Servidor técnico/ } \\
\text { administrativo }\end{array}$ \\
\hline A pé & 75 & $9 \%$ & 72 & $9 \%$ & 9 & $1 \%$ & 2 & $0 \%$ & 9 & $1 \%$ \\
\hline Automóvel & 79 & $10 \%$ & 114 & $14 \%$ & 41 & $5 \%$ & 8 & $10 \%$ & 142 & $17 \%$ \\
\hline Bicicleta & 64 & $8 \%$ & 43 & $5 \%$ & 3 & $0 \%$ & 3 & $0 \%$ & 5 & $1 \%$ \\
\hline Motocicleta & 3 & $0 \%$ & 9 & $1 \%$ & $0 \%$ & $0 \%$ & 16 & $2 \%$ \\
\hline $\begin{array}{l}\text { Ônibus do transporte } \\
\text { público urbano }\end{array}$ & 19 & $2 \%$ & 11 & $1 \%$ & $0 \%$ & $0 \%$ & 5 & $1 \%$ \\
\hline Outro (especifique) & 4 & $0 \%$ & 2 & $0 \%$ & 1 & $0 \%$ & $0 \%$ & 1 & $0 \%$ \\
\hline Skate & 2 & $0 \%$ & & $0 \%$ & $0 \%$ & $0 \%$ & & $0 \%$ \\
\hline Van & 4 & $0 \%$ & 1 & $0 \%$ & $0 \%$ & $0 \%$ & & $0 \%$
\end{tabular}


Com que frequência você vai à Fazenda Areão?

Respostas: 933

Raramente

Não frequento a Fazenda Areão

6 dias por semana

5 dias por semana

4 dias por semana

3 dias por semana

2 dias por semana

1 dia por semana

1 dia a cada quinzena

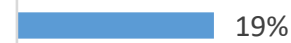

$9 \%$

$78 \%$

$0 \%$

$0 \%$

$0 \%$

$0 \%$

$1 \%$

$1 \%$

$1 \%$

$0 \%$

$20 \%$

$30 \%$

$40 \% \quad 50 \%$

$60 \%$

$70 \%$

$80 \%$

$90 \%$

\begin{tabular}{lcc}
1 dia a cada quinzena & 12 & $1 \%$ \\
\hline 1 dia por semana & 5 & $1 \%$ \\
\hline 2 dias por semana & 6 & $1 \%$ \\
\hline 3 dias por semana & 3 & $0 \%$ \\
\hline 4 dias por semana & 1 & $0 \%$ \\
\hline 5 dias por semana & 3 & $0 \%$ \\
\hline 6 dias por semana & 1 & $0 \%$ \\
\hline Não frequento a Fazenda & 729 & $78 \%$ \\
Areão & 173 & $19 \%$
\end{tabular}


Há quanto tempo você frequenta a Fazenda Areão?

Respostas: 237

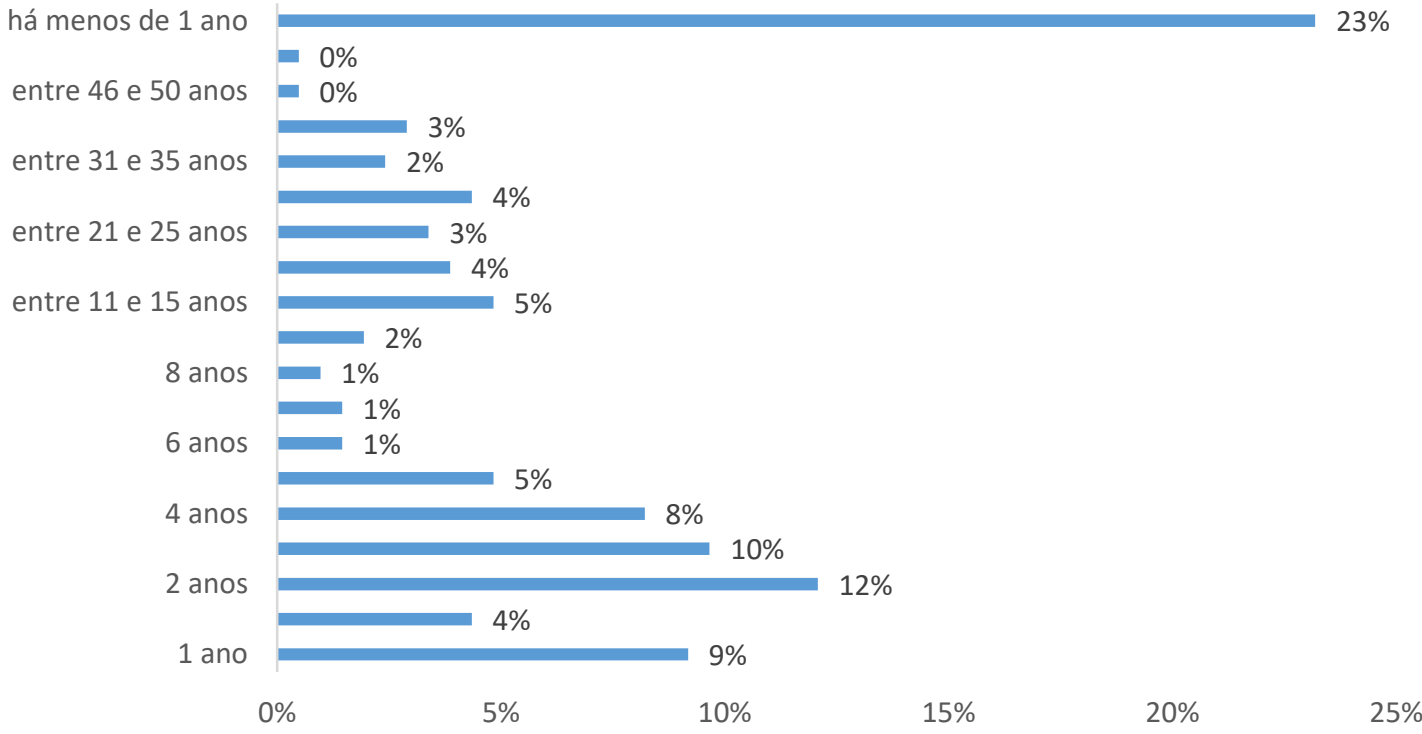

\begin{tabular}{lrr}
1 ano & 19 & $9 \%$ \\
\hline 10 anos & 9 & $4 \%$ \\
\hline 2 anos & 25 & $12 \%$ \\
\hline 4 anos & 20 & $10 \%$ \\
\hline 5 anos & 17 & $8 \%$ \\
\hline 6 anos & 10 & $5 \%$ \\
\hline 7 anos & 3 & $1 \%$ \\
\hline 8 anos & 3 & $1 \%$ \\
\hline 9 anos & 2 & $1 \%$ \\
\hline entre 11 e 15 anos & 4 & $2 \%$ \\
\hline entre 16 e 20 anos & 10 & $5 \%$ \\
\hline entre 21 e 25 anos & 8 & $4 \%$ \\
\hline entre 26 e 30 anos & 7 & $3 \%$ \\
\hline entre 31 e 35 anos & 9 & $4 \%$ \\
\hline entre 36 e 40 anos & 5 & $2 \%$ \\
\hline entre 46 e 50 anos & 1 & $3 \%$ \\
\hline há mais de 55 anos & 1 & $0 \%$ \\
\hline há menos de 1 ano & 48 & $23 \%$
\end{tabular}


Qual é o modo de transporte principal que você utiliza para se deslocar até a Fazenda Areão? Respostas: 200

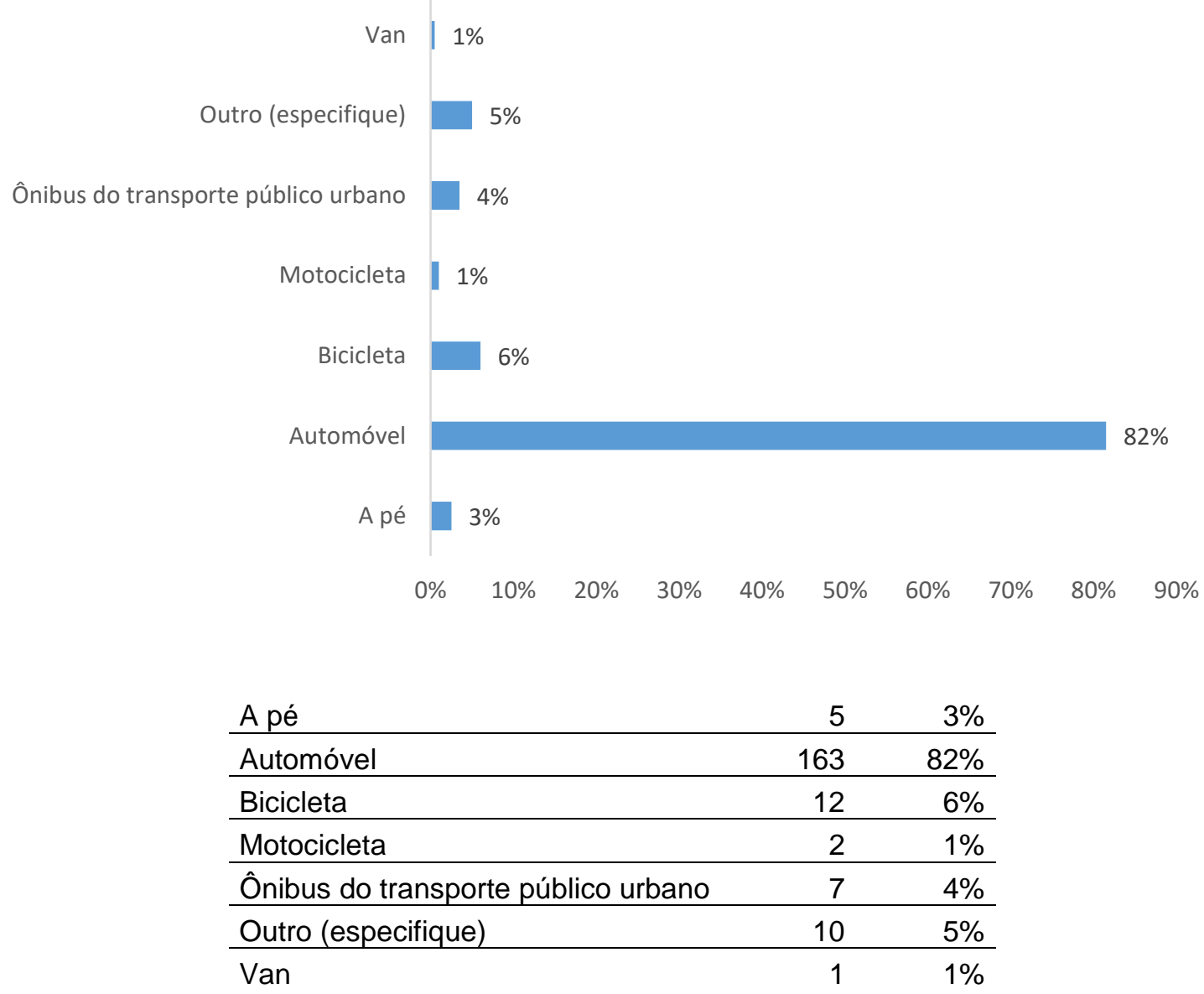


Você tem conhecimento ou participou de alguma AÇÃO DE CONSCIENTIZAÇÃO ao uso de modos mais sustentáveis promovida neste campus?

Respostas: 929

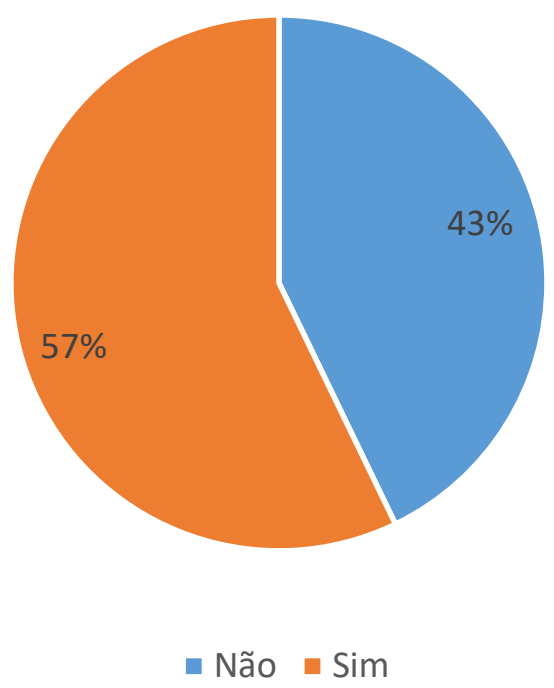

\begin{tabular}{lll} 
Não & 398 & $43 \%$ \\
\hline Sim & 531 & $57 \%$
\end{tabular}


De quais ações você tem conhecimento ou participou? (se for necessário, marque mais de uma alternativa).

Respostas: 530

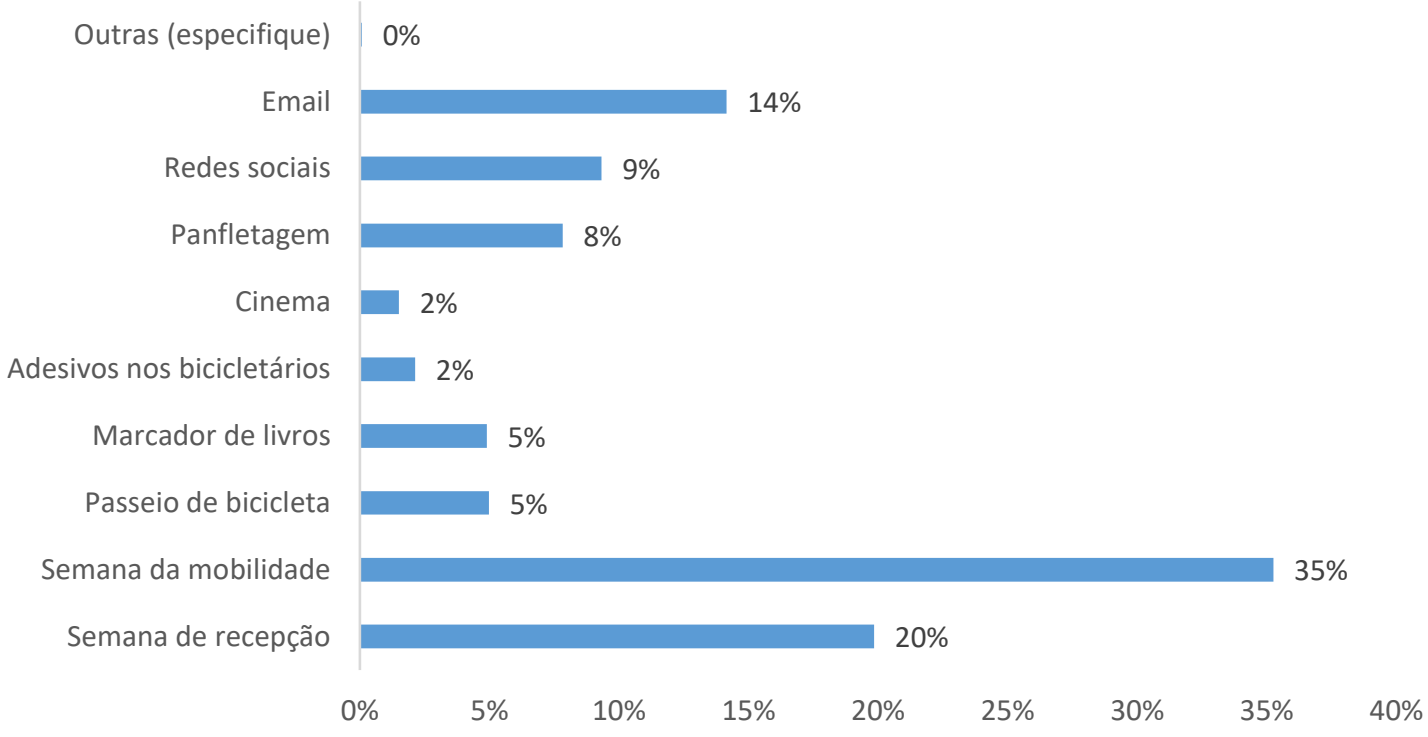

\begin{tabular}{lcc} 
Semana de recepção & 251 & $20 \%$ \\
\hline Semana da mobilidade & 446 & $35 \%$ \\
\hline Passeio de bicicleta & 63 & $5 \%$ \\
\hline Marcador de livros & 62 & $5 \%$ \\
\hline $\begin{array}{l}\text { Adesivos nos } \\
\text { bicicletários }\end{array}$ & 27 & $2 \%$ \\
\hline Cinema & 19 & $2 \%$ \\
\hline Panfletagem & 99 & $8 \%$ \\
\hline Redes sociais & 118 & $9 \%$ \\
\hline Email & 179 & $14 \%$ \\
\hline Outras (especifique) & 1 & $0 \%$
\end{tabular}


Como você classifica a influência destas ações no seu cotidiano? Respostas: 530

Não influenciaram em absolutamente nada

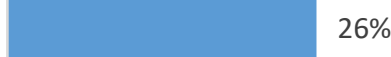

Motivaram-me a, esporadicamente, fazer caminhadas, utilizar bicicleta e/ou oferecer carona para o campus

Motivaram-me a mudar meus hábitos de deslocamento. Atualmente utilizo com frequência modos que julgo mais sustentáveis.

Fizeram-me refletir sobre o meu modo de deslocamento

Motivaram-me a mudar meus hábitos de deslocamento. Atualmente utilizo com frequência modos que julgo mais sustentáveis.

Motivaram-me a, esporadicamente, fazer caminhadas, utilizar bicicleta e/ou oferecer carona para o campus 
Você tem conhecimento ou participou de alguma AÇÃO DE EDUCAÇÃO NO TRÂNSITO promovida neste campus?

Respostas: 927

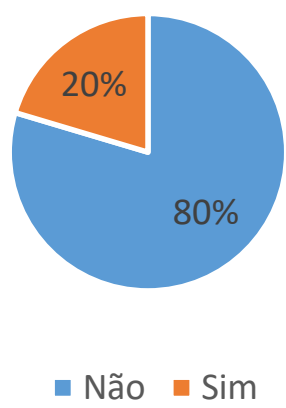

\begin{tabular}{lll} 
Não & 738 & $80 \%$ \\
\hline Sim & 189 & $20 \%$
\end{tabular}


De quais ações você tem conhecimento ou participou? (se for necessário, marque mais de uma alternativa)

Respostas: 186

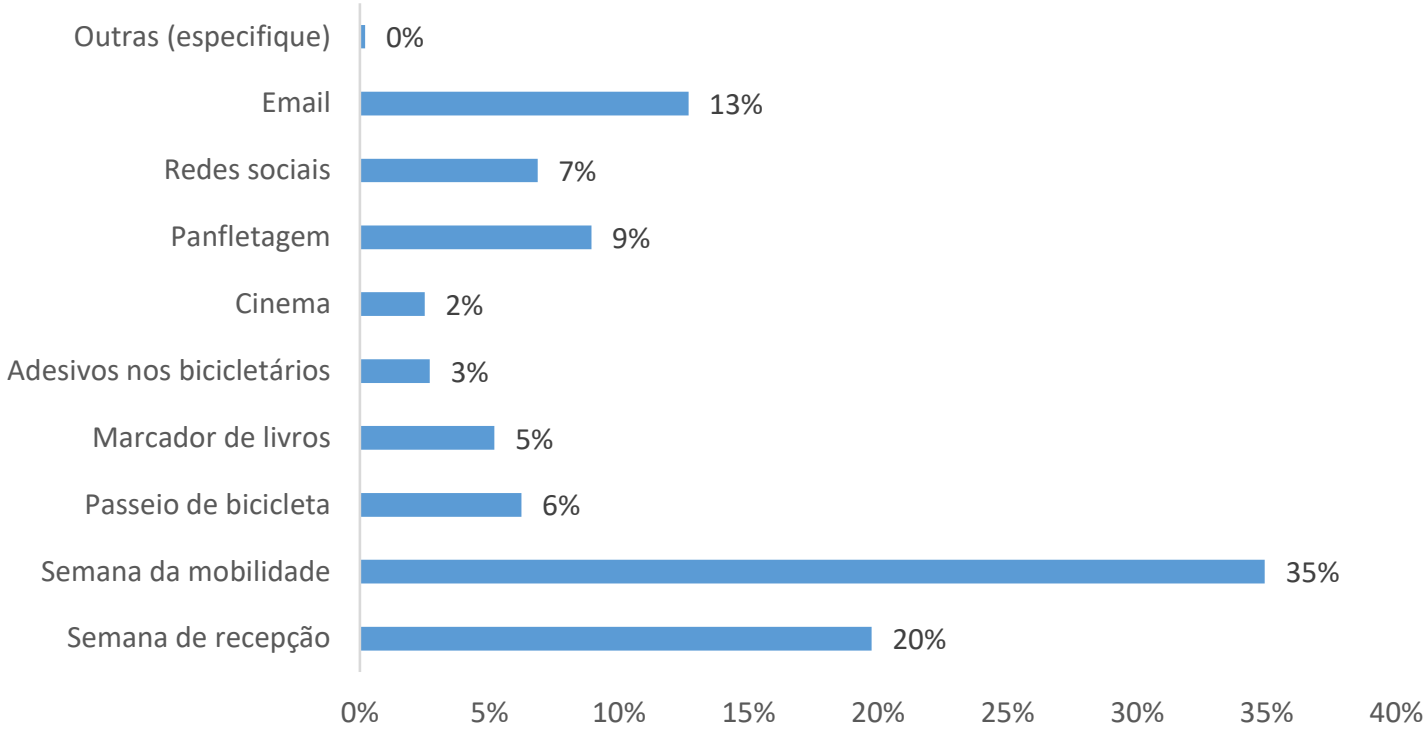

\begin{tabular}{lrr} 
Semana de recepção & 95 & $20 \%$ \\
\hline Semana da mobilidade & 168 & $35 \%$ \\
\hline Passeio de bicicleta & 30 & $6 \%$ \\
\hline Marcador de livros & 25 & $5 \%$ \\
\hline Adesivos nos bicicletários & 13 & $3 \%$ \\
\hline Cinema & 12 & $2 \%$ \\
\hline Panfletagem & 43 & $9 \%$ \\
\hline Redes sociais & 33 & $7 \%$ \\
\hline Email & 61 & $13 \%$ \\
\hline Outras (especifique) & 1 & $0 \%$
\end{tabular}


Como você classifica a influência destas ações no seu comportamento? Respostas: 186

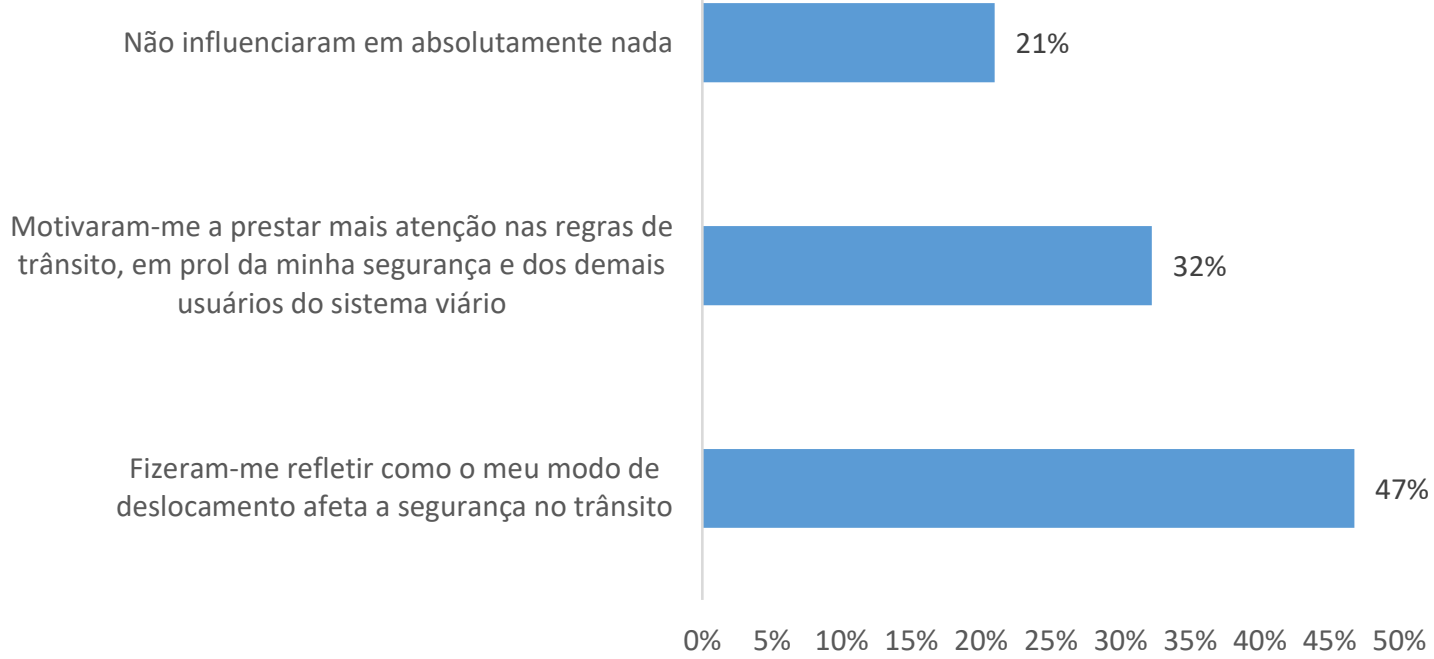

Fizeram-me refletir como o meu modo de deslocamento afeta a segurança no trânsito $87 \quad 47 \%$

Motivaram-me a prestar mais atenção nas regras de trânsito, em prol da minha segurança e dos demais usuários do sistema viário

Não influenciaram em absolutamente nada

$60 \quad 32 \%$

$39 \quad 21 \%$


Como você avalia a influência destas ações na circulação interna do campus, nos seguintes aspectos:

Respostas: 186

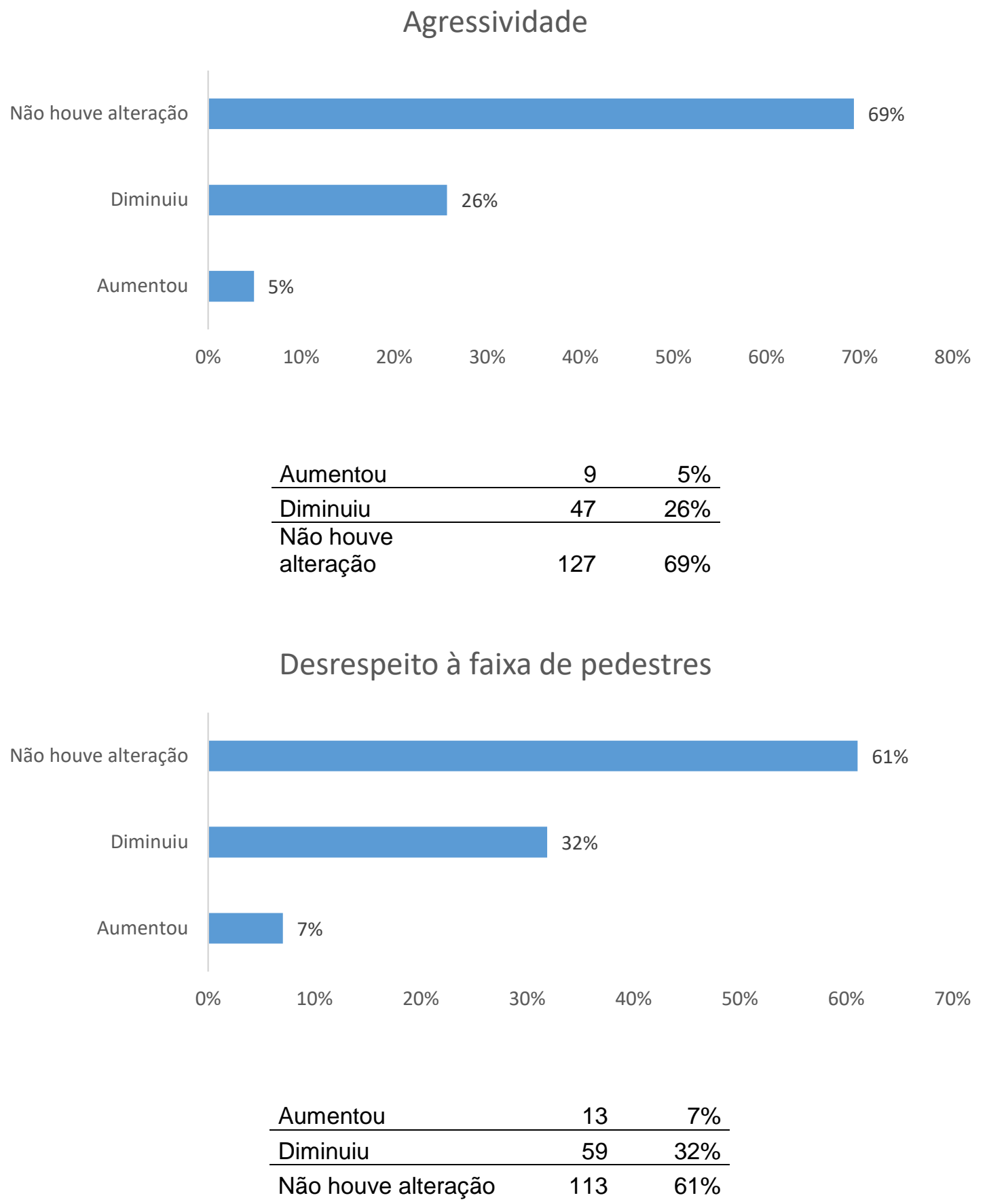




\section{Desrespeito aos ciclistas e às ciclofaixas}

Não houve alteração

Diminuiu

Aumentou

$0 \%$

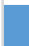

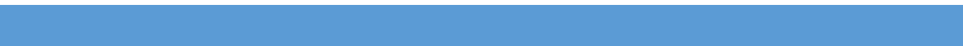

$45 \%$

$46 \%$

\begin{tabular}{lrr} 
Aumentou & 15 & $8 \%$ \\
\hline Diminuiu & 85 & $46 \%$ \\
\hline Não houve alteração & 83 & $45 \%$
\end{tabular}

\section{Excesso de velocidade}

Não houve alteração<smiles>C1CCC1</smiles>

Diminuiu

$0 \%$

\begin{tabular}{lrr} 
Aumentou & 20 & $11 \%$ \\
\hline Diminuiu & 41 & $22 \%$ \\
\hline Não houve alteração & 123 & $67 \%$
\end{tabular}

\section{Desrespeito à sinalização}

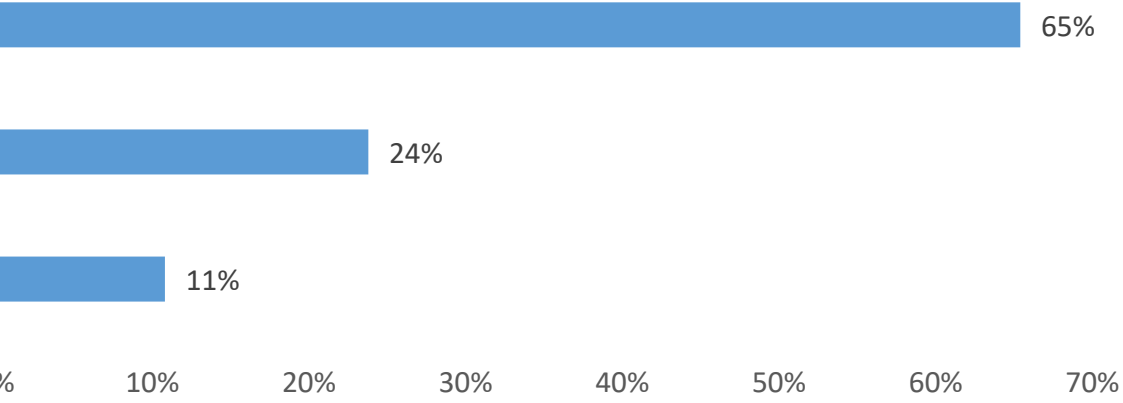




\begin{tabular}{lrr} 
Aumentou & 20 & $11 \%$ \\
\hline Diminuiu & 44 & $24 \%$ \\
\hline Não houve alteração & 121 & $65 \%$
\end{tabular}

Desrespeito às regras de trânsito

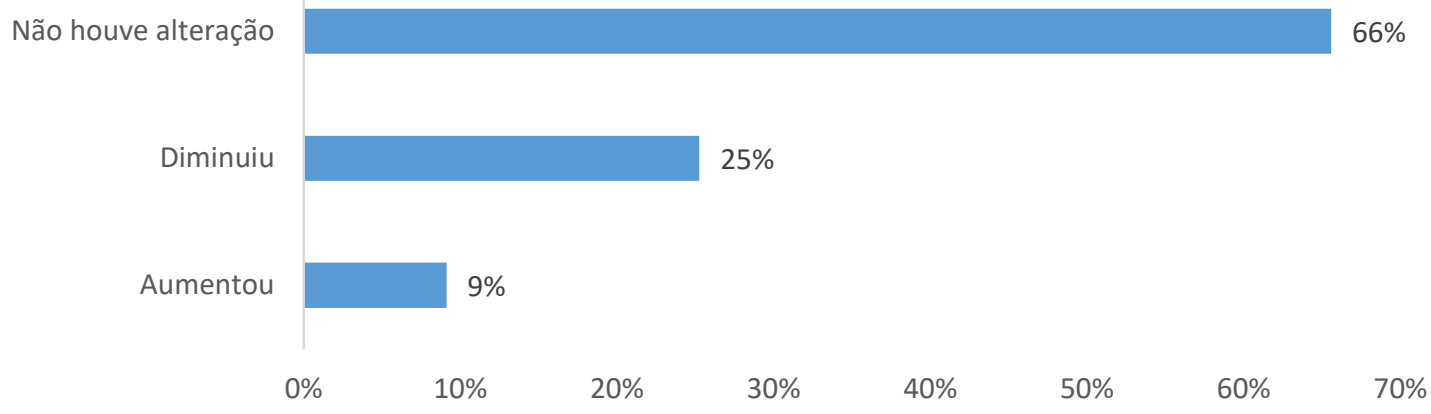

\begin{tabular}{lrr} 
Aumentou & 17 & $9 \%$ \\
\hline Diminuiu & 47 & $25 \%$ \\
\hline Não houve alteração & 122 & $66 \%$
\end{tabular}


Em sua opinião, qual a importância da mobilidade sustentável em um campus universitário? Respostas: 922

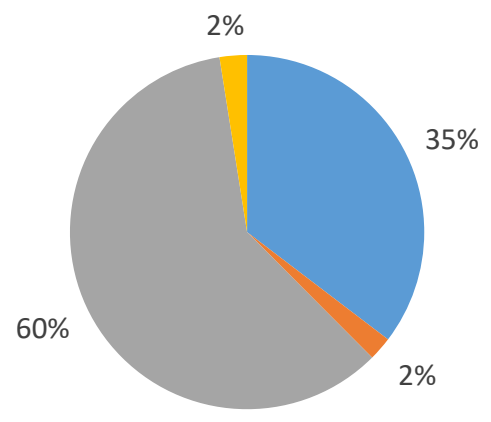

Importante

- Indiferente

Muito importante

- Pouco importante

\begin{tabular}{lrr} 
Importante & 326 & $35 \%$ \\
\hline Indiferente & 20 & $2 \%$ \\
\hline Muito importante & 553 & $60 \%$ \\
\hline Pouco importante & 23 & $2 \%$
\end{tabular}


De maneira geral, como você avalia a mobilidade interna do campus da USP Piracicaba (deslocamentos internos)?

Respostas: 922

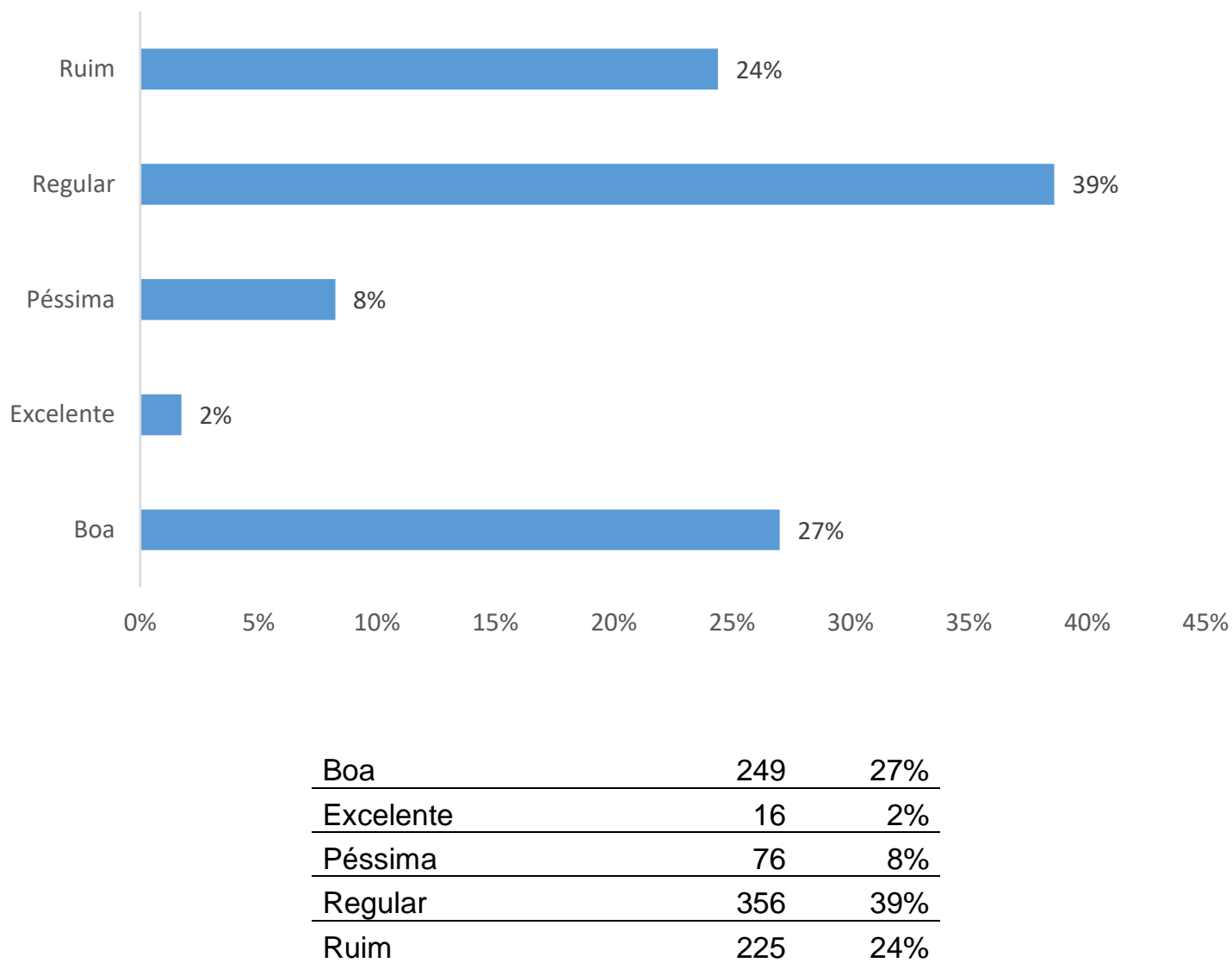


De maneira geral, como você avalia a mobilidade para se acessar o campus da USP Piracicaba (cidade $\mathrm{x}$ campus)?

Respostas: 922

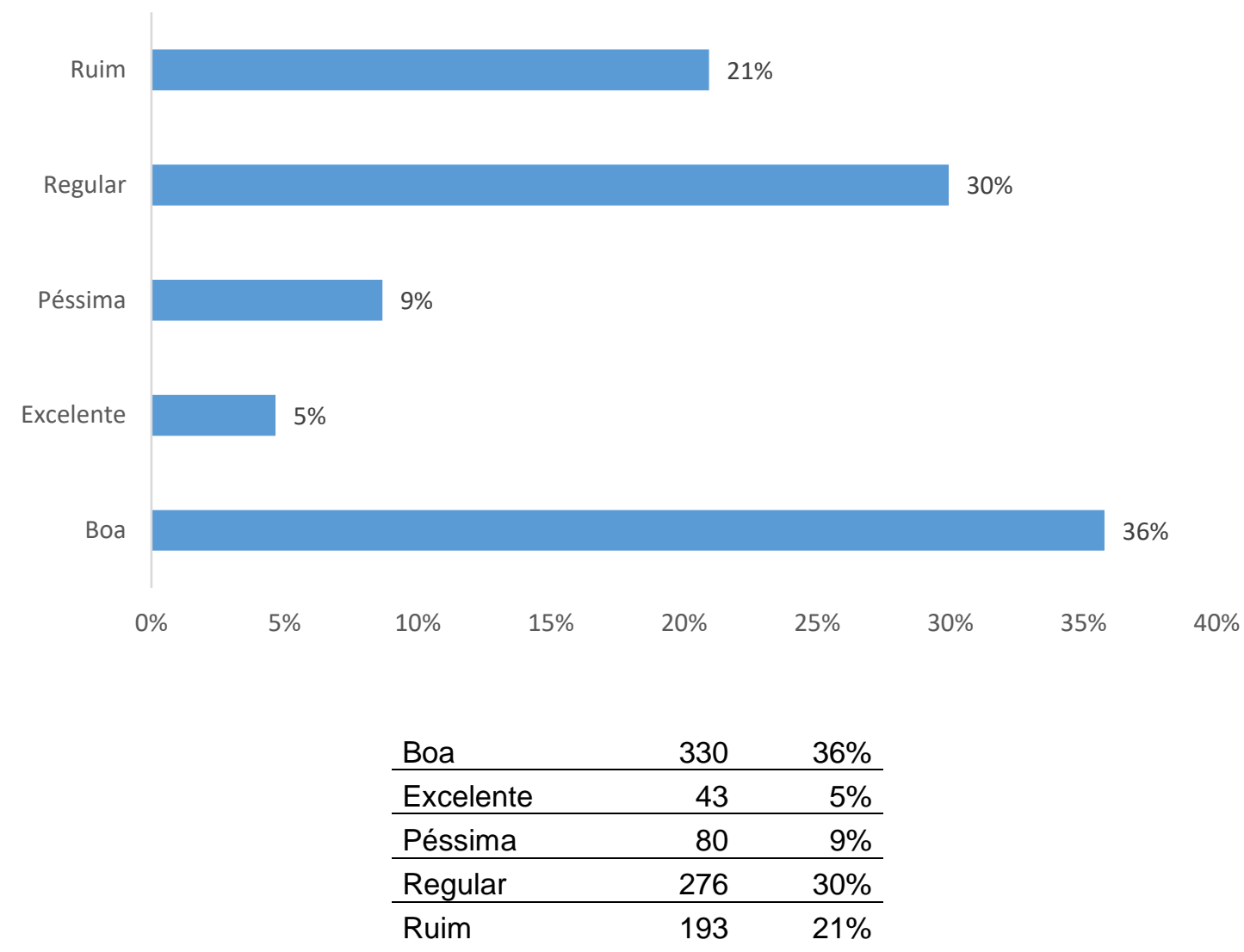


Deixe suas sugestões e comentários abaixo

Ruas principais (como a do restaurante universitário e a do xerox/centro de vivência) deveriam possuir ciclofaixas que comportem duas mãos, assim como outras ruas chave. A mobilidade correta por bicicleta é muito dificultada no Campus por causa das mãos únicas, da falta de ciclofaixa e também de espaço, visto que há muito carros estacionados o dia todo.

A falta de respeito em relação aos limites de velocidade dos veículos que circulam dentro do Campus e às leis de trânsito que também devem ser seguidas por ciclistas.

a utilização de circulares para o deslocamento interno do campus pode ajudar muito mas em compensação pode gerar mais acidentes, envolvendo principalmente ciclistas. Talvez vans podem ser melhores que ônibus (pela maior visão das laterais pelo motorista e por ser um veiculo menor. Caso seja instalado um sistema desse é preferível que seja grátis ou de baixíssimo custo. Outro ponto que pode ser melhorado é o aumento do numero de bikes do projeto pedal e mais locais de empréstimo pelo campus.

Mobilidade interna

++++ CICLOFAIXAS, MELHORAS NAS CALÇADAS

Aluguel de bicicletas para alunos, visitantes, funcionários etc.

Tenho conhecimento que no campus de Ribeirão Preto, existe um ônibus circular dentro do campus, para locomoção dos estudantes. Talvez seria válido pensar em alguma proposta deste tipo, para a movimentação interna, na Esalq, principalmente no período noturno.

sistemas de caronas alunos, docentes...- diminuir numero de carros mobilidade de bicicletasquesito segurança e maior disponibilidade de bicicletas compartilhadas

A possibilidade da Universidade oferecer bicicletas gratuitamente em diversos pontos espalhados pelo campus, nos quais podemos emprestar uma bicicleta e devolvê-la em outro ponto, favorecendo, assim, a mobilidade interna e estimulando o uso da bicicleta.

Calçadas dentro do campus

Onibus q circulasse dentro da faculdade

Poderiam perguntar sobre acidentes ocorridos por falta de ciclo-faixa. Eu, por exemplo, já fui atropelada por um carro em quanto andava de bike.

Acredito que a universidade devia ajudar mais para haver maiores mobilizações para melhorar o acesso dos alunos que não usam carros.

mais ciclovias já

Não acho certo ter dias com vagas reducidas para estimular o uso de transporte publico. $O$ pessoal com experimento no CT precisa de carro para ir ao CT e voltar para estacionar proximo ao laboratorio durante os periodos de coletas.

Mais horários de ônibus que vão e saem da ESALQ Maior número de estacionamento de veículo particular dentro do campus Possibilidade de transporte para o deslocamento de uma aula à outra, cujo intervalo é curto e o campus é grande

O acesso de ônibus deve ser melhorado, bem como aumentar as linhas que passam pela universidade 
Do ponto de vista de mobilidade é preciso saber da comunidade universitária se existem condições adequadas de uso de transportes mais sustentáveis, por exemplo: existem ciclovias ou ciclofaixas? Existem lugares adequados para parar a bicicleta? O acesso a universidade em trajeto a pé é seguro?

Transporte interno: "aluguel" de bicicletas que circulem apenas internamente ao campus, por exemplo.

\section{Mais Ciclovias}

Apenas fazer programas para incentivar o transporte sustentável, não é suficiente. Ë necessario criar condicoes para tal. Não há campanha que mude o pensamento das pessoas, enquanto alunos são atropelados a caminho da Universidade e não foi apenas uma fatalidade. E realmente arriscado andar de bicicleta nas vias de acesso da ESALQ e portando enquanto isso não mudar, irresposabilidade que seja incentivado. //Dentro do campos, o ideal seria não deixar as pessoas entrarem de carro. Como meta a longo prazo, a construção de bolsoes de estacionamento seria, ao meu ver, o ideal. Em que apenas carros oficiais e agricolas pudessem trafegar. Enquanto os alunos teriam bicicleta (como as amarelas) para pegar emprestado.

Embora não faça parte desse grupo, houveram melhorias de acesso para pessoas com deficiência física nos últimos anos. Não sei o quanto dessa demanda foi suprida, mas uma amiga se beneficiou bastante e comemora com orgulho cada uma dessas conquistas.

Devia ter disponível no campus o aluguel de bicicletas, estilo "Itau", porém sem restrição de uso, podendo ser utilizadas por todos os graduandos da universidade, não ficando restrita a quem mora na moradia estudantil, por exemplo.

Voltar com a possibilidade de utilizar bicicletas "emprestadas" dentro do campus

Eu acredito que a mobilidade dos pedestres é altamente negligenciada no Campus. Creio que seria de importância fundamental estudar modos de instalação de calçadas ou proteção aos pedestres elou promover meios de transporte regulares para o deslocamento de pessoas dentro do espaço.

A cidade de Piracicaba deveria ter ciclovias com acesso ao campus ESALQ/CENA, principalmente nas vias mais movimentadas como a Av. Independência. Isso é uma necessidade urgente, já que essa via já foi lugar de acidentes, inclusive seguida de morte! (Estudante de biologia, cujo apelido era Gueta, morreu atropelado por ônibus na Av. Independência enquanto ia para a ESALQ com sua bicicleta)

Boa tarde. Vim há poucos meses transferida do campus da capital. Como trabalho no Cena, tenho que me deslocar diariamente até a Esalq para levar minha filha na creche, ou ir no centro médico e tenho muitas dificuldades para me locomover, pois não dirijo e dependo de transporte público. Deixo minha filha na creche e desço até o Cena andando, diariamente. Em dias chuvosos, esse percurso é inviável, aí devo retornar ao ponto de ônibus da Esalq e aguardar a passagem de um deles para apenas descer a Av. centenário, o que gera muito custo e tempo perdido, pois os ônibus na cidade demoram muito para passar. No campus da capital existem vários ônibus pertencentes à Universidade (os Cinzas) que estão parados, pois a comunidade universitária passou a utilizar transporte publico gratuito (SPTrans), conveniado com a USP.

Mais ciclovias dentro do campus e avisar que bicicletas tem que cumprir regras tbm Acho que dentro da ESALQ não deveria haver o trânsito de carros. Deveria haver um local para deixar o carro estacionado (pois as pessoas podem morar longe da faculdade). como ja existem nos campus de sao carlos e pirassununga, transportes internos via departamentos e portarias, seria uma opçao para este. 
As entradas da avenida centenário deveriam ser abertas, para facilitar ainda mais o acesso ao campus. $O$ incentivo de uso de meios de transporte alternativos também deve ser mais abordado.

Faz tempo que um ônibus circular interno se faz necessário à comunidade, do meu ponto de vista. Se quer exigir mudanças de comportamento referente à mobilidade, dê a contrapartida.

deveria existir pontos de carona, e incentivo para $q$ as pessoas $q$ transitam com carro ofereçam carona

Acredito que a principal ação em relação a mobilidade deveria vir da Prefeitura Municipal, pois se fosse fornecido uma linha de ônibus que circulasse na Avenida Independência e Carlos Botelho, com boa frequencia, nos horários de "pico de entrada e saída de alunos, muitos alunos e servidores não viriam mais de carro. Muitos funcionários vem de carro só por não ter um local adequado e de qualidade para almoçar, dentro do campus, que aceite o cartão sodexo. E aí precisam de carro para o deslocamento neste horário e para este fim. Muitos deixariam de vir de carro se este local existisse.

Precisamos de ciclo faixas dentro do campus, principalmente até a central de aulas/restaurante universitário, que tem a maior quantidade de ciclistas. Também seria legal uma campanha sobre como andar de bike no campus, a importância de usar capacete, por exemplo e de usar a sinalização com as mãos antes de virar.

Ainda acho perigo o transito de bicicleta no campus falta espaço correto para circulação de carros e bicicleta

Poderia haver um estacionamento para alunos e ônibus de circulação interna para atender a comunidade.

Falta de respeitos das pessoas que conduzem carro em relação aos ciclistas e excesso de velocidade

Bondinho deve ser reativado para a circulação dentro do campus. Zootecnia até a Engenharia é o principal percurso e ajudaria muito o deslocamento entre os departamentos. A construção de bolsões de vagas também seria útil, de modo a reduzir a utilização de automoveis dentro do campus.

Há extrema necessidade de colocar um semáforo e faixa de pedestres na portaria para pedestres que existe na secretaria administrativa do campus (onde se coloca o selo USP no carro). Só irão colocar essas coisas quando um estudante for atropelado.

Faz falta um bom painel na entrada do CAMPUS de Piracicaba sobre pavilhões dos cursos, restaurante, institutos e demais equipamentos e sua localização. Sugiro que graduandos interessados, sob orientação de professores, sejam convidados a constituírem um grupo para fazer tanto o painel como também uma maquete do campus (com material reciclado).

Parabéns pela iniciativa! Boa sorte com a análise de dados.

É inacreditável o descaso com que as prefeituras da ESALQ e de Piracicaba tratam a pauta de mobilidade urbana. Para acessarmos a escola, temos de atravessar diariamente o acesso entre duas rodovias muito movimentadas, onde trafegam caminoes, onibus, camionetes, carros e motos, sendo que muitos estao viajando, e mantém as velocidades das rodovias em frente à universidade. Nao existe ciclofaixa que permita o acesso seguro dos ciclistas ao campus. Para atravessar a rodovia a pá deve-se esperar por mais de dois minutos para que fece o sinal e a única faixa de pedestres em frente a escola possa ser atravessada. Questiona-se a "intervencao educadora" do grupo de mobilidade, na qual optou-se por simbolicamente instalar uma ciclo-faixa de sentido único na rua principal do campus, o que gerou maior impaciencia dos motoristas aos ciclistas que nao estao sobre a ciclofaixa; o papel educador do campus sobre a mobilidade urbana foi desprezado no sentido de gerar a tolerancia àqueles que estao sobre a ciclo-faixa, ao 
invés de gerar o respeito e a conscientizaçao sobre os meios de transporte alternativos e sustentáveis. Ainda o descuido da açao se dá representativamente no trecho onde a bicicleta divide a ciclo-faixa com o ponto de parada obrigatoria dos onibus circulares em frente ao PCh que passam de hora em hora pela campus. A administracao do campus se mantém omissa quanto aos projetos de ciclo-faixa que ligam o campus à cidade. Fruto do descuido administrativo acidentes ocorrem dentro e fora do campus com frequencia, sao excessoes os acidentes reistrados; há tres anos morreu um garoto de 21 anos atropelado por um onibus circular na avenida independencia ao realizar o trajeto casa-esalq. Os ciclistas sofrem diariamente com o transito e os perigos do deslocamento até a universidade, seja pela Av Centenário, pela Av Carlos Botello ou ainda pela Av Independencia; muitos desistem da bicicleta por questoes de "segurança" e aderem aos automóveis. Espera-se que a administraçao tome atitudes antes que outras fatalidades venham a acontecer..

Impedir pessoas externas ao campus de utilizar os bancos dentro da Esalq, pois os bancos internos deveriam ser exclusivos de alunos, funcionários e professores. Sendo assim, reduziria muito o número de veículos circulando dentro do campus e também reduziria acidentes e roubos...

O caminho (cidadexfaculdade) é altamente perigoso, quando vou de bicicleta prefiro ir pela calçada. Os motoristas não respeitam os que andam de bike.

\section{Algumas perguntas estão confusas!}

Há grande necessidade de se criar ciclofaixa nas avenidas de principais acessos à universidade, como a Av. Independência, Av. Carlos Botelho e Av. Centenário. Estas todas possuem grandes e intensos tráfegos de automóveis utilitários, motos, caminhões e ciclistas estudantes, sem oferecer uma estrutura adequada à estes últimos.

Pedestrianismo; sistema de caronas dentro da universidade (como na UFLA).

Ônibus de circulação interne e fretados do campus à cidade do estudante

1) Os ônibus urbanos que fazem o trajeto centro-Esalq possuem horários reduzidos. O ônibus Panorâmica que entra no campus tem intervalo de mais de uma hora, o que eu acredito ser insuficiente. O perimetral embora tenha intervalos de 30 minutos não liga o campus ao terminal central. 2) $A$ van que transporta os alunos da vila da ESALQ para a ESALQ só funciona no período noturno e durante $o$ ano letivo da graduação. Pela importância, ela poderia funcionar no perído da manhã e durante o ano todo. 3) Não há um transporte interno da ESALQ, seria importante pelo menos no horário do almoço, que saísse do CENA e fosse para a ESALQ, assim como em outros departamentos distantes, como a Entomologia. 4) Os motoristas não respeitam as faixas de pedestre no interior do campus e alguns dirigem em uma velocidade mais alta do que deveriam. 5) O campus possuem ruas que não apresentam calçadas. Alguns locais estão passando por adequação, mas alguns não tem sinal que haverá obras, 6) Os alunos poderiam ser mais conscientes em relação a caronas, isso poderia ser uma prática mais difundida, como ocorre no campus da UFSCAR de Araras, por exemplo. Com a política de caronas, talvez um transporte interno não fosse necessário. 7) Deveria ter sinalizações que indiquem locais que há passagem de fauna, diversas vezes vi os carros que transitam em velocidade alta quase atropelarem gatos, tatus, seriemas, patos e etc.. Alguns locais essa passagem é mais frequente $e$ deveria estar sinalizada. 8) A ampliação de ciclofaixas no interior do campus e fora dele seria importante para aumentar a segurança dos alunos que optam pela bicicleta como meio de transporte.

Ciclovia no campus! E na cidade!!

\section{Mobilidade dentro do Campus}

Ter mais ciclofaixas pelo Campus, uma vez que algumas vias de deslocamento (para carros e bikes) são estreitas e as vezes acontece de ter carros estacionados dos dois lado da via, tornando-a mais estreita ainda. 
Acredito que a cidade e a Esalq podem facilitar o uso de bicicletas como meio de transporte. No campus, é necessário ter mais estacionamentos seguros para as bicicletas (dentro de prédios ou próximos às guaritas). Na cidade, o acesso a universidade por vias secundárias (ou principais) com ciclo faixas com um período com cones para educação no trânsito.

A segurança no acesso ao campus, por exemplo na entrada de pedestres pelo acesso pela avenida Carlos Botelho o pedestre tem que atravessar a avenida Centenário onde existe um semáforo para os veículos, mas muitas vezes ele passam pelo sinal vermelho, pois não há radar no local o que pode ocasionar acidentes.

\section{Gostaria que houvesse maior incentivo as ciclovia em Piracicaba}

Sugiro a volta de linhas regulares que facilitassem o acesso de funcionários evitando a saturação do trânsito nos horários de pico e nas vagas de estacionamento dentro e nas áreas próximas ao campus. Também, transporte interno para estudantes e funcionários que percorrem longos trajetos entre os departamentos que acabam sendo feitos com automóveis ou a pé, este causando muita perda de tempo e desgaste físico.

Adoção de estacionamento central com disponibilização de bicicletas para locomoção interna, incluindo para refeições.

O problema maior de mobilidade é chegar ao campus e não dentro dele.

Estudei em uma Univerisidade Americana pela ESALQ e pude notar que o que é realizado lá se aplicaria muito bem aqui: o campus é fechado para ser utilizado somente à pé. No entanto, há diversos bolsões e prédios de estacionamentos, nunca falta vaga. A minha sugestão é fechar o campus para passar apenas pedestres e revitalizar a ideia do bondinho, que leve alunos para pontos mais distantes do campus.

Placas indicativas de direção dentro do Campus, por exemplo, "Bancos", "Restaurantes", "Biblioteca", "Serviços", etc...

Possibilidade de utilização de condução (ônibus ou van) interna no Campus, para uso principalmente dos alunos de graduação e pós-graduação, dos funcionários, mas também de docentes.

Talvez funcionários e alunos aderissem à caronas, se tivessem conhecimento de pessoas que residem na mesma região, ou que realizam os mesmos percursos. Um banco de dados para cadastro de interesse em caronas da Comunidade, poderia reduzir a quantidade de veículos no Campus e de custos com deslocamento dos esalqueanos.

O ponto que julgo de extrema importância a ser considerado referente à mobilidade dentro da ESALQ é a falta de calçadas para nós que nos deslocamos à pé dentre os departamentos, $R U$ e biblioteca (em relação à biblioteca estão melhorando a via de acesso para pedestres). Para quem anda de carro ou moto também houveram melhorias quando a sinalização, entretanto quem não conhece o campus fica perdido quando precisa encontrar algum departamento, sendo assim poderiam pensar na possibilidade da colocação de placas com mapa de localização dos principais departamentos ou pavilhões do campus. No mais não tenho reclamações. Obrigada pela oportunidade em me expressar.

É muito interessante a iniciativa de melhorar a mobilidade no campus, evitando congestionamentos e até mesmo acidentes.

Vagas cobertas com painéis solares como em algumas federais e aluguel de bicicletas.

As ciclovias são muito mais ocupadas por pedrestres que adentram o campus para fazer atividades físicas variadas, ou por motococlistas em alta velocidade e sem nenhum 
acompanhamento instrucional por parte da segurança do campus.....Outro problema bastante comum são veículos andando na contra-mão e causando certa preocupação. Acredito que alguma medida de concientização no sentido de promover maior respeito e facilidade de acesso para cadeirantes ou pessoas parcialmente deficientes....FALTAM CORRIMÕES NO CIAGRI E RAMPA +CORRIMOOES NO PRÉDIO CENTRAL..... MESMO QUE FOSSE NAS COSTAS DO PRÉDIO PARA NÃO FERIR A ARQUITETURA. NESTE ANO JÁ CRUZEI COM ALUNO INGRESSANTE CADEIRANTE, TEMOS TAMBÉM ALUNOS PARCIALMENTE LESIONADOS, COM MUITA DIFICULDADE DE LOCOMOÇÃO......

Sugiro alguma forma de deslocamento para os alunos dos cursos de agronomia e eng. florestal durante a troca de aulas. O tempo curto e $o$ a distância longa entre os locais de aula faz com que os alunos utilizem automoveis para se deslocarem internamente.

Falta de ciclovias: - Dentro da universidade existe pouca ciclofaixas, mas o problema está na parte externa ao campus. Não existem ciclovias no entorno da universidade.

- Estacionamento pago dentro do campus, - Áreas específicas para estacionamento dos autorizados, - criação de bolsões de estacionamento, otimizando a área da escola hoje dedicada à prática esportiva ou outras áreas disponíveis - isso acabaria estimulando o uso de bicicletas na locomoção interna ao campus, já que os frequentadores poderiam transportar suas bicicletas até área interna e depois fazerem uso dela exclusivamente na área do campus, onde se espera que o respeito ao ciclista seja maior e o comportamento do ciclista seja o adequado. Substituição do selo por cartão - isso evitaria a multiplicação de selos dentro de famílias, com a justificativa de necessidade do selo para diferentes veículos.

A saída da avenida centenário ser fechada é um grande problema pois ajudava muito o pessoal a evitar o congestionamento na saída principal

-bicicletas que andam na contra-mão -estacionamento (vagas) em ruas estreitas -uso do campus por pessoas sem vínculos com a ESALQ (atividades físicas, competições, projeto "amigos das Esalq) devem ser reavaliados

Alertar, dar exemplos positivos sempre, todo mês, realizar uma ação. Desenvolver campanha aos ciclistas, muitos são estudantes; então, promover ações direcionadas a esse público. Lembrar tb. dos pedestres que estão no Campus para curtir o local - são vivências diferentes dos que estudam e trabalham aqui.

O campus da ESALQ transformou-se em ponto de caminhada para todos os cidadãos e poucos têm a consciência de que há áreas que são impossíveis de se praticar esse esporte por ter fluxo intenso de tráfego. Medidas de proibição de algumas áreas como entradas principais e prédios aos arredores do edifício central deveriam ser tomadas (ex. plaquear áreas como "desaconselháveis" para atividade física, personal trainers etc).

Sugiro que seja liberado o trânsito de bicicletas no campus, como lazer e atividade física (não somente para deslocamento). Predominantemente sou pedestre no campus, mas também motorista de veículo próprio; nesta condição, incomodo-me com o trânsito de pedestres e atletas circulando no meio nas pistas de automóveis - um risco para pedestres e motoristas. Acredito que sejam necessárias orientações aos pedestres/atletas, para que circulem nas calçadas ou em sentido contrário ao dos veículos, para que, na presença destes, retirem-se da linha de passagem dos veículos.

Algumas ruas possuem ciclofaixa, com o a Avenida Principal. No entanto, no restante do Campus, não existe essa preferência aos ciclistas, o que torna o deslocamento de bicicleta muitas vezes perigoso e estressante.

Parabéns por esta iniciativa.

Sucesso no desenvolvimento do trabalho!

Deveria ter ônibus municipal ou interno com vários horário para a fazendo áreao, incentivando os alunos que não tem carro a também poder usar a área de pesquisa.alem disso na áreao tem a Incubadora da ESALQ, que é um polo empreendedor de referência de piracicaba e da esalq, 
com empresas nascentes de tecnologia na agricultura, do qual os alunos deveriam ter contato desde cedo na graduação com esse lado empreendedor. alem de poderem fazer estágio e terem projetos na Incubadora, se puderem chegar lá mais facilmente.

As principais dificuldades que enfrento como ciclista/pedestre são na parte da cidade, principalmente na avenida independência, onde quase nenhum carro respeita a faixa de pedestre, e o sinal de trânsito da entrada da engenharia/monte alegre. Já houve diversas vezes no qual "quase" sofri um acidente, por causa destes desrespeito ao pedestre/ciclista. É preciso um envolvimento maior da prefeitura e uma pressão por parte da ESALQ para melhorar a circulação das pessoas entre os bairros próximos ao campus Luiz de Queiroz.

Nenhum

Priorizar o uso de bicicletas com ciclofaixas diminuindo as vagas de estacionamento nas vias. $O$ estacionamento dentro do Campus deve ser priorizado em bolsões ou nas áreas internas dos departamentos, desestimulando os deslocamentos internos usando carros. Substituir por ônibus circular, bicicletas, e a pé. Ampliando assim o espaço viário para pedestres e bicicletas. As exceções de pessoas com restrição de mobilidade, necessidades especiais, idosos e outras prioridades devem ser tratadas a parte de um plano geral de restrição de acesso ao Campus com carros particulares. Outra sugestão é priorizar o acesso e estacionamento a veículos com 3 ou mais passageiros, estimulando assim o compartihamento do acesso.

O grande problema de mobilidade eu acredito que seja dentro do campus. Talvez um circular interno resolveria o problema do transito interno. Por exemplo, o deslocamento até o restaurante, muitas pessoas saem de seus departamentos e pegam o seu carro para se locomover até $o$ mesmo. Um circular interno passando por pontos de grande acesso resolveria esse problema. $O$ que proporciona ruas com menos carros estacionados e até mais segurança para os pedestres, inclusive para os que usam bicicletas que em alguns lugares não tem ciclovia dentro do campus.

Mais ciclofaixas dentro e fora do campus; Departamentos muito distantes uns dos outros e pouca alternativa para aqueles sem veículos motorizados;

Apenas justificando algumas respostas: Sobre a mobilidade da cidade até o campus da ESALQ: Considero muito complicada. Há um ano, me mudei para o endereço indicado justamente porque o acesso de bicicleta à ESALQ pela Carlos Botelho é mais seguro do que pela $A v$. Independência. Escolhi o endereço para justamente poder ir de bicicleta à universidade. Atualmente, estou me mudando para outra residência, da qual terei que acessar a ESALQ pela Av. Independência. Tenho muito medo de andar de bicicleta ali, porque sei que os automóveis são mais velozes e menos cuidadosos. Assim, sei que não irei de bicicleta à universidade com a mesma frequência. Sobre a mobilidade dentro do campus: Houve melhorias recentemente, como a marcação de uma ciclovia. Contudo, só há via de ida ao meu departamento, não há faixa com mão no sentido da volta. A mobilidade a pé dentro do campus é bastante complicada. É visível que há poucas calçadas. Quando acessamos o campus de carro, temos que tomar cuidado com o grande número de pedestres na rua. Porém, sabemos que há vários motoristas que não têm esse cuidado. Além disso, com o deslocamento do restaurante universitário para outro endereço, pude perceber o quanto esse caminho é ensolarado, o que torna a caminhada bastante desagradável. Vários alunos estão indo almoçar de carro, não pela distância a caminhar, mas pelo sol. Sugiro que sejam plantadas árvores de rápido crescimento no caminho, intercaladas com outras de crescimento mais lento, para aumentar o conforto dessa caminhada (podem ser consultados os laboratórios LERF e LASTROP sobre as melhores espécies para esse plantio)

É um absurdo não existir ciclovias nas principais avenidas que dão acesso ao campus. E em muitas ruas do campus não existe ciclofaixa

Talvez as últimas três questões que tratam da percepção poderiam ser qualitativas. Desse modo, seria possível justificar tais questões o que - ao meu ver - trariam informações interessantes para a pesquisa. Desejo uma boa pesquisa. 
A idéia das ciclovias foi excelente, porém atende um parte do campus.

As ações me fazem refletir, pois reconheço a necessidade e importância de alternativas de mobilidade sustentáveis, porém, com meu filho ainda a completar 3 anos, necessito do carro em nossa rotina. Ainda que fosse possível neste momento utilizar uma bicicleta, por exemplo, 0 acesso ao meu local de trabalho dificulta bastante por ser uma rua de terra bastante esburacada. Acredito que pedras britadas ajudariam bastante a locomoção pelo local, principalmente em dias chuvosos.

\section{Eu só ando a pé}

\section{Mais ciclovias no campus}

mais detalhes sobre mobilidade sustentável. o campus de piracicaba tem uma grande demanda com bicicletas, no entanto, as facilidades para uma melhor locomoção não são tratadas com devida atenção (ciclo faixas)

Estado das calçadas e respeito ao pedestre.

Um problema no campus é a falta de calçadas para os pedestres, que muitas vezes são obrigado a andar nas ruas em algumas áreas por falta de um local adequado para se deslocarem. Outro problema muito observado é a falta do uso de capacete e excesso de velocidade de alguns condutores de motocicleta no interior do campus.

A mobilidade sustentável (cidade vs. campus) é importante no entanto tem certo grau de relatividade haja a distancia da casa ao campus, frequência de transporte coletivo, entre outros. A falta de segurança para atravessar diariamente a avenida independência me faz ir sempre de carro. Falta ciclovia, falta segurança e educação dos motoristas.

Há falta de bebedouros, bancos e sanitários aos frequentadores do campus. Seria interessante ter bolsões de estacionamento e que toda a área central fosse livre de automóveis - somente essenciais, ônibus escolar e/ou para pessoas com necessidades especiais.

Falta de sinalização (chão e postes) e precisa de mais faixa de pedestre elevadas. Ja fiz solicitação para o setor do Svapesq, que está um perigo, devido a comunidade que usa o parque para caminhadas e também porque inverteram a mão do triangulo e não sinalizaram até $o$ momento, nem tem aviso de redutor de velocidade, nem de sentido de direção, nem de velocidade

Obrigada por esse trabalho! Como ciclista, o meu principal problema é a segurança no trajeto entre a minha casa (na Vila Independêcia) e a ESALQ, e na cidade de modo geral. É lastimável a prefeitura nunca ter se movimentado para fazer ciclo faixas nas vias mais movimentadas ao redor das universidades e no centro da cidade, mesmo após a trágica morte do menino Gueta. Todos os dias, ao sair de casa, eu rezo para chegar ao meu destino e voltar dele viva. Após as obras da prefeitura, o trajeto ficou muito mais perigoso. Os motoristas são os que mais precisam de ações de conscientização, fora e dentro da ESALQ. Já passei por situações complicadas dentro do campus, como "finas" e quase atropelamento por um automóvel em alta velocidade. Outra coisa impressionante dentro do campus é ausência de calçadas em vários trechos super movimentados. Também a entrada perto da garagem, pela rodovia, merece atenção. Várias pessoas atravessam aquela via diariamente e o radar de velocidade ao pé da ladeira não adianta em nada, já que os carros aceleram após ultrapassá-lo. Aquele lugar precisa de uma passarela. Em resumo, na cidade e no campus, a mobilidade para pedestres e ciclistas é no mínimo desrespeitosa e negligente. Obrigada.

A ESALQ deveria implementar ciclovias em todo o campus e restringir o estacionamento de carros de alunos e visitantes a poucas áreas do campus.

Precisamos de medida urgentes para conscientizar ou punir motoristas que não respeitem as normas internas de trânsito. Em minha vida tive a oportunidade de estudar na Unicamp (Campus 
Campinas) e (Universidade americana). A diferença no comportamento dos motoristas entre essas duas instituições e a ESALQ é vergonhosa. Nunca vi um motorista na ESALQ parar em um faixa de pedestres ou parar para alguém atravessar, pelo contrário, entram a toda velocidade no campus e agem como se estivessem em uma avenida!

Na semana de Mobilidade, foi colocado um ônibus da Esalq para circular pela av. independência, nos horários de saída e chegada ao campus, fiz uso dele e achei muito interessante no sentido de diminuir o numero de carros que chegam ao campus nesses horários. O trajeto poderia ser ampliado e colocado em teste.

Alguns locais a acessibilidade de deficientes é ruim.

Se for por falta de projetos, temos infinitos exemplos de outros campus que funcionam muito bem em termos de mobilidade. A esalq seria mais um exemplo para o Brasil quando mobilidade for levada a sério.

\section{Ciclovias, passarela}

1. Construir bolsões de estacionamento para os veículos ou fazer faixas para os ciclistas em todo o Campus da Esalq.

Seria interessante mais linhas de onibus e horarios , também ciclovias

Melhora na infraestrutura dentro do campus, para pedestres e ciclistas.

A meu ver a ausência de calçadas em muitas vias do campus e o uso descuidado das mesmas por pedestres se exercitando (correndo) gera situações de risco. Ainda, a ausência de um espaço destinado prioritariamente à ciclistas (ou pelo menos a fiscalização dos trajetos por eles realizados, uma vez que andam na contramão e em calçadas) também os coloca em risco.

Creio que punições mais severas para atos infracionarios envolvendo veículos dentro do Campus, reduziriam as ocorrências. A incidência de assaltos a pessoas no entorno do Campus aumentou muito ultimamente, dificultando a mobilidade para chegar a Universidade.

Movimentação intercâmpus; Bolsa de bicicletas coletivas para movimentação intracâmpus; e Linhas de veículos coletivos para movimentação intracâmpus.

O problema da mobilidade não está no campus, mas nos arredores. Ciclovias na Av. Carlos Botelho, na Av. Independência, na Av. Centenário, e quiçá nas outras principais ruas de acesso são urgentes.

só tenho uma coisa a falar, enquanto os que andam de bike não pararem de andar na contra mao dentro do campus esalq - cena, pra mim isso é papo furado.

Poderia haver um trasporte interno no campus com uma certa frequência para não ser necessário o uso de carro para os deslocamentos internos e para os estudantes que não têm transporte $e$ precisam cobrir grandes distâncias em um espaço curto de tempo caminhando correndo o risco de perder o chegar atrasado para aulas.

Mais linhas de onibus específicos da universidade, com mais horários. Chegamos a ficar 1 h30 esperando onibus para ir a ESALQ e o tempo de viagem chega a $1 \mathrm{~h}$.

Deveriam abrir novamente aos finais de semana a entrada Entomologia (Av. Pádua Dias)

Devia ser feitas mais ciclovias no campo,pois há apenas na Avenida principal e em pequenos trechos do campus. 
Poderia ter mais ciclofaixas pelo campus, pois temos que andar de bicicleta pela calçada ou na rua com os carros.

Tenho sempre problemas para atravessar a faixa de pedestres na entrada. Ela fica mt perto da Cunha

\section{DEVERIA SER COBRADO ESTACIONAMENTO DE CARROS DENTRO DO CAMPUS}

Para melhora da mobilidade na ESALQ, seria interessante estudar a inclusão de um circular interno gratuito como é feito na Unicamp ou na USP sede.

por favor fazer mais ciclofaixas

Deveria haver mais ciclovias no caminho Esalq / Piracicaba pois existe poucas e muitos alunos utilizam bicicleta e passam por perigos todos os dias. E na maioria dos casos as pessoas que vão a pé nao utilizam a bicicleta por medo

Acho que faltam indicações de saída e o sentido das saídas (São Paulo, Limeira etc.) e indicação da localização dos departamentos

Esperamos que essas questões referentes ao questionário sejam, verdadeiramente, solucionadas

Como se deslocar até o campus de bicicleta de forma segura.

Gostaria de esclarecer o motivo de achar pouco importante a mobilidade sustentável dentro do campos. O principal motivo é que para transitar dentro do campos primeiro deve-se chegar a ele, ou seja, deveria haver segurança publica na cidade para poder acessar o campos carregando notebooks por exemplo de formas mais sustentáveis, como a pé ou de bicicleta, o que infelizmente não há. Talvez um sistema de interno de bicicletas disponíveis para transitar apenas dentro do campus ajude.

Infelismente os motoristas não conseguem respeitar as leis de trânsito dentro do campus, $e$ punem de maneira regular os ciclistas.

Melhoria na segurança para os ciclistas no trajeto cidade $x$ campus, como ciclovias nas avenidas de principal acesso, ex. av. Independência. Melhoria na mobilidade dentro do campus, como ônibus ou pontos de empreste de bicicletas, em virtude da distância entre os departamentos entre si e $R U$.

Existe restrição de moradia para aqueles que não possuem veículo, assim como eu, estando sujeitos a custos mais caros com moradia. Apesar da importância da Universidade sua acessibilidade via transporte urbanos é extremamente limitada.

Seria bom se tivesse meios de se deslocar dentro da esalq, como micro onibus, de um departamento para outro. Muitas pessoas que tem carros não viriam com ele para utilizar o meio de trasporte publica dentro da esalq e assim o transito diminuiria.

Segurança no trajeto até a escola, dentro da escola, etc.

Além da mobilidade dentro do campus, a mobilidade para se chegar ao campus é muito importante também. Para os usuários que utilizam a entrada da Entomologia (próximo ao DER), atravessar a avenida Pádua Dias é sempre perigoso, pois o movimento de carros é constante e sua única opção é dar uma "corridinha" para o canteiro central e depois outra para se chegar à calçada do outro lado. Uma passarela ou mesmo uma faixa de pedestres já ajudaria muito os pedestres e ciclistas que trafegam por ali.

No questionário acho que falta incluir se a pessoa faz uso de alguma carona

O Campus é muito grande. Talvez o uso de Vans dentro do Campus ajudasse no deslocamento interno. 
Utilizo o carro no trajeto casa-ESALQ, pois não é possível contar com o transporte público de Piracicaba (frota pequena, poucos horários e demora no trajeto). Um ponto muito ruim nesse trajeto é a rotatória na frente da entrada principal, muitos motoristas não respeitam a sinalização de "PARE" para quem está dentro da rotatória, várias vezes quase bati o carro. Obrigada, MAIS CICLOVIA

Sim. É importante saber se os usuarios do campus Piracicaba estão dispostos a mudar seu modal de deslocamento caso haja investimentos em estrutura que viabilize deslocamento alternativo. Por exemplo, se houvesse uma ciclovia segura acessando o campus pelas principais avenidas, é importante saber se haveria disposição a adesão de seu uso. No meu caso particular, eu não sinto segurança em usar mais a bicicleta em razão da insegurança do transito. Outro aspecto importante que precisa ser perguntado é se as pessoas aceitariam a restrição de trafico de automoveis dentro do campus se houvesse bolsões de estacionamento do lado de fora. Em todos os campi universitários que visitei no exterior o trafego de automóveis é restrito ou proibido nas alamedas internas. Será q se voce oferecido alternativa para viabilizar esse modelo os usuários adeririam?

Me locomovo até a Esalq por automóvel porém se o trajeto de minha casa até a mesma fosse seguro, em questões de furtos e de transito intenso, eu com certeza usaria outro meio de locomoção mais sustentavel. Até mesmo dentro da esalq não considero o trajeto interno seguro; pessoas, bicicletas e carros dividem em muitas ruas o mesmo espaço (mesmo em muitas que possuem calçada lateral) prejudicando a segurança de todos.

Criação de pontos de carona

Gostaria que as ciclofaixas fossem feitas em mais ruas do campus, e não somente nas principais. Acredito que ciclovias seriam mais seguras e respeitadas, mas as ciclofaixas já estariam de bom tamanho em mais ruas do campus. Obrigada!

Fico feliz com a pesquisa. Espero que traga frutos, vamos discutir juntos para que tenha um resultado prático de melhoria a todos. Sobre a última questão: acho que o acesso de carro ao campus é bem tranquilo, mas de bicicleta, o meio de transporte que mais utilizo, não é tão acessível assim. O que a maioria dos ciclistas que vão para a ESALQ fazem é andar pela calçada, atrapalhando os pedestres. Essa é a parte que acho mais crítica. Andamos pela calçada, porque ir pela rua é complicado, os motoristas não respeitam muito e a entrada para a pista da direita é ruim, perigosa. Precisamos de uma ciclovia com urgência. Grata pela atenção.

Construção de Ciclovias realmente úteis dentro do campus e também na parte externa, nos principais acessos da cidade ao campus. Muitos alunos se deslocam de bicicleta e se arriscam no trânsito perigoso de Piracicaba.

Muitos alunos utilizam bicicleta para ir até o campus. Devido até a morte de estudantes por falta de ciclovias ou ciclofaixas de entro para fora do campus e dentro do campus, acredito que há uma deficiência dessa questão dentro do questionário. É uma pauta muito importante e que deveria entrar em questão para melhorar a mobilidade e a segurança dos alunos dentro e fora do campus.

Mobilidade não é somente trocar carro por bicicleta. Muitas pessoas possuem dificuldade (física) de locomoção e bicicleta ou andar a pé podem não ser as principais opções. É preciso regularizar/padronizar as calçadas do Campus (alguns locais não possuem calçadas, outros possuem calçadas danificadas/irregulares). O desrespeito vem de todos os lados: motoristas, bikers, skatistas e pedestres.

Ampliamento da ciclo faixa

Com esse aumento excessivo de veículos esta difícil encontra vagas de estacionamento no campus. Sugestão fazer bolsões de estacionamento e incentivar a fazer caminhando. (apé) 
Gostaria que as bicicletas se tornem prioridade na mobilidade do campus, pois é a gente que está escolhendo uma maneira sustentável para a mobilidade tanto dentro quanto fora da universidade mesmo que nem a cidade de Piracicaba crie esses espaços para a gente mas a nossa universidade precisa se tornar um exemplo para conseguir que esses espaços sejam criados. Gostaria que sejam respeitados e criados mais espaços para bicicletas (não temos lugar suficiente para travar todas as bikes que circulam) e que os carros também respeitem quem não está de carro, repetidas vezes seja andando ou de bike eu e os meus colegas quase fomos atropelados, os carros circulam rápido demais dentro do campus e não deveria de ser assim. Além disso precisam ser criados mais espaços para cadeirantes, é engraçado que o pavilhão da engenharia tenha cadeira para gordos mas nenhum espaço para cadeirantes, a minha colega tem que ficar quase na entrada para assistir uma palestra.

Fiscalização do excesso de velocidade de automóveis, que constantemente vejo no campi, o que prejudica a circulação tranquila e segura de pedrestes.

deve haver um ônibus que passe em todos os departamentos !!!, não somos obrigados a ficar andando Km para assistir aulas

Percebo o empenho da Instituição na melhoria da mobilidade dentro do Campus, tal como a colocação de calçadas na Alameda do Brejo, que deveria ser estendida até a Alameda do Jacarandá Mimoso. Há muito mais a ser feito, principalmente: educação de motoristas, ciclistas e pedestres, nesta ordem de prioridade; colocação de mais calçadas ou reforma das já existentes; melhoria na sinalização (principalmente de solo); como uma medida extrema, colocação de radares para velocidade dentro do Campus.

Deveria ter um bolsão de estacionamento e vans ou microonibus com horários frequentes e definidos de deslocamento. Incentivar o uso de bicicletas

Fazer com que o acesso à parte de entomologia da escola seja mais fácil e segura para as pessoas que se locomovem a pé, da cidade até a escola. A entrada que existe perto da rodovia facilita o acesso, porém é muito perigosa para os pedestres.

Eu apoio os planos de mobilidades. Atualmente, trabalho na ESALQ e tenho utilizado muito o carro devido às minhas atribuições que faz com me desloque constantemente entre prédios, do departamento que trabalho. Acredito que para melhorar se faz necessário melhorias como calçadas em diversas vias principais no campus. Dentro desta questão, penso que a prefeitura deveria pedir o apoio da Prefeitura da cidade, já que grande parte da movimentação de pessoas está vinculado às pessoas externas. Percebo também que ações têm sido feitas, como o desenho da ciclovia. Isso tem sido muito bom, mas tudo só dará certo com a conscientização mesmo das pessoas que circulam pelo campus!

Mais horários de transporte para a vila estudantil.

Solução para o deslocamento entre departamentos da ESALQ.

Ciclovias por todas as ruas e avenidas do campus, e não apenas alguns metros sem muita utilidade como temos. Seria ótimo se tivesse também nas principais vias de acesso (cidade $x$ campus), Av. Independência e Carlos Botelho.

Parabens pela iniciativa e que seja feliz na defesa da dissertação

A ciclofaixa que existe na Avenida Principal é muito pequena e insignificante em relação ao tamanho do campus. A Avenida que dá acesso ao novo Rucas é muito perigosa para ciclistas. Os motoristas de carros devem ser mais pacientes com pedestres e ciclistas, ou seja, tem que haver maneiras de reeducação no trânsito. Acredito que seria necessário um esquema de rotação na entrada de carros na ESALQ. Há muitos carros. Diversos estudantes moram ao lado do Campus e vão todos os dias de carro. É absurdo!!! 
Congratulo os autores da pesquisa pela iniciativa de suma importância para a mobilidade do campus. As vias se encontram atualmente entupidas de carros visto que não foram planejadas para essa quantidade de veículos. Espero que a pesquisa resulte em melhorias concretas a mobilidade e a restrição do número de veículos dentro do campus

O mobilidade CAMPUS-CIDADE e dentro do CAMPUS é bem ruim em relação à utilização de bicicletas (que é um dos meus meios de acesso, mas não o principal). Em relação à mesma mobilidade quando aplicada à utilização da motocicleta, não existem grandes problemas Sim, que houvesse ampliação da ciclofaixa no campus de Piracicaba, pois, frequentemente, as pessoas que utilizam a ciclofaixa no sentido proibido, provocando alguns acidentes de trânsito.

É imprescindível a construção de ciclovias nos principais acessos e por toda a ESALQ. Nossa escola é a única universidade que conheço (Brasil e EUA) que incentiva, de forma indireta, que os alunos venham de carro. O resultado disso todos sabem. Esse tendência (atraso melhor dizendo) é comum no Estado de SP, mas deve ser evitada e combatida pela comunidade acadêmica. A mudança deve começar daqui!

Estudar, junto a prefeitura do município de Piracicaba, um modo de acesso ao campus que diminua os riscos e "competições" entre ciclistas e automóveis nas vias do entorno da ESALQ.

transporte interno, cancela principal á floreta, floreta ao Restaurante dos Docentes, Restaurante dos docentes á entomologia, garagem. Externo ao Campus, cancela principal av Independência ao Centro, Centro, av armando Salles, Santa Cruz, Carlos Botelho, ESALQ

No campus da ESALQ há um grande desrespeito dos motoristas em relação aos ciclistas, eles não respeitam o espaço e somente há uma ciclovia no Campus, dificultando a locomoção aos demais departamentos do Campus.

Fazer uma ciclofaixa na rua que dá acesso ao restaurante universitário (RUCAS), tirando uma faixa de estacionamento.

A elevada inclinação das ruas e passeios do campus da ESALQ ocasionam dores nos joelhos e tornozelos, acredito que pode levar a lesões. Além disso há falta de passeios para pedestres em algumas áreas do campus. Em alguns locais o passeio é muito estreito e obstruído por plantas, como no caso de parte da via que leva ao departamento de ciências florestais. Também existem alguns desníveis abruptos nas calçadas que podem causar acidentes, com na esquina em frente ao antigo prédio do restaurante universitário.

Por favor façam uma ciclofaixa na rua do atual rucas...além de ter ficado super longe esse novo restaurante, agora precisamos ficar desviando de retrovisor de carros que param dos dois lados da rua. Obrigada.

ERRO NA DESIGNAÇÃO DO CAMPUS. O CORRETO É CAMPUS LUIZ DE QUEIROZ -USP
ERRO NA DESIGNAÇÃO USP-ESALQ. O CORRETO É ESALQ-USP. NO MUNDO A ORDEM
CORRETA É DO MENOR PARA O MAIOR. NOS ENDERECSOS.NÃO É A USP QUE TEM UMA
ESALQ E SIM A ESALQ QUE PERTENCE Á USP. O REITOR DA USP QUE INOVOU FOIO
MESMO QUE NO CENTENÁRIO DA ESALQ MANDOU COLOCAR UMA PLACA EM
HOMENAGEM Ȧ MÁRIO COVAS NO GRAMADO DO CAMPUS LUIZ DE QUEIROZ. (ZZM- 55)

No quesito deslocamento interno o campus deixa a desejar para pessoas que andam apenas à pé, pois como não há um ônibus ou bicicletas alugáveis dentro da universidade, alguns trajetos tornam-se um pouco demorados.

A esalq poderia ter um transporte alternativo, como por exemplo, um onibus circular, para diminuir a necessidade do uso de transporte individual dentro do campus.

Deveriam ser disponibilizadas bicicletas para a realização de trajetos dentro do campus, assim como deveria ser realizada uma campanha para incentivar a carona. 
Acesso de ciclistas ao Campus pelas 3 avenidas: Carlos Botelho, Centenário e Independência

Clclofaixas internas do campus (não sei se é possível colocar mão dupla, mas seria uma ótima iniciativa.

Meu principal meio de transporte dentro e fora do campus é a bicicleta. Um ponto positivo importante é que no campus temos acesso fácil aos bicicletários, o que assegura estacionamento seguro para as bicicletas. Entretanto um ponto que ainda deve ser melhorado são as ciclovias. Temos básicamente duas vias, que não apresenta, um começo e um final bem definidos, o que dificulta o acesso a ciclovia. Além disso, pontos importantes como o restaurante universitário e a biblioteca não tem acesso via ciclovia.

recomendo fazer um mapeamento e localização dos usuários do Campus da ESALQ e do CENA para estabelecer as principais vias de translocação e de acesso. Acredito da necessidade de uma ação integrada com a Prefeitura Municipal de Piracicaba, o que, certamente, demanda um processo de negociação e de planejamento viário. Esta iniciativa irá beneficiar não somente os usuários e frequentadores do Campus, mas, também, significativa parte da população de Piracicaba. Algumas iniciativas, como a dos alunos pleiteando uma ciclovia (demanda mais intensa após a morte de aluno atropelado na Av. Independencia por ônibus) devem ser enfatizadas, e, novamente, com a participação da Prefeitura de Piracicaba. Acredito que (a confirmar) mais de $60 \%$ dos usuários do Campus se deslocam pela Av. Independência, o que indica a importancia de iniciativas que priorizem do fluxo e deslocamento (faixa exclusiva de ônibus que cumpra um horário, esta é uma das limitações do pequeno uso do transporte publico; ou, ainda, faixa exclusiva de bicicletas, para propiciar maior segurança e atração para o uso deste tipo de veículo, pois a topografia é bastante favorável). Fico à disposição para contribuir e parabenizo pela iniciativa.

Vagas para motos, é necessário mais vagas. Além disso, em alguns trechos do campus não existe calçada para pedestres

Adoraria ir de bicicleta de casa para o trabalho, mas não é seguro transitar de bike pelas avenidas que levam ao Câmpus. O ideal seria que as avenidas Independência, Carlos Botelho e Centenário tivessem uma ciclovia ou uma ciclofaixa. As avenidas Independência e Carlos Botelho apresentam calçadas amplas, que permitiriam uma ciclovia.

\section{Estacionamentos prioritários}

Construção de calçadas (passeios) para pedestres contornando os canteiros e ouros locais onde faltam. Devido ao intenso tráfico de veículos, alguns em alta velocidade, torna-se perigoso para os pedestres caminhar pelo leito das ruas e alamedas do campus.

A mobilidade não deve ser apenas proibir o uso de automóvel, mas sim apresentar alternativas para se locomover no campus.

O perfil sócio-econômico dos estudantes pode ser determinante para o movimento de veículos automotores no campus. Este aspecto não foi abordado.

Providenciar mais estacionamento para deficiente físico. Providenciar o estacionamento especial e indicações precisas para pessoas com necessidades especiais, principalmente em dias de festas, apresentações, etc. Esta providência tem sido totalmente ausente há anos, embora já tenha sido alertada por mim. A USP não tem sido inclusiva, para nossa vergonha!

1) O túnel de passagem próximo à Casa do Estudante deveria ser ampliado, liberando o acesso durante todo o dia. 2) A passagem de acesso da Av. Pádua Dias à Estrada do Monte Alegre melhorou muito o acesso à área do campus situada próximo ao Pavilhão de Engenharia. 3) Deveriam aumentar as ciclofaixas no campus e contatar a Prefeitura e as empresas de ônibus para instalar suportes para bicicletas nos ônibus e ciclofaixas nas avenidas Carlos Botelho, Independência e Centenário. 
Falta planejamento e construção de ciclovias e ciclofaixas tanto dentro do campus quanto fora dele, nos bairros de Piracicaba mais próximos à ESALQ.

pergunta 13 - não contempla quem vem a pé ! pergunta 20 - tem relação com mobilidade ? pergunta 21 - sem propósito, pergunta mal formulada, português sofrível pergunta 27 (e outras) 0 quer dizer "sustentável" no caso de mobilidade? Parece apenas um modismo.

Mais ciclovias

Precisamos com urgência instituir as ciclovias em todo o campus.

ônibus interno durante o horário do almoço

Mesas dos bares na Av Carlos Botelho que ocupam a maior parte das calçadas. Falta de ciclovia nas principais avenidas de ligação ao campus. Necessidade de mais ciclovias no campus.

Acredito que mais ciclovias seria muito bom para resolver essa questão da mobilidade interna

Ciclovias ou, no mínimo, ciclofaixas na avenida independência e avenida centenário que dão acesso a universidade. Assim como dentro do campus principalmente. Uma única ciclofaixa pequena não soluciona o problema das bicicletas, pois obriga os ciclistas a disputarem a rua com os carros (que além de ser totalmente irregular e com buracos, é bastante perigoso por conta da velocidade com a qual os carros passam por ela)

"Todas" as entradas/saídas devem ter livre acesso aos pedestres e ciclistas, motivando assim os motoristas a deixar seu automóvel em casa.

Creio que a mobilidade do campus e também da cidade está comprometida em virtude do número crescente de veículos, motos e bicicletas. Acho que no campus os pedestres não respeitam os carros, passam em qualquer lugar e quando estão na faixa nem olham para ver se tem carro. Os ciclistas também confundem, ciclofaixas com calçadas e não se atentam para as mãos de direção, aí pensam que são pedestres... lamentável.

O NOVO RESTAURANTE UNIVERSITÁRIO POSSUI UM ACESSO APENAS PARA CARROS. ESQUECERAM DOS CICLISTAS, HÁ UM EMINENTE RISCO DE ACIDENTES COM OS MESMOS PRINCIPALMENTE PELA CONDUÇÃO DAS BICICLETAS NA CONTRA-MÃO.

Os motoristas do município são pouco atentos a quem se desloca a pé, de bicicleta, moto e/ou outros modos que não veículo automotor, tornando a utilização de meios alternativos muito inseguro. Gostaria de utilizar bicicleta rotineiramente, mas o risco de acidente é alto.

Mais ciclovias!!!

O trânsito de alunos com veículos próprios deve ser restrito acompanhado da disponibilidade de transporte coletivo entre os prédios/salas de aulas/departamentos

Mobilidade de universitários dentro do campus.

classificar usuários

Melhorar o número de vagas no novo RESTAURANTE /Jumbão (Lan II) e CENTRAL DE AULAS que em dias de eventos é um verdadeiro CAOS

Necessidade de um meio de transporte coletivo que circule por todo o campus, pois a extensão territorial é grande. Ciclo vias nas avenidas principais da cidade que possibilitem acesso de bicicletas com segurança. 
Deve ser regulada a velocidade interna no campus. Alguns motoristas exceden na velocidade e colocam em risco a vida de pedestres e ciclistas

Minha sugestão é tornar o campus inteiramente bike-friendly. Pedestres na calçada, veículos e bikes nas ruas. A meu ver duas são as modificações principais: 1- gerar algum modo para tornar seguro estacionar a bike no campus, pois muitos não se encorajam a ir de bike devido aos roubos; 2- colocar muitos dos guardas em ação nas ruas, inibindo altas velocidades de veículos (pode ser por exemplo o guarda para a pessoa e ficar uns 10 minutos conversando com ela, assim o motorista vai perceber que ou ele anda devagar ou vai ser parado). Multas acredito que não é uma boa solução, e sim a conscientização.

Relação entre as iniciativas da universidade em conjunto com a prefeitura da cidade de forma a tornar o trajeto mais seguro, mesmo nas ruas do entornos do campus. O trânsito é muito inseguro nas imediações da universidade e dentro do campus há falta de ciclovias.

Há a questão da utilização do campus como área de lazer e prática de esportes. Em muitos horários, o fluxo de pessoas, carros e bicicletas é bastante perigoso.

Gostaria de vir de transporte público para a ESALQ, porém a falta de linhas (e poucos horários) entre minha casa e a faculdade, mais a dificuldade de se locomover dentro da ESALQ me fazem optar pelo carro

\section{Circulação de ônibus no campus}

Acredito que a existência de bicicletas de aluguel (tipo bike Sampa-Itaú) com preços módicos, poderiam ser de interesse da comunidade para distâncias mais longas no campus.

Implantação de ciclovia ou ciclofaixa para o campus e para o acesso ao campus da ESALQ. Nenhuma ação de mobilidade impacta na minha rotina porque moro a $28 \mathrm{~km}$ do campus. Impossível ir de outra forma que não seja carro. Já procurei por vans ou fretados, mas infelizmente não encontrei.

O campus é pouco arborizado (nas calçadas das ruas principais), o que faz com que a maioria dos caminhos sejam feitos debaixo de sol. Esse é um dos motivos para que eu, e a maioria das pessoas que conheço, utilizem carro pra se locomover dentro do campus, ao invés de ir agradavelmente a pé, pelas sombras. Chega a ser cômico um campus com tantas árvores só ter caminhos ensolarados para os principais prédios (Rucas, prédio principal, genética, horticultura, cena, etc). Mobilidade dentro do campus, esse é o principal ponto a ser abordado.

Acessibilidade para pessoas com mobilidade reduzida, estacionamento (motos, bicicletas)

eu transformaria a calçada da atletica das av. Padua Dias e Independencia em ciclovia. Tem como 15 metros inuteis dentro da Atletica, nas margens da mesma (com um mato de 1 metro de alto) e por fora a calçada so pode circular uma linha de pessoas...totalmente ineficiente o uso do espaço..

Melhor as condições de acesso, a pé ou de bicicleta. entre a avenida Centenário e as entrada CENA e a principal e a da Engenharia da ESALQ

a presença de ciclovias em ambiente universitário

É interessante completar que não há experimentos somente na fazenda Areião mas também lá perto do $c p z$, onde se necessita subir um morro bastante inclinado, com estrada de terra que fica muito perigoso em épocas de chuva.

Precisa urgente de um onibus entre a ESALQ e o CENA. O caminho é longo e passa por trechos com terra se você fizer o percurso dentro da universidade. É uma vergonha a ESALQ com tantos 
onibus e motoristas não por a disposição uma van que faça viagens ESALQ-CENA-ESALQ a cada 60 minutos pelo menos.

Frequentei o Campus de 2005 A 2009 (graduação - bike em 2005 e 2006, carona em 2006 e motocicleta 2006 a 2009) e na pós-graduação (2011 a 2013 - Carro e Bike). Sempre que pude optei por ir de Bike à escola, porém a condição de acessibilidade pelas vias públicas pioraram muito. Piracicaba cresceu nesse período. Aumentou muito o fluxo de veículos e a absurdamente a quantidade de semáforos, o que fez com que o transito piorasse e consequentemente a convivência entre veículos motorizados e bicicletas piorou muito. Percebi que com a maior quantidade de semáforos e veículos, o tempo de deslocamento de veículos motorizados aumentou muito em Piracicaba, e com isso os condutores ficaram mais intolerantes aos ciclistas. Isso fez com que, durante a pós graduação, optasse por ir de carro do São Judas até a universidade. Tentei ir a pé, mas não me sentia seguro em caminhar e levar o Notebook todo dia pelas ruas de Piracicaba, sendo um alvo fácil para roubo. Dentro do campus, percebi que de 2005 a 2013 aumentou a quantidade de alunos com carros próprios que não compartilham carona, impactando no aumento de veículos dentro do campus, ausência de vagas, transito na entrada e saída nos horários de pico. Enfim, acredito que está tudo relacionado à tolerância e egoísmo. A facilidade de deslocamento (ter carro próprio) faz com que um aluno não espere o outro que muitas e vezes mora na mesma casa. Há varia formas de explorar esse "aguardo", como estimular o uso das biblioteca, oferecer e estimular atividades físicas no espaço (enquanto aguarda seu colega), estimular atividades culturais e uso de espaços comum, como o centro de vivência, "estude no gramado". Há muito o que podemos fazer pelo Campus para melhorar a mobilidade, internamente e externamente. Para incentivar o usuário a ir caminhando, deveria se ter mais segurança no tranjeto: Iluminação, câmeras de vigilância na calçada da atlética. para incentivar o uso de biciletas, precisaria de uma melhoria viária nas vias secundárias, "aliviando" a circulação das bicicletas nas avenidas principais e conduzindo as bikes por ruas alternativas, como a São João, etc. Para diminuir o fluxo interno de carros, precisamos incentivar o pensamento do bem coletivo. Diminuir o $n^{\circ}$ interno de vagas ao invés de aumentá-los pode ser uma boa alternativa. Caso tenha interesse em conversar a respeito, coloco-me a disposição

Aumentar a frota de ônibus que acessam a ESALQ e melhorar o programa de mobilidade interna do campus via bicicletas.

Os postos de ônibus precisam melhoras pata o resguardo da chuva e o sol. O campus precisa de ciclovias. Engeharia precisa calzadas para pesdestres.

O acesso para o Restaurante Universitario nao tem uma via para bicicleta. O local concentra estudantes em horario de pico e que utilizam-se de bicicleta, mas precisan dividir o espaço na avenida com carros, pedestres, estacionamento ao longo da via. Outro problema na via que leva ao refeitório é o uso de contra-mão pelos ciclistas, pois para voltar de bicicleta pela mão correta, para os predios da aula apos o almoço é preciso dar uma volta grande, pela biblioteca. Tenho certeza que se melhorar o acesso de bicicletas para o RUCAS, mais pessoas usarão bike no campus.

incentivo à criação de um bolsão de estacionamento que, junto a um sistema de transporte eficiente, não predudique o traçado original do Parque da ESALQ, tombado, e atinja o objetivo de levar, com eficiência, o usuário, aonde quer ir. Procurar implantar, junto à PMPiracicaba, o antigo projeto de reforma do traçado da av Centenário, ligando-a, diretamente com a av Independência e av Padua Dias, na caixa d'água, de modo que toda a avenida frontal ao ginásio, assim como a estrada de Monte Alegre, sejam incorporadas à ESALQ. Enquanto os interesses particulares não derem lugar a um bem comum, as discussões e propostas sobre esse tema, por mais bem intencionadas que sejam, não levam a nada.... Escrevo isso, tentando ajudar e como experiência própria, de quem presenciou o fluxo de veículos e de pessoas aumentar muito, além de ter se envolvido pessoal e profissionalmente, para melhorar tais condições.

Acredito que deveria haver alguma medida que fizesse com que os estudantes que residem na vizinhança da Esalq (bairros Vila Independência, São Judas, São Dimas) passassem a utilizar bicicletas, ou caminhar até o campus, contribuindo não apenas para o meio ambiente, bem como para a mobilidade do campus. 
sugestão: nivelar as alamedas do campus, colocando calçadas

\section{Construir uma passarela na Luiz de Queiroz}

Dar mais atenção e fomento às bicicletas. A mobilidade para acessar o campus é ruim, precisaria de uma parceria com a prefeitura para melhorar isso. Ciclovias na Independência, Carlos Botelho e centenário é essencial, na verdade, um absurdo não existir ainda. Dentro do campus também tem o que melhorar. Estudar o custo de existir um transporte coletivo tipo "looping" gratuito entre entomologia e Rucas com horários determinados, este trajeto atenderia várias demandas e não só a de ir almoçar. Fomentar bicicletas e coletivo em detrimento aos carros. Professor também pode pedalar ou é proibido?

Se houvesse a possibilidade de uma ciclovia na centenário, seria ótimo

há necessidade de colocar uma passarela no portão da entomologia, pois o acesso para a faculdade é dificultada devido ao elevado fluxo de veículos na rodovia Luiz de Queiroz.

Os automóveis dentro do Campus ESALQ/Piracicaba, não respeitam sinalizações para estacionar, a guarda nem verbalmente adverte e nem orienta quanto ao assunto. Muitos alunos e funcionários que andam de motocicleta dentro do Campus, circulam sem capacete. Os alunos e as pessoas que praticam atividades físicas, andam fora de calçadas e não desviam do caminho para que os automóveis (também oficiais), possam circular normalmente. As pessoas que praticam atividades físicas, se esquecem que somos uma instituição de ensino e um local de trabalho, desrespeitando o trânsito que muitas das vezes, os veículos oficiais tem de parar o trânsito ou desviar fora da via para eles caminharem ou correrem (não desviam mesmo vindo de frente). Faço parte da comissão (nome suprimido), estou fazendo uma cartilha para distribuirmos. Acredito que podemos melhorar e mudar a Mobilidade da USP. Em aspecto trajeto casa/Esalq, acredito que um ônibus (empresa terceira contratada), seria a soluções para todos virem trabalhar com segurança sem imprevistos, com menos riscos e para que todos cumpram os horários tranquilamente.

O principal problema relacionado a mobilidade está fora do campus, está na cidade. Utilizo a Av. Independência para me deslocar de bicicleta até a universidade e sofro riscos diariamente pela falta de respeito dos motoristas. É necessário que haja uma ciclovia urgentemente, pelo menos na Av. independência e na Carlos Botelho, que são as mais movimentadas por ciclistas.

Um dos grandes problemas de mobilidade interna no campus se refere a falta de respeito que os carros tem com os pedestres e com os ciclistas, principalmente por andarem em alta velocidade. Talvez a instalação de radares que aplicassem multas pudesse ajudar nesse sentido, o dinheiro arrecadado pode ser revertido para benefícios dos alunos. Outra questão fundamental é que é muito difícil reduzir o número de carros no campus se a cidade como um todo não oferece outras boas possibilidades de mobilidade, o transporte público é péssimo e com poucas linhas e quase não há ciclofaixas, esses elementos desestimulam o uso de outros tipo de transporte.

intensificar campanha de valorização do pedestre. Mobilidade não é só bicicleta.

Seria interessante ter ciclovias nas Avenidas principais de acesso à Esalq/Cena para tornar o transporte de bicicleta seguramente viável.

Eu gostaria muito de poder vir de bicicleta ao campus, para isso, usaria a avenida independencia. O problema é que é uma avenida projetada apenas para carros, quase fui atropelada e desisti de usar bicicleta, e acho isso uma pena. Caso houvesse uma ciclovia, viria de bicicleta sem dúvidas. Se vocês puderem ajudar quanto a isso, junto a prefeitura de Piracicaba, agradeceria muito.

Bolsões de estacionamento; Limitação do tráfego de veículos automotores particulares no Campus; Condições para o trânsito de pedestres no Campus. 
Sugiro uma linha de micro-ônibus de circulação interna para facilitar os deslocamentos no campus da ESALQ.

Necessidade de ciclofaixa até o rucas; Aumentar estímulo para diminuição de carros: incentivo à carona, ao uso de bicicleta, caminhadas e transporte público. Conscientização ao uso abusivo e desnecessário de combustíveis fosseis (gasolina e diesel)

As ações no campus sobre modalidade são mal formuladas. É um problema do campus a falta de calçadas para pedestres e transportes para circulação interna. Mas se vê uma ação de mobilidade onde se criou uma ciclofaixa em um lugar com baixa circulação de carros, onde bicicletas e automóveis convivem pacificamente (o problema maior são os roubos de bicicleta no campus... nunca ouvi falar em acidentes). Creio que deveriam se preocupar com pedestres e pessoas com baixa locomoção, e ainda buscar descentralizar os serviços do campus, que obrigam grandes deslocamentos desnecessários. Em outros campus da USP as secretarias, refeitórios, lanchonetes, caixas eletrônicos e etc são descentralizados, o que evita a maior parte dos deslocamentos.

Construção de ciclofaixa na independência e centenário para facilitar o acesso de bicicletas ao campus.

Para quem anda à pé, as ruas do campus não são boas, principalmente na região mais central, onde as laterais são em desnível, obrigando a pessoa a andar no meio da rua.

Sou deficiente fisica e nao posso me locomover de outro modo... ou de forma sustentavel. A nao ser que o campus ofereça algum tipo de transporte interno eu tenho que retirar meu carro para fazer serviços internos de campus pra campus

Acredito que um transporte interno é imprescindível aos alunos, uma vez que, muitos se descolam a pé e possuem aulas que terminam às 9:50h, por exemplo, em um local muito distante da próxima aula que se inicia às $10 \mathrm{~h}$.

Faltam calçadas no campus o que para mim faz com que use o carro para deslocamentos internos.

Estudo para locais de estacionamento fora do campus

Precisamos urgentemente de bolsões de estacionamento dentro do Campus, melhor sinalização, mais fiscalização quanto a infrações (especialmente limites de velocidade), e placas indicativas sobre o caminho a seguir para se chegar a este ou aquele local. Principalmente para quem é de fora. E lugar de pedestre caminhando não é na rua. Precisamos de mais calçadas. Calçadas boas.

Limitação de um selo de veículo por aluno apenas.

\section{PESQUISA PERTINENTE SUCESSO NOS SEUS TRABALHOS E ESTUDOS}

Campanhas educativas e ações de fiscalização de normas de trânsito, em especial no uso de faixas de pedestres.

ciclofaixas em todas as vias principais do campus

campanhas de mobilidade devem ser efetuadas por processos educativos e de conscientização e NUNCA POR FORÇAMENTO DE BARRA COMO FECHAR VIAS, ETC.

Talvez se em alguns departamentos ou na biblioteca tivessem armários que pudéssemos deixar o notebook ou livros até o dia seguinte, fosse mais fácil optar por vir à universidade a pé ou de bicicleta. No entanto, mesmo sabendo sobre sustentabilidade e querendo ser mais sustentável, 
acabo optando por vir de carro por que sempre temos livros pesados, computador etc para carregar.

O dia em que os exigentes mas inconsequentes membros do corpo discente pararem de andar de bicicleta na contramão e que os pedestres que invadem nosso campus entenderem que aqui a gente trabalha mas o pedestre mal educado atrapalha, tudo melhora muito.

Faixas de pedestre e sinalização de redução de velocidade na Pádua Dias para auxiliar os estudantes que vem do bairro para o portão da prefeitura e entrada da entomologia

O problema da mobilidade (transporte das pessoas) - e a sua sustentabilidade - é um problema nacional/internacional. As pessoas utilizam o transporte veicular individual por falta de alternativa de transporte público com relação benefício-custo positivo.

A linha de ônibus é péssima. Eu venho de carro porque o ônibus é ruim. Deveria ter um transporte interno para os estudantes também.

A ESALQ é conhecida por antigamente ser sevida por um serviço de bondes que pegavam os alunos no centro e os levavam até a ESALQ. Uma linha de microonibus nas Avenidas Independencia e Carlos Botelho seriam muito bem vindas. Se tiver a opção de linhas internas, com opção de transportar uma bicicleta, melhor ainda.

Apesar de muitas pessoas não utilizarem o transporte público, e esta pesquisa irá mostrar isso, acho que deveriam haver mais ônibus que se desolcam do terminal central para a Esalq, CENA, e vice e versa. A mobilidade dentro do campus é escassa, os departamentos são distantes, mas não há um transporte interno, como nas outras universidades que tive acesso. Isso deveria ser seriamente pensado... outra sugestão seria o fornecimento de bicicletas para deslocamento dentro do campus. Cabe ressaltar que praticamente nenhum motorista respeita a velocidade dentro do campus, e quase não há calçadas ideais para os pedestres... percebi que em algumas vias isso já está sendo providenciado, espero que todas as vias sejam atendidas... pois há trechos que nós, pedrestres, atrapalhamos o trânsito de veículos por não haver calçada. Eu venho de carona com carro todos os dias, mas para ir de um departamento a outro, vou a pé. Por isso, exponho minhas dificuldades. Att

Estudo do número de vagas disponíveis, estudo de cobrança de estacionamento, estudo de estacionamento rotativo, controle de estacionamento em casos de abandono de veículo por tempo determinado, treinamento dos seguranças nas guaritas para garantir o acesso de pessoas com atividades profissionais no campo.

O respeito as sinalizações por parte das pessoas que vem caminhar no Campus, principalmente na saída ESALQ/ENGENHARIA, onde não se tem visibilidade ao atravessar a via. 


\begin{abstract}
APÊNDICE C
RESPOSTAS DO QUESTIONÁRIO ONLINE (PARTE 2)
\end{abstract}

POTENCIAL DE TRANSFERÊNCIA DE UM ÍNDICE DE MOBILIDADE SUSTENTÁVEL PARA CAMPUS UNIVERSITÁRIO

Francine Marvulle Tan

São Carlos

2018 


\section{Sumário}

Modo: A pé 3

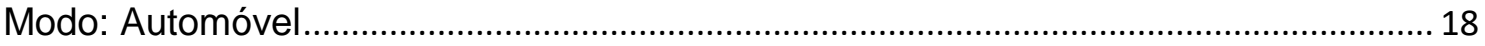

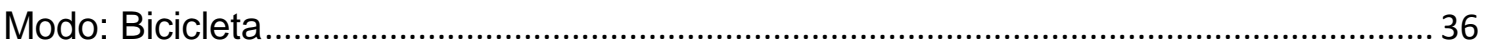

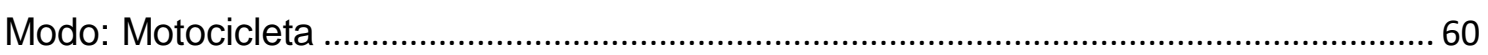

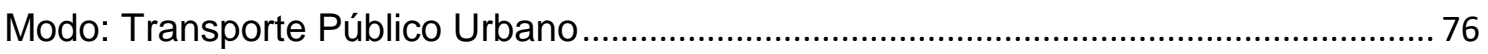




\section{Modo: A pé}

\section{Analisando o campus da ESALQ/CENA como um todo, você o considera acessível aos usuários com algum tipo de restrição de mobilidade?}

Não sou capaz de opinar, pois nunca analisei o campus sob este aspecto

Não. O campus não oferece condições básicas de acessibilidade aos usuários com algum tipo de restrição de mobilidade

Pequena parte do campus é acessível. Há diversas áreas que não oferecem condições básicas de acessibilidade aos usuários com algum tipo de restrição de mobilidade

Grande parte do campus é acessível. Algumas áreas possuem obstáculos, mas de maneira geral considero o campus acessível aos usuários com algum tipo de restrição de...

Sim. Nunca notei obstáculos que dificultassem a acessibilidade aos usuários com algum tipo de restrição de mobilidade nas dependências do campus

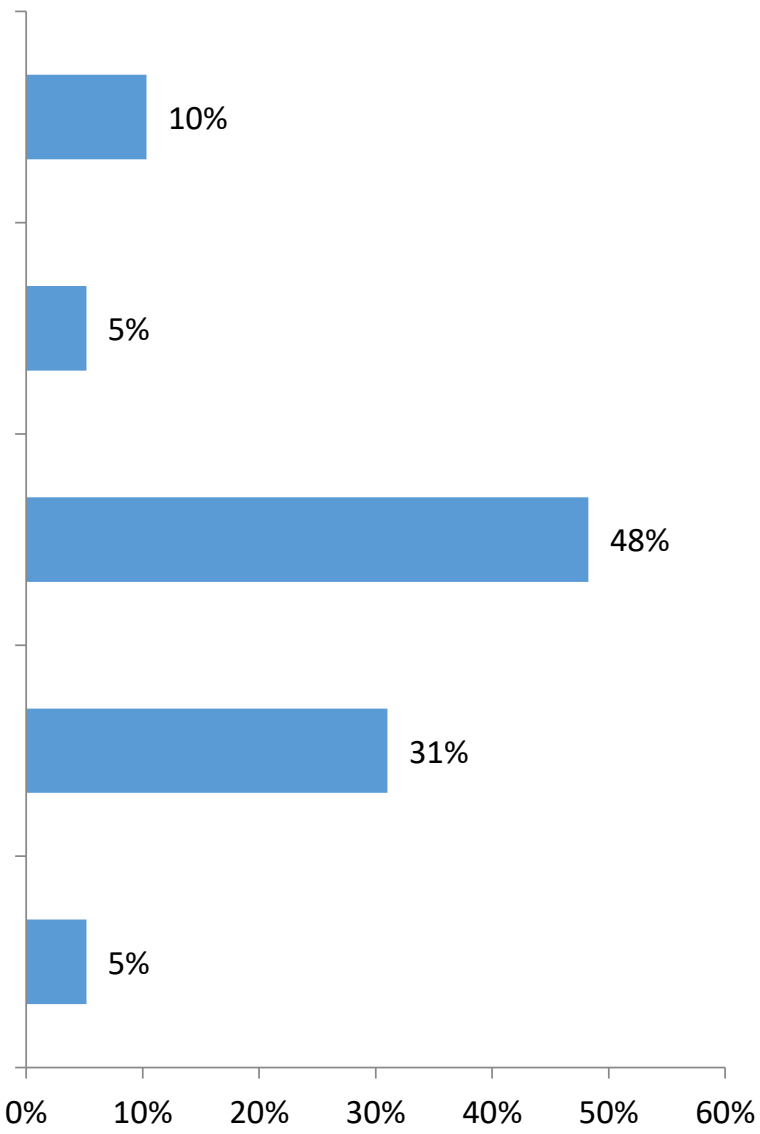

Sim. Nunca notei obstáculos que dificultassem a acessibilidade aos usuários com algum tipo de restrição de mobilidade nas dependências do campus

Grande parte do campus é acessível. Algumas áreas possuem obstáculos, mas de maneira geral considero o campus acessível aos usuários com algum tipo de restrição de mobilidade

Pequena parte do campus é acessível. Há diversas áreas que não oferecem condições básicas de acessibilidade aos usuários com algum tipo de restrição de mobilidade

Não. O campus não oferece condições básicas de acessibilidade aos usuários com algum tipo de restrição de mobilidade

$5 \% \quad 3$

Não sou capaz de opinar, pois nunca analisei o campus sob este aspecto

$10 \% \quad 6$


Dentre os prédios que frequenta na ESALQ/CENA, como você avalia a acessibilidade para os usuários com algum tipo de restrição de mobilidade?

Não sou capaz de avaliar, pois nunca analisei os prédios da ESALQ/CENA sob este aspecto

Ruim. Prédios não equipados para receber os usuários com algum tipo de restrição de mobilidade

Regular. Prédios pouco equipados, com limitações para atender os usuários com algum tipo de restrição de mobilidade

Boa. Prédios parcialmente equipados, mas possuem condições satisfatórias para atender os usuários com algum tipo de restrição de mobilidade

Ótima. Prédios totalmente equipados para receber os usuários com algum tipo de restrição de mobilidade

$7 \%$

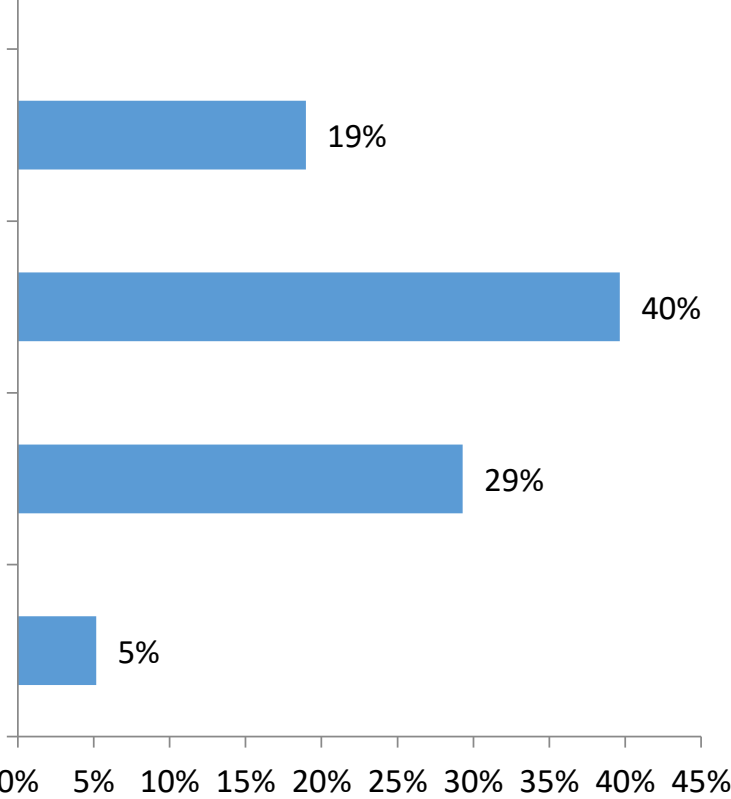

Ótima. Prédios totalmente equipados para receber os usuários com algum tipo de restrição de mobilidade $5 \% \quad 3$

Boa. Prédios parcialmente equipados, mas possuem condições satisfatórias para atender os usuários com algum tipo de restrição de mobilidade $29 \% \quad 17$

Regular. Prédios pouco equipados, com limitações para atender os usuários com algum tipo de restrição de mobilidade $40 \% \quad 23$

Ruim. Prédios não equipados para receber os usuários com algum tipo de restrição de mobilidade $19 \% \quad 11$

Não sou capaz de avaliar, pois nunca analisei os prédios da ESALQ/CENA sob este aspecto

$7 \% \quad 4$


$\mathrm{Na}$ etapa anterior do questionário, você nos informou que seu modo principal para os deslocamentos à ESALQ/CENA é o modo A PÉ. Quais fatores o/a levam a optar por este modo?

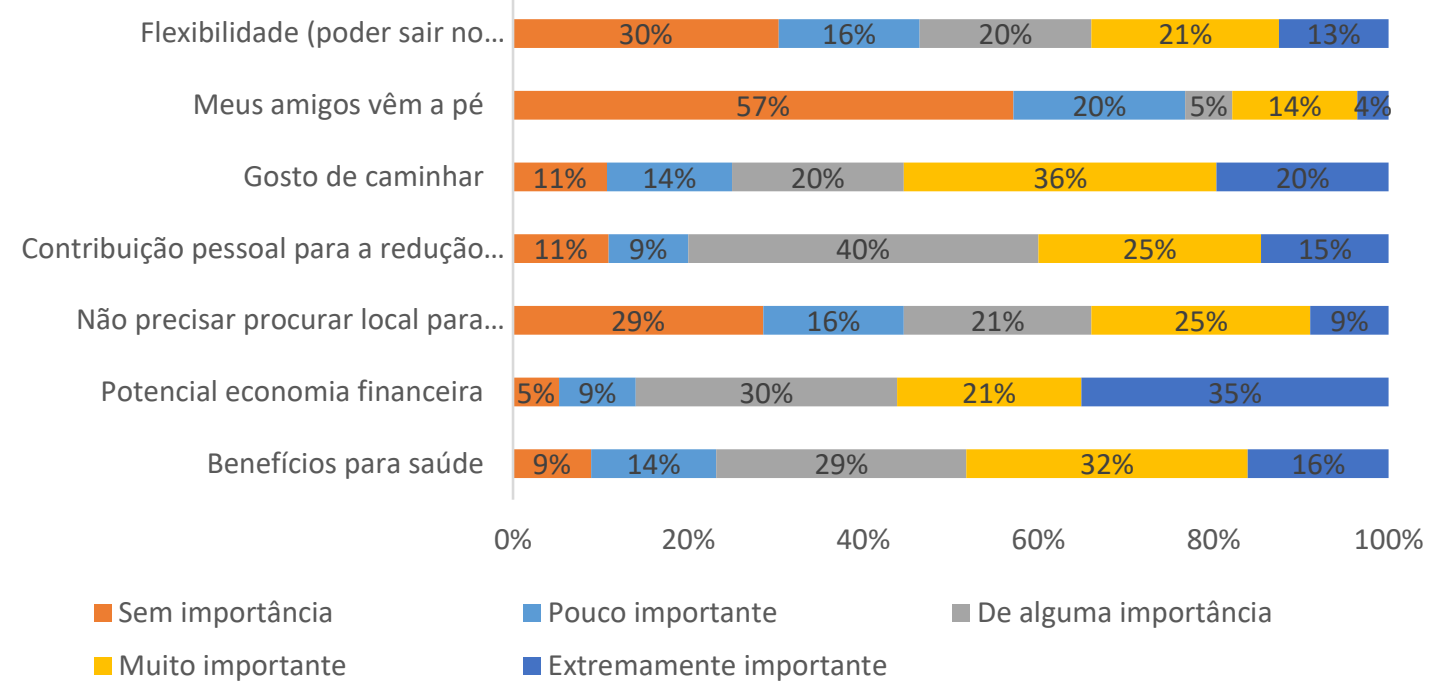

\begin{tabular}{|c|c|c|c|c|c|c|c|c|c|c|}
\hline \multirow[b]{2}{*}{$\begin{array}{l}\text { Benefícios para } \\
\text { saúde }\end{array}$} & \multicolumn{2}{|c|}{$\begin{array}{l}\text { Sem } \\
\text { importância }\end{array}$} & \multicolumn{2}{|c|}{$\begin{array}{c}\text { Pouco } \\
\text { importante }\end{array}$} & \multicolumn{2}{|c|}{$\begin{array}{l}\text { De alguma } \\
\text { importância }\end{array}$} & \multicolumn{2}{|c|}{$\begin{array}{c}\text { Muito } \\
\text { importante }\end{array}$} & \multicolumn{2}{|c|}{$\begin{array}{l}\text { Extremamen } \\
\text { te importante }\end{array}$} \\
\hline & $9 \%$ & 5 & $14 \%$ & 8 & $29 \%$ & 16 & $32 \%$ & 18 & $16 \%$ & 9 \\
\hline $\begin{array}{l}\text { Potencial } \\
\text { economia } \\
\text { financeira }\end{array}$ & $5 \%$ & 3 & $9 \%$ & 5 & $30 \%$ & 17 & $21 \%$ & 12 & $35 \%$ & 20 \\
\hline $\begin{array}{l}\text { Não precisar } \\
\text { procurar local para } \\
\text { estacionar }\end{array}$ & $29 \%$ & 16 & $16 \%$ & 9 & $21 \%$ & 12 & $25 \%$ & 14 & $9 \%$ & 5 \\
\hline $\begin{array}{l}\text { Contribuição } \\
\text { pessoal para a } \\
\text { redução dos níveis } \\
\text { de poluição do ar }\end{array}$ & $11 \%$ & 6 & $9 \%$ & 5 & $40 \%$ & 22 & $25 \%$ & 14 & $15 \%$ & 8 \\
\hline Gosto de caminhar & $11 \%$ & 6 & $14 \%$ & 8 & $20 \%$ & 11 & $36 \%$ & 20 & $20 \%$ & 11 \\
\hline $\begin{array}{l}\text { Meus amigos vêm } \\
\text { a pé }\end{array}$ & $57 \%$ & 32 & $20 \%$ & 11 & $5 \%$ & 3 & $14 \%$ & 8 & $4 \%$ & 2 \\
\hline $\begin{array}{l}\text { Flexibilidade } \\
\text { (poder sair no } \\
\text { momento em que } \\
\text { desejar, fazer } \\
\text { paradas durante o } \\
\text { trajeto, etc.) }\end{array}$ & $30 \%$ & 17 & $16 \%$ & 9 & $20 \%$ & 11 & $21 \%$ & 12 & $13 \%$ & 7 \\
\hline
\end{tabular}


Quais fatores o/a desestimulam a utilizar os demais modos que não o modo a pé em seus deslocamentos?

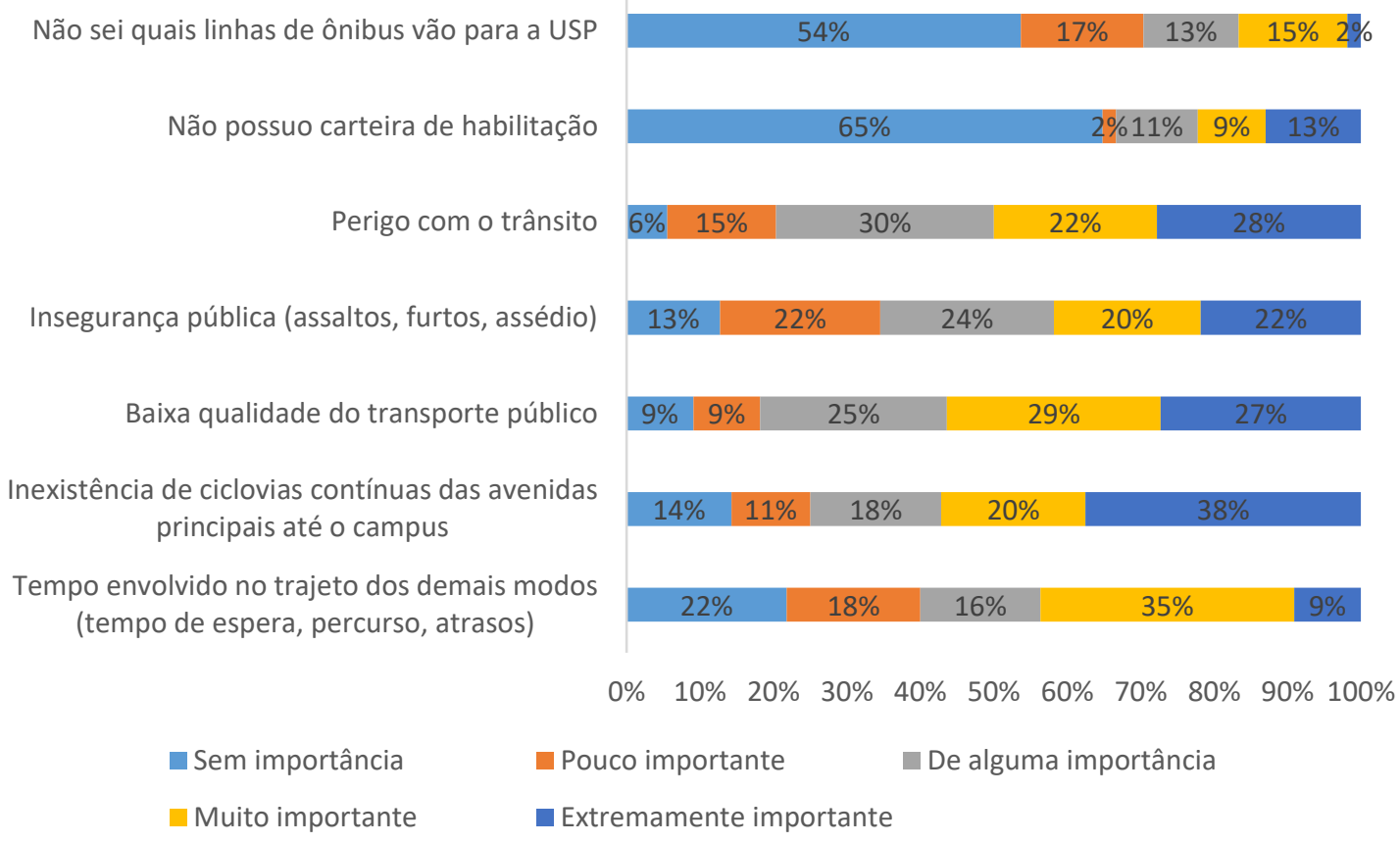

\begin{tabular}{|c|c|c|c|c|c|c|c|c|c|c|}
\hline \multirow{2}{*}{$\begin{array}{l}\text { Tempo envolvido no } \\
\text { trajeto dos demais } \\
\text { modos (tempo de } \\
\text { espera, percurso, } \\
\text { atrasos) }\end{array}$} & \multicolumn{2}{|c|}{$\begin{array}{c}\text { Sem } \\
\text { importância }\end{array}$} & \multicolumn{2}{|c|}{$\begin{array}{c}\text { Pouco } \\
\text { importante }\end{array}$} & \multicolumn{2}{|c|}{$\begin{array}{l}\text { De alguma } \\
\text { importância }\end{array}$} & \multicolumn{2}{|c|}{$\begin{array}{l}\text { Muito } \\
\text { importante }\end{array}$} & \multicolumn{2}{|c|}{$\begin{array}{c}\text { Extremamen } \\
\text { te } \\
\text { importante }\end{array}$} \\
\hline & $22 \%$ & 12 & $18 \%$ & 10 & $16 \%$ & 9 & $35 \%$ & 19 & $9 \%$ & 5 \\
\hline $\begin{array}{l}\text { Inexistência de } \\
\text { ciclovias contínuas } \\
\text { das avenidas } \\
\text { principais até o } \\
\text { campus }\end{array}$ & $14 \%$ & 8 & $11 \%$ & 6 & $18 \%$ & 10 & $20 \%$ & 11 & $38 \%$ & 21 \\
\hline $\begin{array}{l}\text { Baixa qualidade do } \\
\text { transporte público }\end{array}$ & $9 \%$ & 5 & $9 \%$ & 5 & $25 \%$ & 14 & $29 \%$ & 16 & $27 \%$ & 15 \\
\hline $\begin{array}{l}\text { Insegurança pública } \\
\text { (assaltos, furtos, } \\
\text { assédio) }\end{array}$ & $13 \%$ & 7 & $22 \%$ & 12 & $24 \%$ & 13 & $20 \%$ & 11 & $22 \%$ & 12 \\
\hline Perigo com o trânsito & $6 \%$ & 3 & $15 \%$ & 0 & $30 \%$ & 16 & $22 \%$ & 12 & $28 \%$ & 15 \\
\hline $\begin{array}{l}\text { Não possuo carteira } \\
\text { de habilitação }\end{array}$ & $65 \%$ & 35 & $2 \%$ & 1 & $11 \%$ & 6 & $9 \%$ & 5 & $13 \%$ & 7 \\
\hline $\begin{array}{l}\text { Não sei quais linhas } \\
\text { de ônibus vão para a } \\
\text { USP }\end{array}$ & $54 \%$ & 29 & $17 \%$ & 9 & $13 \%$ & 7 & $15 \%$ & 8 & $2 \%$ & 1 \\
\hline
\end{tabular}


Há quanto tempo você utiliza o modo a pé para se deslocar até a ESALQ/CENA?

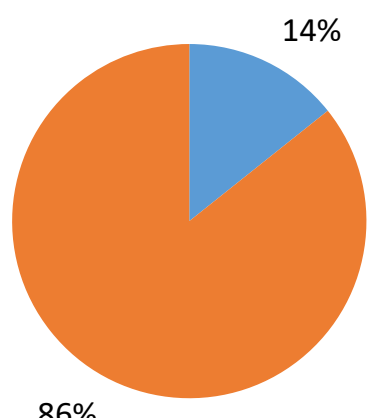

Há menos de 6 meses

$86 \%$

Há menos de 6 meses 14\% 8

Há mais de 6 meses $\quad 86 \% \quad 48$

Dos deslocamentos que você faz hoje a pé, qual modo você utilizava antes?

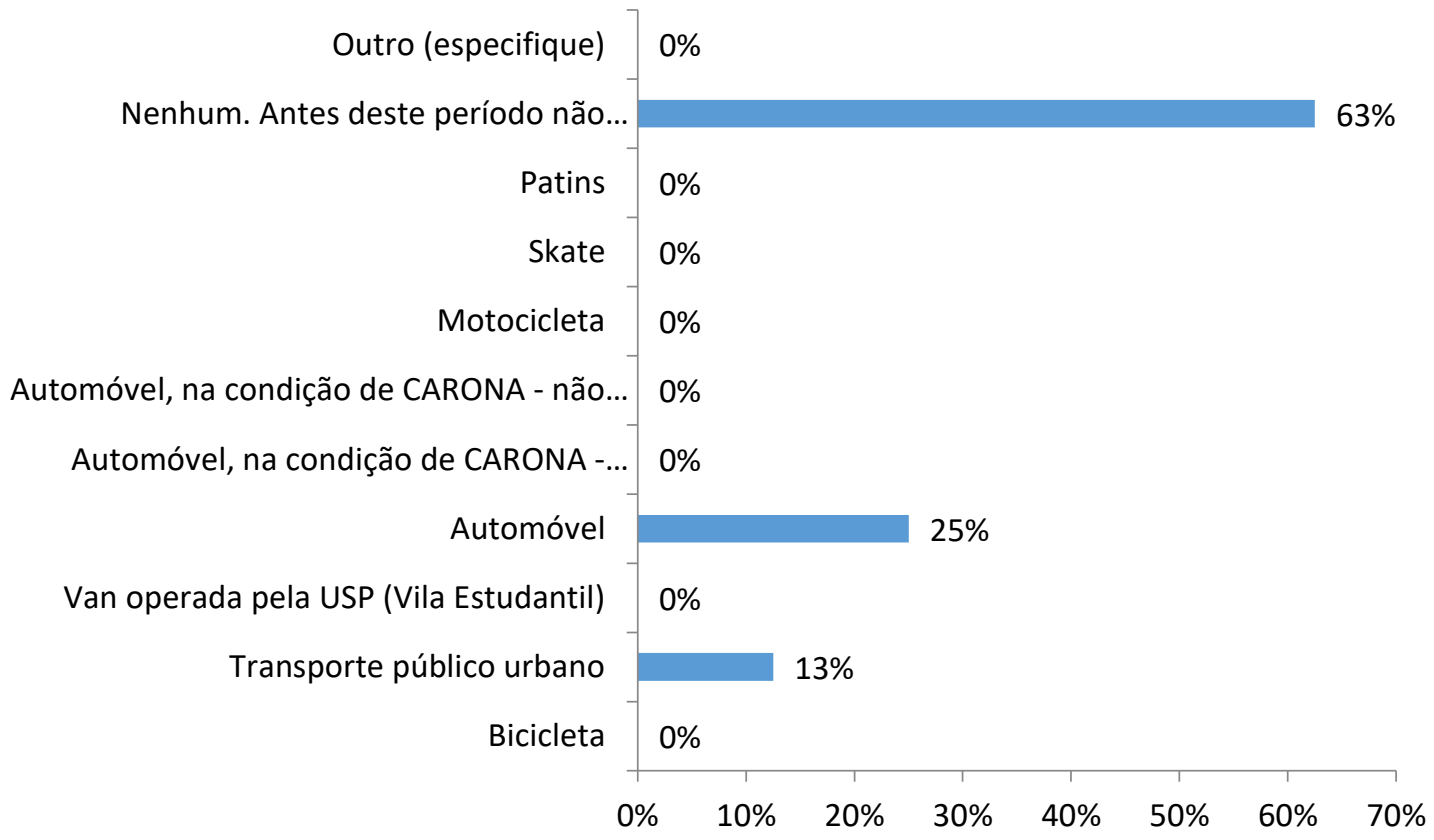




\begin{tabular}{lrr} 
Bicicleta & $0 \%$ & 0 \\
\hline Transporte público urbano & $13 \%$ & 1 \\
\hline Van operada pela USP (Vila Estudantil) & $0 \%$ & 0 \\
\hline Automóvel & $25 \%$ & 2 \\
\hline Automóvel, na condição de CARONA - estaciona no campus & $0 \%$ & 0 \\
\hline Automóvel, na condição de CARONA - não estaciona no campus & $0 \%$ & 0 \\
\hline Motocicleta & $0 \%$ & 0 \\
\hline Skate & $0 \%$ & 0 \\
\hline Patins & $0 \%$ & 0 \\
\hline Nenhum. Antes deste período não frequentava o campus & $63 \%$ & 5 \\
\hline Outro (especifique) & $0 \%$ & 0
\end{tabular}

Classifique, somente para os turnos em que você costuma acessar ou se deslocar AO REDOR da ESALQ/CENA, qual a sua sensação de segurança em relação a assaltos e outros tipos de violência ou assédio:

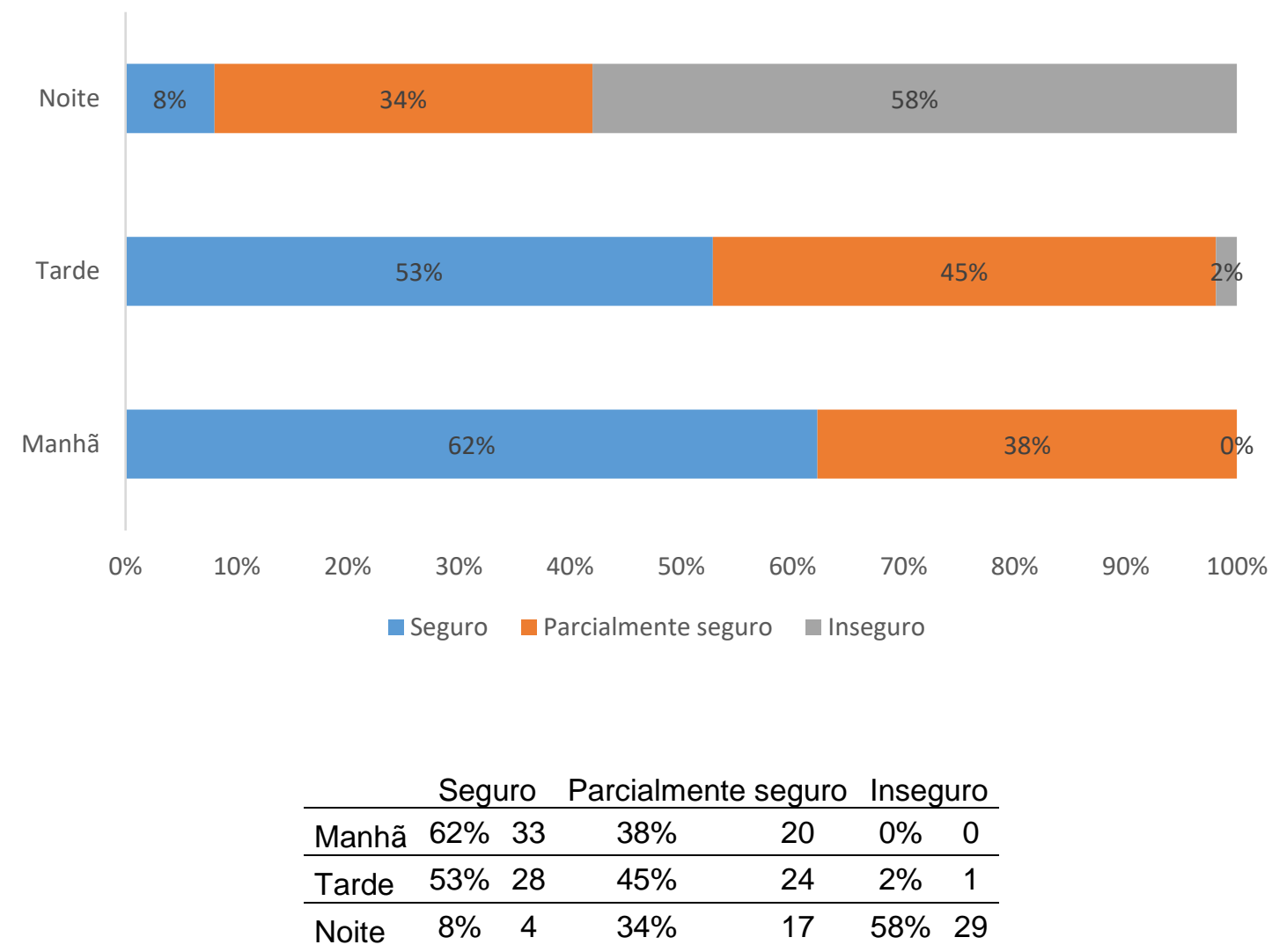


Você presenciou ou sofreu algum tipo de violência ou assédio NO ENTORNO da ESALQ/CENA?

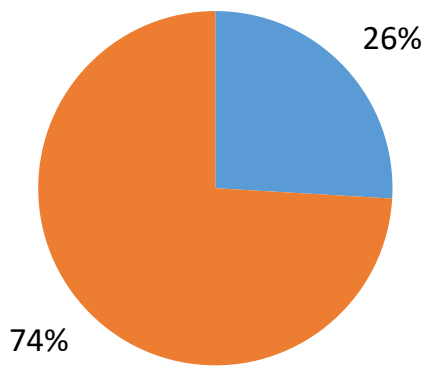

\begin{tabular}{lll} 
Sim & $26 \%$ & 14 \\
\hline Não & $74 \%$ & 40
\end{tabular}

Que tipo de violência ou assédio você presenciou ou sofreu NO ENTORNO da ESALQ/CENA? (se for necessário, marque mais de uma alternativa)

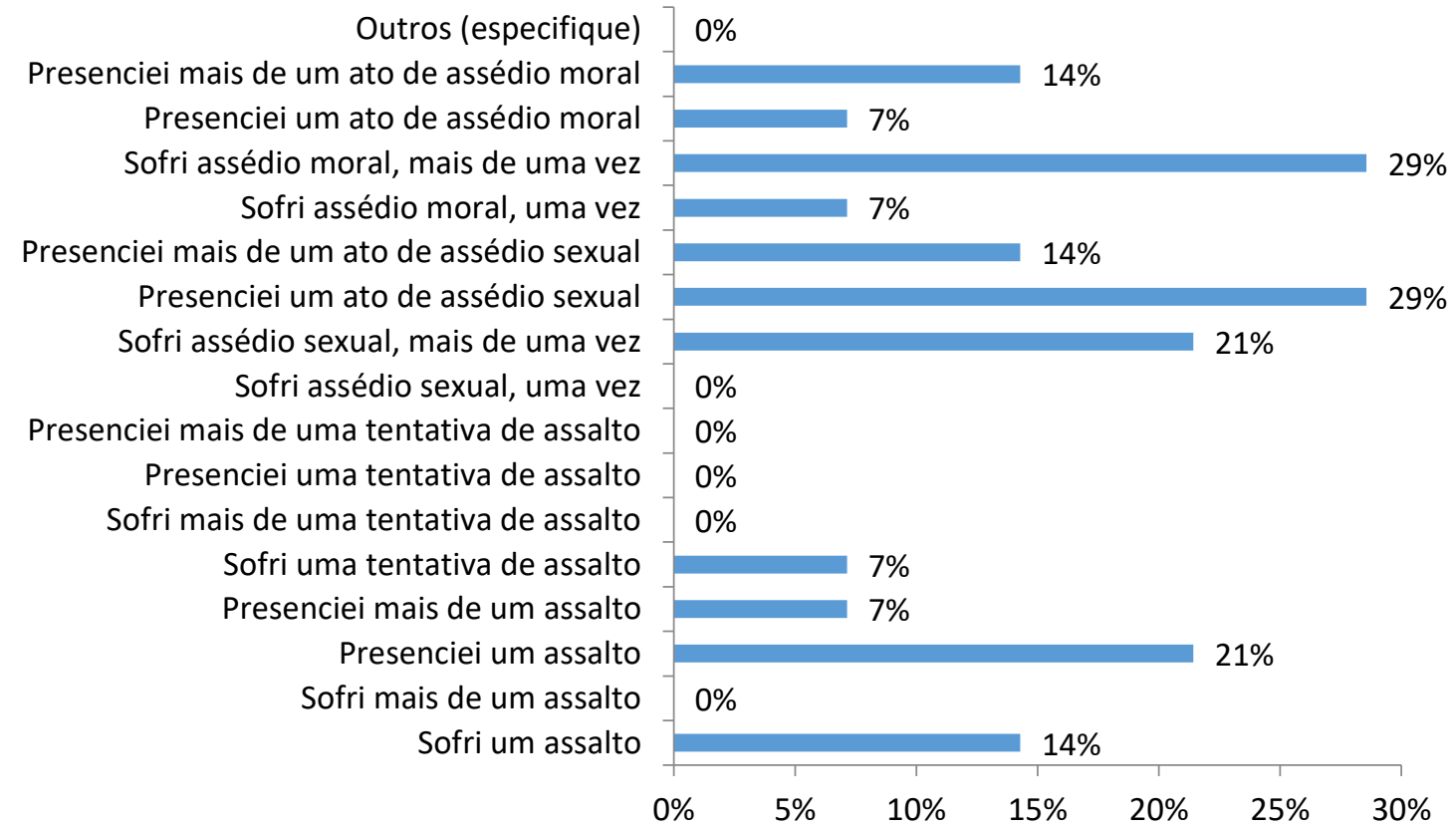




\begin{tabular}{lrr} 
Sofri um assalto & $14 \%$ & 2 \\
\hline Sofri mais de um assalto & $0 \%$ & 0 \\
\hline Presenciei um assalto & $21 \%$ & 3 \\
\hline Presenciei mais de um assalto & $7 \%$ & 1 \\
\hline Sofri uma tentativa de assalto & $7 \%$ & 1 \\
\hline Sofri mais de uma tentativa de assalto & $0 \%$ & 0 \\
\hline Presenciei uma tentativa de assalto & $0 \%$ & 0 \\
\hline Presenciei mais de uma tentativa de assalto & $0 \%$ & 0 \\
\hline Sofri assédio sexual, uma vez & $0 \%$ & 0 \\
\hline Sofri assédio sexual, mais de uma vez & $21 \%$ & 3 \\
\hline Presenciei um ato de assédio sexual & $29 \%$ & 4 \\
\hline Presenciei mais de um ato de assédio sexual & $14 \%$ & 2 \\
\hline Sofri assédio moral, uma vez & $7 \%$ & 1 \\
\hline Sofri assédio moral, mais de uma vez & $29 \%$ & 4 \\
\hline Presenciei um ato de assédio moral & $7 \%$ & 1 \\
\hline Presenciei mais de um ato de assédio moral & $14 \%$ & 2 \\
\hline Outros (especifique) & $0 \%$ & 0
\end{tabular}

Classifique, somente para os turnos em que você costuma acessar ou se deslocar DENTRO da ESALQ/CENA, qual a sua sensação de segurança em relação a assaltos e outros tipos de violência ou assédio:

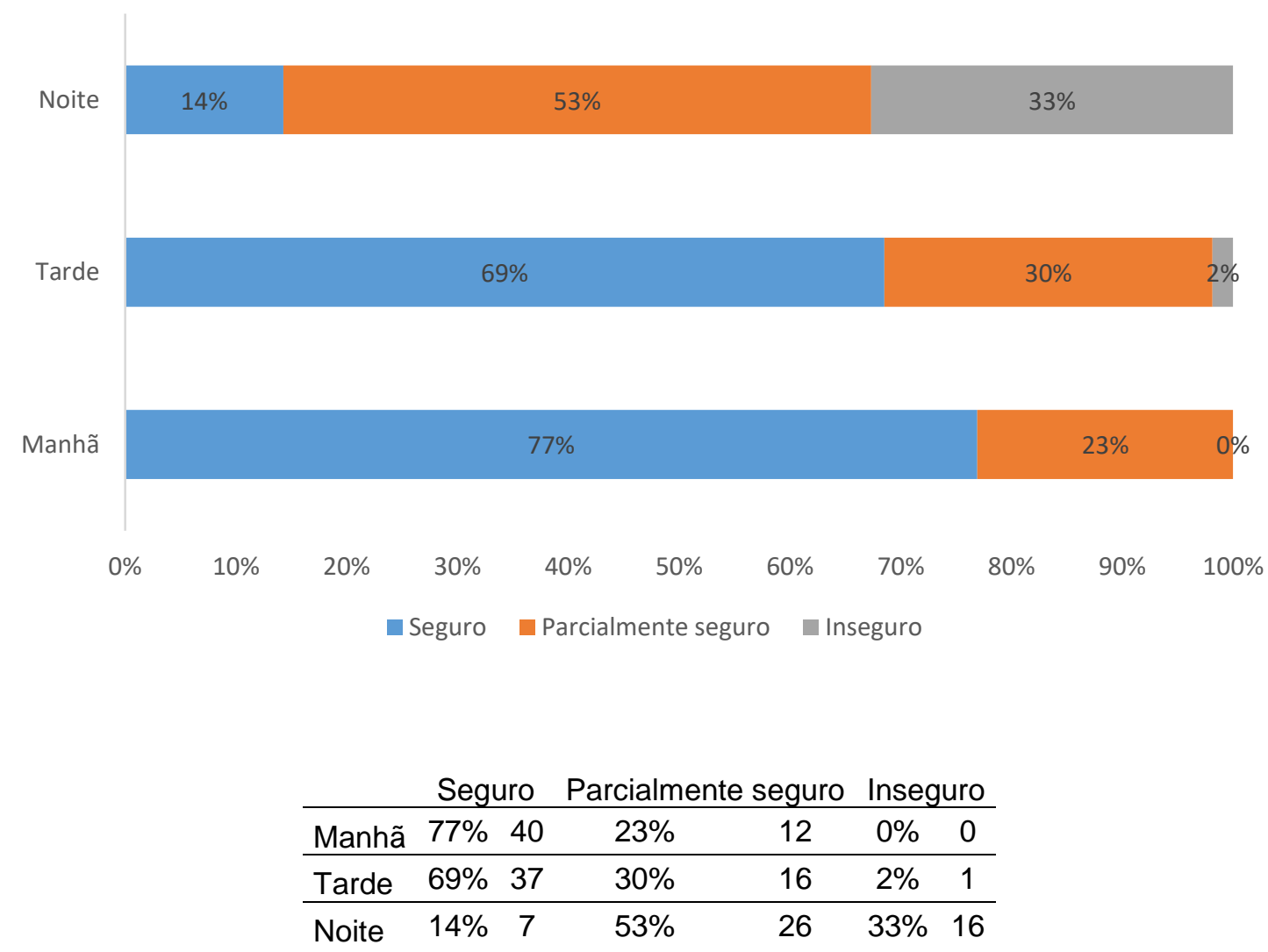


Você presenciou ou sofreu algum tipo de violência ou assédio DENTRO da ESALQ/CENA?

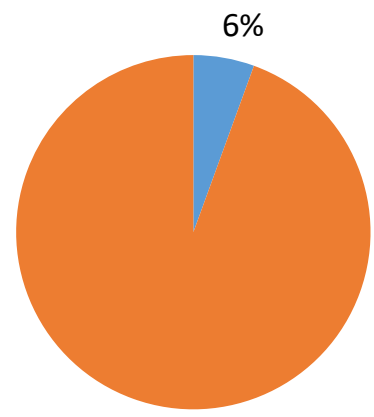

$94 \%$

\begin{tabular}{lrr}
$\operatorname{Sim}$ & $6 \%$ & 3 \\
\hline Não & $94 \%$ & 51
\end{tabular}

Que tipo de violência ou assédio você presenciou ou sofreu DENTRO da ESALQ/CENA? (se for necessário, marque mais de uma alternativa)

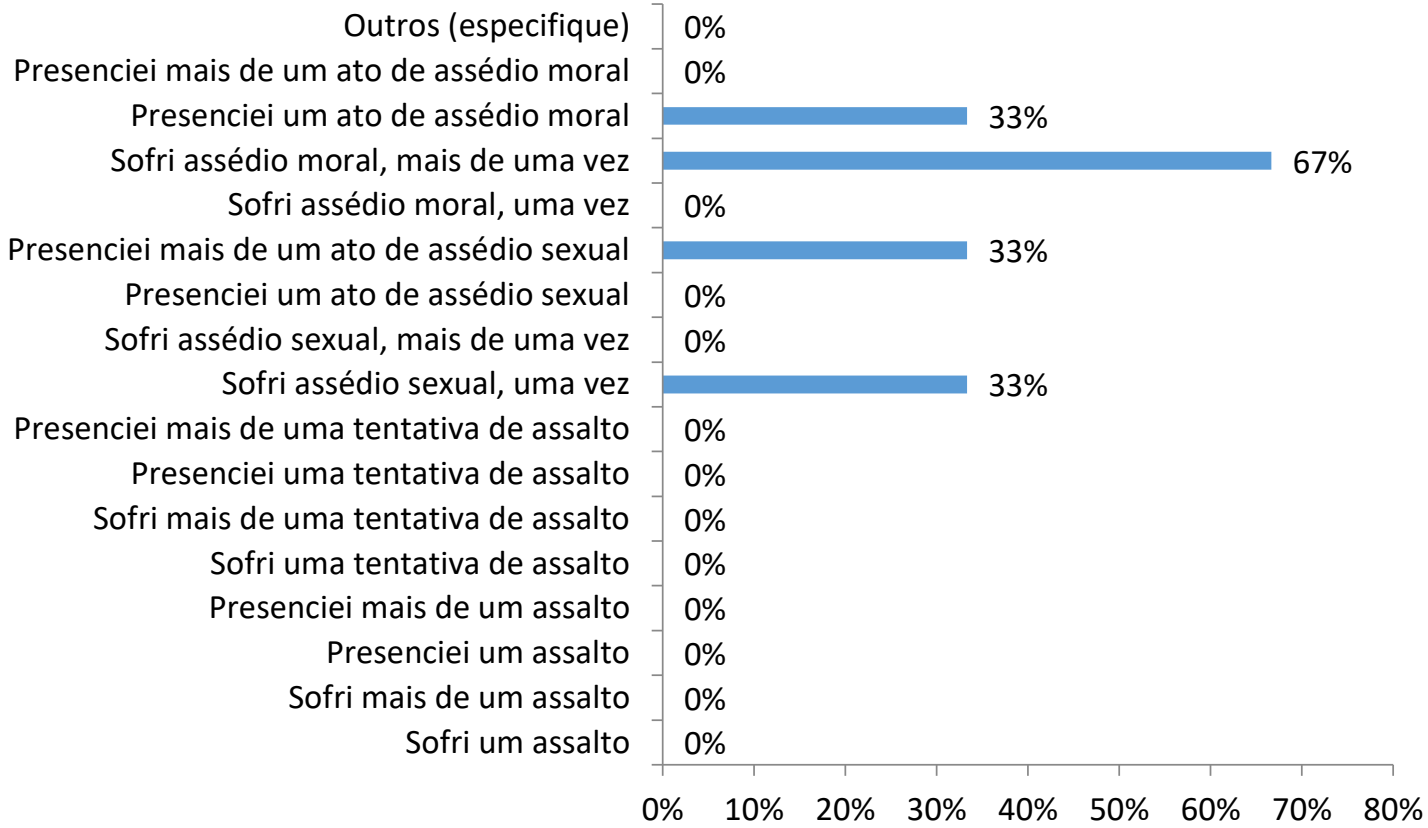


Sofri um assalto

$0 \% \quad 0$

Sofri mais de um assalto

$0 \% \quad 0$

Presenciei um assalto $0 \% \quad 0$

Presenciei mais de um assalto $0 \% \quad 0$

Sofri uma tentativa de assalto $0 \% \quad 0$

Sofri mais de uma tentativa de assalto $0 \% \quad 0$

Presenciei uma tentativa de assalto $0 \% \quad 0$

Presenciei mais de uma tentativa de assalto

Sofri assédio sexual, uma vez $0 \% \quad 0$

Sofri assédio sexual, mais de uma vez $33 \% \quad 1$

Presenciei um ato de assédio sexual $0 \% \quad 0$

$\begin{array}{lll}\text { Presenciei mais de um ato de assédio sexual } & 33 \% & 1\end{array}$

Sofri assédio moral, uma vez $0 \% \quad 0$

Sofri assédio moral, mais de uma vez $67 \% 2$

Presenciei um ato de assédio moral $33 \% 1$

Presenciei mais de um ato de assédio moral Outros (especifique) $0 \% \quad 0$ $0 \% \quad 0$ 
Com relação a medidas de segurança no ENTORNO e DENTRO da ESALQ/CENA, você é favorável a (se for necessário, marque mais de uma alternativa):

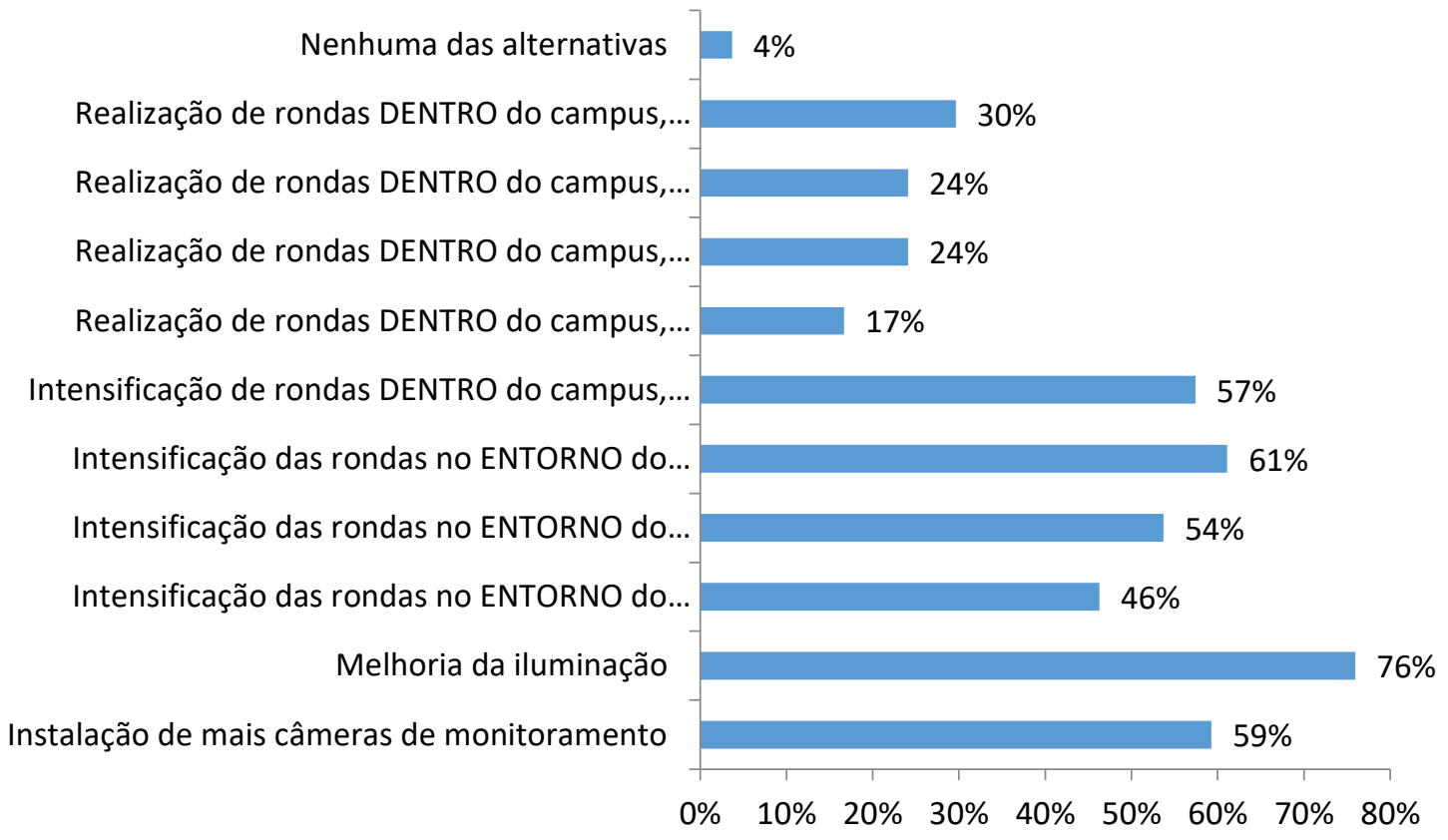

\begin{tabular}{lrr} 
Instalação de mais câmeras de monitoramento & $59 \%$ & 32 \\
\hline Melhoria da iluminação & $76 \%$ & 41 \\
\hline $\begin{array}{l}\text { Intensificação das rondas no ENTORNO do campus, pela Guarda Universitária } \\
\text { (PPUSP) }\end{array}$ & $46 \%$ & 25 \\
\hline Intensificação das rondas no ENTORNO do campus, pela Policia Militar & $54 \%$ & 29 \\
\hline Intensificação das rondas no ENTORNO do campus, pela Guarda Municipal & $61 \%$ & 33 \\
\hline Intensificação de rondas DENTRO do campus, pela Guarda Universitária (PPUSP) & $57 \%$ & 31 \\
\hline Realização de rondas DENTRO do campus, pela Policia Militar & $17 \%$ & 9 \\
\hline $\begin{array}{l}\text { Realização de rondas DENTRO do campus, pela Policia Militar, mas somente nos } \\
\text { horários mais críticos como à noite e durante grandes eventos }\end{array}$ & $24 \%$ & 13 \\
\hline Realização de rondas DENTRO do campus, pela Guarda Municipal & $24 \%$ & 13 \\
\hline $\begin{array}{l}\text { Realização de rondas DENTRO do campus, pela Guarda Municipal, mas somente } \\
\text { nos horários mais críticos como à noite e durante grandes eventos }\end{array}$ & $30 \%$ & 16 \\
\hline Nenhuma das alternativas & $4 \%$ & 2
\end{tabular}


Como você descreveria o trajeto do seu ponto de origem até o campus Luiz de Queiroz (ESALQ/CENA)?

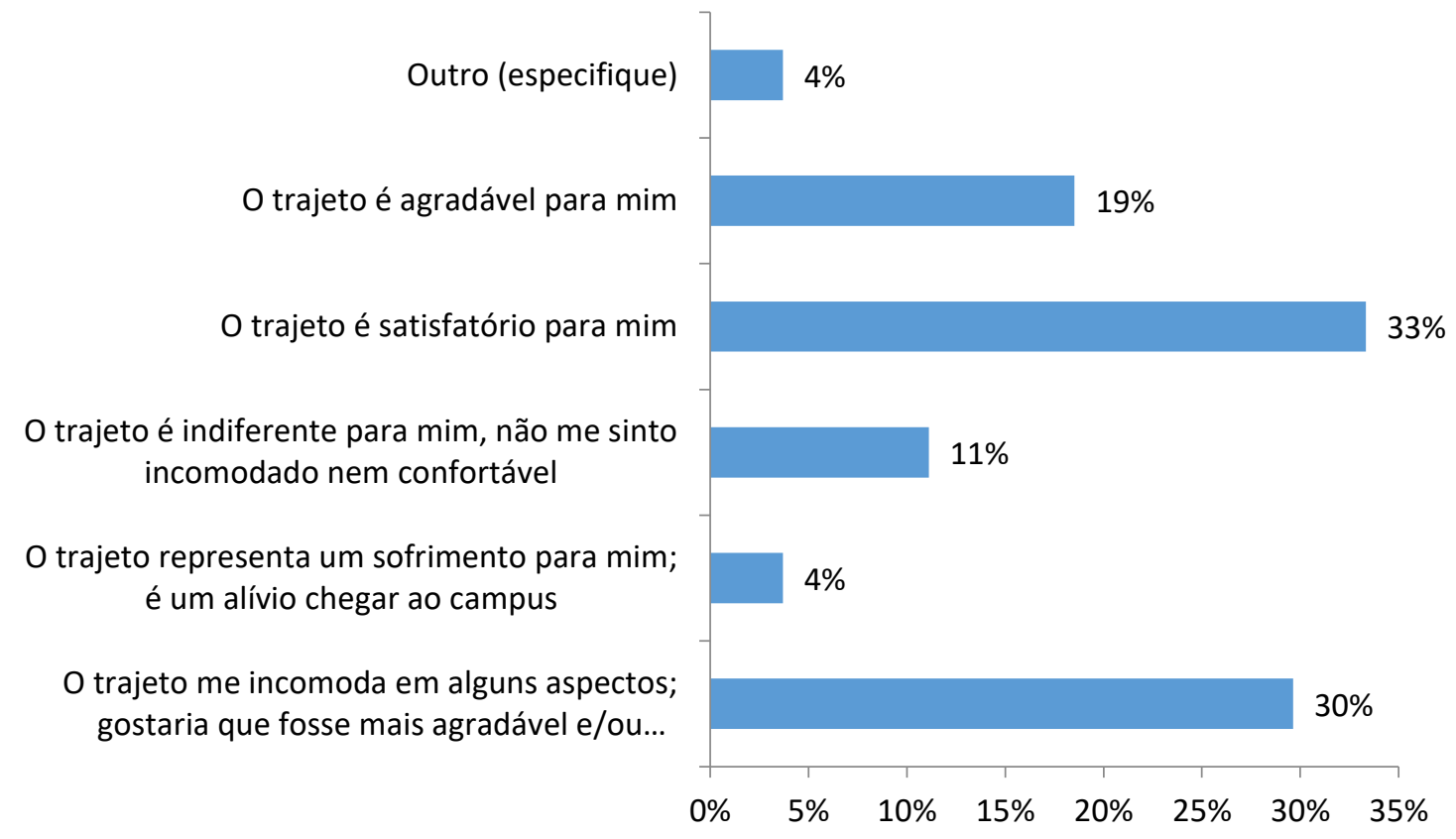

O trajeto me incomoda em alguns aspectos; gostaria que fosse mais agradável e/ou menos demorado

$30 \% \quad 16$

\begin{tabular}{lrr} 
O trajeto representa um sofrimento para mim; é um alívio chegar ao campus & $4 \%$ & 2 \\
\hline O trajeto é indiferente para mim, não me sinto incomodado nem confortável & $11 \%$ & 6 \\
\hline O trajeto é satisfatório para mim & $33 \%$ & 18 \\
\hline O trajeto é agradável para mim & $19 \%$ & 10 \\
\hline Outro (especifique) & $4 \%$ & 2
\end{tabular}


Como você avalia a sinalização do campus Luiz de Queiroz (ESALQ/CENA)?

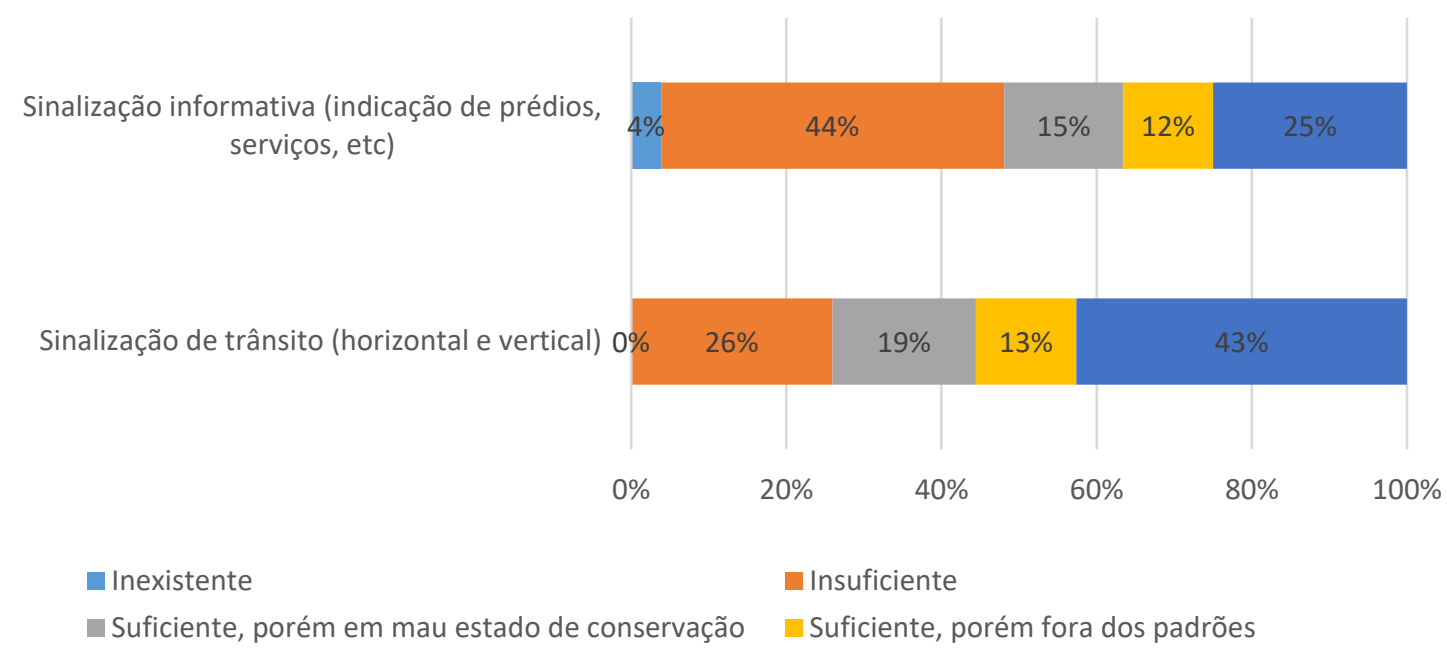

Sinalização de trânsito Sinalização informativa (indicação (horizontal e vertical) de prédios, serviços, etc)

\begin{tabular}{lcccc}
\hline Inexistente & $0 \%$ & 0 & $4 \%$ & 2 \\
\hline Insuficiente & $26 \%$ & 14 & $44 \%$ & 23 \\
\hline $\begin{array}{l}\text { Suficiente, porém em mau } \\
\text { estado de conservação }\end{array}$ & $19 \%$ & 10 & $15 \%$ & 8 \\
$\begin{array}{l}\text { Suficiente, porém fora dos } \\
\text { padrões }\end{array}$ & $13 \%$ & 7 & $12 \%$ & 6 \\
\hline $\begin{array}{l}\text { Suficiente } \\
\text { natra }\end{array}$ & $43 \%$ & 23 & $25 \%$ & 13
\end{tabular}


Na sua opinião, qual a importância destes aspectos para uma mobilidade mais sustentável na USP de Piracicaba? Ordene os temas marcando-os com os respectivos números ou arrastando as caixas de acordo com a prioridade (no topo, o mais importante)

\section{Média}

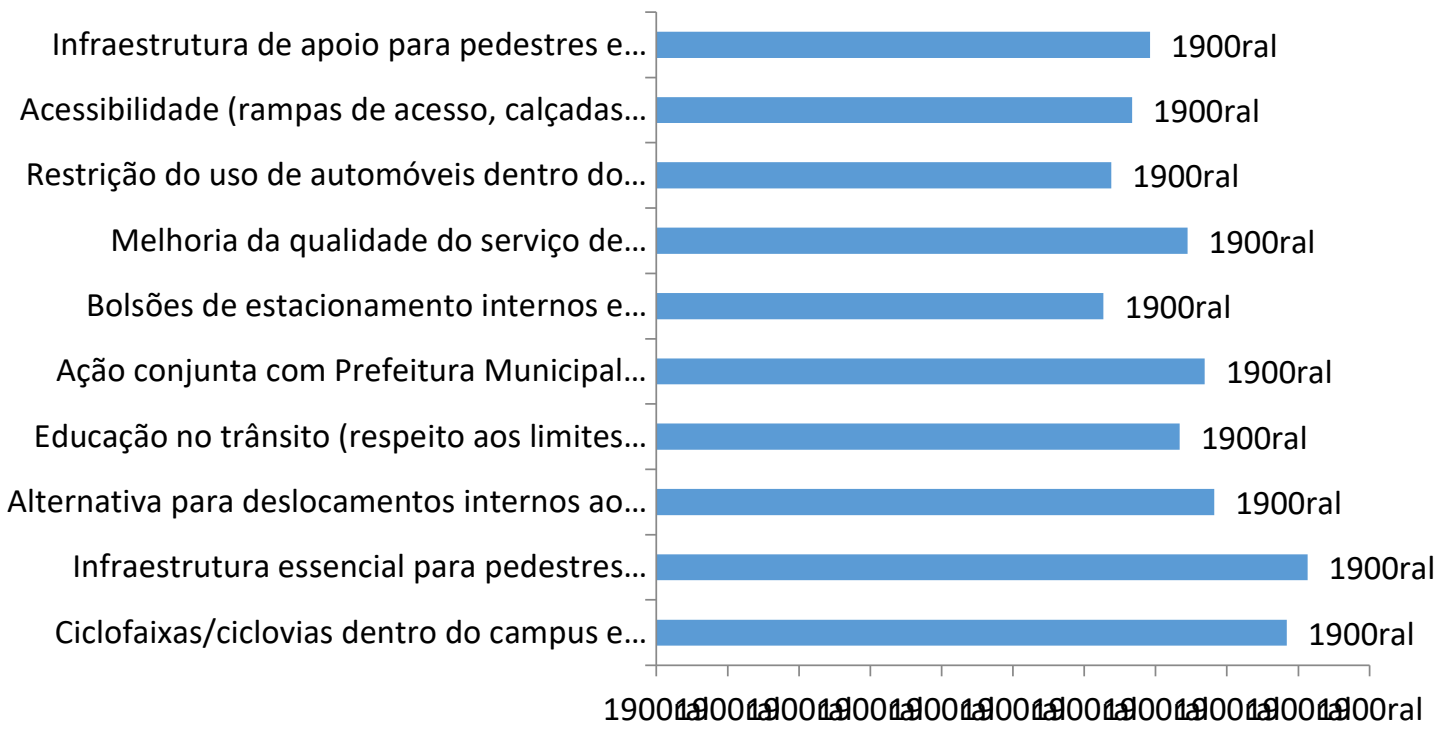

Obs: Quanto maior a média, maior a prioridade 


\begin{tabular}{|c|c|c|c|c|c|c|c|c|c|c|}
\hline Prioridade & 1 & 2 & 3 & 4 & 5 & 6 & 7 & 8 & 9 & 10 \\
\hline $\begin{array}{l}\text { Ciclofaixas/ciclovias dentro } \\
\text { do campus e para acesso } \\
\text { ao mesmo }\end{array}$ & $23 \%$ & $21 \%$ & $9 \%$ & $9 \%$ & $5 \%$ & $9 \%$ & $2 \%$ & $5 \%$ & $9 \%$ & $7 \%$ \\
\hline $\begin{array}{l}\text { Infraestrutura essencial } \\
\text { para pedestres (calçadas } \\
\text { adequadas, iluminação, } \\
\text { arborização, sinalização, } \\
\text { etc.) }\end{array}$ & $26 \%$ & $26 \%$ & $4 \%$ & $13 \%$ & $2 \%$ & $7 \%$ & $4 \%$ & $2 \%$ & $7 \%$ & $9 \%$ \\
\hline $\begin{array}{l}\text { Alternativa para } \\
\text { deslocamentos internos ao } \\
\text { campus (sistema de } \\
\text { transporte coletivo, } \\
\text { sistema de bicicletas } \\
\text { compartilhadas, etc.) }\end{array}$ & $7 \%$ & $11 \%$ & $14 \%$ & $7 \%$ & $16 \%$ & $11 \%$ & $11 \%$ & $16 \%$ & $2 \%$ & $5 \%$ \\
\hline $\begin{array}{l}\text { Educação no trânsito } \\
\text { (respeito aos limites } \\
\text { de velocidade e à } \\
\text { sinalização, melhor } \\
\text { convívio entre motoristas, } \\
\text { ciclistas e pedestres, etc.) }\end{array}$ & $5 \%$ & $5 \%$ & $9 \%$ & $14 \%$ & $18 \%$ & $11 \%$ & $16 \%$ & $11 \%$ & $5 \%$ & $7 \%$ \\
\hline $\begin{array}{l}\text { Ação conjunta com } \\
\text { Prefeitura Municipal para } \\
\text { melhoria da mobilidade na } \\
\text { ligação entre cidade e } \\
\text { campus }\end{array}$ & $7 \%$ & $2 \%$ & $18 \%$ & $16 \%$ & $16 \%$ & $7 \%$ & $13 \%$ & $11 \%$ & $7 \%$ & $4 \%$ \\
\hline $\begin{array}{l}\text { Bolsões de } \\
\text { estacionamento internos e } \\
\text { externos ao campus }\end{array}$ & $2 \%$ & $16 \%$ & $5 \%$ & $2 \%$ & $0 \%$ & $18 \%$ & $7 \%$ & $9 \%$ & $23 \%$ & $18 \%$ \\
\hline $\begin{array}{l}\text { Melhoria da qualidade do } \\
\text { serviço de transporte } \\
\text { público da cidade }\end{array}$ & $6 \%$ & $8 \%$ & $14 \%$ & $8 \%$ & $6 \%$ & $16 \%$ & $16 \%$ & $12 \%$ & $6 \%$ & $6 \%$ \\
\hline $\begin{array}{l}\text { Restrição do uso de } \\
\text { automóveis dentro do } \\
\text { campus }\end{array}$ & $18 \%$ & $2 \%$ & $6 \%$ & $4 \%$ & $8 \%$ & $2 \%$ & $2 \%$ & $8 \%$ & $24 \%$ & $26 \%$ \\
\hline $\begin{array}{l}\text { Acessibilidade (rampas de } \\
\text { acesso, calçadas } \\
\text { adequadas, elevadores, } \\
\text { piso tátil, respeito a vagas } \\
\text { de estacionamento } \\
\text { prioritárias, etc.) }\end{array}$ & $0 \%$ & $2 \%$ & $8 \%$ & $14 \%$ & $12 \%$ & $12 \%$ & $18 \%$ & $20 \%$ & $2 \%$ & $10 \%$ \\
\hline $\begin{array}{l}\text { Infraestrutura de apoio } \\
\text { para pedestres e ciclistas } \\
\text { (bebedouros, bancos, } \\
\text { vestiários, guarda-volume, } \\
\text { bicicletários, oficina para } \\
\text { consertos, etc.) }\end{array}$ & $4 \%$ & $8 \%$ & $10 \%$ & $10 \%$ & $16 \%$ & $10 \%$ & $8 \%$ & $8 \%$ & $10 \%$ & $18 \%$ \\
\hline
\end{tabular}




\section{Modo: Automóvel}

Analisando o campus da ESALQ/CENA como um todo, você o considera acessível aos usuários com algum tipo de restrição de mobilidade?

Não sou capaz de opinar, pois nunca analisei o campus sob este aspecto

Não. O campus não oferece condições básicas de acessibilidade aos usuários com algum tipo de restrição de mobilidade

Pequena parte do campus é acessível. Há diversas áreas que não oferecem condições básicas de acessibilidade aos usuários com...

Grande parte do campus é acessível. Algumas áreas possuem obstáculos, mas de maneira geral considero o campus acessível aos...

Sim. Nunca notei obstáculos que dificultassem a acessibilidade aos usuários com algum tipo de restrição de mobilidade nas dependências...

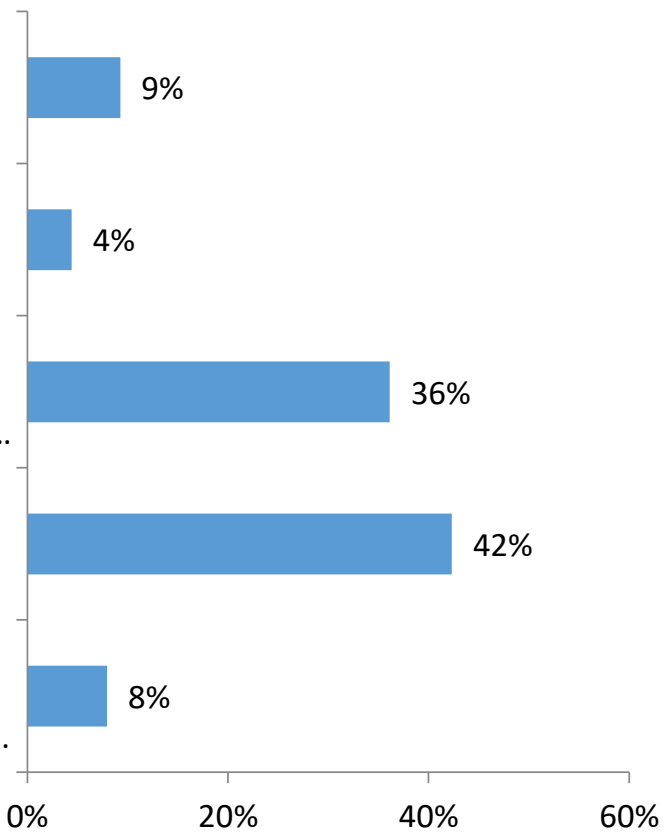

Sim. Nunca notei obstáculos que dificultassem a acessibilidade aos usuários com algum tipo de restrição de mobilidade nas dependências do campus $8 \% \quad 18$ Grande parte do campus é acessível. Algumas áreas possuem obstáculos, mas de maneira geral considero o campus acessível aos usuários com algum tipo de restrição de mobilidade $42 \% \quad 96$

Pequena parte do campus é acessível. Há diversas áreas que não oferecem condições básicas de acessibilidade aos usuários com algum tipo de restrição de mobilidade $36 \% \quad 82$

Não. O campus não oferece condições básicas de acessibilidade aos usuários com algum tipo de restrição de mobilidade

Não sou capaz de opinar, pois nunca analisei o campus sob este aspecto

$4 \% \quad 10$

$9 \% \quad 21$


Dentre os prédios que frequenta na ESALQ/CENA, como você avalia a acessibilidade para os usuários com algum tipo de restrição de mobilidade?

Não sou capaz de avaliar, pois nunca analisei os prédios da ESALQ/CENA sob este aspecto

Ruim. Prédios não equipados para receber os usuários com algum tipo de restrição de mobilidade

Regular. Prédios pouco equipados, com limitações para atender os usuários com algum tipo de restrição de mobilidade

Boa. Prédios parcialmente equipados, mas possuem condições satisfatórias para atender os usuários com algum tipo de restrição de...

Ótima. Prédios totalmente equipados para receber os usuários com algum tipo de restrição de mobilidade

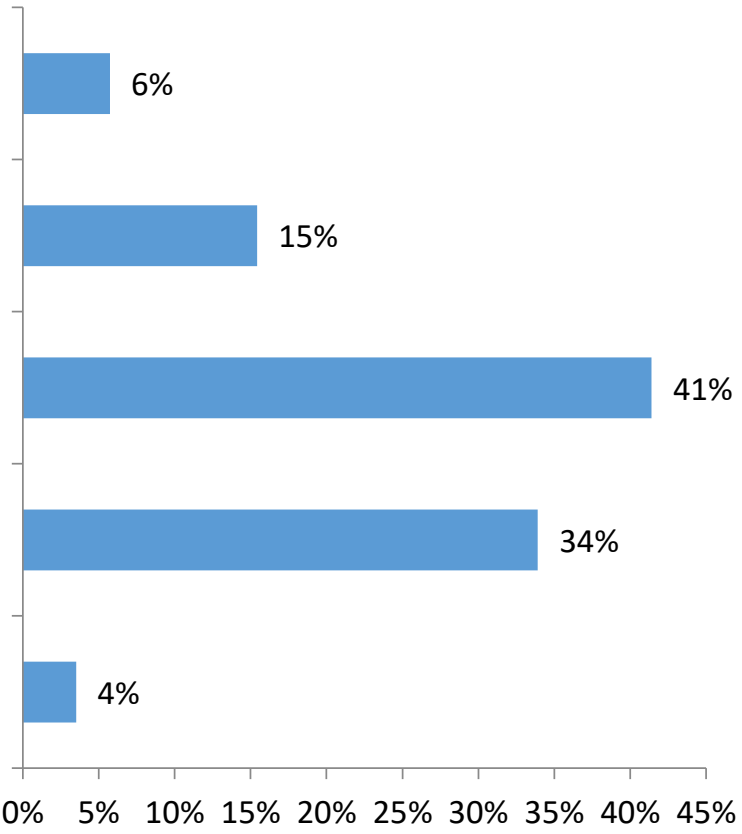

Ótima. Prédios totalmente equipados para receber os usuários com algum tipo de restrição de mobilidade $4 \% \quad 8$

Boa. Prédios parcialmente equipados, mas possuem condições satisfatórias para atender os usuários com algum tipo de restrição de mobilidade $34 \% \quad 77$

Regular. Prédios pouco equipados, com limitações para atender os usuários com algum tipo de restrição de mobilidade $41 \% \quad 94$ Ruim. Prédios não equipados para receber os usuários com algum tipo de restrição de mobilidade $15 \% \quad 35$ Não sou capaz de avaliar, pois nunca analisei os prédios da ESALQ/CENA sob este aspecto 
Na etapa anterior do questionário, você nos informou que seu modo principal para os deslocamentos à ESALQ/CENA é o AUTOMÓVEL. Quais fatores o/a levam a optar por este modo?

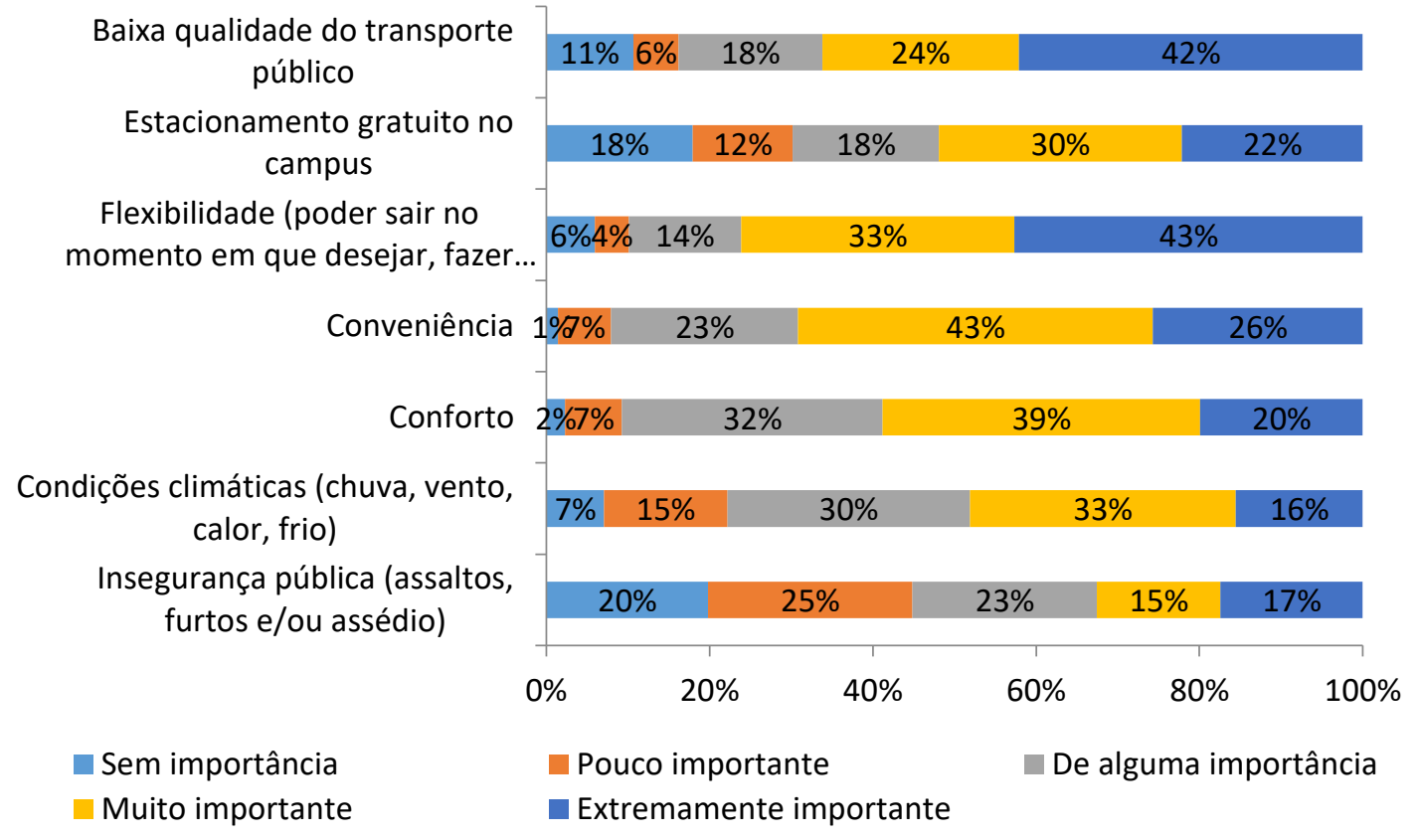

\begin{tabular}{|c|c|c|c|c|c|c|c|c|c|c|}
\hline \multirow[b]{2}{*}{$\begin{array}{l}\text { Insegurança pública } \\
\text { (assaltos, furtos e/ou } \\
\text { assédio) }\end{array}$} & \multicolumn{2}{|c|}{$\begin{array}{c}\text { Sem } \\
\text { importância }\end{array}$} & \multicolumn{2}{|c|}{$\begin{array}{l}\text { Pouco } \\
\text { importante }\end{array}$} & \multicolumn{2}{|c|}{$\begin{array}{l}\text { De alguma } \\
\text { importância }\end{array}$} & \multicolumn{2}{|c|}{$\begin{array}{c}\text { Muito } \\
\text { importante }\end{array}$} & \multicolumn{2}{|c|}{$\begin{array}{c}\text { Extremamen } \\
\text { te important } \\
e\end{array}$} \\
\hline & $20 \%$ & 42 & $25 \%$ & 53 & $23 \%$ & 48 & $15 \%$ & 32 & $17 \%$ & 37 \\
\hline $\begin{array}{l}\text { Condições climáticas } \\
\text { (chuva, vento, calor, } \\
\text { frio) }\end{array}$ & $7 \%$ & 15 & $15 \%$ & 32 & $30 \%$ & 63 & $33 \%$ & 69 & $16 \%$ & 33 \\
\hline Conforto & $2 \%$ & 5 & $7 \%$ & 15 & $32 \%$ & 69 & $39 \%$ & 84 & $20 \%$ & 43 \\
\hline Conveniência & $1 \%$ & 3 & $7 \%$ & 14 & $23 \%$ & 49 & $43 \%$ & 93 & $26 \%$ & 55 \\
\hline $\begin{array}{l}\text { Flexibilidade (poder } \\
\text { sair no momento em } \\
\text { que desejar, fazer } \\
\text { paradas durante o } \\
\text { trajeto, etc.) }\end{array}$ & $6 \%$ & 13 & $4 \%$ & 9 & $14 \%$ & 30 & $33 \%$ & 73 & $43 \%$ & 93 \\
\hline $\begin{array}{l}\text { Estacionamento } \\
\text { gratuito no campus }\end{array}$ & $18 \%$ & 38 & $12 \%$ & 26 & $18 \%$ & 38 & $30 \%$ & 63 & $22 \%$ & 47 \\
\hline $\begin{array}{l}\text { Baixa qualidade do } \\
\text { transporte público }\end{array}$ & $11 \%$ & 23 & $6 \%$ & 12 & $18 \%$ & 38 & $24 \%$ & 52 & $42 \%$ & 91 \\
\hline
\end{tabular}




\section{Quais fatores o/a desestimulam a utilizar os demais modos que não o automóvel em seus deslocamentos?}

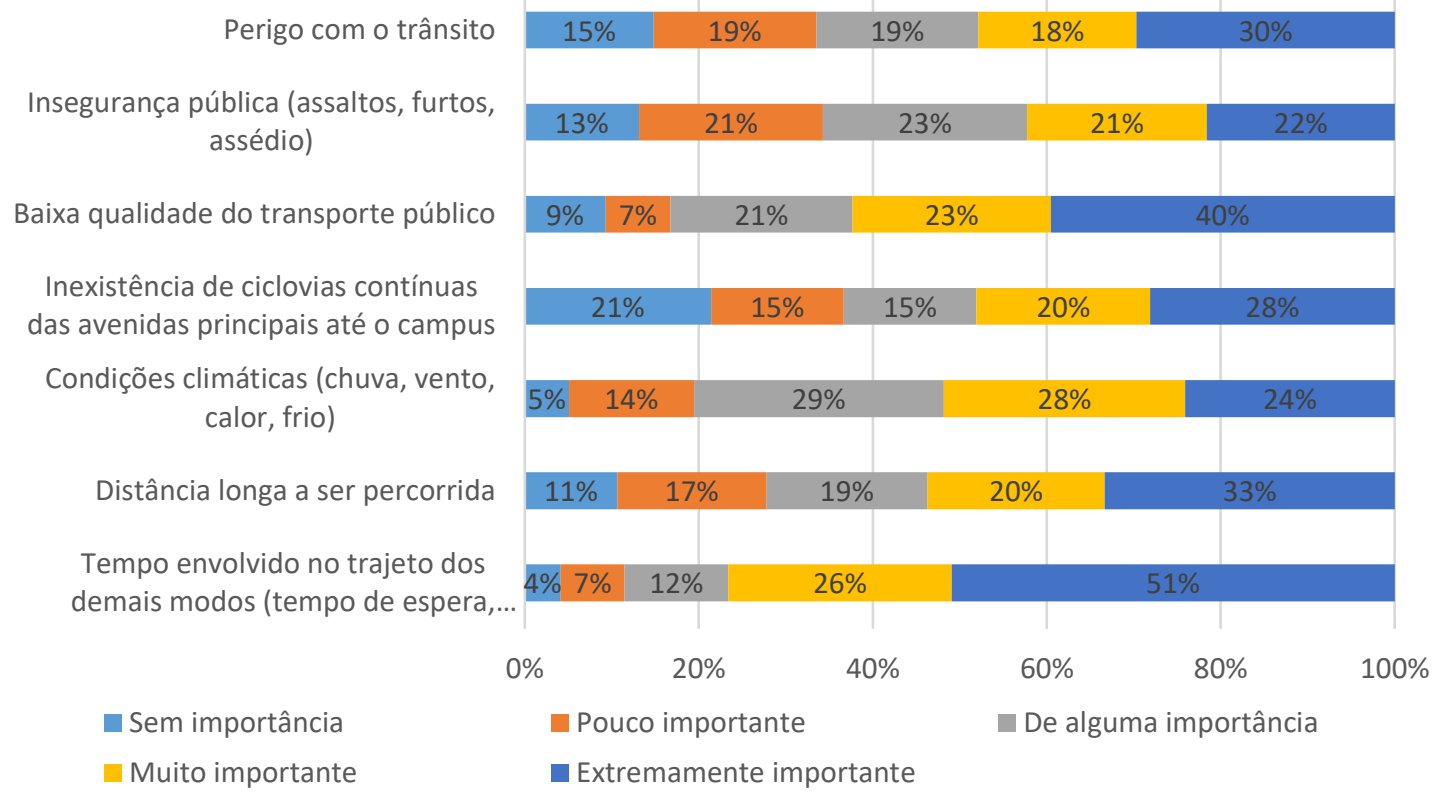

\begin{tabular}{|c|c|c|c|c|c|c|c|c|c|c|}
\hline \multirow{2}{*}{$\begin{array}{l}\text { Tempo envolvido no } \\
\text { trajeto dos demais } \\
\text { modos (tempo de } \\
\text { espera, percurso, } \\
\text { atrasos) }\end{array}$} & \multicolumn{2}{|c|}{$\begin{array}{l}\text { Sem } \\
\text { importância }\end{array}$} & \multicolumn{2}{|c|}{$\begin{array}{c}\text { Pouco } \\
\text { importante }\end{array}$} & \multicolumn{2}{|c|}{$\begin{array}{l}\text { De alguma } \\
\text { importância }\end{array}$} & \multicolumn{2}{|c|}{$\begin{array}{c}\text { Muito } \\
\text { importante }\end{array}$} & \multicolumn{2}{|c|}{$\begin{array}{l}\text { Extremame } \\
\text { nte } \\
\text { importante }\end{array}$} \\
\hline & $4 \%$ & 9 & $7 \%$ & 16 & $12 \%$ & 26 & $26 \%$ & 56 & $51 \%$ & 111 \\
\hline $\begin{array}{l}\text { Distância longa a ser } \\
\text { percorrida }\end{array}$ & $11 \%$ & 23 & $17 \%$ & 37 & $19 \%$ & 40 & $20 \%$ & 44 & $33 \%$ & 72 \\
\hline $\begin{array}{l}\text { Condições climáticas } \\
\text { (chuva, vento, calor, } \\
\text { frio) }\end{array}$ & $5 \%$ & 11 & $14 \%$ & 31 & $29 \%$ & 62 & $28 \%$ & 60 & $24 \%$ & 52 \\
\hline $\begin{array}{l}\text { Inexistência de } \\
\text { ciclovias contínuas das } \\
\text { avenidas principais até } \\
\text { o campus }\end{array}$ & $21 \%$ & 45 & $15 \%$ & 32 & $15 \%$ & 32 & $20 \%$ & 42 & $28 \%$ & 59 \\
\hline $\begin{array}{l}\text { Baixa qualidade do } \\
\text { transporte público }\end{array}$ & $9 \%$ & 20 & $7 \%$ & 16 & $21 \%$ & 45 & $23 \%$ & 49 & $40 \%$ & 85 \\
\hline $\begin{array}{l}\text { Insegurança pública } \\
\text { (assaltos, furtos, } \\
\text { assédio) }\end{array}$ & $13 \%$ & 28 & $21 \%$ & 45 & $23 \%$ & 50 & $21 \%$ & 44 & $22 \%$ & 46 \\
\hline Perigo com o trânsito & $15 \%$ & 31 & $19 \%$ & 39 & $19 \%$ & 39 & $18 \%$ & 38 & $30 \%$ & 62 \\
\hline
\end{tabular}


Há quanto tempo você utiliza o automóvel para se deslocar até a ESALQ/CENA?

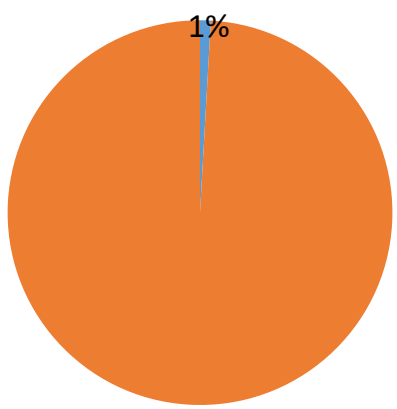

$99 \%$

\begin{tabular}{lrr} 
Há menos de 6 meses & $1 \%$ & 2 \\
\hline Há mais de 6 meses & $99 \%$ & 221
\end{tabular}

Dos deslocamentos que você faz hoje de automóvel, qual modo você utilizava antes?

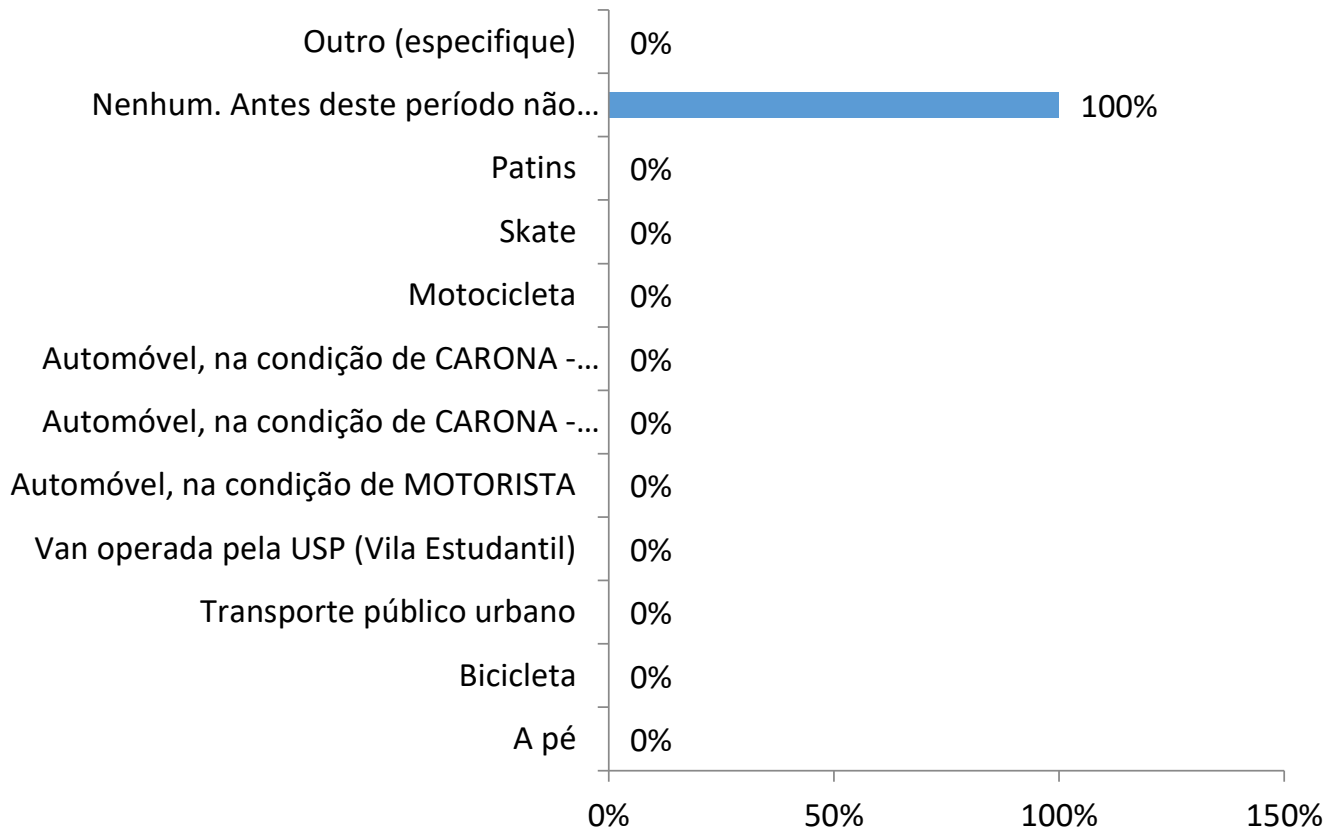




\begin{tabular}{lrr} 
A pé & $0 \%$ & 0 \\
\hline Bicicleta & $0 \%$ & 0 \\
\hline Transporte público urbano & $0 \%$ & 0 \\
\hline Van operada pela USP (Vila Estudantil) & $0 \%$ & 0 \\
\hline Automóvel, na condição de MOTORISTA & $0 \%$ & 0 \\
\hline Automóvel, na condição de CARONA - estaciona no campus & $0 \%$ & 0 \\
\hline Automóvel, na condição de CARONA - não estaciona no campus & $0 \%$ & 0 \\
\hline Motocicleta & $0 \%$ & 0 \\
\hline Skate & $0 \%$ & 0 \\
\hline Patins & $0 \%$ & 0 \\
\hline Nenhum. Antes deste período não frequentava o campus & $100 \%$ & 2 \\
\hline Outro (especifique) & $0 \%$ & 0
\end{tabular}

Você estaciona seu carro em apenas um lugar durante sua permanência no campus ou troca de vaga conforme realiza suas atividades?

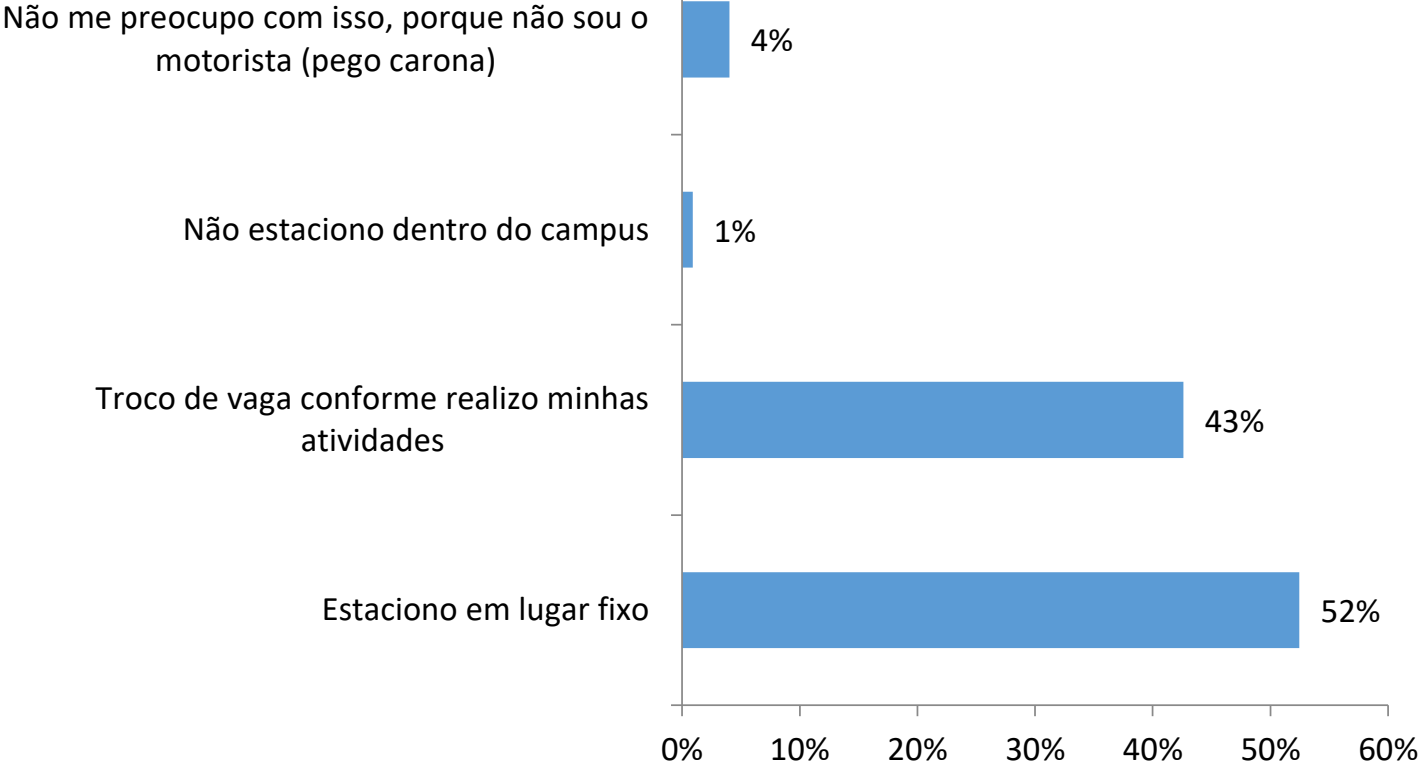

\begin{tabular}{lcc} 
Estaciono em lugar fixo & $52 \%$ & 117 \\
\hline Troco de vaga conforme realizo minhas atividades & $43 \%$ & 95 \\
\hline Não estaciono dentro do campus & $1 \%$ & 2 \\
\hline Não me preocupo com isso, porque não sou o motorista (pego carona) & $4 \%$ & 9
\end{tabular}




\section{Local onde estaciona}

51. Praça Esportiva - Ginásio de Esportes 9\%

48. CENA $\quad 8 \%$

46. Restaurante dos Docentes

$$
\text { 44. Serviço Odontológico | } 1 \%
$$

43. Edifício "Professor Salvador de Toledo Piza Jr."... — 2\%

42. Serviço de Pós-Graduação - 3\%

41. Biblioteca Central

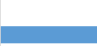

39. Novo restaurante

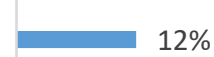

38. Central de Aulas

$29 \%$

37. Departamento de Agroindústria, Alimentos e...

\section{$7 \%$}

36. Edifício Professor Jayme Rocha de Almeida... $6 \%$

35. Pavilhão Walter Ramos Jardim (LZT | ruminantes) — $8 \%$

34. Serviço de Graduação - 3\%

32. Serviço Médico $\quad 26 \%$

31. Pavilhão de Agricultura (LPV e LSO) - $2 \%$

30. Departamento de Genética (LGN) 16\%

29. Departamento de Zootecnia (LZT | não-... - 2\%

28. Centro de Convivência Infantil (CCln) $\quad 2 \%$

27. Centro de Estudos Linguísticos (CEL) | $1 \%$

26. Laboratório de Biotecnologia Agrícola "Prof.... = 2\%

25. Divisão de Atendimento à Comunidade... $3 \%$

24. Centro de Tecnologia da Informação do... $6 \%$

23. Edifício "Prof. José Theófilo do Amaral Gurgel"...

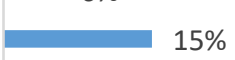

22. Pavilhão de Ciências Humanas (LAN - 3 e LES) — $5 \%$

21. Edifício "Prof. Friedrich Gustav Brieger" (LGN) 6\% $6 \%$

20. Pavilhão de Química

19. Centro de Vivência (C.V.)

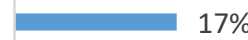

15. Departamento de Ciências Florestais (LCF) e Ipef

13. Pavilhão de Horticultura

12. Microscopia Eletrônica $\quad 3 \%$

$5 \%$

artamento de Ciência do Solo (LSO)

11. Sala dos Grupos Musicais da ESALQ — 9\%

10. Edifício Central $16 \%$

9. Prédio da Pesqusa, Cultura e Extensão... 5\%

8. Departamento de Engenharia de Biossistemas...

6. Departamento de Entomologia e Acarologia (LEA) — 5\%

5. Divisões Administrativa (DA) ede Manutenção e... $6 \%$

4. Galpão USP Recicla $20 \%$

3. Museu e Centro de Ciências "Luiz de Queiroz"

2. Pavilhão de Economia e Sociologia

1. Pavilhão de Engenharia

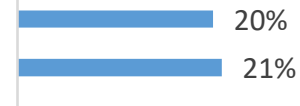

$21 \%$

$7 \%$

$\begin{array}{llllllll}0 \% & 10 \% & 20 \% & 30 \% & 40 \% & 50 \% & 60 \% & 70 \%\end{array}$ 
1. Pavilhão de Engenharia $\quad 21 \%$

2. Pavilhão de Economia e Sociologia $7 \%$

3. Museu e Centro de Ciências "Luiz de Queiroz" 21\%

4. Galpão USP Recicla $20 \%$

5. Divisões Administrativa (DA) ede Manutenção e Operação (DVMANOPER) $\quad 6 \%$

6. Departamento de Entomologia e Acarologia (LEA) $5 \%$

8. Departamento de Engenharia de Biossistemas (LEB) $57 \%$

9. Prédio da Pesqusa, Cultura e Extensão Universitária $5 \%$

10. Edifício Central $16 \%$

11. Sala dos Grupos Musicais da ESALQ $\quad 9 \%$

12. Microscopia Eletrônica $3 \%$

13. Pavilhão de Horticultura $\quad 8 \%$

15. Departamento de Ciências Florestais (LCF) e lpef $\quad 11 \%$

17. Departamento de Ciência do Solo (LSO) $7 \%$

18. Restaurante Universitário (R.U.) 5\%

19. Centro de Vivência (C.V.) $9 \%$

20. Pavilhão de Química $17 \%$

21. Edifício "Prof. Friedrich Gustav Brieger" (LGN) 6\%

22. Pavilhão de Ciências Humanas (LAN - 3 e LES) $\quad 5 \%$

23. Edifício "Prof. José Theófilo do Amaral Gurgel" (LGN) 15\%

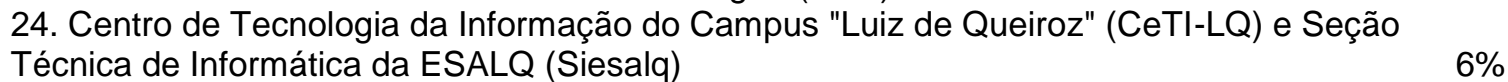

25. Divisão de Atendimento à Comunidade (DVATCOM) 3\%

26. Laboratório de Biotecnologia Agrícola "Prof. Otto Jesu Crocomo" (LCB) 2\%

27. Centro de Estudos Linguísticos (CEL) $1 \%$

28. Centro de Convivência Infantil (CCIn) 2\%

29. Departamento de Zootecnia (LZT | não-ruminantes) $\quad 2 \%$

30. Departamento de Genética (LGN) 16\%

31. Pavilhão de Agricultura (LPV e LSO) $2 \%$

32. Serviço Médico $\quad 26 \%$

34. Serviço de Graduação $\quad 3 \%$

35. Pavilhão Walter Ramos Jardim (LZT | ruminantes) $8 \%$

36. Edifício Professor Jayme Rocha de Almeida (LAN - 1) 6\%

37. Departamento de Agroindústria, Alimentos e Nutrição (LAN - 2) 7\%

38. Central de Aulas $29 \%$

39. Novo restaurante $12 \%$

41. Biblioteca Central $\quad 41 \%$

42. Serviço de Pós-Graduação $\quad 3 \%$

43. Edifício "Professor Salvador de Toledo Piza Jr." (Pavilhão de Zoologia) 2\%

44. Serviço Odontológico $1 \%$

46. Restaurante dos Docentes $\quad 61 \%$

48. CENA $\quad 8 \%$

51. Praça Esportiva - Ginásio de Esportes $\quad 9 \%$ 
Com que frequência você dá carona para outras pessoas até o campus? Ou pega carona?

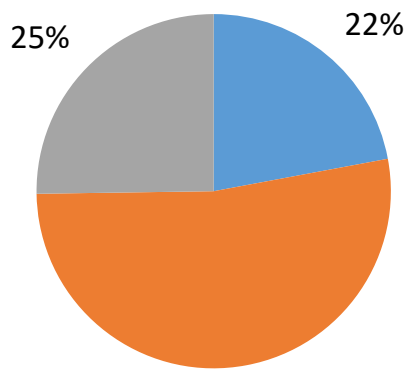

$53 \%$
Frequentemente

Raramente

\begin{tabular}{lrr} 
Frequentemente & $22 \%$ & 49 \\
\hline Raramente & $53 \%$ & 117 \\
\hline Nunca & $25 \%$ & 56
\end{tabular}

Em média, a quantas pessoas você dá carona até o campus? Se você pega carona, quantas pessoas vão com você no carro?

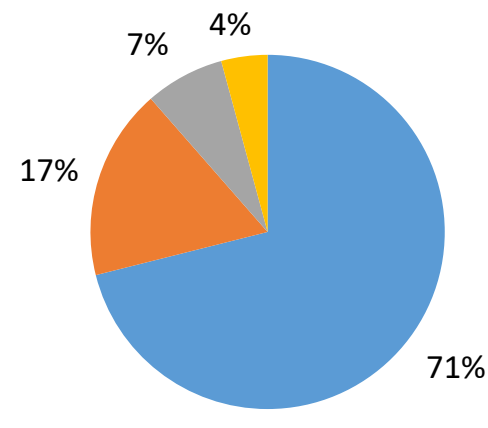

1 pessoa

$\checkmark 2$ pessoas

3 pessoas

\begin{tabular}{lrr}
1 pessoa & $71 \%$ & 118 \\
\hline 2 pessoas & $17 \%$ & 29 \\
\hline 3 pessoas & $7 \%$ & 12 \\
\hline 4 pessoas & $4 \%$ & 7
\end{tabular}


Classifique, somente para os turnos em que você costuma acessar ou se deslocar $A O$ REDOR da ESALQ/CENA, qual a sua sensação de segurança em relação a assaltos e outros tipos de violência ou assédio:

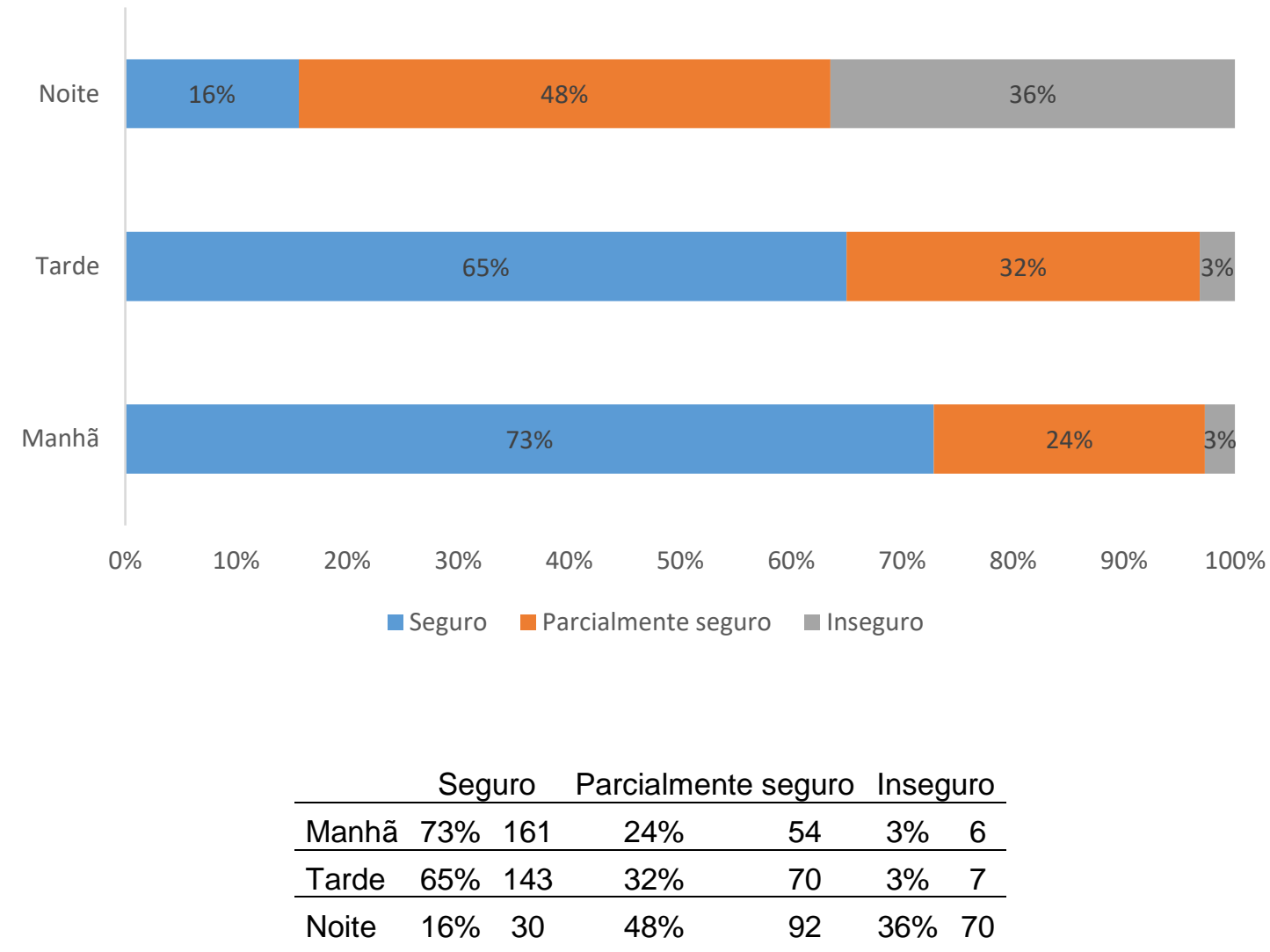

Você presenciou ou sofreu algum tipo de violência ou assédio NO ENTORNO da ESALQ/CENA?

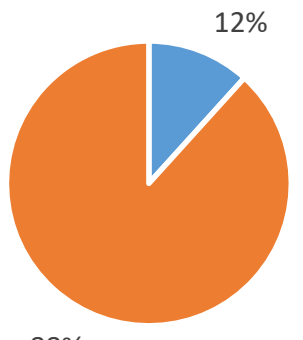

\begin{tabular}{lll}
$\operatorname{Sim} \quad 12 \% \quad 26$ \\
\hline
\end{tabular}

Não $88 \% 196$ 
Que tipo de violência ou assédio você presenciou ou sofreu NO ENTORNO da ESALQ/CENA? (se for necessário, marque mais de uma alternativa)

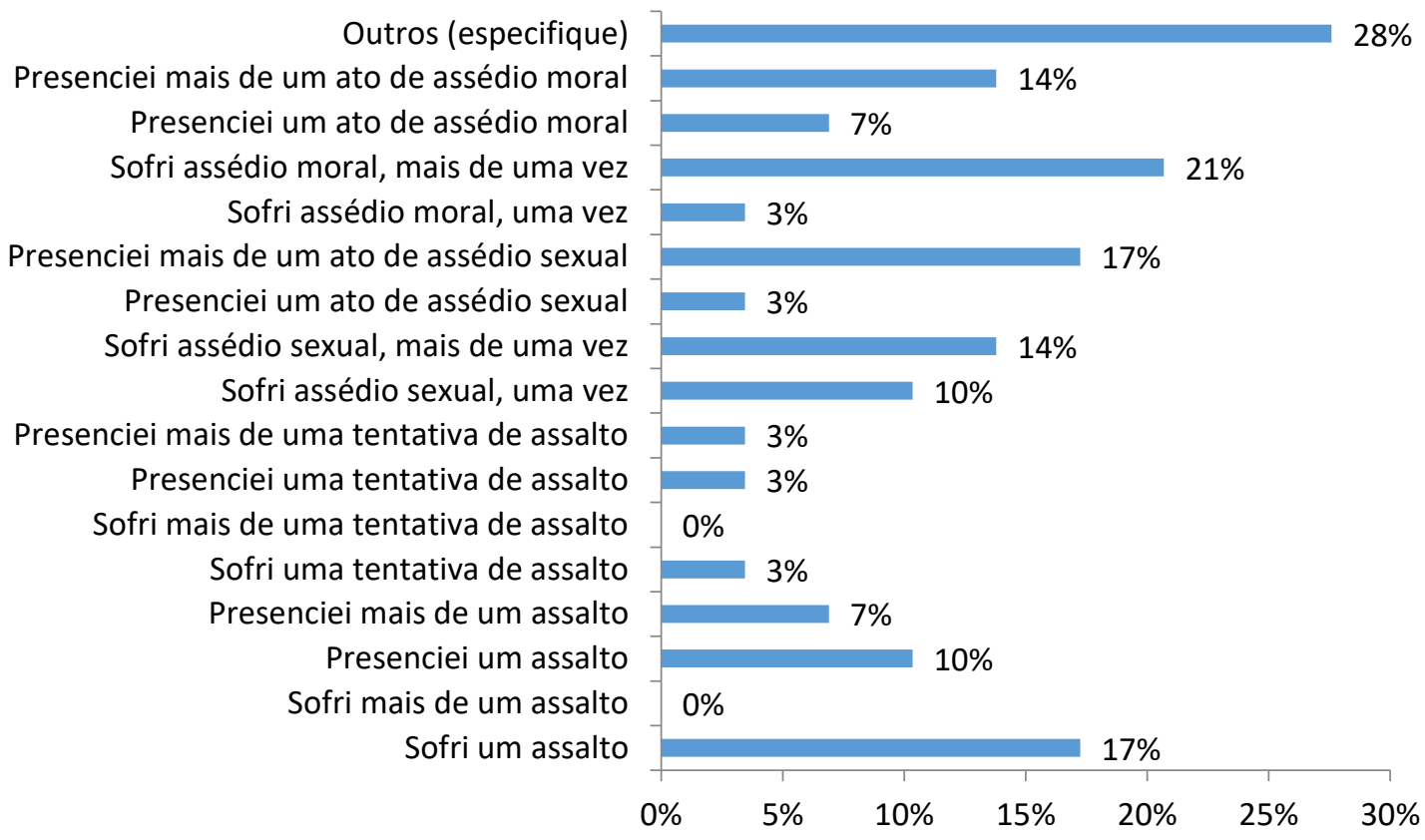

\begin{tabular}{lrr} 
Sofri um assalto & $17 \%$ & 5 \\
\hline Sofri mais de um assalto & $0 \%$ & 0 \\
\hline Presenciei um assalto & $10 \%$ & 3 \\
\hline Presenciei mais de um assalto & $7 \%$ & 2 \\
\hline Sofri uma tentativa de assalto & $3 \%$ & 1 \\
\hline Sofri mais de uma tentativa de assalto & $0 \%$ & 0 \\
\hline Presenciei uma tentativa de assalto & $3 \%$ & 1 \\
\hline Presenciei mais de uma tentativa de assalto & $3 \%$ & 1 \\
\hline Sofri assédio sexual, uma vez & $10 \%$ & 3 \\
\hline Sofri assédio sexual, mais de uma vez & $14 \%$ & 4 \\
\hline Presenciei um ato de assédio sexual & $3 \%$ & 1 \\
\hline Presenciei mais de um ato de assédio sexual & $17 \%$ & 5 \\
\hline Sofri assédio moral, uma vez & $3 \%$ & 1 \\
\hline Sofri assédio moral, mais de uma vez & $21 \%$ & 6 \\
\hline Presenciei um ato de assédio moral & $7 \%$ & 2 \\
\hline Presenciei mais de um ato de assédio moral & $14 \%$ & 4 \\
\hline Outros (especifique) & $28 \%$ & 8
\end{tabular}


Classifique, somente para os turnos em que você costuma acessar ou se deslocar DENTRO da ESALQ/CENA, qual a sua sensação de segurança em relação a assaltos e outros tipos de violência ou assédio:

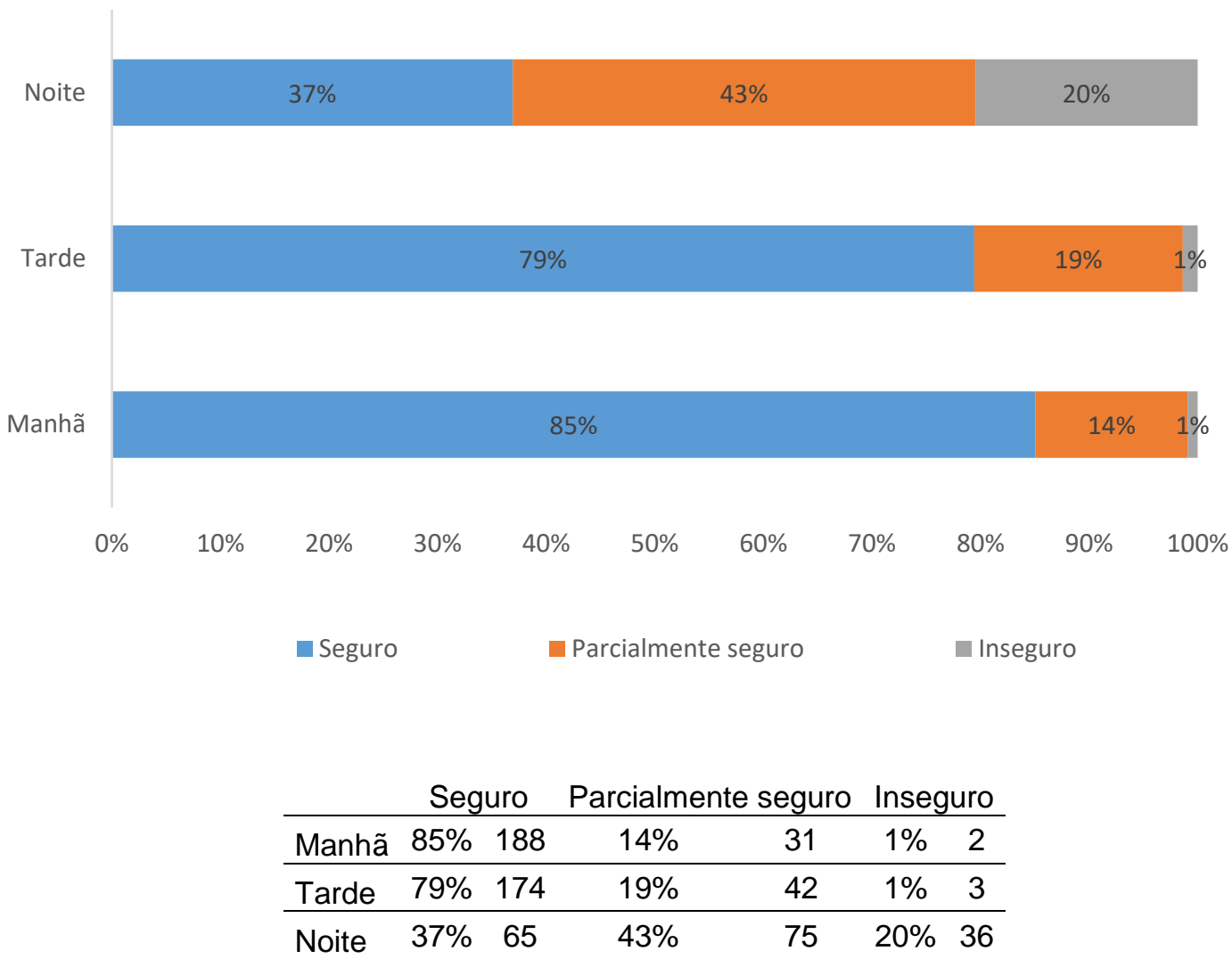

Você presenciou ou sofreu algum tipo de violência ou assédio DENTRO da ESALQ/CENA?

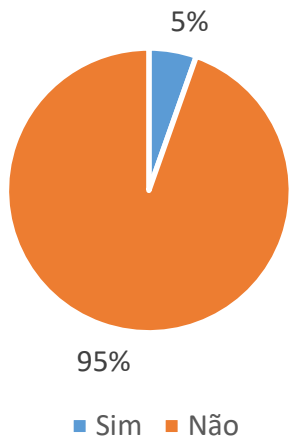

\begin{tabular}{lrr} 
Sim & $5 \%$ & 12 \\
\hline Não & $95 \%$ & 210
\end{tabular}


Que tipo de violência ou assédio você presenciou ou sofreu DENTRO da ESALQ/CENA? (se for necessário, marque mais de uma alternativa)

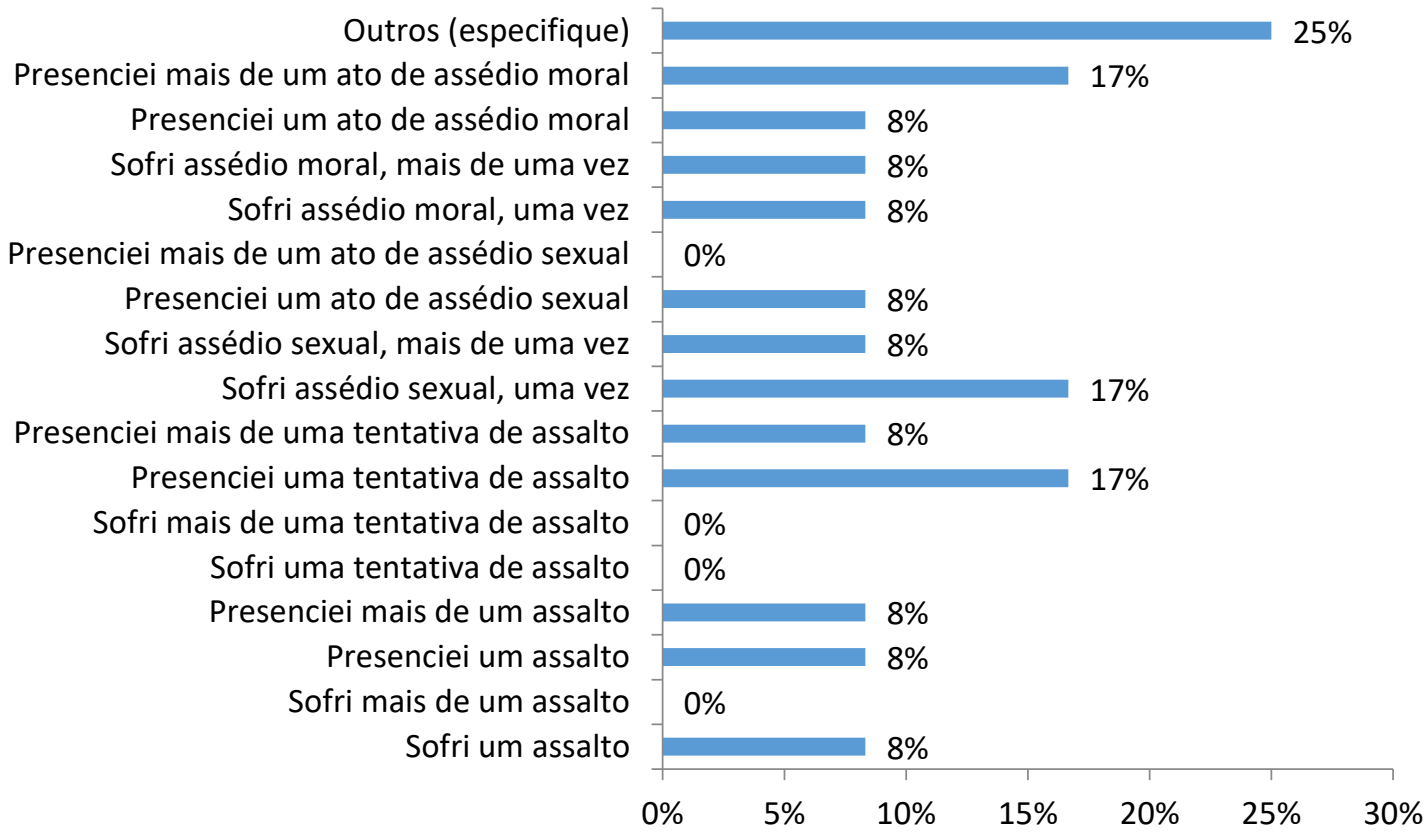

\begin{tabular}{lrr} 
Sofri um assalto & $8 \%$ & 1 \\
\hline Sofri mais de um assalto & $0 \%$ & 0 \\
\hline Presenciei um assalto & $8 \%$ & 1 \\
\hline Presenciei mais de um assalto & $8 \%$ & 1 \\
\hline Sofri uma tentativa de assalto & $0 \%$ & 0 \\
\hline Sofri mais de uma tentativa de assalto & $0 \%$ & 0 \\
\hline Presenciei uma tentativa de assalto & $17 \%$ & 2 \\
\hline Presenciei mais de uma tentativa de assalto & $8 \%$ & 1 \\
\hline Sofri assédio sexual, uma vez & $17 \%$ & 2 \\
\hline Sofri assédio sexual, mais de uma vez & $8 \%$ & 1 \\
\hline Presenciei um ato de assédio sexual & $8 \%$ & 1 \\
\hline Presenciei mais de um ato de assédio sexual & $0 \%$ & 0 \\
\hline Sofri assédio moral, uma vez & $8 \%$ & 1 \\
\hline Sofri assédio moral, mais de uma vez & $8 \%$ & 1 \\
\hline Presenciei um ato de assédio moral & $8 \%$ & 1 \\
\hline Presenciei mais de um ato de assédio moral & $17 \%$ & 2 \\
\hline Outros (especifique) & $25 \%$ & 3
\end{tabular}


Com relação a medidas de segurança no ENTORNO e DENTRO da ESALQ/CENA, você é favorável a (se for necessário, marque mais de uma alternativa):

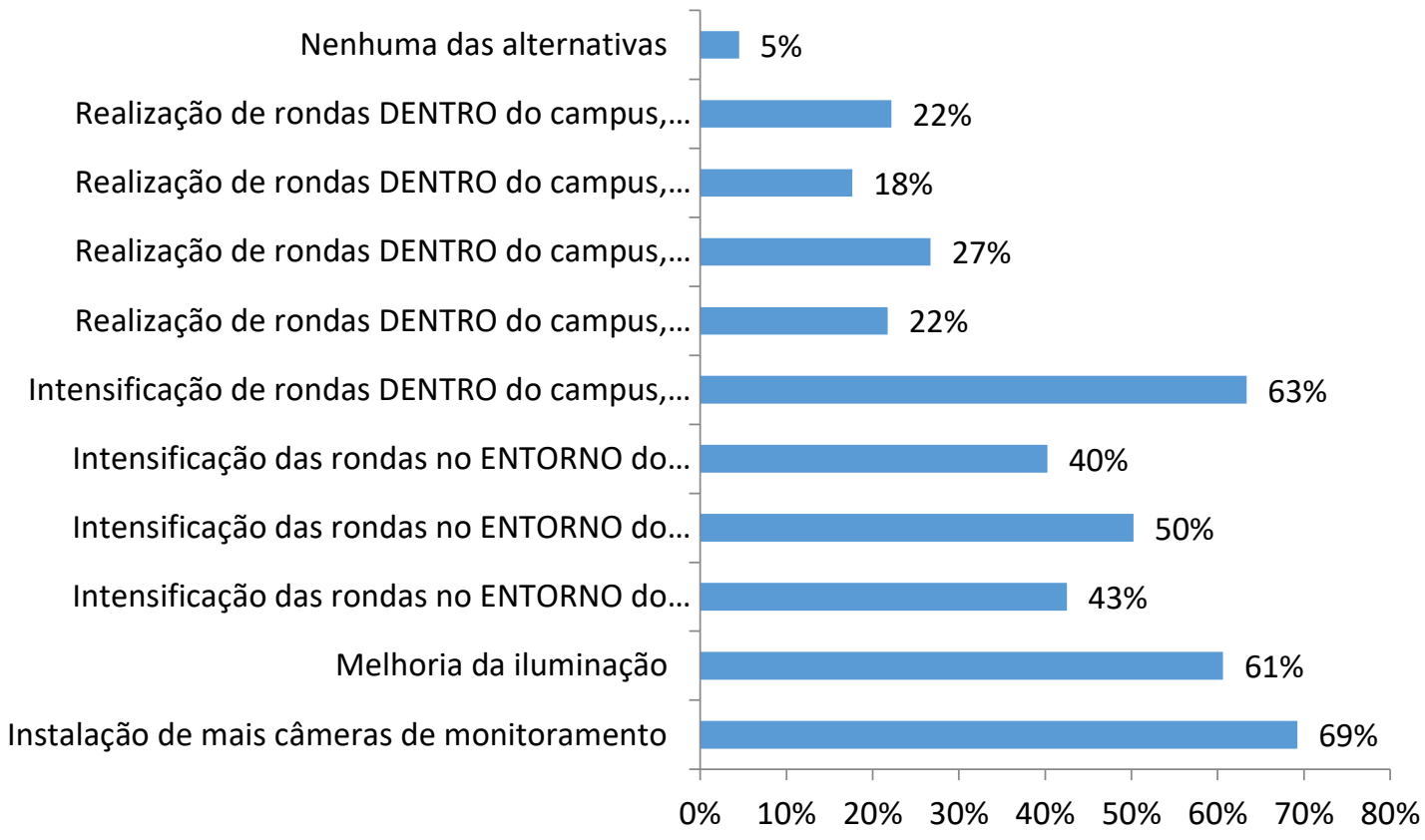

\begin{tabular}{lcc} 
Instalação de mais câmeras de monitoramento & $69 \%$ & 153 \\
\hline Melhoria da iluminação & $61 \%$ & 134 \\
\hline $\begin{array}{l}\text { Intensificação das rondas no ENTORNO do campus, pela Guarda Universitária } \\
\text { (PPUSP) }\end{array}$ & $43 \%$ & 94 \\
\hline Intensificação das rondas no ENTORNO do campus, pela Policia Militar & $50 \%$ & 111 \\
\hline Intensificação das rondas no ENTORNO do campus, pela Guarda Municipal & $40 \%$ & 89 \\
\hline Intensificação de rondas DENTRO do campus, pela Guarda Universitária (PPUSP) & $63 \%$ & 140 \\
\hline Realização de rondas DENTRO do campus, pela Policia Militar & $22 \%$ & 48 \\
\hline $\begin{array}{l}\text { Realização de rondas DENTRO do campus, pela Policia Militar, mas somente nos } \\
\text { horários mais críticos como à noite e durante grandes eventos }\end{array}$ & $27 \%$ & 59 \\
\hline Realização de rondas DENTRO do campus, pela Guarda Municipal & $18 \%$ & 39 \\
\hline $\begin{array}{l}\text { Realização de rondas DENTRO do campus, pela Guarda Municipal, mas somente } \\
\text { nos horários mais críticos como à noite e durante grandes eventos }\end{array}$ & $22 \%$ & 49 \\
\hline Nenhuma das alternativas & $5 \%$ & 10
\end{tabular}


Como você descreveria o trajeto do seu ponto de origem até o campus Luiz de Queiroz (ESALQ/CENA)?

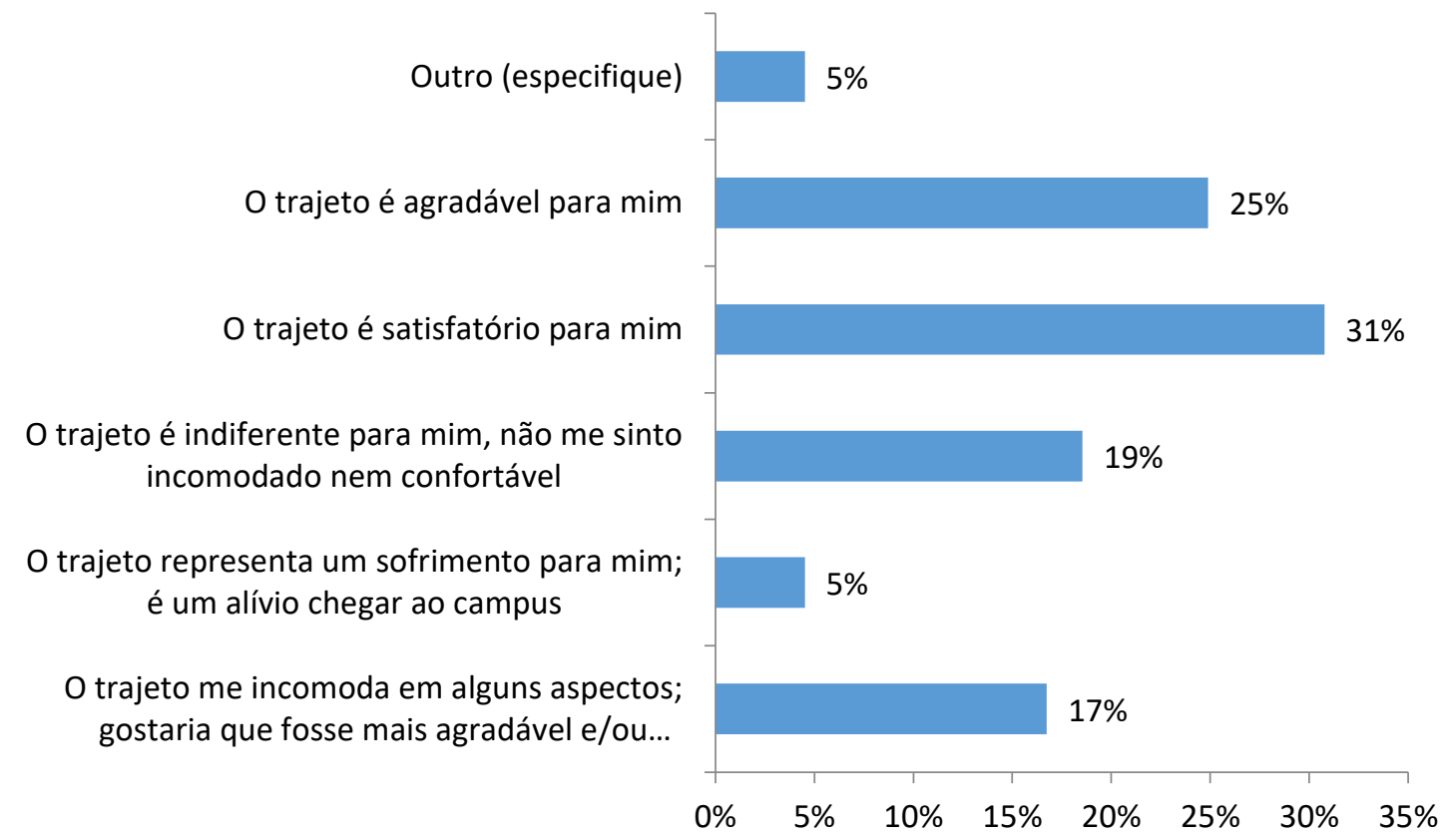

O trajeto me incomoda em alguns aspectos; gostaria que fosse mais agradável e/ou menos demorado $17 \% \quad 37$ O trajeto representa um sofrimento para mim; é um alívio chegar ao campus $\quad 5 \% \quad 10$ O trajeto é indiferente para mim, não me sinto incomodado nem confortável $19 \% \quad 41$ O trajeto é satisfatório para mim $31 \% \quad 68$ O trajeto é agradável para mim $25 \% \quad 55$

Outro (especifique)

$5 \% \quad 10$


Como você avalia a sinalização do campus Luiz de Queiroz (ESALQ/CENA)?

Sinalização informativa (indicação de prédios, serviços, etc)

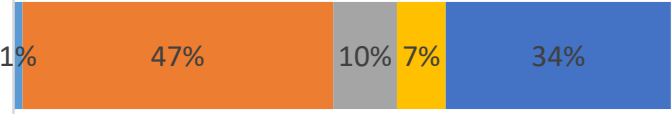

Sinalização de trânsito (horizontal e vertical)

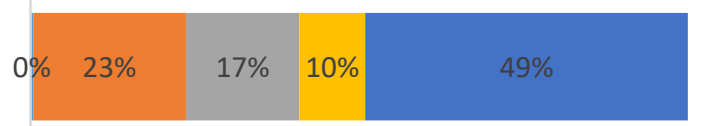

$$
\begin{array}{llllll}
0 \% & 20 \% & 40 \% & 60 \% & 80 \% & 100 \%
\end{array}
$$

- Inexistente

Insuficiente

- Suficiente, porém em mau estado de conservação $\quad$ Suficiente, porém fora dos padrões

- Suficiente

Sinalização de trânsito Sinalização informativa (indicação (horizontal e vertical) de prédios, serviços, etc)

\begin{tabular}{lcccc}
\hline Inexistente & $0 \%$ & 1 & $1 \%$ & 3 \\
\hline $\begin{array}{l}\text { Insuficiente } \\
\begin{array}{l}\text { Suficiente, porém em mau } \\
\text { estado de conservação }\end{array}\end{array}$ & $23 \%$ & 51 & $47 \%$ & 102 \\
\hline $\begin{array}{l}\text { Suficiente, porém fora dos } \\
\text { padrões }\end{array}$ & $17 \%$ & 38 & $10 \%$ & 21 \\
\hline $\begin{array}{l}\text { Suficiente } \\
\text { S }\end{array}$ & $10 \%$ & 22 & $7 \%$ & 16 \\
\hline
\end{tabular}


Na sua opinião, qual a importância destes aspectos para uma mobilidade mais sustentável na USP de Piracicaba? Ordene os temas marcando-os com os respectivos números ou arrastando as caixas de acordo com a prioridade 1 a mais importante.

\section{Média}

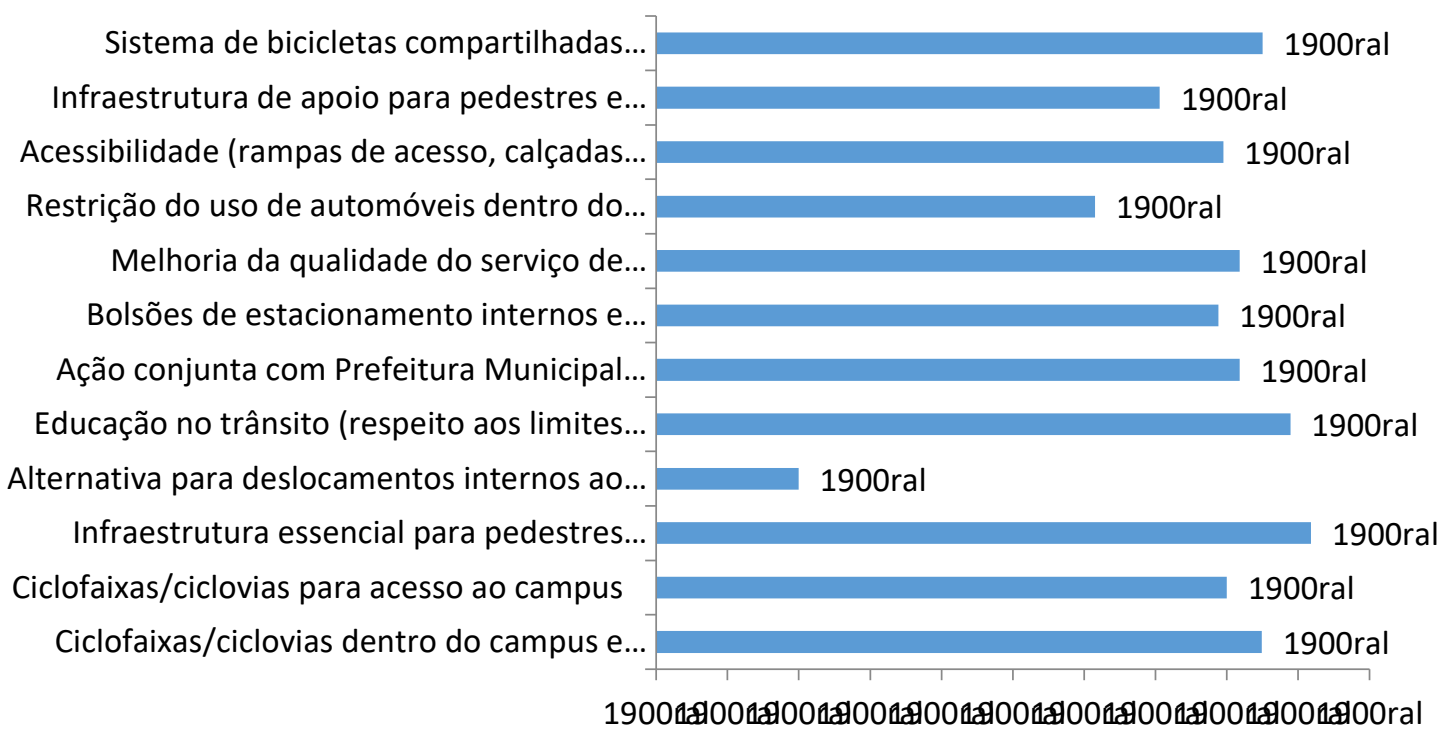

Obs: Quanto maior a média, maior a prioridade 


\begin{tabular}{|c|c|c|c|c|c|c|c|c|c|c|}
\hline Prioridade & 1 & 2 & 3 & 4 & 5 & 6 & 7 & 8 & 9 & 10 \\
\hline $\begin{array}{l}\text { Ciclofaixas/ciclovias dent } \\
\text { ro do campus e para } \\
\text { acesso ao mesmo }\end{array}$ & $13 \%$ & $14 \%$ & $15 \%$ & $10 \%$ & $14 \%$ & $8 \%$ & $13 \%$ & $10 \%$ & $5 \%$ & $0 \%$ \\
\hline $\begin{array}{l}\text { Infraestrutura essencial } \\
\text { para pedestres (calçadas } \\
\text { adequadas, iluminação, } \\
\text { arborização, sinalização, } \\
\text { etc.) }\end{array}$ & $21 \%$ & $18 \%$ & $13 \%$ & $12 \%$ & $12 \%$ & $8 \%$ & $5 \%$ & $4 \%$ & $7 \%$ & $0 \%$ \\
\hline $\begin{array}{l}\text { Educação no trânsito } \\
\text { (respeito aos limites } \\
\text { de velocidade e à } \\
\text { sinalização, melhor } \\
\text { convívio entre } \\
\text { motoristas, ciclistas e } \\
\text { pedestres, etc.) }\end{array}$ & $20 \%$ & $14 \%$ & $11 \%$ & $12 \%$ & $10 \%$ & $12 \%$ & $7 \%$ & $9 \%$ & $4 \%$ & $0 \%$ \\
\hline $\begin{array}{l}\text { Ação conjunta com } \\
\text { Prefeitura Municipal para } \\
\text { melhoria da mobilidade } \\
\text { na ligação entre cidade e } \\
\text { campus }\end{array}$ & $11 \%$ & $10 \%$ & $14 \%$ & $12 \%$ & $12 \%$ & $13 \%$ & $13 \%$ & $10 \%$ & $7 \%$ & $0 \%$ \\
\hline $\begin{array}{l}\text { Bolsões de } \\
\text { estacionamento internos } \\
\text { e externos ao campus }\end{array}$ & $7 \%$ & $13 \%$ & $3 \%$ & $13 \%$ & $8 \%$ & $0 \%$ & $0 \%$ & $0 \%$ & $6 \%$ & $0 \%$ \\
\hline $\begin{array}{l}\text { Melhoria da qualidade do } \\
\text { serviço de transporte } \\
\text { público da cidade }\end{array}$ & $8 \%$ & $13 \%$ & $\%$ & $15 \%$ & $15 \%$ & $3 \%$ & $1 \%$ & $8 \%$ & $6 \%$ & $1 \%$ \\
\hline $\begin{array}{l}\text { Restrição do uso de } \\
\text { automóveis dentro do } \\
\text { campus }\end{array}$ & $14 \%$ & $2 \%$ & $4 \%$ & $2 \%$ & $3 \%$ & $4 \%$ & $6 \%$ & $13 \%$ & $51 \%$ & $1 \%$ \\
\hline $\begin{array}{l}\text { Acessibilidade (rampas } \\
\text { de acesso, calçadas } \\
\text { adequadas, elevadores, } \\
\text { piso tátil, respeito a } \\
\text { vagas de } \\
\text { estacionamento } \\
\text { prioritárias, etc.) }\end{array}$ & $7 \%$ & $9 \%$ & $14 \%$ & $14 \%$ & $16 \%$ & $13 \%$ & $17 \%$ & $7 \%$ & $6 \%$ & $0 \%$ \\
\hline $\begin{array}{l}\text { Infraestrutura de apoio } \\
\text { para pedestres e ciclistas } \\
\text { (bebedouros, bancos, } \\
\text { vestiários, guarda- } \\
\text { volume, bicicletários, } \\
\text { oficina para consertos, } \\
\text { etc.) }\end{array}$ & $4 \%$ & $6 \%$ & $8 \%$ & $9 \%$ & $12 \%$ & $14 \%$ & $15 \%$ & $19 \%$ & $12 \%$ & $0 \%$ \\
\hline
\end{tabular}




\section{Modo: Bicicleta}

Analisando o campus da ESALQ/CENA como um todo, você o considera acessível aos usuários com algum tipo de restrição de mobilidade?

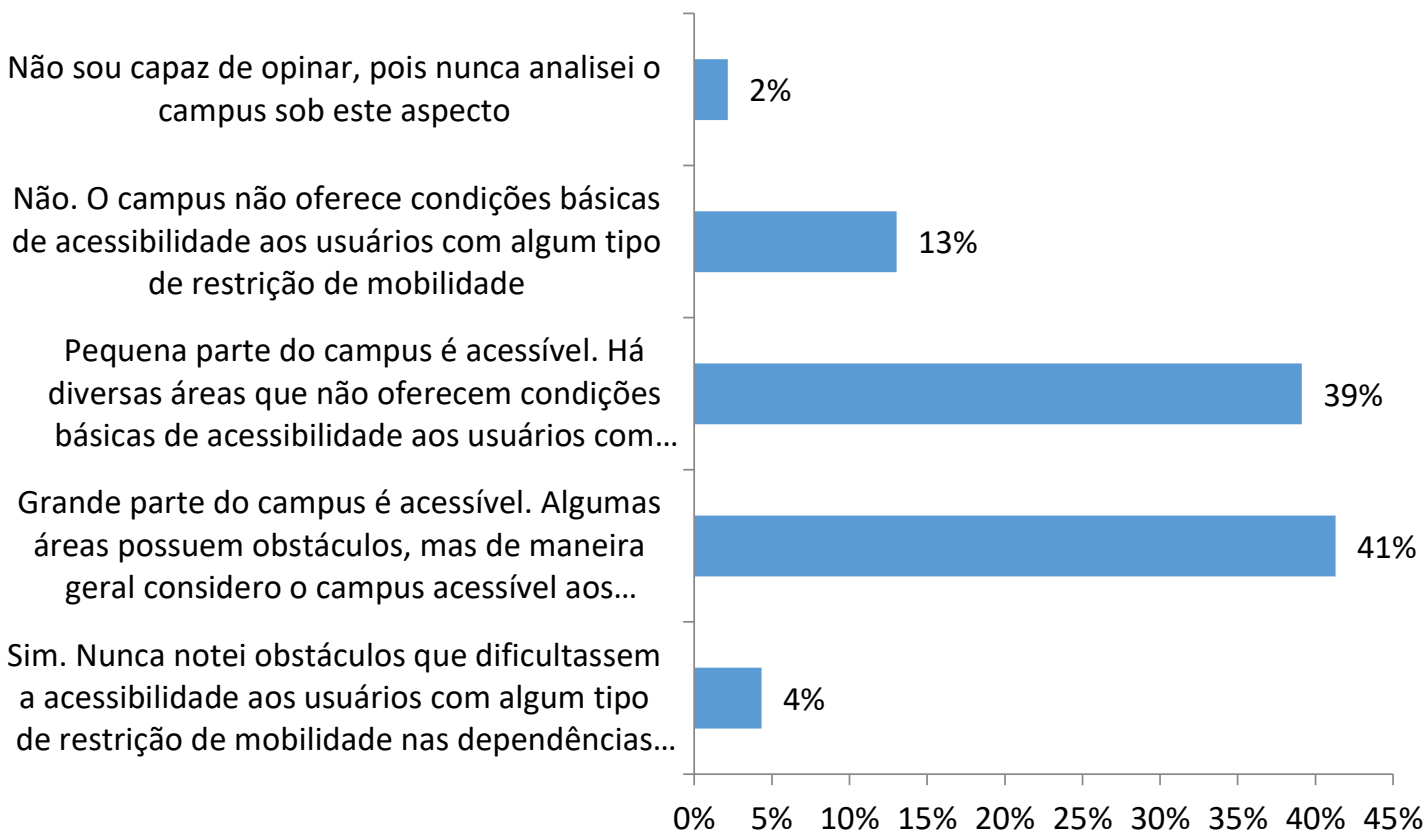

Sim. Nunca notei obstáculos que dificultassem a acessibilidade aos usuários com algum tipo de restrição de mobilidade nas dependências do campus $4 \% \quad 2$ Grande parte do campus é acessível. Algumas áreas possuem obstáculos, mas de maneira geral considero o campus acessível aos usuários com algum tipo de restrição de mobilidade $41 \% \quad 19$

Pequena parte do campus é acessível. Há diversas áreas que não oferecem condições básicas de acessibilidade aos usuários com algum tipo de restrição de mobilidade $39 \% \quad 18$

Não. O campus não oferece condições básicas de acessibilidade aos usuários com algum tipo de restrição de mobilidade

Não sou capaz de opinar, pois nunca analisei o campus sob este aspecto

$13 \% \quad 6$

$2 \% \quad 1$




\section{Dentre os prédios que frequenta na ESALQ/CENA, como você avalia a acessibilidade para os usuários com algum tipo de restrição de mobilidade?}

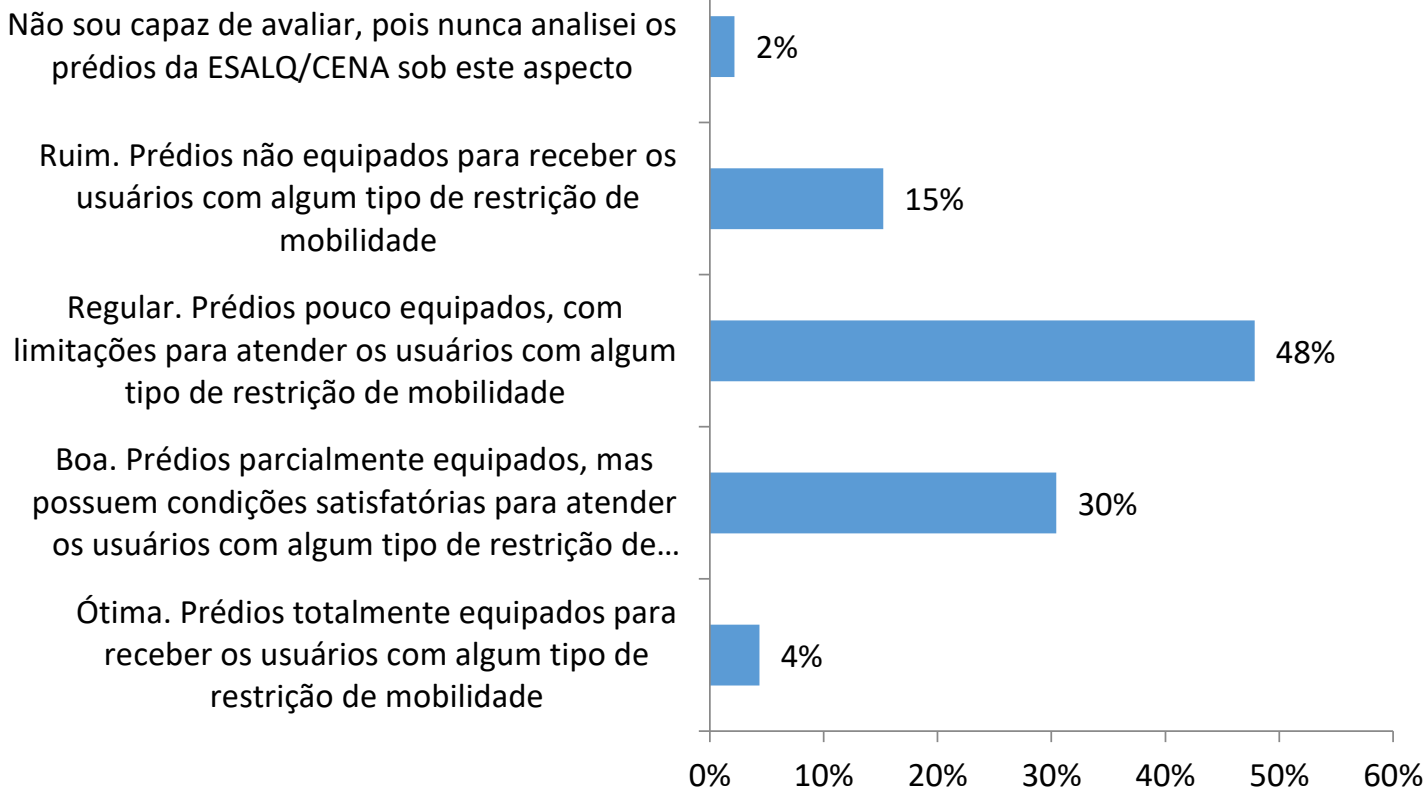

Ótima. Prédios totalmente equipados para receber os usuários com algum tipo de restrição de mobilidade $4 \% \quad 2$

Boa. Prédios parcialmente equipados, mas possuem condições satisfatórias para atender os usuários com algum tipo de restrição de mobilidade $30 \% \quad 14$

Regular. Prédios pouco equipados, com limitações para atender os usuários com algum tipo de restrição de mobilidade $48 \% \quad 22$ Ruim. Prédios não equipados para receber os usuários com algum tipo de restrição de mobilidade $15 \% \quad 7$ Não sou capaz de avaliar, pois nunca analisei os prédios da ESALQ/CENA sob este aspecto 
$\mathrm{Na}$ etapa anterior do questionário, você nos informou que seu modo principal para os deslocamentos à ESALQ/CENA é a BICICLETA. Quais fatores o/a levam a optar por este modo?

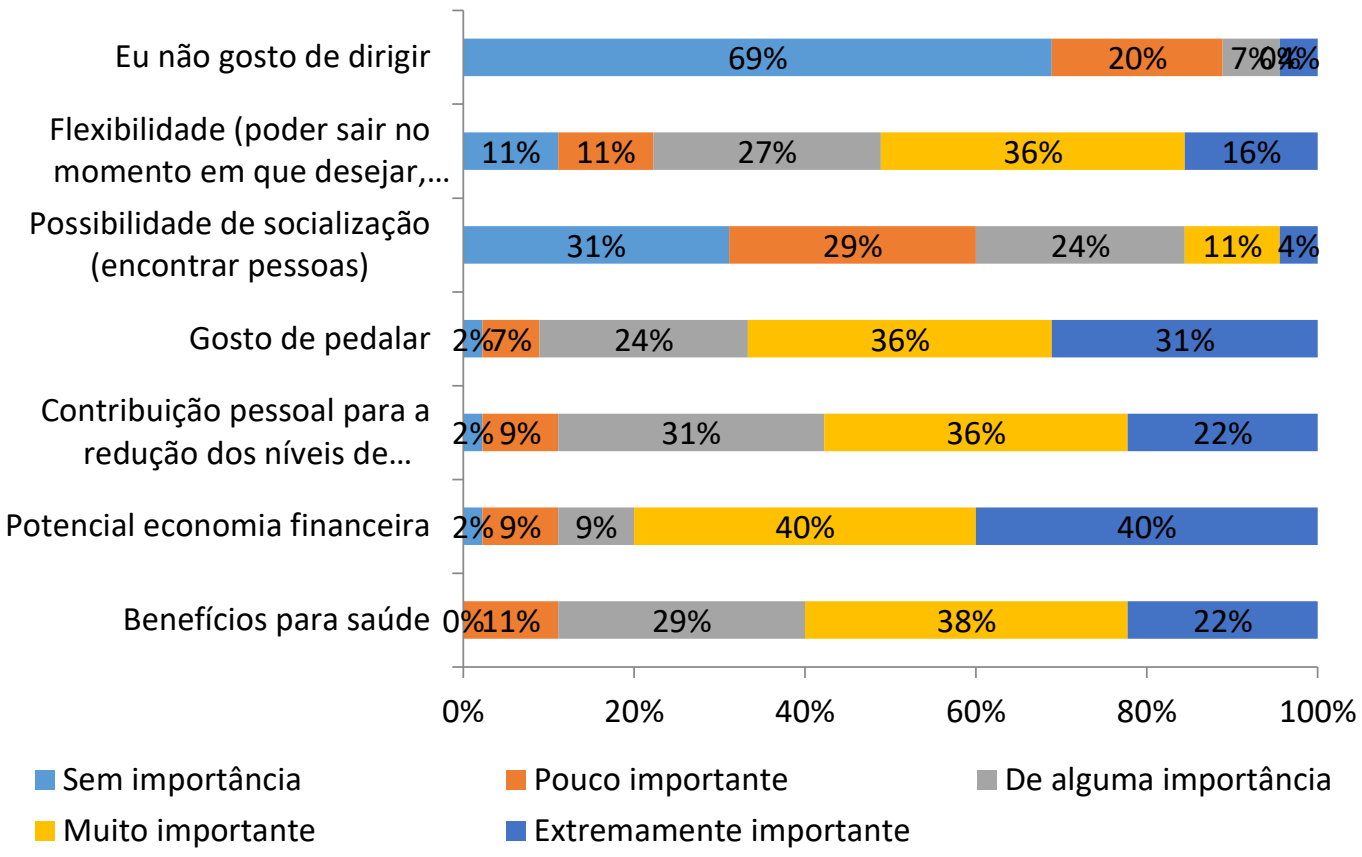

\begin{tabular}{|c|c|c|c|c|c|c|c|c|c|c|}
\hline \multirow[b]{2}{*}{$\begin{array}{l}\text { Benefícios para } \\
\text { saúde }\end{array}$} & \multicolumn{2}{|c|}{$\begin{array}{c}\text { Sem } \\
\text { importância }\end{array}$} & \multicolumn{2}{|c|}{$\begin{array}{c}\text { Pouco } \\
\text { importante }\end{array}$} & \multicolumn{2}{|c|}{$\begin{array}{l}\text { De alguma } \\
\text { importância }\end{array}$} & \multicolumn{2}{|c|}{$\begin{array}{c}\text { Muito } \\
\text { importante }\end{array}$} & \multicolumn{2}{|c|}{$\begin{array}{c}\text { Extremamen } \\
\text { te important } \\
\mathrm{e}\end{array}$} \\
\hline & $0 \%$ & 0 & $11 \%$ & 5 & $29 \%$ & 13 & $38 \%$ & 17 & $22 \%$ & 10 \\
\hline $\begin{array}{l}\text { Potencial economia } \\
\text { financeira }\end{array}$ & $2 \%$ & 1 & $9 \%$ & 4 & $9 \%$ & 4 & $40 \%$ & 18 & $40 \%$ & 18 \\
\hline $\begin{array}{l}\text { Contribuição } \\
\text { pessoal para a } \\
\text { redução dos níveis } \\
\text { de poluição do ar }\end{array}$ & $2 \%$ & 1 & $9 \%$ & 4 & $31 \%$ & 14 & $36 \%$ & 16 & $22 \%$ & 10 \\
\hline Gosto de pedalar & $2 \%$ & 1 & $7 \%$ & 3 & $24 \%$ & 11 & $36 \%$ & 16 & $31 \%$ & 14 \\
\hline $\begin{array}{l}\text { Possibilidade de } \\
\text { socialização } \\
\text { (encontrar pessoas) }\end{array}$ & $31 \%$ & 14 & $29 \%$ & 13 & $24 \%$ & 11 & $11 \%$ & 5 & $4 \%$ & 2 \\
\hline $\begin{array}{l}\text { Flexibilidade (poder } \\
\text { sair no momento em } \\
\text { que desejar, fazer } \\
\text { paradas durante o } \\
\text { trajeto, etc.) }\end{array}$ & $11 \%$ & 5 & $11 \%$ & 5 & $27 \%$ & 12 & $36 \%$ & 16 & $16 \%$ & 7 \\
\hline $\begin{array}{l}\text { Eu não gosto de } \\
\text { dirigir }\end{array}$ & $69 \%$ & 31 & $20 \%$ & 9 & $7 \%$ & 3 & $0 \%$ & 0 & $4 \%$ & 2 \\
\hline
\end{tabular}

Quais fatores o/a desestimulam a utilizar os demais modos que não a bicicleta em seus deslocamentos? 
Ausência de calçadas adequadas até o campus

Distância de viagem

Insegurança pública (assaltos, furtos, assédio)

Baixa qualidade do transporte público

Condições climáticas (chuva, vento, calor, frio)

Distância longa a ser percorrida

Tempo envolvido no trajeto dos demais modos (tempo de espera, percurso, atrasos)
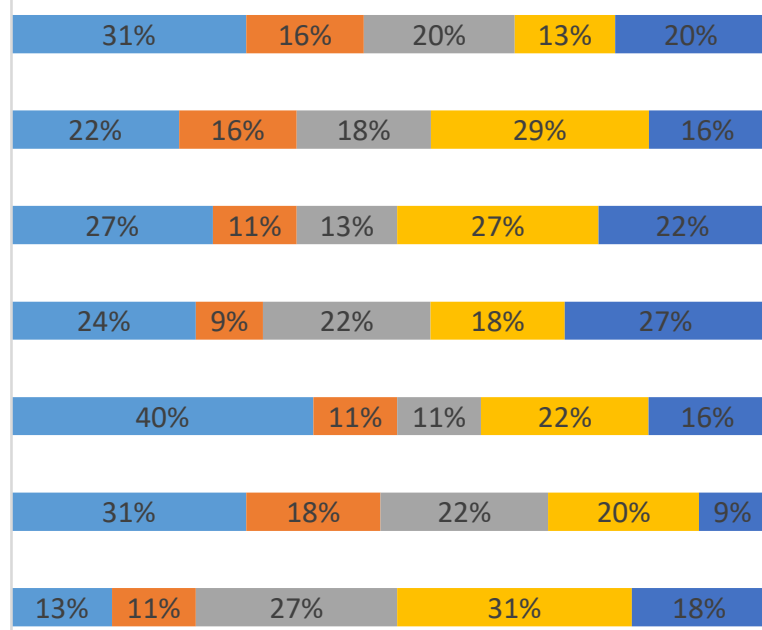

$\begin{array}{lllllllllllllllll}0 \% & 10 \% & 20 \% & 30 \% & 40 \% & 50 \% & 60 \% & 70 \% & 80 \% & 90 \% & 100 \%\end{array}$

\begin{tabular}{|c|c|c|c|c|c|c|c|c|c|c|}
\hline \multirow{2}{*}{$\begin{array}{l} \\
\text { Tempo envolvido no } \\
\text { trajeto dos demais } \\
\text { modos (tempo de } \\
\text { espera, percurso, } \\
\text { atrasos) }\end{array}$} & \multicolumn{2}{|c|}{$\begin{array}{c}\text { Sem } \\
\text { importância }\end{array}$} & \multicolumn{2}{|c|}{$\begin{array}{c}\text { Pouco } \\
\text { importante }\end{array}$} & \multicolumn{2}{|c|}{$\begin{array}{l}\text { De alguma } \\
\text { importância }\end{array}$} & \multicolumn{2}{|c|}{$\begin{array}{c}\text { Muito } \\
\text { importante }\end{array}$} & \multicolumn{2}{|c|}{$\begin{array}{c}\text { Extremame } \\
\text { nte } \\
\text { importante }\end{array}$} \\
\hline & $13 \%$ & 6 & $11 \%$ & 5 & $27 \%$ & 12 & $31 \%$ & 14 & $18 \%$ & 8 \\
\hline $\begin{array}{l}\text { Distância longa a ser } \\
\text { percorrida }\end{array}$ & $31 \%$ & 14 & $18 \%$ & 8 & $22 \%$ & 10 & $20 \%$ & 9 & $9 \%$ & 4 \\
\hline $\begin{array}{l}\text { Condições climáticas } \\
\text { (chuva, vento, calor, } \\
\text { frio) }\end{array}$ & $40 \%$ & 18 & $11 \%$ & 5 & $11 \%$ & 5 & $22 \%$ & 10 & $16 \%$ & 7 \\
\hline $\begin{array}{l}\text { Baixa qualidade do } \\
\text { transporte público }\end{array}$ & $24 \%$ & 11 & $9 \%$ & 4 & $22 \%$ & 10 & $18 \%$ & 8 & $27 \%$ & 12 \\
\hline $\begin{array}{l}\text { Insegurança pública } \\
\text { (assaltos, furtos, } \\
\text { assédio) }\end{array}$ & $27 \%$ & 12 & $11 \%$ & 5 & $13 \%$ & 6 & $27 \%$ & 12 & $22 \%$ & 10 \\
\hline Distância de viagem & $22 \%$ & 10 & $16 \%$ & 7 & $18 \%$ & 8 & $29 \%$ & 13 & $16 \%$ & 7 \\
\hline $\begin{array}{l}\text { Ausência de calçadas } \\
\text { adequadas até o } \\
\text { campus }\end{array}$ & $31 \%$ & 14 & $16 \%$ & 7 & $20 \%$ & 9 & $13 \%$ & 6 & $20 \%$ & 9 \\
\hline
\end{tabular}


Há quanto tempo você utiliza o modo bicicleta para se deslocar até a ESALQ/CENA?

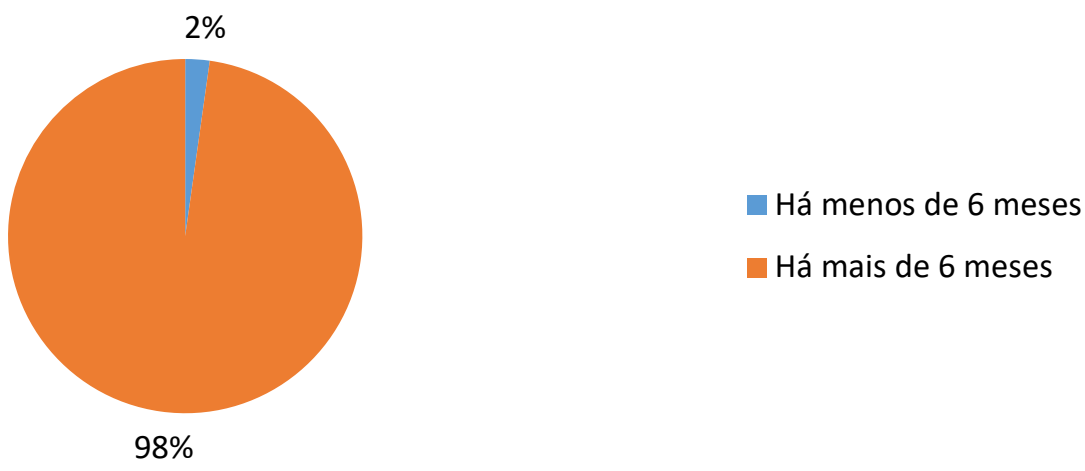

Há menos de 6 meses $\quad 2 \% \quad 1$

Há mais de 6 meses $\quad 98 \% \quad 44$

Dos deslocamentos que você faz hoje de bicicleta, qual modo você utilizava antes?

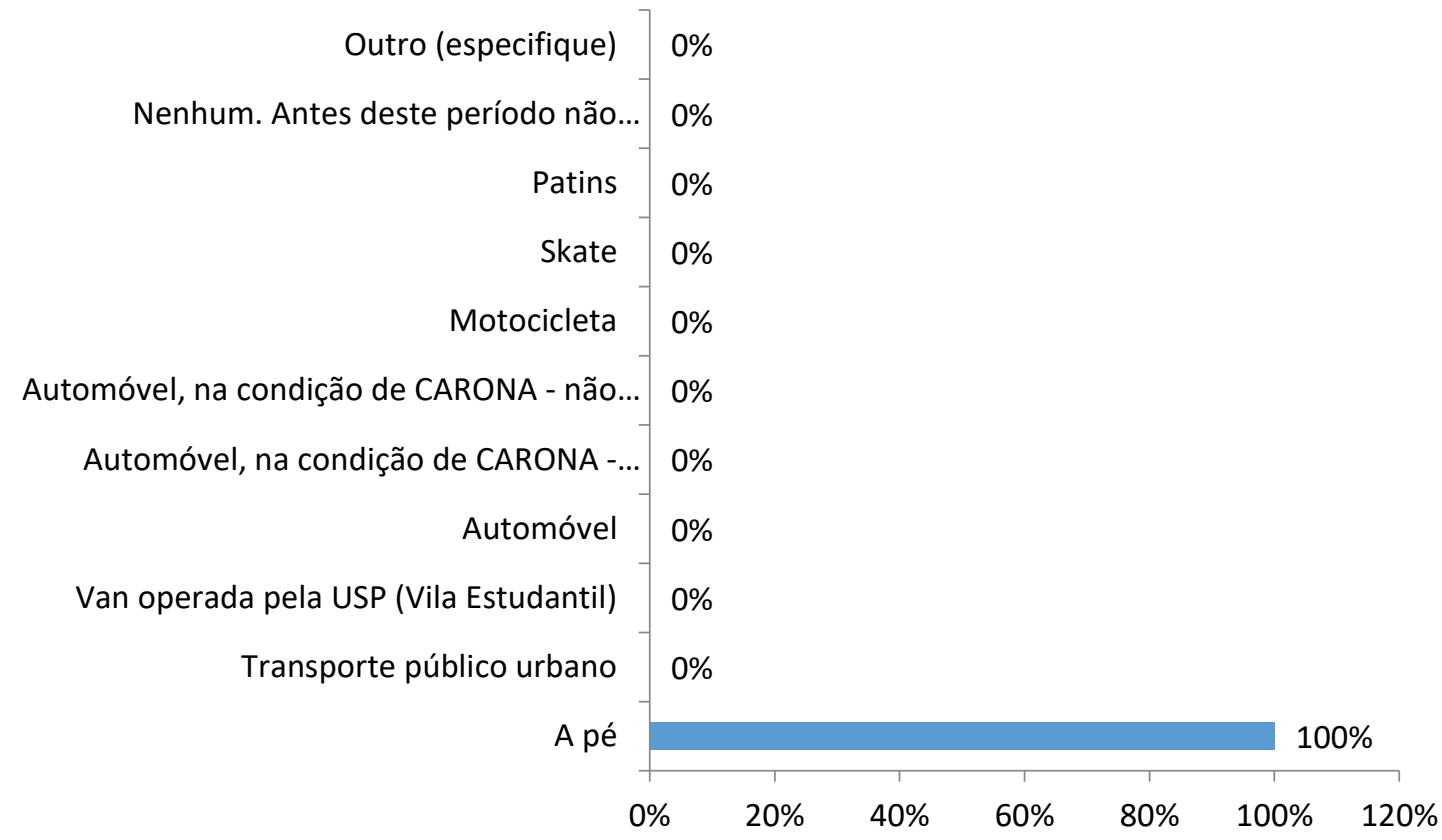




\begin{tabular}{lrl} 
A pé & $100 \%$ & 1 \\
\hline Transporte público urbano & $0 \%$ & 0 \\
\hline Van operada pela USP (Vila Estudantil) & $0 \%$ & 0 \\
\hline Automóvel & $0 \%$ & 0 \\
\hline Automóvel, na condição de CARONA - estaciona no campus & $0 \%$ & 0 \\
\hline Automóvel, na condição de CARONA - não estaciona no campus & $0 \%$ & 0 \\
\hline Motocicleta & $0 \%$ & 0 \\
\hline Skate & $0 \%$ & 0 \\
\hline Patins & $0 \%$ & 0 \\
\hline Nenhum. Antes deste período não frequentava o campus & $0 \%$ & 0 \\
\hline Outro (especifique) & $0 \%$ & 0
\end{tabular}




\section{Estado de conservação}

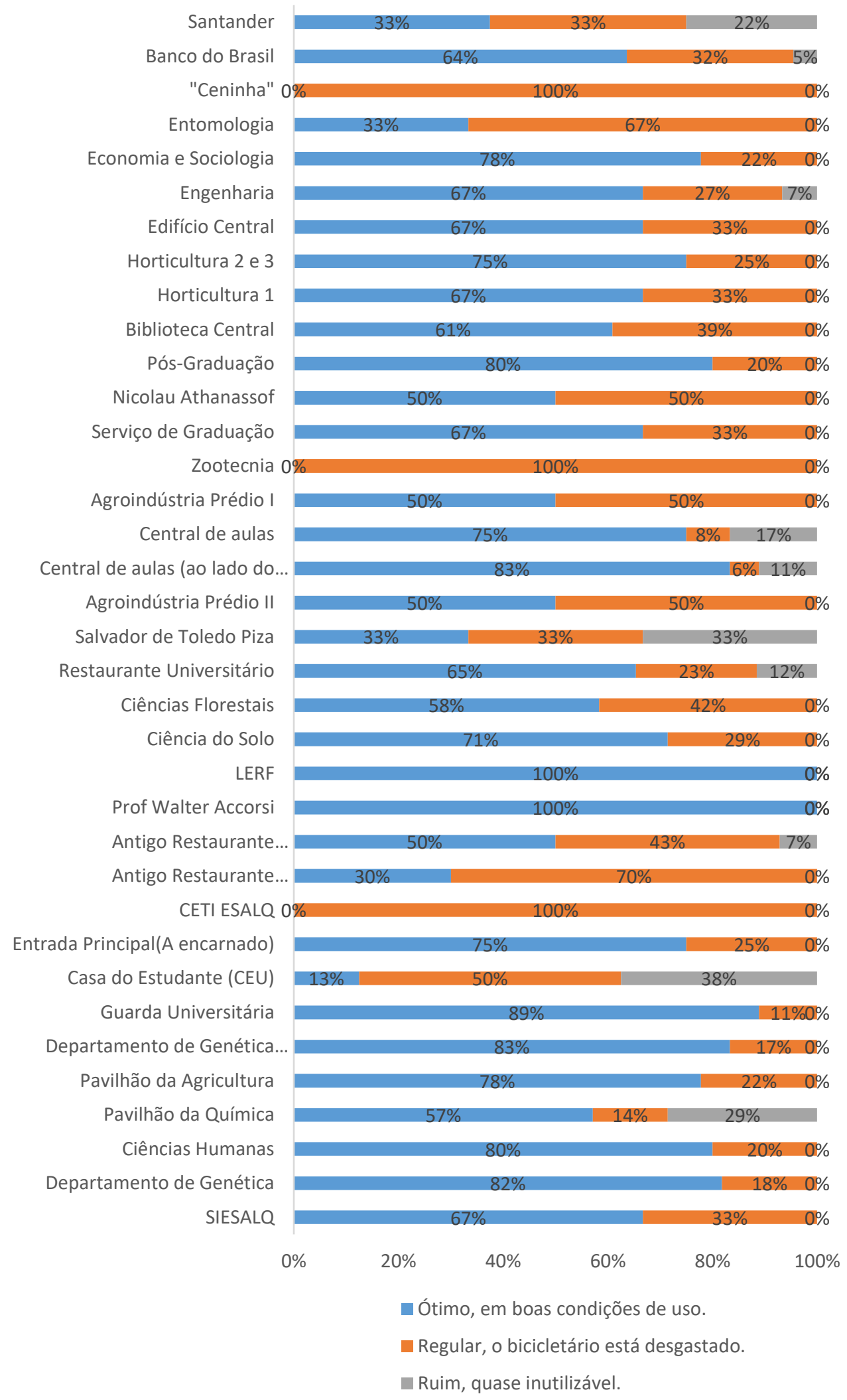


Ótimo, em boas Regular, o bicicletário Ruim, quase condições de uso. está desgastado. inutilizável.

\begin{tabular}{|c|c|c|c|c|c|c|}
\hline \multirow{2}{*}{ SIESALQ } & & & \\
\hline & $67 \%$ & 4 & $33 \%$ & 2 & $0 \%$ & 0 \\
\hline Departamento de Genética & $82 \%$ & 9 & $18 \%$ & 2 & $0 \%$ & 0 \\
\hline Ciências Humanas & $80 \%$ & 12 & $20 \%$ & 3 & $0 \%$ & 0 \\
\hline Pavilhão da Química & $57 \%$ & 4 & $14 \%$ & 1 & $29 \%$ & 2 \\
\hline Pavilhão da Agricultura & $78 \%$ & 7 & $22 \%$ & 2 & $0 \%$ & 0 \\
\hline $\begin{array}{l}\text { Departamento de Genética } \\
\text { (Alameda das Palmeiras) }\end{array}$ & $83 \%$ & 5 & $17 \%$ & 1 & $0 \%$ & 0 \\
\hline Guarda Universitária & $89 \%$ & 8 & $11 \%$ & 1 & $0 \%$ & 0 \\
\hline Casa do Estudante (CEU) & $13 \%$ & 1 & $50 \%$ & 4 & $38 \%$ & 3 \\
\hline $\begin{array}{l}\text { Entrada Principal(A } \\
\text { encarnado) }\end{array}$ & $75 \%$ & 3 & $25 \%$ & 1 & $0 \%$ & 0 \\
\hline CETI ESALQ & $0 \%$ & 0 & $100 \%$ & 1 & $0 \%$ & 0 \\
\hline $\begin{array}{l}\text { Antigo Restaurante } \\
\text { Universitário }\end{array}$ & $30 \%$ & 3 & $70 \%$ & 7 & $0 \%$ & 0 \\
\hline $\begin{array}{l}\text { Antigo Restaurante } \\
\text { Universitário } 2\end{array}$ & $50 \%$ & 7 & $43 \%$ & 6 & $7 \%$ & 1 \\
\hline Prof Walter Accorsi & $100 \%$ & 1 & $0 \%$ & 0 & $0 \%$ & 0 \\
\hline LERF & $100 \%$ & 3 & $0 \%$ & 0 & $0 \%$ & 0 \\
\hline Ciência do Solo & $71 \%$ & 5 & $29 \%$ & 2 & $0 \%$ & 0 \\
\hline Ciências Florestais & $58 \%$ & 7 & $42 \%$ & 5 & $0 \%$ & 0 \\
\hline Restaurante Universitário & $65 \%$ & 17 & $23 \%$ & 6 & $12 \%$ & 3 \\
\hline Salvador de Toledo Piza & $33 \%$ & 1 & $33 \%$ & 1 & $33 \%$ & 1 \\
\hline Agroindústria Prédio II & $50 \%$ & 1 & $50 \%$ & 1 & $0 \%$ & 0 \\
\hline $\begin{array}{l}\text { Central de aulas (ao lado do } \\
\text { Restaurante Universitário) }\end{array}$ & $83 \%$ & 15 & $6 \%$ & 1 & $11 \%$ & 2 \\
\hline Central de aulas & $75 \%$ & 9 & $8 \%$ & 1 & $17 \%$ & 2 \\
\hline Agroindústria Prédio I & $50 \%$ & 2 & $50 \%$ & 2 & $0 \%$ & 0 \\
\hline Zootecnia & $0 \%$ & 0 & $100 \%$ & 2 & $0 \%$ & 0 \\
\hline Serviço de Graduação & $67 \%$ & 6 & $33 \%$ & 3 & $0 \%$ & 0 \\
\hline Nicolau Athanassof & $50 \%$ & 1 & $50 \%$ & 1 & $0 \%$ & 0 \\
\hline Pós-Graduação & $80 \%$ & 8 & $20 \%$ & 2 & $0 \%$ & 0 \\
\hline Biblioteca Central & $61 \%$ & 14 & $39 \%$ & 9 & $0 \%$ & 0 \\
\hline Horticultura 1 & $67 \%$ & 4 & $33 \%$ & 2 & $0 \%$ & 0 \\
\hline Horticultura 2 e 3 & $75 \%$ & 3 & $25 \%$ & 1 & $0 \%$ & 0 \\
\hline Edifício Central & $67 \%$ & 6 & $33 \%$ & 3 & $0 \%$ & 0 \\
\hline Engenharia & $67 \%$ & 10 & $27 \%$ & 4 & $7 \%$ & 1 \\
\hline Economia e Sociologia & $78 \%$ & 7 & $22 \%$ & 2 & $0 \%$ & 0 \\
\hline Entomologia & $33 \%$ & 1 & $67 \%$ & 2 & $0 \%$ & 0 \\
\hline "Ceninha" & $0 \%$ & 0 & $100 \%$ & 1 & $0 \%$ & 0 \\
\hline Banco do Brasil & $64 \%$ & 14 & $32 \%$ & 7 & $5 \%$ & 1 \\
\hline Santander & $33 \%$ & 3 & $33 \%$ & 4 & $22 \%$ & 2 \\
\hline
\end{tabular}




\section{Estado da cobertura}

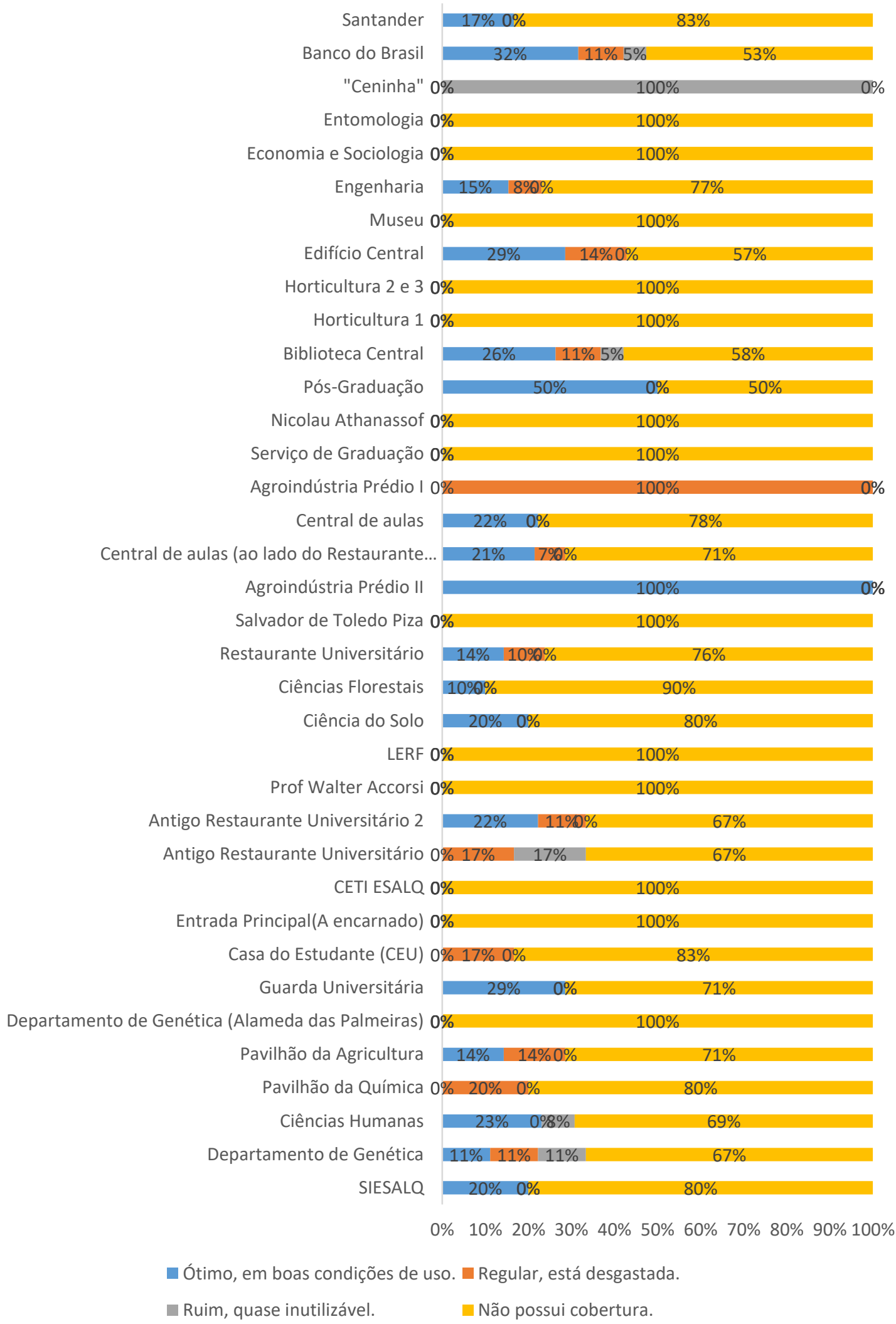


Ótimo, em boas Regular, está Ruim, quase Não possui condições de uso. desgastada. inutilizável. cobertura.

\begin{tabular}{|c|c|c|c|c|c|c|c|c|}
\hline SIESALQ & $20 \%$ & 1 & $0 \%$ & 0 & $0 \%$ & 0 & $80 \%$ & 4 \\
\hline Departamento de Genética & $11 \%$ & 1 & $11 \%$ & 1 & $11 \%$ & 1 & $67 \%$ & 6 \\
\hline Ciências Humanas & $23 \%$ & 3 & $0 \%$ & 0 & $8 \%$ & 1 & $69 \%$ & 9 \\
\hline Pavilhão da Química & $0 \%$ & 0 & $20 \%$ & 1 & $0 \%$ & 0 & $80 \%$ & 4 \\
\hline Pavilhão da Agricultura & $14 \%$ & 1 & $14 \%$ & 1 & $0 \%$ & 0 & $71 \%$ & 5 \\
\hline $\begin{array}{l}\text { Departamento de Genética } \\
\text { (Alameda das Palmeiras) }\end{array}$ & $0 \%$ & 0 & $0 \%$ & 0 & $0 \%$ & 0 & $100 \%$ & 4 \\
\hline Guarda Universitária & $29 \%$ & 2 & $0 \%$ & 0 & $0 \%$ & 0 & $71 \%$ & 5 \\
\hline Casa do Estudante (CEU) & $0 \%$ & 0 & $17 \%$ & 1 & $0 \%$ & 0 & $83 \%$ & 5 \\
\hline $\begin{array}{l}\text { Entrada Principal(A } \\
\text { encarnado) }\end{array}$ & $0 \%$ & 0 & $0 \%$ & 0 & $0 \%$ & 0 & $100 \%$ & 3 \\
\hline CETI ESALQ & $0 \%$ & 0 & $0 \%$ & 0 & $0 \%$ & 0 & $100 \%$ & 1 \\
\hline $\begin{array}{l}\text { Antigo Restaurante } \\
\text { Universitário }\end{array}$ & $0 \%$ & 0 & $17 \%$ & 1 & $17 \%$ & 1 & $67 \%$ & 4 \\
\hline $\begin{array}{l}\text { Antigo Restaurante } \\
\text { Universitário } 2\end{array}$ & $22 \%$ & 2 & $11 \%$ & 1 & $0 \%$ & 0 & $67 \%$ & 6 \\
\hline Prof Walter Accorsi & $0 \%$ & 0 & $0 \%$ & 0 & $0 \%$ & 0 & $100 \%$ & 1 \\
\hline LERF & $0 \%$ & 0 & $0 \%$ & 0 & $0 \%$ & 0 & $100 \%$ & 2 \\
\hline Ciência do Solo & $20 \%$ & 1 & $0 \%$ & 0 & $0 \%$ & 0 & $80 \%$ & 4 \\
\hline Ciências Florestais & $10 \%$ & 1 & $0 \%$ & 0 & $0 \%$ & 0 & $90 \%$ & 9 \\
\hline Restaurante Universitário & $14 \%$ & 3 & $10 \%$ & 2 & $0 \%$ & 0 & $76 \%$ & 16 \\
\hline Salvador de Toledo Piza & $0 \%$ & 0 & $0 \%$ & 0 & $0 \%$ & 0 & $100 \%$ & 3 \\
\hline Agroindústria Prédio II & $100 \%$ & 1 & $0 \%$ & 0 & $0 \%$ & 0 & $0 \%$ & 0 \\
\hline $\begin{array}{l}\text { Central de aulas (ao lado do } \\
\text { Restaurante Universitário) }\end{array}$ & $21 \%$ & 3 & $7 \%$ & 1 & $0 \%$ & 0 & $71 \%$ & 10 \\
\hline Central de aulas & $22 \%$ & 2 & $0 \%$ & 0 & $0 \%$ & 0 & $78 \%$ & 7 \\
\hline Agroindústria Prédio I & $0 \%$ & 0 & $100 \%$ & 3 & $0 \%$ & 0 & $0 \%$ & 0 \\
\hline Serviço de Graduação & $0 \%$ & 0 & $0 \%$ & 0 & $0 \%$ & 0 & $100 \%$ & 5 \\
\hline Nicolau Athanassof & $0 \%$ & 0 & $0 \%$ & 0 & $0 \%$ & 0 & $100 \%$ & 1 \\
\hline Pós-Graduação & $50 \%$ & 4 & $0 \%$ & 0 & $0 \%$ & 0 & $50 \%$ & 4 \\
\hline Biblioteca Central & $26 \%$ & 5 & $11 \%$ & 2 & $5 \%$ & 1 & $58 \%$ & 11 \\
\hline Horticultura 1 & $0 \%$ & 0 & $0 \%$ & 0 & $0 \%$ & 0 & $100 \%$ & 5 \\
\hline Horticultura 2 e 3 & $0 \%$ & 0 & $0 \%$ & 0 & $0 \%$ & 0 & $100 \%$ & 4 \\
\hline Edifício Central & $29 \%$ & 2 & $14 \%$ & 1 & $0 \%$ & 0 & $57 \%$ & 4 \\
\hline Museu & $0 \%$ & 0 & $0 \%$ & 0 & $0 \%$ & 0 & $100 \%$ & 1 \\
\hline Engenharia & $15 \%$ & 2 & $8 \%$ & 1 & $0 \%$ & 0 & $77 \%$ & 10 \\
\hline Economia e Sociologia & $0 \%$ & 0 & $0 \%$ & 0 & $0 \%$ & 0 & $100 \%$ & 7 \\
\hline Entomologia & $0 \%$ & 0 & $0 \%$ & 0 & $0 \%$ & 0 & $100 \%$ & 2 \\
\hline "Ceninha" & $0 \%$ & 0 & $0 \%$ & 0 & $100 \%$ & 1 & $0 \%$ & 0 \\
\hline Banco do Brasil & $32 \%$ & 6 & $11 \%$ & 2 & $5 \%$ & 1 & $53 \%$ & 10 \\
\hline Santander & $17 \%$ & 1 & $0 \%$ & 0 & $0 \%$ & 0 & $83 \%$ & 5 \\
\hline
\end{tabular}




\section{Localização}

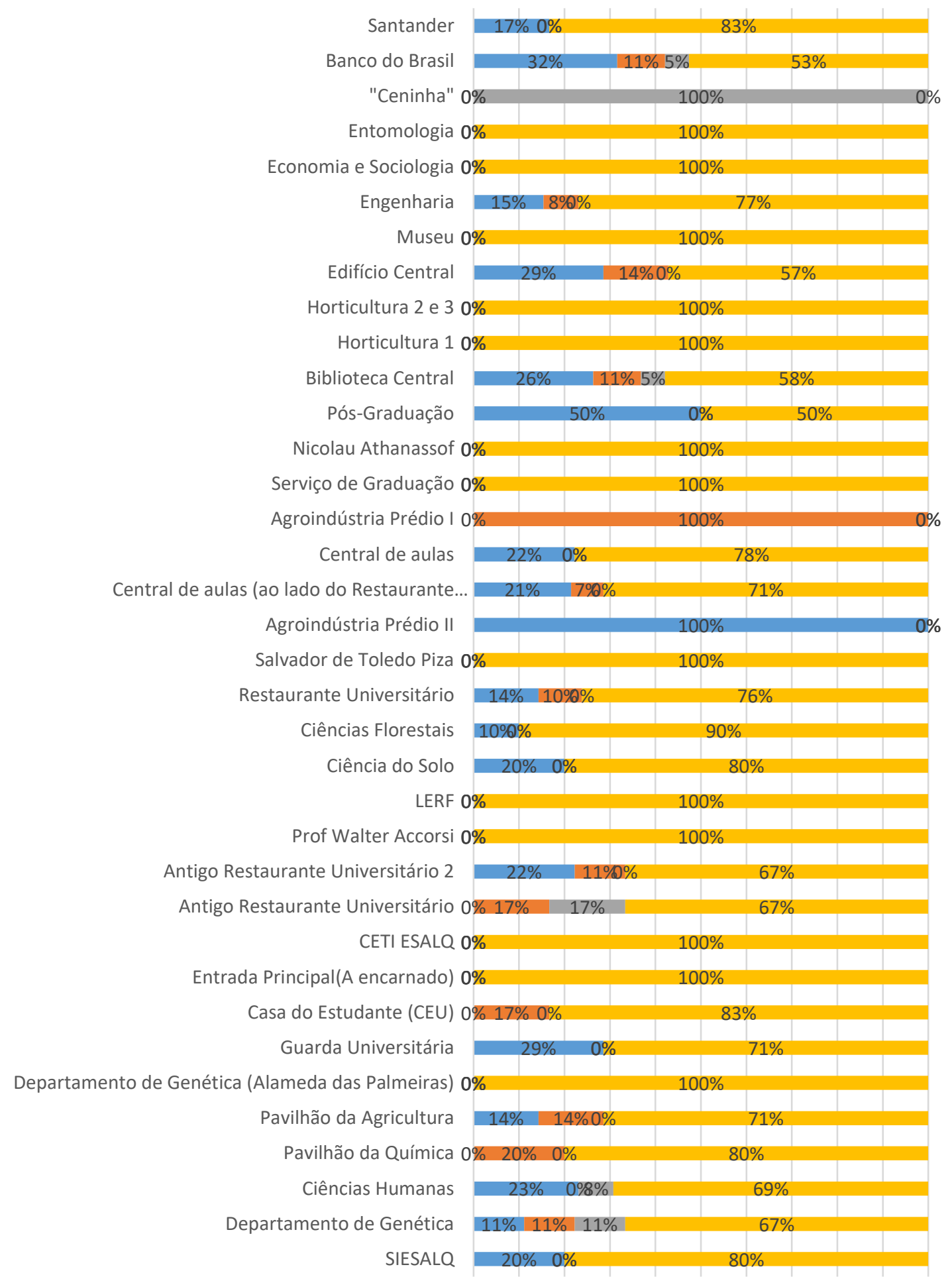

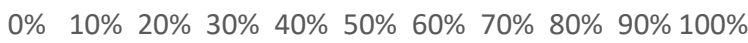

ఐ Ótimo, em boas condições de uso. —Regular, está desgastada.

nuim, quase inutilizável. Não possui cobertura. 
Ótimo, em boas Regular, está Ruim, quase Não possui condições de uso. desgastada. inutilizável. cobertura.

\begin{tabular}{|c|c|c|c|c|c|c|c|c|}
\hline SIESALQ & $20 \%$ & 1 & $0 \%$ & 0 & $0 \%$ & 0 & $80 \%$ & 4 \\
\hline Departamento de Genética & $11 \%$ & 1 & $11 \%$ & 1 & $11 \%$ & 1 & $67 \%$ & 6 \\
\hline Ciências Humanas & $23 \%$ & 3 & $0 \%$ & 0 & $8 \%$ & 1 & $69 \%$ & 9 \\
\hline Pavilhão da Química & $0 \%$ & 0 & $20 \%$ & 1 & $0 \%$ & 0 & $80 \%$ & 4 \\
\hline Pavilhão da Agricultura & $14 \%$ & 1 & $14 \%$ & 1 & $0 \%$ & 0 & $71 \%$ & 5 \\
\hline $\begin{array}{l}\text { Departamento de Genética } \\
\text { (Alameda das Palmeiras) }\end{array}$ & $0 \%$ & 0 & $0 \%$ & 0 & $0 \%$ & 0 & $100 \%$ & 4 \\
\hline Guarda Universitária & $29 \%$ & 2 & $0 \%$ & 0 & $0 \%$ & 0 & $71 \%$ & 5 \\
\hline Casa do Estudante (CEU) & $0 \%$ & 0 & $17 \%$ & 1 & $0 \%$ & 0 & $83 \%$ & 5 \\
\hline $\begin{array}{l}\text { Entrada Principal(A } \\
\text { encarnado) }\end{array}$ & $0 \%$ & 0 & $0 \%$ & 0 & $0 \%$ & 0 & $100 \%$ & 3 \\
\hline CETI ESALQ & $0 \%$ & 0 & $0 \%$ & 0 & $0 \%$ & 0 & $100 \%$ & 1 \\
\hline $\begin{array}{l}\text { Antigo Restaurante } \\
\text { Universitário }\end{array}$ & $0 \%$ & 0 & $17 \%$ & 1 & $17 \%$ & 1 & $67 \%$ & 4 \\
\hline $\begin{array}{l}\text { Antigo Restaurante } \\
\text { Universitário } 2\end{array}$ & $22 \%$ & 2 & $11 \%$ & 1 & $0 \%$ & 0 & $67 \%$ & 6 \\
\hline Prof Walter Accorsi & $0 \%$ & 0 & $0 \%$ & 0 & $0 \%$ & 0 & $100 \%$ & 1 \\
\hline LERF & $0 \%$ & 0 & $0 \%$ & 0 & $0 \%$ & 0 & $100 \%$ & 2 \\
\hline Ciência do Solo & $20 \%$ & 1 & $0 \%$ & 0 & $0 \%$ & 0 & $80 \%$ & 4 \\
\hline Ciências Florestais & $10 \%$ & 1 & $0 \%$ & 0 & $0 \%$ & 0 & $90 \%$ & 9 \\
\hline Restaurante Universitário & $14 \%$ & 3 & $10 \%$ & 2 & $0 \%$ & 0 & $76 \%$ & 16 \\
\hline Salvador de Toledo Piza & $0 \%$ & 0 & $0 \%$ & 0 & $0 \%$ & 0 & $100 \%$ & 3 \\
\hline Agroindústria Prédio II & $100 \%$ & 1 & $0 \%$ & 0 & $0 \%$ & 0 & $0 \%$ & 0 \\
\hline $\begin{array}{l}\text { Central de aulas (ao lado do } \\
\text { Restaurante Universitário) }\end{array}$ & $21 \%$ & 3 & $7 \%$ & 1 & $0 \%$ & 0 & $71 \%$ & 10 \\
\hline Central de aulas & $22 \%$ & 2 & $0 \%$ & 0 & $0 \%$ & 0 & $78 \%$ & 7 \\
\hline Agroindústria Prédio I & $0 \%$ & 0 & $100 \%$ & 3 & $0 \%$ & 0 & $0 \%$ & 0 \\
\hline Serviço de Graduação & $0 \%$ & 0 & $0 \%$ & 0 & $0 \%$ & 0 & $100 \%$ & 5 \\
\hline Nicolau Athanassof & $0 \%$ & 0 & $0 \%$ & 0 & $0 \%$ & 0 & $100 \%$ & 1 \\
\hline Pós-Graduação & $50 \%$ & 4 & $0 \%$ & 0 & $0 \%$ & 0 & $50 \%$ & 4 \\
\hline Biblioteca Central & $26 \%$ & 5 & $11 \%$ & 2 & $5 \%$ & 1 & $58 \%$ & 11 \\
\hline Horticultura 1 & $0 \%$ & 0 & $0 \%$ & 0 & $0 \%$ & 0 & $100 \%$ & 5 \\
\hline Horticultura 2 e 3 & $0 \%$ & 0 & $0 \%$ & 0 & $0 \%$ & 0 & $100 \%$ & 4 \\
\hline Edifício Central & $29 \%$ & 2 & $14 \%$ & 1 & $0 \%$ & 0 & $57 \%$ & 4 \\
\hline Museu & $0 \%$ & 0 & $0 \%$ & 0 & $0 \%$ & 0 & $100 \%$ & 1 \\
\hline Engenharia & $15 \%$ & 2 & $8 \%$ & 1 & $0 \%$ & 0 & $77 \%$ & 10 \\
\hline Economia e Sociologia & $0 \%$ & 0 & $0 \%$ & 0 & $0 \%$ & 0 & $100 \%$ & 7 \\
\hline Entomologia & $0 \%$ & 0 & $0 \%$ & 0 & $0 \%$ & 0 & $100 \%$ & 2 \\
\hline "Ceninha" & $0 \%$ & 0 & $0 \%$ & 0 & $100 \%$ & 1 & $0 \%$ & 0 \\
\hline Banco do Brasil & $32 \%$ & 6 & $11 \%$ & 2 & $5 \%$ & 1 & $53 \%$ & 10 \\
\hline Santander & $17 \%$ & 1 & $0 \%$ & 0 & $0 \%$ & 0 & $83 \%$ & 5 \\
\hline
\end{tabular}


Classifique, somente para os turnos em que você costuma acessar ou se deslocar AO REDOR da ESALQ/CENA, qual a sua sensação de segurança em relação a assaltos e outros tipos de violência ou assédio

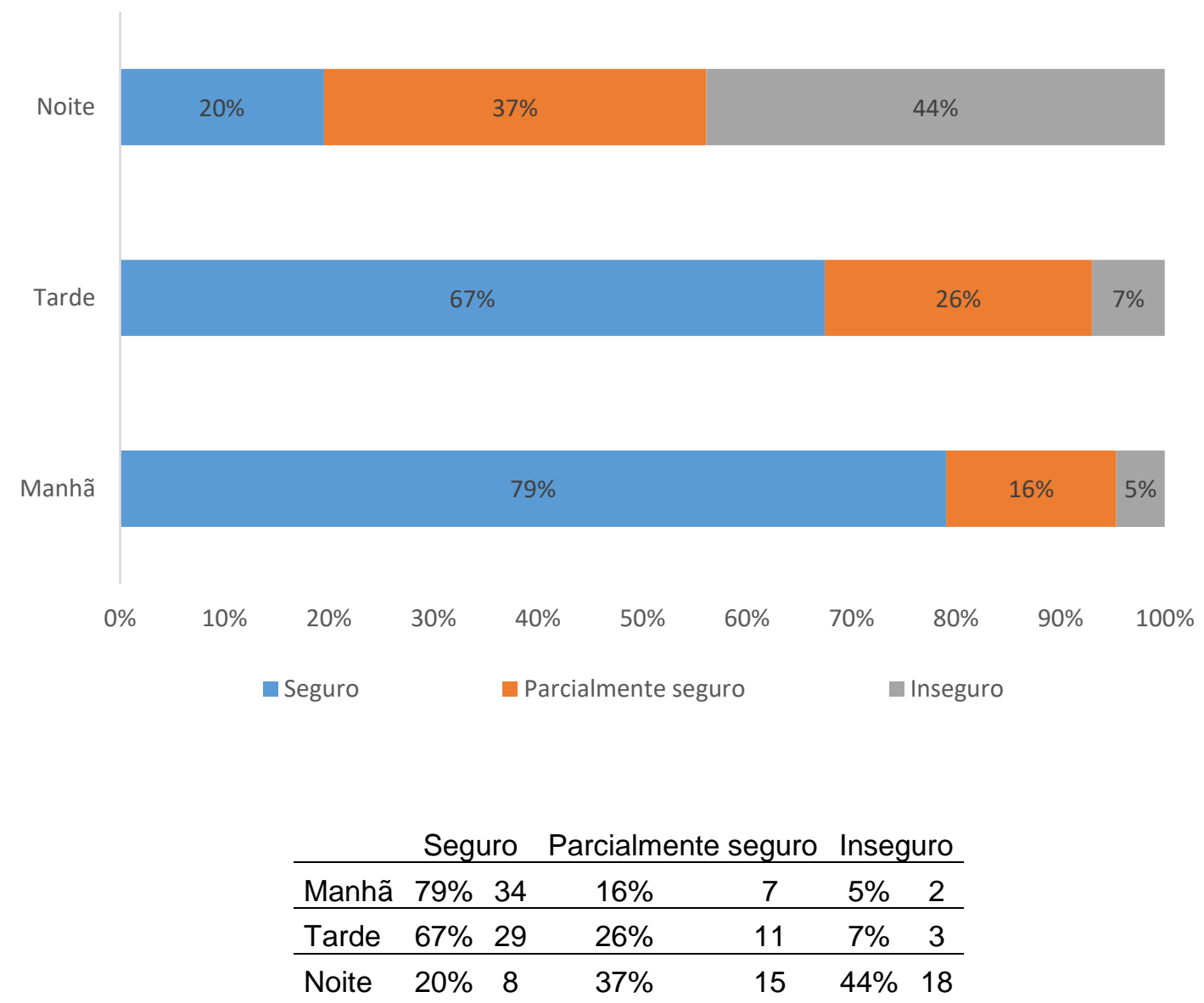


Você presenciou ou sofreu algum tipo de violência, furto ou assédio NO ENTORNO da ESALQ/CENA?
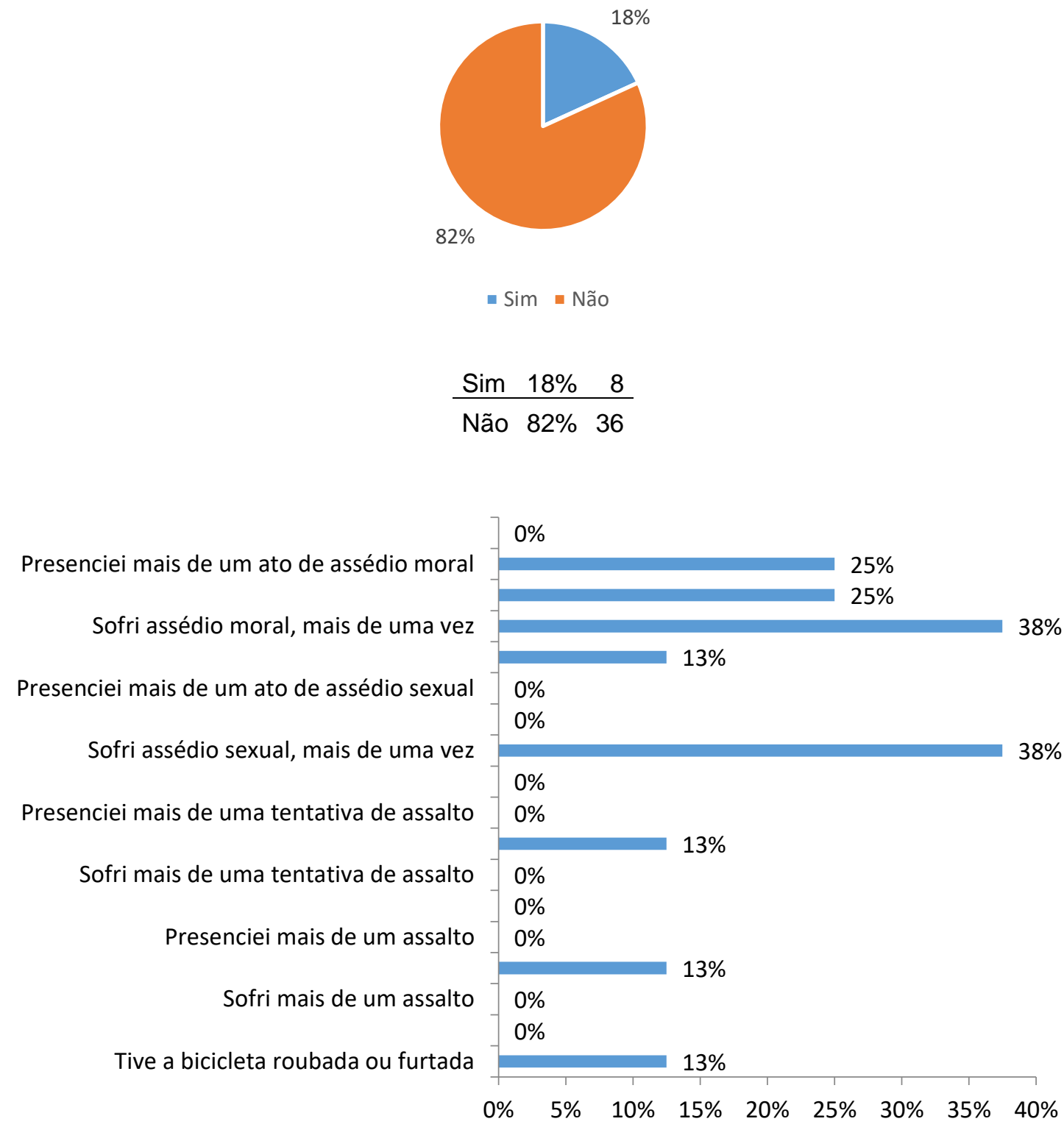


\begin{tabular}{lrc} 
Tive a bicicleta roubada ou furtada & $13 \%$ & 1 \\
\hline Sofri um assalto & $0 \%$ & 0 \\
\hline Sofri mais de um assalto & $0 \%$ & 0 \\
\hline Presenciei um assalto & $13 \%$ & 1 \\
\hline Presenciei mais de um assalto & $0 \%$ & 0 \\
\hline Sofri uma tentativa de assalto & $0 \%$ & 0 \\
\hline Sofri mais de uma tentativa de assalto & $0 \%$ & 0 \\
\hline Presenciei uma tentativa de assalto & $13 \%$ & 1 \\
\hline Presenciei mais de uma tentativa de assalto & $0 \%$ & 0 \\
\hline Sofri assédio sexual, uma vez & $0 \%$ & 0 \\
\hline Sofri assédio sexual, mais de uma vez & $38 \%$ & 3 \\
\hline Presenciei um ato de assédio sexual & $0 \%$ & 0 \\
\hline Presenciei mais de um ato de assédio sexual & $0 \%$ & 0 \\
\hline Sofri assédio moral, uma vez & $13 \%$ & 1 \\
\hline Sofri assédio moral, mais de uma vez & $38 \%$ & 3 \\
\hline Presenciei um ato de assédio moral & $25 \%$ & 2 \\
\hline Presenciei mais de um ato de assédio moral & $25 \%$ & 2 \\
\hline Outros (especifique) & $0 \%$ & 0
\end{tabular}

\section{A sua bicicleta foi:}

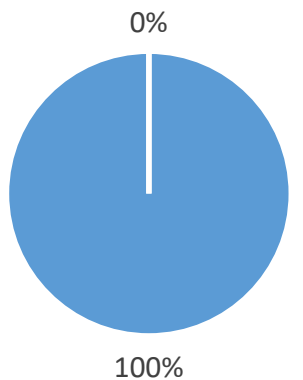

- Furtada - Roubada mediante abordagem

\begin{tabular}{lrl} 
Furtada & $100 \%$ & 2 \\
\hline Roubada mediante abordagem & $0 \%$ & 0
\end{tabular}


Quando o furto/roubo ocorreu?

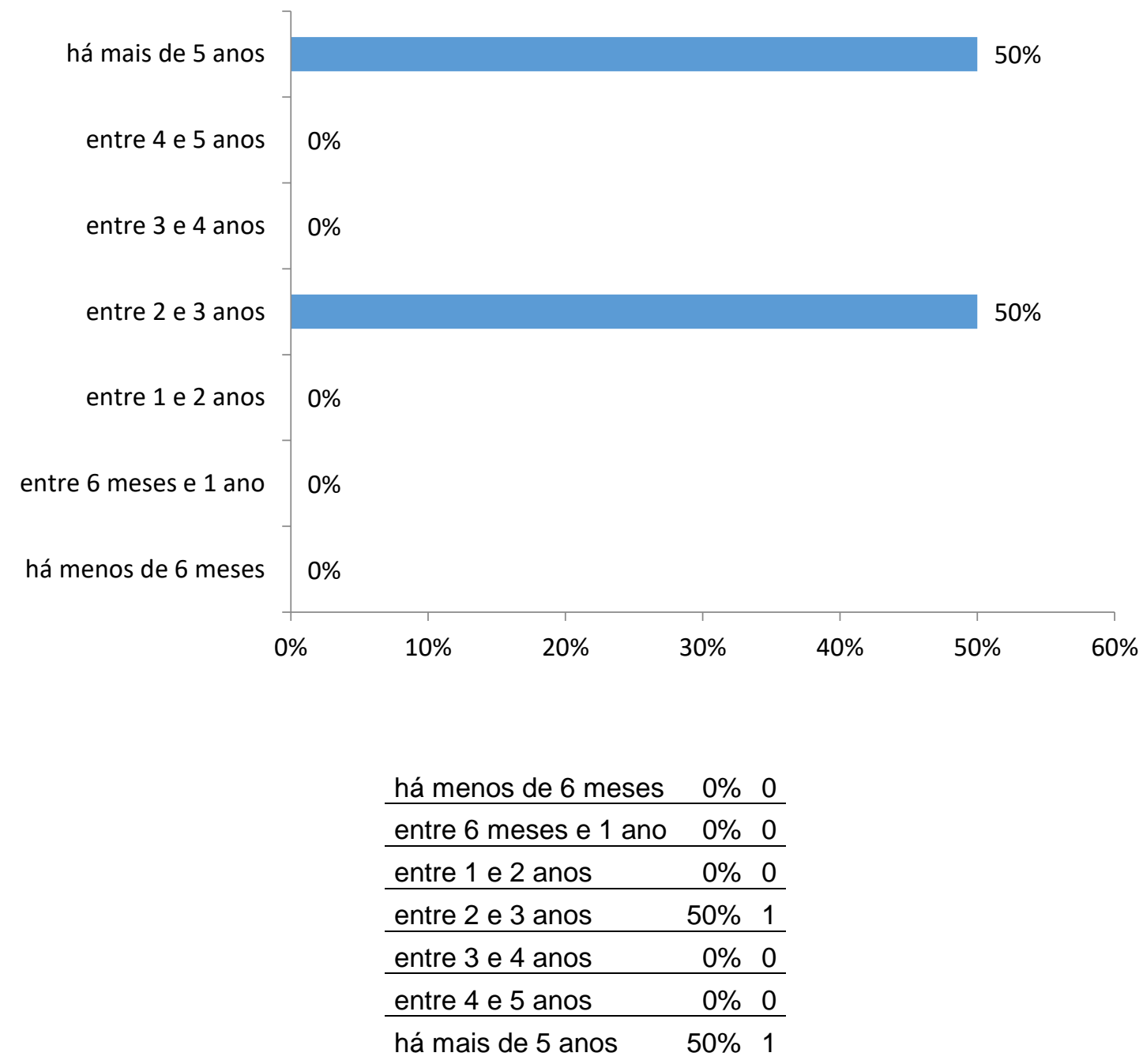


Classifique, somente para os turnos em que você costuma acessar ou se deslocar DENTRO da ESALQ/CENA, qual a sua sensação de segurança em relação a assaltos e outros tipos de violência ou assédio:

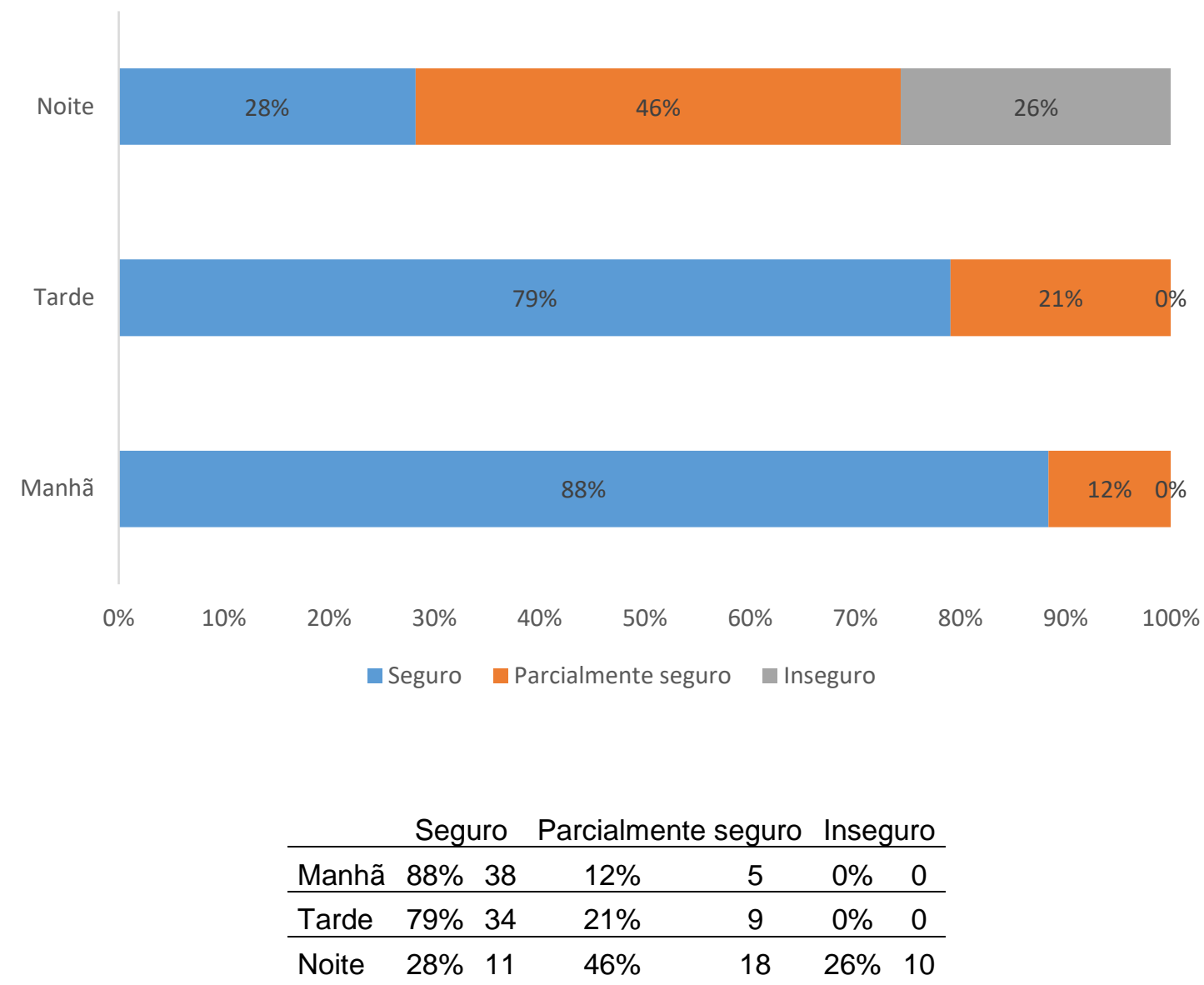


Você presenciou ou sofreu algum tipo de violência, furto ou assédio DENTRO da ESALQ/CENA?

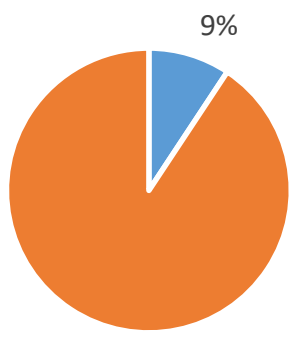

$91 \%$

\begin{tabular}{lrr} 
Sim & $9 \%$ & 4 \\
\hline Não & $91 \%$ & 39
\end{tabular}

Que tipo de violência,furto ou assédio você presenciou ou sofreu DENTRO da ESALQ/CENA? (se for necessário, marque mais de uma alternativa)

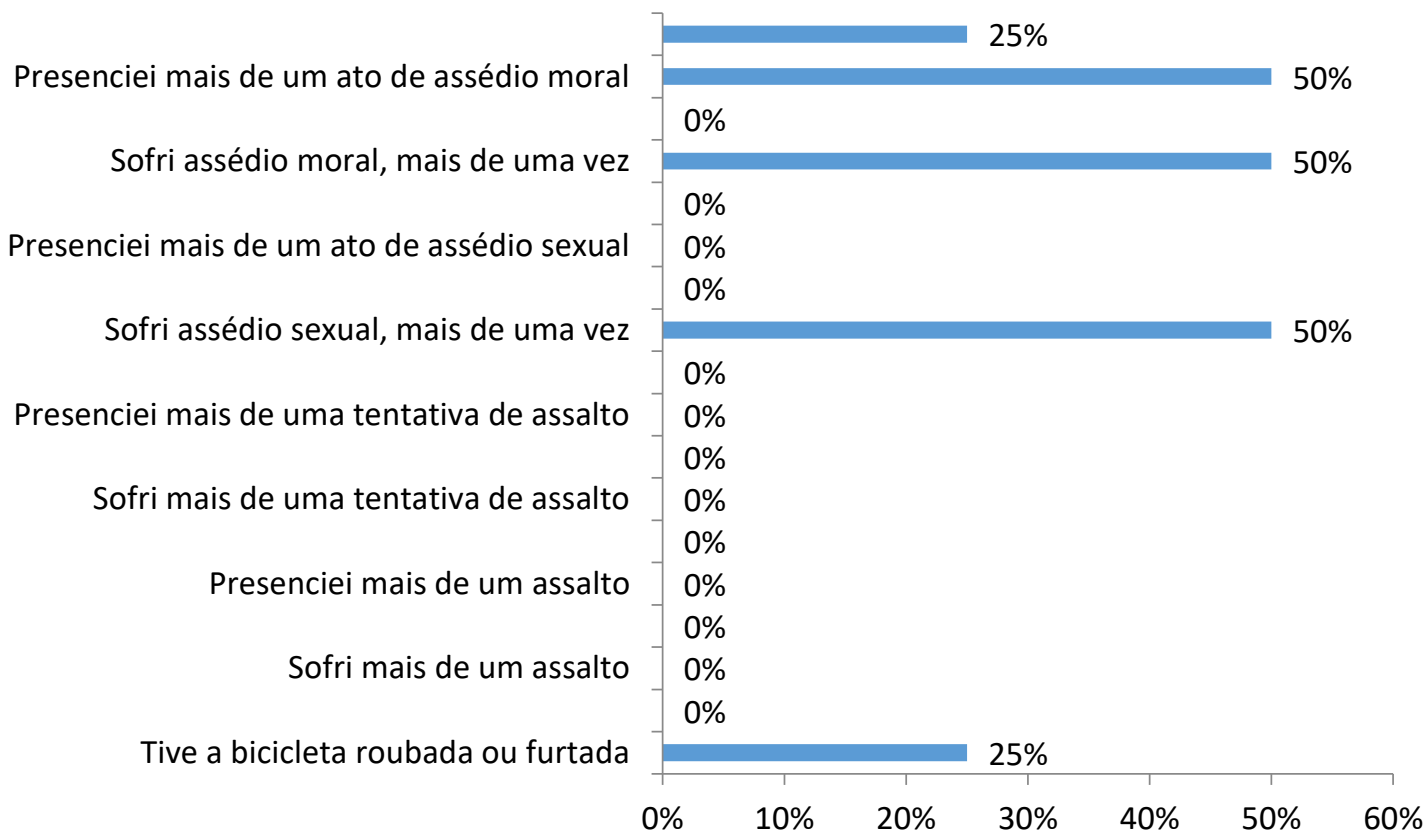




\begin{tabular}{lrl} 
Tive a bicicleta roubada ou furtada & $25 \%$ & 1 \\
\hline Sofri um assalto & $0 \%$ & 0 \\
\hline Sofri mais de um assalto & $0 \%$ & 0 \\
\hline Presenciei um assalto & $0 \%$ & 0 \\
\hline Presenciei mais de um assalto & $0 \%$ & 0 \\
\hline Sofri uma tentativa de assalto & $0 \%$ & 0 \\
\hline Sofri mais de uma tentativa de assalto & $0 \%$ & 0 \\
\hline Presenciei uma tentativa de assalto & $0 \%$ & 0 \\
\hline Presenciei mais de uma tentativa de assalto & $0 \%$ & 0 \\
\hline Sofri assédio sexual, uma vez & $0 \%$ & 0 \\
\hline Sofri assédio sexual, mais de uma vez & $50 \%$ & 2 \\
\hline Presenciei um ato de assédio sexual & $0 \%$ & 0 \\
\hline Presenciei mais de um ato de assédio sexual & $0 \%$ & 0 \\
\hline Sofri assédio moral, uma vez & $0 \%$ & 0 \\
\hline Sofri assédio moral, mais de uma vez & $50 \%$ & 2 \\
\hline Presenciei um ato de assédio moral & $0 \%$ & 0 \\
\hline Presenciei mais de um ato de assédio moral & $50 \%$ & 2 \\
\hline Outros (especifique) & $25 \%$ & 1
\end{tabular}


Com relação a medidas de segurança no ENTORNO e DENTRO da ESALQ/CENA, você é favorável a (se for necessário, marque mais de uma alternativa):

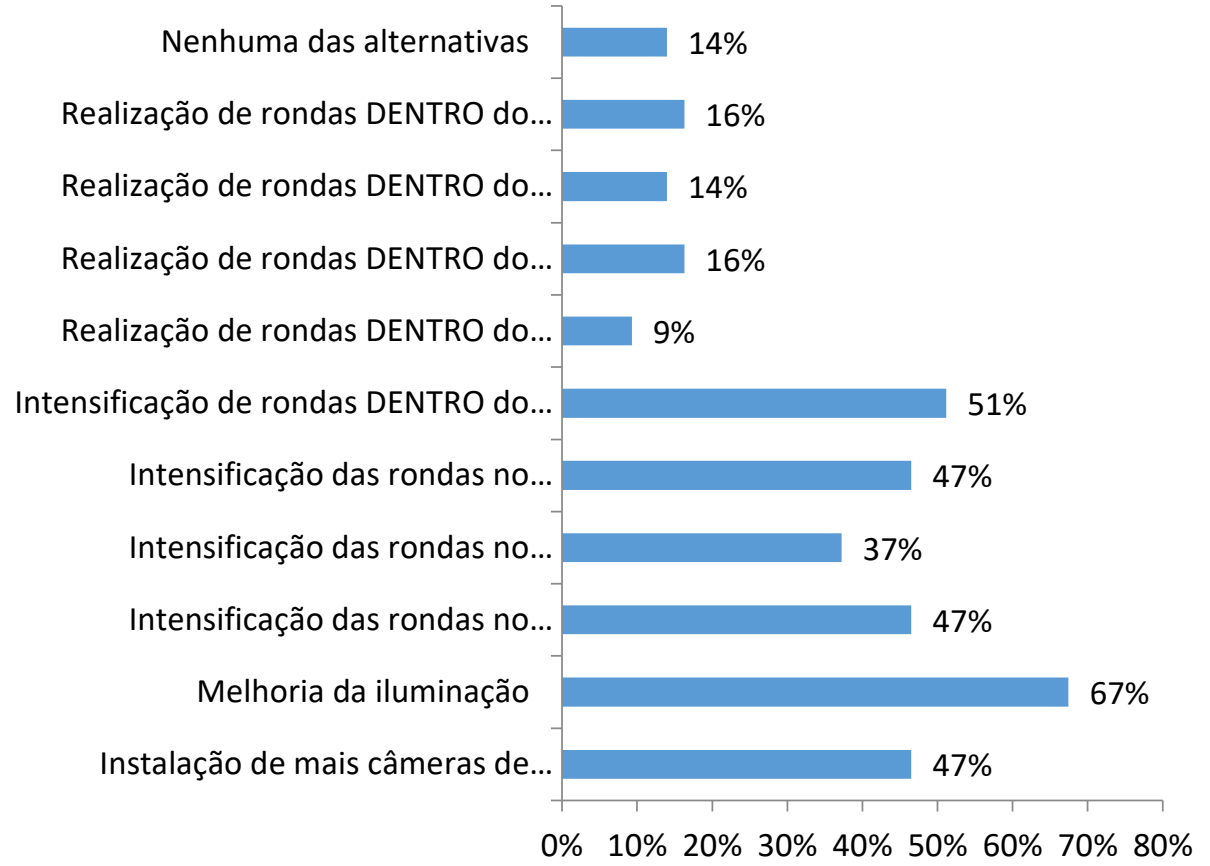

$\begin{array}{lll}\text { Instalação de mais câmeras de monitoramento } & 47 \% \quad 20\end{array}$

\begin{tabular}{lll} 
Melhoria da iluminação & $67 \%$ & 29 \\
\hline
\end{tabular}

Intensificação das rondas no ENTORNO do campus, pela Guarda Universitária (PPUSP)

\begin{tabular}{lll} 
Intensificação das rondas no ENTORNO do campus, pela Policia Militar & $37 \%$ & 16 \\
\hline
\end{tabular}

\begin{tabular}{lll}
\hline Intensificação das rondas no ENTORNO do campus, pela Guarda Municipal & $47 \%$ & 20 \\
\hline
\end{tabular}

\begin{tabular}{lll}
\hline Intensificação de rondas DENTRO do campus, pela Guarda Universitária (PPUSP) & $51 \%$ & 22
\end{tabular}

$\begin{array}{lll}\text { Realização de rondas DENTRO do campus, pela Policia Militar } & 9 \% \quad 4\end{array}$ Realização de rondas DENTRO do campus, pela Policia Militar, mas somente nos

\begin{tabular}{llll} 
horários mais críticos como à noite e durante grandes eventos & $16 \%$ & 7 \\
\hline Realização de rondas DENTRO do campus, pela Guarda Municipal & $14 \%$ & 6 \\
\hline
\end{tabular}

Realização de rondas DENTRO do campus, pela Guarda Municipal, mas somente nos horários mais críticos como à noite e durante grandes eventos

Nenhuma das alternativas

$16 \% \quad 7$

$14 \% \quad 6$


Como você descreveria o trajeto do seu ponto de origem até o campus Luiz de Queiroz (ESALQ/CENA)?

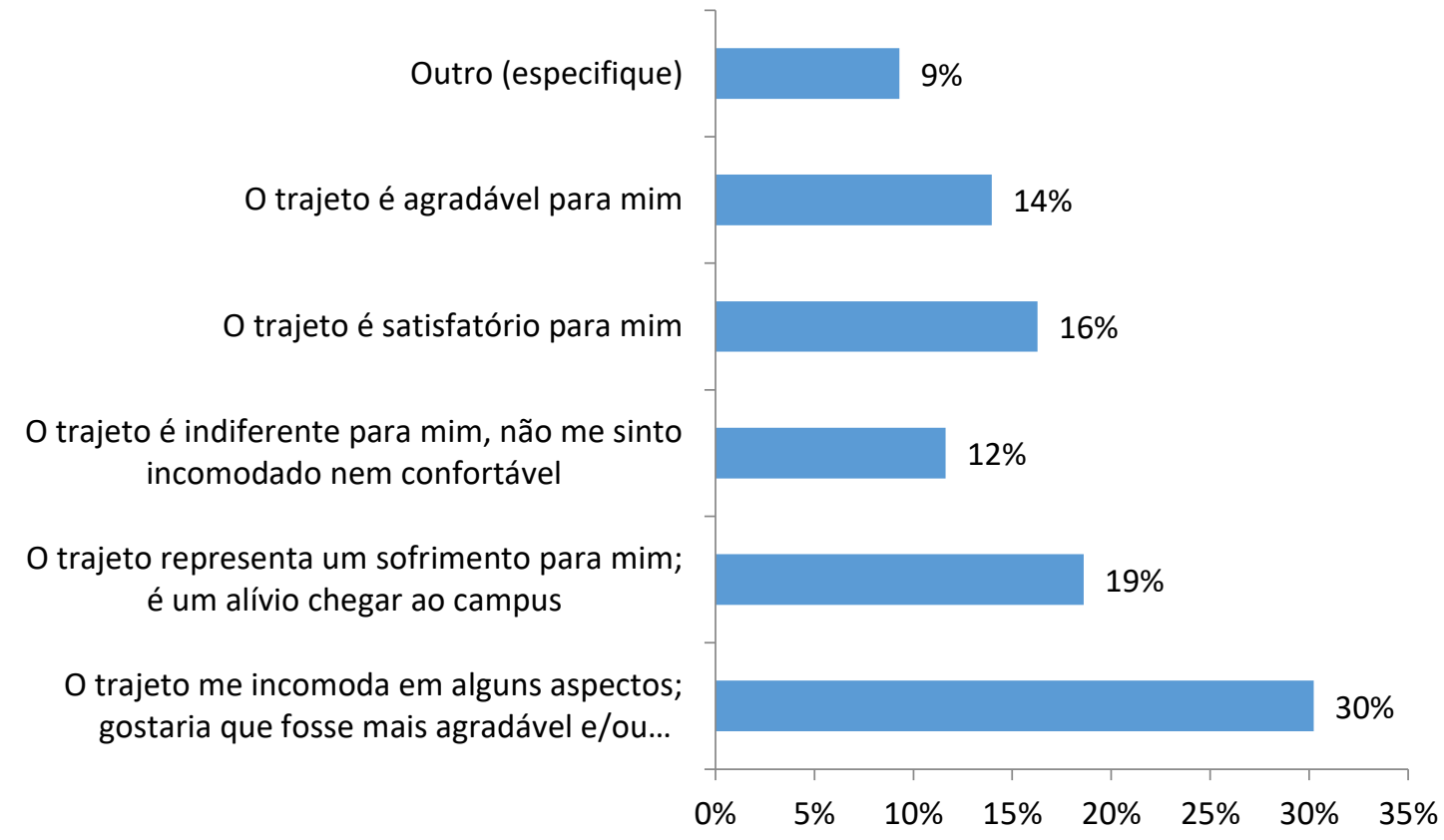

O trajeto me incomoda em alguns aspectos; gostaria que fosse mais agradável e/ou menos demorado

O trajeto representa um sofrimento para mim; é um alívio chegar ao campus $30 \% \quad 13$

O trajeto é indiferente para mim, não me sinto incomodado nem confortável $19 \% \quad 8$

O trajeto é satisfatório para mim

$12 \% \quad 5$

O trajeto é agradável para mim

$16 \% \quad 7$

Outro (especifique)

$14 \% \quad 6$

$9 \% \quad 4$


Como você avalia a sinalização do campus Luiz de Queiroz (ESALQ/CENA)?

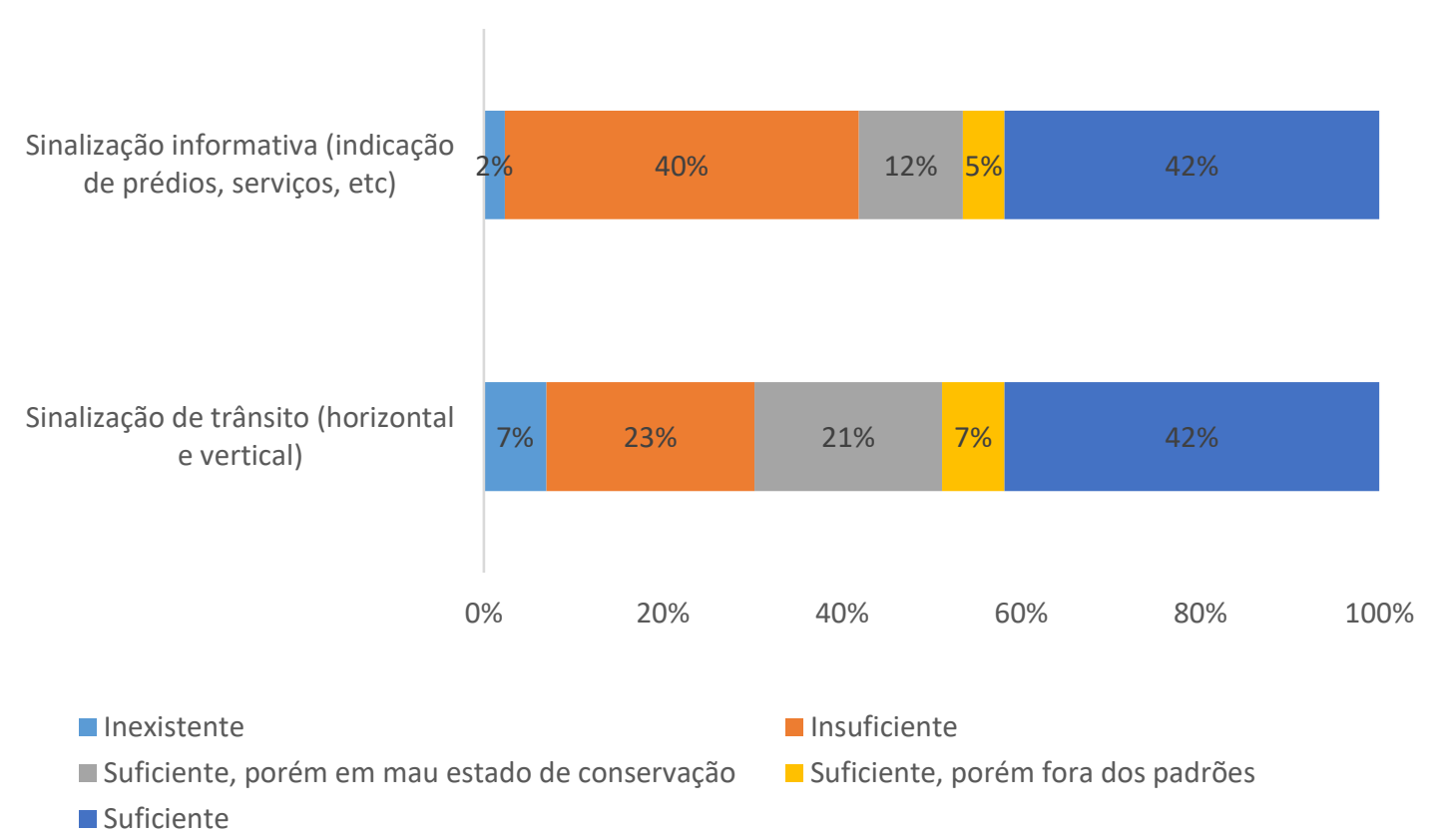

Sinalização de trânsito Sinalização informativa (indicação (horizontal e vertical) de prédios, serviços, etc)

\begin{tabular}{lcccc}
\hline Inexistente & $7 \%$ & 3 & $2 \%$ & 1 \\
\hline Insuficiente & $23 \%$ & 10 & $40 \%$ & 17 \\
\hline $\begin{array}{l}\text { Suficiente, porém em mau } \\
\text { estado de conservação }\end{array}$ & $21 \%$ & 9 & $12 \%$ & 5 \\
\hline $\begin{array}{l}\text { Suficiente, porém fora dos } \\
\text { padrões }\end{array}$ & $7 \%$ & 3 & $5 \%$ & 2 \\
\hline $\begin{array}{l}\text { Suficiente } \\
\text { natrien }\end{array}$ & $42 \%$ & 18 & $42 \%$ & 18
\end{tabular}


Em sua opinião, qual a importância destes aspectos para uma mobilidade mais sustentável na USP de Piracicaba? Ordene os temas marcando-os com os respectivos números ou arrastando as caixas de acordo com a prioridade (no topo, o mais importante)

\section{Média}

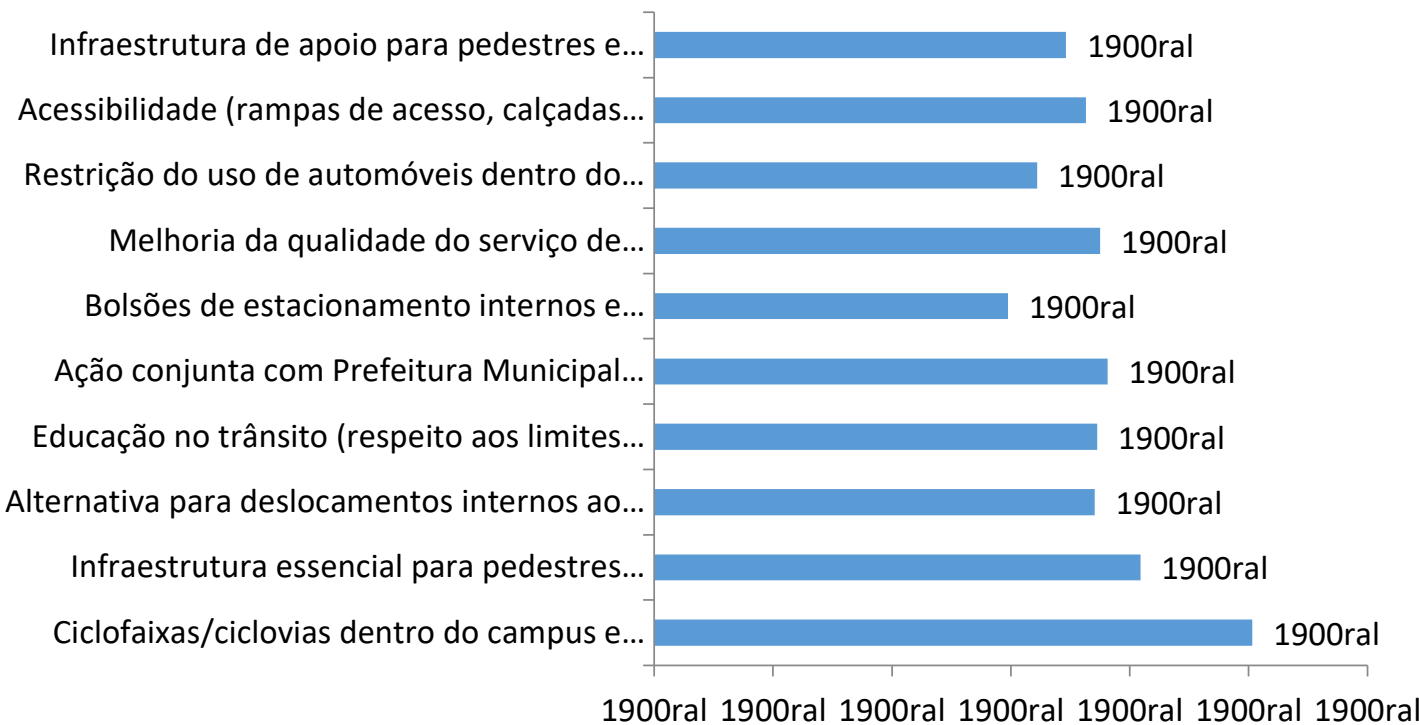

Obs: Quanto maior a média, maior a prioridade 


\begin{tabular}{|c|c|c|c|c|c|c|c|c|c|c|}
\hline Prioridade & 1 & 2 & 3 & 4 & 5 & 6 & 7 & 8 & 9 & 10 \\
\hline $\begin{array}{l}\text { Ciclofaixas/ciclovias dentro } \\
\text { do campus e para acesso } \\
\text { ao mesmo }\end{array}$ & $42 \%$ & $28 \%$ & $3 \%$ & $8 \%$ & $6 \%$ & $0 \%$ & $3 \%$ & $0 \%$ & $3 \%$ & $8 \%$ \\
\hline $\begin{array}{l}\text { Infraestrutura essencial } \\
\text { para pedestres (calçadas } \\
\text { adequadas, iluminação, } \\
\text { arborização, sinalização, } \\
\text { etc.) }\end{array}$ & $8 \%$ & $15 \%$ & $13 \%$ & $18 \%$ & $10 \%$ & $13 \%$ & $3 \%$ & $3 \%$ & $13 \%$ & $5 \%$ \\
\hline $\begin{array}{l}\text { Alternativa para } \\
\text { deslocamentos internos ao } \\
\text { campus (sistema de } \\
\text { transporte coletivo, } \\
\text { sistema de bicicletas } \\
\text { compartilhadas, etc.) }\end{array}$ & $5 \%$ & $3 \%$ & $18 \%$ & $18 \%$ & $8 \%$ & $10 \%$ & $15 \%$ & $8 \%$ & $0 \%$ & $15 \%$ \\
\hline $\begin{array}{l}\text { Educação no trânsito } \\
\text { (respeito aos limites } \\
\text { de velocidade e à } \\
\text { sinalização, melhor } \\
\text { convívio entre motoristas, } \\
\text { ciclistas e pedestres, etc.) }\end{array}$ & $8 \%$ & $11 \%$ & $11 \%$ & $5 \%$ & $11 \%$ & $11 \%$ & $13 \%$ & $18 \%$ & $13 \%$ & $0 \%$ \\
\hline $\begin{array}{l}\text { Ação conjunta com } \\
\text { Prefeitura Municipal para } \\
\text { melhoria da mobilidade na } \\
\text { ligação entre cidade e } \\
\text { campus }\end{array}$ & $11 \%$ & $13 \%$ & $11 \%$ & $5 \%$ & $16 \%$ & $11 \%$ & $5 \%$ & $3 \%$ & $16 \%$ & $11 \%$ \\
\hline $\begin{array}{l}\text { Bolsões de } \\
\text { estacionamento internos e } \\
\text { externos ao campus }\end{array}$ & $3 \%$ & $3 \%$ & $5 \%$ & $8 \%$ & $11 \%$ & $13 \%$ & $8 \%$ & $11 \%$ & $16 \%$ & $24 \%$ \\
\hline $\begin{array}{l}\text { Melhoria da qualidade do } \\
\text { serviço de transporte } \\
\text { público da cidade }\end{array}$ & $8 \%$ & $3 \%$ & $13 \%$ & $8 \%$ & $11 \%$ & $18 \%$ & $21 \%$ & $11 \%$ & $8 \%$ & $0 \%$ \\
\hline $\begin{array}{l}\text { Restrição do uso de } \\
\text { automóveis dentro do } \\
\text { campus }\end{array}$ & $12 \%$ & $10 \%$ & $0 \%$ & $2 \%$ & $10 \%$ & $7 \%$ & $12 \%$ & $10 \%$ & $7 \%$ & $29 \%$ \\
\hline $\begin{array}{l}\text { Acessibilidade (rampas de } \\
\text { acesso, calçadas } \\
\text { adequadas, elevadores, } \\
\text { piso tátil, respeito a vagas } \\
\text { de estacionamento } \\
\text { prioritárias, etc.) }\end{array}$ & $3 \%$ & $13 \%$ & $5 \%$ & $11 \%$ & $11 \%$ & $16 \%$ & $11 \%$ & $21 \%$ & $8 \%$ & $3 \%$ \\
\hline $\begin{array}{l}\text { Infraestrutura de apoio } \\
\text { para pedestres e ciclistas } \\
\text { (bebedouros, bancos, } \\
\text { vestiários, guarda-volume, } \\
\text { bicicletários, oficina para } \\
\text { consertos, etc.) }\end{array}$ & $2 \%$ & $5 \%$ & $17 \%$ & $12 \%$ & $14 \%$ & $2 \%$ & $7 \%$ & $12 \%$ & $19 \%$ & $10 \%$ \\
\hline
\end{tabular}




\section{Modo: Motocicleta}

Analisando o campus da ESALQ/CENA como um todo, você o considera acessível aos usuários com algum tipo de restrição de mobilidade?

Não sou capaz de opinar, pois nunca analisei o campus sob este aspecto

Não. O campus não oferece condições básicas de acessibilidade aos usuários com algum tipo de restrição de mobilidade

Pequena parte do campus é acessível. Há diversas áreas que não oferecem condições básicas de acessibilidade aos usuários com...

Grande parte do campus é acessível. Algumas áreas possuem obstáculos, mas de maneira geral considero o campus acessível aos...

Sim. Nunca notei obstáculos que dificultassem a acessibilidade aos usuários com algum tipo de restrição de mobilidade nas dependências..

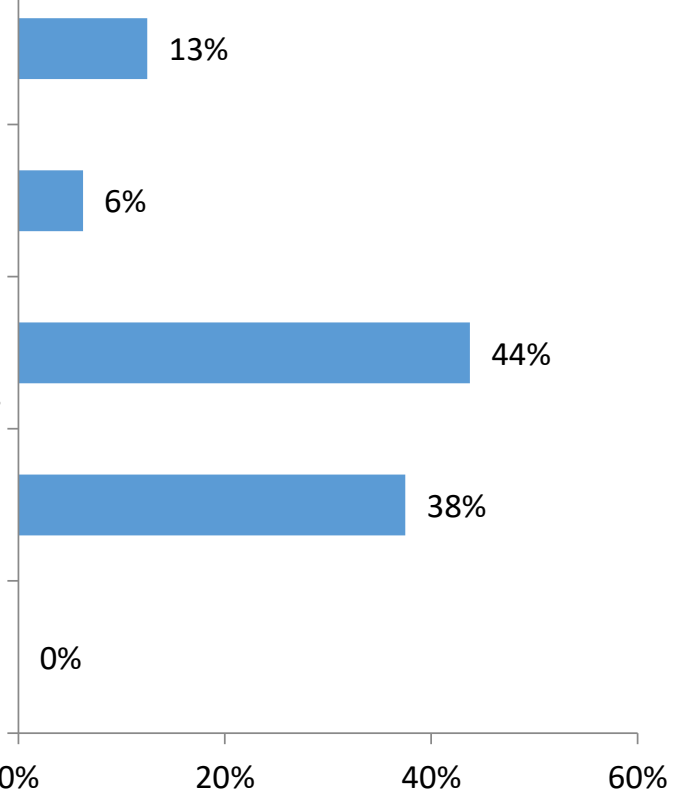

Sim. Nunca notei obstáculos que dificultassem a acessibilidade aos usuários com algum tipo de restrição de mobilidade nas dependências do campus $0 \% \quad 0$ Grande parte do campus é acessível. Algumas áreas possuem obstáculos, mas de maneira geral considero o campus acessível aos usuários com algum tipo de restrição de mobilidade $38 \% \quad 6$

Pequena parte do campus é acessível. Há diversas áreas que não oferecem condições básicas de acessibilidade aos usuários com algum tipo de restrição de mobilidade $44 \% \quad 7$

Não. O campus não oferece condições básicas de acessibilidade aos usuários com algum tipo de restrição de mobilidade

Não sou capaz de opinar, pois nunca analisei o campus sob este aspecto

$\begin{array}{rr}6 \% & 1 \\ 13 \% & 2\end{array}$


Dentre os prédios que frequenta na ESALQ/CENA, como você avalia a acessibilidade para os usuários com algum tipo de restrição de mobilidade?

Não sou capaz de avaliar, pois nunca analisei os prédios da ESALQ/CENA sob este aspecto

Ruim. Prédios não equipados para receber os usuários com algum tipo de restrição de mobilidade

Regular. Prédios pouco equipados, com limitações para atender os usuários com algum tipo de restrição de mobilidade

Boa. Prédios parcialmente equipados, mas possuem condições satisfatórias para atender os usuários com algum tipo de restrição de...

Ótima. Prédios totalmente equipados para receber os usuários com algum tipo de restrição de mobilidade

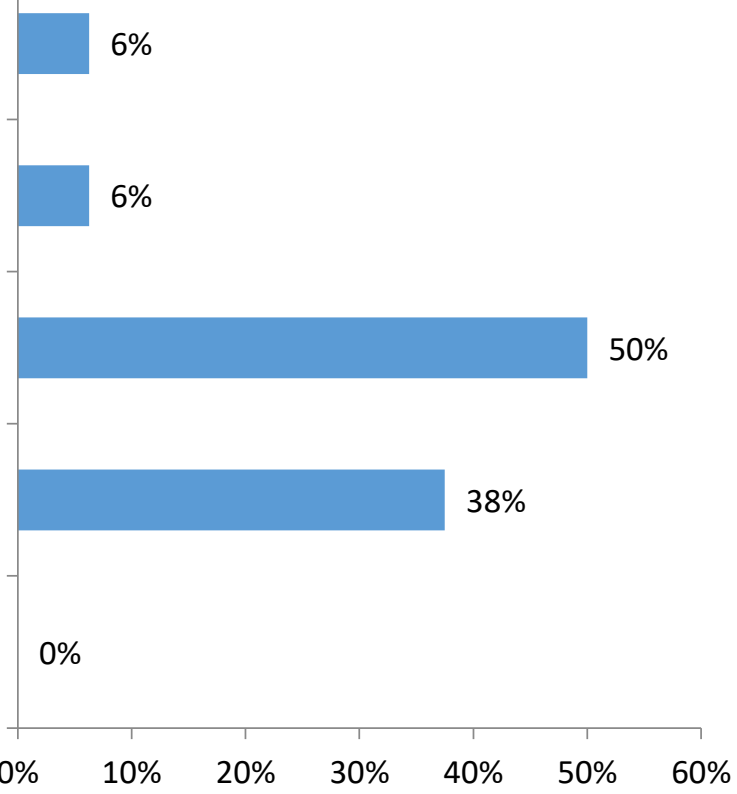

Ótima. Prédios totalmente equipados para receber os usuários com algum tipo de restrição de mobilidade $0 \% \quad 0$

Boa. Prédios parcialmente equipados, mas possuem condições satisfatórias para atender os usuários com algum tipo de restrição de mobilidade $38 \%$ 6

Regular. Prédios pouco equipados, com limitações para atender os usuários com algum tipo de restrição de mobilidade $50 \%$ 8 Ruim. Prédios não equipados para receber os usuários com algum tipo de restrição de mobilidade $6 \% \quad 1$ Não sou capaz de avaliar, pois nunca analisei os prédios da ESALQ/CENA sob este aspecto

$6 \% \quad 1$


Na etapa anterior do questionário, você nos informou que seu modo principal para os deslocamentos à ESALQ/CENA é a MOTOCICLETA. Quais fatores o/a levam a optar por este modo?

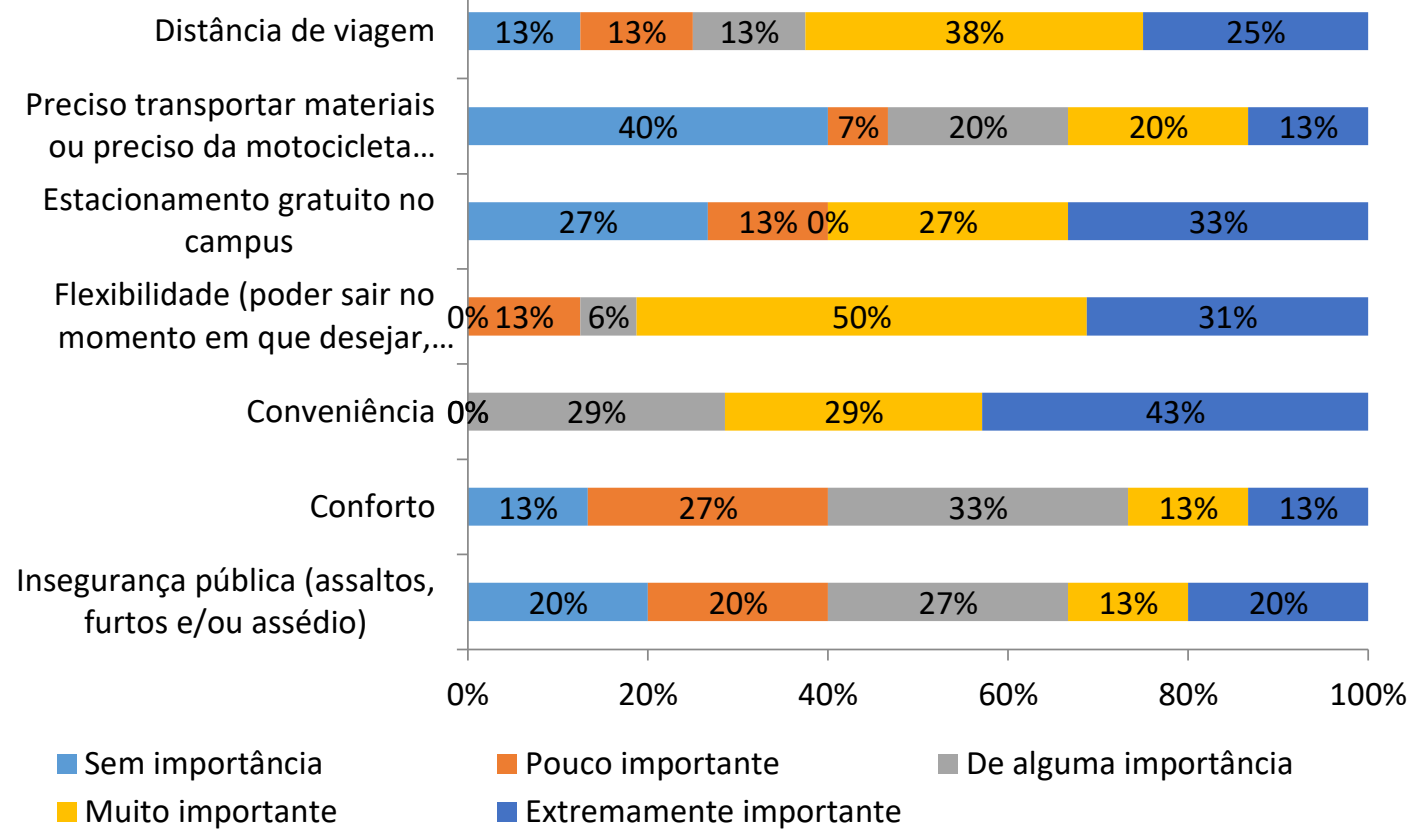

\begin{tabular}{|c|c|c|c|c|c|c|c|c|c|c|}
\hline \multirow[b]{2}{*}{$\begin{array}{l}\text { Insegurança pública } \\
\text { (assaltos, furtos e/ou } \\
\text { assédio) }\end{array}$} & \multicolumn{2}{|c|}{$\begin{array}{c}\text { Sem } \\
\text { importância }\end{array}$} & \multicolumn{2}{|c|}{$\begin{array}{c}\text { Pouco } \\
\text { importante }\end{array}$} & \multicolumn{2}{|c|}{$\begin{array}{l}\text { De alguma } \\
\text { importância }\end{array}$} & \multicolumn{2}{|c|}{$\begin{array}{c}\text { Muito } \\
\text { importante }\end{array}$} & \multicolumn{2}{|c|}{$\begin{array}{c}\text { Extremame } \\
\text { nte importa } \\
\text { nte }\end{array}$} \\
\hline & $20 \%$ & 3 & $20 \%$ & 3 & $27 \%$ & 4 & $13 \%$ & 2 & $20 \%$ & 3 \\
\hline Conforto & $13 \%$ & 2 & $27 \%$ & 4 & $33 \%$ & 5 & $13 \%$ & 2 & $13 \%$ & 2 \\
\hline Conveniência & $0 \%$ & 0 & $0 \%$ & 0 & $29 \%$ & 4 & $29 \%$ & 4 & $43 \%$ & 6 \\
\hline $\begin{array}{l}\text { Flexibilidade (poder sair } \\
\text { no momento em que } \\
\text { desejar, fazer paradas } \\
\text { durante o trajeto, etc.) }\end{array}$ & $0 \%$ & 0 & $13 \%$ & 2 & $6 \%$ & 1 & $50 \%$ & 8 & $31 \%$ & 5 \\
\hline $\begin{array}{l}\text { Estacionamento } \\
\text { gratuito no campus }\end{array}$ & $27 \%$ & 4 & $13 \%$ & 2 & $0 \%$ & 0 & $27 \%$ & 4 & $33 \%$ & 5 \\
\hline $\begin{array}{l}\text { Preciso transportar } \\
\text { materiais ou preciso da } \\
\text { motocicleta para fins de } \\
\text { trabalho }\end{array}$ & $40 \%$ & 6 & $7 \%$ & 1 & $20 \%$ & 3 & $20 \%$ & 3 & $13 \%$ & 2 \\
\hline Distância de viagem & $13 \%$ & 2 & $13 \%$ & 2 & $13 \%$ & 2 & $38 \%$ & 6 & $25 \%$ & 4 \\
\hline
\end{tabular}




\section{Quais fatores o/a desestimulam a utilizar os demais modos que não a motocicleta em} seus deslocamentos?

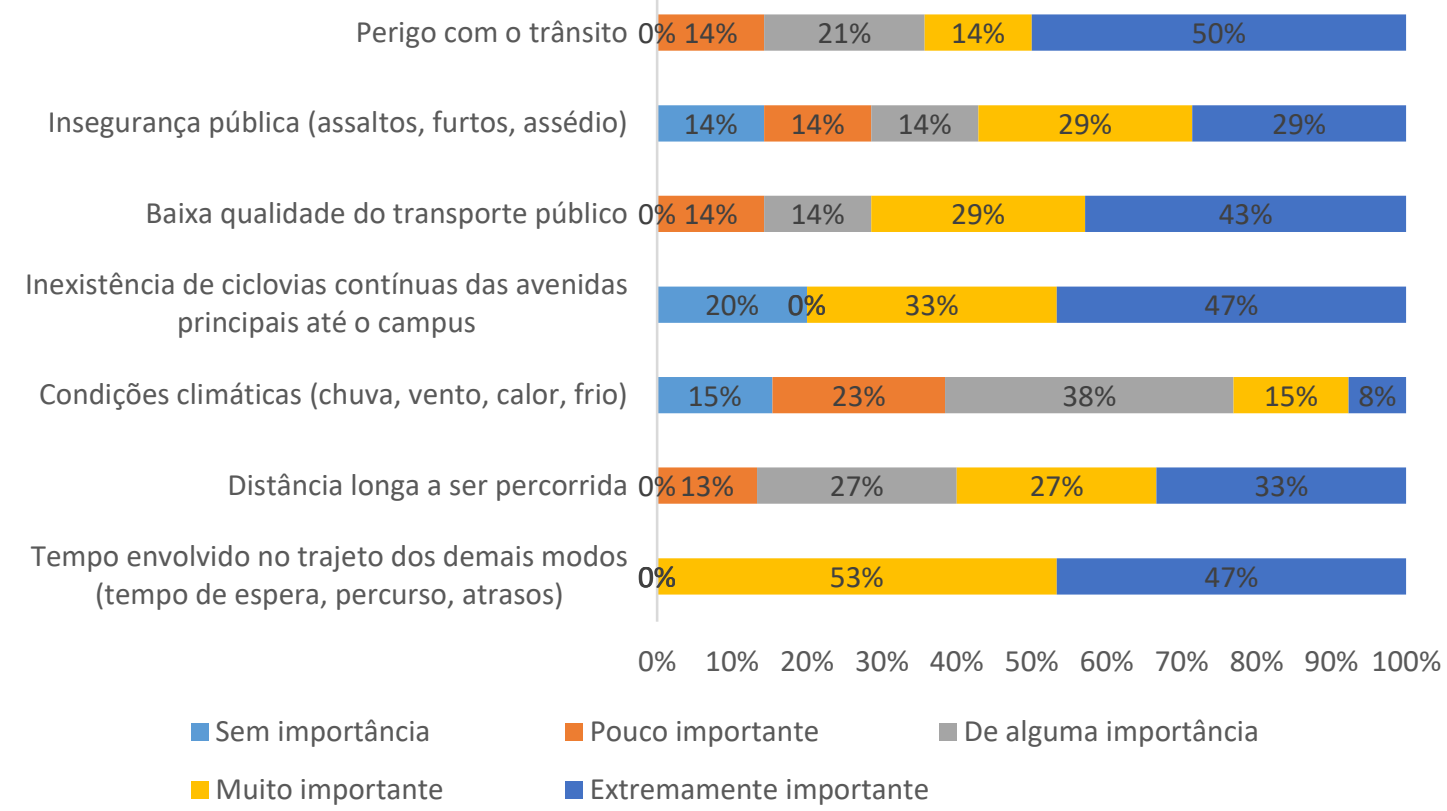

\begin{tabular}{|c|c|c|c|c|c|c|c|c|c|c|}
\hline \multirow{2}{*}{$\begin{array}{l}\text { Tempo envolvido no } \\
\text { trajeto dos demais } \\
\text { modos (tempo de } \\
\text { espera, percurso, } \\
\text { atrasos) }\end{array}$} & \multicolumn{2}{|c|}{$\begin{array}{l}\text { Sem } \\
\text { importância }\end{array}$} & \multicolumn{2}{|c|}{$\begin{array}{c}\text { Pouco } \\
\text { importante }\end{array}$} & \multicolumn{2}{|c|}{$\begin{array}{l}\text { De alguma } \\
\text { importância }\end{array}$} & \multicolumn{2}{|c|}{$\begin{array}{c}\text { Muito } \\
\text { importante }\end{array}$} & \multicolumn{2}{|c|}{$\begin{array}{l}\text { Extremame } \\
\text { nte } \\
\text { importante }\end{array}$} \\
\hline & $0 \%$ & 0 & $0 \%$ & 0 & $0 \%$ & 0 & $53 \%$ & 8 & $47 \%$ & 7 \\
\hline $\begin{array}{l}\text { Distância longa a ser } \\
\text { percorrida }\end{array}$ & $0 \%$ & 0 & $13 \%$ & 2 & $27 \%$ & 4 & $27 \%$ & 4 & $33 \%$ & 5 \\
\hline $\begin{array}{l}\text { Condições climáticas } \\
\text { (chuva, vento, calor, frio) }\end{array}$ & $15 \%$ & 2 & $23 \%$ & 3 & $38 \%$ & 5 & $15 \%$ & 2 & $8 \%$ & 1 \\
\hline $\begin{array}{l}\text { Inexistência de ciclovias } \\
\text { contínuas das avenidas } \\
\text { principais até o campus }\end{array}$ & $20 \%$ & 3 & $0 \%$ & 0 & $0 \%$ & 0 & $33 \%$ & 5 & $47 \%$ & 7 \\
\hline $\begin{array}{l}\text { Baixa qualidade do } \\
\text { transporte público }\end{array}$ & $0 \%$ & 0 & $14 \%$ & 2 & $14 \%$ & 2 & $29 \%$ & 4 & $43 \%$ & 6 \\
\hline $\begin{array}{l}\text { Insegurança pública } \\
\text { (assaltos, furtos, } \\
\text { assédio) }\end{array}$ & $14 \%$ & 2 & $14 \%$ & 2 & $14 \%$ & 2 & $29 \%$ & 4 & $29 \%$ & 4 \\
\hline Perigo com o trânsito & $0 \%$ & 0 & $14 \%$ & 2 & $21 \%$ & 3 & $14 \%$ & 2 & $50 \%$ & 7 \\
\hline
\end{tabular}


Há quanto tempo você utiliza a motocicleta para se deslocar até a ESALQ/CENA?

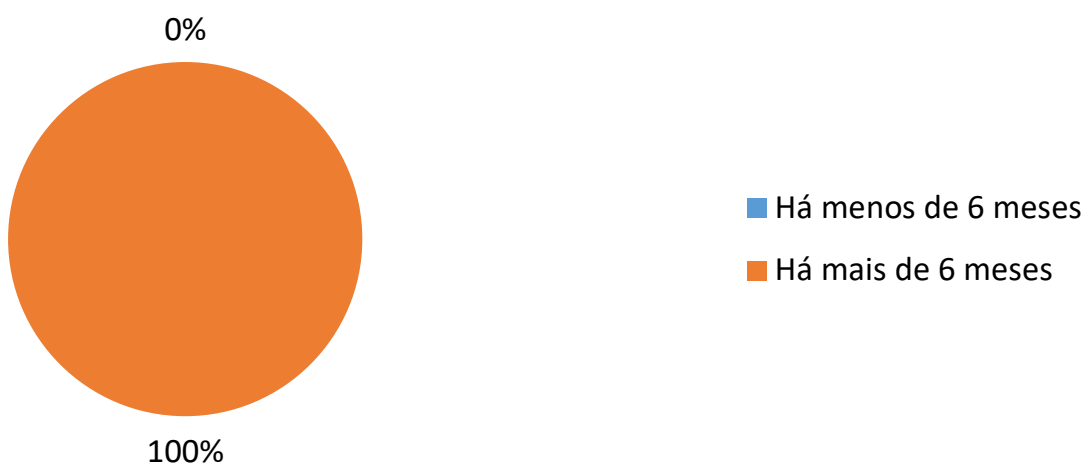

\begin{tabular}{ccc} 
Há menos de 6 meses & $0 \%$ & 0 \\
\hline Há mais de 6 meses & $100 \%$ & 15 \\
\hline
\end{tabular}

Você estaciona sua motocicleta em apenas um lugar durante sua permanência no campus ou troca de vaga conforme realiza suas atividades?

Não me preocupo com isso, porque não sou o motorista (pego carona)

Troco de vaga conforme realizo minhas atividades

$40 \%$

Estaciono em lugar fixo

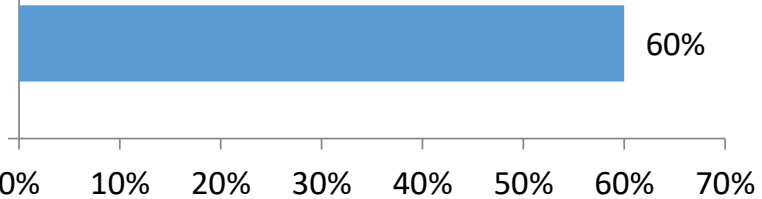

Estaciono em lugar fixo $60 \% 9$

Troco de vaga conforme realizo minhas atividades $40 \% \quad 6$

Não estaciono dentro do campus $0 \% \quad 0$

Não me preocupo com isso, porque não sou o motorista (pego carona) $\quad 0 \% 0$ 
Local de estacionamento

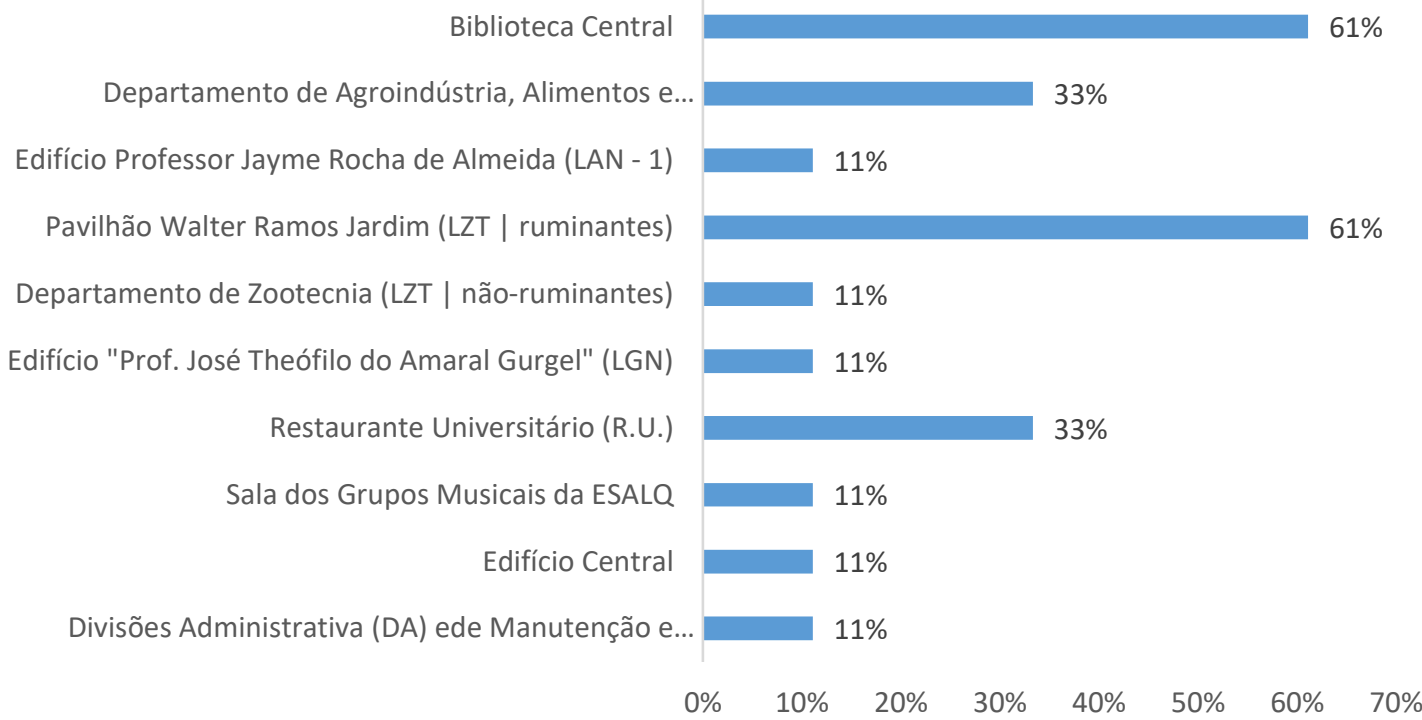

Divisões Administrativa (DA) ede Manutenção e Operação (DVMANOPER) 11\%

Edifício Central $11 \%$

Sala dos Grupos Musicais da ESALQ $11 \%$

Restaurante Universitário (R.U.) $33 \%$

Edifício "Prof. José Theófilo do Amaral Gurgel" (LGN) $11 \%$

Departamento de Zootecnia (LZT | não-ruminantes) $11 \%$

Pavilhão Walter Ramos Jardim (LZT | ruminantes) $61 \%$

Edifício Professor Jayme Rocha de Almeida (LAN - 1) $11 \%$

Departamento de Agroindústria, Alimentos e Nutrição (LAN - 2) $33 \%$

Biblioteca Central 
Com que frequência você dá carona para outras pessoas até o campus? Ou pega carona?

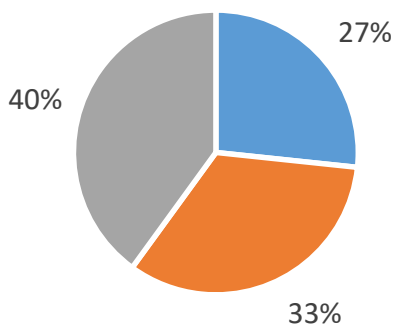

- Frequentemente $\quad$ Raramente $\quad$ Nunca

Frequentemente $27 \% \quad 4$

Raramente $\quad 33 \% \quad 5$

Nunca $\quad 40 \% 6$ 
Classifique, somente para os turnos em que você costuma acessar ou se deslocar AO REDOR da ESALQ/CENA, qual a sua sensação de segurança em relação a assaltos e outros tipos de violência ou assédio:

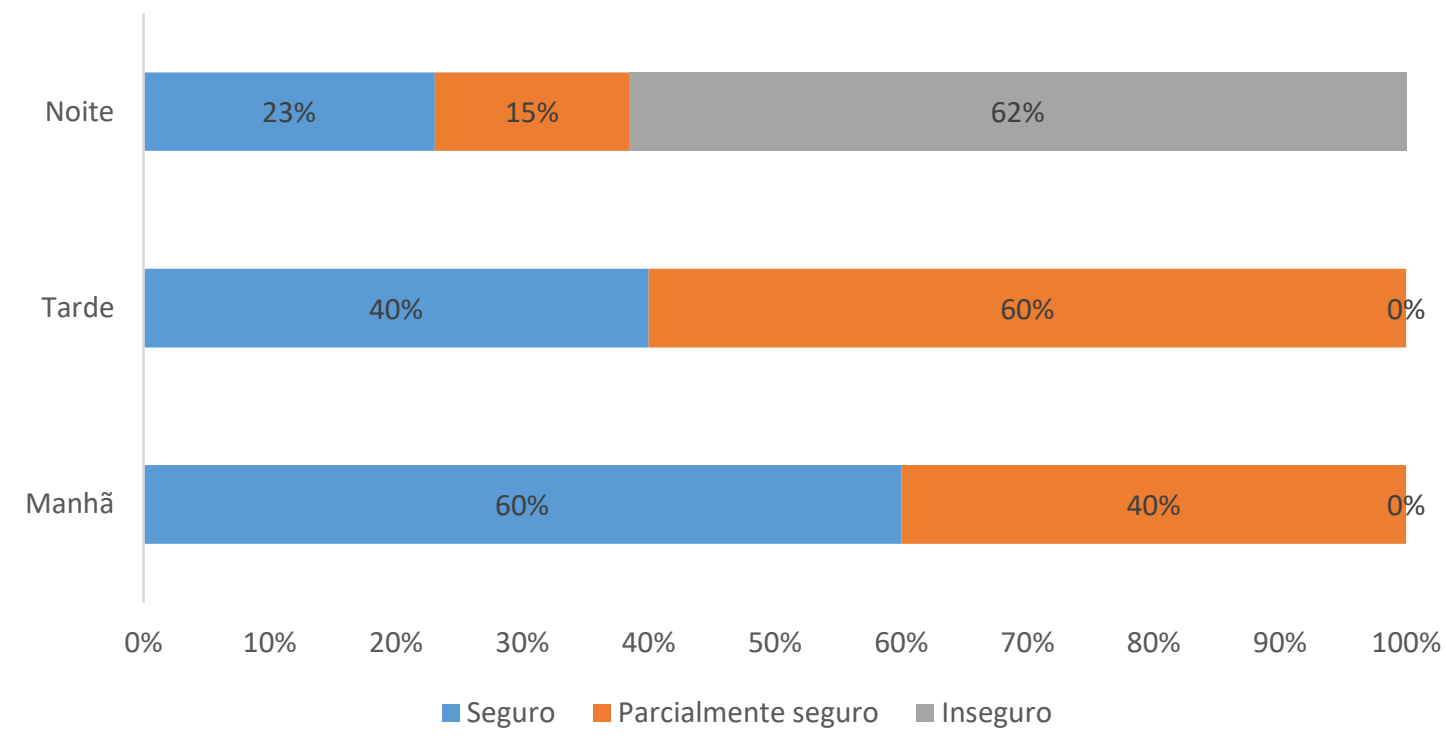

Seguro Parcialmente seguro Inseguro

\begin{tabular}{lrrrrrr}
\hline Manhã & $60 \%$ & 9 & $40 \%$ & 6 & $0 \%$ & 0 \\
\hline Tarde & $40 \%$ & 6 & $60 \%$ & 9 & $0 \%$ & 0 \\
\hline Noite & $23 \%$ & 3 & $15 \%$ & 2 & $62 \%$ & 8
\end{tabular}

Você presenciou ou sofreu algum tipo de violência ou assédio NO ENTORNO da ESALQ/CENA?

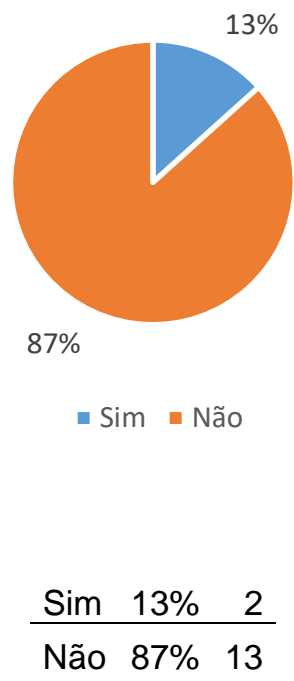


Que tipo de violência ou assédio você presenciou ou sofreu NO ENTORNO da ESALQ/CENA? (se for necessário, marque mais de uma alternativa)

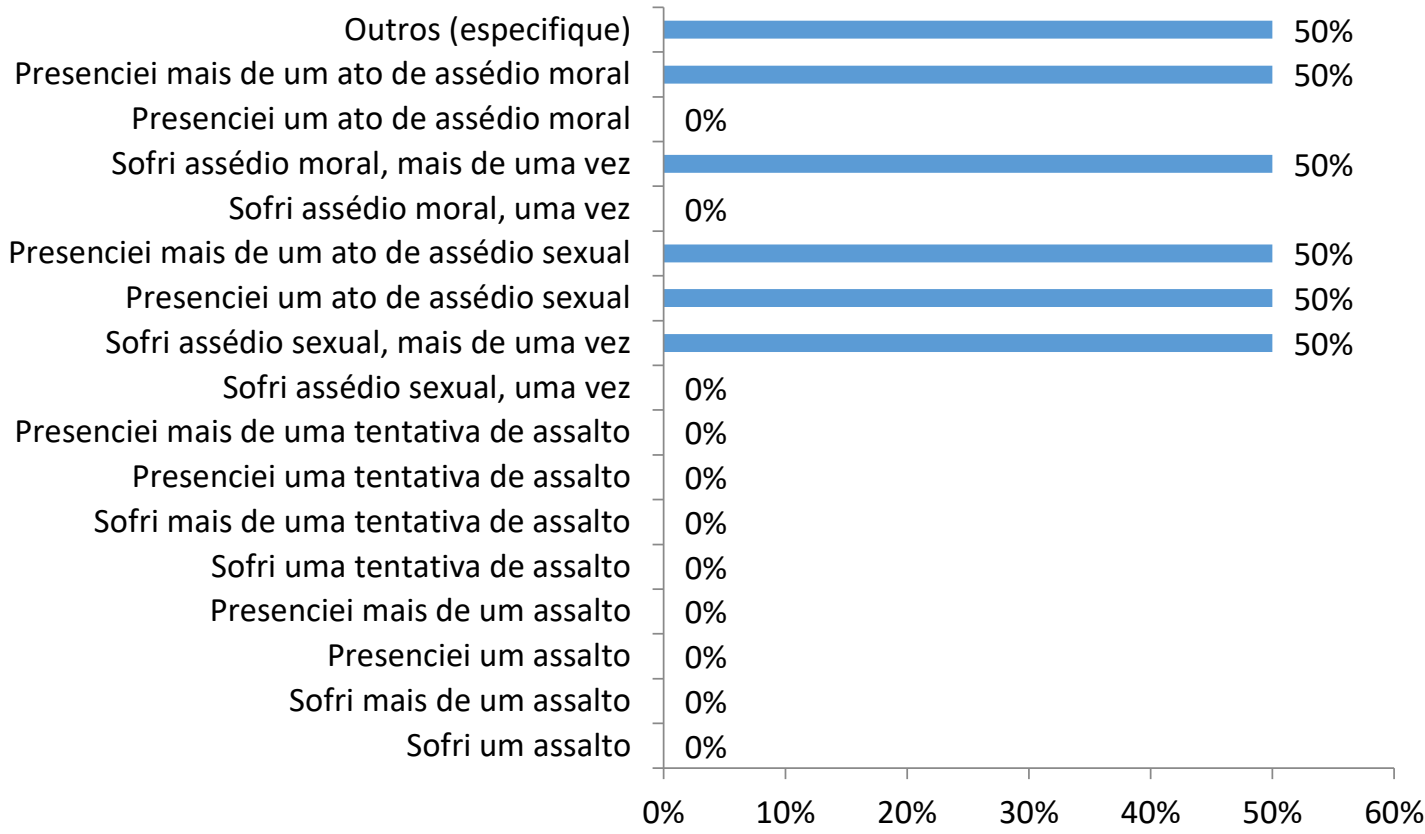

\begin{tabular}{lrl} 
Sofri um assalto & $0 \%$ & 0 \\
\hline Sofri mais de um assalto & $0 \%$ & 0 \\
\hline Presenciei um assalto & $0 \%$ & 0 \\
\hline Presenciei mais de um assalto & $0 \%$ & 0 \\
\hline Sofri uma tentativa de assalto & $0 \%$ & 0 \\
\hline Sofri mais de uma tentativa de assalto & $0 \%$ & 0 \\
\hline Presenciei uma tentativa de assalto & $0 \%$ & 0 \\
\hline Presenciei mais de uma tentativa de assalto & $0 \%$ & 0 \\
\hline Sofri assédio sexual, uma vez & $0 \%$ & 0 \\
\hline Sofri assédio sexual, mais de uma vez & $50 \%$ & 1 \\
\hline Presenciei um ato de assédio sexual & $50 \%$ & 1 \\
\hline Presenciei mais de um ato de assédio sexual & $50 \%$ & 1 \\
\hline Sofri assédio moral, uma vez & $0 \%$ & 0 \\
\hline Sofri assédio moral, mais de uma vez & $50 \%$ & 1 \\
\hline Presenciei um ato de assédio moral & $0 \%$ & 0 \\
\hline Presenciei mais de um ato de assédio moral & $50 \%$ & 1 \\
\hline Outros (especifique) & $50 \%$ & 1
\end{tabular}


Classifique, somente para os turnos em que você costuma acessar ou se deslocar DENTRO da ESALQ/CENA, qual a sua sensação de segurança em relação a assaltos e outros tipos de violência ou assédio:

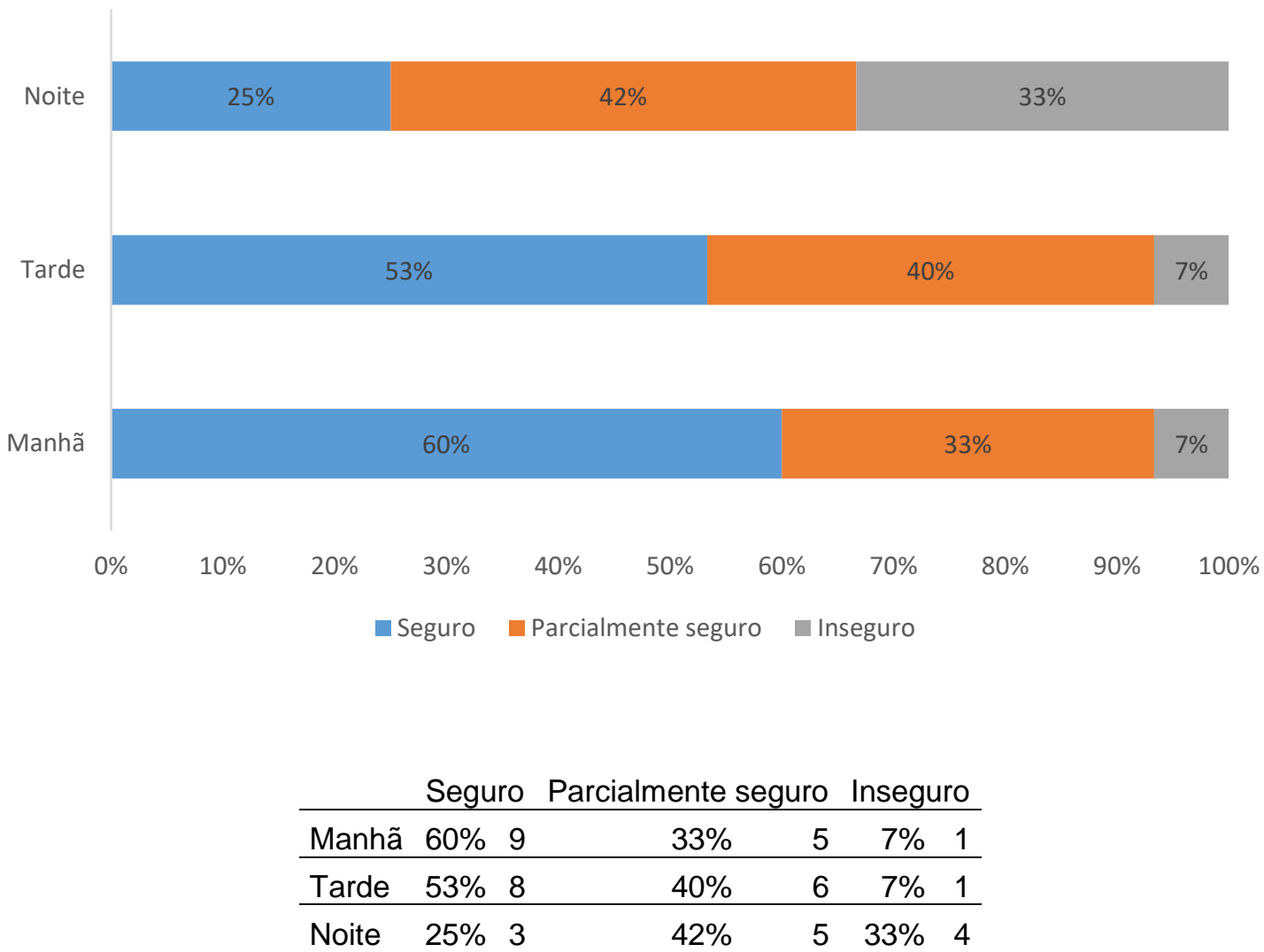

Você presenciou ou sofreu algum tipo de violência ou assédio DENTRO da ESALQ/CENA?

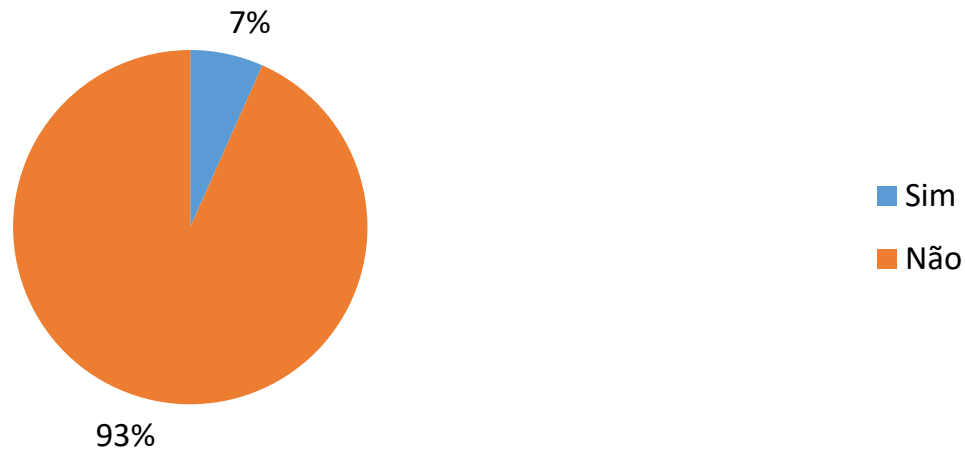

\begin{tabular}{lrr}
$\operatorname{Sim}$ & $7 \%$ & 1 \\
\hline Não & $93 \%$ & 14
\end{tabular}


Que tipo de violência ou assédio você presenciou ou sofreu DENTRO da ESALQ/CENA? (se for necessário, marque mais de uma alternativa)

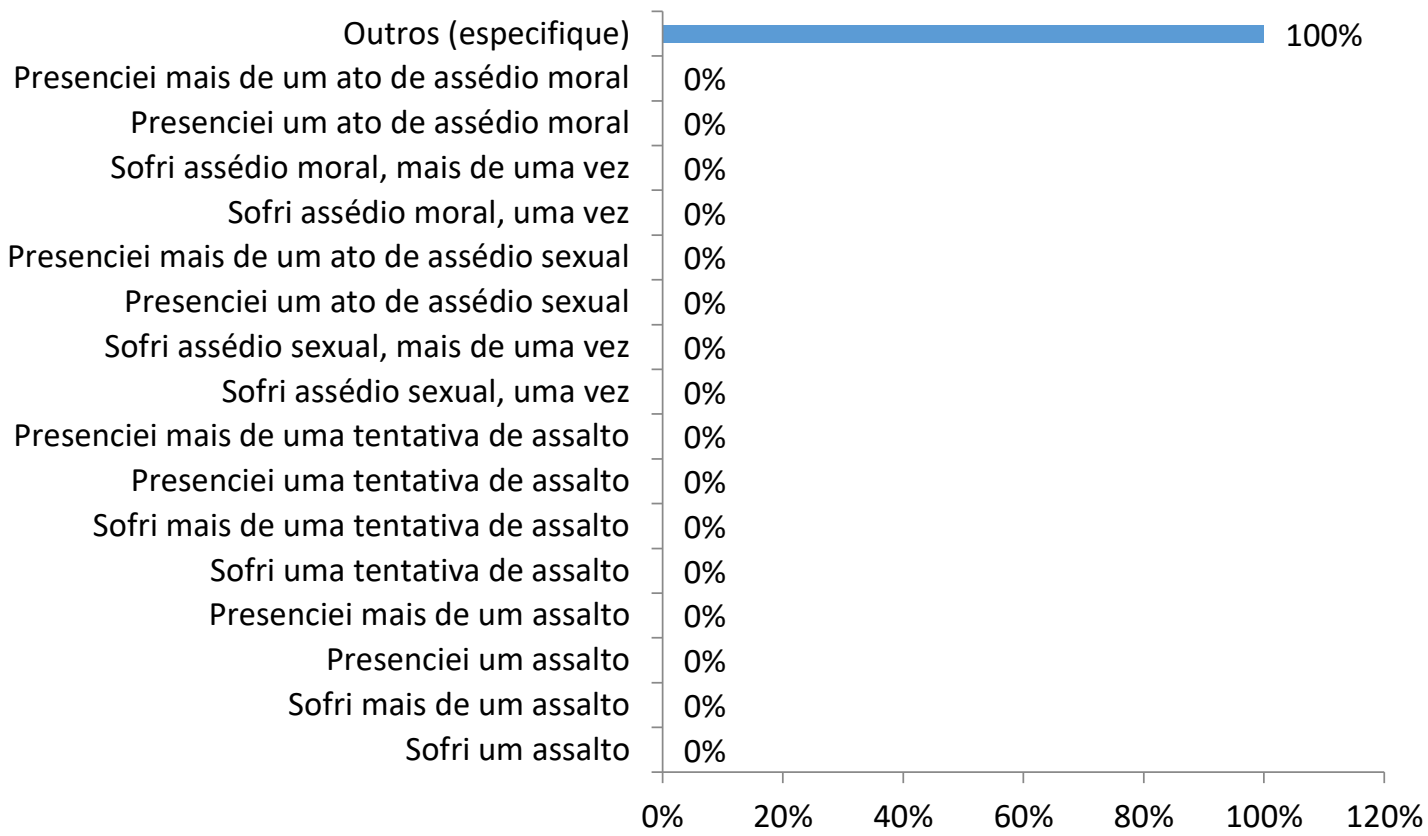

\begin{tabular}{lrl} 
Sofri um assalto & $0 \%$ & 0 \\
\hline Sofri mais de um assalto & $0 \%$ & 0 \\
\hline Presenciei um assalto & $0 \%$ & 0 \\
\hline Presenciei mais de um assalto & $0 \%$ & 0 \\
\hline Sofri uma tentativa de assalto & $0 \%$ & 0 \\
\hline Sofri mais de uma tentativa de assalto & $0 \%$ & 0 \\
\hline Presenciei uma tentativa de assalto & $0 \%$ & 0 \\
\hline Presenciei mais de uma tentativa de assalto & $0 \%$ & 0 \\
\hline Sofri assédio sexual, uma vez & $0 \%$ & 0 \\
\hline Sofri assédio sexual, mais de uma vez & $0 \%$ & 0 \\
\hline Presenciei um ato de assédio sexual & $0 \%$ & 0 \\
\hline Presenciei mais de um ato de assédio sexual & $0 \%$ & 0 \\
\hline Sofri assédio moral, uma vez & $0 \%$ & 0 \\
\hline Sofri assédio moral, mais de uma vez & $0 \%$ & 0 \\
\hline Presenciei um ato de assédio moral & $0 \%$ & 0 \\
\hline Presenciei mais de um ato de assédio moral & $0 \%$ & 0 \\
\hline Outros (especifique) & $100 \%$ & 1
\end{tabular}


Com relação a medidas de segurança no ENTORNO e DENTRO da ESALQ/CENA, você é favorável a (se for necessário, marque mais de uma alternativa):

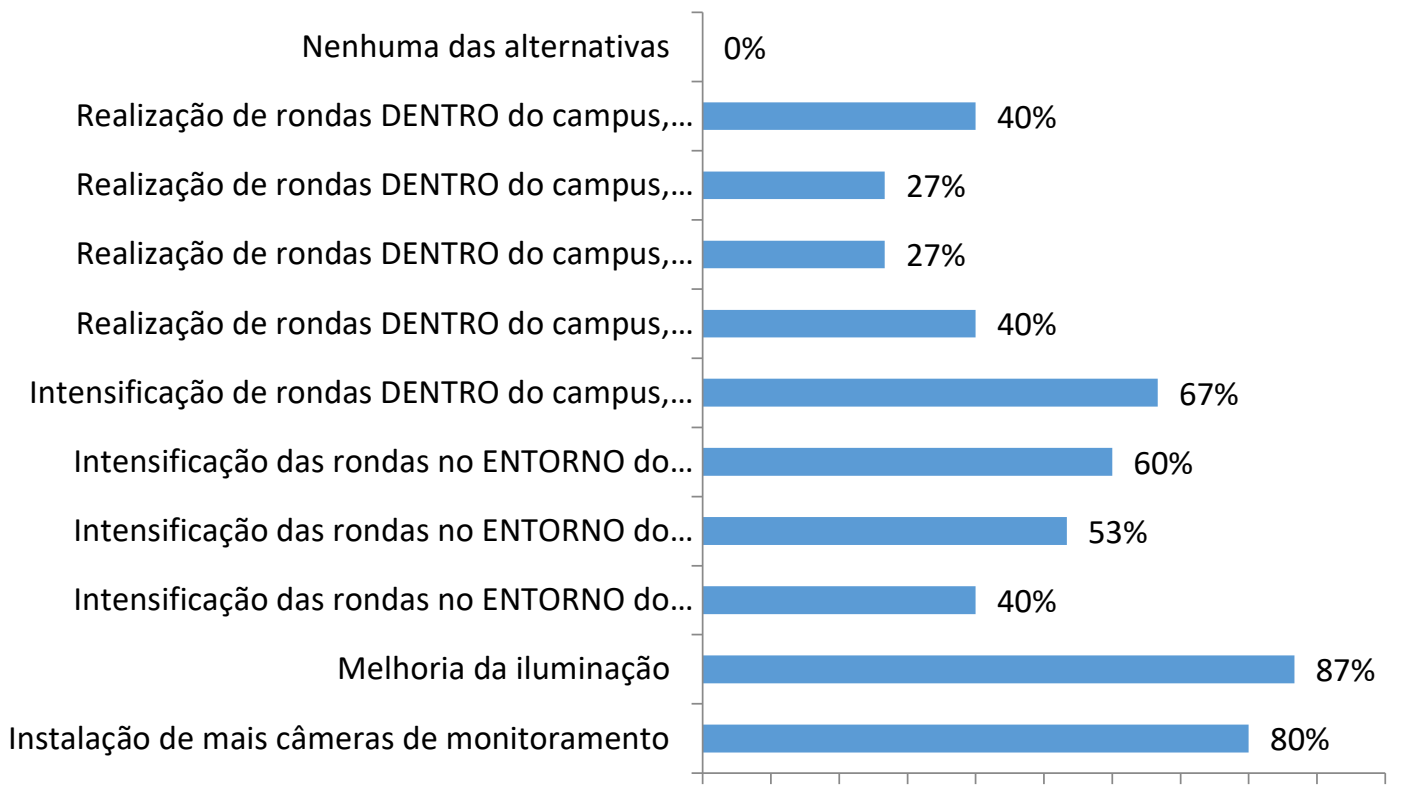

0\% 10\% 20\% 30\% 40\% 50\% 60\% 70\% 80\% 90\%100\%

Instalação de mais câmeras de monitoramento $80 \% \quad 12$

Melhoria da iluminação

$87 \% \quad 13$

Intensificação das rondas no ENTORNO do campus, pela Guarda Universitária (PPUSP)

$40 \% \quad 6$

Intensificação das rondas no ENTORNO do campus, pela Policia Militar

$53 \% \quad 8$

\begin{tabular}{lll}
\hline Intensificação das rondas no ENTORNO do campus, pela Guarda Municipal & $60 \%$ & 9 \\
\hline
\end{tabular}

Intensificação de rondas DENTRO do campus, pela Guarda Universitária (PPUSP)

$67 \% \quad 10$

Realização de rondas DENTRO do campus, pela Policia Militar

$40 \% \quad 6$

Realização de rondas DENTRO do campus, pela Policia Militar, mas somente nos horários mais críticos como à noite e durante grandes eventos $27 \%$

Realização de rondas DENTRO do campus, pela Guarda Municipa

$27 \% \quad 4$
Realização de rondas DENTRO do campus, pela Guarda Municipal, mas somente nos horários mais críticos como à noite e durante grandes eventos

$40 \% \quad 6$

Nenhuma das alternativas

$0 \% \quad 0$


Como você descreveria o trajeto do seu ponto de origem até o campus Luiz de Queiroz (ESALQ/CENA)?

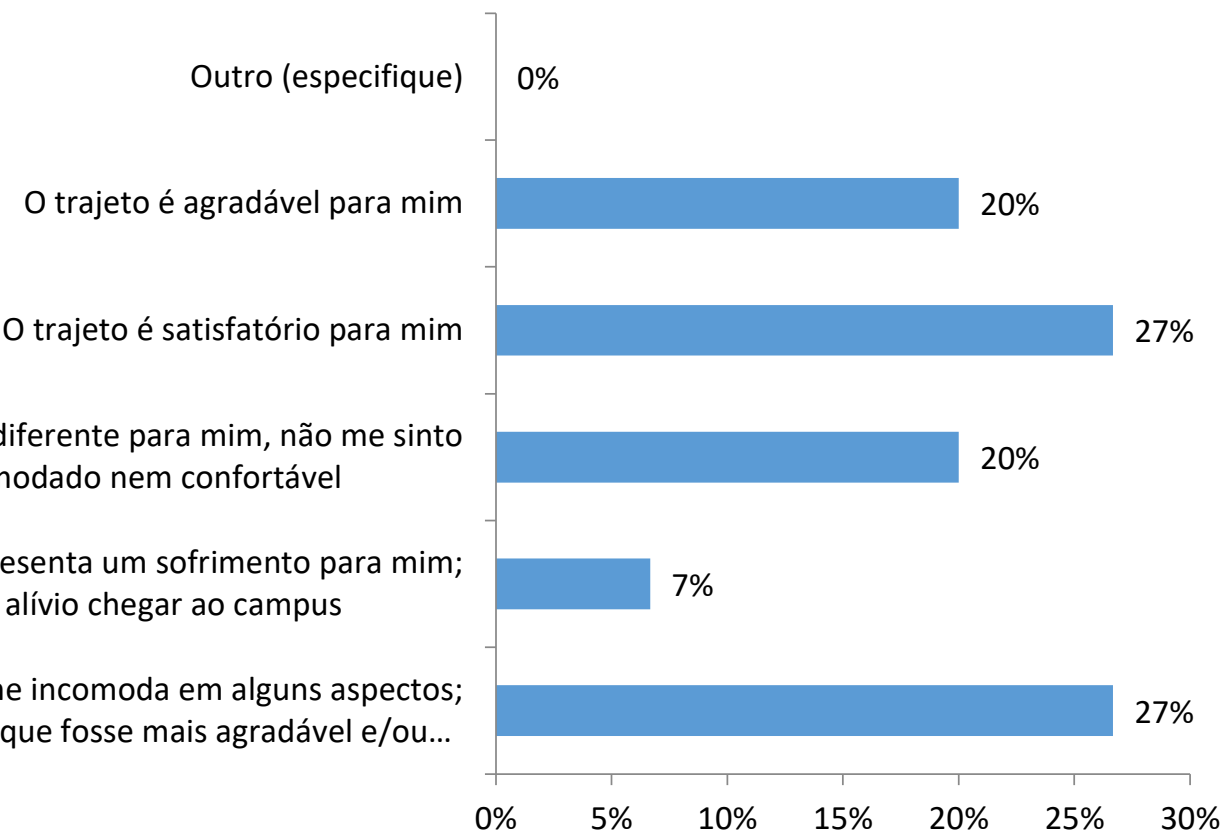

O trajeto me incomoda em alguns aspectos; gostaria que fosse mais agradável e/ou menos demorado

\begin{tabular}{lrr} 
O trajeto representa um sofrimento para mim; é um alívio chegar ao campus & $7 \%$ & 1 \\
\hline O trajeto é indiferente para mim, não me sinto incomodado nem confortável & $20 \%$ & 3 \\
\hline O trajeto é satisfatório para mim & $27 \%$ & 4 \\
\hline O trajeto é agradável para mim & $20 \%$ & 3 \\
\hline Outro (especifique) & $0 \%$ & 0
\end{tabular}


Como você avalia a sinalização do campus Luiz de Queiroz (ESALQ/CENA)?

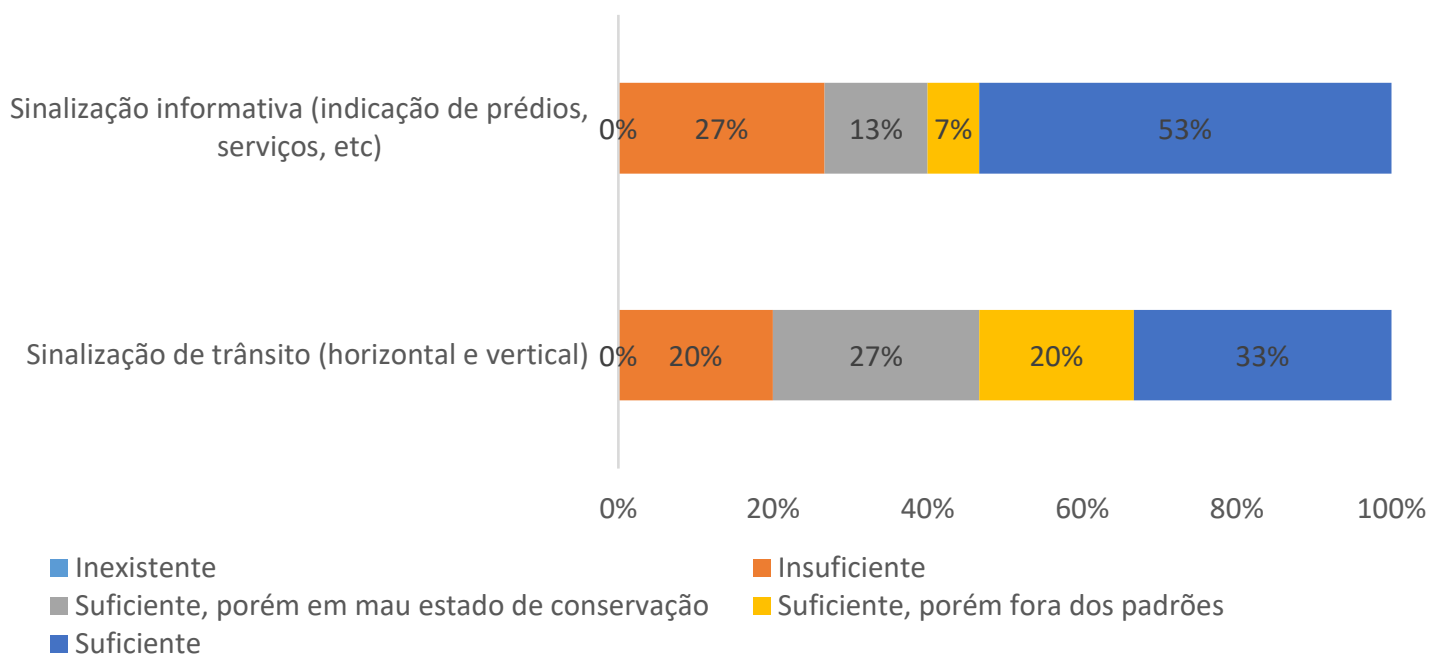

Sinalização informativa

Sinalização de trânsito (indicação de prédios, (horizontal e vertical) serviços, etc)

\begin{tabular}{lcccc}
\hline Inexistente & $0 \%$ & 0 & $0 \%$ & 0 \\
\hline Insuficiente & $20 \%$ & 3 & $27 \%$ & 4 \\
\hline $\begin{array}{l}\text { Suficiente, porém em mau estado de } \\
\text { conservação }\end{array}$ & $27 \%$ & 4 & $13 \%$ & 2 \\
\hline Suficiente, porém fora dos padrões & $20 \%$ & 3 & $7 \%$ & 1 \\
\hline $\begin{array}{l}\text { Suficiente } \\
\text { S }\end{array}$ & $33 \%$ & 5 & $53 \%$ & 8
\end{tabular}


Na sua opinião, qual a importância destes aspectos para uma mobilidade mais sustentável na USP de Piracicaba? Ordene os temas marcando-os com os respectivos números ou arrastando as caixas de acordo com a prioridade (no topo, o mais importante)

\section{Média}

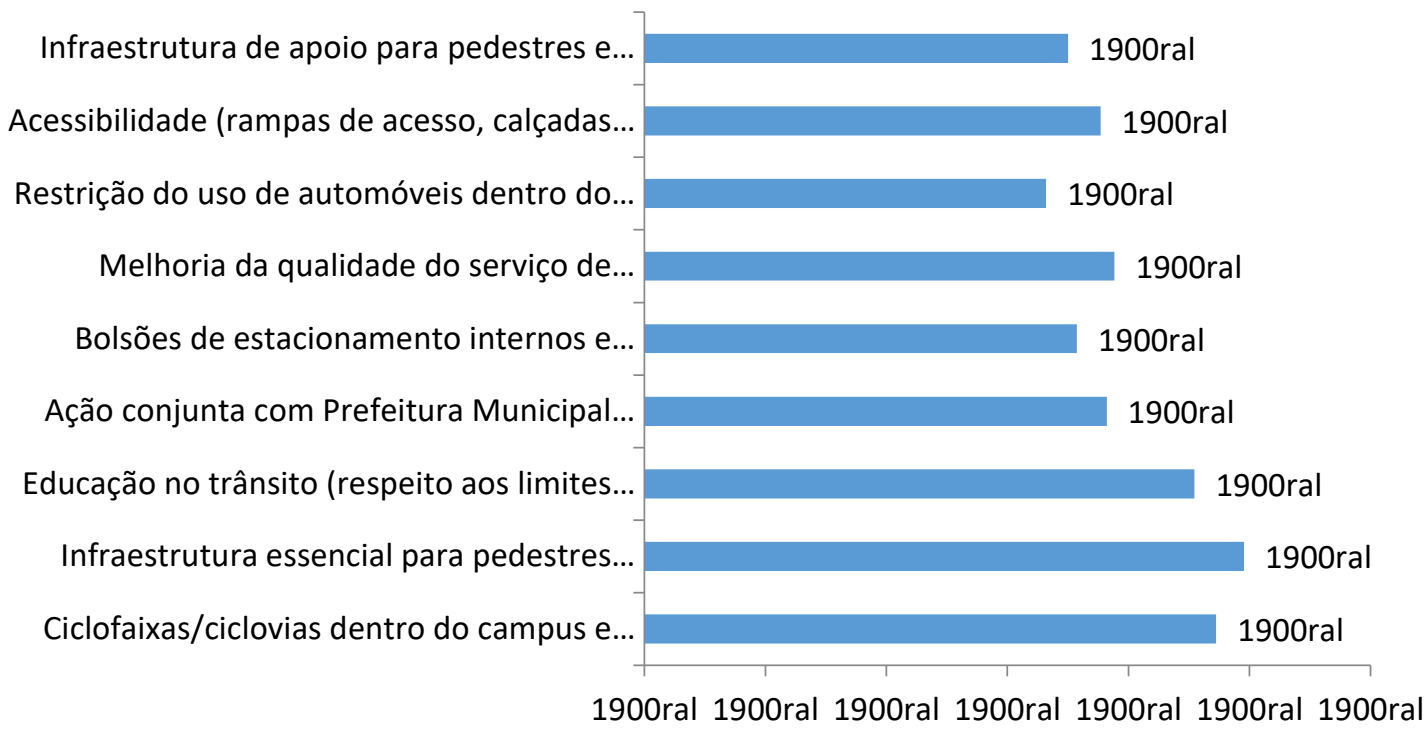

Obs: Quanto maior a média, maior a prioridade 
75

Prioridade

Ciclofaixas/ciclovias dent

ro do campus e para

acesso ao mesmo

Infraestrutura essencial

para pedestres (calçadas

adequadas, iluminação,

arborização, sinalização, etc.)

Educação no trânsito (respeito aos limites

de velocidade e à

sinalização, melhor

convívio entre

motoristas, ciclistas e

pedestres, etc.)

Ação conjunta com

Prefeitura Municipal para

melhoria da mobilidade

na ligação entre cidade e

campus

Bolsões de

estacionamento internos

e externos ao campus

Melhoria da qualidade do

serviço de transporte

público da cidade

Restrição do uso de

automóveis dentro do

campus

Acessibilidade (rampas

de acesso, calçadas

adequadas, elevadores,

piso tátil, respeito a

vagas de

estacionamento

prioritárias, etc.)

Infraestrutura de apoio

para pedestres e ciclistas

(bebedouros, bancos,

vestiários, guarda-

volume, bicicletários,

oficina para consertos, etc.) $\begin{array}{llllll}2 & 3 & 4 & 5 & 6 & 7\end{array}$

8

89

10

$18 \%$

$9 \%$

$9 \%$

$0 \%$

$0 \%$

$0 \%$

\begin{tabular}{llllllllll}
$18 \%$ & $27 \%$ & $27 \%$ & $18 \%$ & $0 \%$ & $0 \%$ & $0 \%$ & $0 \%$ & $9 \%$ & $0 \%$ \\
\hline
\end{tabular}

\begin{tabular}{llllllllll}
$18 \%$ & $18 \%$ & $9 \%$ & $9 \%$ & $18 \%$ & $18 \%$ & $0 \%$ & $9 \%$ & $0 \%$ & $0 \%$ \\
\hline
\end{tabular}

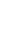




\section{Modo: Transporte Público Urbano}

\section{Analisando o campus da ESALQ/CENA como um todo, você o considera acessível aos usuários com algum tipo de restrição de mobilidade?}

Não sou capaz de opinar, pois nunca analisei o campus sob este aspecto

Não. O campus não oferece condições básicas de acessibilidade aos usuários com algum tipo de restrição de mobilidade

Pequena parte do campus é acessível. Há diversas áreas que não oferecem condições básicas de acessibilidade aos usuários com...

Grande parte do campus é acessível. Algumas áreas possuem obstáculos, mas de maneira geral considero o campus acessível aos...

Sim. Nunca notei obstáculos que dificultassem a acessibilidade aos usuários com algum tipo de restrição de mobilidade nas dependências...

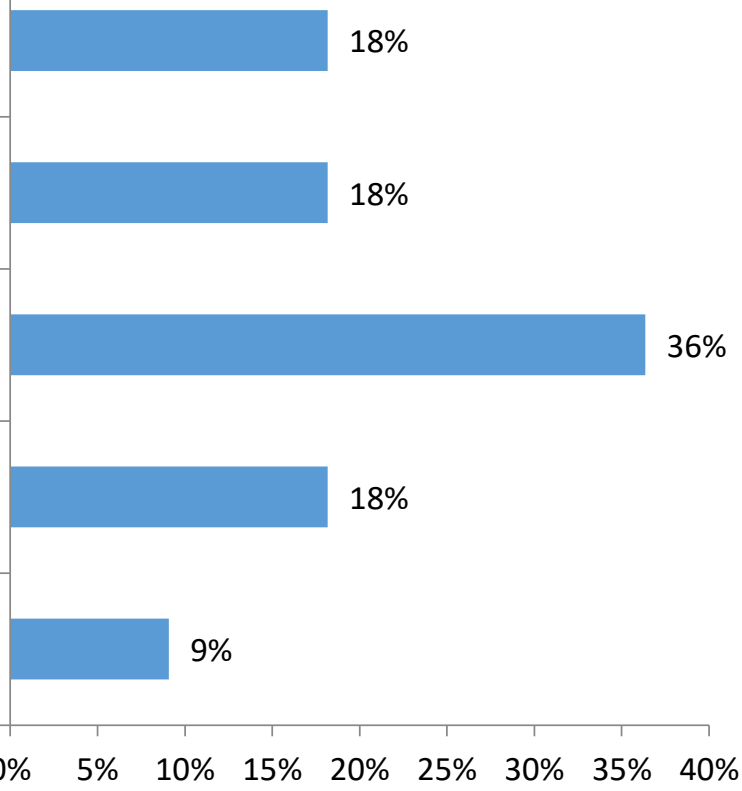

Sim. Nunca notei obstáculos que dificultassem a acessibilidade aos usuários com algum tipo de restrição de mobilidade nas dependências do campus $9 \% \quad 1$

Grande parte do campus é acessível. Algumas áreas possuem obstáculos, mas de maneira geral considero o campus acessível aos usuários com algum tipo de restrição de mobilidade $18 \% \quad 2$

Pequena parte do campus é acessível. Há diversas áreas que não oferecem condições básicas de acessibilidade aos usuários com algum tipo de restrição de mobilidade $36 \% \quad 4$

Não. O campus não oferece condições básicas de acessibilidade aos usuários com algum tipo de restrição de mobilidade $18 \% \quad 2$ Não sou capaz de opinar, pois nunca analisei o campus sob este aspecto

$18 \% \quad 2$


Dentre os prédios que frequenta na ESALQ/CENA, como você avalia a acessibilidade para os usuários com algum tipo de restrição de mobilidade?

Não sou capaz de avaliar, pois nunca analisei os prédios da ESALQ/CENA sob este aspecto

Ruim. Prédios não equipados para receber os usuários com algum tipo de restrição de mobilidade

Regular. Prédios pouco equipados, com limitações para atender os usuários com algum tipo de restrição de mobilidade

Boa. Prédios parcialmente equipados, mas possuem condições satisfatórias para atender os usuários com algum tipo de restrição de...

Ótima. Prédios totalmente equipados para receber os usuários com algum tipo de restrição de mobilidade

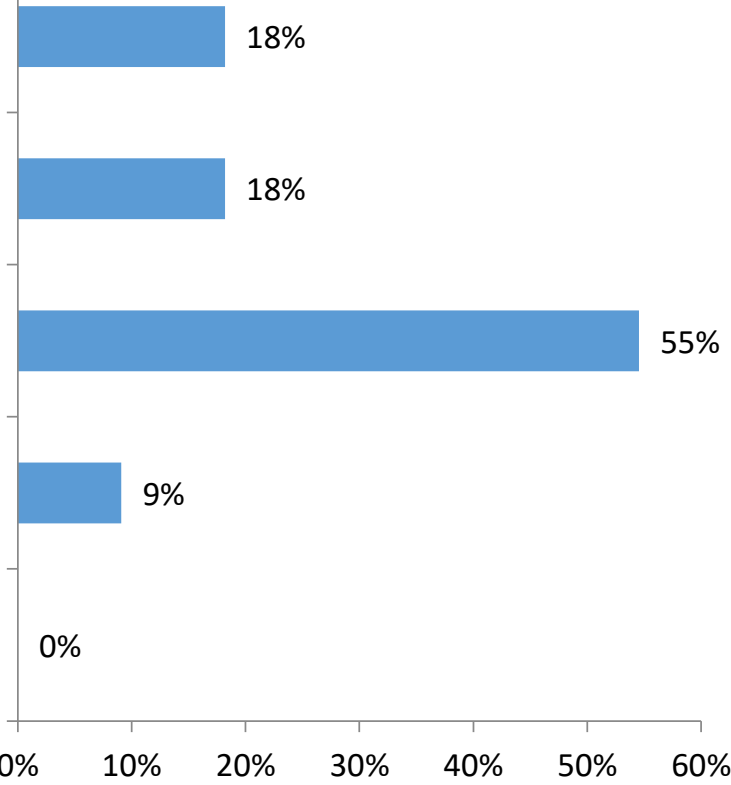

Ótima. Prédios totalmente equipados para receber os usuários com algum tipo de restrição de mobilidade $0 \% \quad 0$

Boa. Prédios parcialmente equipados, mas possuem condições satisfatórias para atender os usuários com algum tipo de restrição de mobilidade $9 \% \quad 1$

Regular. Prédios pouco equipados, com limitações para atender os usuários com algum tipo de restrição de mobilidade $55 \% \quad 6$

Ruim. Prédios não equipados para receber os usuários com algum tipo de restrição de mobilidade $18 \% \quad 2$ Não sou capaz de avaliar, pois nunca analisei os prédios da ESALQ/CENA sob este aspecto 
Na etapa anterior do questionário, você nos informou que seu modo principal para os deslocamentos à ESALQ/CENA é o ÔNIBUS DO TRANSPORTE PÚBLICO URBANO. Quais fatores o/a levam a optar por este modo?

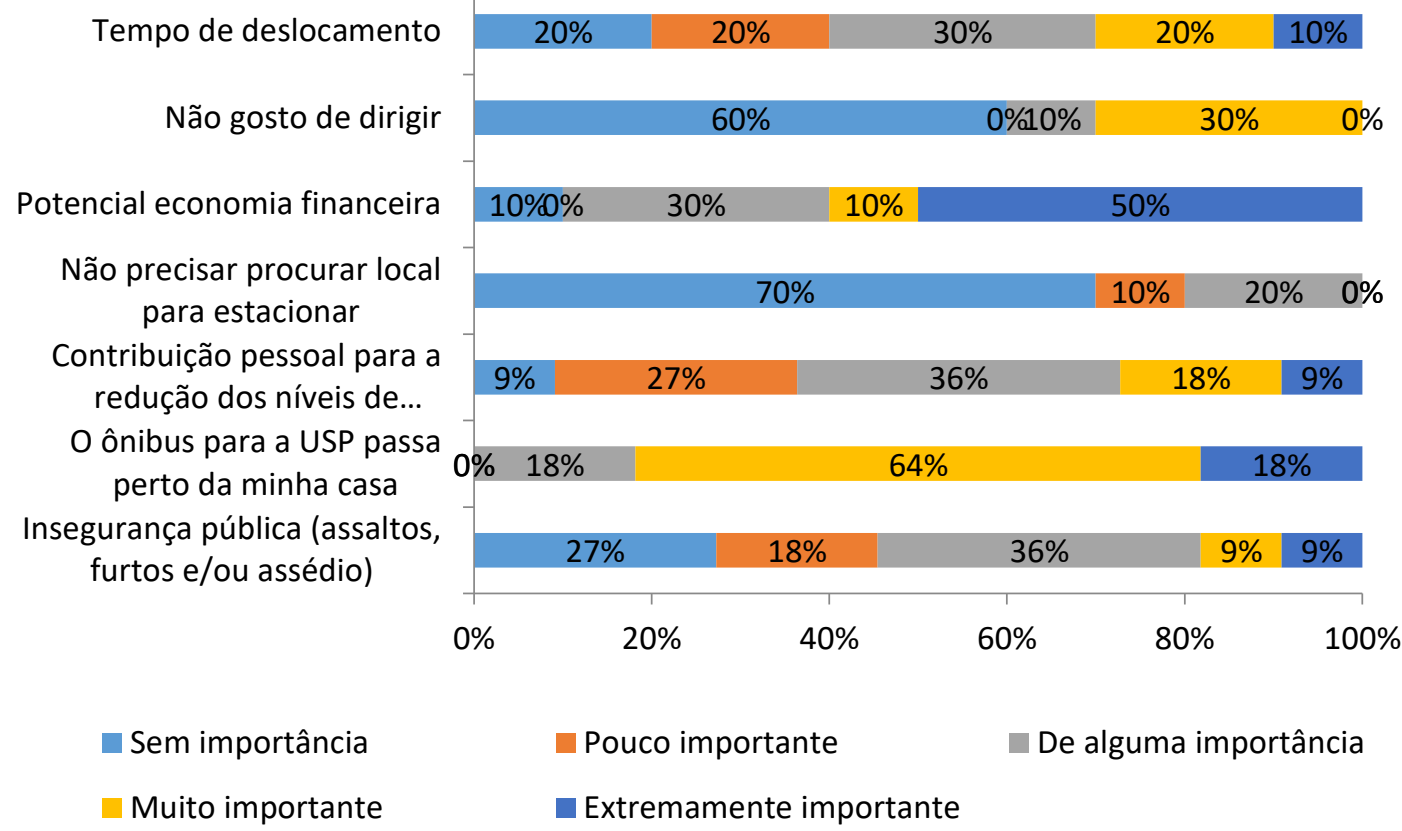

\begin{tabular}{|c|c|c|c|c|c|c|c|c|c|c|}
\hline \multirow{2}{*}{$\begin{array}{l}\text { Insegurança pública } \\
\text { (assaltos, furtos e/ou } \\
\text { assédio) }\end{array}$} & \multicolumn{2}{|c|}{$\begin{array}{c}\text { Sem } \\
\text { importância }\end{array}$} & \multicolumn{2}{|c|}{$\begin{array}{c}\text { Pouco } \\
\text { importante }\end{array}$} & \multicolumn{2}{|c|}{$\begin{array}{l}\text { De alguma } \\
\text { importância }\end{array}$} & \multicolumn{2}{|c|}{$\begin{array}{l}\text { Muito } \\
\text { importante }\end{array}$} & \multicolumn{2}{|c|}{$\begin{array}{c}\text { Extremamen } \\
\text { te } \\
\text { importante }\end{array}$} \\
\hline & $27 \%$ & 3 & $18 \%$ & 2 & $36 \%$ & 4 & $9 \%$ & 1 & $9 \%$ & 1 \\
\hline $\begin{array}{l}\text { O ônibus para a USP } \\
\text { passa perto da minha } \\
\text { casa }\end{array}$ & $0 \%$ & 0 & $0 \%$ & 0 & $18 \%$ & 2 & $64 \%$ & 7 & $18 \%$ & 2 \\
\hline $\begin{array}{l}\text { Contribuição pessoal } \\
\text { para a redução dos } \\
\text { níveis de poluição do } \\
\text { ar }\end{array}$ & $9 \%$ & 1 & $27 \%$ & 3 & $36 \%$ & 4 & $18 \%$ & 2 & $9 \%$ & 1 \\
\hline $\begin{array}{l}\text { Não precisar procurar } \\
\text { local para estacionar }\end{array}$ & $70 \%$ & 7 & $10 \%$ & 1 & $20 \%$ & 2 & $0 \%$ & 0 & $0 \%$ & 0 \\
\hline $\begin{array}{l}\text { Potencial economia } \\
\text { financeira }\end{array}$ & $10 \%$ & 1 & $0 \%$ & 0 & $30 \%$ & 3 & $10 \%$ & 1 & $50 \%$ & 5 \\
\hline Não gosto de dirigir & $60 \%$ & 6 & $0 \%$ & 0 & $10 \%$ & 1 & $30 \%$ & 3 & $0 \%$ & 0 \\
\hline $\begin{array}{l}\text { Tempo de } \\
\text { deslocamento }\end{array}$ & $20 \%$ & 2 & $20 \%$ & 2 & $30 \%$ & 3 & $20 \%$ & 2 & $10 \%$ & 1 \\
\hline
\end{tabular}




\section{Quais fatores o/a desestimulam a utilizar os demais modos que não o ônibus do transporte público urbano em seus deslocamentos?}

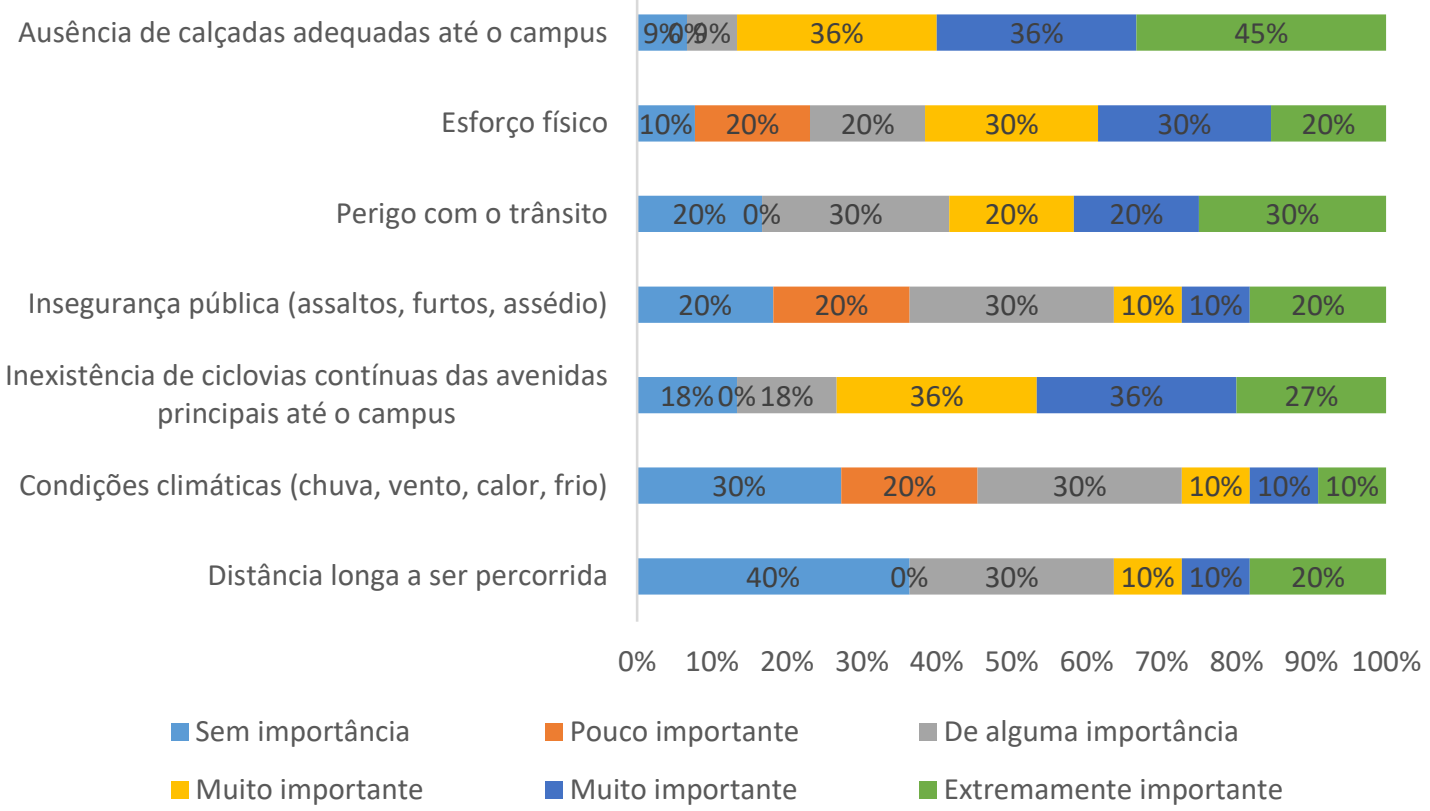

\begin{tabular}{lcccccccccc} 
& $\begin{array}{c}\text { Sem } \\
\text { importância }\end{array}$ & $\begin{array}{c}\text { Pouco } \\
\text { importante }\end{array}$ & $\begin{array}{c}\text { De alguma } \\
\text { importância }\end{array}$ & $\begin{array}{c}\text { Muito } \\
\text { importante }\end{array}$ & $\begin{array}{c}\text { Extremame } \\
\text { nte } \\
\text { importante }\end{array}$ \\
\hline $\begin{array}{l}\text { Distância longa a ser } \\
\text { percorrida }\end{array}$ & $40 \%$ & 4 & $0 \%$ & 0 & $30 \%$ & 3 & $10 \%$ & 1 & $20 \%$ & 2 \\
\hline $\begin{array}{l}\text { Condições climáticas } \\
\text { (chuva, vento, calor, frio) }\end{array}$ & $30 \%$ & 3 & $20 \%$ & 2 & $30 \%$ & 3 & $10 \%$ & 1 & $10 \%$ & 1 \\
\hline $\begin{array}{l}\text { Inexistência de ciclovias } \\
\text { contínuas das avenidas } \\
\text { principais até o campus }\end{array}$ & $18 \%$ & 2 & $0 \%$ & 0 & $18 \%$ & 2 & $36 \%$ & 4 & $27 \%$ & 3 \\
\hline $\begin{array}{l}\text { Insegurança pública } \\
\text { (assaltos, furtos, assédio) }\end{array}$ & $20 \%$ & 2 & $20 \%$ & 2 & $30 \%$ & 3 & $10 \%$ & 1 & $20 \%$ & 2 \\
\hline \begin{tabular}{l} 
Perigo com o trânsito \\
\hline Esforço físico
\end{tabular} & $20 \%$ & 2 & $0 \%$ & 0 & $30 \%$ & 3 & $20 \%$ & 2 & $30 \%$ & 3 \\
\hline $\begin{array}{l}\text { Ausência de calçadas } \\
\text { adequadas até o campus }\end{array}$ & $9 \%$ & 1 & $20 \%$ & 2 & $20 \%$ & 2 & $30 \%$ & 3 & $20 \%$ & 2 \\
\hline
\end{tabular}


Há quanto tempo você utiliza o ônibus do transporte público urbano para se deslocar até a ESALQ/CENA?

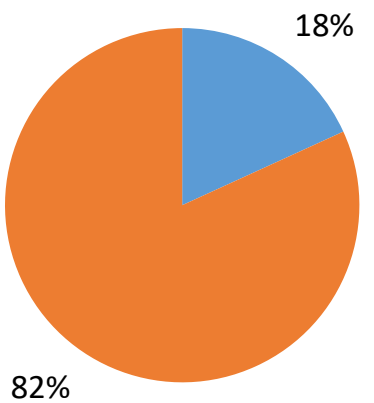

Há menos de 6 meses

Há mais de 6 meses

\begin{tabular}{lll} 
Há menos de 6 meses & $18 \%$ & 2 \\
\hline Há mais de 6 meses & $82 \%$ & 9
\end{tabular}

Dos deslocamentos que você faz hoje de ônibus do transporte público urbano, qual modo você utilizava antes?

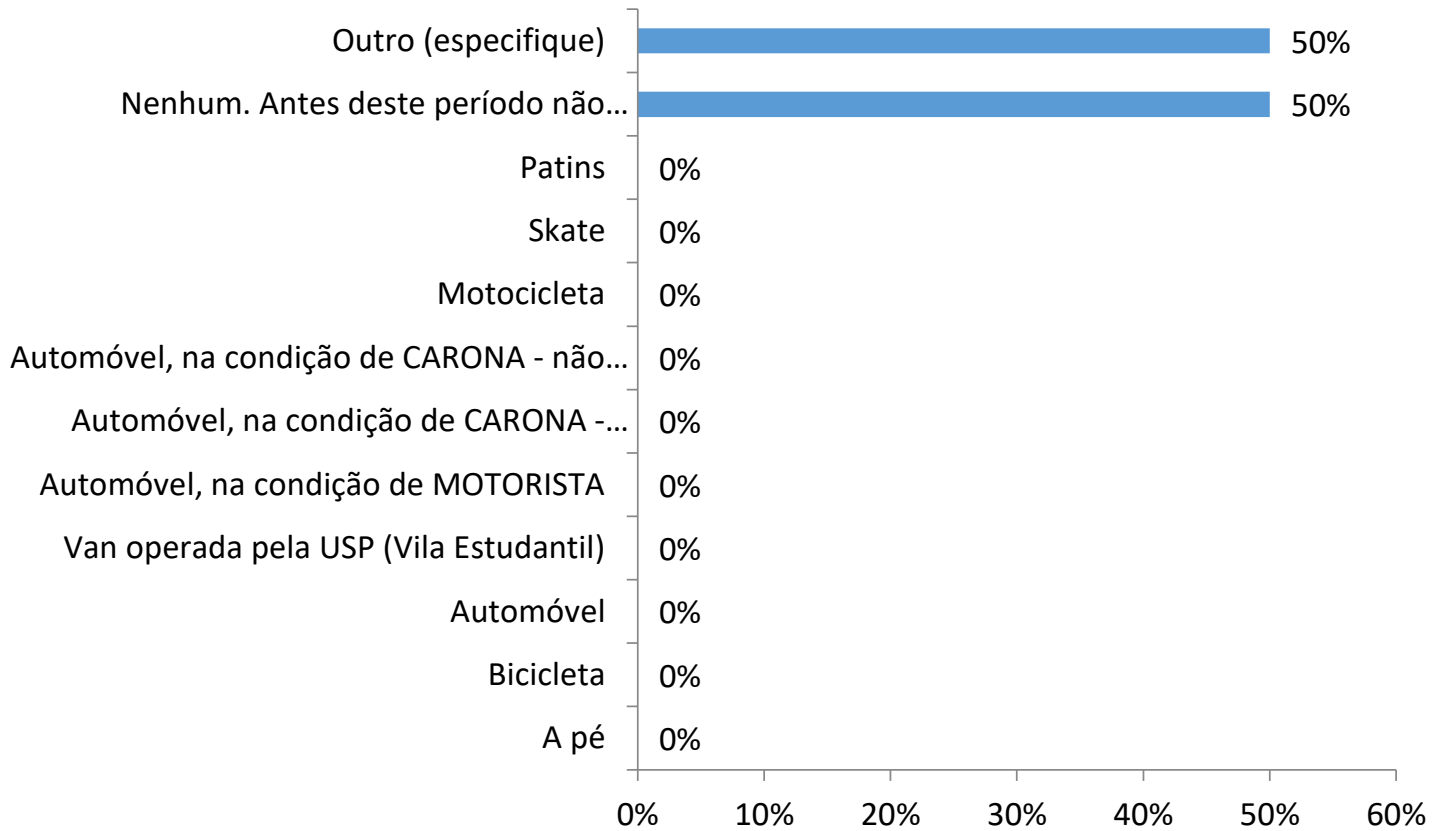




\begin{tabular}{lrr} 
A pé & $0 \%$ & 0 \\
\hline Bicicleta & $0 \%$ & 0 \\
\hline Automóvel & $0 \%$ & 0 \\
\hline Van operada pela USP (Vila Estudantil) & $0 \%$ & 0 \\
\hline Automóvel, na condição de MOTORISTA & $0 \%$ & 0 \\
\hline Automóvel, na condição de CARONA - estaciona no campus & $0 \%$ & 0 \\
\hline Automóvel, na condição de CARONA - não estaciona no campus & $0 \%$ & 0 \\
\hline Motocicleta & $0 \%$ & 0 \\
\hline Skate & $0 \%$ & 0 \\
\hline Patins & $0 \%$ & 0 \\
\hline Nenhum. Antes deste período não frequentava o campus & $50 \%$ & 1 \\
\hline Outro (especifique) & $50 \%$ & 1
\end{tabular}

\section{Como você avalia a frequência de atendimento?}

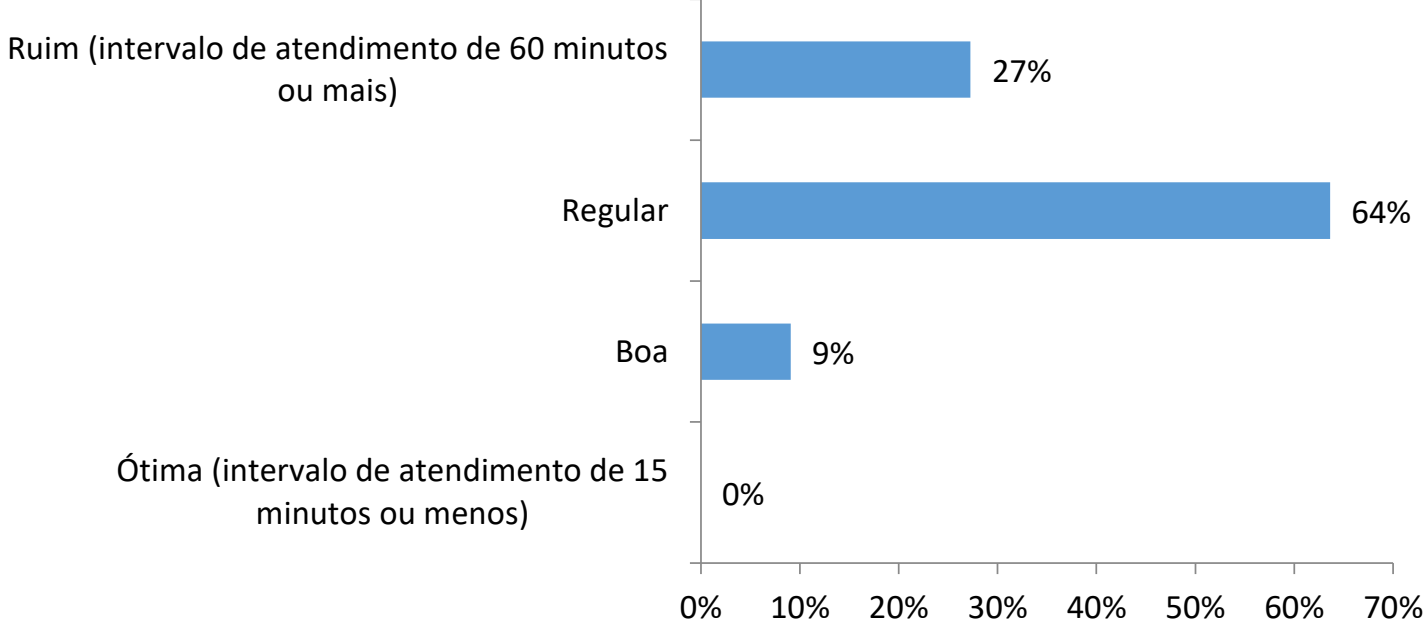

\begin{tabular}{lrr} 
Ótima (intervalo de atendimento de 15 minutos ou menos) & $0 \%$ & 0 \\
\hline Boa & $9 \%$ & 1 \\
\hline Regular & $64 \%$ & 7 \\
\hline Ruim (intervalo de atendimento de 60 minutos ou mais) & $27 \%$ & 3
\end{tabular}




\section{Como você avalia a pontualidade?}

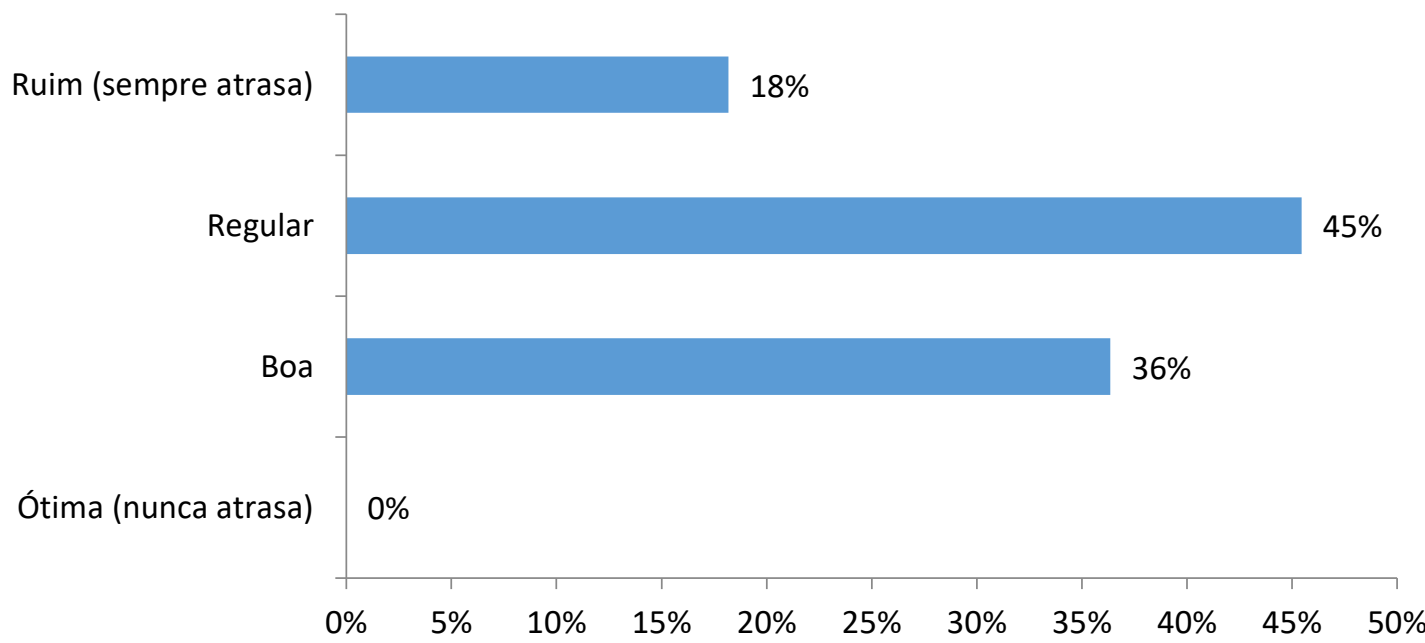

\begin{tabular}{lcc} 
Ótima (nunca atrasa) & $0 \%$ & 0 \\
\hline Boa & $36 \%$ & 4 \\
\hline Regular & $45 \%$ & 5 \\
\hline Ruim (sempre atrasa) & $18 \%$ & 2
\end{tabular}

\section{Como você avalia o tempo de viagem?}

Ruim (duas ou mais vezes o tempo que levaria de automóvel)

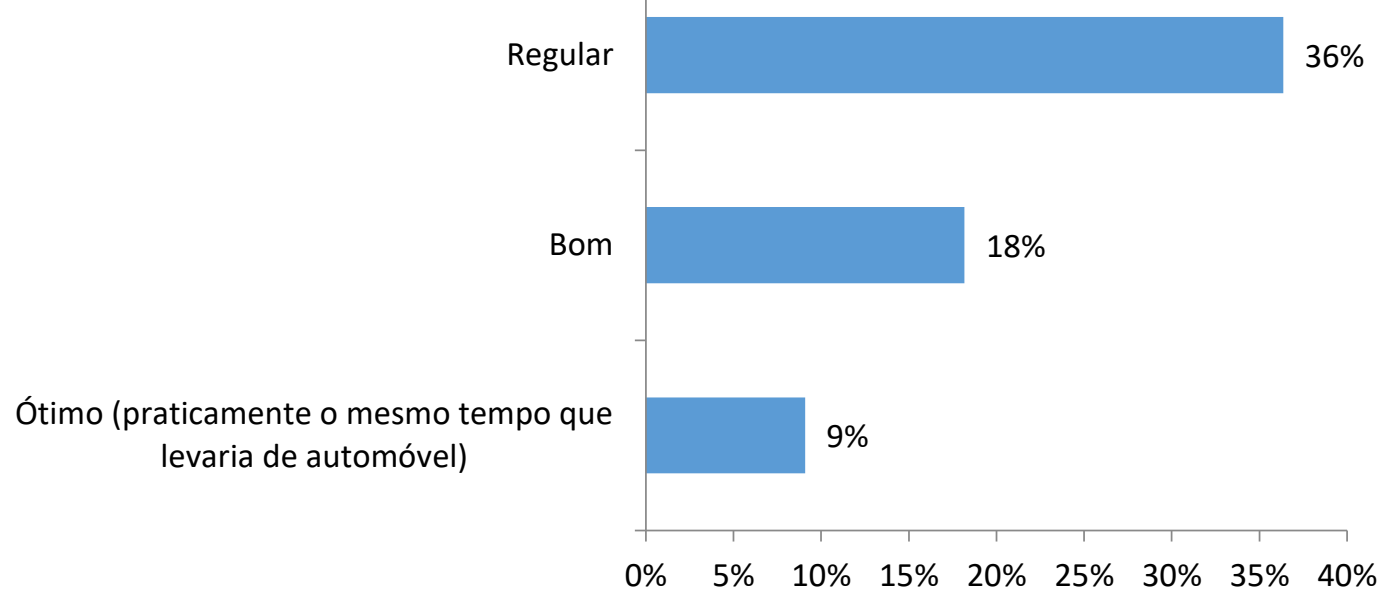

Ótimo (praticamente o mesmo tempo que levaria de automóvel) $\quad 9 \% \quad 1$

\begin{tabular}{lll} 
Bom & $18 \%$ & 2 \\
\hline Regular & $36 \%$ & 4 \\
\hline Ruim (duas ou mais vezes o tempo que levaria de automóvel) & $36 \%$ & 4
\end{tabular}




\section{Como você avalia a lotação dos veículos?}

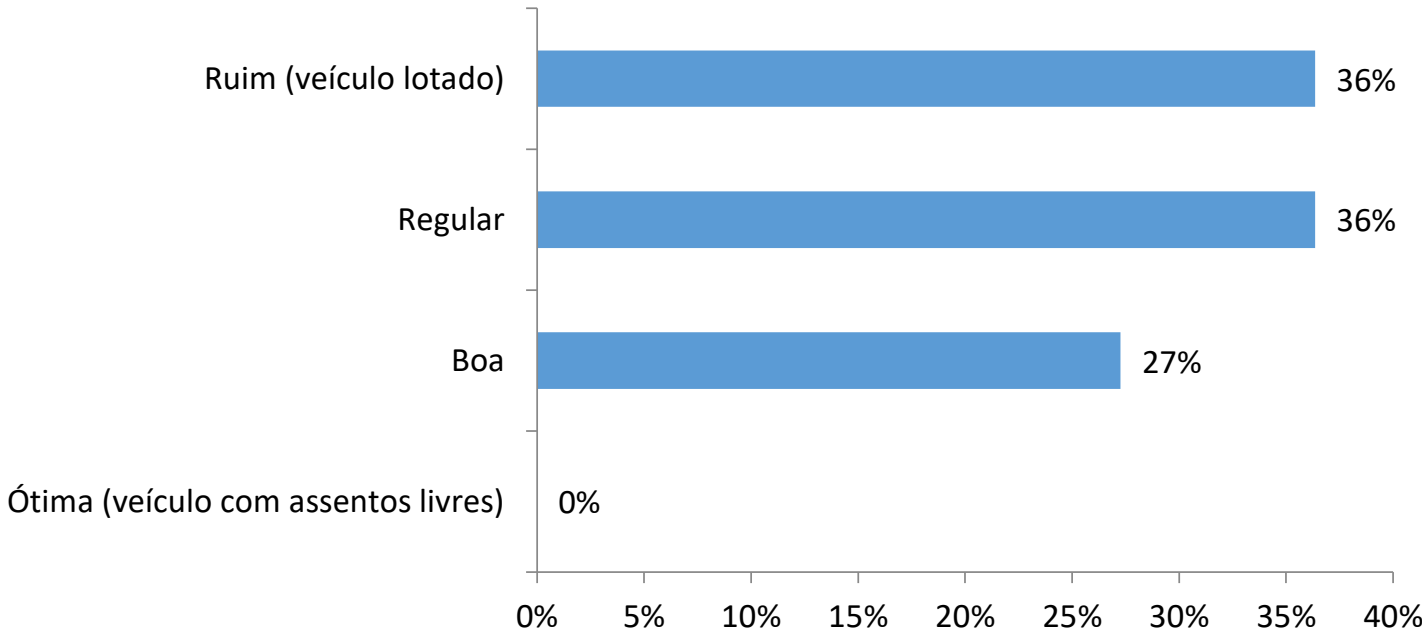

\begin{tabular}{lll} 
Ótima (veículo com assentos livres) & $0 \%$ & 0 \\
\hline Boa & $27 \%$ & 3 \\
\hline Regular & $36 \%$ & 4 \\
\hline Ruim (veículo lotado) & $36 \%$ & 4
\end{tabular}

\section{Ponto de ônibus em que você desce quando vai à USP.}

13. Estrada Monte Alegre, próximo à... $0 \%$

12. Av. Centenário, próximo ao cruzamento... $0 \%$

11. Dentro da ESALQ, na Alameda dos..

10. Dentro da ESALQ, rotatória do A...

9. Av. Centenário, em frente à rotatória...

8. Dentro da ESALQ, na Alameda Principal,..

7. Av. Centenário, próximo ao cruzamento..

6. CENA. Av. Centenário, próximo à esquina..

5. CENA. Rod. Luiz de Queiroz, próximo à... $0 \%$

4. Em frente à FEALQ, Rod. Luiz de Queiroz,... $0 \%$

3. CEBTEC, Av. Centenário, próximo à...

2. Av. Carlos Botelho, próximo à esquina... $0 \%$

1. Av. Independência, em frente ao Posto...

Answer Choices

$9 \%$

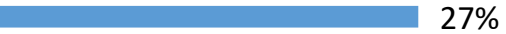

$9 \%$

$9 \%$

$9 \%$

$9 \%$

1900ral

1900ral 1900ral 1900ral 1900ral 1900ral 1900ral 1900ral 


\begin{tabular}{|c|c|c|}
\hline Av. Independência, em frente ao Posto Shell & $9 \%$ & 1 \\
\hline Av. Carlos Botelho, próximo à esquina com Av. Centenário & $0 \%$ & 0 \\
\hline CEBTEC, Av. Centenário, próximo à esquina com Av. Carlos Botelho & $9 \%$ & 1 \\
\hline $\begin{array}{l}\text { Em frente à FEALQ, Rod. Luiz de Queiroz, próximo à esquina com Av. Duque } \\
\text { de Caxias. }\end{array}$ & $0 \%$ & 0 \\
\hline $\begin{array}{l}\text { CENA. Rod. Luiz de Queiroz, próximo à esquina com R. Padre Lopes, sentido } \\
\text { Centro }\end{array}$ & $0 \%$ & 0 \\
\hline $\begin{array}{l}\text { CENA. Av. Centenário, próximo à esquina com R. Padre Lopes, sentido Rio } \\
\text { Piracicaba }\end{array}$ & $9 \%$ & 1 \\
\hline Av. Centenário, próximo ao cruzamento com a Estrada Monte Alegre & $9 \%$ & 1 \\
\hline $\begin{array}{l}\text { Dentro da ESALQ, na Alameda Principal, em frente ao Departamento de } \\
\text { Genética }\end{array}$ & $18 \%$ & 2 \\
\hline Av. Centenário, em frente à rotatória próxima à entrada principal ( $A$ encarnado) & $9 \%$ & 1 \\
\hline Dentro da ESALQ, rotatória do A Encarnado & $27 \%$ & 3 \\
\hline $\begin{array}{l}\text { Dentro da ESALQ, na Alameda dos Alecrins, próximo à esquina com Alameda } \\
\text { Principal }\end{array}$ & $9 \%$ & 1 \\
\hline $\begin{array}{l}\text { Av. Centenário, próximo ao cruzamento com a Estrada Monte Alegre, em } \\
\text { frente à "Nova Mercantil Veículos" }\end{array}$ & $0 \%$ & 0 \\
\hline Estrada Monte Alegre, próximo à entrada da Engenharia & $0 \%$ & 0 \\
\hline Utilizo um ponto de ônibus próximo ao campus que não & $0 \%$ & 0 \\
\hline
\end{tabular}

\section{Como você avalia a distância de caminhada do ponto de ônibus até a portaria do campus?}

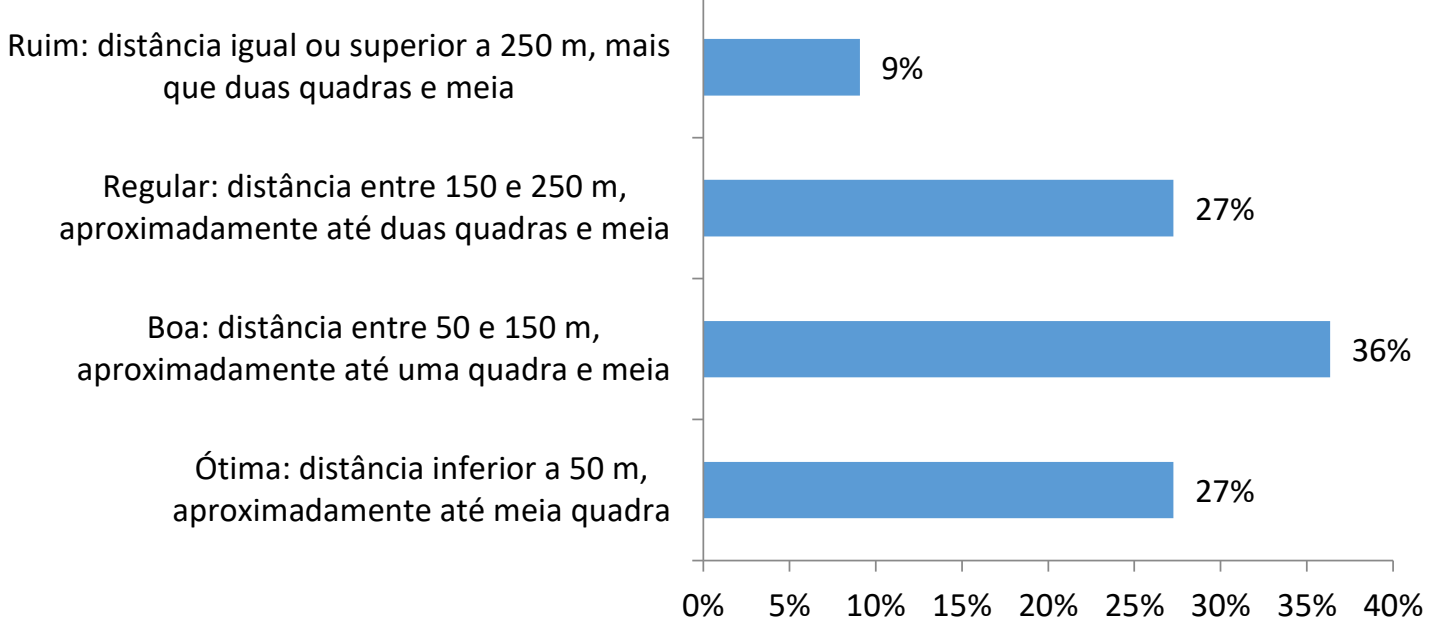

\begin{tabular}{lccc} 
Ótima: distância inferior a 50 m, aproximadamente até meia quadra & $27 \%$ & 3 \\
\hline Boa: distância entre 50 e 150 m, aproximadamente até uma quadra e meia & $36 \%$ & 4 \\
\hline Regular: distância entre 150 e 250 m, aproximadamente até duas quadras e meia & $27 \%$ & 3 \\
\hline Ruim: distância igual ou superior a 250 m, mais que duas quadras e meia & $9 \%$ & 1
\end{tabular}


Em qual horário você normalmente utiliza este ponto de ônibus?

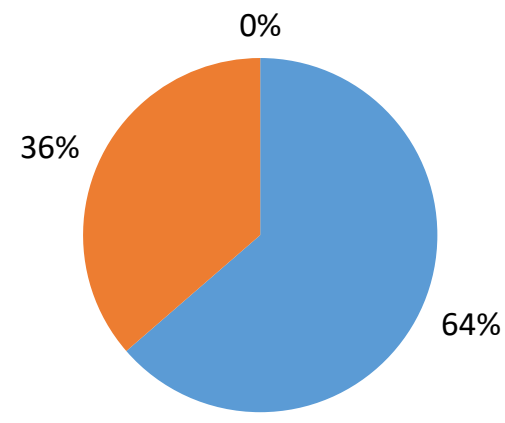

Manhã

Tarde

Noite

\begin{tabular}{lcc} 
Manhã & $64 \%$ & 7 \\
\hline Tarde & $36 \%$ & 4 \\
\hline Noite & $0 \%$ & 0
\end{tabular}

Ponto em que vai embora da USP.

Utilizo um ponto de ônibus próximo ao...

13. Estrada Monte Alegre, próximo à entrada... $0 \%$

12. Av. Centenário, próximo ao cruzamento... $0 \%$

11. Dentro da ESALQ, na Alameda dos... $0 \%$

10. Dentro da ESALQ, rotatória do A Encarnado

9. Av. Centenário, em frente à rotatória...

8. Dentro da ESALQ, na Alameda Principal, em...

$9 \%$

7. Av. Centenário, próximo ao cruzamento... $0 \%$

6. CENA. Av. Centenário, próximo à esquina... $0 \%$

5. CENA. Rod. Luiz de Queiroz, próximo à...

4. Em frente à FEALQ, Rod. Luiz de Queiroz,... $0 \%$

3. CEBTEC, Av. Centenário, próximo à esquina...

$$
\text { ... }
$$

$0 \%$

2. Av. Carlos Botelho, próximo à esquina com...

1. Av. Independência, em frente ao Posto Shell $0 \%$ 
1. Av. Independência, em frente ao Posto Shell $0 \% \quad 0$

2. Av. Carlos Botelho, próximo à esquina com Av. Centenário $\quad 0 \% \quad 0$

3. CEBTEC, Av. Centenário, próximo à esquina com Av. Carlos Botelho $\quad 9 \%$

4. Em frente à FEALQ, Rod. Luiz de Queiroz, próximo à esquina com Av.

Duque de Caxias.

$0 \% \quad 0$

5. CENA. Rod. Luiz de Queiroz, próximo à esquina com R. Padre Lopes, sentido Centro

$9 \% \quad 1$

6. CENA. Av. Centenário, próximo à esquina com R. Padre Lopes, sentido Rio

Piracicaba

7. Av. Centenário, próximo ao cruzamento com a Estrada Monte Alegre

8. Dentro da ESALQ, na Alameda Principal, em frente ao Departamento de

Genética

9 . Av. Centenário, em frente à rotatória próxima à entrada principal $(A$ encarnado)

10. Dentro da ESALQ, rotatória do A Encarnado

$0 \% \quad 0$

$0 \% \quad 0$

11. Dentro da ESALQ, na Alameda dos Alecrins, próximo à esquina com Alameda Principal

12. Av. Centenário, próximo ao cruzamento com a Estrada Monte Alegre, em frente à "Nova Mercantil Veículos"

13. Estrada Monte Alegre, próximo à entrada da Engenharia

$9 \% \quad 1$

Utilizo um ponto de ônibus próximo ao campus que não está na lista.

$36 \% \quad 4$

$27 \% \quad 3$

$0 \% \quad 0$

$0 \% \quad 0$

$0 \% \quad 0$

\section{Como você avalia a distância de caminhada da portaria do campus até o ponto de ônibus?}

Ruim: distância igual ou superior a $250 \mathrm{~m}$, mais que duas quadras e meia

$9 \%$

Regular: distância entre 150 e 250 m, aproximadamente até duas quadras e meia

Boa: distância entre 50 e 150 m, aproximadamente até uma quadra e meia

Ótima: distância inferior a 50 m, aproximadamente até meia quadra

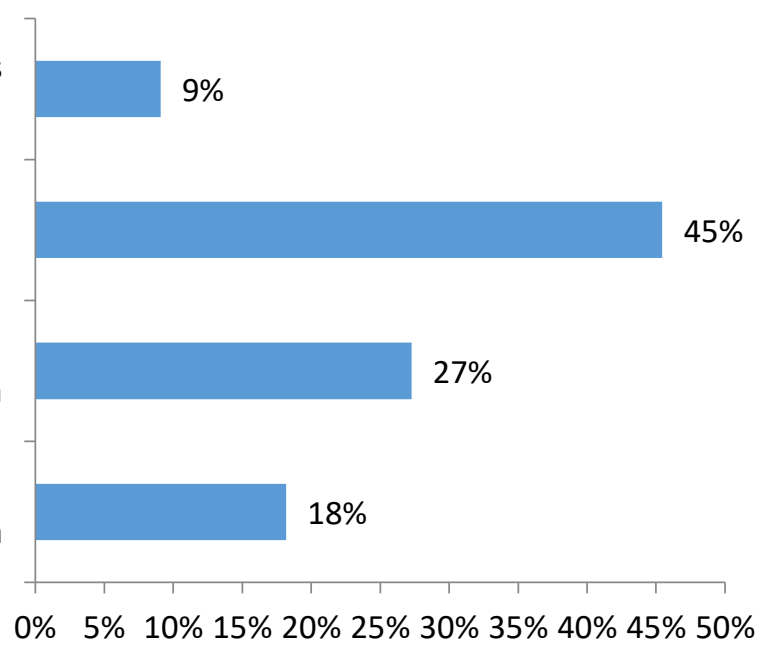

Ótima: distância inferior a $50 \mathrm{~m}$, aproximadamente até meia quadra $18 \% \quad 2$

Boa: distância entre 50 e $150 \mathrm{~m}$, aproximadamente até uma quadra e meia $27 \% \quad 3$

Regular: distância entre 150 e 250 m, aproximadamente até duas quadras e meia

$45 \% \quad 5$

Ruim: distância igual ou superior a $250 \mathrm{~m}$, mais que duas quadras e meia

$9 \% \quad 1$


Em qual horário você normalmente utiliza este ponto de ônibus?

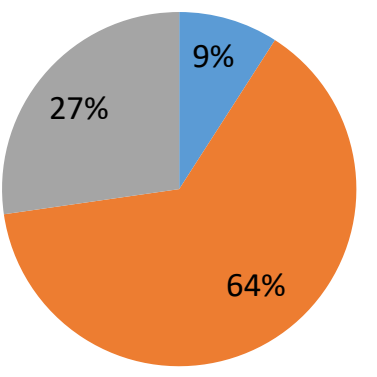

- Manhã

- Tarde

\begin{tabular}{lcl} 
Manhã & $9 \%$ & 1 \\
\hline Tarde & $64 \%$ & 7 \\
\hline Noite & $27 \%$ & 3
\end{tabular}


Médias de Cada Ponto de ônibus

\begin{tabular}{|c|c|c|c|c|c|c|c|}
\hline Ponto & $\begin{array}{l}\text { Distânc } \\
\text { ia }\end{array}$ & $\begin{array}{c}\text { Iluminaç } \\
\text { ão }\end{array}$ & $\begin{array}{l}\text { Seguran } \\
\text { ça }\end{array}$ & $\begin{array}{c}\text { Cobertur } \\
\text { a }\end{array}$ & $\begin{array}{l}\text { Sinalizaç } \\
\text { ão e } \\
\text { identifica } \\
\text { ção } \\
\end{array}$ & $\begin{array}{c}\text { Disponi } \\
\text { bilidade } \\
\text { de } \\
\text { Assento }\end{array}$ & $\begin{array}{l}\text { Ponto } \\
\text { de } \\
\text { onibus }\end{array}$ \\
\hline $\begin{array}{l}\text { 1. Av. } \\
\text { Independência, em } \\
\text { frente ao Posto } \\
\text { Shell }\end{array}$ & 0,33 & 0,00 & 1,00 & 1,00 & 1,00 & 1,00 & 0,682 \\
\hline $\begin{array}{l}\text { 2. Av. Carlos } \\
\text { Botelho, próximo à } \\
\text { esquina com Av. } \\
\text { Centenário }\end{array}$ & 0,00 & 0,00 & 0,00 & 0,00 & 0,00 & 0,00 & 0,000 \\
\hline $\begin{array}{l}\text { 3. CEBTEC, Av. } \\
\text { Centenário, } \\
\text { próximo à esquina } \\
\text { com Av. Carlos } \\
\text { Botelho }\end{array}$ & 0,50 & 0,50 & 0,50 & 0,00 & 0,33 & 0,00 & 0,442 \\
\hline $\begin{array}{l}\text { 4. Em frente à } \\
\text { FEALQ, Rod. Luiz } \\
\text { de Queiroz, } \\
\text { próximo à esquina } \\
\text { com Av. Duque de } \\
\text { Caxias }\end{array}$ & 0,00 & 0,00 & 0,00 & 0,00 & 0,00 & 0,00 & 0,000 \\
\hline $\begin{array}{l}\text { 5. CENA. Rod. } \\
\text { Luiz de Queiroz, } \\
\text { próximo à esquina } \\
\text { com R. Padre } \\
\text { Lopes, sentido } \\
\text { Centro }\end{array}$ & 0,67 & 0,00 & 0,00 & 0,00 & 0,00 & 0,00 & 0,268 \\
\hline $\begin{array}{l}\text { 6. CENA. Av. } \\
\text { Centenário, } \\
\text { próximo à esquina } \\
\text { com R. Padre } \\
\text { Lopes, sentido Rio } \\
\text { Piracicaba }\end{array}$ & 0,00 & 0,33 & 0,00 & 0,67 & 0,67 & 0,67 & 0,117 \\
\hline $\begin{array}{l}\text { 7. Av. Centenário, } \\
\text { próximo ao } \\
\text { cruzamento com a } \\
\text { Estrada Monte } \\
\text { Alegre }\end{array}$ & 0,67 & 0,00 & 0,00 & 0,33 & 0,00 & 0,67 & 0,318 \\
\hline $\begin{array}{l}\text { 8. Dentro da } \\
\text { ESALQ, na } \\
\text { Alameda Principal, } \\
\text { em frente ao } \\
\text { Departamento de } \\
\text { Genética }\end{array}$ & 0,67 & 0,00 & 0,33 & 0,44 & 0,78 & 0,67 & 0,496 \\
\hline $\begin{array}{l}\text { 9. Av. Centenário, } \\
\text { em frente à } \\
\text { rotatória próxima à } \\
\text { entrada principal } \\
\text { (A encarnado) }\end{array}$ & 0,40 & 0,34 & 0,40 & 0,60 & 0,47 & 0,75 & 0,427 \\
\hline
\end{tabular}




\begin{tabular}{|c|c|c|c|c|c|c|c|}
\hline Ponto & $\begin{array}{c}\text { Distânc } \\
\text { ia }\end{array}$ & $\begin{array}{l}\text { Iluminaç } \\
\text { ão }\end{array}$ & $\begin{array}{l}\text { Seguran } \\
\text { ça }\end{array}$ & $\begin{array}{c}\text { Cobertur } \\
a\end{array}$ & $\begin{array}{l}\text { Sinalizaç } \\
\text { ão e } \\
\text { identifica } \\
\text { ção }\end{array}$ & $\begin{array}{c}\text { Disponi } \\
\text { bilidade } \\
\text { de } \\
\text { Assento }\end{array}$ & $\begin{array}{l}\text { Ponto } \\
\text { de } \\
\text { onibus }\end{array}$ \\
\hline $\begin{array}{l}\text { 10. Dentro da } \\
\text { ESALQ, rotatória } \\
\text { do A Encarnado }\end{array}$ & 0,83 & 0,33 & 0,75 & 0,56 & 0,78 & 0,73 & 0,753 \\
\hline $\begin{array}{l}\text { 11. Dentro da } \\
\text { ESALQ, na } \\
\text { Alameda dos } \\
\text { Alecrins, próximo à } \\
\text { esquina com } \\
\text { Alameda Principal }\end{array}$ & 0,33 & 0,67 & 0,50 & 0,33 & 0,33 & 0,67 & 0,432 \\
\hline $\begin{array}{l}\text { 12. Av. } \\
\text { Centenário, } \\
\text { próximo ao } \\
\text { cruzamento com a } \\
\text { Estrada Monte } \\
\text { Alegre, em frente à } \\
\text { "Nova Mercantil } \\
\text { Veículos" }\end{array}$ & 0,00 & 0,00 & 0,00 & 0,00 & 0,00 & 0,00 & 0,000 \\
\hline $\begin{array}{l}\text { 13. Estrada Monte } \\
\text { Alegre, próximo à } \\
\text { entrada da } \\
\text { Engenharia }\end{array}$ & 0,00 & 0,00 & 0,00 & 0,00 & 0,00 & 0,00 & 0,000 \\
\hline $\begin{array}{l}\text { Utilizo um ponto } \\
\text { de ônibus próximo } \\
\text { ao campus que } \\
\text { não está na lista. }\end{array}$ & 0,33 & 0,00 & 1,00 & 1,00 & 1,00 & 1,00 & 0,682 \\
\hline
\end{tabular}


Você presenciou ou sofreu algum tipo de violência ou assédio NO ENTORNO da ESALQ/CENA?

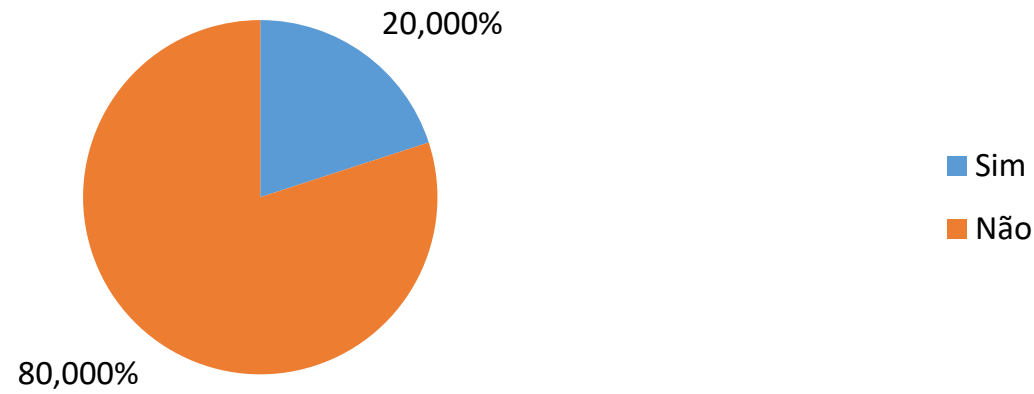

\begin{tabular}{lll} 
Sim $20 \%$ & 2 \\
\hline Não & $80 \%$ & 8
\end{tabular}

Que tipo de violência ou assédio você presenciou ou sofreu NO ENTORNO da ESALQ/CENA? (se for necessário, marque mais de uma alternativa)

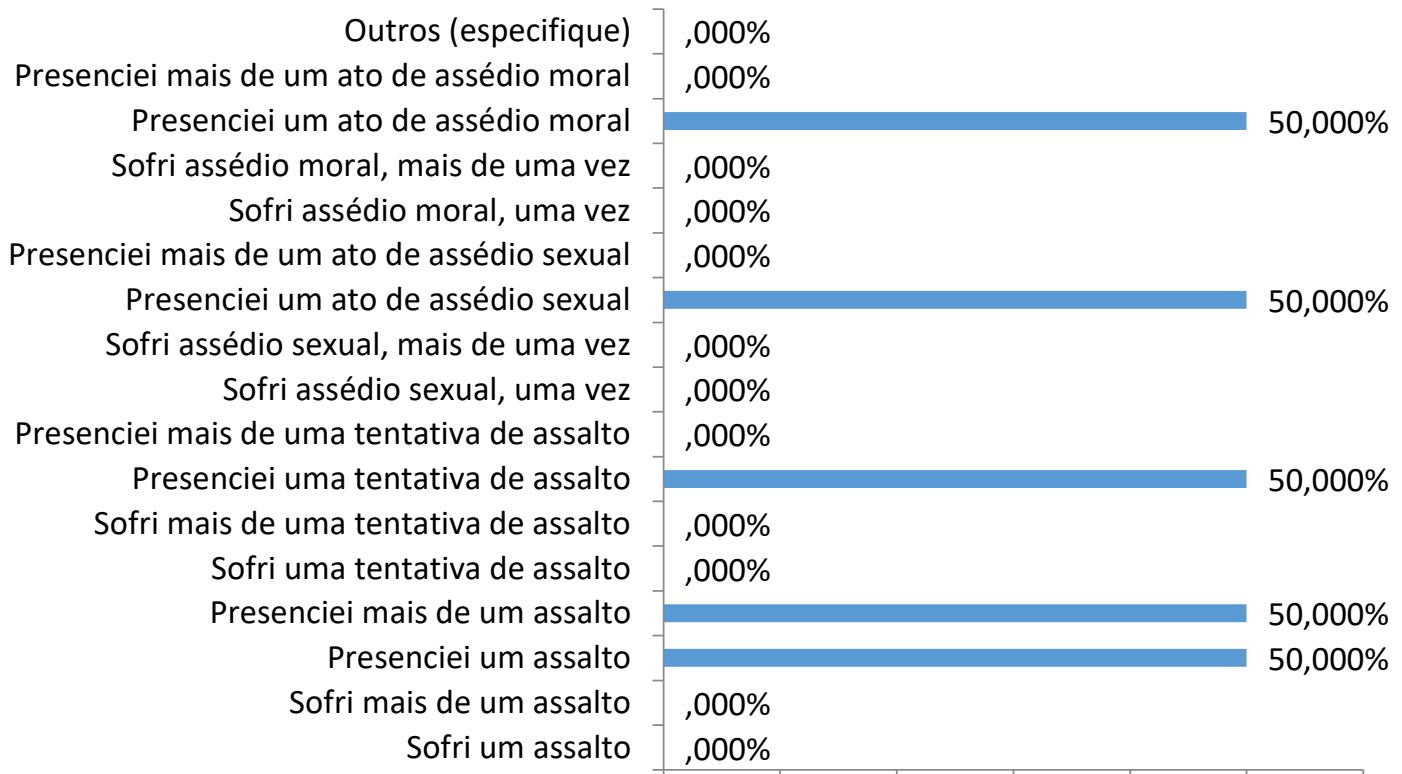

,000\% 10,000\%20,000\%30,000\%40,000\%50,000\%60,000\% 


\begin{tabular}{lcc} 
Sofri um assalto & $0 \%$ & 0 \\
\hline Sofri mais de um assalto & $0 \%$ & 0 \\
\hline Presenciei um assalto & $50 \%$ & 1 \\
\hline Presenciei mais de um assalto & $50 \%$ & 1 \\
\hline Sofri uma tentativa de assalto & $0 \%$ & 0 \\
\hline Sofri mais de uma tentativa de assalto & $0 \%$ & 0 \\
\hline Presenciei uma tentativa de assalto & $50 \%$ & 1 \\
\hline Presenciei mais de uma tentativa de assalto & $0 \%$ & 0 \\
\hline Sofri assédio sexual, uma vez & $0 \%$ & 0 \\
\hline Sofri assédio sexual, mais de uma vez & $0 \%$ & 0 \\
\hline Presenciei um ato de assédio sexual & $50 \%$ & 1 \\
\hline Presenciei mais de um ato de assédio sexual & $0 \%$ & 0 \\
\hline Sofri assédio moral, uma vez & $0 \%$ & 0 \\
\hline Sofri assédio moral, mais de uma vez & $0 \%$ & 0 \\
\hline Presenciei um ato de assédio moral & $50 \%$ & 1 \\
\hline Presenciei mais de um ato de assédio moral & $0 \%$ & 0 \\
\hline Outros (especifique) & $0 \%$ & 0
\end{tabular}

Com relação a medidas de segurança no ENTORNO e DENTRO da ESALQ/CENA, você é favorável a (se for necessário, marque mais de uma alternativa):

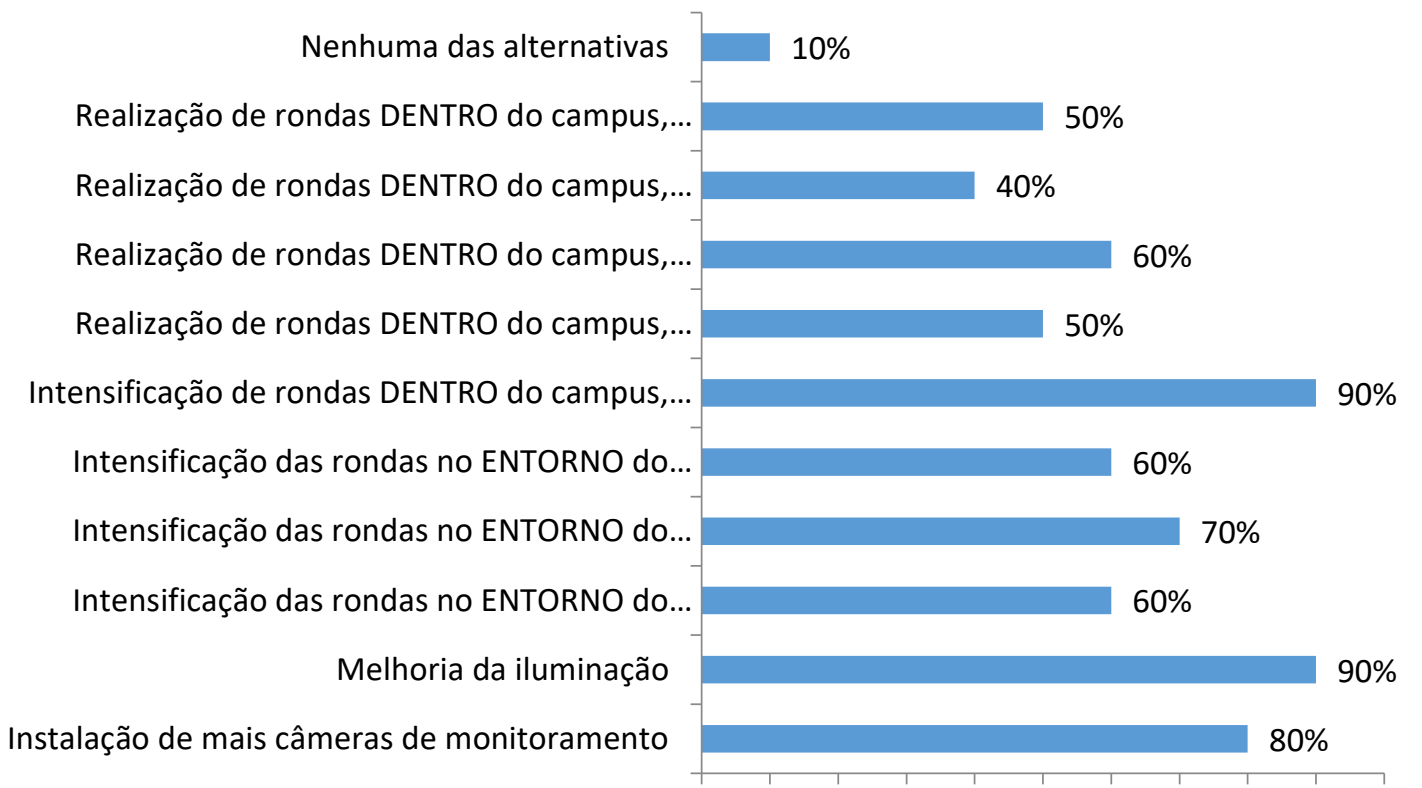

0\% 10\% 20\% 30\% 40\% 50\% 60\% 70\% 80\% 90\%100\% 


\begin{tabular}{llr} 
Instalação de mais câmeras de monitoramento & $80 \%$ & 8 \\
\hline Melhoria da iluminação & $90 \%$ & 9 \\
\hline $\begin{array}{l}\text { Intensificação das rondas no ENTORNO do campus, pela Guarda Universitária } \\
\text { (PPUSP) }\end{array}$ & $60 \%$ & 6 \\
\hline Intensificação das rondas no ENTORNO do campus, pela Policia Militar & $70 \%$ & 7 \\
\hline Intensificação das rondas no ENTORNO do campus, pela Guarda Municipal & $60 \%$ & 6 \\
\hline Intensificação de rondas DENTRO do campus, pela Guarda Universitária (PPUSP) & $90 \%$ & 9 \\
\hline Realização de rondas DENTRO do campus, pela Policia Militar & $50 \%$ & 5 \\
\hline $\begin{array}{l}\text { Realização de rondas DENTRO do campus, pela Policia Militar, mas somente nos } \\
\text { horários mais críticos como à noite e durante grandes eventos }\end{array}$ & $60 \%$ & 6 \\
\hline Realização de rondas DENTRO do campus, pela Guarda Municipal & $40 \%$ & 4 \\
\hline $\begin{array}{l}\text { Realização de rondas DENTRO do campus, pela Guarda Municipal, mas somente } \\
\text { nos horários mais críticos como à noite e durante grandes eventos }\end{array}$ & $50 \%$ & 5 \\
\hline Nenhuma das alternativas & $10 \%$ & 1
\end{tabular}

\section{Como você descreveria o trajeto do seu ponto de origem até o campus Luiz de Queiroz (ESALQ/CENA)?}

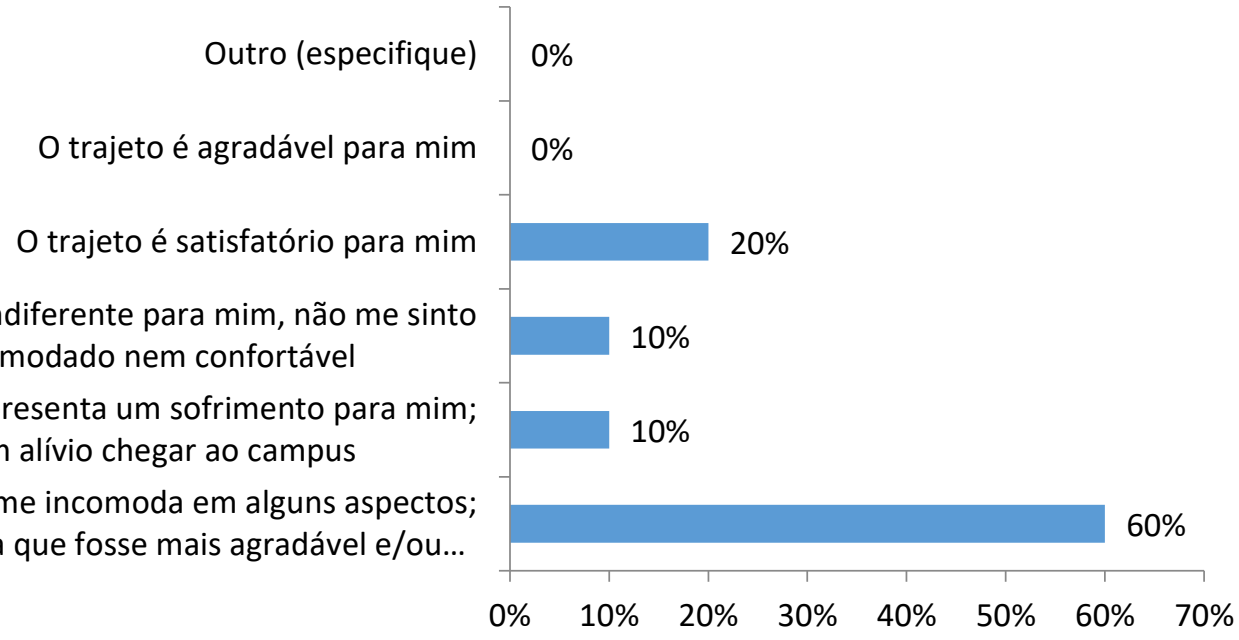

O trajeto me incomoda em alguns aspectos; gostaria que fosse mais agradável e/ou menos demorado $60 \% \quad 6$

\begin{tabular}{lrr}
\hline O trajeto representa um sofrimento para mim; é um alívio chegar ao campus & $10 \%$ & 1 \\
\hline O trajeto é indiferente para mim, não me sinto incomodado nem confortável & $10 \%$ & 1 \\
\hline O trajeto é satisfatório para mim & $20 \%$ & 2 \\
\hline O trajeto é agradável para mim & $0 \%$ & 0 \\
\hline Outro (especifique) & $0 \%$ & 0
\end{tabular}


Na sua opinião, qual a importância destes aspectos para uma mobilidade mais sustentável na USP de Piracicaba? Ordene os temas marcando-os com os respectivos números ou arrastando as caixas de acordo com a prioridade (no topo, o mais importante)

\section{Média}

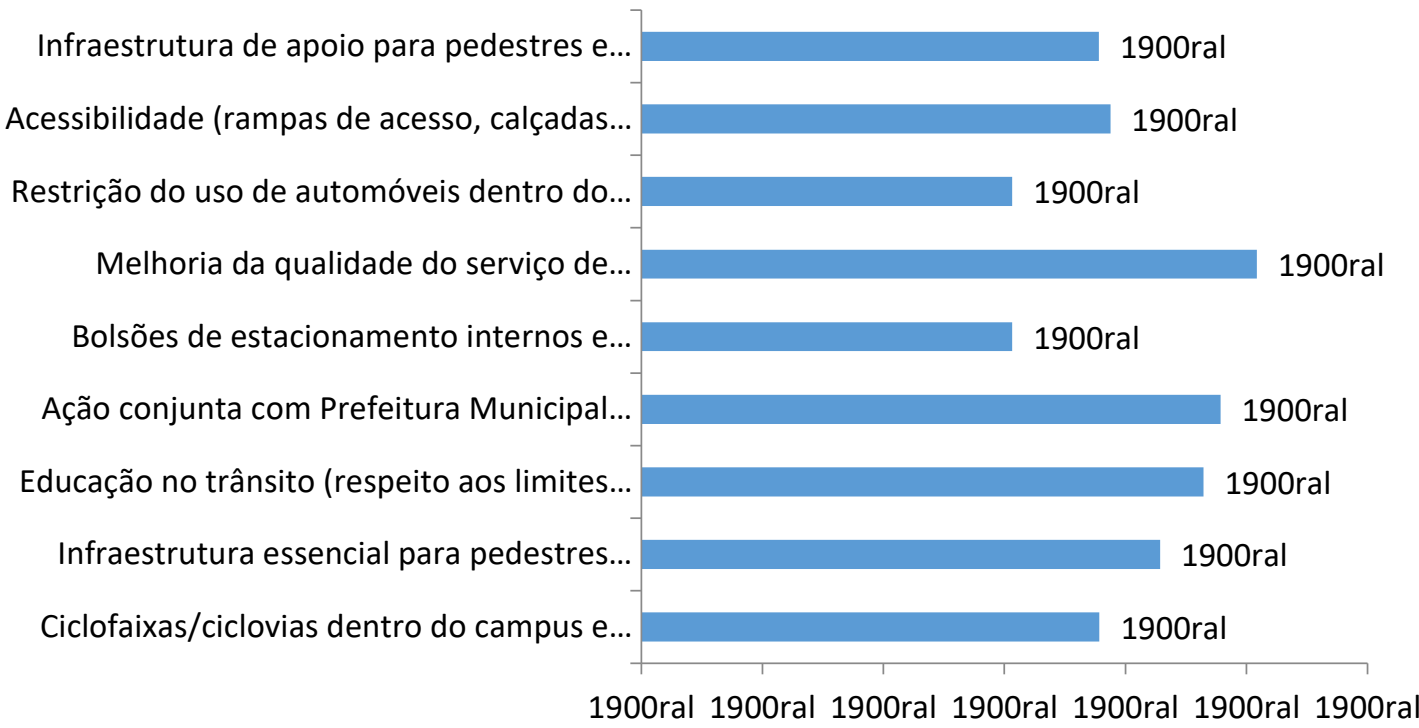




\begin{tabular}{|c|c|c|c|c|c|c|c|c|c|c|}
\hline & 1 & 2 & 3 & 4 & 5 & 6 & 7 & 8 & 9 & 10 \\
\hline $\begin{array}{l}\text { Ciclofaixas/ciclovias dentro } \\
\text { do campus e para acesso ao } \\
\text { mesmo }\end{array}$ & $14 \%$ & $0 \%$ & $14 \%$ & $0 \%$ & $0 \%$ & $29 \%$ & $29 \%$ & $14 \%$ & $0 \%$ & $0 \%$ \\
\hline $\begin{array}{l}\text { Infraestrutura essencial para } \\
\text { pedestres (calçadas } \\
\text { adequadas, iluminação, } \\
\text { arborização, sinalização, } \\
\text { etc.) }\end{array}$ & $0 \%$ & $0 \%$ & $29 \%$ & $29 \%$ & $29 \%$ & $0 \%$ & $14 \%$ & $0 \%$ & $0 \%$ & $0 \%$ \\
\hline $\begin{array}{l}\text { Educação no trânsito } \\
\text { (respeito aos limites } \\
\text { de velocidade e à } \\
\text { sinalização, melhor convívio } \\
\text { entre motoristas, ciclistas e } \\
\text { pedestres, etc.) }\end{array}$ & $29 \%$ & $29 \%$ & $0 \%$ & $14 \%$ & $0 \%$ & $0 \%$ & $14 \%$ & $0 \%$ & $14 \%$ & $0 \%$ \\
\hline $\begin{array}{l}\text { Ação conjunta com } \\
\text { Prefeitura Municipal para } \\
\text { melhoria da mobilidade na } \\
\text { ligação entre cidade e } \\
\text { campus }\end{array}$ & $14 \%$ & $43 \%$ & $0 \%$ & $0 \%$ & $14 \%$ & $29 \%$ & $0 \%$ & $0 \%$ & $0 \%$ & $0 \%$ \\
\hline $\begin{array}{l}\text { Bolsões de estacionamento } \\
\text { internos e externos ao } \\
\text { campus }\end{array}$ & $0 \%$ & $0 \%$ & $0 \%$ & $13 \%$ & $25 \%$ & $0 \%$ & $0 \%$ & $50 \%$ & $13 \%$ & $0 \%$ \\
\hline $\begin{array}{l}\text { Melhoria da qualidade do } \\
\text { serviço de transporte público } \\
\text { da cidade }\end{array}$ & $50 \%$ & $0 \%$ & $17 \%$ & $17 \%$ & $0 \%$ & $0 \%$ & $17 \%$ & $0 \%$ & $0 \%$ & $0 \%$ \\
\hline $\begin{array}{l}\text { Restrição do uso de } \\
\text { automóveis dentro do } \\
\text { campus }\end{array}$ & $13 \%$ & $13 \%$ & $0 \%$ & $0 \%$ & $0 \%$ & $0 \%$ & $0 \%$ & $25 \%$ & $50 \%$ & $0 \%$ \\
\hline $\begin{array}{l}\text { Acessibilidade (rampas de } \\
\text { acesso, calçadas } \\
\text { adequadas, elevadores, piso } \\
\text { tátil, respeito a vagas de } \\
\text { estacionamento prioritárias, } \\
\text { etc.) }\end{array}$ & $0 \%$ & $0 \%$ & $25 \%$ & $13 \%$ & $13 \%$ & $25 \%$ & $13 \%$ & $13 \%$ & $0 \%$ & $0 \%$ \\
\hline $\begin{array}{l}\text { Infraestrutura de apoio para } \\
\text { pedestres e ciclistas } \\
\text { (bebedouros, bancos, } \\
\text { vestiários, guarda-volume, } \\
\text { bicicletários, oficina para } \\
\text { consertos, etc.) }\end{array}$ & $0 \%$ & $11 \%$ & $11 \%$ & $22 \%$ & $11 \%$ & $11 \%$ & $11 \%$ & $0 \%$ & $22 \%$ & $0 \%$ \\
\hline
\end{tabular}




\section{Modo: Van}

\section{Analisando o campus da ESALQ/CENA como um todo, você o considera acessível aos usuários com algum tipo de restrição de mobilidade?}

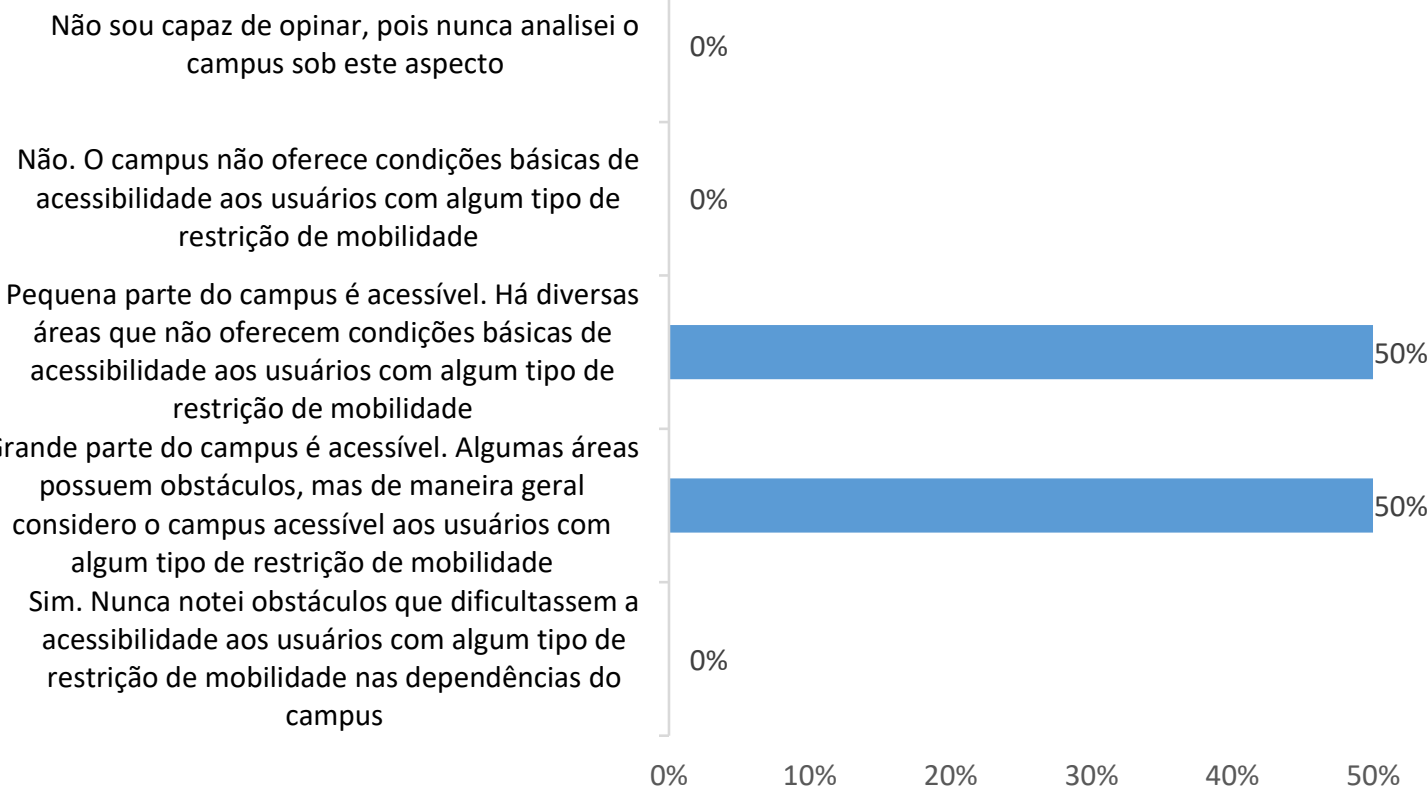

Sim. Nunca notei obstáculos que dificultassem a acessibilidade aos usuários com algum tipo de restrição de mobilidade nas dependências do campus $0 \% \quad 0$ Grande parte do campus é acessível. Algumas áreas possuem obstáculos, mas de maneira geral considero o campus acessível aos usuários com algum tipo de restrição de mobilidade $50 \% \quad 1$ Pequena parte do campus é acessível. Há diversas áreas que não oferecem condições básicas de acessibilidade aos usuários com algum tipo de restrição de mobilidade

Não. O campus não oferece condições básicas de acessibilidade aos usuários com algum tipo de restrição de mobilidade

Não sou capaz de opinar, pois nunca analisei o campus sob este aspecto

\begin{tabular}{ll}
$0 \%$ & 0 \\
\hline $0 \%$ & 0
\end{tabular}


Dentre os prédios que frequenta na ESALQ/CENA, como você avalia a acessibilidade para os usuários com algum tipo de restrição de mobilidade?

Não sou capaz de avaliar, pois nunca analisei os prédios da ESALQ/CENA sob este aspecto

Ruim. Prédios não equipados para receber os usuários com algum tipo de restrição de mobilidade

Regular. Prédios pouco equipados, com limitações para atender os usuários com algum tipo de restrição de mobilidade

Boa. Prédios parcialmente equipados, mas possuem condições satisfatórias para atender os usuários com algum tipo de restrição de mobilidade

Ótima. Prédios totalmente equipados para receber os usuários com algum tipo de restrição de mobilidade
$0 \%$

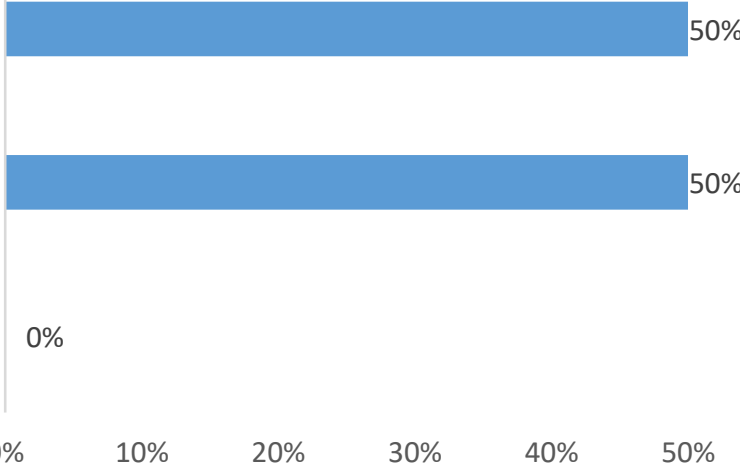

Ótima. Prédios totalmente equipados para receber os usuários com algum tipo de restrição de mobilidade $0 \% \quad 0$ Boa. Prédios parcialmente equipados, mas possuem condições satisfatórias para atender os usuários com algum tipo de restrição de mobilidade $50 \% \quad 1$ Regular. Prédios pouco equipados, com limitações para atender os usuários com algum tipo de restrição de mobilidade

$50 \% \quad 1$

Ruim. Prédios não equipados para receber os usuários com algum tipo de restrição de mobilidade

$0 \% \quad 0$
Não sou capaz de avaliar, pois nunca analisei os prédios da ESALQ/CENA sob este aspecto

$0 \% \quad 0$


$\mathrm{Na}$ etapa anterior do questionário, você nos informou que seu modo principal para os deslocamentos à ESALQ/CENA é a VAN OPERADA PELA USP (Vila Estudantil). Quais fatores o/a levam a optar por este modo?

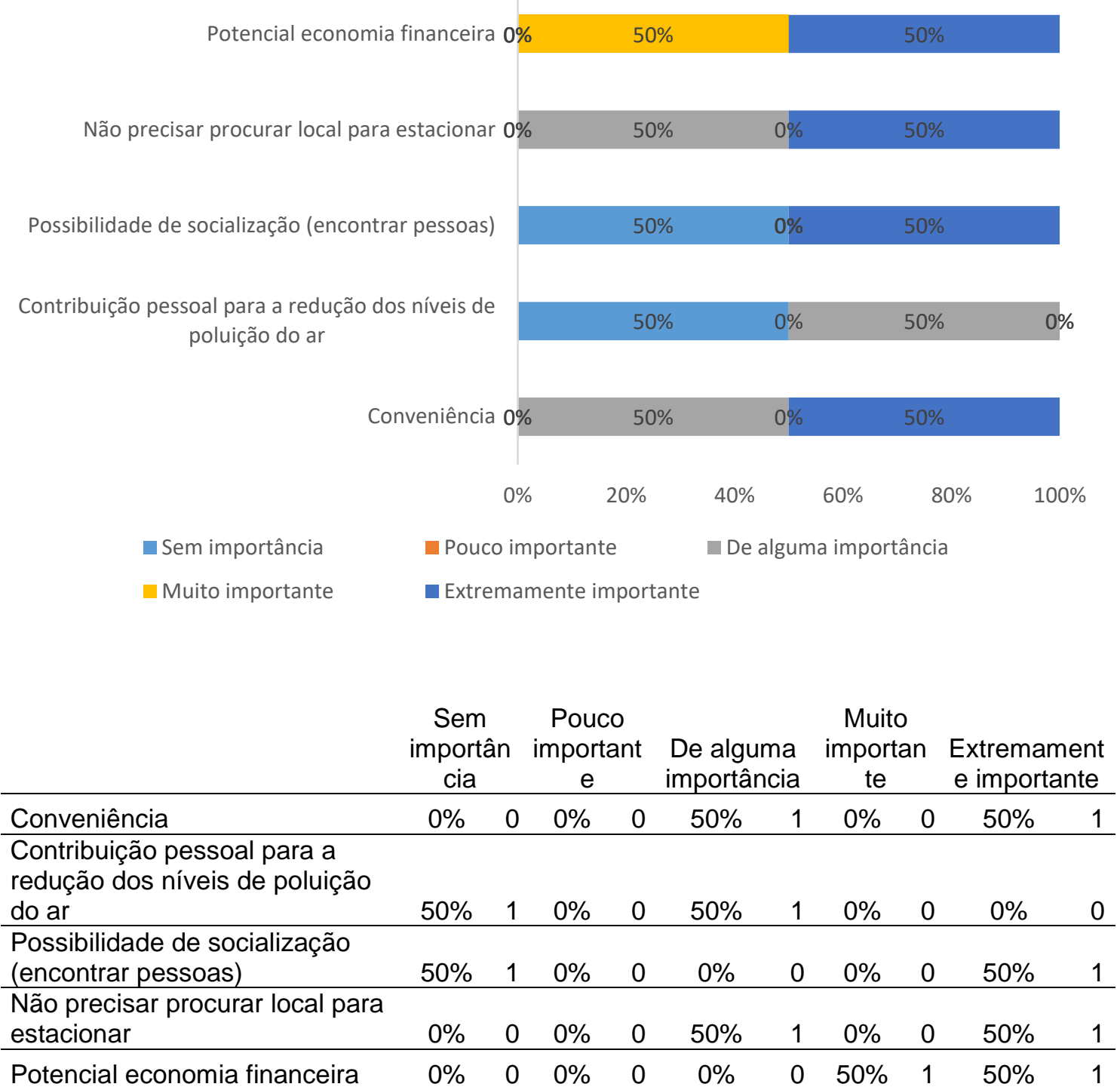




\section{Quais fatores o/a desestimulam a utilizar os demais modos que não a van operada pela} USP em seus deslocamentos?

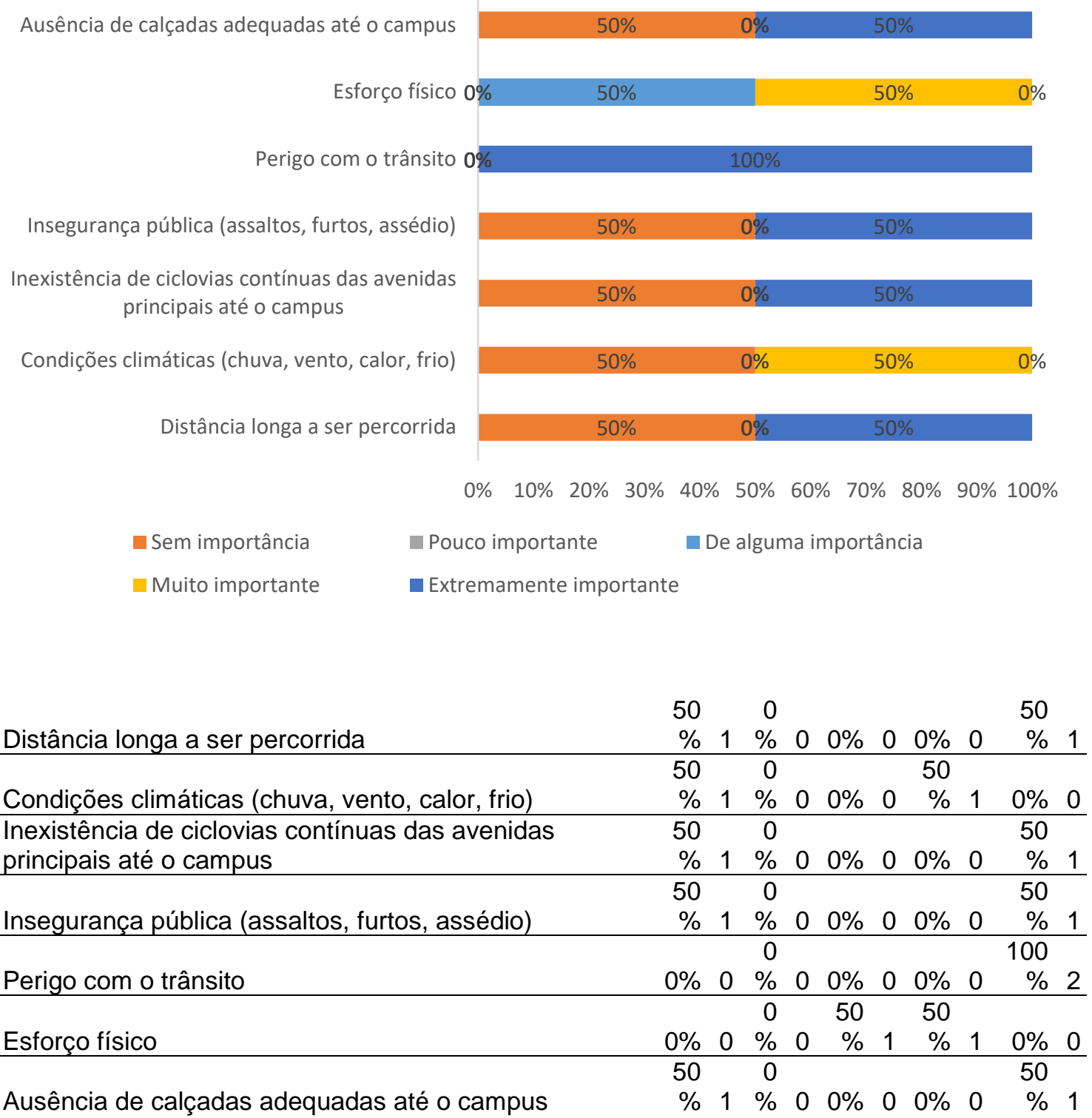


Há quanto tempo você utiliza a van operada pela USP para se deslocar até a ESALQ/CENA?

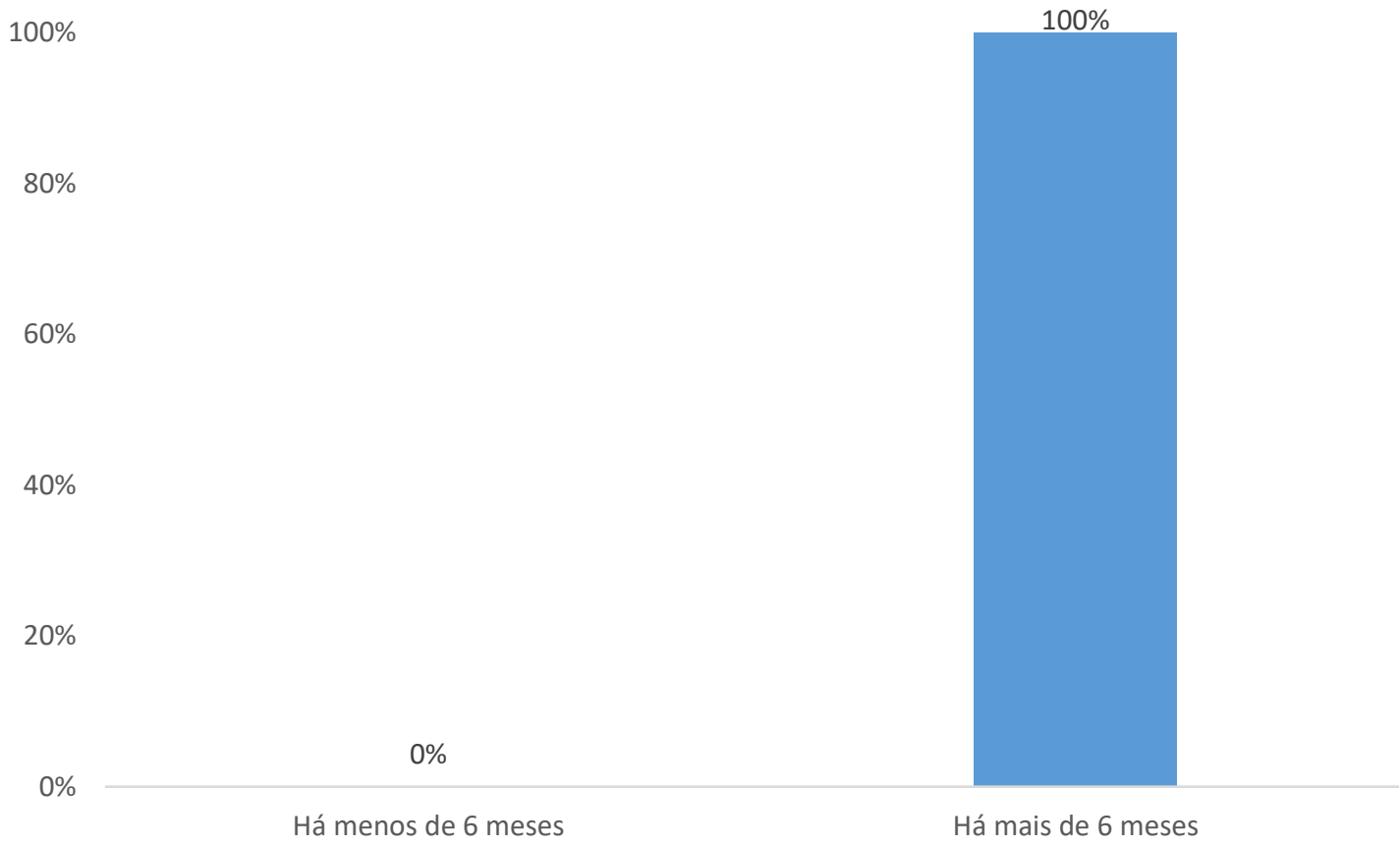

\begin{tabular}{lrr} 
Há menos de 6 meses & $0 \%$ & 0 \\
\hline Há mais de 6 meses & $100 \%$ & 2
\end{tabular}

Dos deslocamentos que você faz hoje com a van operada pela USP, qual modo você utilizava antes?

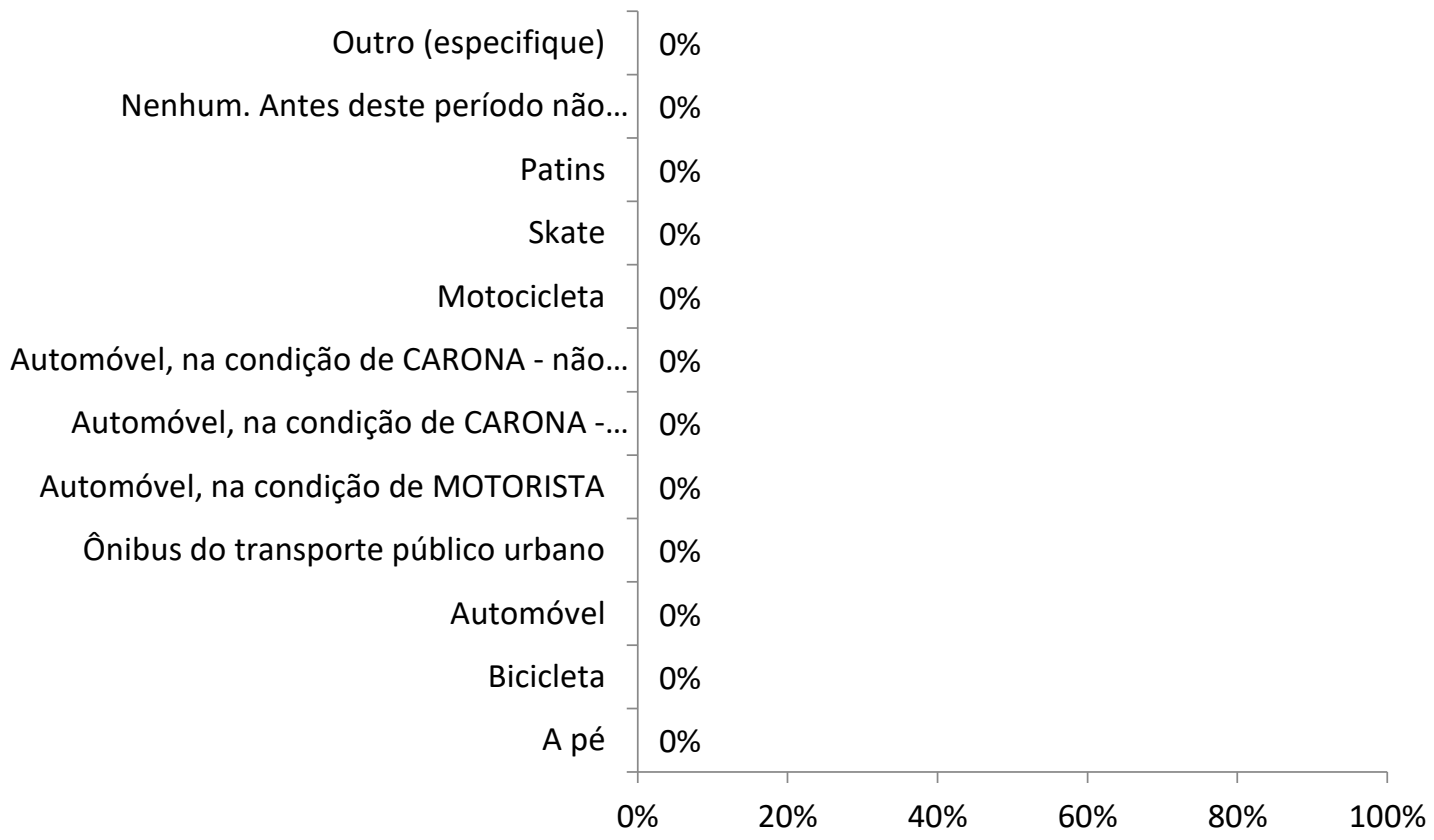


Bicicleta $0 \%$

Automóvel

$0 \%$
0

Ônibus do transporte público urbano

$0 \%$

Automóvel, na condição de MOTORISTA

$0 \%$

0

Automóvel, na condição de CARONA - estaciona no campus

$0 \%$

$0 \% \quad 0$

Automóvel, na condição de CARONA - não estaciona no campus

Motocicleta

$0 \%$

\begin{tabular}{ll}
$0 \%$ & 0 \\
\hline $0 \%$ & 0 \\
\hline $0 \%$ & 0 \\
\hline $0 \%$ & 0 \\
\hline $0 \%$ & 0
\end{tabular}

0

Skate

Patins

Nenhum. Antes deste período não frequentava o campus

Outro (especifique)

\section{Como você avalia a frequência de atendimento?}

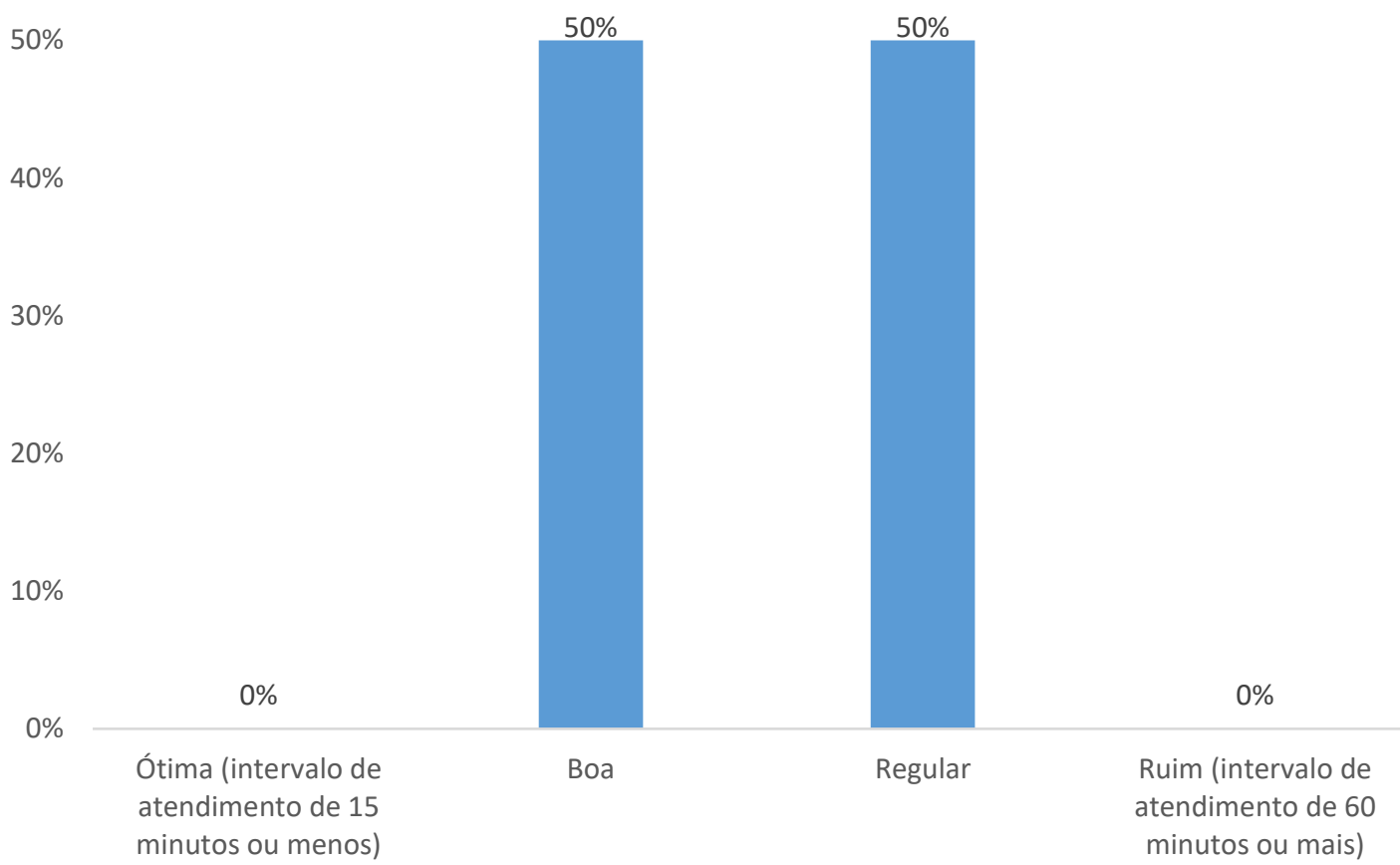

Ótima (intervalo de atendimento de 15 minutos ou menos) 


\section{Como você avalia a pontualidade?}
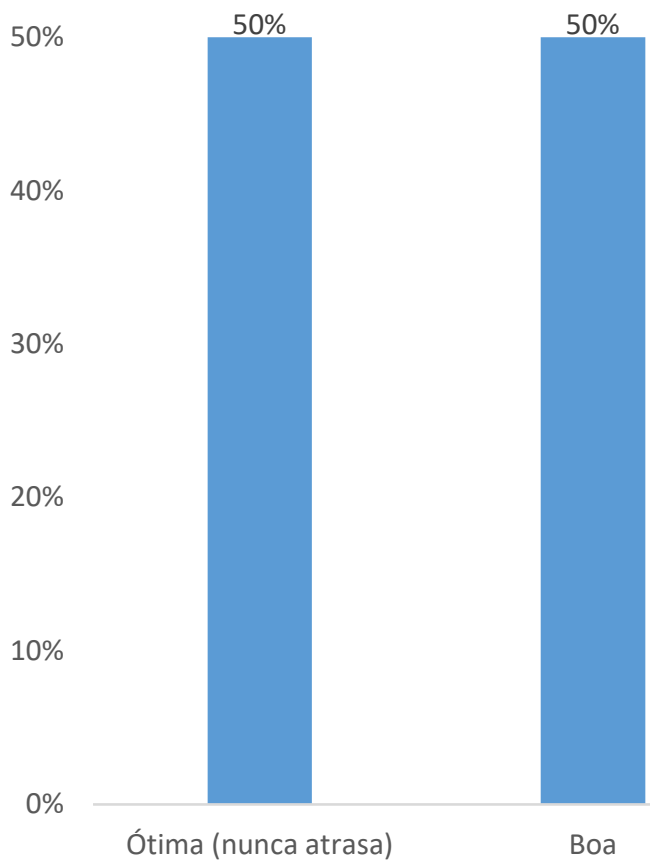

$0 \%$ $0 \%$

Ótima (nunca atrasa) $\quad 50 \% \quad 1$

\begin{tabular}{lrr} 
Boa & $50 \%$ & 1 \\
\hline Regular & $0 \%$ & 0 \\
\hline Ruim (sempre atrasa) & $0 \%$ & 0
\end{tabular}




\section{Como você avalia o tempo de viagem?}

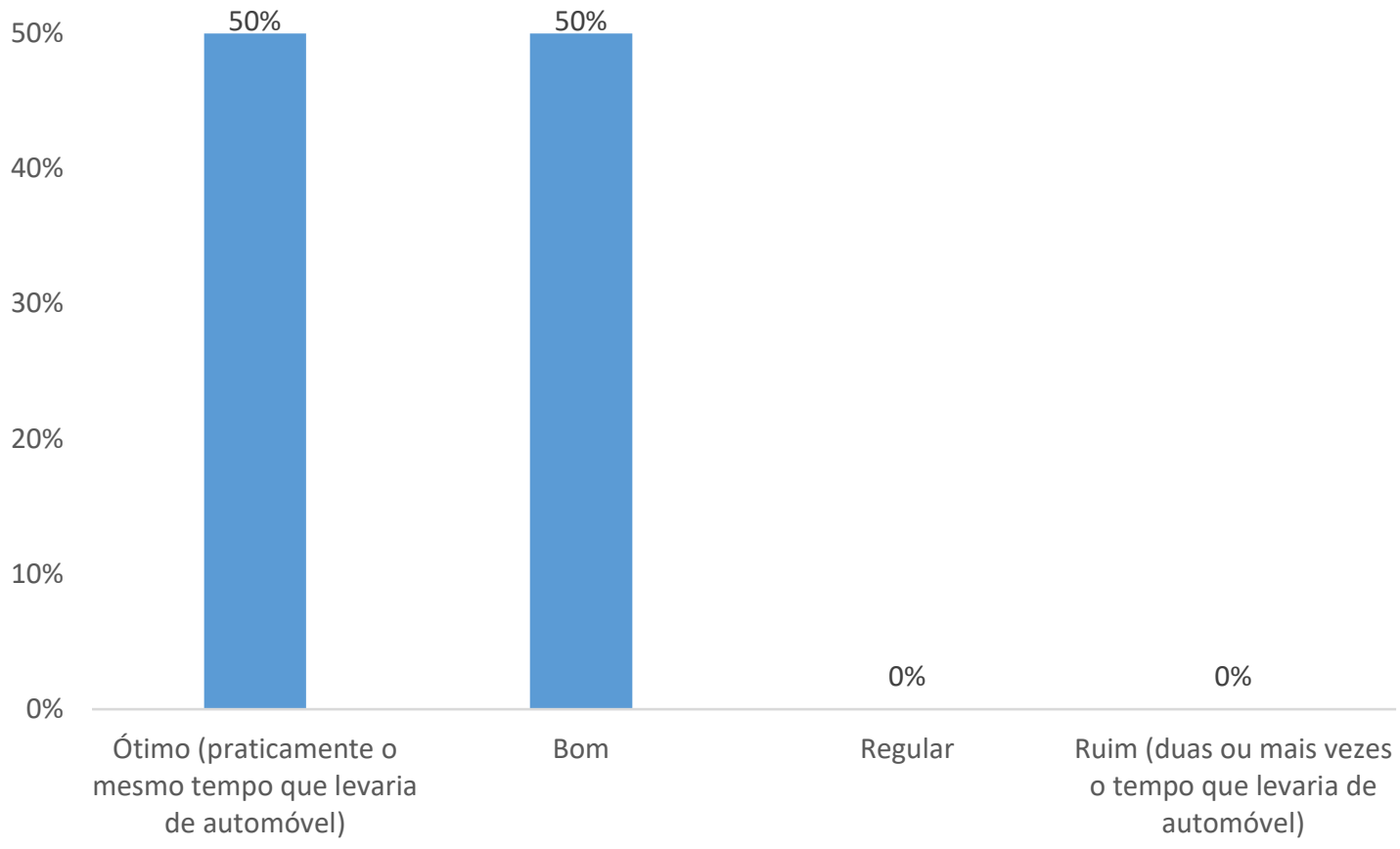

Ótimo (praticamente o mesmo tempo que levaria de automóvel) $50 \% 1$

\begin{tabular}{lrl} 
Bom & $50 \%$ & 1 \\
\hline Regular & $0 \%$ & 0 \\
\hline Ruim (duas ou mais vezes o tempo que levaria de automóvel) & $\begin{array}{lll}0 \% & 0\end{array}$
\end{tabular}


Como você avalia a lotação dos veículos?

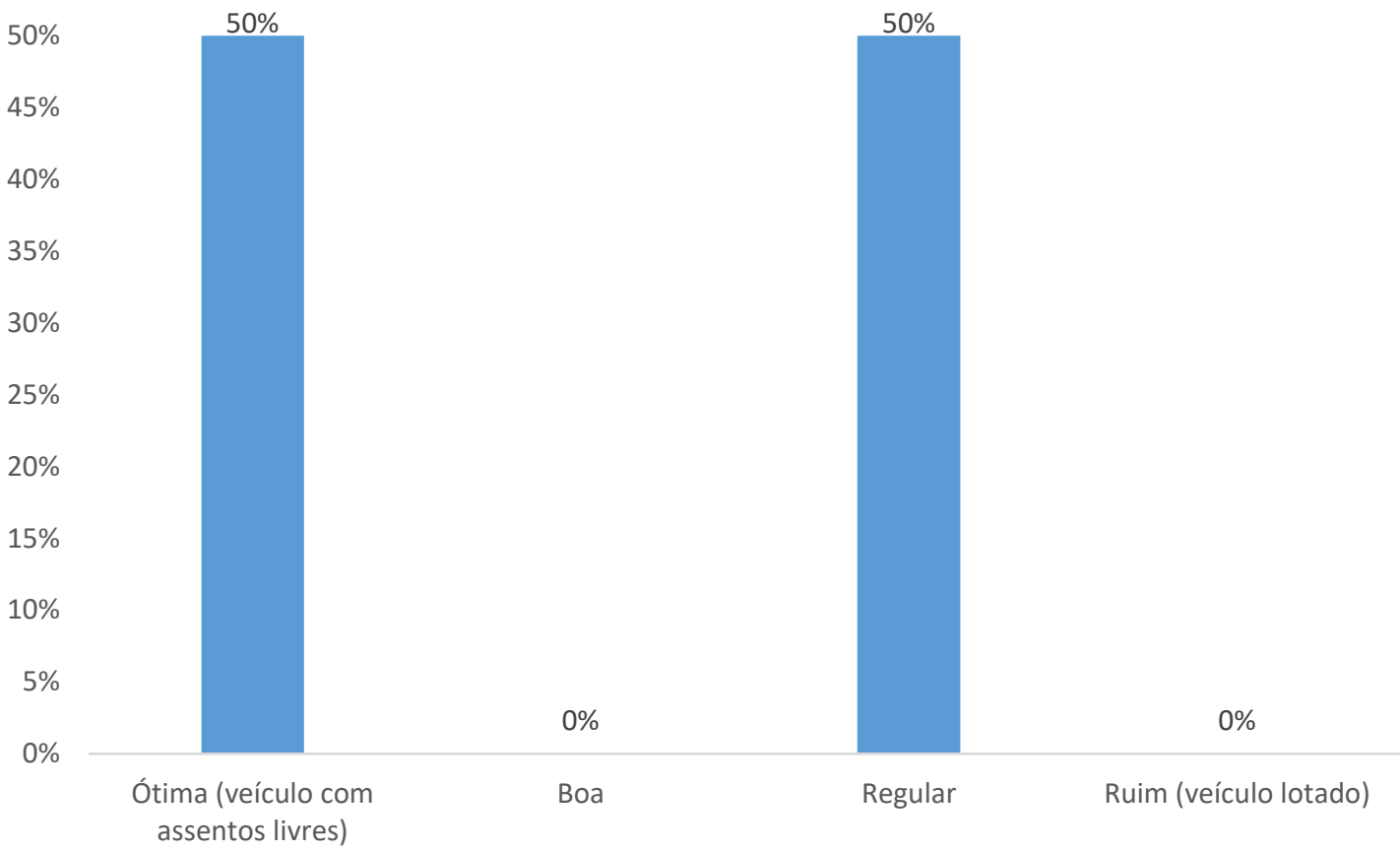

\begin{tabular}{lrr} 
Ótima (veículo com assentos livres) & $50 \%$ & 1 \\
\hline Boa & $0 \%$ & 0 \\
\hline Regular & $50 \%$ & 1 \\
\hline Ruim (veículo lotado) & $0 \%$ & 0
\end{tabular}

Classifique, somente para os turnos em que você costuma acessar ou se deslocar $A O$ REDOR da ESALQ/CENA, qual a sua sensação de segurança em relação a assaltos e outros tipos de violência ou assédio:

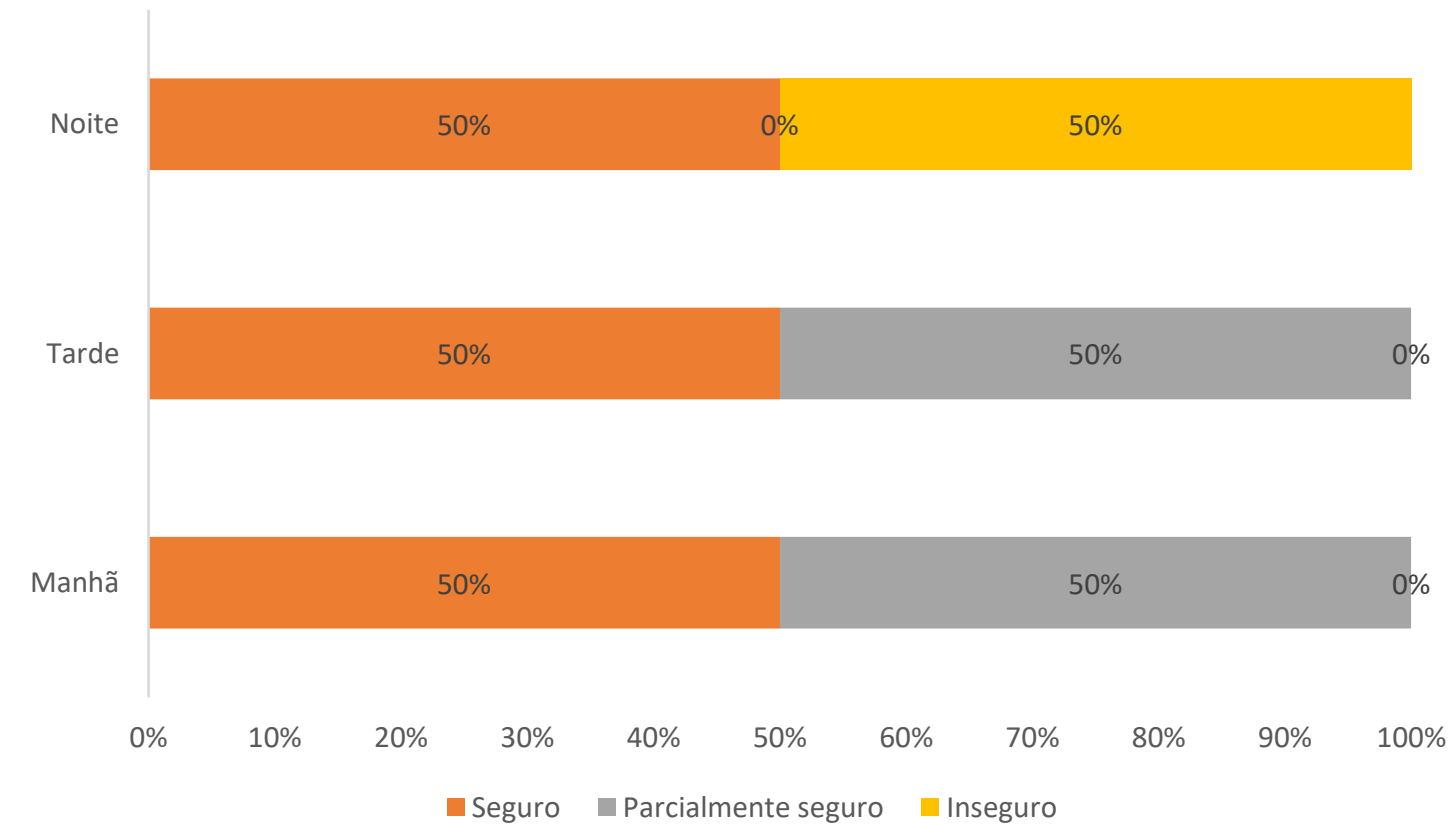


Seguro Parcialmente seguro Inseguro

\begin{tabular}{lrrrrrr}
\hline Manhã & $50 \%$ & 1 & $50 \%$ & 1 & $0 \%$ & 0 \\
\hline Tarde & $50 \%$ & 1 & $50 \%$ & 1 & $0 \%$ & 0 \\
\hline Noite & $50 \%$ & 1 & $0 \%$ & 0 & $50 \%$ & 1
\end{tabular}

Você presenciou ou sofreu algum tipo de violência ou assédio NO ENTORNO da ESALQ/CENA?

$100 \%$

$80 \%$

$60 \%$

$40 \%$

$20 \%$

0\%

$0 \%$

$\operatorname{Sim}$

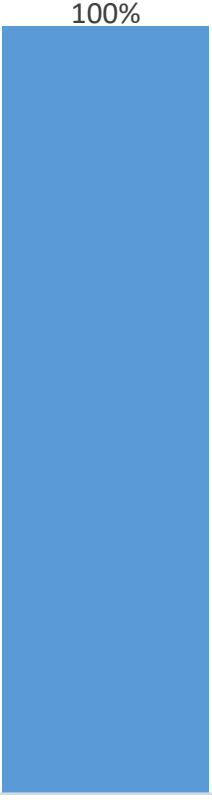

Não

Sim $0 \% \quad 0$

Não $100 \% 2$ 


\section{Que tipo de violência ou assédio você presenciou ou sofreu NO ENTORNO da} ESALQ/CENA? (se for necessário, marque mais de uma alternativa)

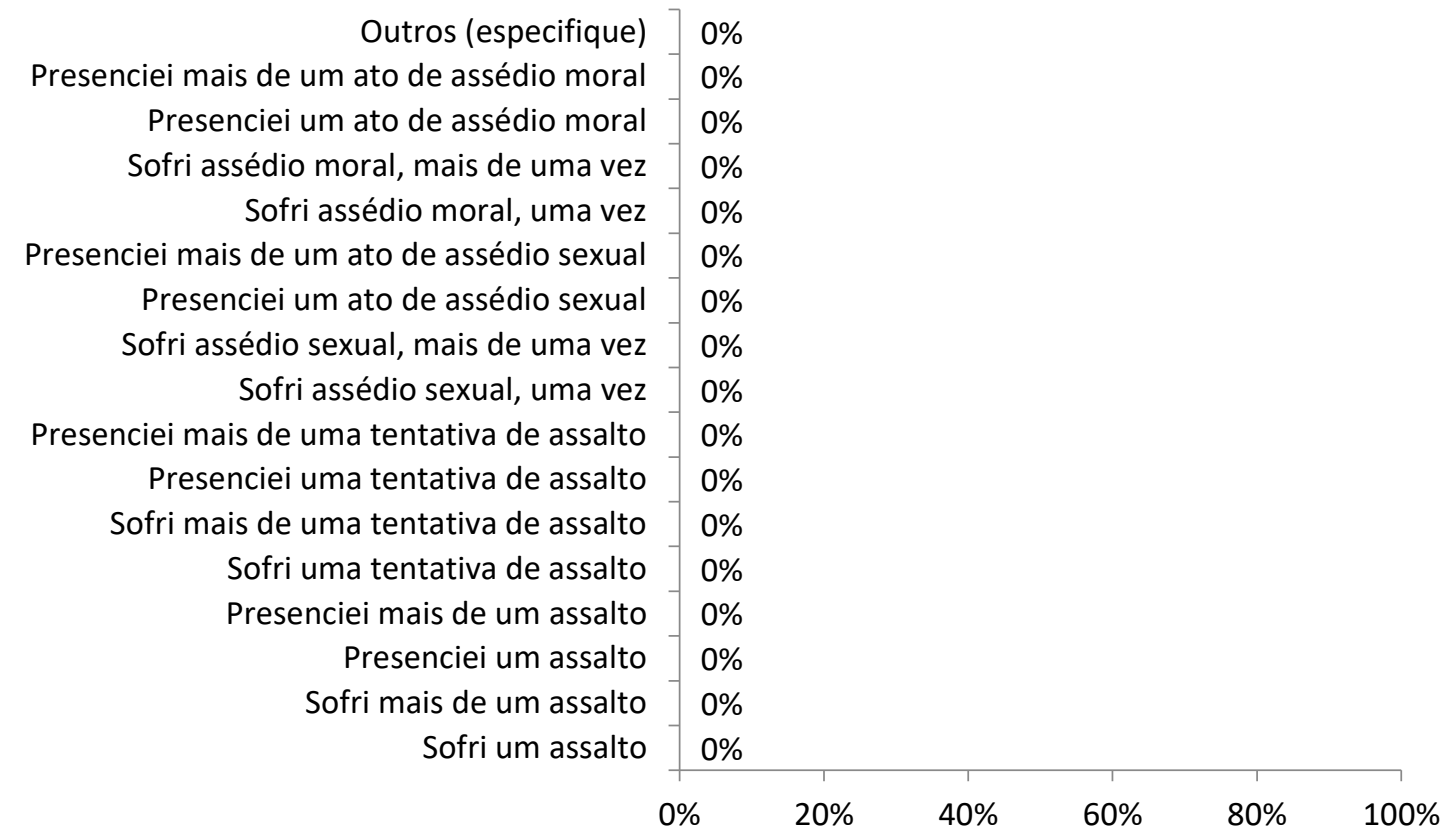

\begin{tabular}{lll} 
Sofri um assalto & $0 \%$ & 0 \\
\hline Sofri mais de um assalto & $0 \%$ & 0 \\
\hline Presenciei um assalto & $0 \%$ & 0 \\
\hline Presenciei mais de um assalto & $0 \%$ & 0 \\
\hline Sofri uma tentativa de assalto & $0 \%$ & 0 \\
\hline Sofri mais de uma tentativa de assalto & $0 \%$ & 0 \\
\hline Presenciei uma tentativa de assalto & $0 \%$ & 0 \\
\hline Presenciei mais de uma tentativa de assalto & $0 \%$ & 0 \\
\hline Sofri assédio sexual, uma vez & $0 \%$ & 0 \\
\hline Sofri assédio sexual, mais de uma vez & $0 \%$ & 0 \\
\hline Presenciei um ato de assédio sexual & $0 \%$ & 0 \\
\hline Presenciei mais de um ato de assédio sexual & $0 \%$ & 0 \\
\hline Sofri assédio moral, uma vez & $0 \%$ & 0 \\
\hline Sofri assédio moral, mais de uma vez & $0 \%$ & 0 \\
\hline Presenciei um ato de assédio moral & $0 \%$ & 0 \\
\hline Presenciei mais de um ato de assédio moral & $0 \%$ & 0 \\
\hline Outros (especifique) & $0 \%$ & 0
\end{tabular}


Classifique, somente para os turnos em que você costuma acessar ou se deslocar DENTRO da ESALQ/CENA, qual a sua sensação de segurança em relação a assaltos e outros tipos de violência ou assédio:

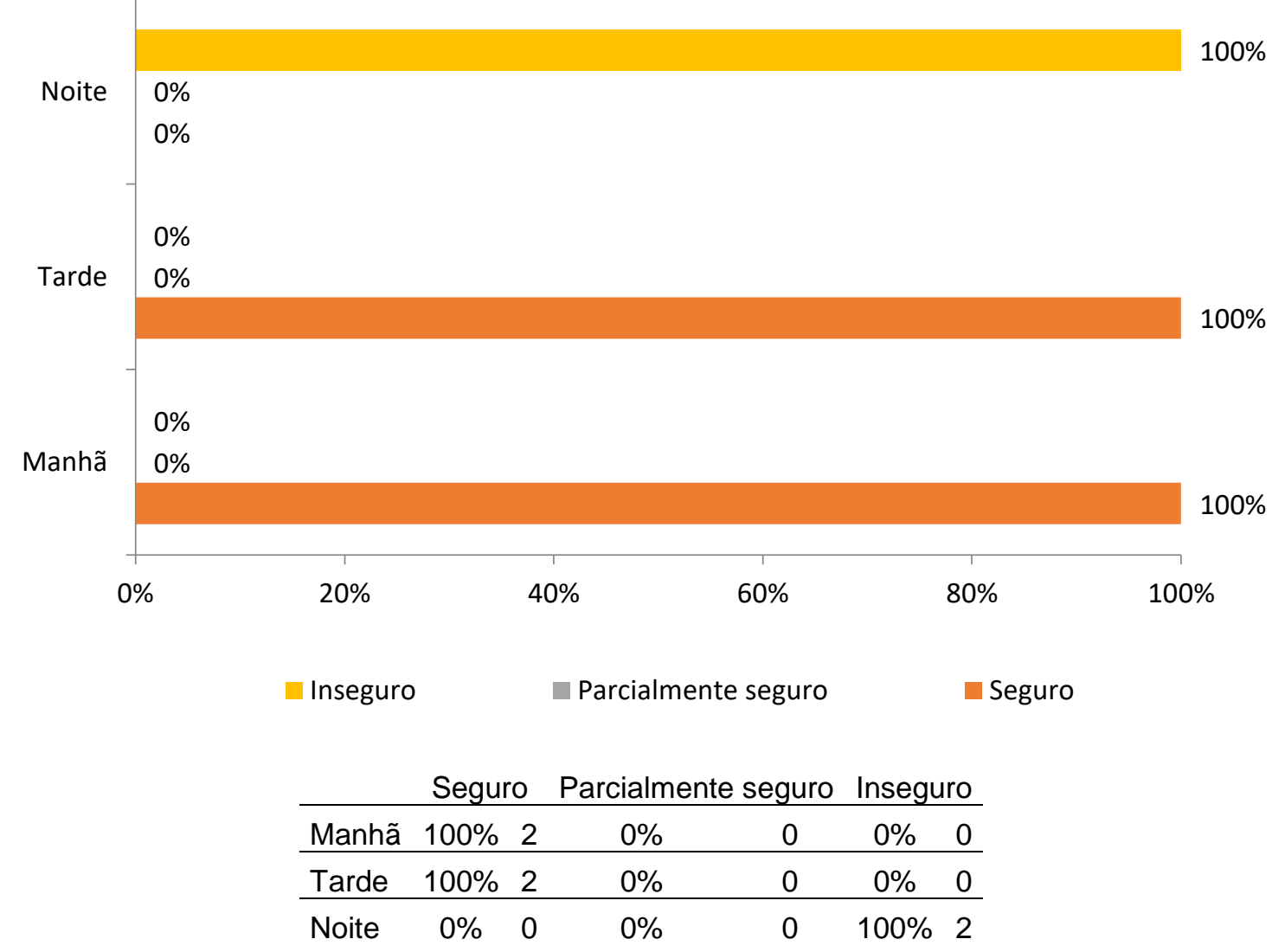


Você presenciou ou sofreu algum tipo de violência ou assédio DENTRO da ESALQ/CENA?

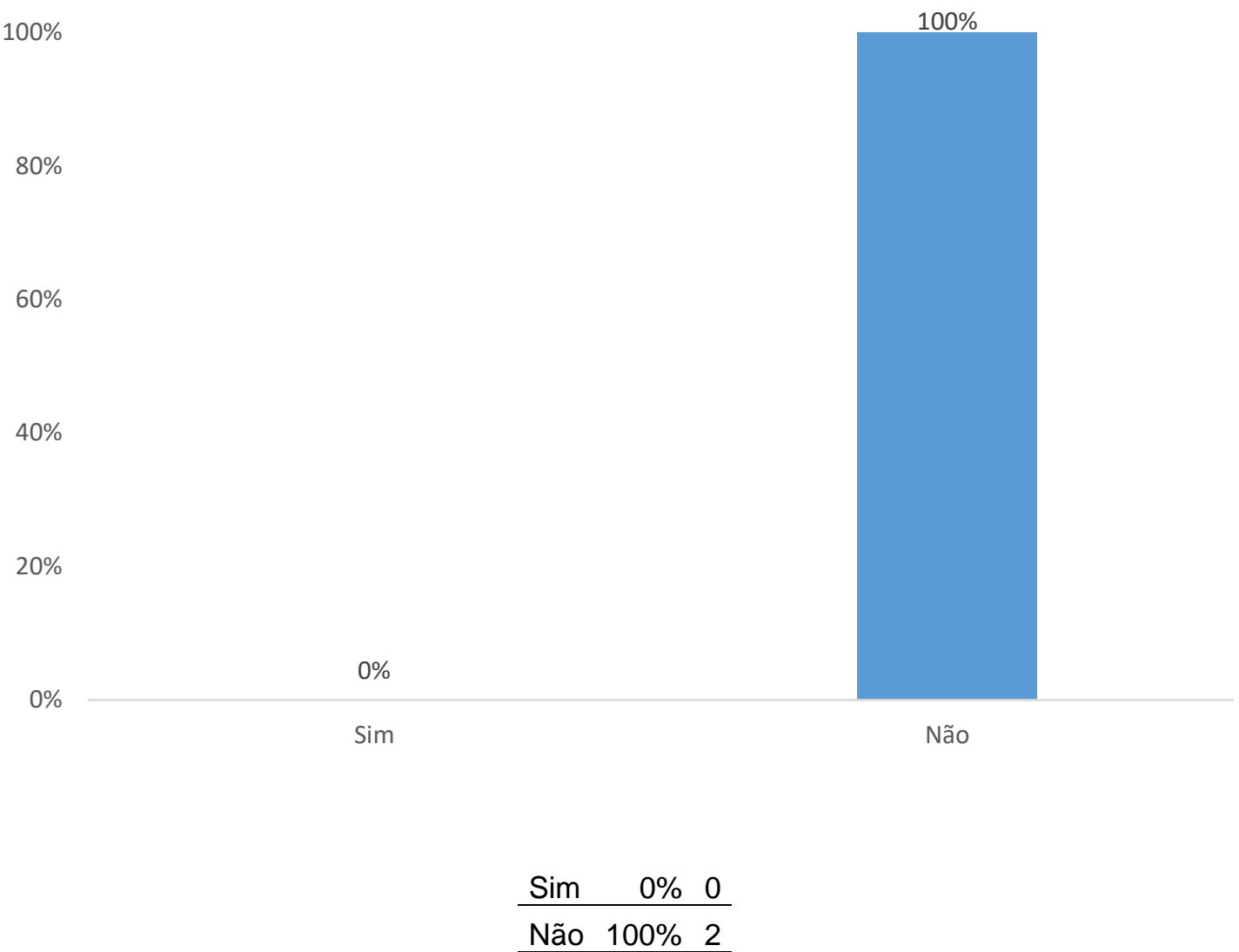

Que tipo de violência ou assédio você presenciou ou sofreu DENTRO da ESALQ/CENA? (se for necessário, marque mais de uma alternativa)

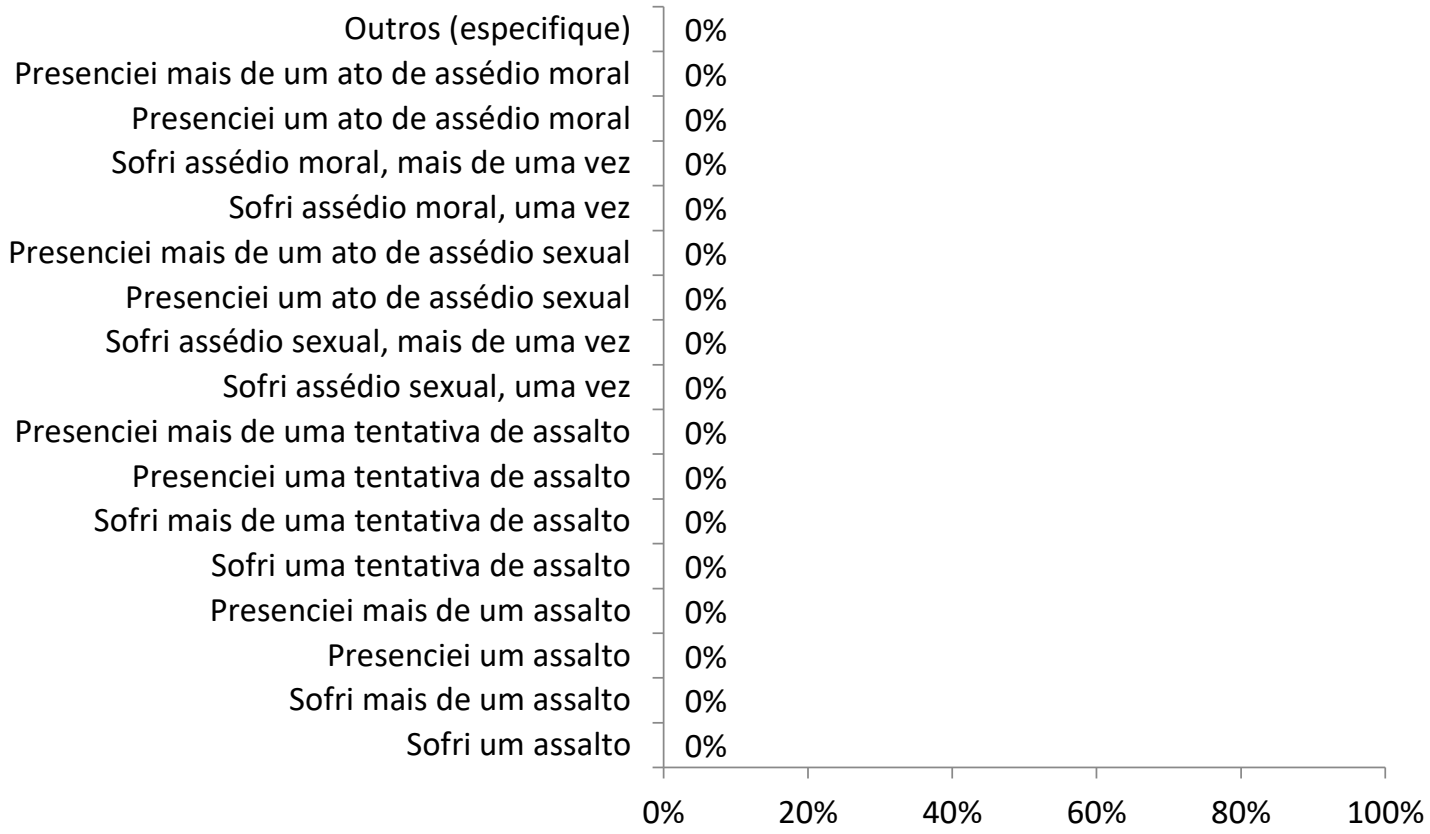




\begin{tabular}{lll} 
Sofri um assalto & $0 \%$ & 0 \\
\hline Sofri mais de um assalto & $0 \%$ & 0 \\
\hline Presenciei um assalto & $0 \%$ & 0 \\
\hline Presenciei mais de um assalto & $0 \%$ & 0 \\
\hline Sofri uma tentativa de assalto & $0 \%$ & 0 \\
\hline Sofri mais de uma tentativa de assalto & $0 \%$ & 0 \\
\hline Presenciei uma tentativa de assalto & $0 \%$ & 0 \\
\hline Presenciei mais de uma tentativa de assalto & $0 \%$ & 0 \\
\hline Sofri assédio sexual, uma vez & $0 \%$ & 0 \\
\hline Sofri assédio sexual, mais de uma vez & $0 \%$ & 0 \\
\hline Presenciei um ato de assédio sexual & $0 \%$ & 0 \\
\hline Presenciei mais de um ato de assédio sexual & $0 \%$ & 0 \\
\hline Sofri assédio moral, uma vez & $0 \%$ & 0 \\
\hline Sofri assédio moral, mais de uma vez & $0 \%$ & 0 \\
\hline Presenciei um ato de assédio moral & $0 \%$ & 0 \\
\hline Presenciei mais de um ato de assédio moral & $0 \%$ & 0 \\
\hline Outros (especifique) & $0 \%$ & 0
\end{tabular}


Com relação a medidas de segurança no ENTORNO e DENTRO da ESALQ/CENA, você é favorável a (se for necessário, marque mais de uma alternativa):

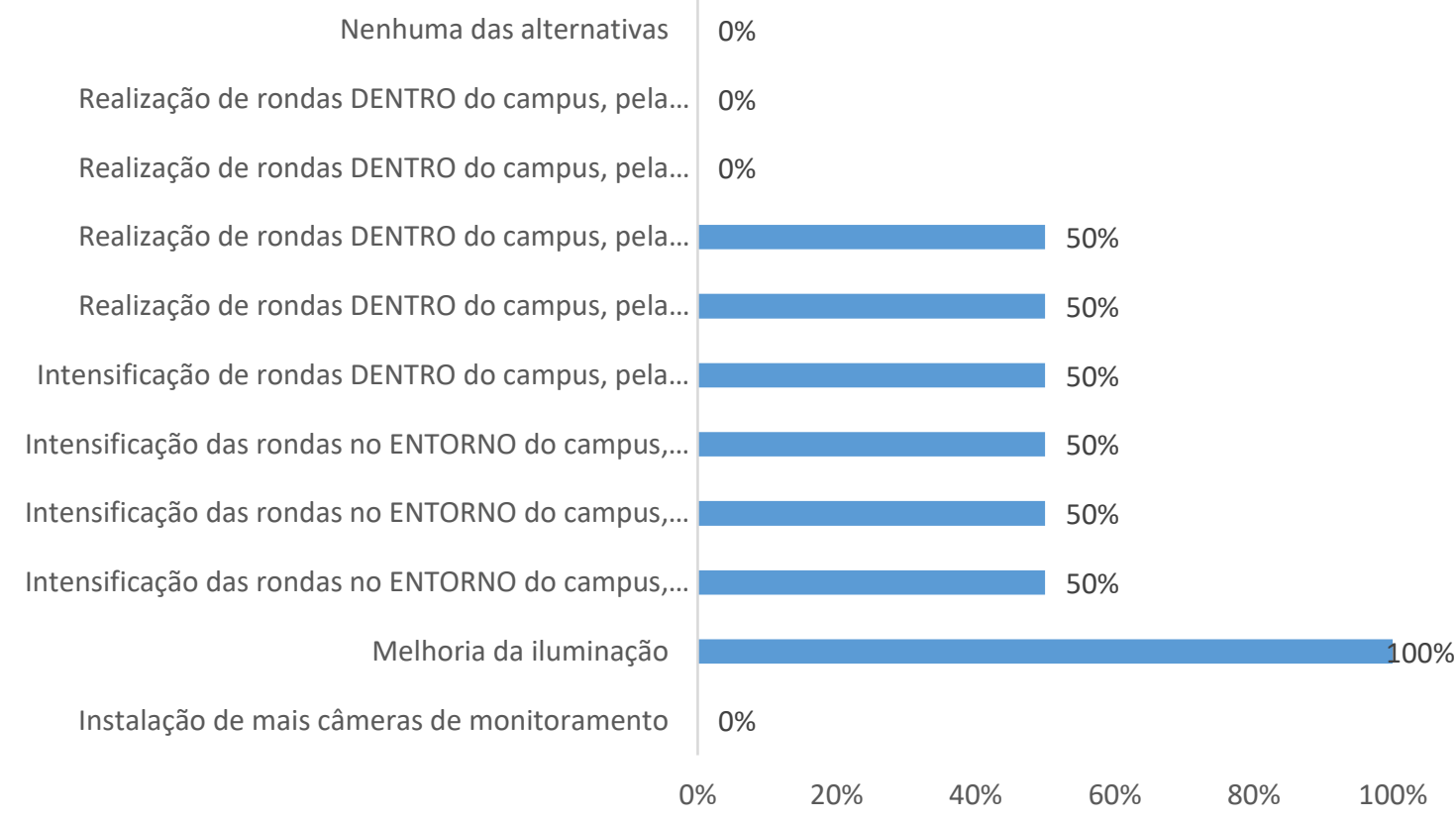

Instalação de mais câmeras de monitoramento $0 \%$

Melhoria da iluminação $100 \% \quad 2$ Intensificação das rondas no ENTORNO do campus, pela Guarda Universitária (PPUSP)

Intensificação das rondas no ENTORNO do campus, pela Policia Militar $50 \% \quad 1$ Intensificação das rondas no ENTORNO do campus, pela Guarda Municipal $50 \% \quad 1$ \begin{tabular}{lll}
\hline Intensificação de rondas DENTRO do campus, pela Guarda Universitária (PPUSP) & $50 \%$ & 1
\end{tabular}

Realização de rondas DENTRO do campus, pela Policia Militar $50 \% \quad 1$ Realização de rondas DENTRO do campus, pela Policia Militar, mas somente nos horários mais críticos como à noite e durante grandes eventos $50 \% \quad 1$

\begin{tabular}{lll} 
Realização de rondas DENTRO do campus, pela Guarda Municipal & $0 \%$ & 0 \\
\hline
\end{tabular}
Realização de rondas DENTRO do campus, pela Guarda Municipal, mas somente nos horários mais críticos como à noite e durante grandes eventos

\begin{tabular}{ll}
$0 \%$ & 0 \\
\hline $0 \%$ & 0
\end{tabular}

Nenhuma das alternativas 
Como você descreveria o trajeto do seu ponto de origem até o campus Luiz de Queiroz (ESALQ/CENA)?

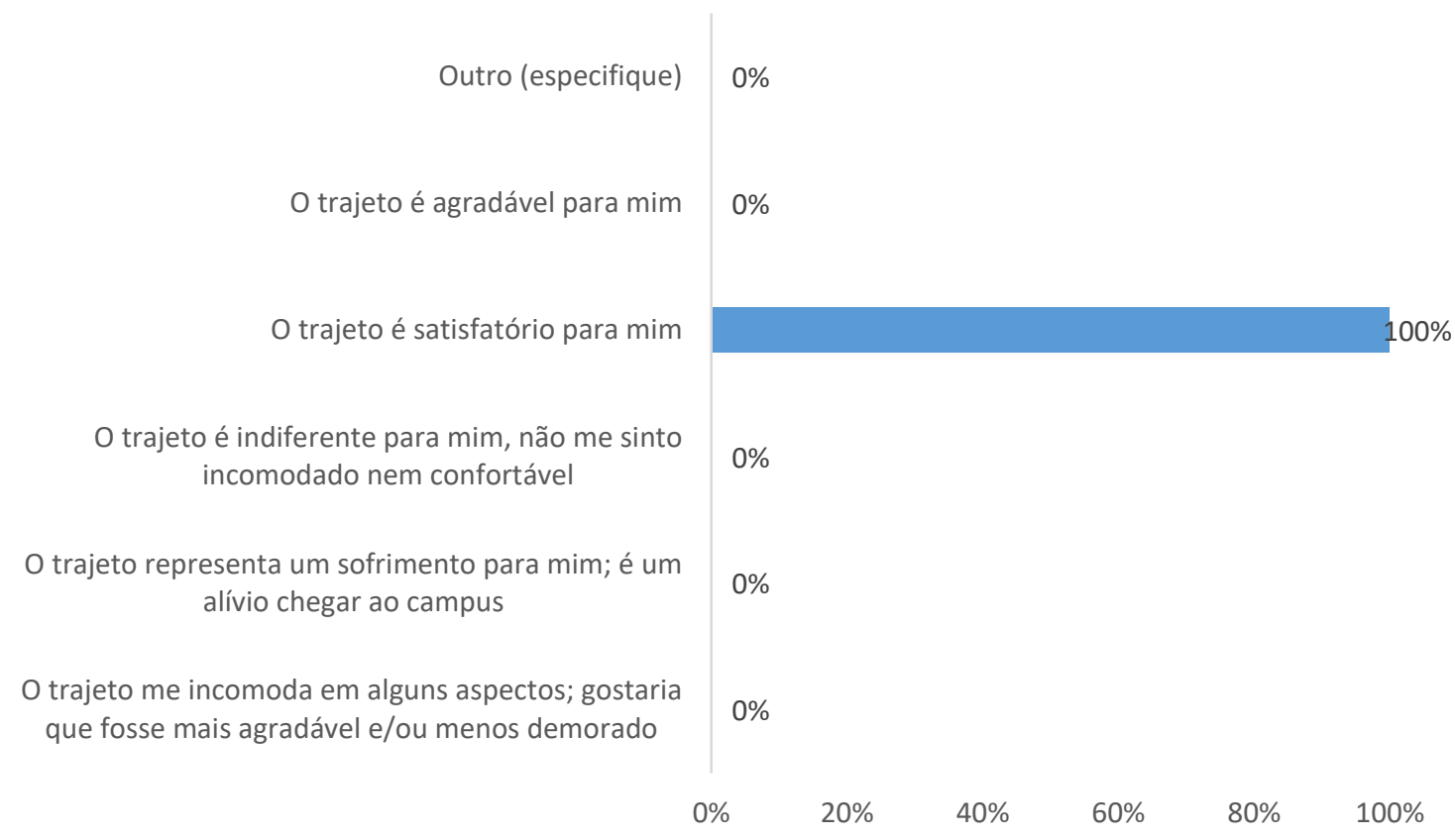

O trajeto me incomoda em alguns aspectos; gostaria que fosse mais agradável e/ou menos demorado $0 \%$ 0 O trajeto representa um sofrimento para mim; é um alívio chegar ao campus

$0 \% \quad 0$

O trajeto é indiferente para mim, não me sinto incomodado nem confortável

O trajeto é satisfatório para mim

$0 \%$ 0

O trajeto é agradável para mim $0 \%$ 0 Outro (especifique)

$0 \%$


Como você avalia a sinalização do campus Luiz de Queiroz (ESALQ/CENA)?

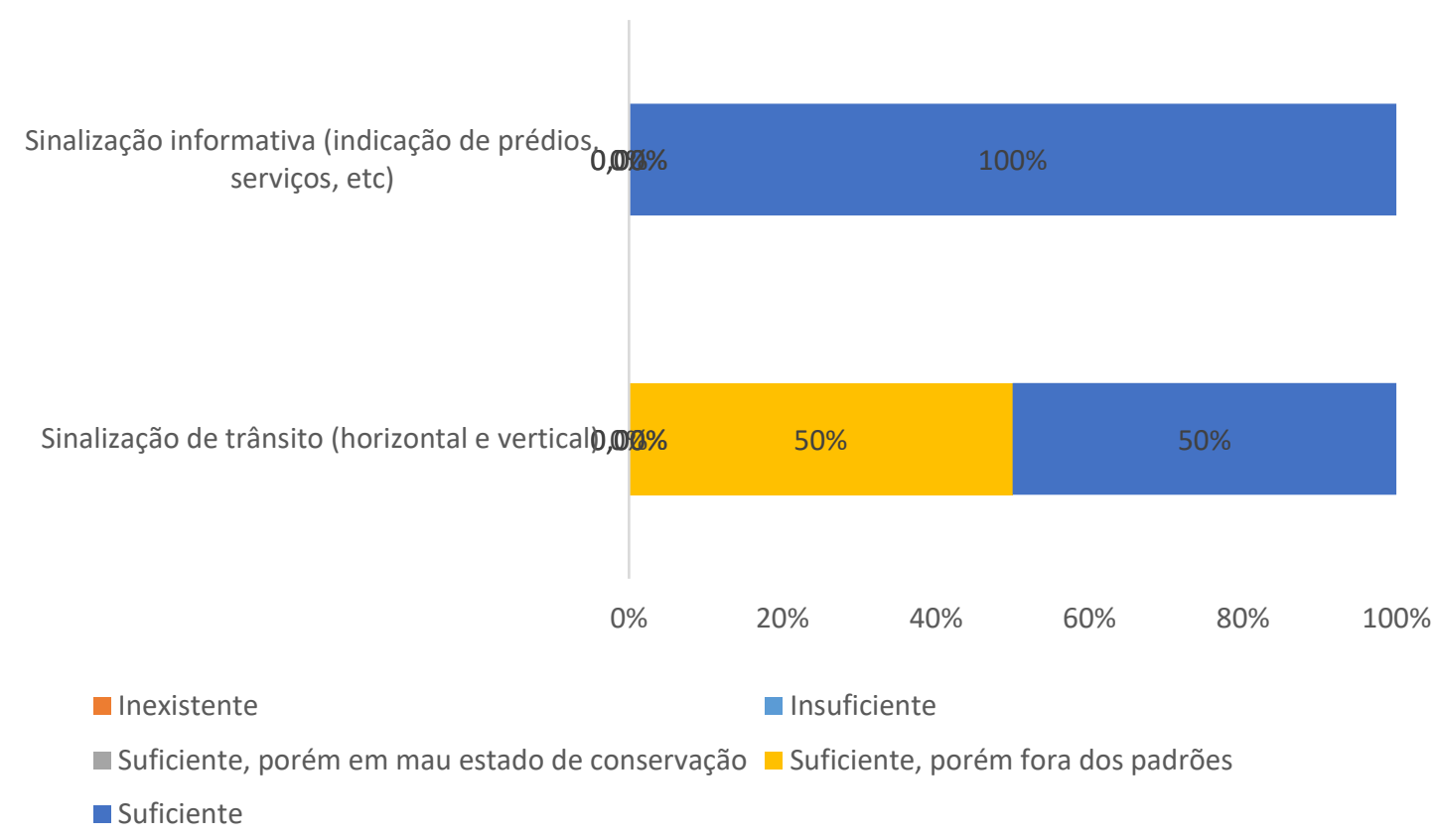

Suficiente,

porém em Suficiente,

$\begin{array}{cccc}\text { Inexistente } & \begin{array}{c}\text { Insufi- } \\ \text { ciente }\end{array} & \begin{array}{c}\text { mau } \\ \text { estado de } \\ \text { conservaçã }\end{array} & \begin{array}{c}\text { porém } \\ \text { fora dos } \\ \text { padrões }\end{array}\end{array}$ Suficiente

\begin{tabular}{lcccccccccc}
\hline $\begin{array}{l}\text { Sinalização de trânsito } \\
\text { (horizontal e vertical) }\end{array}$ & $0 \%$ & 0 & $0 \%$ & 0 & $0 \%$ & 0 & $50 \%$ & 1 & $50 \%$ & 1 \\
\hline $\begin{array}{l}\text { Sinalização informativa } \\
\text { (indicação de prédios, }\end{array}$ & $0 \%$ & 0 & $0 \%$ & 0 & $0 \%$ & 0 & $0 \%$ & 0 & $100 \%$ & 2
\end{tabular}
serviços, etc) 
Na sua opinião, qual a importância destes aspectos para uma mobilidade mais sustentável na USP de Piracicaba? Ordene os temas marcando-os com os respectivos números ou arrastando as caixas de acordo com a prioridade (no topo, o mais importante)

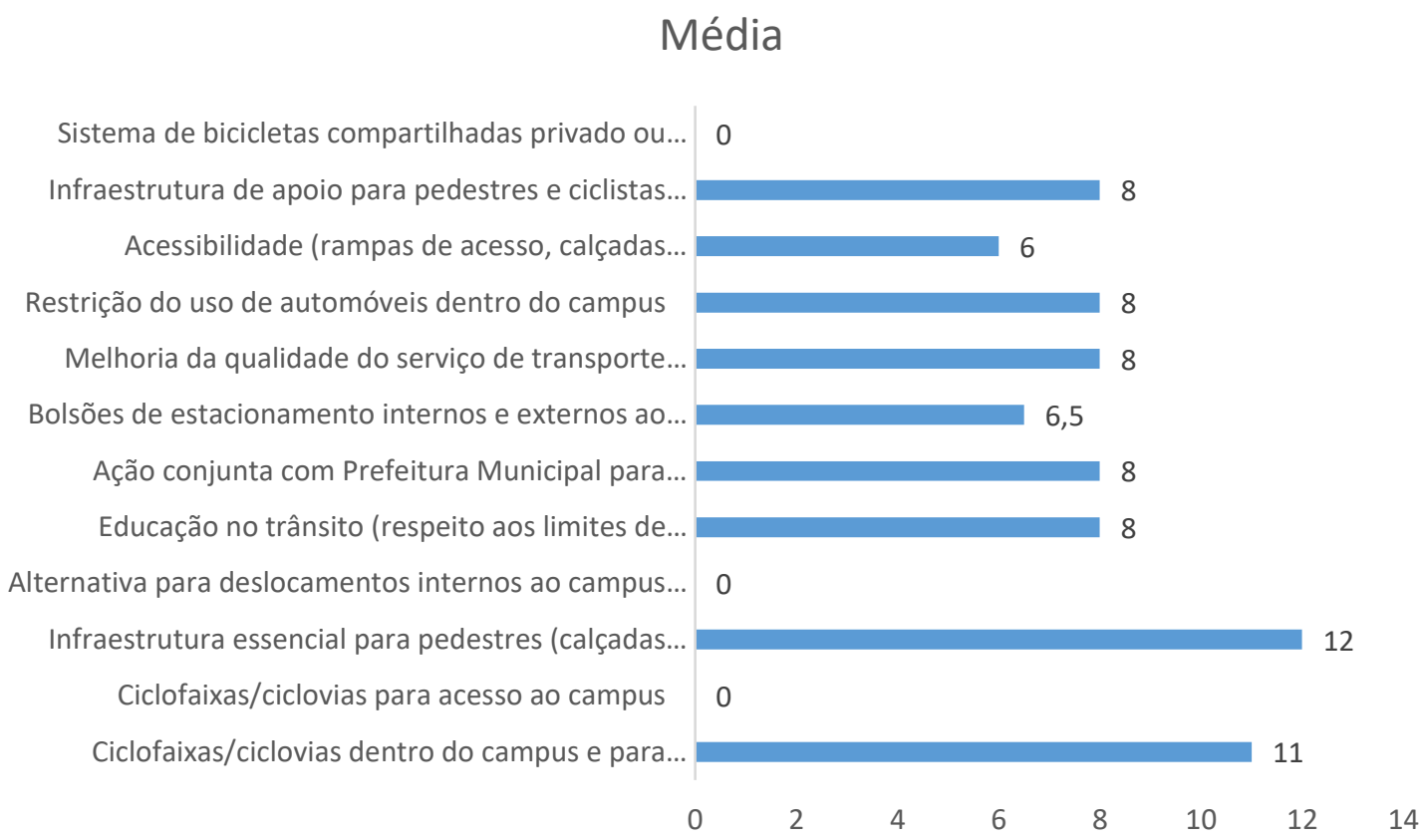


113

\begin{tabular}{llllllllllll}
1 & 2 & 3 & 4 & 5 & 6 & 7 & 8 & 9 & 10 & 11 & 12 \\
\hline
\end{tabular}

Ciclofaixas/ciclovias dentro

do campus e para acesso ao

mesmo

$\begin{array}{rrrrrrrrrrrr}100 & 0 \% & 0 \% & 0 \% & 0 \% & 0 \% & 0 \% & 0 \% & 0 \% & 0 \% & 0 \% & 0 \%\end{array}$

Ciclofaixas/ciclovias para

acesso ao campus

\begin{tabular}{llllllllllll}
$0 \%$ & $0 \%$ & $0 \%$ & $0 \%$ & $0 \%$ & $0 \%$ & $0 \%$ & $0 \%$ & $0 \%$ & $0 \%$ & $0 \%$ & $0 \%$ \\
\hline
\end{tabular}

Infraestrutura essencial para

pedestres (calçadas

adequadas, iluminação,

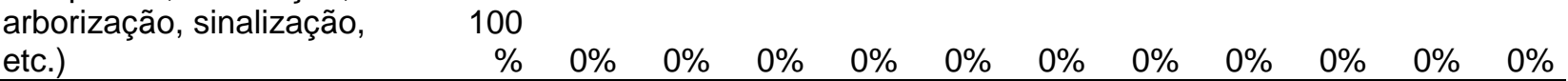

Alternativa para

deslocamentos internos ao

campus (sistema de

transporte coletivo, sistema

de bicicletas compartilhadas,

etc.)

\begin{tabular}{llllllllllll}
$0 \%$ & $0 \%$ & $0 \%$ & $0 \%$ & $0 \%$ & $0 \%$ & $0 \%$ & $0 \%$ & $0 \%$ & $0 \%$ & $0 \%$ & $0 \%$ \\
\hline
\end{tabular}

Educação no trânsito

(respeito aos limites

de velocidade e à

sinalização, melhor convívio

entre motoristas, ciclistas e

pedestres, etc.)

Ação conjunta com

Prefeitura Municipal para

melhoria da mobilidade na

ligação entre cidade e

campus

\begin{tabular}{llllllllllll}
$0 \%$ & $0 \%$ & $0 \%$ & $50 \%$ & $0 \%$ & $50 \%$ & $0 \%$ & $0 \%$ & $0 \%$ & $0 \%$ & $0 \%$ & $0 \%$ \\
\hline
\end{tabular}

Bolsões de estacionamento

internos e externos ao

campus

\begin{tabular}{llllllllllll}
$0 \%$ & $0 \%$ & $0 \%$ & $0 \%$ & $50 \%$ & $0 \%$ & $0 \%$ & $50 \%$ & $0 \%$ & $0 \%$ & $0 \%$ & $0 \%$ \\
\hline
\end{tabular}

Melhoria da qualidade do

serviço de transporte público

da cidade

$\begin{array}{llllllllllll}0 \% & 0 \% & 50 \% & 0 \% & 0 \% & 0 \% & 50 \% & 0 \% & 0 \% & 0 \% & 0 \% & 0 \%\end{array}$

Restrição do uso de

automóveis dentro do

campus

\begin{tabular}{llllllllllll}
$50 \%$ & $0 \%$ & $0 \%$ & $0 \%$ & $0 \%$ & $0 \%$ & $0 \%$ & $0 \%$ & $50 \%$ & $0 \%$ & $0 \%$ & $0 \%$ \\
\hline
\end{tabular}

Acessibilidade (rampas de

acesso, calçadas

adequadas, elevadores, piso

tátil, respeito a vagas de

estacionamento prioritárias, etc.)

$\begin{array}{llllllllllll}0 \% & 0 \% & 0 \% & 0 \% & 0 \% & 50 \% & 0 \% & 50 \% & 0 \% & 0 \% & 0 \% & 0 \%\end{array}$

Infraestrutura de apoio para

pedestres e ciclistas

(bebedouros, bancos,

vestiários, guarda-volume,

bicicletários, oficina para

consertos, etc.)

Sistema de bicicletas

compartilhadas privado ou

Esalqueano

\begin{tabular}{llllllllllll}
$0 \%$ & $0 \%$ & $50 \%$ & $0 \%$ & $0 \%$ & $0 \%$ & $50 \%$ & $0 \%$ & $0 \%$ & $0 \%$ & $0 \%$ & $0 \%$ \\
\hline
\end{tabular}

$\begin{array}{llllllllllll}0 \% & 0 \% & 0 \% & 0 \% & 0 \% & 0 \% & 0 \% & 0 \% & 0 \% & 0 \% & 0 \% & 0 \%\end{array}$ 


\title{
APÊNDICE D \\ MEMÓRIA DE CÁLCULO DA APLICAÇÃO DO IMSCAMP NO CAMPUS DA USP DE PIRACICABA
}

\begin{abstract}
POTENCIAL DE TRANSFERÊNCIA DE UM ÍNDICE DE MOBILIDADE SUSTENTÁVEL PARA CAMPUS UNIVERSITÁRIO
\end{abstract}

Francine Marvulle Tan

São Carlos

2018 


\section{Sumário}

Conscientização dos modos de transportes sustentáveis .................................................... 3

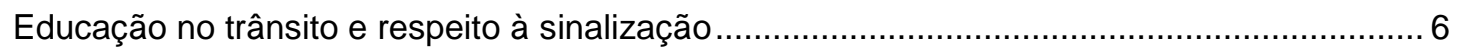

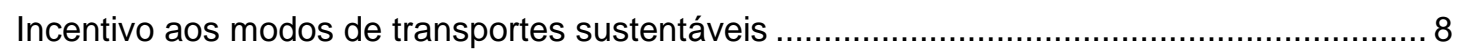

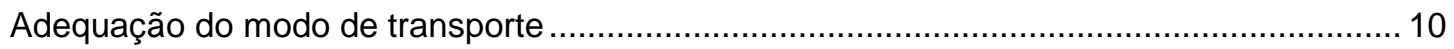

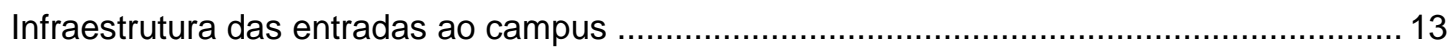

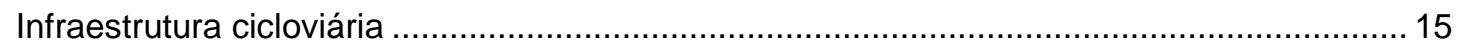

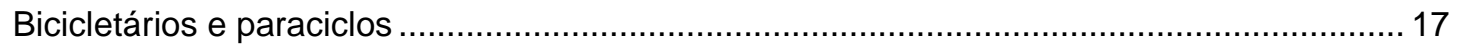

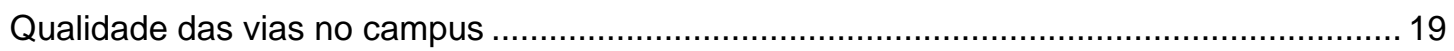

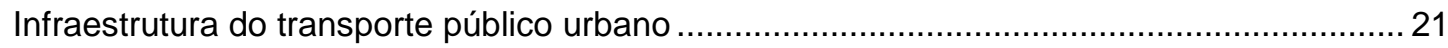

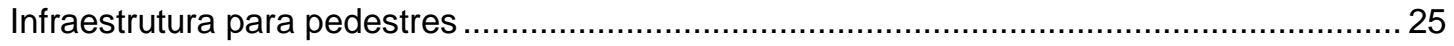

Vagas destinadas a pessoas com restrição de mobilidade e idosos..................................... 27

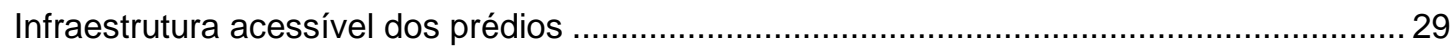

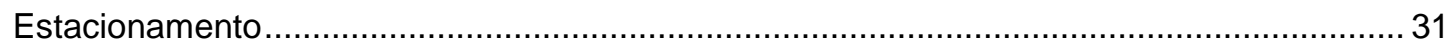

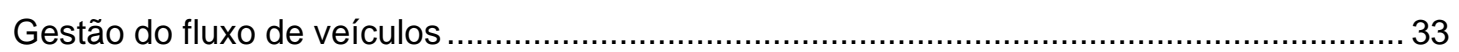

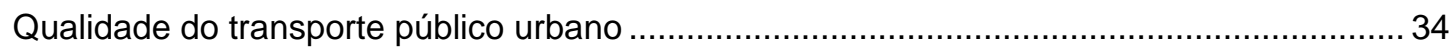

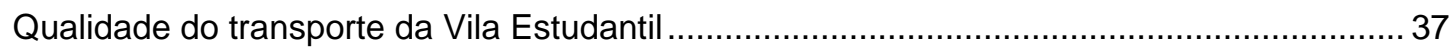

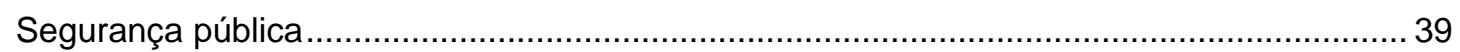

Fiscalização de infrações de trânsito no campus ............................................................... 42

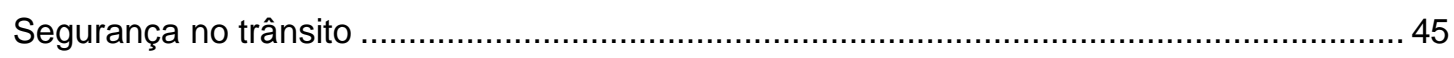




\begin{tabular}{|l|l|}
\hline DOMÍNIO & Educação \\
\hline TEMA & Ações de educação permanente \\
\hline INDICADOR 1.1.1 & Conscientização dos modos de transportes sustentáveis \\
\hline
\end{tabular}

\section{A. Definição}

Porcentagem dos usuários do campus (alunos de graduação, alunos de pós-graduação, servidores docentes e servidores técnicos/administrativos) que participam e/ou têm conhecimento das ações de conscientização promovidas pela universidade, bem como a eficácia destas ações.

\section{B. Referências}

Stein (2013); Wilhelm e Posch (2005).

\section{Relevância}

A mudança ou manutenção de hábitos saudáveis, em acordo com os princípios de sustentabilidade, está diretamente relacionada com o nível de conscientização e de motivação de cada usuário. Entre estes hábitos saudáveis, encontra-se a escolha diária do meio de transportes. De acordo com as possibilidades acessíveis a cada pessoa, a escolha por um modo de transporte considerado mais sustentável apenas ocorrerá se esta apresentar vantagens econômicas, sociais e/ou relacionadas à saúde, entre outras (WILHELM e POSCH, 2005). Desse modo, para promover a mudança ou manutenção de hábitos sustentáveis em relação à mobilidade no campus é necessária a realização de ações de conscientização promovidas e/ou apoiadas pela universidade. Para investigar os hábitos de mobilidade dos usuários do campus, Stein (2013) sugere uma metodologia capaz de classificar os usuários de acordo com o comportamento e potencial de mudança, em três classes:

Pré-contemplados: usuários que utilizam automóveis como modo principal para o deslocamento e não esboçam nenhuma pré-disposição para a adoção de modos alternativos;

Contemplados: usuários que têm o automóvel como seu modo principal, porém utilizam também algum modo alternativo nos seus deslocamentos. Estes usuários apresentam predisposição para mudança quanto ao modo de transporte;

Ativos/Em manutenção: usuários que não utilizam automóveis como modo principal de deslocamento.

As ações de conscientização devem ser acessíveis a todos os usuários do campus; porém, no contexto apresentado, destaca-se o grupo dos pré-contemplados como público alvo destas ações. Estes usuários assíduos de veículos motorizados causam um grande impacto no sistema viário do campus, todos os dias. Apesar de possuir grande resistência à mudança de modo, cada vez que isso ocorre, significa que menos um carro frequentará diariamente as vias do campus.

\section{Pesos}

\begin{tabular}{|c|c|c|c|c|c|c|}
\hline DOMÍNIO & PESO & TEMA & PESO & INDICADOR & PESO & $\begin{array}{c}\text { PESO } \\
\text { FINAL }\end{array}$ \\
\hline EDUCAÇÃO & 0,339 & $\begin{array}{l}\text { Campanhas } \\
\text { educativas }\end{array}$ & 0,865 & $\begin{array}{l}\text { Conscientização dos } \\
\text { modos de transportes } \\
\text { sustentáveis }\end{array}$ & 0,168 & 0,049 \\
\hline
\end{tabular}




\section{E. Fontes de Dados}

- Levantamento realizado por meio da aplicação de questionários aos usuários do campus.

\section{F. Ferramentas empregadas}

- Questionário online;

- Planilhas eletrônicas.

\section{G. Método de Cálculo}

Esse indicador será calculado a partir da média ponderada entre a avaliação da qualidade das ações e a parcela de usuários atingidos pelas ações, separados em grupos de acordo com a pré-disposição ao uso de modos sustentáveis. Estes grupos são: pré-contemplados (cativos do automóvel), contemplados (usuários que têm o automóvel como seu modo principal, porém utilizam também algum modo alternativo nos seus deslocamentos e apresentam predisposição para mudança permanente quanto ao modo de transporte) e ativos/manutenção (adeptos de modos de deslocamento sustentáveis, como a pé, bicicleta e transporte público).

$$
I_{1.1 .1}=0,200\left(a+\frac{b}{c}\right)+0,175\left(d+\frac{e}{f}\right)+0,125\left(g+\frac{h}{j}\right)
$$

Onde:

a: Média da avaliação das ações dos usuários pré-contemplados;

b: Número de usuários pré-contemplados atingidos pelas ações;

c: Número total de usuários pré-contemplados identificados no campus;

d: Média da avaliação das ações dos usuários contemplados;

e: Número de usuários contemplados atingidos pelas ações;

f: Número total de usuários contemplados identificados no campus;

g: Média da avaliação das ações dos usuários ativos/em manutenção;

h: Número de usuários ativos/em manutenção atingidos pelas ações;

j: Número total de usuários ativos/em manutenção identificados no campus.

As variáveis, apresentadas na equação, podem ser quantificadas por meio de um questionário aplicado a todas as categorias de usuários do campus. Nesta pesquisa devem ser abordados três aspectos:

- Qual é o modo principal de deslocamento do usuário, se possui um modo alternativo e qual é este modo alternativo;

- Se o usuário participou ou tem conhecimento de alguma ação de conscientização promovida pela universidade (pedalada, palestra, oficina/workshop, entre outros);

- Como ele avalia a efetividade das ações promovidas pela universidade (analisado através de uma escala a critério do aplicador), cujo valor deve ser normalizado na escala de 0 (zero) a 1 (um), antes de ser inserido na equação mostrada acima.

Os cálculos realizados são mostrados nas Tabelas 1 e 2 . 
Tabela 1 - Síntese dos dados (indicador 1.1.1)

\begin{tabular}{|c|c|c|c|c|c|c|c|c|c|}
\hline & \multicolumn{3}{|c|}{ Ativo/Em manutenção } & \multicolumn{3}{|c|}{ Contemplado } & \multicolumn{3}{|c|}{ Pré-contemplado } \\
\hline $\begin{array}{c}\text { Vinculaçã } \\
0\end{array}$ & $\begin{array}{l}\text { Atingi- } \\
\text { dos } \\
\text { pelas } \\
\text { ações } \\
\end{array}$ & $\begin{array}{l}\text { Total } \\
\text { de } \\
\text { respon- } \\
\text { dentes } \\
\end{array}$ & $\begin{array}{c}\text { Média } \\
\text { das } \\
\text { avalia- } \\
\text { ções }\end{array}$ & $\begin{array}{l}\text { Atingi- } \\
\text { dos } \\
\text { pelas } \\
\text { ações } \\
\end{array}$ & $\begin{array}{l}\text { Total } \\
\text { de } \\
\text { respon- } \\
\text { dentes } \\
\end{array}$ & $\begin{array}{c}\text { Média } \\
\text { das } \\
\text { avalia- } \\
\text { ções }\end{array}$ & $\begin{array}{l}\text { Atingi- } \\
\text { dos } \\
\text { pelas } \\
\text { ações } \\
\end{array}$ & $\begin{array}{l}\text { Total } \\
\text { de } \\
\text { respon- } \\
\text { dentes } \\
\end{array}$ & $\begin{array}{c}\text { Média } \\
\text { das } \\
\text { avalia- } \\
\text { ções }\end{array}$ \\
\hline $\begin{array}{l}\text { Aluno de } \\
\text { graduação }\end{array}$ & 101 & 171 & 0,422 & 28 & 45 & 0,405 & 19 & 34 & 0,351 \\
\hline $\begin{array}{l}\text { Aluno de } \\
\text { pós- } \\
\text { graduação }\end{array}$ & 70 & 138 & 0,261 & 30 & 60 & 0,400 & 30 & 54 & 0,322 \\
\hline $\begin{array}{l}\text { Servidor } \\
\text { docente }\end{array}$ & 3 & 5 & 0,111 & 17 & 29 & 0,412 & 31 & 51 & 0,236 \\
\hline $\begin{array}{l}\text { Servidor } \\
\text { técnico/ } \\
\text { administra } \\
\text {-tivo }\end{array}$ & 23 & 36 & 0,455 & 33 & 47 & 0,424 & 65 & 95 & 0,266 \\
\hline $\begin{array}{l}\text { Total } \\
\text { Geral }\end{array}$ & 197 & 350 & 0,364 & 108 & 181 & 0,410 & 145 & 234 & 0,283 \\
\hline
\end{tabular}

Tabela 2 - Expansão dos dados (indicador 1.1.1)

\begin{tabular}{lcc}
\hline \multicolumn{1}{c}{ Vinculação } & Contribuição & $\begin{array}{c}\text { Contribuição } \\
\text { com } \\
\text { expansão }\end{array}$ \\
\hline Aluno de graduação & 0,488 & 0,214 \\
\hline Aluno de pós-graduação & 0,429 & 0,133 \\
\hline Servidor docente & 0,432 & 0,024 \\
\hline Servidor técnico/administrativo & 0,524 & 0,102 \\
\hline & Score final & 0,474 \\
\hline
\end{tabular}

H. Score

Final $-\mathbf{0 , 4 7 4}$ 


\begin{tabular}{|l|l|}
\hline DOMÍNIO & Educação \\
\hline TEMA & Ações de educação permanente \\
\hline INDICADOR 1.1.2 & Educação no trânsito e respeito à sinalização \\
\hline
\end{tabular}

\section{A. Definição}

Porcentagem dos usuários do campus (alunos de graduação, alunos de pós-graduação, servidores docentes e servidores técnicos/administrativos) que participam e/ou têm conhecimento das ações de educação no trânsito promovidas pela universidade, bem como a eficácia destas ações.

\section{B. Referências}

Faria e Braga (2005).

\section{Relevância}

Todas as áreas de circulação pública são regidas por regras e limites, frequentemente expressos na forma de sinalização horizontal e vertical. Teoricamente, todos os usuários têm conhecimento destas regras que regem o sistema viário, mas cabe a cada um deles respeitá-las. Atitudes como a de não exceder o limite de velocidade, atravessar na faixa de pedestre e respeitar a sinalização, entre outras, influenciam diretamente a funcionalidade e a segurança do sistema viário.

Focando nos Polos Geradores de Viagem, como é caso de um campus universitário, a importância da educação no trânsito não se altera. Como nas vias urbanas, os PGV's geralmente atendem a diversos tipos de usuários (pedestres, ciclistas, motociclistas, etc.), provenientes de diferentes contextos (cidades grandes e pequenas, por exemplo), o que pode gerar alguns pontos de conflitos. No contexto da universidade, é importante a existência de campanhas de educação no trânsito voltadas para os diferentes tipos de usuários. Estas ações podem trazer, como resultado, maior segurança e a otimização do sistema viário.

D. Pesos

\begin{tabular}{|c|c|c|c|c|c|c|}
\hline DOMÍNIO & PESO & TEMA & PESO & INDICADOR & PESO & $\begin{array}{c}\text { PESO } \\
\text { FINAL }\end{array}$ \\
\hline EDUCAÇÃO & 0,339 & $\begin{array}{l}\text { Campanhas } \\
\text { educativas }\end{array}$ & 0,865 & $\begin{array}{l}\text { Educação no trânsito e } \\
\text { respeito à sinalização }\end{array}$ & 0,381 & 0,111 \\
\hline
\end{tabular}

\section{E. Fonte de dados}

- Questionários aplicados aos usuários (2017).

\section{F. Ferramentas empregadas}

- Questionário online;

- Planilhas eletrônicas.

\section{G. Método de cálculo}

Esse indicador será calculado a partir da média ponderada de três quesitos: a porcentagem dos usuários atingidos pelas ações de educação no trânsito, a influência destas ações no comportamento do próprio usuário e na circulação interna do campus, como mostra a equação: 


$$
I_{1.1 .2}=0,4 \times \frac{a}{b}+0,3 \times c+0,3 * d
$$

Onde:

a: Número de usuários que participam e/ou conhecem as ações;

b: Número total de usuários;

c: Eficácia das ações no comportamento do indivíduo;

d: Eficácia das ações na circulação interna do campus.

A variável a pode ser quantificada por meio da aplicação de um questionário a todos os usuários do campus (alunos de graduação, alunos de pós-graduação, servidores docentes e servidores técnicos/administrativos). Este questionário deve abordar os seguintes aspectos:

- Se o usuário conhece e/ou participou de alguma ação de educação no trânsito promovida pela universidade;

- Se o usuário tem conhecimento de alguma intervenção realizada no campus que promova a educação no trânsito.

Deste modo, as variáveis a e b serão obtidas a partir da expansão da amostra coletada, considerando os diferentes usuários do campus. A variável c será oriunda da média de avaliações atribuídas à eficácia das ações de educação no trânsito no que diz respeito ao comportamento do próprio indivíduo. Já a variável d é resultante da média de avaliações da influência das ações na circulação interna do campus, referente aos seguintes aspectos: Agressividade dos motoristas, desrespeito à faixa de pedestres, desrespeito aos ciclistas e às ciclofaixas, excesso de velocidade, desrespeito à sinalização e desrespeito às regras de trânsito.

A escala de avaliação fica a critério do aplicador, porém o valor deve ser normalizado na escala de 0 (zero) a 1 (um), antes de ser inserido na equação mostrada acima.

- Separação da amostra por tipo de usuários - alunos de graduação (373), alunos de pósgraduação (297), servidores técnicos/administrativo (98) e servidores docentes (208);

- Quantificação do número de usuários atingidos pelas ações de educação no trânsito alunos de graduação (70), alunos de pós-graduação (45), servidores técnicos/administrativo (20) e servidores docentes (42);

- Cálculo da média da avaliação, das ações de educação no trânsito, feita pelos usuários atingidos por ações de educação no trânsito - alunos de graduação $(0,423)$, alunos de pós-graduação $(0,383)$, servidores técnicos/administrativo $(0,389)$ e servidores docentes $(0,468)$;

- Cálculo do indicador de ações de educação no transito, realizado separadamente para cada tipo de usuário utilizando a equação a seguir:

\section{Onde:}

$$
I_{1.1 .2}=0,5 \times a b+0,5 \times c
$$

a: Número de usuários que participam e/ou conhecem as ações;

b: Número total de usuários;

c: Eficácia das ações.

- Expansão dos resultados da amostra de cada tipo de usuário para a população do campus, respeitando as diferentes distribuições - alunos de graduação (44\%); alunos de pós-graduação (31\%); servidores técnicos/administrativo $(6 \%)$ e servidores docentes $(19 \%)$.

\section{H. Score}

Final $-0,417$ 


\begin{tabular}{|l|l|}
\hline DOMÍNIO & Educação \\
\hline TEMA & Ações de educação permanente \\
\hline INDICADOR 1.1.3 & Incentivo aos modos de transportes sustentáveis \\
\hline
\end{tabular}

\section{A. Definição}

Porcentagem dos usuários que fazem uso de carona e de sistema de bicicletas compartilhadas.

\section{B. Referências}

Wilhelm e Posch (2005).

\section{Relevância}

Segundo Wilhelm e Posch (2005), as estratégias de conscientização devem mostrar aos usuários o potencial dos meios alternativos em suprir as suas necessidades individuais. Assim, as ações de incentivo à utilização de modos alternativos devem criar cenários favoráveis à escolha destes modos de transporte. Neste contexto, os programas de incentivos promovidos através da concessão de benefícios visam motivar os usuários na escolha do modo de transporte e torná-los usuários assíduos.

D. Pesos

\begin{tabular}{|c|c|c|c|c|c|c|}
\hline DOMÍNIO & PESO & TEMA & PESO & INDICADOR & PESO & $\begin{array}{c}\text { PESO } \\
\text { FINAL }\end{array}$ \\
\hline EDUCAÇÃO & 0,339 & $\begin{array}{l}\text { Campanhas } \\
\text { educativas }\end{array}$ & 0,865 & $\begin{array}{l}\text { Incentivo aos modos de } \\
\text { transportes sustentáveis }\end{array}$ & 0,451 & 0,132 \\
\hline
\end{tabular}

\section{E. Fontes de Dados}

- Pesquisa realizada com os usuários do campus.

- Prefeitura do campus.

\section{F. Ferramentas empregadas}

- Questionário online;

- Planilhas eletrônicas.

\section{G. Método de Cálculo}

O cálculo deste indicador é dividido em duas partes: a primeira é relacionada à parcela de usuários que declaram oferecer caronas e a segunda, ao sistema de bicicletas compartilhadas.

A parcela de usuários que oferecem caronas é estimada através de informações obtidas por meio de pesquisa. A frequência com que cada usuário oferece carona é associada a um fator (Nunca: 0; raramente: 0,5; frequentemente: 1,0 ), que é, por sua vez, multiplicado pelo número de pessoas a quem este oferece carona (de 1 a 4, visto que o padrão dos veículos privados é de uma ocupação máxima de 5 lugares). O resultado é, então, dividido pelo número de vagas possíveis de serem ocupadas por caronistas (número de veículos multiplicado por 4).

$$
I_{1.1 .3 \text { Carona }}=\frac{\sum_{i=1}^{n} a_{i} \times b_{i}}{n \times 4}
$$

Sendo: 
n: número de usuários cujo modo de transporte principal é o automóvel

a: fator de frequência (Nunca: 0 ; raramente: 0,5; frequentemente: 1,0 )

b: número de caronistas por veículo

Este cálculo é mostrado na Tabela 3.

Tabela 3 - Contribuição - Carona (indicador 1.1.3)

\begin{tabular}{lc}
\hline $\begin{array}{l}\text { Vagas possíveis de serem } \\
\text { ocupadas }\end{array}$ & 912 \\
\hline \% de vagas ocupadas & $16,5 \%$ \\
\hline Contribuição - Carona & 0,165 \\
\hline
\end{tabular}

O sistema de bicicletas compartilhadas é avaliado pela parcela da área do campus considerada ciclável, ou seja, a área do campus contemplada pelas estações de empréstimo dada uma distância praticável de bicicleta, como na equação:

$$
I_{1.1 .3 \text { Bicicletas compartilhadas }}=\frac{\text { Área ciclável do campus }}{\text { Área total do campus }}
$$

Estações de empréstimo de bicicletas: 0

O valor final do indicador é dado pela média aritmética entre as duas partes (Tabela 4).

Tabela 4 - Síntese dos dados (indicador 1.1.3)

\begin{tabular}{lr}
\hline Contribuição - Carona & 0,165 \\
\hline Contribuição - Bicicletas compartilhadas & 0,000 \\
\hline Valor indicador & 0,083 \\
\hline
\end{tabular}

H. Score

Final $-0,083$ 


\begin{tabular}{|l|l|}
\hline DOMÍNIO & Educação \\
\hline TEMA & Modo de transporte \\
\hline INDICADOR 1.2.1 & Adequação do modo de transporte \\
\hline
\end{tabular}

\section{A. Definição}

Porcentagem dos usuários que optam por um modo de transporte compatível com a distância a ser percorrida.

\section{B. Referências}

Amaral (2010); Stein et al. (2012); Ferraz e Torres (2004).

\section{Relevância}

A escolha do modo de transporte está diretamente associada à distância, custo econômico e tempo disponível para o deslocamento. Conhecendo estes parâmetros, é possível analisar se a escolha do modo de transporte é adequada às necessidades do usuário.

\section{Pesos}

\begin{tabular}{|c|c|c|c|c|c|c|}
\hline DOMÍNIO & PESO & TEMA & PESO & INDICADOR & PESO & $\begin{array}{c}\text { PESO } \\
\text { FINAL }\end{array}$ \\
\hline EDUCAÇÃO & 0,339 & $\begin{array}{l}\text { Modo de } \\
\text { transporte }\end{array}$ & 0,135 & $\begin{array}{l}\text { Adequação do modo de } \\
\text { transporte }\end{array}$ & 1,000 & 0,046 \\
\hline
\end{tabular}

\section{E. Fonte de dados}

- Base georreferenciada da rede de Piracicaba, Open Street Map (2017);

- Questionário aplicado aos usuários do campus (2017).

\section{F. Ferramentas empregadas}

- Sistema de Informações Geográficas (SIG);

- Questionário online;

- Google Earth;

- Planilhas eletrônicas.

\section{G. Método de cálculo}

A avaliação da conscientização dos usuários na escolha do modo de transporte está diretamente associada às medidas de impedância ao deslocamento como, por exemplo, a distância a ser percorrida. Porém, independente destas distâncias, os modos a pé ou bicicleta sempre serão opções sustentáveis. No entanto, para o uso do automóvel deve ser considerada uma distância mínima que justifique o seu uso. No caso, a distância percorrida deve ser associada às distâncias máximas alcançáveis pelos modos a pé ou bicicleta, em um tempo de deslocamento aceitável pelo usuário. Ou seja, o uso do automóvel se justifica se não foi viável percorrer uma dada distância a pé ou de bicicleta.

Para a mensuração deste indicador é necessário obter um banco de dados da amostra com informações de local de residência (ou ponto de origem da viagem) e modo principal utilizado. Estes dados podem ser levantados a partir de pesquisa de opinião. A representação geográfica destas informações, por meio de um SIG (Sistema de Informação Geográfica) permite o cálculo 
das distâncias médias percorridas por cada usuário do sistema. Além disso, é possível também determinar a distância média percorrida por pedestres e ciclistas, utilizada como parâmetro para a verificação da adequação da escolha do modo.

Para classificar se a escolha do modo de transporte é ou não adequada, compara-se a maior distância média praticada, entre pedestres e ciclistas, com a percorrida por cada um dos usuários de automóveis e motocicletas. Se a distância for superior à praticada por ciclistas ou pedestres, se justificaria a utilização de veículos motorizados para o deslocamento. Porém, se a distância for menor, o usuário está fazendo um uso desnecessário do veículo motorizado. O valor final do indicador será a razão entre o número dos usuários que utilizam o modo de transporte adequado pelo total de usuários.

- Padronização do formato dos locais de início de viagem (esquina mais próxima ao local de início de deslocamento para a universidade), em formato de planilha eletrônica, e posterior transferência para um SIG;

- Criação de um arquivo geográfico no SIG com os pontos de origem de viagem, a partir da localização das esquinas, realizada manualmente através do Google Earth;

- Localização dos pontos de destino de cada viagem no SIG (portaria do campus utilizada com maior frequência pelo usuário);

- Definição de duas redes: a primeira considerando o sentido das vias (para modos motorizados), a segunda desconsiderando o sentido das vias (para modos não motorizados);

- Cálculo do caminho mínimo entre os pontos de origem e destino da viagem, para as duas redes;

- Inserção das distâncias resultantes no questionário que continha as demais informações dos usuários;

- Cálculo da média de distância percorrida para pedestres e ciclistas, selecionando a maior como distância padrão, a qual será usada na comparação com os demais modos (1400 $\mathrm{m})$;

- Avaliação da adequação do modo de transporte utilizado, através de comparação entre a distância percorrida por cada usuário de veículos motorizados e a distância padrão (1400 m). Uma distância superior à praticada por ciclistas ou pedestres justifica a utilização de veículos motorizados para o deslocamento, caso contrário não justifica;

- Razão entre o número dos usuários que utilizam o modo de transporte adequado em relação ao total, por tipo de usuários;

- Expansão dos resultados da amostra de cada tipo de usuário para a população do campus, respeitando as diferentes distribuições - alunos de graduação (44\%); alunos de pós-graduação (31\%); servidores técnicos/administrativo (19\%) e servidores docentes $(6 \%)$;

- Cálculo do valor do indicador.

As Tabelas 5 e 6 mostram os cálculos realizados. 
Tabela 5 - Síntese dos dados coletados (indicador 1.2.1)

\begin{tabular}{|c|c|c|c|c|}
\hline Tipo de usuário & $\begin{array}{l}\text { Usuários com } \\
\text { modo } \\
\text { adequado }\end{array}$ & $\begin{array}{c}\text { Usuários com } \\
\text { modo } \\
\text { inadequado }\end{array}$ & Total & $\begin{array}{c}\text { Fator de } \\
\text { ponderação: } \\
\text { População do } \\
\text { campus (\%) }\end{array}$ \\
\hline Aluno de graduação & 37 & 13 & 50 & 44 \\
\hline $\begin{array}{l}\text { Aluno de pós- } \\
\text { graduação }\end{array}$ & 60 & 20 & 80 & 31 \\
\hline $\begin{array}{l}\text { Servidor } \\
\text { técnico/adm. }\end{array}$ & 96 & 8 & 104 & 19 \\
\hline Servidor docente & 41 & 8 & 49 & 6 \\
\hline $\begin{array}{l}\text { Sem vinculação } \\
\text { com a universidade } \\
\text { - visitante }\end{array}$ & 2 & 1 & 3 & 0 \\
\hline Outros & 19 & 6 & 25 & 0 \\
\hline Total & 255 & 56 & 311 & 100 \\
\hline
\end{tabular}

Tabela 6 - Expansão dos dados(indicador 1.2.1)

\begin{tabular}{lcc}
\hline & $\begin{array}{c}\text { Usuários com } \\
\text { modo adequado }\end{array}$ & $\begin{array}{c}\text { Usuários com } \\
\text { modo inadequado }\end{array}$ \\
\hline Aluno de graduação & 1578 & 555 \\
\hline Aluno de pós-graduação & 1130 & 377 \\
\hline Servidor docente & 230 & 45 \\
\hline $\begin{array}{l}\text { Servidor } \\
\text { técnico/administrativo }\end{array}$ & 870 & 73 \\
\hline Total & 3809 & 1049 \\
\hline
\end{tabular}

$$
I_{1.2 .1}=\frac{3809}{3809+1049}=0,784
$$

\section{H. Score}

Final $\mathbf{0} \mathbf{0 , 7 8 4}$ 


\begin{tabular}{|l|l|}
\hline DOMÍNIO & Infraestrutura \\
\hline TEMA & Modos não motorizados \\
\hline INDICADOR 2.1.1 & Infraestrutura das entradas ao campus \\
\hline
\end{tabular}

\section{A. Definição}

Qualidade, localização e número de entradas do campus disponíveis para pedestres e ciclistas.

\section{B. Referências}

Stein (2013); Ferraz e Torres (2004).

\section{Relevância}

A acessibilidade do campus aos pedestres e ciclistas está diretamente relacionada com a disponibilidade e qualidade das portarias. Se estas estruturas não forem bem localizadas, os usuários podem ser obrigados a percorrer longas distâncias para acessar o campus. Deste modo, sabendo que a distância a ser percorrida influencia diretamente na escolha do modo de transporte, a adequação dos acessos do campus aos seus usuários poderá motivar a escolha de modos mais sustentáveis.

\section{Pesos}

\begin{tabular}{|c|c|c|c|c|c|c|}
\hline DOMÍNIO & PESO & TEMA & PESO & INDICADOR & PESO & $\begin{array}{c}\text { PESO } \\
\text { FINAL }\end{array}$ \\
\hline INFRAESTRUTURA & 0,331 & $\begin{array}{l}\text { Modos não } \\
\text { motorizados }\end{array}$ & 0,626 & $\begin{array}{l}\text { Infraestrutura de } \\
\text { acesso ao } \\
\text { campus }\end{array}$ & 0,122 & 0,025 \\
\hline
\end{tabular}

\section{E. Fonte de dados}

- Base georreferenciada da rede de vias de Piracicaba (Open Street Map, 2017);

- Questionário aplicado aos alunos do campus (2017);

- Inspeção visual das portarias.

\section{F. Ferramentas empregadas}

- Sistema de Informações Geográficas (SIG);

- Questionário online;

- Google Earth;

- Planilhas eletrônicas.

\section{G. Método de cálculo}

- Compatibilização dos dados do questionário com os dados da base de vias em SIG;

- Criação de um arquivo geográfico para os pontos de origem de viagem do questionário, localizando as esquinas através do Google Earth;

- Criação de um arquivo geográfico para o perímetro do campus;

- Criação de bandas de 400 m em relação ao perímetro do campus (total: 186 usuários comtemplados);

- Localização dos seis (06) pontos de destino de viagem (portarias do campus);

- Criação de bandas de $400 \mathrm{~m}$ em relação às portarias do campus ( 148 usuários são comtemplados pelas portarias); 
- 1 parte do indicador: Cálculo da porcentagem de usuários contemplados pelas portarias do campus $(0,796 \%)$;

- 2 parte do indicador: Avaliação da infraestrutura física dos acessos para pedestres e ciclista, realizada por 5 técnicos. As notas atribuídas para cada quesito ou variam de 0 a 4, sendo 0 (zero) inexistente, 1 (um) ruim e 4 (quatro) ótimo. Neste caso, foi necessário realizar a normalização das avaliações $(0,417)$;

- Resultado final: média entre partes 1 e 2 do indicador.

A Tabela 7 mostra os cálculos realizados.

Tabela 7 - Síntese dos dados calculados (indicador 2.1.1)

\begin{tabular}{|c|c|c|c|}
\hline $\begin{array}{l}\text { Usuários } \\
\text { contemplados com } \\
\text { relação ao } \\
\text { perímetro do } \\
\text { campus }(400 \mathrm{~m})\end{array}$ & $\begin{array}{l}\text { Usuários } \\
\text { contemplados com } \\
\text { relação às portarias } \\
\text { do campus }(400 \mathrm{~m})\end{array}$ & $\begin{array}{c}\text { Porcentagem de } \\
\text { usuários } \\
\text { contemplados pelas } \\
\text { portarias do campus }\end{array}$ & $\begin{array}{c}\text { Avaliação da } \\
\text { infraestrutura física } \\
\text { dos acessos para } \\
\text { ciclistas e pedestres }\end{array}$ \\
\hline
\end{tabular}

\begin{tabular}{lllll}
186 & 148 & 0,796 & 0,417 & 0,606 \\
\hline
\end{tabular}

\section{H. Score}

Final $-0,606$ 


\begin{tabular}{|l|l|}
\hline DOMÍNIO & Infraestrutura \\
\hline TEMA & Modos não motorizados \\
\hline INDICADOR 2.1.2 & Infraestrutura cicloviária \\
\hline
\end{tabular}

\section{A. Definição}

Extensão, localização e qualidade da infraestrutura cicloviária de acesso e interna ao campus e sinalização.

\section{B. Referências}

Kuijper e Braakman (2009); Costa (2008); Stein (2013); Guerreiro et al. (2013).

\section{Relevância}

A implantação de ciclovias e ciclofaixas têm grande impacto no trânsito em geral, pois permite segregar o tráfego de bicicletas, resultando em vias potencialmente mais seguras. Estas estruturas também servem de incentivo ao uso de bicicletas, trazendo benefícios para os indivíduos através da prática de exercícios físicos. Além disso, se resultar em uma redução efetiva no número de carros nas vias, minimiza outros problemas acarretados pelos mesmos, tais como congestionamentos, poluição sonora, atmosférica, etc.

\section{Pesos}

\begin{tabular}{|c|l|l|l|l|l|c|}
\hline DOMÍNIO & PESO & \multicolumn{1}{|c|}{ TEMA } & PESO & INDICADOR & PESO & $\begin{array}{c}\text { PESO } \\
\text { FINAL }\end{array}$ \\
\hline INFRAESTRUTURA & 0,331 & $\begin{array}{l}\text { Modos não } \\
\text { motorizados }\end{array}$ & 0,626 & $\begin{array}{l}\text { Infraestrutura } \\
\text { cicloviária }\end{array}$ & 0,790 & 0,164 \\
\hline
\end{tabular}

\section{E. Fonte de dados}

- Questionário aplicado a um grupo de técnicos (2017);

- Inspeção visual dos trechos de infraestrutura cicloviária.

\section{F. Ferramentas empregadas}

- Sistema de informações geográficas (SIG);

- Google planilhas eletrônicas.

\section{G. Método de cálculo}

- Identificação e localização dos trechos de ciclovias e ciclofaixas internas e externas ao Campus (que conecte o campus é outro ponto de interesse);

- Avaliação da infraestrutura física acesso das ciclovias ou ciclofaixas realizada por cinco técnicos. As notas atribuídas para cada quesito ou variam de 1 a 4 , sendo 1 (um) ruim e 4 (quatro) ótimo;

- Normalização das avaliações das estruturas internas e externas do campus e sinalização $(0,767 ; 0,000 ; 0,385)$ - Tabela 8 ;

- O método de cálculo deste indicador avalia duas partes a infraestrutura dentro do campus (peso 0,60), ao redor do campus (peso 0,20) e a sinalização (peso 0,20) - Tabela 9. 
Tabela 8 - Avaliações das estruturas internas (indicador 2.1.2)

\begin{tabular}{|c|c|c|}
\hline Identificação & Nota Média & Nota Padronizada \\
\hline 1 & 3,300 & 0,767 \\
\hline \multicolumn{2}{|c|}{ Total } & 0,767 \\
\hline
\end{tabular}

Tabela 9 - Síntese dos dados calculados (indicador 2.1.2)

\begin{tabular}{cccc}
\hline $\begin{array}{c}\text { Avaliação das } \\
\text { Infraestruturas } \\
\begin{array}{c}\text { internas do campus } \\
\text { (peso 0,60) }\end{array}\end{array}$ & $\begin{array}{c}\text { Avaliação das } \\
\text { Infraestruturas } \\
\text { externas ao campus } \\
\text { (peso 0,20) }\end{array}$ & $\begin{array}{c}\text { Avaliação da } \\
\text { sinalização } \\
\text { (peso 0,20) }\end{array}$ & Score \\
\hline 0,767 & 0,000 & 0,385 & 0,537 \\
\hline
\end{tabular}

\section{H. Score}

Final $-0,537$ 


\begin{tabular}{|l|l|}
\hline DOMÍNIO & Infraestrutura \\
\hline TEMA & Modos não motorizados \\
\hline INDICADOR 2.1.3 & Bicicletários e paraciclos \\
\hline
\end{tabular}

\section{A. Definição}

Tipo, número, distribuição, localização, estado de conservação e segurança dos bicicletários e paraciclos dentro do campus.

\section{B. Referências}

Amaral (2010); Oliveira et al. (2014).

\section{Relevância}

No processo de incentivo ao uso de modos mais sustentáveis, como a bicicleta, é importante oferecer condições favoráveis para o uso. Um dos fatores apontados pelos usuários como empecilho para o deslocamento de bicicleta é a condição atual dos bicicletários e paraciclos. A falta de qualidade destas instalações inibe o uso de bicicletas no campus.

\section{Pesos}

\begin{tabular}{|c|l|l|l|l|l|c|}
\hline DOMÍNIO & PESO & \multicolumn{1}{|c|}{ TEMA } & PESO & INDICADOR & PESO & $\begin{array}{c}\text { PESO } \\
\text { FINAL }\end{array}$ \\
\hline INFRAESTRUTURA & 0,331 & $\begin{array}{l}\text { Modos não } \\
\text { motorizados }\end{array}$ & 0,626 & $\begin{array}{l}\text { Bicicletários } \\
\text { e paraciclos }\end{array}$ & 0,248 & 0,018 \\
\hline
\end{tabular}

\section{E. Fonte de dados}

- Questionário aplicado ao usuários do campus (2017);

- Inspeção visual dos bicicletários.

\section{F. Ferramentas empregadas}

- Sistema de informações geográficas (SIG);

- Questionário online;

- Planilhas eletrônicas.

\section{G. Método de cálculo}

O cálculo deste indicador divididos em 5 partes:

Primeira parte: localização dos bicicletários e paraciclos.

- Levantamento da localização dos bicicletários e paraciclos do campus;

- Avaliação da localização dos bicicletários ou paraciclos em relação ao ponto de interesse $(0,842)$.

Segunda parte: a segurança dos bicicletários e paraciclos.

- Quantificação do número de usuários de bicicleta que frequentam o campus, por tipos de usuários - alunos de graduação (24), pós-graduação (22), servidores técnicos /administrativos (2) e servidores docentes (3); 
- Quantificação do número de furtos ou roubos de bicicleta ocorridos no campus há menos de 5 anos - alunos de graduação (1), pós-graduação (0), servidores técnicos /administrativos (0) e servidores docentes (0);

- Razão entre de furtos e usuários de bicicleta $(1,96 \%)$ e normalização dos valores de acordo com o indicado no Guia de Indicadores $(0,637)$.

Terceira etapa: estado de conservação dos bicicletários e paraciclos.

- Avaliação dos bicicletários e paraciclos, considerando a avaliação atribuída pelos usuários (Ruim, Regular, Bom e Ótimo) e normalização deste resultado $(0,793)$.

Quarta etapa: avaliação da ocupação do bicicletários e paraciclos em horário de pico.

- Média da taxa de ocupação de cada um dos bicicletários e paraciclos e normalização deste valor como proposto pelo Guia dos Indicadores $(0,238)$.

Quinta etapa: avaliação da cobertura $(0,227)$.

Cálculo do indicador: média aritmética dos valores encontrados nas cinco etapas (Tabela 10).

Tabela 10 - Síntese das avaliações (indicador 2.1.3)

\begin{tabular}{lc}
\hline Avaliação da localização & 0,842 \\
\hline Avaliação da segurança & 0,638 \\
\hline Avaliação da conservação & 0,793 \\
\hline Avaliação da ocupação & 0,238 \\
\hline Avaliação média da cobertura & 0,227 \\
\hline
\end{tabular}

\section{H. Score}

Final $-0,548$ 


\begin{tabular}{|l|l|}
\hline DOMÍNIO & Infraestrutura \\
\hline TEMA & Modos motorizados \\
\hline INDICADOR 2.2.1 & Qualidade das vias no campus \\
\hline
\end{tabular}

\section{A. Definição}

Avaliação do Índice de Condição do Pavimento (ICP) das vias internas e qualidade da sinalização horizontal e vertical do campus.

\section{B. Referências}

Fernandes Jr., Oda e Zerbini (2011); SHRP (1993); Bernucci et al. (2006); AASHTO, (1986); CONTRAN (2005, 2007a e 2007b) e Fernandes Jr. (2001).

\section{Relevância}

O estado de conservação das vias, pavimentadas ou não, influencia a qualidade do fluxo interno ao campus e contribui para a ocorrência de acidentes. Entre os defeitos normalmente observados nas vias pavimentadas, destacam-se trincas por fadiga, desagregação e afundamentos como defeitos que podem desencadear problemas estruturais mais severos. Por isso, estes pontos devem ser localizados e analisados. Nas vias não pavimentadas, destacam-se os trechos com afundamento.

Outro aspecto importante para a mobilidade é a qualidade da sinalização existente nas vias. A sinalização vertical e horizontal orienta e regulamenta os fluxos do sistema viário. Quando ausente, em local inapropriado ou em condições precárias de conservação pode vir a comprometer o fluxo ou a gerar acidentes.

\section{Pesos}

\begin{tabular}{|c|c|c|c|l|c|c|}
\hline DOMÍNIO & PESO & \multicolumn{1}{|c|}{ TEMA } & PESO & \multicolumn{1}{|c|}{ INDICADOR } & PESO & $\begin{array}{c}\text { PESO } \\
\text { FINAL }\end{array}$ \\
\hline INFRAESTRUTURA & 0,331 & $\begin{array}{l}\text { Modos } \\
\text { motorizados }\end{array}$ & 0,098 & $\begin{array}{l}\text { Qualidade das vias dentro } \\
\text { do campus }\end{array}$ & 0,513 & 0,017 \\
\hline
\end{tabular}

\section{E. Fonte de dados}

- Planta do sistema viário do campus da USP de Piracicaba em formato CAD (Prefeitura do campus);

- Inspeção visual.

\section{F. Ferramentas empregadas}

- Planilhas eletrônicas;

- AutoCAD;

- Método de cálculo do ICP.

\section{G. Método de cálculo}

Primeira etapa:

- Classificação das vias do campus em vias principais, vias secundárias e pontos de interseção;

- Divisão e identificação das vias em trechos de $20 \mathrm{~m}$ de comprimento; 
- Criação de uma planilha com identificação, comprimento e área dos trechos das vias;

- Escolha de amostras nos trechos de acordo com o documento "ASTM Standard Practice for Roads and Parking Lots Pavement Condition Index Surveys" para o número de amostras a serem consideradas;

- Demarcação das amostras em campo;

- Avaliação da condição do pavimento das amostras com base no ICP $(0,532)$.

Segunda etapa:

- Avaliação da qualidade da sinalização horizontal e vertical de acordo com o seu estado de conservação, localização;

- Cálculo da parcela de elementos que estão de acordo com os itens avaliados $(0,740)$.

Terceira etapa:

- Cálculo do indicador: média aritmética das avaliações do pavimento e da sinalização $(0,636)$ (Tabela 11).

Tabela 11 - Síntese dos dados calculados (indicador 2.2.1)

\begin{tabular}{cc}
\hline ICP & 0,532 \\
\hline Sinalização & 0,740 \\
\hline Valor final do indicador & 0,636 \\
\hline
\end{tabular}

\section{H. Score}

Final $-\mathbf{0 , 6 3 6}$ 


\begin{tabular}{|l|l|}
\hline DOMÍNIO & Infraestrutura \\
\hline TEMA & Modos motorizados \\
\hline INDICADOR 2.2.2 & Infraestrutura do transporte público urbano \\
\hline
\end{tabular}

\section{A. Definição}

Avaliação dos pontos de parada do transporte público urbano, próximos ao campus, quanto à distância até as entradas do campus, iluminação, sensação de segurança, cobertura, sinalização e disponibilidade de assento.

\section{B. Referências}

Ferraz e Torres (2004).

\section{Relevância}

Uma das alternativas de transporte ditas mais sustentáveis é o transporte coletivo urbano. Visando o incentivo ao uso deste modo é primordial oferecer aos usuários acessibilidade, segurança e conforto. Estes aspectos são analisados neste indicador através da avaliação das condições dos pontos de ônibus que atendem à universidade.

\section{Pesos}

\begin{tabular}{|c|l|l|l|l|c|c|}
\hline DOMÍNIO & PESO & \multicolumn{1}{|c|}{ TEMA } & PESO & INDICADOR & PESO & $\begin{array}{c}\text { PESO } \\
\text { FINAL }\end{array}$ \\
\hline INFRAESTRUTURA & 0,331 & $\begin{array}{l}\text { Modos } \\
\text { motorizados }\end{array}$ & 0,098 & $\begin{array}{l}\text { Infraestrutura de } \\
\text { transporte público coletivo }\end{array}$ & 0,487 & 0,016 \\
\hline
\end{tabular}

\section{E. Fonte de dados}

- Questionário aplicado aos usuários do transporte público urbano.

\section{F. Ferramentas empregadas}

- Planilhas eletrônicas;

- Questionário online.

\section{G. Método de cálculo}

Para avaliação dos pontos de ônibus, são catalogados os pontos de ônibus próximos às portarias do campus. Estes pontos devem ser avaliados qualitativamente, com auxílio de um questionário que deverá abordar os seguintes aspectos:

- Distância: considerando a distância de caminhada da portaria do campus até o ponto de ônibus.
○ Ótimo: distância inferior a $50 \mathrm{~m}$;
- Boa: distância entre 50 a 150 m;
- Regular: distância entre 150 e 250 m
- Ruim: distância igual ou superior a $250 \mathrm{~m}$.

- Iluminação: é avaliado se a iluminação pública é capaz de garantir a visibilidade do entorno do ponto de ônibus.

- Ótimo: iluminação boa, com visibilidade superior a $100 \mathrm{~m}$;

- Boa: iluminação com visibilidade entre 50 a 100 m; 
- Regular: iluminação com visibilidade entre 20 a 50 m;

- Ruim: iluminação inexistente ou precária, com visibilidade inferior a $20 \mathrm{~m}$.

- Segurança: a sensação de segurança dos usuários que utilizam o ponto. Esta medida pode ser obtida por meio de perguntas aplicadas aos usuários dos respectivos pontos de ônibus e em diferentes turnos do dia.

- Ótimo: me sinto seguro (a);

- Regular: me sinto parcialmente seguro (a);

- Ruim: me sinto insegura.

- Cobertura: se o ponto possui estrutura para proteção de intempéries aos usuários.

- Ótimo: com cobertura capaz de proteger de sol e chuvas;

- Regular: protege do sol e chuvas, mas possui algumas imperfeições;

- Ruim: em péssimo estado. A estrutura não possui funcionalidade;

- Inexistente: não possui cobertura.

- Sinalização e identificação: se o ponto de ônibus possui a sinalização adequada e em boas condições de manutenção.

- Ótimo: sinalização e identificação do ponto do ônibus de forma clara, correta e em boas condições de manutenção;

- Regular: sinalização e identificação dos pontos de ônibus de forma clara e correta, mas em péssimas condições de manutenção;

- Ruim: sinalização e/ou identificação precárias do ponto de ônibus;

- Inexistente: não possui sinalização e/ou identificação.

- Disponibilidade de assento: se o ponto de ônibus possui assentos em condições de uso e a disponibilidade do número de assentos em relação à demanda de usuários, nos horários de pico.

- Ótimo: disponibilidade de assentos em condições adequadas para uso;

- Regular: disponibilidade de assentos em condições parciais de uso (danificados ou sujos)

- Ruim: disponibilidade de assentos sem condições de uso;

- Indisponibilidade de assentos.

Cada um dos pontos de ônibus identificados deve ser avaliado de forma independente. A avaliação de cada unidade se dá pela equação mostrada abaixo:

$$
P O_{1}=0,4 \times D+0,4 \times S e+0,2 \times(I+C+S i+D A)
$$

Onde:

$P O:$ Avaliação do ponto de ônibus;

$D$ : Distância;

$S e$ : Sensação de segurança;

I: lluminação;

$C$ : Cobertura;

Si: Sinalização;

DA: Disponibilidade de assento.

A Tabela 12 mostra as avaliações dos pontos de ônibus. 
Tabela 12 - Avaliações dos pontos de ônibus (indicador 2.2.2)

\begin{tabular}{|c|c|c|c|c|c|c|c|}
\hline Ponto & $\begin{array}{l}\text { Distân- } \\
\text { cia }\end{array}$ & $\begin{array}{l}\text { Ilumina } \\
\text {-ção }\end{array}$ & $\begin{array}{l}\text { Segu- } \\
\text { rança }\end{array}$ & $\begin{array}{l}\text { Cober- } \\
\text { tura }\end{array}$ & $\begin{array}{l}\text { Sinaliz } \\
\text { a-ção e } \\
\text { identifi- } \\
\text { cação }\end{array}$ & $\begin{array}{c}\text { Dispo- } \\
\text { nibili- } \\
\text { dade } \\
\text { de } \\
\text { assent } \\
0 \\
\end{array}$ & PO \\
\hline $\begin{array}{l}\text { 1. Av. Independência, em } \\
\text { frente ao Posto Shell }\end{array}$ & 0,33 & 0,00 & 1,00 & 1,00 & 1,00 & 1,00 & 0,682 \\
\hline $\begin{array}{l}\text { 2. Av. Carlos Botelho, } \\
\text { próximo à esquina com Av. } \\
\text { Centenário }\end{array}$ & 0,00 & 0,00 & 0,00 & 0,00 & 0,00 & 0,00 & 0,000 \\
\hline $\begin{array}{l}\text { 3. CEBTEC, Av. Centenário, } \\
\text { próximo à esquina com Av. } \\
\text { Carlos Botelho }\end{array}$ & 0,50 & 0,50 & 0,50 & 0,00 & 0,33 & 0,00 & 0,442 \\
\hline $\begin{array}{l}\text { 4. Em frente à FEALQ, Rod. } \\
\text { Luiz de Queiroz, próximo à } \\
\text { esquina com Av. Duque de } \\
\text { Caxias }\end{array}$ & 0,00 & 0,00 & 0,00 & 0,00 & 0,00 & 0,00 & 0,000 \\
\hline $\begin{array}{l}\text { 5. CENA. Rod. Luiz de } \\
\text { Queiroz, próximo à esquina } \\
\text { com R. Padre Lopes, } \\
\text { sentido Centro }\end{array}$ & 0,67 & 0,00 & 0,00 & 0,00 & 0,00 & 0,00 & 0,268 \\
\hline $\begin{array}{l}\text { 6. CENA. Av. Centenário, } \\
\text { próximo à esquina com R. } \\
\text { Padre Lopes, sentido Rio } \\
\text { Piracicaba }\end{array}$ & 0,00 & 0,33 & 0,00 & 0,67 & 0,67 & 0,67 & 0,117 \\
\hline $\begin{array}{l}\text { 7. Av. Centenário, próximo } \\
\text { ao cruzamento com a } \\
\text { Estrada Monte Alegre }\end{array}$ & 0,67 & 0,00 & 0,00 & 0,33 & 0,00 & 0,67 & 0,318 \\
\hline $\begin{array}{l}\text { 8. Dentro da ESALQ, na } \\
\text { Alameda Principal, em frente } \\
\text { ao Departamento de } \\
\text { Genética }\end{array}$ & 0,67 & 0,00 & 0,33 & 0,44 & 0,78 & 0,67 & 0,496 \\
\hline $\begin{array}{l}\text { 9. Av. Centenário, em frente } \\
\text { à rotatória próxima à entrada } \\
\text { principal (A encarnado) }\end{array}$ & 0,40 & 0,34 & 0,40 & 0,60 & 0,47 & 0,75 & 0,427 \\
\hline $\begin{array}{l}\text { 10. Dentro da ESALQ, } \\
\text { rotatória do A Encarnado }\end{array}$ & 0,83 & 0,33 & 0,75 & 0,56 & 0,78 & 0,73 & 0,753 \\
\hline $\begin{array}{l}\text { 11. Dentro da ESALQ, na } \\
\text { Alameda dos Alecrins, } \\
\text { próximo à esquina com } \\
\text { Alameda Principal }\end{array}$ & 0,33 & 0,67 & 0,50 & 0,33 & 0,33 & 0,67 & 0,432 \\
\hline
\end{tabular}




\begin{tabular}{|c|c|c|c|c|c|c|c|}
\hline Ponto & $\begin{array}{l}\text { Distân- } \\
\text { cia }\end{array}$ & $\begin{array}{l}\text { Ilumina } \\
\text {-ção }\end{array}$ & $\begin{array}{l}\text { Segu- } \\
\text { rança }\end{array}$ & $\begin{array}{c}\text { Cober- } \\
\text { tura }\end{array}$ & $\begin{array}{l}\text { Sinaliz } \\
\text { a-ção e } \\
\text { identifi- } \\
\text { cação }\end{array}$ & $\begin{array}{l}\text { Dispo- } \\
\text { nibili- } \\
\text { dade } \\
\text { de } \\
\text { assent } \\
0 \\
0\end{array}$ & PO \\
\hline $\begin{array}{l}\text { 12. Av. Centenário, próximo } \\
\text { ao cruzamento com a } \\
\text { Estrada Monte Alegre, em } \\
\text { frente à "Nova Mercantil } \\
\text { Veículos" }\end{array}$ & 0,00 & 0,00 & 0,00 & 0,00 & 0,00 & 0,00 & 0,000 \\
\hline $\begin{array}{l}\text { 13. Estrada Monte Alegre, } \\
\text { próximo à entrada da } \\
\text { Engenharia }\end{array}$ & 0,00 & 0,00 & 0,00 & 0,00 & 0,00 & 0,00 & 0,000 \\
\hline $\begin{array}{l}\text { Utilizo um ponto de ônibus } \\
\text { próximo ao campus que não } \\
\text { está na lista. }\end{array}$ & 0,33 & 0,00 & 1,00 & 1,00 & 1,00 & 1,00 & 0,682 \\
\hline
\end{tabular}

H. Score

Final $-\mathbf{0 , 3 3 0}$ 


\begin{tabular}{|l|l|}
\hline DOMÍNIO & Infraestrutura \\
\hline TEMA & Acessibilidade \\
\hline INDICADOR 2.3.1 & Infraestrutura para pedestres \\
\hline
\end{tabular}

\section{A. Definição}

Avaliação da sinalização para pedestres; avaliação da acessibilidade universal do campus; e a razão entre a área com cobertura vegetal do campus e sua área total.

\section{B. Referências}

ABNT (2004); Costa (2008).

\section{Relevância}

Ações de incentivo ao uso de modos não motorizados, quando realizadas isoladamente, podem não trazer o resultado esperado, uma vez que é necessária também a provisão de infraestrutura adequada. Sinalização inadequada, ausência de arborização e de rampas de acessibilidade e/ou nivelamento, por exemplo, dificultam e desestimulam o deslocamento dos pedestres com e sem restrição de mobilidade. Desse modo, na promoção da mobilidade sustentável é fundamental desenvolver medidas que abordem essas estruturas.

\section{Pesos}

\begin{tabular}{|c|c|c|c|c|c|c|}
\hline DOMÍNIO & PESO & TEMA & PESO & INDICADOR & PESO & $\begin{array}{c}\text { PESO } \\
\text { FINAL }\end{array}$ \\
\hline INFRAESTRUTURA & 0,331 & Acessibilidade & 0,276 & $\begin{array}{l}\text { Infraestrutura para } \\
\text { pedestres }\end{array}$ & 0,479 & 0,044 \\
\hline
\end{tabular}

\section{E. Fontes de Dados}

- Prefeitura do campus;

- Inspeção das calçadas.

\section{F. Ferramentas empregadas}

- Planilhas eletrônicas.

\section{G. Método de Cálculo}

O método de cálculo consiste na ponderação entre três razões: avaliação da sinalização para pedestres; avaliação da acessibilidade universal do campus; e a razão entre a área com cobertura vegetal do campus e sua área total.

A avaliação da qualidade da sinalização é feita por meio de questionário, no qual o usuário deve considerar o estado de conservação, podendo classificá-lo como péssimo, regular e ótimo; e a representação da sinalização, que pode ser adequada ou inadequada. Estes aspectos serão analisados conforme as recomendações do CONTRAN (2005; 2007a; 2007b). Para a avaliação serão adotados os seguintes critérios:

- Estado de conservação:

- Ótimo: sinalização em bom estado de conservação;

- Regular: sinalização com desgaste, mas visível; 
- Péssimo: sinalização com desgaste, amassada ou encoberta por limo, ou algo do tipo.

- Representação:

- Adequada: de acordo com o especificado nos manuais do CONTRAN;

- Inadequada: em descordo com o especificado nos manuais do CONTRAN.

Para a quantificação da análise da sinalização horizontal e vertical será considerada a fração dos elementos total ou parcialmente de acordo com os itens avaliados, levando em consideração o coeficiente para cada nível de avaliação. Se o estado de conservação for avaliado como ótimo e a representação adequada, o elemento estará de acordo $(1,00)$. Se a sinalização for regular e a representação adequada, o elemento estará parcialmente de acordo $(0,50)$. Porém, se a sinalização estiver em péssimo estado de conservação ou inadequado, o elemento estará em desacordo $(0,00)$.

A avaliação da acessibilidade universal do campus é também realizada através de questionário, no qual os respondentes registram sua opinião através de conceitos. Estes conceitos estão associados a fatores de ponderação como mostra a Tabela 13.

Tabela 13 - Fatores de ponderação para avaliação da acessibilidade universal (indicador 2.3.1)

\begin{tabular}{lc}
\hline \multicolumn{1}{c}{ Conceito } & Fator de ponderação \\
\hline Inacessível & 0 \\
\hline Pequena parte do campus é acessível & 0,33 \\
\hline Grande parte do campus é acessível & 0,67 \\
\hline Acessível & 1,0 \\
\hline Não sou capaz de opinar & desconsiderado \\
\hline
\end{tabular}

As respostas dos usuários com restrição de mobilidade recebem peso 0,70 e as demais, 0,30.

O quesito cobertura é dado pela porcentagem de área do campus com cobertura ou arborização. Neste caso pode também ser utilizada a extensão total de calçadas dentro do campus e comparada com a extensão que possui algum tipo de cobertura.

O valor final do indicador é então calculado pela média aritmética das três avaliações referidas.

- Avaliação da acessibilidade (Tabela 14)

Tabela 14 - Avaliação da acessibilidade (indicador 2.3.1)

\begin{tabular}{lcc}
\hline & Avaliação & Peso \\
\hline $\begin{array}{l}\text { Usuários COM restrição de } \\
\text { mobilidade }\end{array}$ & 0,491 & 0,7 \\
\hline $\begin{array}{l}\text { Usuários SEM restrição de } \\
\text { mobilidade }\end{array}$ & 0,510 & 0,3 \\
\hline Avaliação - Acessibilidade & \multicolumn{2}{c}{0,497} \\
\hline
\end{tabular}

- Avaliação da sinalização: 0,833

- Avaliação da cobertura: 0,540

H. Score

Final $-0,623$ 


\begin{tabular}{|l|l|}
\hline DOMÍNIO & Infraestrutura \\
\hline TEMA & Acessibilidade \\
\hline INDICADOR 2.3.2 & $\begin{array}{l}\text { Vagas destinadas a pessoas com restrição de mobilidade e } \\
\text { idosos }\end{array}$ \\
\hline
\end{tabular}

\section{A. Definição}

Disponibilidade e localização das vagas para usuários com restrição de mobilidade permanente e idosos.

\section{B. Referências}

CONTRAN (2008)

\section{Relevância}

Visando a construção de espaços acessíveis, é importante também atender às necessidades dos usuários que possuem algum tipo de restrição de mobilidade. Esses usuários podem eventualmente depender de veículos motorizados para realizar deslocamentos de longa distância. Deste modo, é importante fornecer vagas, próximo ao acesso dos locais de interesse, para este grupo de usuários. Os parâmetros para realizar a reserva de vagas são estabelecidos pelas normas vigentes no país.

D. Pesos

\begin{tabular}{|c|c|c|c|c|c|c|}
\hline DOMÍNIO & PESO & TEMA & PESO & INDICADOR & PESO & $\begin{array}{c}\text { PESO } \\
\text { FINAL }\end{array}$ \\
\hline INFRAESTRUTURA & 0,331 & Acessibilidade & 0,276 & $\begin{array}{l}\text { Vagas para usuários } \\
\text { com restrição de } \\
\text { mobilidade e idosas }\end{array}$ & 0,233 & 0,021 \\
\hline
\end{tabular}

\section{E. Fonte de dados}

- Planta do sistema viário do campus da USP de Piracicaba em formato CAD (Prefeitura do campus);

- Levantamento do número de vagas disponíveis para usuários com restrição de mobilidade.

\section{F. Ferramentas empregadas}

- Planilhas eletrônicas.

\section{G. Método de cálculo}

Cálculo da porcentagem de vagas disponíveis para Usuários com Restrição Permanente de Mobilidade (URPM) e para idosos em relação ao total de vagas exigidas pelas normas, considerando o número máximo de vagas igual ao exigido na norma:

- Vagas oferecidas: URPM: 12; Idosos: 2

- Vagas exigidas pela norma: URPM: 9; Idosos: 41

- Porcentagens:

- URPM: $12 / 9=100,00 \%$ atendida

- Idosos: $2 / 41=4,88 \%$ atendida 
Cálculo do indicador:

$$
I_{2.3 .2}=\frac{100,00+4,88}{2}=0,524
$$

H. Score

Final $-0,524$ 


\begin{tabular}{|l|l|}
\hline DOMÍNIO & Infraestrutura \\
\hline TEMA & Acessibilidade \\
\hline INDICADOR 2.3.3 & Infraestrutura acessível dos prédios \\
\hline
\end{tabular}

\section{A. Definição}

Avaliação qualitativa da acessibilidade dos prédios.

\section{B. Referências}

Costa (2008); Stein (2013); Camisão (2003).

\section{Relevância}

A construção de um campus universitário acessível a todos os usuários inclui adaptação dos espaços aos usuários com restrição temporária ou permanente de mobilidade. No âmbito do planejamento da mobilidade, os prédios caracterizam, em sua maioria, os pontos de interesse do campus. Se estes prédios não possuem condições de acessibilidade universal, adequação da infraestrutura das calçadas e vagas reservadas para usuários com restrição de mobilidade, a acessibilidade não será efetiva. Desta maneira, os usuários não conseguirão desfrutar das instalações do campus.

\section{Pesos}

\begin{tabular}{|c|c|c|c|c|c|c|}
\hline DOMÍNIO & PESO & TEMA & PESO & INDICADOR & PESO & $\begin{array}{c}\text { PESO } \\
\text { FINAL }\end{array}$ \\
\hline INFRAESTRUTURA & 0,331 & Acessibilidade & 0,276 & $\begin{array}{l}\text { Acessibilidade dos } \\
\text { prédios }\end{array}$ & 0,289 & 0,026 \\
\hline
\end{tabular}

\section{E. Fonte de dados}

- Questionário aplicado aos usuários do campus.

\section{F. Ferramentas empregadas}

- Planilhas eletrônicas;

- Questionário online.

\section{G. Método de cálculo}

O cálculo deste indicador baseia-se na avaliação qualitativa dos usuários em relação à acessibilidade dos prédios. Atribui-se um maior peso para as avaliações de pessoas com restrição de mobilidade, visto que estes usuários vivenciam e estão mais sensíveis a dificuldades e, portanto, estão mais aptos a analisar a infraestrutura acessível. Esta avaliação pode ser obtida com o auxilio de um questionário que deve abordar as seguintes questões:

- Possuir ou não restrição de mobilidade;

- Que área do campus o usuário frequenta;

- Dentre os prédios que ele frequenta no campus, como ele avalia a acessibilidade;

Para a qualidade da acessibilidade dos prédios, os respondentes devem atribuir conceitos (ruim, regular, bom e ótimo) que estarão associados aos fatores de ponderação (por exemplo, Ótimo = 1,00; Bom = 0,67; Regular = 0,33 e Ruim=0,00). As respostas dos usuários com restrição de 
mobilidade recebem peso 0,70 e as demais, 0,30. Desse modo, o valor final do indicador será obtido pela equação:

$$
\begin{array}{r}
I_{2.3 .3}=0,3 * \text { Avaliação dos índividuos sem restrição de mobilidade }+0,7 \\
* \text { Avaliação dos indivíduos com restrição de mobilidade }
\end{array}
$$

Resultados:

- Avaliação dos indivíduos sem restrição de mobilidade: 0,419

- Avaliação dos indivíduos com restrição de mobilidade: 0,391

\section{H. Score}

Final $-0,400$ 


\begin{tabular}{|l|l|}
\hline DOMÍNIO & Administração/Gestão \\
\hline TEMA & Acesso e estacionamento \\
\hline INDICADOR 3.1.1 & Estacionamento \\
\hline
\end{tabular}

\section{A. Definição}

Capacidade das áreas de estacionamento.

\section{B. Referências}

Setti (2002).

\section{Relevância}

A limitação do número de vagas de estacionamento no campus obriga os usuários a realizarem mais deslocamentos à procura de lugar para deixar o veículo, ou até mesmo a estacionar fora do campus. A procura por vaga, além de gerar uma maior emissão de $\mathrm{CO}_{2}$ e gasto de energia, também representa um tempo perdido ao usuário. Isso significa que, quanto mais próxima de $100 \%$ o grau de saturação das áreas de estacionamento, mais difícil é encontrar uma vaga. Desse modo, medindo o grau de saturação das áreas de estacionamento ao longo do dia podemos estimar o grau de complexidade que o usuário enfrenta para usar o estacionamento.

\section{Pesos}

\begin{tabular}{|l|l|l|l|l|c|c|}
\hline \multicolumn{1}{|c|}{ DOMÍNIO } & PESO & \multicolumn{1}{|c|}{ TEMA } & PESO & INDICADOR & PESO & $\begin{array}{c}\text { PESO } \\
\text { FINAL }\end{array}$ \\
\hline $\begin{array}{l}\text { ADMINISTRAÇÃO } \\
\text { / GESTÃO }\end{array}$ & 0,330 & $\begin{array}{l}\text { Acesso e } \\
\text { estacionamentos }\end{array}$ & 0,222 & Estacionamento & 0,567 & 0,041 \\
\hline
\end{tabular}

\section{E. Fontes de Dados}

- Levantamento da ocupação das vagas ao longo do dia;

- Prefeitura do campus.

\section{F. Ferramentas empregadas}

- Planilhas eletrônicas.

\section{G. Método de Cálculo}

Este indicador permite analisar o grau de saturação das áreas de estacionamento do campus. Para isso, deve ser realizada uma contagem dos veículos nos estacionamentos do campus ao longo do dia. As contagens devem contemplar os principais horários de utilização do estacionamento. Os dados podem ser apresentados em forma de porcentagem e representam 0 grau de saturação do estacionamento. Neste indicador, são consideradas apenas as áreas abertas de estacionamento, segregadas em blocos de estacionamento de acordo com os prédios ou departamento que atendem.

Para obter o valor final deste indicador deve ser realizada uma média ponderada da porcentagem de saturação, de acordo com o número de vagas de cada bloco de estacionamento.

$$
\boldsymbol{I}_{3.1 .1}=\frac{\boldsymbol{V}_{i} \times \% \boldsymbol{S}_{B i}+\boldsymbol{V}_{i+1} \times \% \boldsymbol{S}_{B i+1}+\ldots+\boldsymbol{V}_{n} \times \% \boldsymbol{S}_{B \boldsymbol{n}}}{\sum_{i}^{n} \boldsymbol{V}}
$$


Onde:

$V_{i}$ : Número de vagas do bloco de estacionamento;

$\% S_{B i}$ : Porcentagem de saturação do bloco de estacionamento;

Os valores de referência para normalização do grau de saturação das áreas de estacionamento no campus estão apresentados na Figura 1.

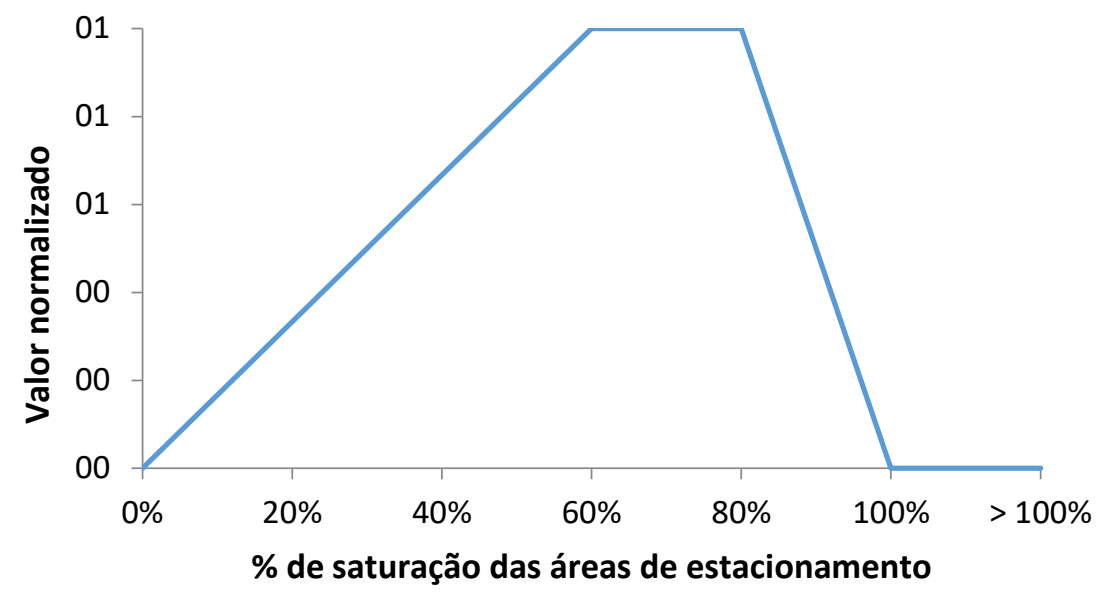

Figura 1 - Valores de referência para normalização do grau de saturação das áreas de estacionamento do campus

H. Score

Final $-0,643$ 


\begin{tabular}{|l|l|}
\hline DOMÍNIO & Administração/Gestão \\
\hline TEMA & Acesso e estacionamento \\
\hline INDICADOR 3.1.2 & Gestão do fluxo de veículos \\
\hline
\end{tabular}

\section{A. Definição}

Avaliação da eficiência das medidas de gestão do fluxo, por meio da quantificação de ocorrências de obstrução de fluxo percebidas no campus (estacionamento irregular, operação de carga e descarga realizada em local inapropriado, mau funcionamento dos tags de identificação dos veículos, etc.) e o nível de transtorno associado.

\section{B. Referências}

Stein (2013).

\section{Relevância}

A gestão de fluxo dentro do campus é muito importante para garantir a fluidez e otimização do sistema viário. Estacionamento ou operação de carga e descarga em local inapropriado, por exemplo, gera um determinado grau de transtorno. Se este tipo de ocorrência caracteriza um fato isolado, certamente não haverá grandes impactos na mobilidade do campus. Porém, se eventos da mesma natureza se repetem com frequência dentro do campus, a qualidade da mobilidade poderá ser comprometida.

\section{Pesos}

\begin{tabular}{|l|l|l|l|l|l|c|}
\hline \multicolumn{1}{|c|}{ DOMÍNIO } & PESO & \multicolumn{1}{|c|}{ TEMA } & PESO & INDICADOR & PESO & $\begin{array}{c}\text { PESO } \\
\text { FINAL }\end{array}$ \\
\hline $\begin{array}{l}\text { ADMINISTRAÇÃO } \\
\text { / GESTÃO }\end{array}$ & 0,330 & $\begin{array}{l}\text { Acesso e } \\
\text { estacionamento }\end{array}$ & 0,222 & $\begin{array}{l}\text { Gestão do fluxo } \\
\text { de veículos }\end{array}$ & 0,433 & 0,032 \\
\hline
\end{tabular}

\section{E. Fontes de Dados}

- Pesquisa de opinião realizada com os agentes da segurança patrimonial do campus.

\section{F. Ferramentas empregadas}

- Planilhas eletrônicas.

\section{G. Método de Cálculo}

No cálculo deste indicador deve ser analisada a frequência das ocorrências de interrupção do fluxo veicular e o grau de transtorno gerado. A avaliação destas ocorrências pode ser obtida a partir da aplicação de questionários aos funcionários responsáveis pela segurança do campus.

Neste questionário, uma amostra de funcionários da guarda patrimonial da USP classifica a frequência dos tipos de ocorrências observadas dentro do campus, em: baixa (até 3 vezes no último semestre), média (até 10 vezes no último semestre) e alta (mais de 10 vezes no último semestre). Já o grau de transtorno pode ser assim avaliado: pequeno (interrompeu parcialmente o fluxo dos usuários, motorizados ou não), médio (interrompeu o fluxo parcialmente, gerando pequenas filas de veículos motorizados e/ou desvio dos usuários não motorizados) e grande (interrompeu totalmente o fluxo dos usuários, gerando grandes filas de veículos e/ou a necessidade de longos desvios aos usuários não motorizados). 
Os dados obtidos no questionário devem ser pontuados de acordo com o impacto gerado no sistema de mobilidade do campus. Como mostrado na Tabela 15, quanto maior for a frequência, duração e/ou grau de transtorno da ocorrência observada, maior será o seu impacto negativo e menor será o valor atribuído ao evento. O resultado deste indicador será a média da avaliação de todos os eventos relatados pelos entrevistados.

Tabela 15 - Valor atribuído as diferentes ocorrências de interrupção de fluxo observadas no campus

(indicador 3.1.2)

\begin{tabular}{lccccccccc}
\hline & \multicolumn{3}{c}{$\begin{array}{c}\text { Baixo grau de } \\
\text { transtorno }\end{array}$} & \multicolumn{3}{c}{$\begin{array}{c}\text { Médio grau de } \\
\text { transtorno }\end{array}$} & \multicolumn{2}{c}{ Alto grau de transtorno } \\
\cline { 2 - 10 } Frequênciancy & \multicolumn{3}{c}{ Duração } & \multicolumn{3}{c}{ Duração } & \multicolumn{3}{c}{ Duração } \\
\cline { 2 - 10 } & Curta & Média & Longa & Curta & Média & Longa & Curta & Média & Longa \\
\hline Baixa & 1,00 & 0,95 & 0,90 & 0,90 & 0,80 & 0,70 & 0,70 & 0,60 & 0,50 \\
\hline Média & 0,75 & 0,70 & 0,65 & 0,65 & 0,55 & 0,45 & 0,45 & 0,35 & 0,25 \\
\hline Alta & 0,50 & 0,45 & 0,40 & 0,40 & 0,30 & 0,20 & 0,20 & 0,10 & 0,00 \\
\hline
\end{tabular}

- Definição da amostra de funcionários da guarda patrimonial da USP para aplicação do questionário, que classifica a frequência dos tipos de ocorrências observadas dentro do campus (baixa, média e alta) e grau de transtorno (pequeno, médio e grande);

- Pontuação dos dados obtidos no questionário de acordo com o impacto gerado no sistema de mobilidade do campus (Tabela 16).

Tabela 16 - Síntese dos dados (indicador 3.1.2)

\begin{tabular}{lc}
\hline \multicolumn{1}{c}{ Tipo de ocorrência } & Avaliação média \\
\hline Estacionamento irregular & 0,767 \\
\hline Eventos & 0,617 \\
\hline Fluxo na contramão & 0,475 \\
\hline Infração de trânsito & 0,917 \\
\hline Sistema de identificação nas portarias & 0,550 \\
\hline Veículos agrícolas & 0,700 \\
\hline Veículos de transporte de alunos (ônibus) & 0,783 \\
\hline
\end{tabular}

\section{H. Score}

Final $-0,706$

\begin{tabular}{|l|l|}
\hline DOMÍNIO & Administração/Gestão \\
\hline TEMA & Transporte coletivo \\
\hline INDICADOR 3.2.1 & Qualidade do transporte público urbano \\
\hline
\end{tabular}

\section{A. Definição}

Porcentagem dos usuários do transporte público urbano que avaliam como satisfatório o serviço prestado. 


\section{B. Referências}

Ferraz e Torres (2004).

\section{Relevância}

No processo de incentivo a modos mais sustentáveis, o transporte público urbano exerce um papel importante na substituição do uso de veículos particulares, principalmente para longas distâncias. Estes veículos podem transportar de 75 (ônibus convencional) a 190 passageiros (biarticulado), capacidade muito superior à de automóveis e motocicletas. A diferença também é significativa se for comparada a emissão de poluentes por usuário.

É importante ressaltar que os usuários de automóvel e motocicleta só migrarão para este modo de transporte se for vantajoso em diversos aspectos, como por exemplo, custo, tempo de trajeto, conforto, status social. Deste modo, é preciso que o serviço de transporte público oferecido possua um padrão de qualidade aceitável.

$\mathrm{Na}$ avaliação da qualidade do serviço de transporte público urbano oferecido, os usuários consideram um conjunto de aspectos, como a pontualidade, lotação, frequência, por exemplo. Porém, este julgamento varia individualmente, de acordo com idade, cultura, condição social, situação econômica, entre outros.

D. Pesos

\begin{tabular}{|l|l|l|l|l|l|c|}
\hline \multicolumn{1}{|c|}{ DOMÍNIO } & PESO & \multicolumn{1}{|c|}{ TEMA } & PESO & INDICADOR & PESO & $\begin{array}{c}\text { PESO } \\
\text { FINAL }\end{array}$ \\
\hline $\begin{array}{l}\text { ADMINISTRAÇÃO } \\
\text { / GESTÃO }\end{array}$ & 0,330 & Transporte público & 0,282 & $\begin{array}{l}\text { Transporte público } \\
\text { urbano }\end{array}$ & 0,660 & 0,061 \\
\hline
\end{tabular}

\section{E. Fontes de Dados}

- Questionário aplicado aos usuários.

\section{F. Ferramentas empregadas}

- Planilhas eletrônicas;

- Questionário online.

\section{G. Método de Cálculo}

Para o cálculo deste indicador, deve ser avaliado o grau de satisfação dos usuários em relação ao serviço oferecido pelo transporte público urbano da cidade. A avaliação dos quesitos abordados neste indicador pode ser levantada por meio de questionário aplicado aos usuários do campus. Neste questionário, os quesitos podem ser apresentados na forma de questões com múltipla escolha, de até quatro níveis, com os respectivos pesos: ótimo $(1,00)$, Bom ou Boa $(0,66)$, Regular $(0,33)$ e Ruim $(0,00)$. A partir destes pesos é realizada uma média ponderada entre as avaliações obtidas no questionário. Abaixo são apresentadas as definições dos extremos (parâmetros ótimos e ruins) para os itens avaliados.

\section{Usuários do transporte público urbano:}

- Distância do ponto de ônibus até a residência do usuário

- Ótima (menos de $100 \mathrm{~m}$ ou 1 quadra);

- Ruim (igual ou superior a $400 \mathrm{~m}$ ou 4 quadras).

- Frequência de atendimento 
- Ótima (intervalos de atendimento de 15 minutos ou menos);

- Ruim (intervalo de atendimento de 60 min ou mais).

- Pontualidade

- Ótima (nunca atrasa);

- Ruim (sempre atrasa).

- Tempo de viagem

- Ótimo (praticamente o mesmo tempo que levaria de automóvel);

- Ruim (duas vezes ou mais o tempo que levaria de automóvel).

- Lotação dos veículos

- Ótima (quando há assentos livres);

- Ruim (quando o veículo está lotado).

O cálculo final do indicador poderá ser obtido por meio da média de avaliação dos quesitos (Tabela 17).

Tabela 17 - Síntese dos dados (indicador 3.2.1)

\begin{tabular}{lc}
\hline \multicolumn{1}{c}{ Item avaliado } & Média \\
\hline Frequência & 0,272 \\
\hline Pontualidade & 0,393 \\
\hline Tempo de viagem & 0,333 \\
\hline Lotação & 0,303 \\
\hline
\end{tabular}

\section{H. Score}

Final $-0,326$ 


\begin{tabular}{|l|l|}
\hline DOMÍNIO & Administração/Gestão \\
\hline TEMA & Transporte coletivo \\
\hline INDICADOR 3.2.2 & Qualidade do transporte da Vila Estudantil \\
\hline
\end{tabular}

\section{A. Definição}

Grau de satisfação dos usuários do transporte da Vila Estudantil oferecido pela universidade, em relação ao serviço prestado.

\section{B. Referências}

Ferraz e Torres (2004).

\section{Relevância}

Na difusão dos princípios de mobilidade urbana sustentável no campus, a universidade deve motivar a prática de hábitos mais sustentáveis de seus usuários, como o uso do transporte coletivo oferecido gratuitamente pela universidade, para o deslocamento entre a moradia estudantil e o campus.

$\mathrm{Na}$ avaliação da qualidade do serviço de transporte coletivo oferecido pela universidade, os usuários consideram um conjunto de aspectos, como a pontualidade, lotação, frequência, por exemplo.

\section{Pesos}

\begin{tabular}{|c|c|c|c|c|c|c|}
\hline \multicolumn{1}{|c|}{ DOMÍNIO } & PESO & TEMA & PESO & INDICADOR & PESO & $\begin{array}{c}\text { PESO } \\
\text { FINAL }\end{array}$ \\
\hline $\begin{array}{l}\text { ADMINISTRAÇÃO } \\
\text { / GESTÃO }\end{array}$ & 0,330 & Transporte público & 0,282 & $\begin{array}{l}\text { Qualidade do } \\
\text { transporte da Vila } \\
\text { Estudantil }\end{array}$ & 0,340 & 0,032 \\
\hline
\end{tabular}

\section{E. Fontes de Dados}

- Questionário aplicado aos usuários que utilizam o transporte coletivo oferecido pela universidade, para o deslocamento entre a Vila Estudantil e o campus.

\section{F. Ferramentas empregadas}

- Planilhas eletrônicas;

- Questionário online.

\section{G. Método de Cálculo}

Para o cálculo deste indicador deve ser avaliado o grau de satisfação dos usuários em relação ao serviço do transporte oferecido pela universidade. A avaliação dos quesitos deste indicador pode ser coletada por meio de questionário aplicado aos usuários que utilizam este serviço. Neste questionário, os quesitos podem ser apresentados na forma de questão de múltipla escolha e avaliados em até quatro níveis, com os respectivos pesos: ótimo $(1,00)$, Bom ou Boa $(0,66)$, Regular $(0,33)$ e Ruim $(0,00)$. A partir destes pesos é realizada uma média ponderada entre as avaliações obtidas no questionário. Abaixo são apresentadas as definições dos extremos (parâmetros ótimos e ruins) para os itens avaliados. 
Usuários do transporte oferecido pela universidade:

- Frequência de atendimento

- Ótima (intervalos de atendimento de 15 minutos ou menos);

- Ruim (intervalo de atendimento de 60 min ou mais).

- Pontualidade

- Ótima (nunca atrasa);

- Ruim (sempre atrasa).

- Tempo de viagem

- Ótimo (praticamente o mesmo tempo que levaria de automóvel);

- Ruim (duas vezes ou mais o tempo que levaria de automóvel).

- Lotação dos veículos

- Ótima (quando há assentos livres);

- Ruim (quando o veículo está lotado).

O cálculo final do indicador poderá ser obtido por meio da média de avaliação dos quesitos (Tabela 18).

Tabela 18 - Síntese dos dados (indicador 3.2.2)

\begin{tabular}{lc}
\hline \multicolumn{1}{c}{ Item avaliado } & Média \\
\hline Frequência & 0,500 \\
\hline Pontualidade & 0,833 \\
\hline Tempo de viagem & 0,833 \\
\hline Lotação & 0,666 \\
\hline
\end{tabular}

H. Score

Final $-0,708$ 


\begin{tabular}{|l|l|}
\hline DOMÍNIO & Administração/Gestão \\
\hline TEMA & Segurança \\
\hline INDICADOR 3.3.1 & Segurança pública \\
\hline
\end{tabular}

\section{A. Definição}

Sensação de segurança dos usuários em torno do campus, nos diferentes turnos.

\section{B. Referências}

Stein (2013).

\section{Relevância}

A sensação de segurança, sentida pelos estudantes e funcionários ao acessar o campus, é um dos fatores importantes para a escolha do modo de transporte. Na medida em que os usuários se sentem ameaçados no entorno do campus, quando possível evitam as condições de exposição, como frequentar o campus a pé ou de bicicleta. Muitos destes usuários têm a necessidade de transportar, diariamente, itens de valor, como telefone, computador, livros, entre outros. Por esse motivo, uma parcela dos usuários opta por realizar o deslocamento de automóvel ou motocicleta, independente da distância residência-campus.

D. Pesos

\begin{tabular}{|l|l|l|l|l|l|c|}
\hline \multicolumn{1}{|c|}{ DOMÍNIO } & PESO & \multicolumn{1}{|c|}{ TEMA } & PESO & INDICADOR & PESO & $\begin{array}{c}\text { PESO } \\
\text { FINAL }\end{array}$ \\
\hline $\begin{array}{l}\text { ADMINISTRAÇÃO } \\
\text { / GESTÃO }\end{array}$ & 0,330 & Segurança & 0,496 & Segurança pública & 0,221 & 0,036 \\
\hline
\end{tabular}

\section{E. Fontes de Dados}

- Questionário aplicado aos usuários do campus.

\section{F. Ferramentas empregadas}

- Planilhas eletrônicas;

- Questionário online.

\section{G. Método de Cálculo}

Os dados referentes à sensação de segurança podem ser quantificados a partir da aplicação de questionário a todos os usuários do campus (alunos de graduação, alunos de pós-graduação, servidores docentes, servidores técnicos/administrativos). Este questionário permite avaliar a sensação de segurança por acesso, de cada área, e por períodos do dia (manhã, tarde e noite).

Para o cálculo do indicador pode ser atribuída uma escala numérica à sensação de segurança dos usuários, como mostrado na Tabela 19. 
Tabela 19 - Escala numérica atribuída a sensação de segurança dos usuários do campus (indicador 3.3.1)

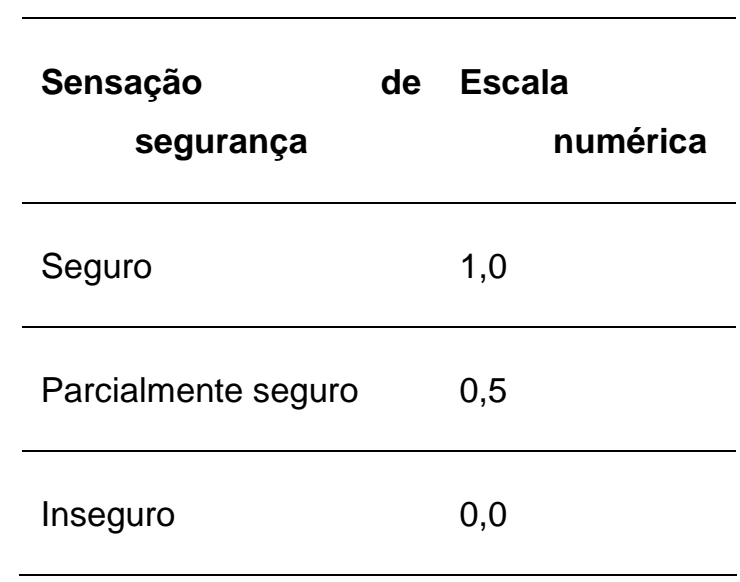

Esta escala será utilizada para ponderar a sensação de segurança por acesso e turno do dia, como mostrado nas equações a seguir.

$$
\begin{gathered}
A_{1 m}=\frac{S \times\left(\sum \boldsymbol{U}_{s m}\right)+P \times\left(\sum \boldsymbol{U}_{p m}\right)+\boldsymbol{I} \times\left(\sum \boldsymbol{U}_{i m}\right)}{\sum \boldsymbol{U}_{s m}+\sum \boldsymbol{U}_{p m}+\sum \boldsymbol{U}_{i m}} \\
A_{1}=\mathbf{0 , 3} \times \boldsymbol{A}_{1 m}+\mathbf{0 , 3} \times \boldsymbol{A}_{1 t}+\mathbf{0 , 4} \times \boldsymbol{A}_{1 n}
\end{gathered}
$$

Onde:

$\boldsymbol{A}_{1 m}$ : Sensação de segurança do acesso 1 (varia de 1 a 5 ) no turno $\boldsymbol{m}$ ( $\boldsymbol{m}$ - manhã,

$\boldsymbol{t}$ - tarde, $\boldsymbol{n}$ - noite);

$A_{1}$ : Sensação de segurança do acesso 1;

$S$ : Seguro, igual a 1,0;

$\boldsymbol{P}$ : Parcialmente seguro, igual a 0,5;

$I$ : Inseguro, igual a 0,0;

$\boldsymbol{U}_{s}$ : somatório dos usuários que se sentem seguros no turno $\boldsymbol{m}$;

$\boldsymbol{U}_{\boldsymbol{p}}$ : somatório dos usuários que se sentem parcialmente seguros no turno $\boldsymbol{m}$

$\boldsymbol{U}_{\boldsymbol{i}}$ : somatório dos usuários que se sentem inseguros no turno $\boldsymbol{m}$.

O valor final da sensação de segurança do campus será obtido por meio da média ponderada da sensação de segurança de cada acesso e do número de usuários que utilizam as respectivas portarias. A forma de realizar este cálculo é mostrada na equação abaixo:

$$
I_{3.3 .1 .}=\frac{\sum\left(A_{1} \times U_{1}\right)}{\sum U_{1}}
$$

Onde:

$U_{1}$ : somatório dos usuários que utilizam a entrada 1.

A Tabela 20 mostra os cálculos realizados. 
Tabela 20 - Síntese dos dados (indicador 3.3.1)

\begin{tabular}{|c|c|c|c|c|c|}
\hline \multirow{2}{*}{ Acesso } & \multirow{2}{*}{$\begin{array}{l}\text { Número de } \\
\text { respostas }\end{array}$} & \multicolumn{3}{|c|}{$\begin{array}{c}\text { Sensação de } \\
\text { segurança por turno }\end{array}$} & \multirow{2}{*}{$\begin{array}{c}\text { Sensação de segurança } \\
\text { por acesso }\end{array}$} \\
\hline & & Manhã & Tarde & Noite & \\
\hline $\begin{array}{l}\text { Acesso para } \\
\text { pedestres }\end{array}$ & 29 & 0,848 & 0,761 & 0,391 & 0,639 \\
\hline CENA & 43 & 0,905 & 0,878 & 0,375 & 0,685 \\
\hline Entrada da Atlética & 12 & 0,792 & 0,750 & 0,250 & 0,563 \\
\hline $\begin{array}{l}\text { Entrada Engenharia } \\
\text { Monte Alegre }\end{array}$ & 76 & 0,822 & 0,774 & 0,341 & 0,615 \\
\hline Entrada Entomologia & 26 & 0,860 & 0,720 & 0,227 & 0,565 \\
\hline Entrada Principal & 182 & 0,826 & 0,784 & 0,384 & 0,637 \\
\hline Total Geral & 368 & 0,837 & 0,785 & 0,359 & 0,631 \\
\hline
\end{tabular}

H. Score

Final $-\mathbf{0 , 6 3 1}$ 


\begin{tabular}{|l|l|}
\hline DOMÍNIO & Administração/Gestão \\
\hline TEMA & Segurança \\
\hline INDICADOR 3.3.2 & Fiscalização de infrações de trânsito no campus \\
\hline
\end{tabular}

\section{A. Definição}

Eficiência das ações de fiscalização de infrações de trânsito realizada pelos agentes de segurança do campus.

\section{B. Referências}

Stein (2013).

\section{Relevância}

A fiscalização de infrações de trânsito dentro do campus garante a fluidez do tráfego e promove, de certa forma, a educação no trânsito aos usuários. Porém, é necessário dispor de funcionários instruídos, banco de registro de notificações e políticas punitivas a usuários reincidentes, para garantir a eficiência da fiscalização. Quando um dos três elementos é inexiste ou falho, compromete todo o sistema de fiscalização. Este efeito se reflete na deseducação dos usuários e na desmotivação dos agentes da segurança em realizar as notificações.

\section{Pesos}

\begin{tabular}{|l|l|c|c|c|c|c|}
\hline \multicolumn{1}{|c|}{ DOMÍNIO } & PESO & TEMA & PESO & INDICADOR & PESO & $\begin{array}{c}\text { PESO } \\
\text { FINAL }\end{array}$ \\
\hline $\begin{array}{l}\text { ADMINISTRAÇÃO } \\
\text { / GESTÃO }\end{array}$ & 0,330 & Segurança & 0,496 & $\begin{array}{l}\text { Fiscalização de infrações de } \\
\text { trânsito no campus }\end{array}$ & 0,253 & 0,042 \\
\hline
\end{tabular}

\section{E. Fonte de dados}

- Pesquisa realizada com os agentes de segurança.

\section{F. Ferramentas empregadas}

- Planilhas eletrônicas.

\section{G. Método de cálculo}

Este indicador pode ser mensurado a partir da avaliação da efetividade da fiscalização de infração de trânsito e do número de infrações registradas no campus. Os agentes da segurança do campus, que realizam a fiscalização, são solicitados a avaliar a efetividade de todo o sistema de fiscalização que envolve: os tipos de ocorrências notificadas, o banco de dados com o registro das notificações e as políticas aplicadas a usuários reincidentes. Recomenda-se selecionar amostra, entre os agentes de segurança, que envolvam entrevistados de diferentes turnos. A avaliação destes quesitos pode ser obtida com o auxílio de um questionário, que deve abordar os seguintes pontos:

- Quais os tipos de ocorrência que são notificadas no campus (estacionamento em local proibido, estacionamento em vaga imprópria, operação de carga e descarga em local inapropriado, excesso de velocidade, desrespeito a faixa de pedestres, entre outros);

- Se os agentes de segurança estão aptos a realizar notificações de infração de trânsito;

- Qual a frequência com que é realizada notificações no campus (todos os dias, pelo menos uma vez por semana, por exemplo); 
- Se os agentes de segurança têm algum tipo de feedback a respeito das notificações realizadas;

- Sugestão de como deveria ser o processo de fiscalização de infração de trânsito do campus.

Cada um destes pontos pode ser avaliado por meio de uma escala qualitativa, que pode ser traduzida em um valor numérico, como mostrado na Figura 2.

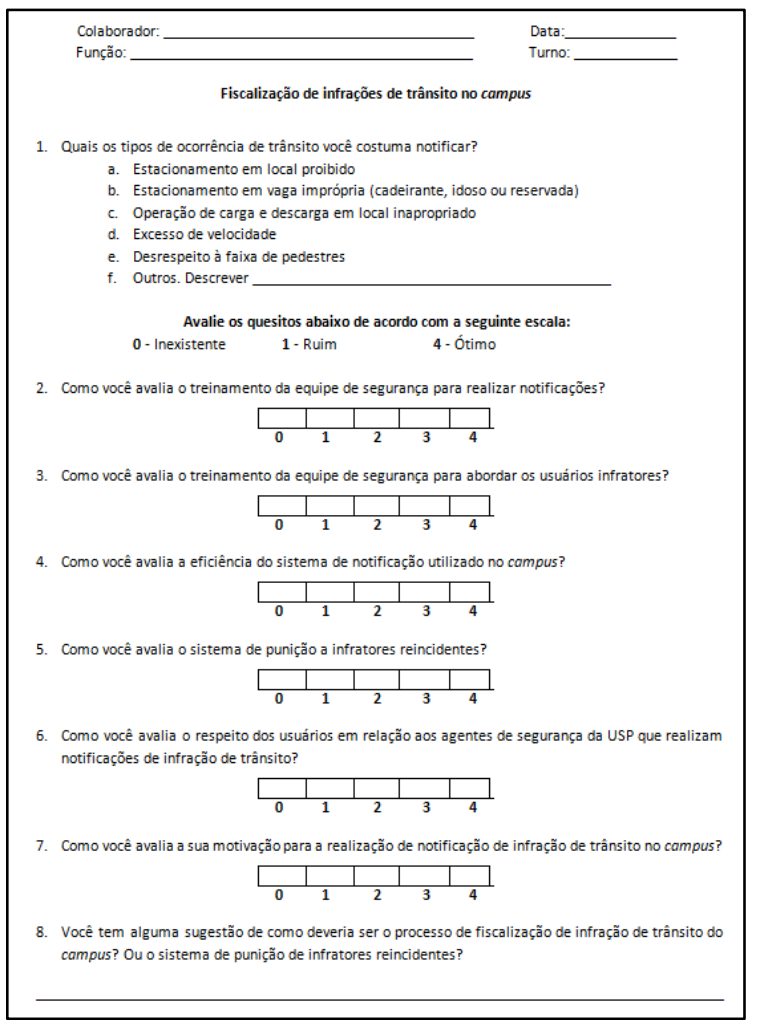

Figura 2- Ficha de para avaliação do sistema de fiscalização de infrações de trânsito no campus (indicador 3.3.2)

- Avaliação da efetividade de todo o sistema de fiscalização que envolve: os tipos de ocorrências notificadas, o banco de dados com o registro das notificações e as políticas aplicadas a usuários reincidentes;

- Cálculo da média aritmética de todos os pontos avaliados no questionário.

Além disso, é levantado o número de infrações dentro do campus em determinado período de tempo. Este valor é então normalizado por meio da interpolação da porcentagem de infrações em relação ao número de usuários da amostra, segundo os valores de referência da Tabela 21:

Tabela 21 - Normalização - indicador 3.3.2

\begin{tabular}{cc}
\hline Valor normalizado & $\%$ de acidentes \\
\hline 1,0 & $0 \%$ \\
\hline 0,0 & $5 \%$ \\
\hline
\end{tabular}

O valor final do indicador é dado pela média aritmética da avaliação (segundo questionário) e do valor normalizado das infrações (Tabela 22). 
Tabela 22 - Síntese dos dados calculados (indicador 3.3.2)

\begin{tabular}{lc}
\hline Média da avaliação (questionário) & 0,589 \\
\hline Usuários de automóveis & 229 \\
\hline Total de usuários respondentes & 1082 \\
\hline Número total de Infrações em 2016 e 2017 & 214 \\
\hline \% Infrações/usuários & $19,78 \%$ \\
\hline Valor Normalizado de Infrações & 0,000 \\
\hline Score & $\mathbf{0 , 2 9 4}$ \\
\hline
\end{tabular}

H. Score

Final - 0,294 


\begin{tabular}{|l|l|}
\hline DOMÍNIO & Administração/Gestão \\
\hline TEMA & Segurança \\
\hline INDICADOR 3.3.3 & Segurança no trânsito \\
\hline
\end{tabular}

\section{A. Definição}

Número de acidentes com vítimas e sem vítimas no campus.

\section{B. Relevância}

A fiscalização de infrações de trânsito dentro do campus garante a fluidez do tráfego e promove, de certa forma, a educação no trânsito aos usuários. Porém, é necessário dispor de funcionários instruídos, banco de registro de notificações e políticas punitivas a usuários reincidentes, para garantir a eficiência da fiscalização. Quando um dos três elementos é inexiste ou falho, compromete todo o sistema de fiscalização. Este efeito se reflete na deseducação dos usuários e na desmotivação dos agentes da segurança em realizar as notificações.

C. Pesos

\begin{tabular}{|l|l|c|c|c|c|c|}
\hline \multicolumn{1}{|c|}{ DOMÍNIO } & PESO & TEMA & PESO & INDICADOR & PESO & $\begin{array}{c}\text { PESO } \\
\text { FINAL }\end{array}$ \\
\hline $\begin{array}{l}\text { ADMINISTRAÇÃO } \\
\text { / GESTÃO }\end{array}$ & 0,330 & Segurança & 0,496 & $\begin{array}{l}\text { Fiscalização de infrações de } \\
\text { trânsito no campus }\end{array}$ & 0,253 & 0,042 \\
\hline
\end{tabular}

\section{Fontes de Dados}

- Relatório de acidentes no campus

\section{E. Ferramentas empregadas}

- Planilhas eletrônicas

\section{F. Método de Cálculo}

Os acidentes são divididos em dois grupos: com vítimas e sem vítimas. Para cada um destes grupos, calcula-se a razão entre o número de acidentes e o número total de usuários do campus. Estes valores são então normalizados por meio da interpolação das porcentagens de acidentes, segundo os valores de referência da Tabela 23:

Tabela 23 - Normalização - indicador 3.3.3

\begin{tabular}{cc}
\hline Valor normalizado & \% de acidentes \\
\hline 1,0 & $0 \%$ \\
\hline 0,0 & $5 \%$ \\
\hline
\end{tabular}

Atribui-se o peso de 0,8 para os acidentes com vítimas e 0,2 para os acidentes sem vítimas. Assim, o valor do indicador é dado pela equação:

$$
\begin{aligned}
& I_{3.3 .3}=0,8 \times \text { valor normalizado de acidentes com vítimas } \\
& \quad+0,2 \times \text { valor normalizado de acidentes sem vítimas }
\end{aligned}
$$

A Tabela 24 mostra os cálculos realizados. 
Tabela 24 - Síntese dos dados (indicador 3.3.3)

\begin{tabular}{lcccc}
\hline & $\begin{array}{c}\text { Número de } \\
\text { acidentes }\end{array}$ & $\begin{array}{c}\% \text { de } \\
\text { acidentes }\end{array}$ & $\begin{array}{c}\text { Valor } \\
\text { normalizado }\end{array}$ & Peso \\
\hline Acidentes com vítimas & 5 & 0,46 & 0,908 & 0,8 \\
\hline Acidentes sem vítimas & 31 & 2,87 & 0,427 & 0,2 \\
\hline
\end{tabular}

Número total de usuários respondentes: 1082

G. Score

Final - 0,811 
Bibliografia

AASHTO. Guide for Design of Pavement Structures. Association of State Highway and Transportation Officials. Washington. 1986. Appendix K: Typical Pavement Distress TypeSeverity Descriptions.

ABNT. NBR 9050:2004 Acessibilidade a edificações, mobiliário, espaços e equipamentos urbanos. Associação Brasileira de Normas Técnicas, Rio de Janeiro, p. 97, 2004.

AMARAL, R. C. Análise da aplicação da pegada ecológica em contexto universitário: estudo de caso no campus de São Carlos da Universidade de São Paulo. Trabalho de conclusão de curso. Universidade de São Paulo. São Carlos. 2010.

BERNUCCI, L. B. et al. Pavimentação asfáltica: formação básica para engenheiros. 1a. ed. Rio de Janeiro: ABEDA, v. Único, 2006.

CAMISÃO, V. Manual para acessibilidade aos prédios residenciais da cidade do Rio de Janeiro. PMRJ/FUNLAR/CVI Rio/IBAM. Rio de Janeiro, p. 44. 2003. (720(CDD 15.ed.)).

CONTRAN. Sinalização Vertical de Regulamentação. Conselho Nacional de Trânsito. Brasília, p. 218. 2005.

CONTRAN. Sinalização Horizontal. Conselho Nacional de Trânsito. Brasília, p. 128. 2007a.

CONTRAN. Sinalização Vertical de Advertência. Conselho Nacional de Trânsito. Brasília, p. 214. 2007b.

CONTRAN. Resolução 303 de 18 de Dezembro de 2008. Conselho Nacional de Trânsito. Brasília, p. 6. 2008.

COSTA, M. D. S. Um índice de mobilidade urbana sustentável. Tese de Doutorado. Universidade de São Paulo. São Carlos, p. 248. 2008.

FARIA, E. D. O.; BRAGA, M. G. D. C. Avaliar programas educativos para o trânsito não é medir a redução de acidentes ou de exposição ao risco de acidentes. XIX Congresso de Pesquisa e Ensino em Transportes, Recife, I, Novembro 2005. 1000-1011.

FERNANDES JR., J. L. Sistemas de gerência de pavimento urbanos para cidades de médio porte. Apostila didática. Universidade de São Paulo. São Carlos. 2001.

FERNANDES JR., J. L.; ODA, S.; ZERBINI, L. F. Defeitos e atividades de manutenção e reabilitação em pavimentos asfálticos. Tese de Livre docência. Universidade de São Paulo. São Carlos, p. 101. 2011.

FERRAZ, A. C.". P.; TORRES, I. G. E. Transporte público urbano. 2ª . ed. São Carlos: RiMa, 2004. 428 p. ISBN 85-86552-88-7.

GUERREIRO, T. D. C. M.; STEIN, P. P.; SILVA, A. N. R. D. Potencial de uma infraestrutura cicloviária para diferentes usuários de um polo gerador de viagens: o caso de um campus universitário. XXVII Associação de Pesquisa e Ensino em Transportes, Belém, 2013.

KUIJPER, D.; BRAAKMAN, B. Five main requirements for cycling-inclusive infrastructure. In: ICE, G. S. A. Cycling-inclusive policy development: a handbook. Utrecht: [s.n.], 2009. Cap. 5, p. 248.

OLIVEIRA, A. M. Um índice para o planejamento de mobilidade com foco em grandes Polos Geradores de Viagens - Desenvolvimento e aplicação em um campus universitário. Dissertação de Mestrado. Universidade de São Paulo. São Carlos, p. 197. 2015.

OLIVEIRA, A. M.; RAMOS, T. C.; SILVA, A. N. R. D. Introduzindo conceitos de mobilidade sustentável no ensino superior a partir de problemas de mobilidade do campus. PLURIS, Lisboa, 2014. 
SETTI, J. R. A. Tecnologia de transportes. Apostila Didática. Universidade de São Paulo. São Carlos, p. 214. 2002.

SHRP. Distress identification manual for the long-term pavement performance studies. National Academy of Science. Washington. 1993.

STEIN, P. P. Barreiras, motivações e estratégias para mobilidade sustentável no campus São Carlos da USP. Dissertação de Mestrado. Universidade de São Paulo. São Carlos, p. 116. 2013.

STEIN, P. P.; SILVA JUNIOR, C. A. P. D.; SILVA, A. N. R. D. Impactos nas distâncias de caminhada decorrentes de acessos exclusivos para pedestres em um campus universitário. Paranoá: Caderno de arquitetura e urbanismo, Brasília, v. 6, p. 113-121, 2012. ISSN 16790944.

WILHELM, A.; POSCH, K.-H. Mobility management strategies for the next decades. Transportation Research Board, Washington, v. 82, p. 173-181, Janeiro 2005. 


\author{
APÊNDICE E \\ RESPOSTAS DO PAINEL DE ESPECIALISTAS
}

\begin{abstract}
POTENCIAL DE TRANSFERÊNCIA DE UM ÍNDICE DE MOBILIDADE SUSTENTÁVEL PARA CAMPUS UNIVERSITÁRIO
\end{abstract}

Francine Marvulle Tan

São Carlos

2018 


\section{Sumário}

Caracterização do campus 3

Identifique o seu campus (nome, cidade, endereço ou CEP - da maneira que julgar mais clara e de fácil identificação para pessoas sem vinculação ao campus) .................. 3

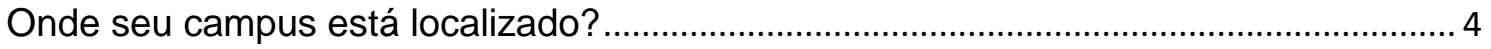

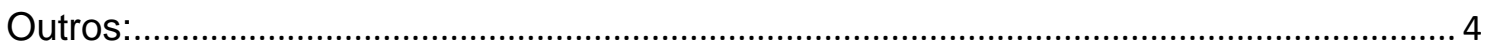

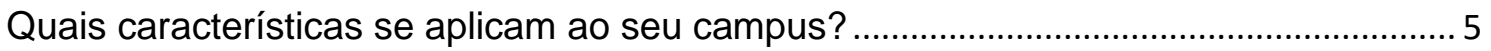

O seu campus apresenta alguma particularidade relevante, ou seja, alguma característica que o faça apresentar necessidades específicas do ponto de vista de transportes?.

Avaliações dos indicadores - Adaptações necessárias (Resposta aberta)....................... 8

1) Ações de conscientização do uso de modos alternativos ......................................... 8

2) Ações de educação no trânsito ……………...................................................... 9

3) Ações de incentivo à preferência de modos alternativos ....................................... 10

4) Adequação do modo de transporte ....................................................................... 11

5) Infraestrutura de acesso ao campus ................................................................ 12

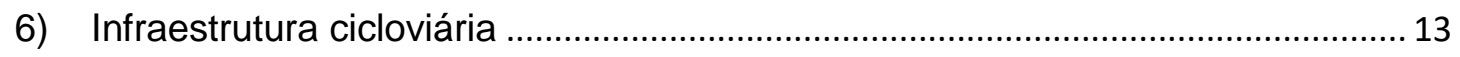

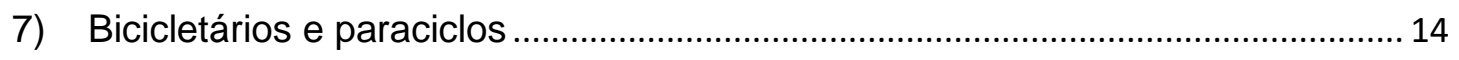

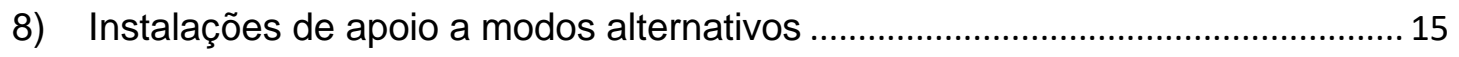



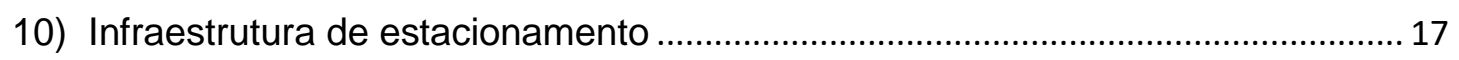

11) Infraestrutura de transporte público urbano .......................................................... 18

12) Qualidade das calçadas dentro e de acesso ao campus....................................... 19

13) Vagas para usuários com restrição de mobilidade ................................................. 20

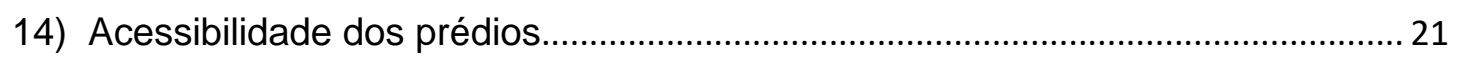

15) Medidas de gestão das áreas de estacionamento................................................... 22

16) Medidas de gestão do fluxo e estacionamentos .................................................... 23

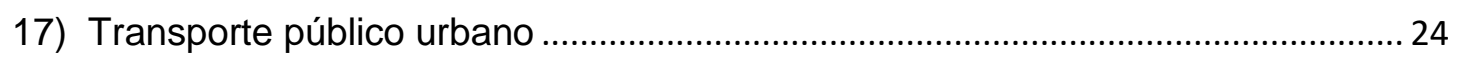

18) Transporte coletivo interno ou entre áreas do campus ......................................... 25

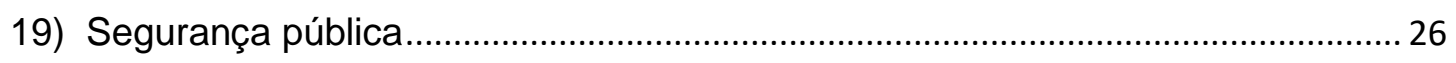

20) Fiscalização de infrações de trânsito no campus................................................... 27

Deseja fazer algum comentário adicional ou sugestão sobre o índice de mobilidade sustentável para campus universitário?. 


\section{Caracterização do campus}

Identifique o seu campus (nome, cidade, endereço ou CEP - da maneira que julgar mais clara e de fácil identificação para pessoas sem vinculação ao campus)

Universidade de Brasília - Campus Darcy Ribeiro

Universidade Federal de Goiás - Campus Colemar Natal e Silva

Universidade Federal de Alagoas

Universidade Federal do Ceará - Campus do Pici

Universidade Federal da Paraíba - Campus I

Universidade Federal do Rio Grande do Norte - Campus Central

Universidade Federal do Amazonas - Campus Universitário Senador

Arthur Virgílio Filho

Unifei - Itajubá

Universidade Federal de Minas Gerais - Campus Pampulha

Universidade Federal de Ouro Preto - Campus Morro do Cruzeiro

CEFET/MG - Campus 1

Universidade Federal do Rio de Janeiro - llha do Fundão

UNICAMP

PUC Campinas - Campus 1

USP - EESC

USP LESTE

UFSCar - Campus São Carlos

USP - CUASO

UNESP Bauru - Faculdade de Arquitetura, Artes e Comunicação -.

USP - Campus Fernando Costa

Universidade Tecnológica Federal do Paraná - Campus Apucarana

Universidade Federal do Paraná - Centro Politécnico

Universidade Estadual de Londrina

Universidade Federal de Santa Catarina - Campus Trindade 
Onde seu campus está localizado?

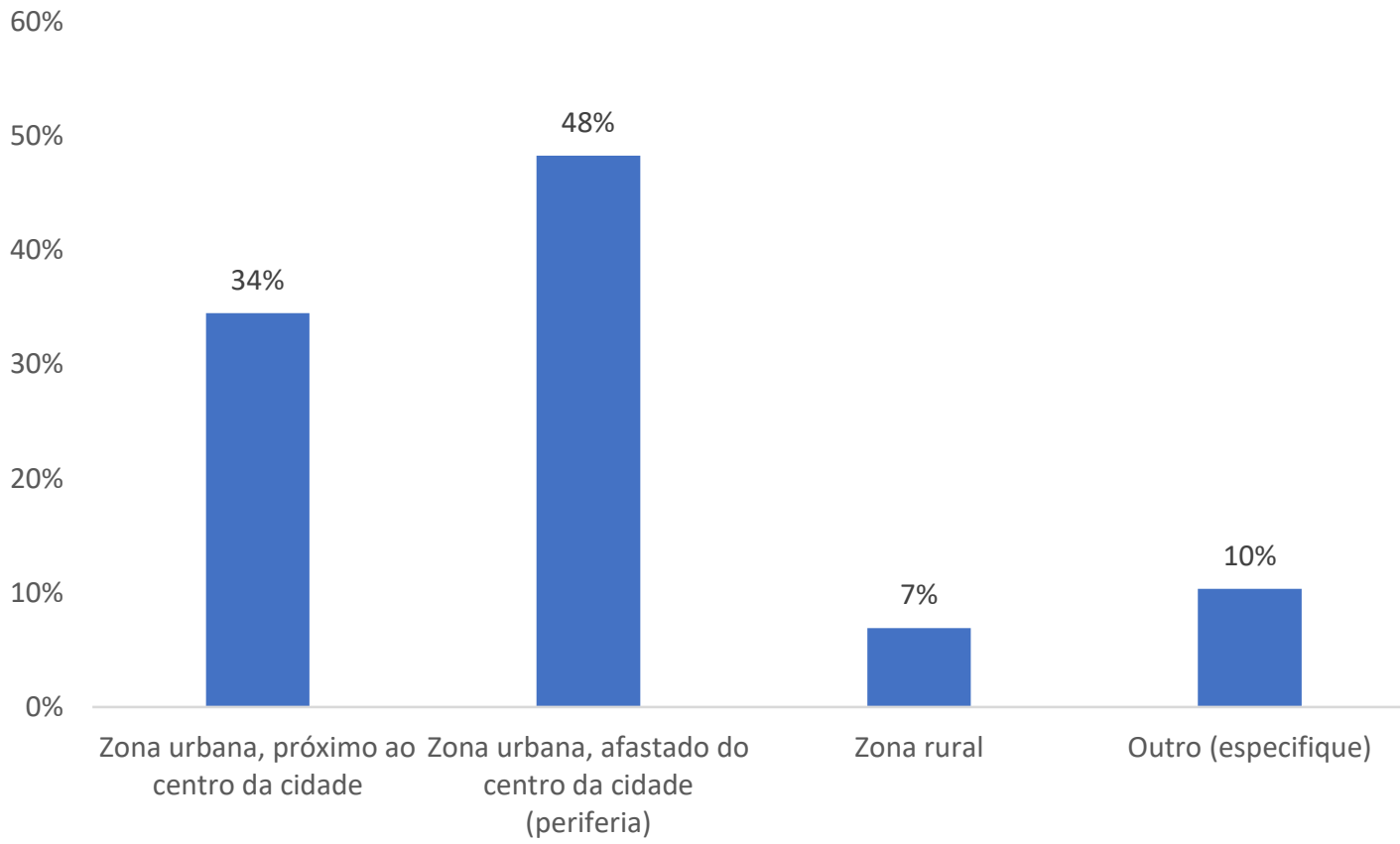

Zona urbana, próximo ao centro da cidade $34 \%$

Zona urbana, afastado do centro da cidade (periferia)

Zona rural

$48 \% \quad 14$

Outro (especifique)

$7 \% \quad 2$

$10 \% \quad 3$

\section{Outros:}

No distrito de Barão Geraldo

Zona urbana, próximo a quadras residenciais e de serviços, e setores de clubes.

Está a menos de $4 \mathrm{~km}$ do centro da cidade. Fortaleza só tem área urbana. 


\section{Quais características se aplicam ao seu campus?}

Selecione uma ou mais opções.

Nenhuma das anteriores

Possui cursos de apenas uma área de conhecimento

Possui cursos de diversas áreas de conhecimento

Dividido em 2 ou mais áreas físicas (terrenos)

Extenso

Compacto

$0 \%$
$0 \%$

$10 \%$

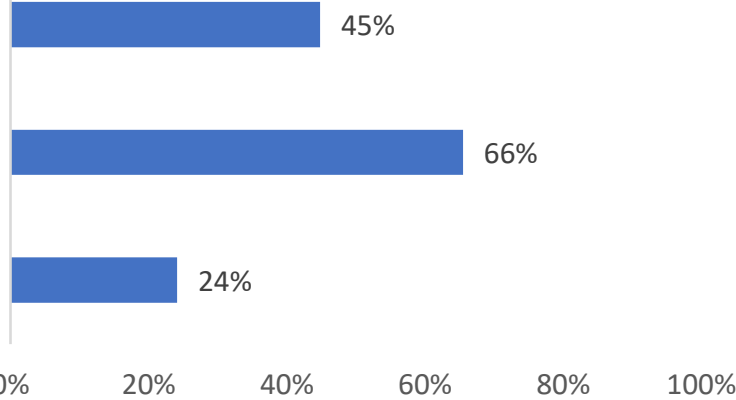

\begin{tabular}{lrr} 
Compacto & $24 \%$ & 7 \\
\hline Extenso & $66 \%$ & 19 \\
\hline Dividido em 2 ou mais áreas físicas (terrenos) & $45 \%$ & 13 \\
\hline Possui cursos de diversas áreas de conhecimento & $90 \%$ & 26 \\
\hline Possui cursos de apenas uma área de conhecimento & $10 \%$ & 3 \\
\hline Nenhuma das anteriores & $0 \%$ & 0
\end{tabular}

\section{Outros:}

Além da Unidade Sede em Maceió, existem campi espalhados em diversas cidades do interior do Estado.

A UFBA é conformada por vários campi, em área urbana.

São 4 setores neste campi: setor de tecnologia, setor de ciências biológicas, ciências exatas e ciências da terra

Localizado em uma área de preservação ambiental (APA)

Existem outros campi - um em Limeira e outro em Piracicaba.

Inclui Parque Tecnológico onde se localizam várias empresas desenvolvendo pesquisas em conjunto com a Universidade; Centro de Pesquisa da Eletrobrás; Centro de Pesquisa da Petrobrás; Centro de Tecnologia Mineral

Campus muito extenso, cortado por uma rodovia e com acesso único em área de expansão da trama urbana. 
O seu campus apresenta alguma particularidade relevante, ou seja, alguma característica que o faça apresentar necessidades específicas do ponto de vista de transportes?

Comente.

O campus é extenso e possui trechos com declividades elevadas.

Apresenta terreno de alta declividade (inclinação média $=2.8 \%$ )

O espaço físico disponível para o estacionamento de veículos dentro do campus é limitado. Nos últimos meses foi estabelecida uma nova regra: somente servidores podem estacionar dentro do campus. Como a universidade apresenta uma tendência de crescimento, é possível que nos próximos anos não haja espaço suficiente para o estacionamento de veículos para estudantes nos arredores do campus.

Não. Localizado afastado do centro da cidade, mas possui ruas pavimentadas em torno do campus

Terreno acidentados, apresenta ladeiras longas e muitas escadas

Para a unidade sede não. A cobertura do sistema de transporte público urbano é razoável. No entanto, tem uma unidade descentralizada, que fica na cidade de Rio Largo (20km de distância), que possui uma sofrível cobertura do sistema de TPU.

Tem uma estação de trem na porta da Escola e uma rodovia na outra porta.

Está inserido em bairros residenciais densos e cortado por vias importantes para a cidade. Além do grande fluxo de veículos que atrai também possui intenso tráfego de passagem.

Muitas. Alto fluxo de pedestres. Muitos prédios. Alta extensão territorial.

Sim, desnível geográfico considerável (acima de 5\% de inclinação) entre as duas áreas (norte e sul).

Sim. O relevo acidentado da cidade de Salvador constitui uma barreira para a integração física dos Cursos e produz deslocamentos os quais são resolvidos na maioria dos casos por modos motorizados.

Áreas restritas para estacionamento e sistema de transporte público deficiente

O Campus está situado entre a Av. Salgado Filho (extensão urbana da BR-101 em Natal) e o Parque das Dunas, reserva florestal urbana. A área total do Campus é de 123 hectares, quase totalmente servido por uma via perimetral usada por muitos automobilistas em percursos entra a Zona Sul e as demais zonas da cidade.

Não

Sim. As vias da CUASO são utilizadas como tráfego de passagem, por motoristas que evitam as vias arteriais do seu entorno. Estimativa de circulação de 50.000 veículos ao longo do dia, sendo $30.000 \mathrm{com}$ vínculo com a USP.

Sim. Dividido em dois setores, Setor Sul e Setor Norte, que distam aproximadamente $1.700 \mathrm{~km}$, em linha reta. A ligação entre estes dois setores se dá exclusivamente por automóveis ou por ônibus. Os ônibus que operam no Campus UFAM (capital), são da Prefeitura Municipal de Manaus, e a qualidade do serviço prestado não apresenta níveis satisfatórios. Não há infraestrutura para pedestres e bicicletas na via que liga os referidos setores. Não plano estratégico para gerenciamento da demanda de viagens. A velocidade regulamentada para as vias do Campus é de $40 \mathrm{~km} / \mathrm{h}$, por estar em área de preservação ambiental. No entanto, pouco respeitada. Estudos vem sendo desenvolvidos no meio acadêmico com intuito de identificar parâmetros mobilidade e acessibilidade naquele Campus.

Vou responder pelo campus de Campinas. Este campus é compacto. Aqui está a reitoria da universidade e a maior parte dos cursos. Observo que o campus não é acessível para pessoas com deficiência. As rotas acessíveis são deficientes. Existe rota acessível, em locais específicos. Agora que a Unicamp está se adaptando para a inclusão social. O transporte sustentável (a pé e de bicicleta) também é incompleto. Faltam calçamentos. Existem ciclofaixas, que em alguns trechos divide espaço com os veículos motorizados. Os estacionamentos para bicicletas são insuficientes. A Unicamp implantou um sistema de bicicleta compartilhada, mas foi desativado antes da implantação final. Quanto ao transporte coletivo, existem linhas circulares no campus gratuitas que vão até a moradia estudantil da universidade. Outras linhas do transporte coletivo atendem a Unicamp.

O campus recebe cerca de 40 mil pessoas por dia e, mesmo localizado em um dos principais corredores de transporte da RMR, não é atendido por nenhum sistema de transporte de massa (metrô, BRT ou VLT) 
o campus está localizado no topo de um morro, dificultando o acesso não motorizado

Grande distâncias entre as áreas comuns (biblioteca, restaurante universitário) e salas de aula e departamentos de ensino dos diversos cursos.

Sim. Localizado entre 3 vias expressas o que praticamente impede o acesso via transporte ativo. 1) RU, moradia e área esportiva em uma área, situada a $5 \mathrm{~km}$ da maior parte das áreas com atividades acadêmicas. 2) Transporte de animais e rebanhos pelo campus, antes realizado pelas próprias vias, hoje realizado embarcado. 3) Um terço das áreas são declaradas como reserva ambiental USP, com trilhas para fruição da paisagem.

Pelo fato de ser dividido em várias áreas, faltam estudos mais específicos no Campus sobre a possibilidade da construção ou adaptação de acessos alternativos interligando internamente essas diversas áreas de forma a oferecer mais segurança para pedestres e ciclistas.

Pela extensão do campus, parte das viagens internas não podem ser feitas caminhando. As pessoas dependem de modos motorizados privados ou das linhas de ônibus internas. Alguns usam a bicicleta, mas o tipo de pavimento não favorece muito este modo.

O Campus I, da UFPB, está praticamente todo ocupado com exceção de áreas de preservação, que são cercadas e sem possibilidade de acesso

Ligação entre o campus 1 e 2 por intercampi pois algumas atividades acadêmicas de alguns cursos são divididas entre os dois campi. 


\section{Avaliações dos indicadores - Adaptações necessárias (Resposta aberta)}

\section{1) Ações de conscientização do uso de modos alternativos}

Definição: Porcentagem dos usuários do campus que participam e/ou têm conhecimento das ações de conscientização promovidas pela universidade, bem como a eficácia destas ações.

Este indicador necessita das seguintes adaptações para ser aplicado em meu campus:

O indicador é dependente das ações ou não de conscientização da universidade. Poderia simplesmente avaliar qual a porcentagem de usuários do campus que têm conhecimento das ações de conscientização do uso de modos alternativos, bem como a eficácia destas ações. Não existe uma infraestrutura adequada para estímulo do uso de bicletas no campus, como por exemplo presença de ciclofaixa ou paraciclos. No entanto, alguns projetos de extensão foram recentemente desenvolvidos na IES com o intuito de fomentar a discussão destes aspectos. Primeiro: ações efetivamente práticas de conscientização sobre o uso dos modos alternativos, bem como o respeito ao mesmo devem ser implementadas no campus. Em segundo lugar, divulgação de tais ações.

Divulgação de linhas de ônibus e carona solidária, sendo este último com desenvolvimento e ampla divulgação de aplicativo próprio, possivelmente oficial, desenvolvido pela própria USP. Existem alguns estudos acadêmicos, elaborados em diferentes cursos (ex.: Arquitetura, Engenharia Civil, Geografia e Engenharia de Produção) que apontam estratégias para a mobilidade e acessibilidade ao Campus por modos alternativos, porém, não há ações contínuas da Universidade Federal do Amazonas nesse sentido. É preciso que a Instituição estabeleça essas ações.

Não tenho os dados. Seria preciso levantar.

Acredito que a porcentagem de uso de modos alternativos, através da frequência semanal, traria maior significância na avaliação do campus quanto ao indicador de mobilidade sustentável em comparação com a pergunta se usuários do campus participam, ou tem conhecimento de ações de conscientização, promovidas pela Universidade. Acredito que poderia ser mantida a pergunta atual desde que fosse criado outro indicador referente à frequência semanal de uso de modos alternativos.

Não sei se é possível saber "eficácia" destas ações. Ou pelo menos não no mesmo indicador de porcentagem de usuários. 


\section{2) Ações de educação no trânsito}

Definição: Porcentagem dos usuários do campus que participam e/ou têm conhecimento das ações de educação no trânsito promovidas pela universidade, bem como a eficácia destas ações.

Este indicador necessita das seguintes adaptações para ser aplicado em meu campus:

O indicador é dependente das ações ou não de conscientização da universidade. Poderia simplesmente avaliar qual a porcentagem de usuários do campus que têm conhecimento das ações de educação no trânsito, bem como a eficácia dessas ações

O indicador é muito importante, mas infelizmente não existe atualmente uma política institucional que vise abordar tais aspectos. Essas campanhas na Universidade são promovidas pelos órgãos externos, por exemplo SMTT, em períodos já consagrados, como o Maio Amarelo.

diferenciar quem usa transporte público $X$ privado

Deve ser aplicado para os usuários dos diferentes meios de transporte (auto, ônibus, bicicleta, a pé)

Dentro do campus constata-se um número elevadíssimo de desrespeito à legislação de trânsito, principalmente relacionado ao estacionamento de veículos em locais proibidos. Para o indicador em questão ser aplicado no campus, poder-se-ia fazer um levantamento do número de irregularidades de carros estacionados, despertando assim a necessidade de conscientização de ações voltadas à educação no trânsito.

Educação no trânsito é uma expressão limitadora do conjunto de ações que podem ser desenvolvidas institucionalmente; sugiro encampar a noção de educação para a mobilidade sustentável, orientada pelos ditames da Política Nacional de Mobilidade Urbana.

Executar ações de educação no trânsito dentro do CAMPUS hoje inexistentes Campanhas educativas são essenciais, haja vista que não existe fiscalização com autuação por órgão de trânsito dentro da Campus da Capital.

Não há ações neste sentido. Em função dos acidentes registrados no Campus devido a alta velocidade, houve uma tentativa junto ao órgão gestor municipal do trânsito , em 2014, no sentido de minimizar o índice de acidentes dentro do Campus UFAM. Porém não saiu do papel.

No campus não se percebe muitos problemas relacionados a educação de trânsito.

idem

No âmbito da Universidade, o indicador poderia ser inválido já que, na maioria das vezes, as campanhas educativas de trânsito acontecem em nível urbano municipal, promovidas pelas Prefeituras. O indicador poderia ser alterado para "Porcentagem dos usuários do campus que participam e/ou têm conhecimento das ações de educação promovidas pelos órgãos gestores municipais..."

Reitero a questão de "eficácia". 


\section{3) Ações de incentivo à preferência de modos alternativos}

Definição: Porcentagem dos usuários que participam de programas de benefícios oferecidos para usuários assíduos de modos mais sustentáveis de deslocamento (a pé, bicicleta, sistema de carona, etc.).

Este indicador necessita das seguintes adaptações para ser aplicado em meu campus:

O indicador cria uma relação de dependência da criação de programas de benefícios aos usuários de modos alternativos de transporte para ser avaliado. Poderia avaliar simplesmente qual a quantidade de usuários que fazem uso desses modos de deslocamento. Assim, complementaria o indicador 1

O campus apresenta 5 cursos de graduação, com aproximadamente 800 alunos. A grande maioria dos alunos (em torno de uns 550 a 600 alunos) moram em edifícios residenciais para estudantes que se encontram a cerca de no máximo 100 metros da entrada do campus, portanto a maioria dos alunos vem a pé. Portanto a prefeitura além da passagem pela metade do preço para estudantes, não faz nenhum outro tipo de incentivo.

Necessidade de desenvolver projetos e/ou ações mais constantes e contínuas relacionados com o tema.

Devem se adaptados aos diferentes tipos de usuários do campus (funcionários, alunos, professores) que possuem diferentes hábitos e comportamentos.

Em geral as pessoas se deslocam de muito longe, sendo o uso de bicicleta apenas para alguns que moram no entorno, e talvez para deslocamentos internos. Longe de ser uma solução, dada a dimensão da cidade e o percurso médio dos que utilizam o Campus. No entanto, a carona solidária parece uma solução adequada para compartilhamento de despesas.

Não há programas de benefícios.

Não se aplica para transporte a pé ou por bicicleta.

$O$ indicador proposto é relevante, porém não se adéqua às condições atuais pois inexistem benefícios para usuários assíduos de modos mais sustentáveis de deslocamento. Uma adequação a ser feita no indicador poderia ser: Porcentagem de usuários que poderiam ser assíduos de modos mais sustentáveis, caso fossem oferecidos benefícios, e a identificação do tipo de benefício. Cabe ressaltar que o transporte coletivo é subsidiado para os estudantes, mas não existem incentivos à assiduidade.

No meu campus eu acho que a utilidade do indicador é mostrar que precisamos ter alguns desses programas, para que os usuários possam participar.

A universidade não tem programas de benefícios. Para o indicador poder ser aplicado, teria que ser "porcentagem de usuários que participariam (hipotético)..." 


\section{4) Adequação do modo de transporte}

Definição: Porcentagem dos usuários que optam por um modo de transporte compatível com a distância a ser percorrida.

Este indicador necessita das seguintes adaptações para ser aplicado em meu campus:

Acredito que este indicador deveria ser fragmentado em outros 4 indicadores de acordo com a distância de deslocamento do usuário com o campus. Indicador para usuários que moram em um raio de até $1 \mathrm{~km}$ do campus; indicador para usuários que moram em um raio de até $5 \mathrm{~km}$ do campus; indicador para usuários que moram na cidade do campus; e indicador para usuários que moram em outra cidade do campus. Desta forma, seria possível de forma mais detalhada a adequação do transporte compatível com a distância percorrida e, inclusive, avaliar indiretamente a qualidade dos transportes públicos municipais e intermunicipais. Além disso, para Universidades particulares, seria uma forma de avaliar a correlação do uso do carro com o perfil médio dos alunos destas universidades.

Para distâncias menores, o uso da bicicleta poderia ser incentivado, mas a infraestrutura disponibilizada aos usuários não é adequada. Isso termina culminando no uso tradicional do ônibus e/ou carro.

$\vec{E}$ necessário grande processo de conscientização. No nosso campus $80 \%$ dos professores usam o automóvel embora morem a distâncias pequenas do campus.

Entretanto, a expressão "compatível" é por demais subjetiva.

Não há pesquisa realizada sobre isso

Existe uma demanda reprimida de viagens por bicicleta, por exemplo, haja vista que não há infraestrutura para o modal cicloviário.

A percepção de distância a ser percorrida pode ser diferente para os diversos tipos de usuários. O indicador precisa ser reformulado, com incorporação do modo frequentemente utilizado e o que estimulou o seu uso. 


\section{5) Infraestrutura de acesso ao campus}

Definição: Qualidade, localização e número de entradas do campus disponíveis para pedestres e ciclistas.

Este indicador necessita das seguintes adaptações para ser aplicado em meu campus:

Neste indicador poderia também ser incluído na definição o quesito iluminação, pois o mesmo pode influenciar no maior ou menor uso do acesso em estudo.

No momento a UFAM só possui um acesso, o que gera muitos conflitos. A Prefeitura do Campus justifica tal fato por se tratar de uma APA.

O campus da UnB é aberto, não tendo entradas físicas (portarias etc). As variáveis localização e número de entradas não se aplicam uma vez que pedestres e ciclistas podem entrar na área do campus por vários caminhos. O interessante para o campus é a análise da qualidade da infraestrutura.

Não se aplica no caso desse campus.

O campus se situa em área de expansão da trama urbana, no entanto apenas uma pequena parte dele tem interface com a cidade. Há apenas um acesso atualmente. Não é considerada estratégica a abertura de um acesso pela Rodovia que corta o campus.

O Campus Urbano da UFG é composto por várias unidades com entradas e saídas independentes. $O$ indicador teria que se adequar à essa situação. 


\section{6) Infraestrutura cicloviária}

Definição: Extensão, localização e qualidade da infraestrutura cicloviária de acesso e interna ao campus.

Este indicador necessita das seguintes adaptações para ser aplicado em meu campus:

Por ser um campus novo (10 anos) ele não apresenta infraestrutura cicloviária ainda, mas eu junto com alunos estamos traçando um projeto com a melhor rota de uma rede cicloviária dentro do campus, para posteriormente ser executado este projeto

Melhoria da infraestrutura para estímulo do uso da bicicleta. Recentemente foi desenvolvido um TCC, promovendo um estudo para verificar a possibilidade da implantação de uma ciclofaixa, bem como postos de empréstimo, ao longo do Campus.

Nosso campus possui um projeto pronto de ciclovias interna e de circulação externa que não saiu do papel e é fundamental para incentivo ao uso da bicicleta.

Considerar o desnível acima de 5\% no tocante à localização.

Não há

Não há infraestrutura cicloviária no Campus UFAM. Relevante, porém, considerando as condições atuais não teriam dados.

Seria viável apenas uma ciclovia interna ao campus, já que o acesso ao campus é muito íngreme.

O campus não oferece infraestrutura cicloviária.

Só aplicável para a ciclovia interna ao campus.

$O$ indicador deverá ser adaptado às condições descritas no item anterior (várias unidades independentes).

Não é viável infraestrutura cicloviária interna ao campus (ciclovia por exemplo). Mas é viável estacionamento. $O$ indicador deveria ainda ser segregado: acesso e outro para interno. 


\section{7) Bicicletários e paraciclos}

Definição: Tipo, número, distribuição, localização, estado de conservação e segurança dos bicicletários e paraciclos dentro do campus.

Este indicador necessita das seguintes adaptações para ser aplicado em meu campus:

Não apresenta.

Não existem bicicletários e paraciclos instalados na IES.

idem comentário pergunta anterior.

Interessante se o usuário se sentir seguro. Porém, furtos de bicicletas são constantes na

CUASO. Bicicletários protegidos contra intempéries e mais seguros são essenciais.

Não há facilidades para o usuário de bicicletas

Em função da localização do campus, um número muito pequeno dos usuários utiliza bicicleta e, por consequência, os bicicletários.

Há apenas um paraciclo.

Não são muitos, mas o número tem aumentado 


\section{8) Instalações de apoio a modos alternativos}

Definição: Porcentagem de usuários do campus que é atendida por estas instalações de suporte (vestiários e guarda-volumes).

Este indicador necessita das seguintes adaptações para ser aplicado em meu campus:

Necessário também avaliar a distância destas instalações aos prédios

Atualmente o fluxo de ciclistas que circulam dentro da UFAL é caracterizado por usuários terceirizados ou moradores que se utilizam da UFAL para ter acesso as suas casas. A parcela da comunidade acadêmica (discente, técnicos e docentes) que utiliza a bicicleta é muito pequena.

Não há...não sei

Pode motivar mais usuários de bicicleta

O indicador é extremamente relevante, porém, o Campus UFAM não dispõem de instalações de apoio a modos alternativos

Não há no campus. 


\section{9) Qualidade das vias no campus}

Definição: Avaliação do Índice de Condição do Pavimento (ICP) das vias internas e qualidade da sinalização horizontal e vertical de trânsito do campus.

Este indicador necessita das seguintes adaptações para ser aplicado em meu campus:

Existem 3 estacionamentos: 2 asfaltados e 1 de cascalho

Reforço da sinalização horizontal com relação às faixas de pedestres e lombadas. Nos pontos de ônibus, deveria ser delimitada uma que não permitisse o estacionamento de veículos, evitando que o ônibus fique no meio da faixa de rolamento, causando retenção no fluxo.

Este indicador é importante para os modos automóvel e ônibus. Para o pedestre e ciclista é importante a infraestrutura de calçadas e ciclovias. A sinalização é importante para todos os modos.

Considerar também as condições dos redutores de velocidade (ondulações transversais e sonorizadores).

Mas teria que fazer essa avaliação

A sinalização deve ser reforçada para indicar o compartilhamento de vias entre veículos e ciclistas, tendo em vista a atual redução da velocidade para $40 \mathrm{~km} / \mathrm{h}$.

Acrescentaria, na avaliação, as condições de drenagem e de iluminação das vias. Poderia também ser criado outro item, separando iluminação das vias dos itens Pavimento, Sinalização e Drenagem. 


\section{0) Infraestrutura de estacionamento}

Definição: Nível de saturação do conjunto de estacionamentos do campus (medido através de levantamentos).

Este indicador necessita das seguintes adaptações para ser aplicado em meu campus:

Pelo fato de haver uma grande preferência do transporte individual, em relação ao público, existem unidades acadêmicas que sofrem com este problema da falta de lugar para estacionar. No Centro de Tecnologia (unidade acadêmica) foi definida uma Comissão para que seja feito um planejamento do estacionamento, desde com relação aos locais de parada, bem como definição do fluxo de tráfego.

O ideal é a restrição do número de vagas para não estimular o uso do automóvel. Considerar não somente o conjunto de estacionamentos, mas também o estacionamento de acordo com o seu departamento e/ou centro.

De alguma maneira, ss estacionamentos deveriam ser cobrados.

O uso do carro, saturando o conjunto de estacionamentos, seria péssimo para indicador de mobilidade sustentável, correto? Se sim, concordo totalmente com o indicador. 


\section{1) Infraestrutura de transporte público urbano}

Definição: Avaliação dos pontos de parada do transporte público urbano, próximos ao campus, quanto à distância até as entradas do campus, iluminação, sensação de segurança, cobertura, sinalização e disponibilidade de assento. Também é avaliada a distância de acesso dos usuários aos pontos de recarga do passe escolar.

Este indicador necessita das seguintes adaptações para ser aplicado em meu campus:

Existem 08 paradas no Campus, promovendo uma boa acessibilidade aos usuários. Com relação à iluminação, assentos e cobertura dos pontos o cenário encontrado é aceitável.

Considerar também a distância até os blocos de sala de aula (AT's), uma vez que os pontos, em determinado lugares, encontram-se distantes de tais blocos.

É muito reduzido o uso de transporte público urbano pelos usuários do campus e há uma linha (com apenas 2 horários) que percorre o interior do campus. 


\section{2) Qualidade das calçadas dentro e de acesso ao}

\section{campus}

Definição: Extensão das calçadas com largura superior a 1,20 m, rampas de acessibilidade e boas condições de calçamento dentro e no entorno do campus, bem como a extensão de calçamento que possui cobertura ou arborização.

Este indicador necessita das seguintes adaptações para ser aplicado em meu campus:

Muitas ações precisam ser executadas. O próprio calçamento principal da IES está sofrendo um melhoramento, para oferecer uma condição mais favorável aos usuários.

Considerar também a existência de elementos que dificultam a locomoção, como bancos, postes de energia elétrica, lixeira, etc., os quais podem prejudicar a qualidade das calçadas, sobretudo quando ocorre um largura inferior a 1,20m.

Mas precisa levantamento, não há

Continuo achando que o acesso é uma coisa e o interno é outra. 
13) Vagas para usuários com restrição de mobilidade Definição: Disponibilidade e localização das vagas para usuários com restrição de mobilidade permanente e idosos.

Este indicador necessita das seguintes adaptações para ser aplicado em meu campus:

Não é comum percebermos locais exclusivos para usuários com restrição de mobilidade e a ação não requer dificuldades no que concerne ao direcionamento de recurso financeiro. Basta apenas que a política institucional seja estimular a promove ações em prol deste quesito. 


\section{4) Acessibilidade dos prédios}

Definição: Avaliação qualitativa da acessibilidade universal nos prédios.

Este indicador necessita das seguintes adaptações para ser aplicado em meu campus:

Os prédios que foram construídos recentemente, principalmente a partir de 2006, já contemplam uma maior preocupação com relação essa questão. É mais comum, percebermos dificuldades de acessibilidade nas construções mais antigas. Mas a IES tem sim procurado atender estes gargalos.

Há muitos edifícios destinados a interface com animais, que possuem restrições de uso a pessoas com mobilidade reduzida pelas próprias características da função do edifício. 


\section{5) Medidas de gestão das áreas de estacionamento}

Definição: Avaliação da eficiência das medidas de gestão, aplicadas nas áreas de estacionamento do campus, por meio da comparação entre o grau de utilização dos estacionamentos de uso comum e de uso restrito.

Este indicador necessita das seguintes adaptações para ser aplicado em meu campus:

Não percebi nenhuma ação institucional dentro deste contexto.

Teria que calcular, não há

As áreas de uso restrito volta e meia deixam de ser restritas por falhas nos equipamentos de controle e falta de fiscalização.

Acredito que o indicador deveria abordar se o campus possui áreas específicas para carga/descarga e para acúmulo de caçambas de lixo, que seriam retiradas com frequência conhecida. 


\section{6) Medidas de gestão do fluxo e estacionamentos}

Definição: Avaliação da eficiência das medidas de gestão do fluxo, por meio da quantificação de ocorrências de obstrução de fluxo percebidas no campus (estacionamento irregular, operação de carga e descarga realizada em local inapropriado, mau funcionamento dos tags de identificação dos veículos, etc.) e o nível de transtorno associado.

Este indicador necessita das seguintes adaptações para ser aplicado em meu campus:

Me parece um levantamento mais complicado 


\section{7) Transporte público urbano}

Definição: Porcentagem dos usuários do transporte público urbano que avaliam como satisfatório o serviço prestado.

Este indicador necessita das seguintes adaptações para ser aplicado em meu campus:

A insatisfação com a qualidade do TPU é geral não somente com os usuários da UFAL, da cidade de Maceió e do Brasil. Trata-se da necessidade de sensibilização dos gestores públicos com relação à efetivação da política nacional de mobilidade urbana, que ainda se encontra em processo tímido de consolidação. 


\section{8) Transporte coletivo interno ou entre áreas do}

\section{campus}

Definição: Grau de satisfação dos usuários do transporte coletivo oferecido pela universidade, em relação ao serviço prestado.

Este indicador necessita das seguintes adaptações para ser aplicado em meu campus:

Não se aplica. Campus consideravelmente pequeno.

Não possuímos este tipo de serviço no campus e não foram feitos estudos neste sentido. Depende da localização dos pontos de TC e distâncias entre os prédios.

O Campus Central da UFRN não dispõe desse serviço especificamente. Necessidades de deslocamento intra campus são cobertas por serviços integrados ao STPP-Natal (Circular do Campus). Seria portanto importante alterar ligeiramente o indicador para incluir a possibilidade.

Precisa fazer pesquisa, não há

Não há TP interno no campus.

A UnB tem outros 2 campus localizados em outras cidades. Poucos são os alunos que conhecem a existência desse serviço e do serviço de transporte interno. Seria interessante ter um indicador para identificar o percentual de alunos que usam o serviço ofertado e depois seu grau de satisfação.

\footnotetext{
A universidade não oferece transporte coletivo a alunos ou funcionários Dependendo do tamanho, ainda existe ainda a opção do campus ser acessado por linhas regulares de transporte coletivo urbano. Como seria abordado no indicador?
} 


\section{9) Segurança pública}

Definição: Porcentagem de usuários que se sentem seguros, parcialmente seguros e inseguros no entorno do campus nos diferentes períodos do dia.

Este indicador necessita das seguintes adaptações para ser aplicado em meu campus:

Outra problema geral, que foge até da política institucional da UFAL. É o clássico problema da segurança pública em locais públicos. O que poderia ser feito na IES seria um maior controle com relação à entrada dos usuários. Não existe qualquer controle no acesso dos usuários, o que facilita a possibilidade da ocorrência de sinistros. A IES pretende controlar o acesso a partir de uma cartão institucional. Esse assunto já vem sendo discutido há muito tempo, mas sem real implantação de alguma medida mais funcional.

Considerar também a segurança pública dentro do campus, pois vários são os relatos de furtos internos.

O indicador poderia medir a percepção de segunraça nao só no entorno do campus mas dentro do campus. Como o campus é aberto, muitas pessoas circulam por ele. O número de assaltos e furtos dentro do campus tem aumentado nos últimos anos.

Há que se levar em consideração que a maior parte do entorno do campus é formada por sítios e fazendas (mas no trecho urbano o indicador é adequado e relevante). 


\section{0) Fiscalização de infrações de trânsito no campus}

Definição: Eficiência das ações de fiscalização de infrações de trânsito realizadas pelos agentes de segurança no campus.

Este indicador necessita das seguintes adaptações para ser aplicado em meu campus:

Praticamente não existe esse tipo de ação no Campus.

Este tipo de ação é bastante deficiente no nosso campus, pois os agentes de segurança são em número pequeno e a policia militar atua apenas nas vias públicas do campus.

Não há fiscalização de infrações de trânsito no campus UFAM.

Não há fiscalização no campus.

A fiscalização é pouca.

Acredito que o indicador poderia ser alterado para item que identifique que há o mau comportamento de condutores dentro do campus. 


\section{Deseja fazer algum comentário adicional ou sugestão sobre o índice de mobilidade sustentável para campus universitário?}

Necessário um indicador sobre capacitação/treinamento dos fiscais de trânsito interno dentro do campus. Poderia haver um indicador sobre número de linhas de transporte público municipal e intermunicipal que abrangem a área do campus. Esta informação poderia posteriormente ser avaliada com as informações levantadas pelos indicadores 3 e 4

Esqueci que são dois campi!

Que os resultados deste estudo sejam compartilhados com as pessoas que participaram desta pesquisa, objetivando sensibilizar os nossos gestores da importância destas questões.

Fiz alguns comentários sobre a situação do nosso campus no espaço destinado a adequações. A ideia é promissora. Entretanto, creio que os indicadores estão muito fechados em torno da mobilidade realizada e das dificuldades/facilidades percebidas pelo frequentador do Campus. Sabemos que a localização relativa de facilidades no Campus ou em seu entorno têm um papel importante na sustentabilidade em virtude do fato de contribuir positiva ou negativamente com a maior/menor necessidade de viagens, bem como com a extensão destas. Temas como restaurantes/lanchonetes, bibliotecas, dispositivos de esporte e lazer, convivência etc poderiam estar inseridos no inidcador.

Poderia ser abordado o layout do campus (ou uso do solo no campus) ...como é distribuído: porcentagem do campus utilizado para area de educação, laser, alimentação, conveniencias, estacionamento, vazio...

Tempos gastos para acessar o campus

Alguns dos indicadores não se aplicam ao campus, pois atualmente não é percebido problemas de falta de vaga, de gestão ou estacionamento irregular. Pelas características do campus o transporte público e o sistema de caronas teriam maior relevância.

O número de linhas e a frequência do transporte público ofertado pelo Governo do Distrito Federal é importante. A demanda de alunos é alta e o metrô não chega até o Campus. Há reclamação constante da falta de linhas de ônibus da Rodoviária do Plano Piloto ao Campus Darcy Ribeiro. Assim, poderia ser levantado o grau de satisfação do usuário do transporte público ofertado pelo GDF para acesso ao campus.

Talvez um indicador que de alguma forma represente alguma dificuldade (controle) de acesso ao campus por aqueles que não participam das atividades diárias do campus. Isso se deve ao aumento do número de assaltos á estudantes, professores e funcionários, no caso do Campus da Ilha do Fundão. Verifica'se ainda elevado número de roubo de veículos e "sequestro relâmpago". Eu acabei usando a caixa de sugestão de adaptações, como caixa de comentários gerais. $A$ maioria dos dados ainda precisam ser levantados, mas é algo possível. Não sei se era bem esta a ideia do seu levantamento. Qualquer coisa, me avise que eu responderei novamente.

Gostaria de aplicar o indicador no campus universitário e, quem sabe, produzir estudo comparativo entre diversos campus.

Em geral, acredito que deva ser separado questões de dentro do campus e as questões de acesso ou externas ao campus. O campus CEFET-MG por exemplo, é compacto. Não tem vias internas. Por isto o entorno é extremamente importante e passível de ser avaliado por estes indicadores. 
Avaliação dos indicadores - Quesito adequação

\begin{tabular}{|c|c|c|c|c|c|c|c|c|c|c|c|c|c|c|c|c|c|c|c|c|}
\hline & \multicolumn{20}{|c|}{ Indicadores } \\
\hline Avaliadores & 1 & 2 & 3 & 4 & 5 & 6 & 7 & 8 & 9 & 10 & 11 & 12 & 13 & 14 & 15 & 16 & 17 & 18 & 19 & 20 \\
\hline A & 7 & 7 & 7 & 7 & 7 & 7 & 7 & 7 & 7 & 7 & 7 & 7 & 7 & 7 & 7 & 7 & 7 & 7 & 7 & 7 \\
\hline B & 2 & 5 & 3 & 5 & 7 & 7 & 7 & 7 & 7 & 7 & 7 & 7 & 7 & 7 & 7 & 7 & 7 & 6 & 7 & 7 \\
\hline $\mathrm{C}$ & 4 & 5 & 4 & 7 & 7 & 7 & 2 & 6 & 6 & 7 & 4 & 7 & 5 & 4 & 6 & 6 & 6 & 1 & 7 & 2 \\
\hline D & 6 & 6 & 6 & 6 & 7 & 6 & 6 & 6 & 7 & 6 & 7 & 7 & 7 & 6 & 4 & 6 & 7 & 6 & 7 & 4 \\
\hline$E$ & 7 & 7 & 6 & 7 & 6 & 7 & 6 & 5 & 5 & 4 & 4 & 5 & 4 & 4 & 4 & 4 & 4 & 4 & 6 & 4 \\
\hline $\mathrm{F}$ & 4 & 6 & 4 & 4 & 6 & 4 & 1 & 4 & 4 & 4 & 5 & 4 & 4 & 4 & 3 & 4 & 4 & 6 & 4 & 4 \\
\hline$G$ & 5 & 6 & 6 & 6 & 6 & 5 & 5 & 4 & 6 & 3 & 6 & 5 & 7 & 6 & 6 & 3 & 7 & 2 & 4 & 2 \\
\hline $\mathrm{H}$ & 7 & 7 & 7 & 7 & 6 & 7 & 6 & 6 & 5 & 6 & 7 & 7 & 6 & 6 & 6 & 6 & 7 & 5 & 6 & 5 \\
\hline 1 & 7 & 7 & 7 & 7 & 7 & 7 & 7 & 6 & 7 & 7 & 7 & 7 & 7 & 7 & 7 & 7 & 7 & 7 & 7 & 7 \\
\hline $\mathrm{J}$ & 7 & 7 & 7 & 7 & 5 & 6 & 7 & 5 & 5 & 6 & 6 & 5 & 7 & 7 & 6 & 7 & 7 & 7 & 5 & 7 \\
\hline $\mathrm{K}$ & 5 & 7 & 4 & 6 & 6 & 7 & 6 & 2 & 6 & 4 & 7 & 6 & 7 & 2 & 1 & 4 & 6 & 1 & 4 & 2 \\
\hline $\mathrm{L}$ & 6 & 2 & 7 & 2 & 6 & 6 & 6 & 4 & 6 & 7 & 6 & 6 & 6 & 6 & 6 & 6 & 6 & 6 & 7 & 4 \\
\hline M & 6 & 7 & 5 & 4 & 4 & 5 & 5 & 5 & 5 & 5 & 6 & 6 & 6 & 6 & 4 & 4 & 5 & 5 & 5 & 7 \\
\hline $\mathrm{N}$ & 3 & 3 & 1 & 2 & 7 & 1 & 1 & 1 & 7 & 7 & 7 & 7 & 7 & 7 & 7 & 7 & 7 & 7 & 7 & 2 \\
\hline 0 & 5 & 4 & 4 & 6 & 6 & 3 & 4 & 4 & 6 & 5 & 6 & 6 & 6 & 6 & 4 & 3 & 7 & 4 & 6 & 4 \\
\hline $\mathrm{P}$ & 7 & 7 & 7 & 7 & 7 & 1 & 2 & 1 & 7 & 7 & 7 & 7 & 7 & 7 & 7 & 1 & 7 & 1 & 7 & 1 \\
\hline Q & 6 & 6 & 6 & 7 & 3 & 7 & 7 & 5 & 6 & 7 & 7 & 7 & 6 & 7 & 6 & 7 & 7 & 7 & 7 & 7 \\
\hline $\mathrm{R}$ & 7 & 7 & 5 & 6 & 2 & 5 & 7 & 4 & 7 & 7 & 7 & 7 & 7 & 7 & 7 & 7 & 7 & 7 & 7 & 7 \\
\hline$S$ & 6 & 6 & 6 & 6 & 1 & 6 & 6 & 6 & 6 & 6 & 6 & 6 & 6 & 5 & 6 & 6 & 6 & 6 & 5 & 6 \\
\hline $\mathrm{T}$ & 6 & 6 & 2 & 7 & 3 & 3 & 7 & 6 & 6 & 6 & 7 & 7 & 7 & 7 & 6 & 6 & 6 & 1 & 7 & 6 \\
\hline U & 5 & 3 & 4 & 4 & 4 & 6 & 6 & 7 & 4 & 4 & 4 & 4 & 4 & 6 & 4 & 6 & 6 & 4 & 7 & 4 \\
\hline V & 6 & 6 & 6 & 7 & 7 & 7 & 7 & 6 & 7 & 6 & 7 & 7 & 7 & 7 & 4 & 4 & 7 & 7 & 7 & 5 \\
\hline W & 3 & 2 & 7 & 2 & 7 & 7 & 7 & 6 & 6 & 7 & 7 & 7 & 7 & 6 & 2 & 6 & 6 & 6 & 6 & 4 \\
\hline$X$ & 6 & 6 & 2 & 6 & 7 & 5 & 7 & 7 & 2 & 7 & 7 & 7 & 7 & 7 & 7 & 7 & 6 & 7 & 7 & 2 \\
\hline
\end{tabular}


Avaliação dos indicadores - Quesito relevância

\begin{tabular}{|c|c|c|c|c|c|c|c|c|c|c|c|c|c|c|c|c|c|c|c|c|}
\hline & \multicolumn{20}{|c|}{ Indicadores } \\
\hline Avaliadores & 1 & 2 & 3 & 4 & 5 & 6 & 7 & 8 & 9 & 10 & 11 & 12 & 13 & 14 & 15 & 16 & 17 & 18 & 19 & 20 \\
\hline$A$ & 7 & 7 & 7 & 7 & 7 & 7 & 7 & 7 & 7 & 7 & 7 & 7 & 7 & 7 & 7 & 7 & 7 & 7 & 7 & 7 \\
\hline B & 3 & 5 & 2 & 5 & 7 & 7 & 7 & 7 & 7 & 7 & 7 & 7 & 7 & 7 & 7 & 7 & 7 & 6 & 7 & 7 \\
\hline C & 2 & 3 & 1 & 7 & 6 & 7 & 2 & 4 & 4 & 7 & 4 & 7 & 4 & 3 & 5 & 5 & 4 & 1 & 7 & 1 \\
\hline D & 6 & 6 & 6 & 6 & 7 & 6 & 6 & 6 & 7 & 6 & 6 & 7 & 7 & 6 & 4 & 6 & 7 & 6 & 7 & 4 \\
\hline$E$ & 7 & 7 & 7 & 7 & 6 & 7 & 7 & 5 & 6 & 5 & 5 & 6 & 6 & 4 & 4 & 5 & 5 & 4 & 6 & 6 \\
\hline $\mathrm{F}$ & 6 & 6 & 6 & 4 & 7 & 7 & 7 & 6 & 6 & 6 & 7 & 7 & 7 & 7 & 6 & 6 & 6 & 6 & 6 & 6 \\
\hline$G$ & 6 & 6 & 7 & 6 & 6 & 5 & 5 & 4 & 6 & 2 & 6 & 5 & 7 & 6 & 6 & 3 & 7 & 2 & 4 & 2 \\
\hline $\mathrm{H}$ & 7 & 7 & 7 & 7 & 6 & 7 & 6 & 6 & 5 & 6 & 7 & 7 & 6 & 6 & 6 & 6 & 7 & 5 & 6 & 5 \\
\hline 1 & 7 & 7 & 7 & 7 & 7 & 7 & 7 & 6 & 7 & 7 & 7 & 7 & 7 & 7 & 7 & 7 & 7 & 7 & 7 & 7 \\
\hline $\mathrm{J}$ & 7 & 7 & 7 & 7 & 7 & 7 & 7 & 5 & 7 & 7 & 7 & 7 & 7 & 7 & 7 & 7 & 7 & 7 & 7 & 7 \\
\hline $\mathrm{K}$ & 6 & 7 & 2 & 7 & 6 & 7 & 6 & 7 & 6 & 4 & 7 & 6 & 7 & 6 & 1 & 5 & 7 & 1 & 5 & 4 \\
\hline $\mathrm{L}$ & 6 & 6 & 7 & 6 & 7 & 7 & 7 & 7 & 6 & 7 & 7 & 6 & 7 & 6 & 4 & 7 & 6 & 6 & 7 & 5 \\
\hline$M$ & 6 & 7 & 5 & 4 & 4 & 5 & 5 & 5 & 5 & 5 & 6 & 6 & 6 & 6 & 4 & 4 & 5 & 5 & 5 & 7 \\
\hline $\mathrm{N}$ & 7 & 7 & 7 & 7 & 7 & 7 & 7 & 7 & 7 & 7 & 7 & 7 & 7 & 7 & 7 & 7 & 7 & 7 & 7 & 6 \\
\hline 0 & 5 & 6 & 6 & 6 & 7 & 3 & 4 & 4 & 6 & 5 & 7 & 6 & 6 & 6 & 4 & 3 & 7 & 4 & 6 & 4 \\
\hline $\mathrm{P}$ & 7 & 7 & 7 & 7 & 7 & 7 & 7 & 7 & 7 & 7 & 7 & 7 & 7 & 7 & 7 & 7 & 7 & 7 & 7 & 7 \\
\hline Q & 6 & 6 & 6 & 7 & 3 & 7 & 7 & 5 & 6 & 7 & 7 & 7 & 6 & 7 & 6 & 7 & 7 & 7 & 7 & 7 \\
\hline $\mathrm{R}$ & 7 & 7 & 5 & 6 & 2 & 5 & 7 & 4 & 7 & 7 & 7 & 7 & 7 & 7 & 7 & 7 & 7 & 7 & 7 & 7 \\
\hline$S$ & 6 & 6 & 6 & 6 & 4 & 6 & 6 & 6 & 6 & 6 & 5 & 6 & 6 & 6 & 6 & 6 & 6 & 6 & 6 & 6 \\
\hline $\mathrm{T}$ & 6 & 6 & 6 & 7 & 6 & 7 & 7 & 6 & 6 & 6 & 7 & 7 & 7 & 7 & 6 & 6 & 6 & 1 & 7 & 6 \\
\hline$U$ & 3 & 3 & 5 & 4 & 6 & 6 & 6 & 7 & 4 & 4 & 4 & 4 & 4 & 6 & 4 & 4 & 6 & 4 & 7 & 4 \\
\hline $\mathrm{V}$ & 6 & 6 & 6 & 7 & 7 & 7 & 7 & 6 & 7 & 6 & 7 & 7 & 7 & 7 & 6 & 4 & 7 & 7 & 7 & 5 \\
\hline W & 4 & 2 & 7 & 3 & 7 & 7 & 7 & 6 & 6 & 7 & 7 & 7 & 7 & 6 & 2 & 6 & 6 & 6 & 6 & 4 \\
\hline$X$ & 7 & 7 & 7 & 6 & 7 & & 7 & 7 & 2 & 7 & 7 & 7 & 7 & 7 & 7 & 7 & 7 & 7 & 7 & 2 \\
\hline
\end{tabular}




\author{
APÊNDICE F \\ PAINEL DE ESPECIALISTAS - TESTE DE FRIEDMAN
}

POTENCIAL DE TRANSFERÊNCIA DE UM ÍNDICE DE MOBILIDADE SUSTENTÁVEL PARA CAMPUS UNIVERSITÁRIO

Francine Marvulle Tan

São Carlos

2018 


\section{Sumário}

Tabela 1 - Avaliação dos indicadores - Quesito adequação ................................................ 3

Tabela 2 - Ranks dos indicadores - Quesito adequação ................................................... 4

Tabela 3 - Avaliação dos indicadores - Quesito relevância.................................................. 5

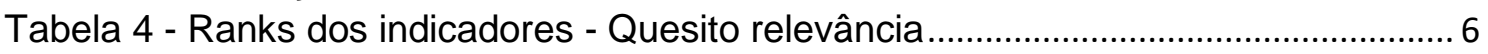

Tabela 5 - Comparações múltiplas - Quesito adequação ................................................... 7

Tabela 6 - Comparações múltiplas - Quesito relevância .................................................... 8 
Tabela 1 - Avaliação dos indicadores - Quesito adequação

\begin{tabular}{|c|c|c|c|c|c|c|c|c|c|c|c|c|c|c|c|c|c|c|c|c|}
\hline & & & & & & & & & & Indic & dores & & & & & & & & & \\
\hline Avaliadores & 1 & 2 & 3 & 4 & 5 & 6 & 7 & 8 & 9 & 10 & 11 & 12 & 13 & 14 & 15 & 16 & 17 & 18 & 19 & 20 \\
\hline A & 7 & 7 & 7 & 7 & 7 & 7 & 7 & 7 & 7 & 7 & 7 & 7 & 7 & 7 & 7 & 7 & 7 & 7 & 7 & 7 \\
\hline $\mathrm{B}$ & 2 & 5 & 3 & 5 & 7 & 7 & 7 & 7 & 7 & 7 & 7 & 7 & 7 & 7 & 7 & 7 & 7 & 6 & 7 & 7 \\
\hline C & 4 & 5 & 4 & 7 & 7 & 7 & 2 & 6 & 6 & 7 & 4 & 7 & 5 & 4 & 6 & 6 & 6 & 1 & 7 & 2 \\
\hline $\mathrm{D}$ & 6 & 6 & 6 & 6 & 7 & 6 & 6 & 6 & 7 & 6 & 7 & 7 & 7 & 6 & 4 & 6 & 7 & 6 & 7 & 4 \\
\hline$E$ & 7 & 7 & 6 & 7 & 6 & 7 & 6 & 5 & 5 & 4 & 4 & 5 & 4 & 4 & 4 & 4 & 4 & 4 & 6 & 4 \\
\hline$F$ & 4 & 6 & 4 & 4 & 6 & 4 & 1 & 4 & 4 & 4 & 5 & 4 & 4 & 4 & 3 & 4 & 4 & 6 & 4 & 4 \\
\hline $\mathrm{G}$ & 5 & 6 & 6 & 6 & 6 & 5 & 5 & 4 & 6 & 3 & 6 & 5 & 7 & 6 & 6 & 3 & 7 & 2 & 4 & 2 \\
\hline $\mathrm{H}$ & 7 & 7 & 7 & 7 & 6 & 7 & 6 & 6 & 5 & 6 & 7 & 7 & 6 & 6 & 6 & 6 & 7 & 5 & 6 & 5 \\
\hline 1 & 7 & 7 & 7 & 7 & 7 & 7 & 7 & 6 & 7 & 7 & 7 & 7 & 7 & 7 & 7 & 7 & 7 & 7 & 7 & 7 \\
\hline $\mathrm{J}$ & 7 & 7 & 7 & 7 & 5 & 6 & 7 & 5 & 5 & 6 & 6 & 5 & 7 & 7 & 6 & 7 & 7 & 7 & 5 & 7 \\
\hline $\mathrm{K}$ & 5 & 7 & 4 & 6 & 6 & 7 & 6 & 2 & 6 & 4 & 7 & 6 & 7 & 2 & 1 & 4 & 6 & 1 & 4 & 2 \\
\hline $\mathrm{L}$ & 6 & 2 & 7 & 2 & 6 & 6 & 6 & 4 & 6 & 7 & 6 & 6 & 6 & 6 & 6 & 6 & 6 & 6 & 7 & 4 \\
\hline $\mathrm{M}$ & 6 & 7 & 5 & 4 & 4 & 5 & 5 & 5 & 5 & 5 & 6 & 6 & 6 & 6 & 4 & 4 & 5 & 5 & 5 & 7 \\
\hline $\mathrm{N}$ & 3 & 3 & 1 & 2 & 7 & 1 & 1 & 1 & 7 & 7 & 7 & 7 & 7 & 7 & 7 & 7 & 7 & 7 & 7 & 2 \\
\hline 0 & 5 & 4 & 4 & 6 & 6 & 3 & 4 & 4 & 6 & 5 & 6 & 6 & 6 & 6 & 4 & 3 & 7 & 4 & 6 & 4 \\
\hline $\mathrm{P}$ & 7 & 7 & 7 & 7 & 7 & 1 & 2 & 1 & 7 & 7 & 7 & 7 & 7 & 7 & 7 & 1 & 7 & 1 & 7 & 1 \\
\hline Q & 6 & 6 & 6 & 7 & 3 & 7 & 7 & 5 & 6 & 7 & 7 & 7 & 6 & 7 & 6 & 7 & 7 & 7 & 7 & 7 \\
\hline $\mathrm{R}$ & 7 & 7 & 5 & 6 & 2 & 5 & 7 & 4 & 7 & 7 & 7 & 7 & 7 & 7 & 7 & 7 & 7 & 7 & 7 & 7 \\
\hline S & 6 & 6 & 6 & 6 & 1 & 6 & 6 & 6 & 6 & 6 & 6 & 6 & 6 & 5 & 6 & 6 & 6 & 6 & 5 & 6 \\
\hline $\mathrm{T}$ & 6 & 6 & 2 & 7 & 3 & 3 & 7 & 6 & 6 & 6 & 7 & 7 & 7 & 7 & 6 & 6 & 6 & 1 & 7 & 6 \\
\hline$U$ & 5 & 3 & 4 & 4 & 4 & 6 & 6 & 7 & 4 & 4 & 4 & 4 & 4 & 6 & 4 & 6 & 6 & 4 & 7 & 4 \\
\hline $\mathrm{V}$ & 6 & 6 & 6 & 7 & 7 & 7 & 7 & 6 & 7 & 6 & 7 & 7 & 7 & 7 & 4 & 4 & 7 & 7 & 7 & 5 \\
\hline W & 3 & 2 & 7 & 2 & 7 & 7 & 7 & 6 & 6 & 7 & 7 & 7 & 7 & 6 & 2 & 6 & 6 & 6 & 6 & 4 \\
\hline$x$ & 6 & 6 & 2 & 6 & 7 & 5 & 7 & 7 & 2 & 7 & 7 & 7 & 7 & 7 & 7 & 7 & 6 & 7 & 7 & 2 \\
\hline Soma & 133 & 135 & 123 & 135 & 134 & 132 & 132 & 120 & 140 & 142 & 151 & 151 & 151 & 144 & 127 & 131 & 152 & 120 & 149 & 110 \\
\hline
\end{tabular}


Tabela 2 - Ranks dos indicadores - Quesito adequação

\begin{tabular}{|c|c|c|c|c|c|c|c|c|c|c|c|c|c|c|c|c|c|c|c|c|}
\hline & & & & & & & & & & Indic & dores & & & & & & & & & \\
\hline Avaliadores & $\mathrm{R} 1$ & $\mathrm{R} 2$ & R3 & R4 & R5 & R6 & $\mathrm{R7}$ & $\mathrm{R} 8$ & $\mathrm{R} 9$ & $\mathrm{R} 10$ & $\mathrm{R} 11$ & $\mathrm{R} 12$ & $\mathrm{R} 13$ & $\mathrm{R} 14$ & $\mathrm{R} 15$ & $\mathrm{R} 16$ & $\mathrm{R} 17$ & $\mathrm{R} 18$ & R19 & $\mathrm{R} 20$ \\
\hline A & 10,5 & 10,5 & 10,5 & 10,5 & 10,5 & 10,5 & 10,5 & 10,5 & 10,5 & 10,5 & 10,5 & 10,5 & 10,5 & 10,5 & 10,5 & 10,5 & 10,5 & 10,5 & 10,5 & 10,5 \\
\hline B & 1 & 3,5 & 2 & 3,5 & 13 & 13 & 13 & 13 & 13 & 13 & 13 & 13 & 13 & 13 & 13 & 13 & 13 & 5 & 13 & 13 \\
\hline C & 5,5 & 8,5 & 5,5 & 17,5 & 17,5 & 17,5 & 2,5 & 12 & 12 & 17,5 & 5,5 & 17,5 & 8,5 & 5,5 & 12 & 12 & 12 & 1 & 17,5 & 2,5 \\
\hline D & 8 & 8 & 8 & 8 & 17 & 8 & 8 & 8 & 17 & 8 & 17 & 17 & 17 & 8 & 1,5 & 8 & 17 & 8 & 17 & 1,5 \\
\hline$E$ & 18,5 & 18,5 & 14,5 & 18,5 & 14,5 & 18,5 & 14,5 & 11 & 11 & 5 & 5 & 11 & 5 & 5 & 5 & 5 & 5 & 5 & 14,5 & 5 \\
\hline $\mathrm{F}$ & 9,5 & 19 & 9,5 & 9,5 & 19 & 9,5 & 1 & 9,5 & 9,5 & 9,5 & 17 & 9,5 & 9,5 & 9,5 & 2 & 9,5 & 9,5 & 19 & 9,5 & 9,5 \\
\hline G & 8,5 & 14,5 & 14,5 & 14,5 & 14,5 & 8,5 & 8,5 & 5,5 & 14,5 & 3,5 & 14,5 & 8,5 & 19,5 & 14,5 & 14,5 & 3,5 & 19,5 & 1,5 & 5,5 & 1,5 \\
\hline $\mathrm{H}$ & 16,5 & 16,5 & 16,5 & 16,5 & 8 & 16,5 & 8 & 8 & 2 & 8 & 16,5 & 16,5 & 8 & 8 & 8 & 8 & 16,5 & 2 & 8 & 2 \\
\hline 1 & 11 & 11 & 11 & 11 & 11 & 11 & 11 & 1 & 11 & 11 & 11 & 11 & 11 & 11 & 11 & 11 & 11 & 11 & 11 & 11 \\
\hline $\mathrm{J}$ & 15 & 15 & 15 & 15 & 3 & 7,5 & 15 & 3 & 3 & 7,5 & 7,5 & 3 & 15 & 15 & 7,5 & 15 & 15 & 15 & 3 & 15 \\
\hline$K$ & 10 & 18,5 & 7,5 & 13,5 & 13,5 & 18,5 & 13,5 & 4 & 13,5 & 7,5 & 18,5 & 13,5 & 18,5 & 4 & 1,5 & 7,5 & 13,5 & 1,5 & 7,5 & 4 \\
\hline$L$ & 11 & 1,5 & 19 & 1,5 & 11 & 11 & 11 & 3,5 & 11 & 19 & 11 & 11 & 11 & 11 & 11 & 11 & 11 & 11 & 19 & 3,5 \\
\hline$M$ & 16 & 19,5 & 9 & 2,5 & 2,5 & 9 & 9 & 9 & 9 & 9 & 16 & 16 & 16 & 16 & 2,5 & 2,5 & 9 & 9 & 9 & 19,5 \\
\hline $\mathrm{N}$ & 7,5 & 7,5 & 2,5 & 5,5 & 14,5 & 2,5 & 2,5 & 2,5 & 14,5 & 14,5 & 14,5 & 14,5 & 14,5 & 14,5 & 14,5 & 14,5 & 14,5 & 14,5 & 14,5 & 5,5 \\
\hline 0 & 10,5 & 6 & 6 & 15,5 & 15,5 & 1,5 & 6 & 6 & 15,5 & 10,5 & 15,5 & 15,5 & 15,5 & 15,5 & 6 & 1,5 & 20 & 6 & 15,5 & 6 \\
\hline$P$ & 13,5 & 13,5 & 13,5 & 13,5 & 13,5 & 3 & 6 & 3 & 13,5 & 13,5 & 13,5 & 13,5 & 13,5 & 13,5 & 13,5 & 3 & 13,5 & 3 & 13,5 & 3 \\
\hline Q & 5,5 & 5,5 & 5,5 & 14,5 & 1 & 14,5 & 14,5 & 2 & 5,5 & 14,5 & 14,5 & 14,5 & 5,5 & 14,5 & 5,5 & 14,5 & 14,5 & 14,5 & 14,5 & 14,5 \\
\hline $\mathrm{R}$ & 13 & 13 & 3,5 & 5 & 1 & 3,5 & 13 & 2 & 13 & 13 & 13 & 13 & 13 & 13 & 13 & 13 & 13 & 13 & 13 & 13 \\
\hline$S$ & 12 & 12 & 12 & 12 & 1 & 12 & 12 & 12 & 12 & 12 & 12 & 12 & 12 & 2,5 & 12 & 12 & 12 & 12 & 2,5 & 12 \\
\hline$T$ & 9 & 9 & 2 & 17 & 3,5 & 3,5 & 17 & 9 & 9 & 9 & 17 & 17 & 17 & 17 & 9 & 9 & 9 & 1 & 17 & 9 \\
\hline U & 13 & 1 & 7 & 7 & 7 & 16 & 16 & 19,5 & 7 & 7 & 7 & 7 & 7 & 16 & 7 & 16 & 16 & 7 & 19,5 & 7 \\
\hline V & 6 & 6 & 6 & 14,5 & 14,5 & 14,5 & 14,5 & 6 & 14,5 & 6 & 14,5 & 14,5 & 14,5 & 14,5 & 1,5 & 1,5 & 14,5 & 14,5 & 14,5 & 3 \\
\hline W & 4 & 2 & 16,5 & 2 & 16,5 & 16,5 & 16,5 & 9 & 9 & 16,5 & 16,5 & 16,5 & 16,5 & 9 & 2 & 9 & 9 & 9 & 9 & 5 \\
\hline$x$ & 6,5 & 6,5 & 2 & 6,5 & 14,5 & 4 & 14,5 & 14,5 & 2 & 14,5 & 14,5 & 14,5 & 14,5 & 14,5 & 14,5 & 14,5 & 6,5 & 14,5 & 14,5 & 2 \\
\hline Soma $(R)$ & 241,5 & 246,5 & 219 & 255 & 257,5 & 250,5 & 258 & 183,5 & 252,5 & 260 & 315,5 & 310,5 & 306 & 275,5 & 198,5 & 225 & 305 & 208,5 & 293 & 178,5 \\
\hline
\end{tabular}


Tabela 3 - Avaliação dos indicadores - Quesito relevância

\begin{tabular}{|c|c|c|c|c|c|c|c|c|c|c|c|c|c|c|c|c|c|c|c|c|}
\hline & & & & & & & & & & Indic & dores & & & & & & & & & \\
\hline Avaliadores & 1 & 2 & 3 & 4 & 5 & 6 & 7 & 8 & 9 & 10 & 11 & 12 & 13 & 14 & 15 & 16 & 17 & 18 & 19 & 20 \\
\hline A & 7 & 7 & 7 & 7 & 7 & 7 & 7 & 7 & 7 & 7 & 7 & 7 & 7 & 7 & 7 & 7 & 7 & 7 & 7 & 7 \\
\hline B & 3 & 5 & 2 & 5 & 7 & 7 & 7 & 7 & 7 & 7 & 7 & 7 & 7 & 7 & 7 & 7 & 7 & 6 & 7 & 7 \\
\hline $\mathrm{C}$ & 2 & 3 & 1 & 7 & 6 & 7 & 2 & 4 & 4 & 7 & 4 & 7 & 4 & 3 & 5 & 5 & 4 & 1 & 7 & 1 \\
\hline $\mathrm{D}$ & 6 & 6 & 6 & 6 & 7 & 6 & 6 & 6 & 7 & 6 & 6 & 7 & 7 & 6 & 4 & 6 & 7 & 6 & 7 & 4 \\
\hline$E$ & 7 & 7 & 7 & 7 & 6 & 7 & 7 & 5 & 6 & 5 & 5 & 6 & 6 & 4 & 4 & 5 & 5 & 4 & 6 & 6 \\
\hline $\mathrm{F}$ & 6 & 6 & 6 & 4 & 7 & 7 & 7 & 6 & 6 & 6 & 7 & 7 & 7 & 7 & 6 & 6 & 6 & 6 & 6 & 6 \\
\hline $\mathrm{G}$ & 6 & 6 & 7 & 6 & 6 & 5 & 5 & 4 & 6 & 2 & 6 & 5 & 7 & 6 & 6 & 3 & 7 & 2 & 4 & 2 \\
\hline $\mathrm{H}$ & 7 & 7 & 7 & 7 & 6 & 7 & 6 & 6 & 5 & 6 & 7 & 7 & 6 & 6 & 6 & 6 & 7 & 5 & 6 & 5 \\
\hline 1 & 7 & 7 & 7 & 7 & 7 & 7 & 7 & 6 & 7 & 7 & 7 & 7 & 7 & 7 & 7 & 7 & 7 & 7 & 7 & 7 \\
\hline $\mathrm{J}$ & 7 & 7 & 7 & 7 & 7 & 7 & 7 & 5 & 7 & 7 & 7 & 7 & 7 & 7 & 7 & 7 & 7 & 7 & 7 & 7 \\
\hline $\mathrm{K}$ & 6 & 7 & 2 & 7 & 6 & 7 & 6 & 7 & 6 & 4 & 7 & 6 & 7 & 6 & 1 & 5 & 7 & 1 & 5 & 4 \\
\hline$L$ & 6 & 6 & 7 & 6 & 7 & 7 & 7 & 7 & 6 & 7 & 7 & 6 & 7 & 6 & 4 & 7 & 6 & 6 & 7 & 5 \\
\hline $\mathrm{M}$ & 6 & 7 & 5 & 4 & 4 & 5 & 5 & 5 & 5 & 5 & 6 & 6 & 6 & 6 & 4 & 4 & 5 & 5 & 5 & 7 \\
\hline $\mathrm{N}$ & 7 & 7 & 7 & 7 & 7 & 7 & 7 & 7 & 7 & 7 & 7 & 7 & 7 & 7 & 7 & 7 & 7 & 7 & 7 & 6 \\
\hline 0 & 5 & 6 & 6 & 6 & 7 & 3 & 4 & 4 & 6 & 5 & 7 & 6 & 6 & 6 & 4 & 3 & 7 & 4 & 6 & 4 \\
\hline $\mathrm{P}$ & 7 & 7 & 7 & 7 & 7 & 7 & 7 & 7 & 7 & 7 & 7 & 7 & 7 & 7 & 7 & 7 & 7 & 7 & 7 & 7 \\
\hline Q & 6 & 6 & 6 & 7 & 3 & 7 & 7 & 5 & 6 & 7 & 7 & 7 & 6 & 7 & 6 & 7 & 7 & 7 & 7 & 7 \\
\hline $\mathrm{R}$ & 7 & 7 & 5 & 6 & 2 & 5 & 7 & 4 & 7 & 7 & 7 & 7 & 7 & 7 & 7 & 7 & 7 & 7 & 7 & 7 \\
\hline$S$ & 6 & 6 & 6 & 6 & 4 & 6 & 6 & 6 & 6 & 6 & 5 & 6 & 6 & 6 & 6 & 6 & 6 & 6 & 6 & 6 \\
\hline $\mathrm{T}$ & 6 & 6 & 6 & 7 & 6 & 7 & 7 & 6 & 6 & 6 & 7 & 7 & 7 & 7 & 6 & 6 & 6 & 1 & 7 & 6 \\
\hline$U$ & 3 & 3 & 5 & 4 & 6 & 6 & 6 & 7 & 4 & 4 & 4 & 4 & 4 & 6 & 4 & 4 & 6 & 4 & 7 & 4 \\
\hline $\mathrm{V}$ & 6 & 6 & 6 & 7 & 7 & 7 & 7 & 6 & 7 & 6 & 7 & 7 & 7 & 7 & 6 & 4 & 7 & 7 & 7 & 5 \\
\hline W & 4 & 2 & 7 & 3 & 7 & 7 & 7 & 6 & 6 & 7 & 7 & 7 & 7 & 6 & 2 & 6 & 6 & 6 & 6 & 4 \\
\hline$x$ & 7 & 7 & 7 & 6 & 7 & 5 & 7 & 7 & 2 & 7 & 7 & 7 & 7 & 7 & 7 & 7 & 7 & 7 & 7 & 2 \\
\hline Soma & 140 & 144 & 139 & 146 & 146 & 153 & 151 & 140 & 143 & 145 & 155 & 157 & 156 & 151 & 130 & 139 & 155 & 126 & 155 & 126 \\
\hline
\end{tabular}


Tabela 4 - Ranks dos indicadores - Quesito relevância

\begin{tabular}{|c|c|c|c|c|c|c|c|c|c|c|c|c|c|c|c|c|c|c|c|c|}
\hline & \multicolumn{20}{|c|}{ Indicadores } \\
\hline Avaliadores & $\mathrm{R} 1$ & $\mathrm{R} 2$ & $\mathrm{R} 3$ & $\mathrm{R} 4$ & $\mathrm{R} 5$ & R6 & $\mathrm{R} 7$ & $\mathrm{R} 8$ & $\mathrm{R} 9$ & $\mathrm{R} 10$ & $\mathrm{R} 11$ & $\mathrm{R} 12$ & $\mathrm{R} 13$ & R14 & $\mathrm{R} 15$ & $\mathrm{R} 16$ & $\mathrm{R} 17$ & $\mathrm{R} 18$ & R19 & $\mathrm{R} 20$ \\
\hline A & 10,5 & 10,5 & 10,5 & 10,5 & 10,5 & 10,5 & 10,5 & 10,5 & 10,5 & 10,5 & 10,5 & 10,5 & 10,5 & 10,5 & 10,5 & 10,5 & 10,5 & 10,5 & 10,5 & 10,5 \\
\hline B & 2 & 3,5 & 1 & 3,5 & 13 & 13 & 13 & 13 & 13 & 13 & 13 & 13 & 13 & 13 & 13 & 13 & 13 & 5 & 13 & 13 \\
\hline $\mathrm{C}$ & 4,5 & 6,5 & 2 & 18 & 15 & 18 & 4,5 & 10 & 10 & 18 & 10 & 18 & 10 & 6,5 & 13,5 & 13,5 & 10 & 2 & 18 & 2 \\
\hline $\mathrm{D}$ & 8,5 & 8,5 & 8,5 & 8,5 & 17,5 & 8,5 & 8,5 & 8,5 & 17,5 & 8,5 & 8,5 & 17,5 & 17,5 & 8,5 & 1,5 & 8,5 & 17,5 & 8,5 & 17,5 & 1,5 \\
\hline$E$ & 17,5 & 17,5 & 17,5 & 17,5 & 11,5 & 17,5 & 17,5 & 6 & 11,5 & 6 & 6 & 11,5 & 11,5 & 2 & 2 & 6 & 6 & 2 & 11,5 & 11,5 \\
\hline $\mathrm{F}$ & 7,5 & 7,5 & 7,5 & 1 & 17 & 17 & 17 & 7,5 & 7,5 & 7,5 & 17 & 17 & 17 & 17 & 7,5 & 7,5 & 7,5 & 7,5 & 7,5 & 7,5 \\
\hline $\mathrm{G}$ & 13,5 & 13,5 & 19 & 13,5 & 13,5 & 8 & 8 & 5,5 & 13,5 & 2 & 13,5 & 8 & 19 & 13,5 & 13,5 & 4 & 19 & 2 & 5,5 & 2 \\
\hline $\mathrm{H}$ & 16,5 & 16,5 & 16,5 & 16,5 & 8 & 16,5 & 8 & 8 & 2 & 8 & 16,5 & 16,5 & 8 & 8 & 8 & 8 & 16,5 & 2 & 8 & 2 \\
\hline 1 & 11 & 11 & 11 & 11 & 11 & 11 & 11 & 1 & 11 & 11 & 11 & 11 & 11 & 11 & 11 & 11 & 11 & 11 & 11 & 11 \\
\hline $\mathrm{J}$ & 11 & 11 & 11 & 11 & 11 & 11 & 11 & 1 & 11 & 11 & 11 & 11 & 11 & 11 & 11 & 11 & 11 & 11 & 11 & 11 \\
\hline K & 10,5 & 17 & 3 & 17 & 10,5 & 17 & 10,5 & 17 & 10,5 & 4,5 & 17 & 10,5 & 17 & 10,5 & 1,5 & 6,5 & 17 & 1,5 & 6,5 & 4,5 \\
\hline$L$ & 6,5 & 6,5 & 15,5 & 6,5 & 15,5 & 15,5 & 15,5 & 15,5 & 6,5 & 15,5 & 15,5 & 6,5 & 15,5 & 6,5 & 1 & 15,5 & 6,5 & 6,5 & 15,5 & 2 \\
\hline$M$ & 16 & 19,5 & 9 & 2,5 & 2,5 & 9 & 9 & 9 & 9 & 9 & 16 & 16 & 16 & 16 & 2,5 & 2,5 & 9 & 9 & 9 & 19,5 \\
\hline $\mathrm{N}$ & 11 & 11 & 11 & 11 & 11 & 11 & 11 & 11 & 11 & 11 & 11 & 11 & 11 & 11 & 11 & 11 & 11 & 11 & 11 & 1 \\
\hline 0 & 8,5 & 13,5 & 13,5 & 13,5 & 19 & 1,5 & 5 & 5 & 13,5 & 8,5 & 19 & 13,5 & 13,5 & 13,5 & 5 & 1,5 & 19 & 5 & 13,5 & 5 \\
\hline $\mathrm{P}$ & 10,5 & 10,5 & 10,5 & 10,5 & 10,5 & 10,5 & 10,5 & 10,5 & 10,5 & 10,5 & 10,5 & 10,5 & 10,5 & 10,5 & 10,5 & 10,5 & 10,5 & 10,5 & 10,5 & 10,5 \\
\hline Q & 5,5 & 5,5 & 5,5 & 14,5 & 1 & 14,5 & 14,5 & 2 & 5,5 & 14,5 & 14,5 & 14,5 & 5,5 & 14,5 & 5,5 & 14,5 & 14,5 & 14,5 & 14,5 & 14,5 \\
\hline $\mathrm{R}$ & 13 & 13 & 3,5 & 5 & 1 & 3,5 & 13 & 2 & 13 & 13 & 13 & 13 & 13 & 13 & 13 & 13 & 13 & 13 & 13 & 13 \\
\hline$S$ & 11,5 & 11,5 & 11,5 & 11,5 & 1 & 11,5 & 11,5 & 11,5 & 11,5 & 11,5 & 2 & 11,5 & 11,5 & 11,5 & 11,5 & 11,5 & 11,5 & 11,5 & 11,5 & 11,5 \\
\hline $\mathrm{T}$ & 7 & 7 & 7 & 16,5 & 7 & 16,5 & 16,5 & 7 & 7 & 7 & 16,5 & 16,5 & 16,5 & 16,5 & 7 & 7 & 7 & 1 & 16,5 & 7 \\
\hline U & 1,5 & 1,5 & 13 & 7,5 & 16 & 16 & 16 & 19,5 & 7,5 & 7,5 & 7,5 & 7,5 & 7,5 & 16 & 7,5 & 7,5 & 16 & 7,5 & 19,5 & 7,5 \\
\hline V & 5,5 & 5,5 & 5,5 & 14,5 & 14,5 & 14,5 & 14,5 & 5,5 & 14,5 & 5,5 & 14,5 & 14,5 & 14,5 & 14,5 & 5,5 & 1 & 14,5 & 14,5 & 14,5 & 2 \\
\hline W & 4,5 & 1,5 & 16,5 & 3 & 16,5 & 16,5 & 16,5 & 9 & 9 & 16,5 & 16,5 & 16,5 & 16,5 & 9 & 1,5 & 9 & 9 & 9 & 9 & 4,5 \\
\hline$x$ & 12,5 & 12,5 & 12,5 & 4 & 12,5 & 3 & 12,5 & 12,5 & 1,5 & 12,5 & 12,5 & 12,5 & 12,5 & 12,5 & 12,5 & 12,5 & 12,5 & 12,5 & 12,5 & 1,5 \\
\hline Soma $(R)$ & 226,5 & 242 & 242 & 248,5 & 266,5 & 291,5 & 285,5 & 208 & 238 & 242,5 & 303 & 308,5 & 309,5 & 276,5 & 187 & 216,5 & 293 & 188,5 & 290,5 & 176 \\
\hline
\end{tabular}


Tabela 5 - Comparações múltiplas - Quesito adequação

\begin{tabular}{|c|c|c|c|c|c|c|c|c|c|c|c|c|c|c|c|c|c|c|c|c|}
\hline & $\mathrm{R} 20$ & $\mathrm{R} 8$ & $\mathrm{R} 15$ & $\mathrm{R} 18$ & R3 & $\mathrm{R} 16$ & $\mathrm{R} 1$ & $\mathrm{R} 2$ & $\mathrm{R} 6$ & R9 & $\mathrm{R} 4$ & R5 & R7 & R10 & R14 & R19 & R17 & R13 & R12 & R11 \\
\hline $\mathrm{R} 20$ & 0 & 5 & 20 & 30 & 40,5 & 46,5 & 63 & 68 & 72 & 74 & 76,5 & 79 & 79,5 & 81,5 & 97 & 114,5 & 126,5 & 127,5 & 132 & 137 \\
\hline $\mathrm{R} 8$ & 5 & 0 & 15 & 25 & 35,5 & 41,5 & 58 & 63 & 67 & 69 & 71,5 & 74 & 74,5 & 76,5 & 92 & 109,5 & 121,5 & 122,5 & 127 & 132 \\
\hline $\mathrm{R} 15$ & 20 & 15 & 0 & 10 & 20,5 & 26,5 & 43 & 48 & 52 & 54 & 56,5 & 59 & 59,5 & 61,5 & 77 & 94,5 & 106,5 & 107,5 & 112 & 117 \\
\hline $\mathrm{R} 18$ & 30 & 25 & 10 & 0 & 10,5 & 16,5 & 33 & 38 & 42 & 44 & 46,5 & 49 & 49,5 & 51,5 & 67 & 84,5 & 96,5 & 97,5 & 102 & 107 \\
\hline R3 & 40,5 & 35,5 & 20,5 & 10,5 & 0 & 6 & 22,5 & 27,5 & 31,5 & 33,5 & 36 & 38,5 & 39 & 41 & 56,5 & 74 & 86 & 87 & 91,5 & 96,5 \\
\hline $\mathrm{R} 16$ & 46,5 & 41,5 & 26,5 & 16,5 & 6 & 0 & 16,5 & 21,5 & 25,5 & 27,5 & 30 & 32,5 & 33 & 35 & 50,5 & 68 & 80 & 81 & 85,5 & 90,5 \\
\hline $\mathrm{R} 1$ & 63 & 58 & 43 & 33 & 22,5 & 16,5 & 0 & 5 & 9 & 11 & 13,5 & 16 & 16,5 & 18,5 & 34 & 51,5 & 63,5 & 64,5 & 69 & 74 \\
\hline $\mathrm{R} 2$ & 68 & 63 & 48 & 38 & 27,5 & 21,5 & 5 & 0 & 4 & 6 & 8,5 & 11 & 11,5 & 13,5 & 29 & 46,5 & 58,5 & 59,5 & 64 & 69 \\
\hline $\mathrm{R} 6$ & 72 & 67 & 52 & 42 & 31,5 & 25,5 & 9 & 4 & 0 & 2 & 4,5 & 7 & 7,5 & 9,5 & 25 & 42,5 & 54,5 & 55,5 & 60 & 65 \\
\hline $\mathrm{R} 9$ & 74 & 69 & 54 & 44 & 33,5 & 27,5 & 11 & 6 & 2 & 0 & 2,5 & 5 & 5,5 & 7,5 & 23 & 40,5 & 52,5 & 53,5 & 58 & 63 \\
\hline $\mathrm{R} 4$ & 76,5 & 71,5 & 56,5 & 46,5 & 36 & 30 & 13,5 & 8,5 & 4,5 & 2,5 & 0 & 2,5 & 3 & 5 & 20,5 & 38 & 50 & 51 & 55,5 & 60,5 \\
\hline R5 & 79 & 74 & 59 & 49 & 38,5 & 32,5 & 16 & 11 & 7 & 5 & 2,5 & 0 & 0,5 & 2,5 & 18 & 35,5 & 47,5 & 48,5 & 53 & 58 \\
\hline R7 & 79,5 & 74,5 & 59,5 & 49,5 & 39 & 33 & 16,5 & 11,5 & 7,5 & 5,5 & 3 & 0,5 & 0 & 2 & 17,5 & 35 & 47 & 48 & 52,5 & 57,5 \\
\hline $\mathrm{R} 10$ & 81,5 & 76,5 & 61,5 & 51,5 & 41 & 35 & 18,5 & 13,5 & 9,5 & 7,5 & 5 & 2,5 & 2 & 0 & 15,5 & 33 & 45 & 46 & 50,5 & 55,5 \\
\hline $\mathrm{R} 14$ & 97 & 92 & 77 & 67 & 56,5 & 50,5 & 34 & 29 & 25 & 23 & 20,5 & 18 & 17,5 & 15,5 & 0 & 17,5 & 29,5 & 30,5 & 35 & 40 \\
\hline R19 & 114,5 & 109,5 & 94,5 & 84,5 & 74 & 68 & 51,5 & 46,5 & 42,5 & 40,5 & 38 & 35,5 & 35 & 33 & 17,5 & 0 & 12 & 13 & 17,5 & 22,5 \\
\hline $\mathrm{R} 17$ & 126,5 & 121,5 & 106,5 & 96,5 & 86 & 80 & 63,5 & 58,5 & 54,5 & 52,5 & 50 & 47,5 & 47 & 45 & 29,5 & 12 & 0 & 1 & 5,5 & 10,5 \\
\hline $\mathrm{R} 13$ & 127,5 & 122,5 & 107,5 & 97,5 & 87 & 81 & 64,5 & 59,5 & 55,5 & 53,5 & 51 & 48,5 & 48 & 46 & 30,5 & 13 & 1 & 0 & 4,5 & 9,5 \\
\hline $\mathrm{R} 12$ & 132 & 127 & 112 & 102 & 91,5 & 85,5 & 69 & 64 & 60 & 58 & 55,5 & 53 & 52,5 & 50,5 & 35 & 17,5 & 5,5 & 4,5 & 0 & 5 \\
\hline $\mathrm{R} 11$ & 137 & 132 & 117 & 107 & 96,5 & 90,5 & 74 & 69 & 65 & 63 & 60,5 & 58 & 57,5 & 55,5 & 40 & 22,5 & 10,5 & 9,5 & 5 & 0 \\
\hline
\end{tabular}


Tabela 6 - Comparações múltiplas - Quesito relevância

\begin{tabular}{|c|c|c|c|c|c|c|c|c|c|c|c|c|c|c|c|c|c|c|c|c|}
\hline & 220 & 115 & 118 & R8 & R16 & $\mathrm{R} 1$ & R9 & $\mathrm{R} 2$ & R3 & R10 & $\mathrm{R} 4$ & R5 & 14 & R7 & R19 & R6 & 7 & 111 & R12 & 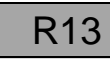 \\
\hline 20 & 0 & 11 & 2,5 & 32 & 40,5 & 50,5 & 62 & 66 & 66 & 66,5 & 72,5 & 90,5 & 100,5 & 109,5 & 14,5 & 5,5 & 117 & 27 & 32,5 & 33,5 \\
\hline 15 & 1 & 0 & 1,5 & 21 & 29,5 & 39,5 & 51 & 55 & 55 & 55,5 & 61,5 & 79,5 & & 98,5 &, 5 & 4,5 & & & & 22,5 \\
\hline 18 & 2,5 &, 5 & 0 & 9,5 & 28 & 38 & 49,5 & 53,5 & 53,5 & 54 & 60 & 78 & 8 & 97 & 2 & 103 &, 5 &, 5 & 20 & 21 \\
\hline $\mathrm{R} 8$ & 32 & & & 0 & 8,5 & 18,5 & 30 & 34 & 34 & 34,5 & 40,5 & 58,5 & 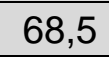 & 7,5 & 82,5 & 83,5 & & & 00,5 & 101,5 \\
\hline 16 & 0,5 & , & 28 & 8,5 & 0 & 10 & 21,5 & 25,5 & 25,5 & 26 & 32 & 50 & 6 & 69 & 74 & 75 & 76,5 & 6,5 & 92 & 93 \\
\hline R1 & 50,5 & & 8 & 3,5 & 10 & 0 & 11,5 & 15,5 & 15,5 & 16 & 22 & 40 & 6 & 59 & & 65 & $6 c$ & & 82 & 83 \\
\hline 29 & 62 & 51 & & 30 &, 5 &, 5 & 0 & 4 & 4 & 4,5 & 10,5 & 28,5 & 38, & 47 & 5 & 53,5 & 5 & 65 & & 71,5 \\
\hline $\mathrm{R} 2$ & 66 & 5 &, 5 & 34 & ,5 &, 5 & 4 & 0 & 0 & 0,5 & 6,5 & 24,5 & 34 & 43 & $4 \varepsilon$ & 49,5 & 5 & & 5 & 67,5 \\
\hline 3 & 66 & & & & 5,5 & 5,5 & 4 & 0 & 0 & 0,5 & 6,5 & 24,5 & 34 & 43,5 & 48,5 & 49,5 & 5 & & 66,5 & 67,5 \\
\hline 10 & 66,5 &, 5 & 54 &, 5 & 26 & 16 & 4,5 & 0,5 & 0,5 & 0 & 6 & 24 & 3 & 43 & 48 & 49 & 50 & 0,5 & 66 & 67 \\
\hline 34 & 72,5 & .5 & 0 &, 5 & 32 & 22 & 10,5 & 6,5 & 6,5 & 6 & 0 & 18 & 2 & 3 & 4 & 43 & 44 & & & 61 \\
\hline R5 & 90,5 & , 5 & 78 & 3,5 & 50 & 40 & 28,5 & 24,5 & 24,5 & 24 & 18 & 0 & 1( & $1 s$ & 2 & 25 & 26,5 & 6,5 & 4 & 43 \\
\hline 14 & 0,5 & 9,5 & 88 & 68,5 & 60 & 50 & 38,5 & 34,5 & 34,5 & 34 & 28 & 10 & 0 & s & 1 & 15 & 16,5 & 26,5 & 3 & 33 \\
\hline $\mathrm{R} 7$ & 09,5 & 3,5 & 97 & 77,5 & 69 & 59 & 47,5 & 43,5 & 43,5 & 43 & 37 & 19 & & 0 & & 6 & 7 & 7,5 & 23 & 24 \\
\hline 19 & 4,5 & 3,5 & 02 & 82,5 & 74 & 64 & 52,5 & 48,5 & 48,5 & 48 & 42 & 24 & 1 & 5 & & 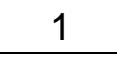 & 2 & 12,5 & 1 & 19 \\
\hline $\mathrm{R} 6$ & 115,5 & 4,5 & נק & 83,5 & 75 & 65 & 53,5 & 49,5 & 49,5 & 49 & 43 & 25 & 15 & 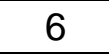 & & 0 & 1, & 11,5 & 17 & 18 \\
\hline 117 & 117 & 106 & 4,5 & 85 & 6,5 & 66,5 & 55 & 51 & 51 & 50,5 & 44,5 & 26,5 & 16, & 7,5 & 2 & 1, & 0 & 10 & 15,5 & 16,5 \\
\hline 11 & 127 & 116 & 114,5 & 95 & 86,5 & 76,5 & 65 & 61 & 61 & 60,5 & 54,5 & 36,5 & 26,5 & 17,5 & 12,5 & 11,5 & 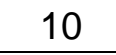 & 0 & 5,5 & 6,5 \\
\hline 12 & 32,5 & 1,5 & 120 & 0,5 & 92 & 82 & 70,5 & 66,5 & 66,5 & 66 & 60 & 42 & 3 & 23 & 1 & 17 & 15 & 5 & 0 & 1 \\
\hline 13 & 133,5 & 122,5 & 121 & 101,5 & 93 & 83 & 71,5 & 67,5 & 67,5 & 67 & 61 & 43 & 33 & 24 & 19 & 18 & 16,5 & 6,5 & 1 & 0 \\
\hline
\end{tabular}

